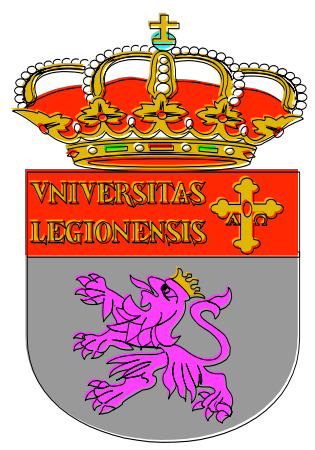

UNIVERSIDAD DE LÉON

DEPARTAMENTO DE DIDÁCTICA GENERAL, ESPECÍFICAS Y TEORÍA DE LA EDUCACIÓN. ÁREA DE DIDÁCTICA Y ORGANIZACIÓN ESCOLAR

\title{
LA PRÁCTICA PROFESIONAL COMO ÁREA PARA POTENCIAR LAS COMPETENCIAS PEDAGÓGICAS NECESARIAS PARA LA ENSEÑANZA EN EDUCACIÓN INFANTIL
}

The Teaching Practice as a field to empower pedagogical competences needed for the teaching in infant education.

Tesis Doctoral

Presentada por Reina Lisbeth Galindo Navas

Dirigida por la Dra. Rosa Eva Valle Flórez

León, 2012 



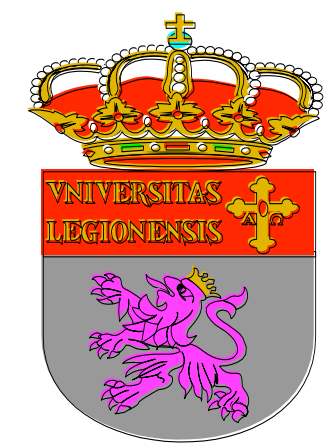

\section{UNIVERSIDAD DE LÉON}

DEPARTAMENTO DE DIDÁCTICA GENERAL, ESPECÍFICAS Y TEORÍA DE LA EDUCACIÓN

\section{AUTORIZACIÓN DEL DIRECTOR DE TESIS PARA SU PRESENTACIÓN}

La Dra. Rosa Eva Valle Flórez, como Directora de la Tesis Doctoral: LA PRÁCTICA PROFESIONAL COMO ÁREA PARA POTENCIAR LAS COMPETENCIAS PEDAGÓGICAS NECESARIAS PARA LA ENSEÑANZA EN EDUCACIÓN INFANTIL, presentada en el DEPARTAMENTO DE DIDÁCTICA GENERAL, ESPECÍFICAS Y TEORÍA DE LA EDUCACIÓN por la Doctoranda Doña, Reina Lisbeth Galindo Navas autorizó la presentación de la citada Tesis Doctoral, dado que reúne las condiciones necesarias para su defensa.

En León a 03 de Julio de 2012

La Directora de la Tesis

Fdo.: Dra. Rosa Eva Valle Flórez 



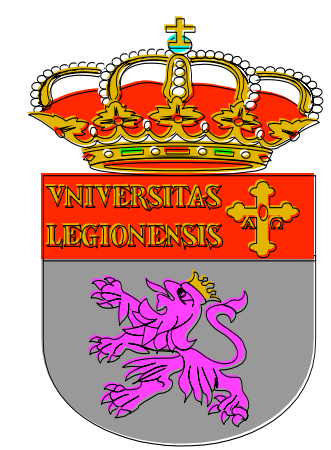

\section{UNIVERSIDAD DE LÉON}

DEPARTAMENTO DE DIDÁCTICA GENERAL, ESPECÍFICAS Y TEORÍA DE LA EDUCACIÓN

\section{CONFORMIDAD DEL DEPARTAMENTO}

El DEPARTAMENTO DE DIDÁCTICA GENERAL, ESPECÍFICAS Y TEORÍA DE LA EDUCACIÓN

En su reunión de Septiembre de 2012, ha acordado dar la conformidad a la admisión a trámite de lectura de la Tesis Doctoral titulada:

\section{LA PRÁCTICA PROFESIONAL COMO ÁREA PARA POTENCIAR LAS COMPETENCIAS PEDAGÓGICAS NECESARIAS PARA LA ENSEÑANZA EN EDUCACIÓN INFANTIL}

Dirigida por la Dra. Rosa Eva Valle Flórez, y presentada por Doña Reina Lisbeth Galindo Navas ante este Departamento

En León Septiembre de 2012

V으으

El Director del Departamento

Fdo.: D. José Antonio Resines Gordaliza
La Secretaria del Departamento

Fdo.: Dña. Ana Isabel Llamas Fernández 



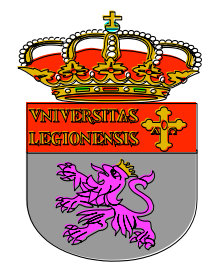

\section{UNIVERSIDAD DE LÉON}

DEPARTAMENTO DE DIDÁCTICA GENERAL, ESPECÍFICAS Y TEORÍA DE LA EDUCACIÓN

\section{DEPÓSITO DE TESIS DOCTORAL}

La licenciada Doña Reina Lisbeth Galindo Navas, una vez autorizada la presentación por la Directora de la Tesis, Dra. Rosa Eva Valle Flórez, y tras la conformidad del DEPARTAMENTO DE DIDÁCTICA GENERAL, ESPECÍFICAS Y TEORÍA DE LA EDUCACIÓN para el inicio de trámites,

PROCEDE al Depósito de la misma en el Departamento y en la Comisión de Doctorado, así como al envío de un ejemplar a cada uno de los miembros del Tribunal nombrado a efecto para su aprobación y eventual defensa pública.

El título: LA PRÁCTICA PROFESIONAL COMO ÁREA PARA POTENCIAR LAS COMPETENCIAS PEDAGÓGICAS NECESARIAS PARA LA ENSEÑANZA EN EDUCACIÓN INFANTIL Realizada en el DEPARTAMENTO DE DIDÁCTICA GENERAL, ESPECÍFICAS Y TEORÍA DE LA EDUCACIÓN por la Doctoranda Doña Reina Lisbeth Galindo Navas

En León Septiembre de 2012

Doctoranda

Fdo.: Doña Reina Lisbeth Galindo Navas 


\section{AGRADECIMIENTOS.}

Dar gracias a la vida todos los días por las infinitas bendiciones que nos ofrece nos abre el camino para que nos Ileguen más regalos del Universo. Cuando nos sentimos agradecidos por nuestras experiencias pasadas y presentes, transcendemos los juicios de lo que consideramos que está bien o mal. Louise Hay.

Culminado este proyecto de vida quiero agradecer a:

Dios, que con su infinita presencia espiritual, me acompaña siempre.

A todos mis familiares, por su bondad, paciencia y apoyo incondicional. ¡Los Amo con todo mi corazón!

A la doctora Rosa Eva Valle Flórez, profesional genuina quien me oriento hacia la creación de este trabajo de investigación, que aún en la distancia, supo estar siempre cerca de mí, alentándome con sus palabras alegres y oportunas, con gran calidad como ser humano, no sólo para la tutoría, sino como apoyo de una gran amiga, que superan con mucho las exigencias del deber.

A mis compañeros y amigos, quienes me brindaron su ayuda, apoyo y compañía, impulsándome siempre con palabras de aliento y un consejo oportuno.

A la Universidad Pedagógica Experimental Libertador, por haberme brindado la oportunidad de realizar los estudios de doctorado. Mi reconocimiento a todos por el compromiso y dedicación en la formación de profesionales para la educación.

A la Universidad de León, por los aprendizajes logrados, por el apoyo y constancia al propiciar y llevar a cabo el convenio en la formación de doctorandos en Psicología y Ciencias de la Educación.

A las profesoras y estudiantes de Educación Preescolar de la UPEL Maracay, que gentilmente fueron las informantes y cuyos aportes contribuyen a mejorar la calidad de nuestra educación.

Agradezco las oportunidades que me ofrece la vida de aprender, avanzar y alcanzar mis sueños.

¡Bendiciones! 


\section{ÍNDICE GENERAL}

I. MARCO TEÓRICO 25

1. Capítulo 1. Introducción General 25

1. Marco referencial justificativo 25

1.1 Relevancia del tema 25

1.2 Justificación personal y profesional 31

1.3 Justificación académica social 33

1.4 Contextualización 35

1.5 Revisión de otros estudios sobre la formación inicial de profesores y la $\begin{array}{ll}\text { práctica profesional } & 40\end{array}$

1.5.1 Antecedentes sobre formación inicial de profesores 41

$\begin{array}{lll}\text { 1.5.2 Antecedentes sobre la práctica profesional } & 48\end{array}$

1.6 Descripción general de la investigación y objetivos perseguidos. 55

2 Capítulo 2. La Formación Superior del Profesorado 65

2.1 Conceptualización de la educación superior $\quad 65$

$\begin{array}{lll}\text { 2.1.1 La formación superior del profesorado } & 67\end{array}$

2.1.2 La formación del docente en América Latina y Europa 70

2.1.3 La formación del profesorado en España 75

2.1.4 La formación superior del profesorado en Venezuela $\quad 84$

2.2 La Universidad Pedagógica Experimental Libertador (UPEL) 88

2.2.1 Misión y visión de la Universidad Pedagógica 89

2.2.2 Diseño curricular de la UPEL 92

2.2.3 El compromiso profesional de la Universidad con la sociedad 95

2.3 Resumen de formación superior del profesorado 98

3 Capítulo 3. Profesionales para Ia Educación Infantil 101

9

La Práctica Profesional como área para potenciar las competencias pedagógicas necesarias para la enseñanza en Educación Infantil 
3.1 Conceptualización educación infantil 101

3.2 Acuerdos mundiales para la educación infantil 102

3.2.1 Declaración de los Derechos del Niño 1959

3.2.2 Conferencia mundial Educación para Todos $1990 \quad 104$

3.2.3 Informe Delors (UNESCO 1996) 105

3.2.4 Declaración de Salamanca (2005) 106

3.2.5 Declaración de Montevideo (2006) 106

3.2.6 Declaración de Valparaíso (2007) 106

3.2.7 Declaración de El Salvador (2008) 106

3.2.8 XIX Conferencia de Portugal, Declaración de Lisboa (2009) 107

3.2.9 X Conferencia Iberoamericana de jefes de estado y presidentes de $\begin{array}{ll}\text { gobierno (2000). } & 107\end{array}$

3.3 Evolución curricular de la educación infantil Venezolana 109

3.3.1 Cobertura nacional de la educación inicial 112

3.4 El profesional para educación infantil 114

3.5 Rol del profesional de educación infantil 121

3.6 Resumen profesionales para la educación infantil 125

4 Capítulo 4. Didáctica del Nivel de Educación Infantil. 129

$\begin{array}{ll}4.1 \text { Conceptualización de la didáctica } & 129\end{array}$

4.2 Evolución histórica de la didáctica en educación infantil 130

4.3 Didáctica en educación infantil 136

4.3.1 Organización del ambiente y los recursos 138

4.3.2 La planificación 139

$\begin{array}{lll}\text { 4.3.3 La evaluación } & 141\end{array}$

4.3.4 La articulación con la familia y la comunidad 145

4.4 Resumen didáctica del nivel de educación infantil 148

10

La Práctica Profesional como área para potenciar las competencias pedagógicas necesarias para la enseñanza en Educación Infantil 
5 Capítulo 5. Formación Profesional Basada en Competencias

Pedagógicas 151

5.1 Construcciones teóricas que respaldan el término competencias 151

5.2 Competencias básicas definidas por la Unión Europea. 155

5.3 Consideraciones generales sobre educación, enseñanza y aprendizaje 156

$\begin{array}{ll}5.4 \text { Competencias pedagógicas } & 161\end{array}$

5.5 Resumen formación profesional basada en competencias pedagógicas 166

6 Capítulo 6. Formación del Profesorado en Educación Preescolar. 171

6.1 Formación de profesores de educación preescolar en Venezuela 171

6.2 Instituciones de educación superior en Venezuela 174

6.3 Formación de profesores de educación preescolar en la UPEL 177

$\begin{array}{lll}\text { 6.3.1 Propósitos del currículo } & 178\end{array}$

$\begin{array}{ll}\text { 6.3.2 Organización curricular } & 179\end{array}$

6.4 Práctica profesional: conceptos, propósitos, fines 183

6.5 La Práctica profesional en la formación del docente: enfoques y criterios. 185

6.6 Práctica profesional en la formación del docente de educación inicial en

Venezuela 192

6.7 La práctica profesional en la formación del docente de educación inicial en la UPEL 200

6.8 Resumen de formación de profesionales para educación preescolar 203

$\begin{array}{ll}\text { II PARTE EMPÍRICA } & 207\end{array}$

7 Capítulo 7. Planteamiento y Desarrollo de la Investigación. 207

7.1 Introducción 207

$\begin{array}{ll}7.2 \text { El problema } & 209\end{array}$

$\begin{array}{ll}7.3 \text { Objetivos del estudio } & 211\end{array}$

11

La Práctica Profesional como área para potenciar las competencias pedagógicas necesarias para la enseñanza en Educación Infantil 
7.4 Metodología 212

7.4.1 Modelo y diseño de investigación 213

$\begin{array}{ll}\text { 7.4.2 Enfoque mixto o complementario } & 214\end{array}$

$\begin{array}{ll}7.5 \text { Instrumentos de recogida de datos } & 217\end{array}$

$\begin{array}{lll}\text { 7.5.1 El cuestionario } & 218\end{array}$

7.5.1.1 Proceso de construcción, validación y fiabilidad del cuestionario 218

7.5.1.2 Fiabilidad y Validez 221

7.5.2 Planes y programas oficiales de práctica profesional de educación preescolar de la UPEL Maracay 224

$\begin{array}{lll}\text { 7.5.3 Talleres reflexivos } & 230\end{array}$

7.5.3.1 Diseño general de los talleres reflexivos 233

7.5.3.1.1 Descripción de los talleres dirigidos a los profesores. 233

7.5.3.1.2 Descripción de los talleres dirigidos a los alumnos. 239

7.6 Población y muestra 242

7.6.1 Selección de la muestra no probabilística intencional 247

$8 \quad$ Capítulo 8. Análisis de los Resultados. 249

8.1 Introducción 249

8.2 Descripción del análisis de las fases de la investigación 252

8.2.1 Descripción de la fase I 252

8.2.1.1 Cuestionario aplicado a los alumnos 252

8.2.1.2 Introducción 252

8.2.1.3 Resultados cuestionario aplicado a los alumnos 253

8.2.1.3.1 Análisis de los datos socio-académicos de los alumnos 253

8.2.1.3.2 Dimensión procesos de aprendizaje 261

8.2.1.3.3 Dimensión didáctica específica educación inicial 265

12

La Práctica Profesional como área para potenciar las competencias pedagógicas necesarias para la enseñanza en Educación Infantil 
8.2.1.3.4 Dimensión enseñanza universitaria 270

8.2.1.3.5 Dimensión académico estudiantil 274

8.2.1.4 Cuestionario aplicado a los profesores 277

8.2.1.4.1 Introducción 277

8.2.1.4.2 Resultado cuestionario aplicado a los profesores 278

8.2.1.4.3 Análisis de los datos socio-académicos de los profesores 278

8.2.1.4.4 Dimensión procesos de aprendizaje 284

8.2.1.4.5 Dimensión didáctica específica educación inicial 287

8.2.1.4.6 Dimensión enseñanza universitaria 293

8.2.1.4.7 Dimensión académico estudiantil 298

8.2.1.5 Conclusiones del análisis de los cuestionarios 302

8.2.1.6 Análisis general a las respuestas del cuestionario 306

8.2.2 Descripción de la fase II $\quad 310$

8.2.2.1 Análisis documental planes oficiales de práctica profesional educación preescolar $\quad 310$

8.2.2.2 Resultados del análisis al diseño curricular UPEL $1996 \quad 310$

8.2.2.3 Características programas de práctica profesional educación preescolar UPEL 316

8.2.2.3.1 Análisis comparativo de cada programa de fase 318

8.2.2.3.1.1 Fase de observación 318

8.2.2.3.1.2 Fase de ensayo didáctico 321

8.2.2.3.1.3 Fase de ejecución proyectos educativos $\quad 324$

8.2.2.3.1.4 Fase de integración docencia administración 327

8.2.2.4 Análisis FODA programas práctica profesional 329

8.2.2.4.1 Análisis estrategias FODA 331

8.2.2.5 Conclusiones análisis programas práctica profesional 332

8.2.3 Análisis de los talleres reflexivos 334 
8.2.3.2 Talleres reflexivos realizados con los profesores

8.2.3.2.1 Primer taller con los profesores 335

8.2.3.2.1.1 Resultados primer con los profesores 352

8.2.3.2.2 Segundo taller con los profesores 354

8.2.3.2.2.1 Resultados segundo taller 354

8.2.3.2.3 Tercer taller con los profesores 358

8.2.3.2.4 Resultados Tercer Taller con los profesores 359

8.2.3.3 Talleres reflexivos realizados con los alumnos 361

8.2.3.3.1 Primer taller estudiantes: evaluar la práctica profesional en educación preescolar 362

8.2.3.3.1.1 Resultados primer taller con las alumnas 363

8.2.3.3.2 Segundo taller: valorar programas de práctica profesional 367

8.2.3.3.2.1 Resultados segundo taller con alumnos 367

8.2.3.3.3 Tercer taller: propuestas de mejora práctica profesional educación preescolar UPEL $\quad 372$

8.2.3.3.3.1 Resultados tercer taller con alumnos 373

8.2.3.4 Conclusiones generales de los talleres reflexivos con los alumnos y profesores $\quad 374$

8.2.3.4.1 Comparación de los resultados análisis talleres reflexivos 376

8.3 Triangulación de los resultados 377

8.3.1 Proceso de triangulación de resultados: dimensión procesos de $\begin{array}{ll}\text { aprendizaje } & 378\end{array}$

8.3.2 Proceso de triangulación de resultados: dimensión didáctica específica en educación inicial

8.3.3 Proceso de triangulación de resultados: dimensión enseñanza universitaria 
8.3.4 Proceso de triangulación de resultados: dimensión académicaestudiantil

8.4 Limitaciones de la investigación 384

8.5 Conclusiones y propuesta 386

8.5.1 Analizar la valoración sobre la práctica profesional 387

8.5.2 Características pedagógicas presentes en los planes y programas de Estudio del área de práctica profesional, de la especialidad de educación preescolar de la UPEL Maracay

8.5.3 Fortalezas y debilidades en el proceso de administración de la práctica profesional 390

8.5.4 Lineamientos para la propuesta del plan de mejora 391

8.5.4.1 Propuesta de programa de práctica profesional, que potencie las competencias pedagógicas necesarias para la enseñanza en educación infantil (P-5)

8.5.4.2 Propósito del programa de práctica profesional (P-5) 392

8.5.4.3 Justificación del programa P-5 392

8.5.4.4 Responsables 393

8.5.4.5 Fases del desarrollo de la propuesta 394

8.5.4.5.1 Fase I diagnóstica 396

8.5.4.5.2 Fase II desarrollo 397

8.5.4.5.2.1 Esquema general del P-5 398

8.5.4.5.2.2 Manuales operativos 400

8.5.4.5.2.3 Programas de cada fase 402

8.5.4.5.3 Fase III evaluación 403

8.5.4.6 Consideraciones finales $\quad 408$

8.5.4.7 Nuevas Líneas de Investigación Sugeridas por los Hallazgos $\quad 410$

15

La Práctica Profesional como área para potenciar las competencias pedagógicas necesarias para la enseñanza en Educación Infantil 
Referencias Bibliográficas

Anexos

Anexo 1 Cuestionario estudiantes

Anexo 2 Cuestionario Profesores

A nexo 3 Matriz de categorías, dimensiones, indicadores e ítems.

Anexo 4 Criterios de decisión para la confiabilidad del instrumento

Anexo 5 Validación del instrumento.

A nexo 6 Matriz de ubicación y secuencia de los cursos y fases. 
Índice de Gráficos

$\begin{array}{lll}\mathrm{N}^{\circ} 1 & \text { Diseño de la investigación } & 63\end{array}$

$\begin{array}{lll}\mathrm{N}^{\circ} 2 & \text { Mapa UPEL- nacional } & 90\end{array}$

№3 Roles de la educación universitaria $\quad 96$

$\begin{array}{lll}\mathrm{N}^{\circ} 4 & \text { El proceso didáctico en educación infantil } & 147\end{array}$

$\begin{array}{lll}\mathrm{N}^{\circ} 5 & \text { Competencias pedagógicas } & 166\end{array}$

$\begin{array}{lll}\mathrm{N}^{\circ} 6 & \text { Diseño de la investigación } & 216\end{array}$

$\mathrm{N}^{\circ} 7$ Esquema talleres reflexivos 232

No 8 Mapa geográfico ubicación UPEL IPMAR 242

$\begin{array}{lll}\mathrm{N}^{\circ} 9 & \text { Estructura organizativa UPEL-IPMAR } & 243\end{array}$

$\begin{array}{ll}\mathrm{N}^{\circ} 10 \text { Informantes segunda fase investigación } & 247\end{array}$

$\mathrm{N}^{\circ} 11$ Procesos del pensamiento que participan en el análisis de la información 249

No 12 Distribución de los alumnos por edad 253

No13 Distribución de los alumnos por sexo. 254

No 14 Distribución de los alumnos por estado civil 255

$\mathrm{N}^{\circ} 15$ Distribución de los alumnos por número de semestres cursados en la universidad 253

N 16 Distribución de los alumnos por número de asignaturas aprobadas 257

$\begin{array}{ll}N^{\circ} 17 & \text { Distribución de los alumnos por asistencia a eventos. }\end{array}$

$\mathrm{N}^{\circ} 18$ Distribución de los alumnos por número de horas dedicadas al estudio 259

No19 Distribución de los alumnos por formación complementaria 260

No20 Categoría aprender a aprender (alumnos) 261

No21 Categoría actualización permanente (alumnos). 263

No22 Categoría capacidad de autoevaluar sus aprendizajes (alumnos) 264

№23 Categoría organización situación enseñanza aprendizaje (alumnos) 265

$\begin{array}{ll}\mathrm{N}^{\circ} 24 \text { Categoría proceso de planificación (alumnos) } & 267\end{array}$ 
$\mathrm{N}^{\circ} 25$ Categoría proceso de evaluación (alumnos) 268

№26 Categoría interacción pedagógica (alumnos) 269

$\begin{array}{ll}\mathrm{N}^{\circ} 27 \text { Categoría didáctica universitaria (alumnos) } & 270\end{array}$

№ 28 Categoría metodología universitaria (alumnos) 272

No29 Categoría contextos de aprendizaje (alumnos) 273

$\begin{array}{ll}\mathrm{N}^{\circ} 30 \text { Categoría métodos y criterios de evaluación. } & 274\end{array}$

№31 Categoría créditos académicos (alumnos) 275

No32 Categoría planes y programas (alumnos) 276

No33 Categoría servicios estudiantiles (alumnos) 277

\begin{tabular}{ll}
$N^{\circ} 34$ & Distribución de los profesores por edad \\
\hline
\end{tabular}

$\begin{array}{ll}\mathrm{N}^{\circ} 35 \text { Distribución de los profesores por sexo. } & 279\end{array}$

No36 Distribución de los profesores por estado civil 279

$\mathrm{N}^{\circ} 37$ Distribución de los profesores por años de servicio en la universidad 280

No38 Distribución de los profesores por condición. 281

No39 Distribución de los profesores por escalafón 282

$\mathrm{N}^{\circ} 40$ Distribución de los profesores por título de pregrado 283

$\mathrm{N}^{\circ} 41$ Distribución de los profesores por título de postgrado 283

No 42 Categoría aprender a aprender (profesores) 284

No 43 Categoría actualización permanente (profesores) 285

No 44 Categoría capacidad de autoevaluar sus aprendizajes (profesores) 286

$N^{\circ} 45$ Categoría organización de la situación enseñanza aprendizaje (profesores) 288

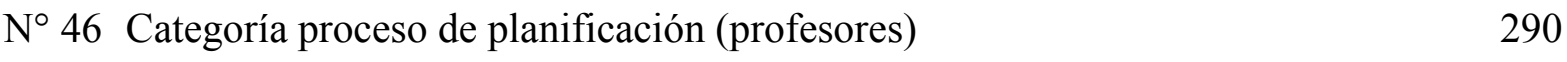

No 47 Categoría proceso de evaluación (profesores) 291

No 48 Categoría interacción pedagógica (profesores) 292

No 49 Categoría didáctica universitaria (profesores) 293

No 50 Categoría metodología universitaria (profesores) 295

N51 Categoría contextos de aprendizaje (profesores) 296 18

La Práctica Profesional como área para potenciar las competencias pedagógicas necesarias para la enseñanza en Educación Infantil 
N 52 Categoría métodos y criterios de evaluación (profesores) 297

No 53 Categoría créditos académicos (profesores) 299

No 54 Categoría planes y programas (profesores) 300

No 55 Categoría servicios estudiantiles (profesores) 301

N 56 Diseño Curricular UPEL 1996, Visión General. 311

No 57 Organización Curricular UPEL 312

N 58 Representación gráfica Profesora \#1 337

N 59 Representación gráfica Profesora \#2 338

N 60 Representación gráfica Profesora \#3 340

N 61 Representación gráfica Profesora \#4 341

N 62 Representación gráfica Profesora \#5 342

N 63 Representación gráfica Profesora \#6 344

N ${ }^{\circ} 64$ Representación gráfica Profesora \#7 345

N 65 Representación gráfica Profesora \#8 347

N 66 Representación gráfica Profesora \#9 349

N $\mathrm{N}^{\circ} 67$ Fases P- 5.

$\begin{array}{ll}N^{\circ} 68 \text { Diseño general P-5 } & 409\end{array}$ 


\section{Índice de Cuadros}

$\mathrm{N}^{\circ} 1$ Crecimiento de la UPEL, como casa formadora de profesores en Venezuela (1965-2010).

$\mathrm{N}^{\circ} 2$ Resumen investigaciones previas sobre formación inicial de docentes

$\mathrm{N}^{\circ} 3$ Resumen investigaciones previas sobre práctica profesional

$\mathrm{N}^{\circ} 4$ Formación inicial y continua de los docentes de preescolar en América Latina y Europa.

N5 Caracterización de tendencias o enfoques pedagógicos.

$\mathrm{N}^{\circ} 6$ Enfoques y corrientes teóricas en relación al currículo.

$\mathrm{N}^{\circ} 7$ Aportes que enriquecen la pedagogía infantil.

$N^{\circ} 8$ Rol del educador infantil

$\mathrm{N}^{\circ} 9$ Etapas de desarrollo de los profesores

$\mathrm{N}^{\circ} 10$ Usos de las competencias en lo social

$\mathrm{N}^{\circ} 11$ Métodos didácticos.

$\mathrm{N}^{\circ} 12$ Universidades Públicas con la carrera de educación preescolar en Venezuela

$\mathrm{N}^{\circ} 13$ Componentes Curriculares

$\mathrm{N}^{\circ} 14$ Actividad práctica del estudiante

No 15 Criterios actividad Práctica.

$\mathrm{N}^{\circ} 16$ Practica profesional Universidades Venezolanas

$\mathrm{N}^{\circ} 17$ Técnicas e instrumentos utilizados en la investigación.

№ 18 Dimensiones del cuestionario y cantidad de ítems

$\mathrm{N}^{\circ} 19$ Valores del Alfa de Cronbach para los dos cuestionarios

$\mathrm{N}^{\circ} 20$ Criterios de evaluación del instrumento

$\mathrm{N}^{\circ} 21$ Distribución por tipos de curso o fase

$\mathrm{N}^{\circ} 22$ Distribución de las unidades crédito por curso y componentes

$\mathrm{N}^{\circ} 23$ Matriz análisis FODA

$\mathrm{N}^{\circ} 24$ Matriz de estrategias 
$\mathrm{N}^{\circ} 25$ Talleres dirigidos a los profesores

$\mathrm{N}^{\circ} 26$ Afirmaciones primer taller reflexivo con los profesores

$N^{\circ} 27$ Segundo taller, relación dimensiones- preguntas generadoras

$N^{\circ} 28$ Resumen talleres reflexivos con los estudiantes

$\mathrm{N}^{\circ} 29$ Tiempo de dedicación profesores práctica profesional

$\mathrm{N}^{\circ} 30$ Escalafón docente

$\mathrm{N}^{\circ} 31$ Sujetos primera fase investigación

$\mathrm{N}^{\circ} 32$ Categoría Aprender a aprender (alumnos)

$\mathrm{N}^{\circ} 33$ Categoría actualización permanente (alumnos)

No 34 Categoría capacidad de autoevaluar sus aprendizajes (alumnos)

No35 Categoría organización de la situación enseñanza aprendizaje (alumnos)

$\mathrm{N}^{\circ} 36$ Categoría proceso de planificación (alumnos)

No 37 Categoría proceso de evaluación (alumnos)

No38 Categoría interacción pedagógica (alumnos)

$\mathrm{N}^{\circ} 39$ Categoría didáctica universitaria (alumnos)

N40 Categoría metodología universitaria (alumnos)

$\mathrm{N}^{\circ} 41$ Categoría contextos de aprendizaje (alumnos)

$\mathrm{N}^{\circ} 42$ Categoría métodos y criterios de evaluación (alumnos)

N43 Categoría créditos académicos (alumnos)

$\mathrm{N}^{\circ}$ 44. Categoría planes y programas (alumnos)

$\mathrm{N}^{\circ} 45$ Categoría servicios estudiantiles (alumnos)

$\mathrm{N}^{\circ} 46$ Categoría aprender a aprender (profesores)

$N^{\circ} 47$ Categoría actualización permanente (profesores)

$\mathrm{N}^{\circ} 48$ Categoría capacidad de autoevaluar sus aprendizajes (profesores)

N 49 Categoría organización de la situación enseñanza aprendizaje (profesores)

No 50 Categoría proceso de planificación (profesores)

$\mathrm{N}^{\circ} 51$ Categoría procesos de evaluación (profesores) 
№ 52 Categoría interacción pedagógica (profesores) 291

N 53 Categoría didáctica universitaria (profesores) 293

№ 54 Categoría metodología universitaria (profesores) 294

№ 55 Categoría contextos de aprendizaje (profesores) 295

N 56 Categoría métodos y criterios de evaluación (profesores) 297

№ 57 Categoría créditos académicos (profesores) 298

$\mathrm{N}^{\circ} 58$ Categoría planes y programas (profesores) 300

No59 Categoría servicios estudiantiles (profesores) 301

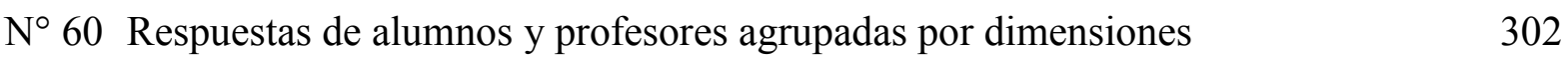

No 61 Características académicas de la especialidad Educación Preescolar 314

$\mathrm{N}^{\circ} 62$ Resumen Programas Oficiales de: FO, FED, FEPE, FIDA 316

No63 Comparación Fase de Observación 319

$\mathrm{N}^{\circ} 64$ Comparación programa fase de ensayo didáctico 322

No65 Comparación fase de ejecución de proyectos. 325

N 66 Comparación Fase de integración docencia administración 327

№67 Matriz FODA plan y programas práctica profesional Educación

Preescolar. 329

$\mathrm{N}^{\circ} 68$ Matriz Estrategias 331

No 69 Descripción general talleres profesores 335

No 70 Análisis global primer taller profesores 352

$\mathrm{N}^{\circ} 71$ Resumen categorías emergentes segundo taller profesores 357

N 72 Descripción general talleres reflexivos con las estudiantes 361

$\mathrm{N}^{\circ} 73$ Resumen acciones primer taller estudiantes 363

No 74 Análisis del primer taller con alumnas 363

N $\mathrm{N}^{\circ} 75$ Resumen acciones segundo taller estudiantes 367

$\mathrm{N}^{\circ} 76$ Resumen categorías emergentes segundo taller alumnas 370

No 77 Resumen acciones tercer taller estudiantes 372

No 78 Comparación resultado general talleres reflexivos. 376 
No 79 Triangulación de resultados, dimensión P.A 378

Nº 80 Triangulación de resultados, dimensión DEEI 380

N 81 Triangulación de resultados, dimensión E.U. 381

N 82 Triangulación de resultados, dimensión A.E. 383

N 83 Fase I Diagnóstica P-5 396

Nº 84 Fase II Desarrollo P-5 397

No 85 Programa sinóptico PRACTICA I 402

Nº 86 Programa sinóptico PRACTICA II 403

No 87 Programa sinóptico PRACTICA III 404

No 88 Programa sinóptico PRACTICA IV 405

Nº 89 Fase III evaluación del P-5 407 


\section{Capítulo 1. Introducción General}

$>$ Marco referencial justificativo

$>$ Relevancia del tema

$>$ Justificación personal y profesional

> Justificación académica social

$>$ Contextualización

$>$ Revisión de otros estudios sobre la formación inicial de profesores y la práctica profesional

$>$ Antecedentes sobre formación inicial de profesores

$>$ Antecedentes sobre la práctica profesional

$>$ Descripción general de la investigación y objetivos perseguidos.

La Práctica Profesional como área para potenciar las competencias pedagógicas necesarias para la enseñanza en Educación Infantil 


\section{Capítulo 1. INTRODUCCIÓN GENERAL}

Este capítulo introductorio pretende reflejar de forma sintética la estructura del presente trabajo de investigación, justificar la importancia en la elección del tema, definir el problema y los objetivos de investigación perseguidos. El objetivo general que se pretende con este trabajo, es diseñar un programa de práctica profesional para la Universidad Pedagógica Experimental Libertador, Instituto "Rafael Alberto Escobar Lara" de Maracay (Venezuela) que desarrolle las competencias profesionales necesarias para ejercer la función docente en la etapa de Educación Infantil. Para alcanzar este objetivo, se ha fundamentado en la primera parte el marco teórico como punto de partida y se delimitan sus principales núcleos conceptuales. En la segunda parte, se fundamenta el modelo de investigación utilizado, así como la presentación y justificación de los instrumentos de obtención de datos. Se realiza una valoración de los planes de formación de Educación Preescolar en el área de práctica profesional y se triangulan los datos de diversas fuentes para concluir con una propuesta de mejora en función de las fortalezas y debilidades encontradas. A continuación, comenzamos por realizar una justificación de la importancia de nuestro objeto de estudio.

\subsection{Relevancia del tema.}

De acuerdo con el informe de la UNESCO (1998) la Educación Superior, ha experimentado una creciente demanda y diversificación en la primera década del siglo XXI, así como una mayor toma de conciencia de la importancia fundamental que este tipo de educación reviste para el desarrollo sociocultural y económico. Para este organismo internacional la Educación Superior comprende "todo tipo de estudios de formación o de formación para la investigación en el nivel postsecundario, impartidos por una universidad u otros establecimientos de enseñanza que estén acreditados por las autoridades competentes del Estado como centros de enseñanza superior" (p.1) 
Justamente en el caso de Venezuela se ha avanzado en un programa para implantar a nivel nacional un Sistema de Evaluación y Acreditación de las Universidades; este proyecto contempla en su justificación que:

Las universidades deben realizar procesos internos de evaluación de modo que se les facilite la inserción en la planificación y desarrollo del sistema. Esta debe ser una evaluación voluntaria y rutinaria de la institución, aunque en algunos casos pudiera considerarse moralmente obligatoria ya que esta debe engranar el proceso evaluativo con el que realiza el estado. (UNESCO- SEA, 1998:28).

Sobre esta afirmación es válido argumentar que, bien vale la pena la implantación de procesos evaluativos en el interior de las universidades, pero no de una manera mecánica o rutinaria, al contrario, se requiere de evaluaciones que permitan la participación y reflexión de todos los actores, en el marco de las políticas educativas y de las propuestas de acción que surgen a propósito de los cambios.

Visto de este modo, emprender una investigación sobre la práctica profesional como factor de interés constante en la comunidad científica de las Ciencias de la Educación, constituye un valioso aporte. De acuerdo con la referencias al respecto, la práctica profesional es uno de los componentes de la formación pedagógica de mayor transcendencia e importancia para la construcción del conocimiento profesional de los futuros docentes, (González 2006; Latorre, 2007). El tema de la mejora de la calidad en la Educación Superior, y por tanto la formación de maestros excelentes, se ha convertido en una de las prioridades más defendidas tanto en el proceso de convergencia europea (Declaración de Bolonia 1999) como en las instituciones de Educación Superior en América Latina (Proyecto Tuning 2007).

Con el propósito de indagar sobre la formación que reciben los estudiantes de Educación Preescolar, se realizo el análisis de los diferentes cursos (cuatro fases) que componen el área de práctica profesional, al considerar que esta área es cardinal en la construcción del marco de acción 
que fundamentará su práctica educativa. Del mismo modo, se identificaran formas en que el currículo se desarrolla, privilegiando el abordaje en dos dimensiones: lo previsto para su ejecución en los planes y programas de estudio y la manera en que estos son llevados a la práctica.

En este sentido, se busca constatar las particularidades de la formación práctica de alumnos universitarios; conocer sus competencias pedagógicas, referidas a la enseñanza en educación infantil, adquiridas en este proceso de formación, así como la valoración que de ellas realizan, los profesores tutores; para posteriormente diseñar un programa de formación, pertinente con los avances y propuestas locales, nacionales e internacionales, referidas a las competencias pedagógicas requeridas para un profesional responsable de la educación, cuidado y atención a los niños y niñas de 0 a 6 años de edad.

El contexto en el cual se realizó este estudio es el del programa de educación preescolar de la Universidad Pedagógica Experimental Libertador instituto "Rafael Alberto Escobar Lara", de Maracay (Venezuela), bajo el título "La práctica profesional como área para potenciar las competencias pedagógicas necesarias para la enseñanza en educación infantil". 1

La investigación reviste una marcada vigencia debido a que aborda un proceso de transición que actualmente marca el contexto de la educación superior en Venezuela, y específicamente en la práctica profesional de educación preescolar. Esta vigencia temática puede servir de antecedente a futuros interesados en generar en torno a la educación infantil, una posible línea de investigación, pues brindaría información de interés acerca de la práctica del docente y la visión del alumno en torno a la realidad, en lo que atañe a la educación de calidad que se pretende lograr.

Siguiendo las propuestas de la UNESCO (1998), con relación a los cuatro pilares del conocimiento, el currículo de formación del profesorado debería comprender: formación general,

\footnotetext{
${ }^{1}$ En el caso de este estudio, y en consideración a la contextualización del mismo, se quiere dejar en claro que cuando nos referimos en esta investigación a educación infantil y/o educador infantil, se hace para citar al nivel educativo y/o al maestro de la primera infancia o nivel inicial, (de cero años hasta el ingreso a la escuela primaria), tomando a todos estos términos: infantil, inicial o preescolar, como sinónimos.
} 
un dominio solido sobre teorías psicológicas que sustentan el desarrollo y aprendizaje infantil y un buen dominio de los métodos y las técnicas didácticas en el área de educación infantil. Sin embargo, el rápido avance de los conocimientos implicados en esos elementos y las demandas sociales crecientes en la formación de los niños y niñas, convierten en insuficientes los cuatro o cinco años de formación superior. Ésta es una de las razones por la cual la formación del futuro profesor de educación inicial debe concebirse en relación directa con la formación continua y orientarse hacia el desarrollo profesional. En este punto vale resaltar la siguiente afirmación:

Muy pocos formadores de profesores aceptarían la opinión de que es posible proporcionar al futuro profesor todos los conocimientos y destrezas que requerirá a lo largo de su carrera profesional. Existe una opinión generalizada de que ningún programa de formación de profesores, cualquiera que sea su orientación e independientemente de su calidad, puede proporcionar una formación completa sin fisura alguna. Siendo esto así, es esencial que cada experiencia dentro de la etapa inicial sirva para enriquecer más que para impedir la capacidad de desarrollo ulterior. (Zeichner, 1987: 166).

En la misma dirección se pronuncia Ríos (2004), para quien la formación debe permitir al educando adquirir los medios para la formación continuada, es decir, un entrenamiento mental y un bagaje metodológico que garanticen su autonomía intelectual.

En la formación del futuro profesional de la educación infantil, ciertamente no es posible enseñarle todo lo pertinente a su desarrollo profesional, sin embargo, es impostergable hacer énfasis en el aprendizaje de competencias para enfrentarse a las variadas condiciones profesionales en su ejercicio laboral, por tanto tiene que ser profundamente modificada, específicamente en esa articulación con los centros de práctica, es decir el contacto con la realidad social, cultural y educativa en la cual le corresponderá desarrollar su profesión; de este modo, no puede dejarse todo para cuando obtenga el título, y entonces sean los niños quienes validen y certifiquen los aprendizajes específicos y prácticos de sus maestros. 
Al respecto Montero (2002:77) advierte sobre el "abismo entre la formación inicial y las demandas de la vida real a profesores y profesoras; decepción expresada también en la escasa valoración de la formación por los propios profesores, en la creencia que la mejor formación es la que tiene lugar a partir de la experiencia profesional”.

Así mismo, Katz (2005: 29) considera que los aspectos de mayor preocupación para el profesor profesional, debería ser la aplicación del conocimiento más avanzado, en las actividades que realiza y el uso del juicio basado en ese conocimiento avanzado y la adopción de estándares de desempeño

Es bien sabido los esfuerzos que las universidades hacen por garantizar prácticas profesionales de calidad durante el periodo que abarca la formación académica de sus estudiantes, sin embargo, existen limitaciones que ineludiblemente se le plantean a una institución formadora, en el momento en que necesita establecer contactos con la realidad escolar, por ejemplo: qué centros seleccionar; qué profesores; qué puede demandar a unos y a otros; qué compromisos está dispuesta a aceptar, entre otros.

El proceso de transformación curricular de las universidades y entre ellas la UPEL requiere la revisión de las propias capacidades del profesorado, donde se procure la enseñanza más contextualizada, que potencie la evaluación continua y formativa, y los contenidos se conecten con la experiencia real; de este modo, brindar al estudiante habilidades de solución de problemas y desarrollo del pensamiento crítico y reflexivo que le permitiría progresar a su propio ritmo, usar sus propias estrategias y en definitiva, aprender a aprender.

Lo anterior indica de manera implícita y casi subliminal, un cambio en el rol de los profesores responsables de la formación inicial de los futuros profesionales de la educación infantil, donde el proceso de enseñanza, deje el paso libre al proceso de aprendizaje de los estudiantes. Esto es, darle mayor importancia al rol protagonista del estudiante como constructor de su propio aprendizaje. Sin embargo, para alcanzar esta meta, se deben modificar drásticamente aspectos estructurales de una universidad que pide calidad pero que parece seguir anclada en el pasado.

Prueba de ello es, por ejemplo, la preponderancia en procesos formativos estrictamente presenciales, lo cual implica masificación que se observa en muchas aulas, evidenciando la 29 La Práctica Profesional como área para potenciar las competencias pedagógicas necesarias para la enseñanza en Educación Infantil 
necesidad de incorporar estrategias de enseñanza apoyadas en las nuevas tecnologías (TIC) tal como el Elearning. Teniendo en cuenta este tipo de problemas, los profesores universitarios deberán dar cuenta de su calidad, a través de su competencia, participación y motivación en la labor docente. Asumiendo que todos los elementos del sistema universitario han de implicarse para generar calidad en el conjunto de la Educación Superior. De este modo, si el aprendizaje de los alumnos va a ser el eje central de la actividad universitaria, el profesorado tendrá que enfrentarse a nuevos retos y, por tanto, al desarrollo de nuevas competencias. Pasará de ser un expositor de contenidos a convertirse en orientador del aprendizaje de los alumnos. La "profesionalización” en el ámbito de la enseñanza es un requisito básico a tener en cuenta en su formación, con vistas al proceso de transformación y modernización curricular de la UPEL.

El proceso educativo, tal como lo establece la Constitución de la República Bolivariana de Venezuela, en su artículo 3; la Ley Orgánica para la Protección del Niño y del Adolescente, en su artículo 58; y la Ley Orgánica de Educación, en su artículo 7; están estrechamente vinculadas al trabajo, a fin de armonizar educación con las actividades productivas propias del desarrollo social local, regional y nacional a través de la orientación de niños, niñas, adolescentes y jóvenes; formándolos (as) en, por y para el trabajo creador y productivo con visión dignificadora de lo humano, que permita satisfacer necesidades básicas, contribuir al desarrollo regional y nacional.

Por tanto, en la formación universitaria, se requiere la incorporación de nuevos contenidos curriculares, particularmente referidos al desarrollo de competencias y valores que se requieren para un desempeño productivo y ciudadano. Estas competencias (capacidad de trabajar en equipo, de resolver problemas, de experimentar, de interactuar con el diferente, entre otras), y los valores propios de la formación ciudadana (solidaridad, tolerancia, respeto a los derechos humanos) no se enseñan necesariamente a través de los contenidos de una disciplina sino a través de modalidades transversales que exigen también una modificación profunda en la organización curricular y en las modalidades de trabajo de los profesores. 


\subsection{Justificación personal y profesional}

Toda ciencia, como lo es la educación, de manera permanente debe revisar actualizar y construir su saber a partir de las prácticas, la investigación y el desarrollo teórico. En este sentido, el saber pedagógico se construye desde dos fuentes: aquel producido por una comunidad de personas directamente involucradas y el que proviene de la externalidad de estas comunidades (Peralta, 2008:20).

Al primer tipo de conocimientos se le denomina "saber pedagógico especifico" y es producido y reproducido cotidianamente en el hacer profesional, en sus interacciones con otros actores del hecho educativo. Así mismo, el conocimiento que se produce desde la externalidad de la práctica de los educadores, es igualmente valido, y proviene generalmente de la psicología, de las neurociencias, de la sociología, entre otros conocimientos que han sido sistematizados y difundidos en educación.

Cualquiera que sea el origen del conocimiento pedagógico, es esencial su permanente revisión y reconstrucción, ya que implican avances en la teoría y la práctica de toda ciencia o disciplina (Peralta, ob. Cit.). Este proceso, es apremiante realizarlo dentro de las instituciones de educación superior y más específicamente en el contexto venezolano, el cual, en la actualidad está sometido a procesos de actualización y transformación en el marco de los cambios legales ocurridos en este país, por lo que, no se justifica una actitud pasiva frente a la construcción de propuestas realizadas desde el ámbito administrativo-gerencial, en desmedro del pensamiento y práctica pedagógica de los actores que hacen vida en estas instituciones. Razón de peso, para propiciar la realización de investigaciones a partir de la propia realidad y demandas reales.

Entre las razones que impulsaron esta investigación, acerca de la práctica profesional de educación preescolar de la UPEL-IPMAR, se destaca la decisión de centrar la atención en la educación superior, ya que éste es el ámbito laboral en el que se desempeña la investigadora y por tanto el acceso a la información e impacto será de mayor contribución. Así mismo, es necesario señalar que en estudios previos (Galindo, 2008, 2009) se indicó que tanto el egresado, como el estudiante en formación de UPEL IPMAR, demuestran serias debilidades en cuanto a conocimientos y habilidades prácticas referidas a la didáctica del nivel inicial. 
La experiencia mencionada, permitió confirmar las discrepancias entre lo planteado en el pensum de formación académica, como por ejemplo: adquirir conocimientos y destrezas para diseñar planes, instrumentos de evaluación, estrategias y recursos cónsonos con las características evolutivas, y psicológicas del niño, entre otros, y lo que expresan poseer como conocimiento y habilidad las estudiantes en formación, además argumentan que sus procesos formativos están alejados de la escuela y sus prácticas (Galindo, 2009); Así mismo, estas estudiantes plantean confusión o vacíos cognitivos para trasponer dichos conocimientos de la teoría a la práctica, por lo que al momento de cursar las fases de práctica profesional, se hace necesario implementar un periodo de repaso y puesta en común sobre los contenidos que sean necesarios de recordar, lo que ocasiona una reducción considerable del tiempo disponible para la ejecución de sus actividades prácticas, propiamente dichas.

De modo que, este estudio surge de la experiencia profesional de la autora, al desempeñarse como profesora de la UPEL IPMAR en el área de práctica profesional, tal y como lo señala Stenhouse (1998) quien defendió el papel activo que deben tener los profesionales en el campo de la educación. Este autor argumentó que no era suficiente que el trabajo docente sea analizado por otros investigadores, sino que ellos mismos necesitan estudiarlo. Fue con ese marco de referencia como se desarrolló el proceso investigativo de la práctica profesional del área de educación preescolar, lo cual implicó una construcción individual y colectiva del conocimiento.

Construcción que fue realizada a través de la interacción del investigador con su entorno laboral, a partir de las estructuras del conocimiento producto de las investigaciones previas, con el propósito de ser transferido y aplicado a situaciones particulares.

Lo anteriormente descrito consigue fundamento en Morín (2001:35) cuando afirma que, es necesario beneficiar la aptitud para plantear problemas, la posibilidad de vincular conocimientos. Así mismo, considera que la cultura de las humanidades favorece la aptitud para abrirse a todos los grandes problemas, la aptitud para reflexionar, para aprehender las complejidades humanas, para meditar sobre el saber y para integrarlo en la vida propia para, correlativamente, ver con mayor claridad la conducta y el conocimiento de uno mismo.

32

La Práctica Profesional como área para potenciar las competencias pedagógicas necesarias para la enseñanza en Educación Infantil 
Así mismo, en el presente estudio se asume una postura socio cognitiva, según la cual, en la formación docente se deben conformar procesos cognoscitivos, afectivos y sociales, que faculten al futuro profesional para actuar frente a diversas situaciones pedagógicas, realizando diagnósticos, diseñando planes, con sus respectivas alternativas de solución fundamentadas en enfoques teóricos, así como las técnicas e instrumentos que utilizará para su respectiva evaluación y sistematización. De este modo, y de acuerdo con Freire (2004:25), es importante que el profesor universitario asuma que en todo acto educativo existe una relación recíproca, en donde "quien enseña aprende al enseñar y quién aprende enseña al aprender", desde este punto de vista, es necesario también destacar que el autor antes mencionado, alerta a los docentes, que no se pueden conformar con enseñar los contenidos, sino también enseñar a los educandos a pensar correctamente, trabajar con rigor metodológico, aproximándose a los objetos con curiosidad, capacidad crítica, asumiendo la enseñanza, el aprendizaje y la investigación como un ciclo gnoseológico, en fin superar la enseñanza bancaria.

Desde esta perspectiva, Osorio y Rubio (2007:38), argumentan lo siguiente: "pareciera una redundancia el enfatizar "lo práctico" en un contexto pedagógico, no obstante ello se debe considerar más bien como un énfasis e intención clara de integrar las diversas prácticas desarrolladas y sus reflexiones emergentes", por lo que es imperativo el diseño de alternativas de formación que aspiren a superar la práctica pedagógica irreflexiva y mecanizada, con enfoques prescriptivos donde se le indica al estudiante en formación, lo que debe pensar, hacer y evitar. Para ello el futuro docente debe participar en un proceso de deliberación permanente que lo lleve a cuestionar lo que hace, cómo lo hace, y cómo podría hacerlo mejor.

\subsection{Justificación Académica -social}

Resulta oportuno resaltar lo que Octavio Paz, premio nobel de literatura en 1990, manifestó en su discurso titulado "la búsqueda del presente", donde identificó los desafíos que la modernidad le plantea al hombre contemporáneo y muy particularmente a los intelectuales y profesionales, al sostener que el imperativo esta en pensar, lo cual a su juicio significa recobrar la mirada crítica. Esta preposición es pertinente y vigente, sobre todo para las universidades y quienes en ella se desempeñan, donde la mirada crítica debe existir por excelencia. 
En este sentido el presente estudio se justifica desde el punto de vista institucional, para la Universidad Pedagógica Experimental Libertador, Instituto Rafael Alberto Escobar Lara, ya que permite presentar una mirada crítica y auto crítica respecto a ella misma. Así mismo, admite darle vigencia a sus planteamientos curriculares de vocación por la investigación, al presentar resultados de evaluaciones sobre ella misma y sus principales actores (estudiantes y profesores) como objeto de investigación, para generar información que le permita identificar fortalezas y debilidades, de modo de potenciar las primeras y fortalecer las segundas. Además con este estudio se abren ventanas de oportunidades para enrumbar el cambio y la innovación, al asumir una posición anticipatoria y no reactiva, al adjudicarse la iniciativa de evaluar su gestión y proponer alternativas de solución, como las que, en este estudio se presentan.

En la actualidad, la Universidad Pedagógica Experimental Libertador, en cumplimiento a las exigencias del estado venezolano, está realizando el proceso de transformación y modernización del currículo, como respuesta a los cambios legales que han modificado las políticas educativas, las cuales implican nuevos desafíos relativos a la financiación, la igualdad de condiciones de acceso a los estudios, mejor capacitación del personal, la formación basada en las competencias, la mejora y conservación de la calidad de la enseñanza, la investigación y los servicios, la pertinencia de los planes de estudios, las posibilidades de empleo de los egresados, entre otros. Razón de peso para desarrollar estudios cuyos resultados signifique una contribución, al referido proceso de transformación y modernización del currículo. Esta vigencia temática puede servir de antecedente a futuros interesados en generar en torno a la educación infantil, una posible línea de investigación, pues brindaría información de interés acerca de la práctica del docente y la visión del alumno en torno a la realidad, en lo que atañe a la educación de calidad que se pretende lograr.

Al respecto, Díaz y Mayz (2004:172), refieren que la formación de los docentes de la educación inicial en Venezuela, tiene entre sus antecedentes, aproximadamente en el año 1996, y de acuerdo a resultados de estudios recientes (2000-2004), existen serias discrepancias, entre el profesional que se está formando en las distintas Instituciones de Educación Superior para desempeñarse en el nivel de educación preescolar y el profesional que se está requiriendo en el 
campo de trabajo para la atención integral de los niños y niñas de 0 a 6 años. Esta situación dio lugar a la organización, por parte del Ministerio de Educación Superior, para que las universidades y los institutos universitarios encargados de la formación docente del futuro profesional de educación preescolar, asuman la revisión curricular como una actividad permanente de cada institución, que contribuya a la actualización y mejoramiento constante del currículo, y especialmente establecer que las prácticas profesionales se desarrollen en los diferentes escenarios y contextos en donde se atendieran niños y niñas de 0 a 6 años con estrategias diversas y todo ello vinculado a las actividades de investigación.

En este mismo orden de ideas, el no incluir e implementar en la formación de docentes los avances sobre desarrollo y aprendizaje humano, constituye un problema ético, ya que implicaría restarles a los alumnos un mejor aprendizaje y formación profesional. No obstante, no se trata de impulsar investigaciones para simplemente cambiar lo existente, sino por la posibilidad de actualizar los procesos formativos y de ponerlos en práctica para el mejoramiento de la calidad educativa.

Todas estas razones justifican una investigación sobre la práctica profesional como área para potenciar las competencias pedagógicas necesarias para la enseñanza en educación infantil, ya que se asume que si se mejoran los procesos formativos, se garantiza una educación de calidad para los niños y niñas venezolanos. La mejora de los procesos formativos no solo preocupa a sus principales actores (estudiantes, profesores, investigadores, autoridades), sino también a la comunidad en la que los egresados demostrarán sus competencias para contribuir con el desarrollo e impulso del país

\subsection{Contextualización}

Tal como se ha venido afirmado, la unidad objeto en estudio está representada por la Universidad Pedagógica Experimental Libertador (UPEL), específicamente el Instituto Rafael Alberto Escobar Lara, ubicado en Maracay, estado Aragua (IPMAR).En este sentido, la UPEL tiene como misión: formar, capacitar, perfeccionar y actualizar los recursos humanos, para la educación que se requiere en el país; asesorar al Estado venezolano en la formulación de políticas 
educativas y generar, aplicar y divulgar nuevos conocimientos, teorías y prácticas pedagógicas que contribuyan al desarrollo humanístico, científico, tecnológico y social del país a través de sus funciones de docencia, investigación y extensión (reglamento general de la UPEL:3) .

Así mismo en el citado documento, se afirma que la universidad tiene como visión, convertirse en una universidad de prestigio y cobertura nacional, líder en la formación y actualización docente, promotora de los cambios necesarios del sector educativo, en concordancia con las transformaciones y exigencias del entorno y asesorar al Estado en la formulación de las políticas educativas nacionales y regionales, para contribuir al desarrollo y mejoramiento de la calidad de la educación, y en consecuencia de la calidad de vida del venezolano.

En este sentido, y ubicándonos en el contexto venezolano, de acuerdo con datos de la Oficina de Planificación del Sector Universitario (OPSU 2009) existen 120 institutos de Educación Superior y 46 Universidades en pleno funcionamiento. Entre las últimas, se ubica la Universidad Pedagógica Experimental Libertador, la cual es la única casa de estudios universitarios para la formación de profesores en Venezuela. Ésta institución, fue creada mediante el Decreto No.2176 de fecha 28 de Julio de 1983 del Ejecutivo Nacional como un homenaje a la memoria del Libertador Simón Bolívar en el Bicentenario de su nacimiento.

Su reconocimiento como universidad se logró, a través de la unión de los Institutos Oficiales de Formación Docente conocidos como Institutos Pedagógicos, los cuales funcionaban de manera independiente, en todo el territorio nacional. Este proceso de integración articuló a todos los Institutos Oficiales de Formación Docente que para ese momento eran conocidos como los Institutos Pedagógicos : Caracas, creado en 1936, Barquisimeto, 1959, Maturín y "Rafael Alberto Escobar Lara” (Maracay), 1971; y el de Miranda “José Manuel Siso Martínez”, en 1976.

En este orden de ideas, la Universidad Pedagógica Experimental Libertador, como garante de la formación de profesores ha experimentado un acelerado crecimiento, que exige cada vez procesos que le ayude a cumplir su misión, cónsona con los principios fundamentales requeridos para la educación en general. Este crecimiento ha sido más notorio desde el año 1990, tanto en número de instituciones como en matricula estudiantil. El cuadro $\mathrm{N}^{\circ} 1$, elaborado con 
información proveniente del Departamento de Estadística de la Oficina de Presupuesto del Sector Universitario (OPSU) evidencia esta afirmación.

\begin{tabular}{|l|l|l|}
\hline AÑOS & No INSTITUTOS & MATRICULA ESTUDIANTIL \\
\hline $\begin{array}{l}1965-1969 \\
1970-1978\end{array}$ & 2 & 3754 \\
\hline $1980-1989$ & 6 (creación UPEL) & 34166 \\
\hline $1990-1999$ & 8 & 46424 \\
\hline $2000-2007$ & 8 & 86136 \\
\hline $2008-$ en adelante & 8 & 88682 \\
\hline
\end{tabular}

Cuadro $\mathrm{n}^{\circ}$ 1. Crecimiento de la UPEL, como casa formadora de profesores en Venezuela (1965-2010).

La información institucional relacionada con la matrícula de las universidades (1965-2010), permite apreciar desde una perspectiva amplia la dinámica de la matrícula, la cual se ha incrementado considerablemente, está situación refleja la importancia que progresivamente ha ido adquiriendo la formación de profesores, los cuales, "se enfrenta también a un mundo en continuo cambio, que requiere continuar aprendiendo y ajustar su actuación a nuevas reglas", (Montero 2002:71) Del mismo modo, esta autora pone de manifiesto la relevancia de la formación inicial como puerta de entrada al desarrollo profesional, al considerarla como una práctica social en un contexto sociocultural determinado, inmersa, simultáneamente, en un contexto más amplio de condiciones, en una historia interminable de mejora de sí mismos y mejora de sus prácticas, lo que permite entenderla como un fenómeno transcultural.

En este orden de ideas, el contexto en el cual se realiza la presente investigación es el Instituto Pedagógico "Rafael Alberto Escobar Lara", de Maracay, en adelante UPEL IPMAR, en el programa de Educación Preescolar, área de Práctica Profesional, en el cual se ofrece la formación inicial del futuro educador responsable de la atención, cuidado y educación de los niños y niñas de 0 a 6 años de edad. 
En este instituto, se atiende una matrícula estudiantil proveniente, en su mayoría de diferentes estados que conforman la llamada zona central de Venezuela: Aragua, Carabobo, Apure y Guárico. En la actualidad esta población estudiantil, es de cinco mil quinientos sesenta y cuatro (5564), distribuidos en las siguientes especialidades de pregrado: Informática, Matemática, Castellano, Educación Pre-Escolar, Educación Integral, Educación Especial, Educación Física, Biología, Química, Física, Educación Musical, Inglés, Geografía e Historia. Asimismo, esta casa de estudios, oferta formación de postgrado (especializaciones, maestrías y doctorado) compuesto por: cinco (5) sub programas de especialización: Educación Preescolar, Educación Inicial, Educación Especial para la Integración de las Personas con Discapacidad, Gestión Comunitaria, Procesos Didácticos; diez (10) subprogramas de Maestrías: Enseñanza de la Geografía, Enseñanza de la Educación Física, Enseñanza de la Biología, Enseñanza de la Química, Enseñanza de la Matemática, Enseñanza de la Historia, Educación Superior, Gerencia Educacional, Lingüística, Literatura, Orientación, Educación Infantil, Enseñanza del Inglés y un (01) doctorado en Ciencias de la Educación.

En relación con la formación de pregrado y de acuerdo con los documentos oficiales (UPEL, 1996) el plan de estudio está diseñado para ser administrado en diez periodos académicos, de dieciséis semanas cada uno. Así mismo, el currículo de la UPEL, está organizado en cuatro componentes curriculares: Formación General, Formación Especializada, Formación Pedagógica y Práctica Profesional. A su vez, estos componentes, están conformados por estructuras denominadas cursos o fases. En el caso del componente de práctica Profesional se considera como

Un eje de integración y confrontación teórico-práctico de la formación docente, distribuido a lo largo de la carrera, en torno al cual los objetivos de los componentes de Formación General, Pedagógica, y Especializada se integran en función del perfil profesional del egresado. (UPEL, 1996:36) 
En este mismo orden de ideas, el componente de Práctica Profesional, está conformado por cuatro fases: Observación, Ensayo, Ejecución de Proyectos Educativos e Integración Docencia Administración, las cuales poseen en sí mismas diferencias curriculares en atención a las distintas especialidades que en la UPEL se ofrecen.

Otro aspecto que resulta importante mencionar, es que en la UPEL de Maracay, contexto objeto en estudio, la Práctica Profesional se gerencia dentro de una estructura de organización denominada "Área de Práctica Profesional", que de acuerdo con la concepción administrativa universal, se corresponde con el de cátedra universitaria. También es significativo destacar, que en esta área, confluyen diferentes profesores cuyos títulos de pregrado responden a las distintas especialidades que en la UPEL existen y que además, son estos profesionales los responsables de planificar, organizar, controlar y evaluar la administración de cada una de las fases, sin importar su grado de conocimiento y experiencia, en relación con disciplinas distintas a su formación académica.

En el caso específico de la formación de profesoras para la Especialidad de Educación Preescolar en la UPEL, Maracay, se cuenta con un diseño curricular que data de dieciséis años (16) años de elaborado, el cual ha tenido algunas modificaciones como producto de la experiencia e inquietud de algunos docentes; en este sentido, es necesario destacar que desde el año 2005 la UPEL, a través del Vicerrectorado de Docencia, ha venido desarrollando el proceso de transformación y modernización curricular, del cual solo se evidencian cambios muy lentos, todo esto justificado por la imperiosa necesidad de unificar el currículo de todos los institutos que componen esta gran universidad.

Del mismo, modo, y como parte de esta problemática, el estado venezolano, en el diseño e implementación de políticas educativas, ha presentado un nuevo diseño curricular para el nivel de Educación Inicial, el cual debe ser del conocimiento obligado para el docente en servicio, pero también la UPEL, en su carácter de formadora de docentes, debe revisar, analizar, proponer alternativas para que sus estudiantes en formación tengan una visión crítica, reflexiva y científica en la implementación de diseños curriculares ajustados a la realidades familiares, sociales, 
evolutivas, psicológicas, de los niños y sus familias con los cuales les tocara desarrollar su profesión.

\subsection{Revisión de otros estudios sobre la Formación Inicial de Profesores y la Práctica Profesional.}

Un mundo en permanente cambio exige una educación superior amplia y especializada e interdisciplinar; Se hace necesario, por tanto, revisar las investigaciones que estén relacionadas con la situación objeto en estudio para considerar sus aportes, sus aciertos y debilidades, lo cual pudiera dar origen a la introducción de nuevos contenidos o de nuevas formas de organizarlos.

En este orden de ideas, también es necesario considerar que la realización de estudios científicos, exige la revisión de distintas formas de abordar problemáticas similares con la presente investigación, como lo es indagar acerca de la opinión que tiene los estudiantes y profesores de la UPEL IPMAR, acerca de la forma como se está administrando la práctica profesional, para intentar presentar un plan de mejora, de la práctica profesional como área para potenciar las competencias pedagógicas, necesarias para la enseñanza en Educación Infantil.

Este proceso de revisión de estudios previos, permite deliberar con metodologías que fomentan el pensamiento crítico y la creatividad, que invitan a considerar nuevas formas de desarrollar la capacidad de analizar los problemas, de aportar soluciones y de asumir responsabilidades sociales y educativas.

A continuación se presentan algunas investigaciones desarrolladas con anterioridad, organizadas en dos apartados (de acuerdo al interés investigativo) y luego de cada descripción se expone sus respectivos cuadros resumen.

En estos estudios se detectó, por una parte, las situaciones particulares de las universidades y sus docentes, acerca de la formación inicial de profesores; y por la otra, algunos donde se analizan problemáticas referidas a la práctica profesional, el practicum o las prácticas pedagógicas, según el contexto geográfico en donde se realizaron. Es necesario aclarar que todos 40

La Práctica Profesional como área para potenciar las competencias pedagógicas necesarias para la enseñanza en Educación Infantil 
estos estudios previos se organizaron atendiendo al momento histórico en el cual se ejecutó, sin diferenciarlos por el país de origen, ya que si bien es cierto responden a su propia realidad, en cuanto a políticas educativas se refiere, también revelan a un contexto universal, como lo es la educación y sus formas de administrarla.

\subsubsection{Antecedentes sobre Formación Inicial de Profesores}

Varios autores han escrito sobre la formación inicial de docentes, cabe citar al estudio de Zurita (1995), quien presenta un trabajo titulado: La formación de profesores: desafíos y prioridades en el Chile de hoy, cuyo objetivo consistió en destacar el rol protagónico del profesor en el proceso educativo y el imperativo de concebir e introducir reformas significativas en el proceso de formación de los profesionales de la educación. Este estudio documental, describe en detalle algunos indicadores que a juicio del autor, constituyen la principal causa de debilidad en las universidades chilenas (lo cual perfectamente es extrapolable a otros países), en este sentido se destacan: a) la autorreferencia, vista como el aislamiento de las facultades de educación de los escenarios que surgen, así como de su entorno; b) están ancladas en el pasado, anomia metodológica, formación disciplinaria tenue; c) procesos formativos alejados de las escuelas y sus prácticas; d) presta poca atención a la diversidad cultural del país; e) atraso en la discusión y bibliografías de 20 o 15 años.

Por tanto, el autor insiste en que las universidades deben volver la mirada crítica hacia sus propias prácticas, en tanto y en cuanto instituciones formadoras de profesores. Para ello presenta algunas ideas que pudieran ayudar a enfrentar la situación descrita:

1.- Los problemas pedagógicos no son sólo problemas de métodos, procedimientos, planificaciones o medios, sino con un problema de fondo: el replanteamiento del conocer, de la comunicación, de la información y del aprendizaje.

41

La Práctica Profesional como área para potenciar las competencias pedagógicas necesarias para la enseñanza en Educación Infantil 
2.- Privilegiar la reflexión crítica sobre las prácticas cotidianas de los profesores del respectivo departamento, instituto o facultad, en relación con la formación de profesores. Reflexión crítica de y para acciones innovadoras.

3.- Una estrategia de cambio que revele una relación de ayuda, entendida como el apoyo que los miembros ubicados en los niveles más altos son capaces de proporcionar a los miembros ubicados en los niveles más bajos.

Entre las fortalezas de este estudio documental puede destacarse que el autor reconoce y asume con libertad las principales debilidades que poseen en su práctica didáctica, las cuales son muy parecidas a las que presenta la Universidad Pedagógica, en su Instituto Rafael Alberto Escobar Lara, de Maracay; también es importante destacar que sus estrategias de cambio, no son demasiado difíciles, al contrario, son caminos legítimos y posibles. Se observa como debilidad, el hecho de que no hace mención a la situación del alumnado, el cual tiene una importante cuota de responsabilidad, al ser el sujeto al cual van dirigido los objetivos de estas estrategias.

Gonzaga (2005), en la Universidad de Costa Rica, realizo una investigación cuyo propósito principal fue indagar la formación de los docentes de educación primaria, desde las estrategias didácticas aplicadas en el desarrollo de los cursos del área pedagógica, al considerar que ésta área es esencial en la construcción del marco conceptual y de acción que fundamenta la práctica educativa.

Este estudio se desarrolló a través de la metodología cualitativa, sustentada en los datos provenientes del plan de estudios, de los programas y de lo que los sujetos dicen y hacen (opiniones, percepciones de docentes y estudiantes). La población estuvo conformada por siete profesores que atienden parte de los cursos indicados; se consideraron además doce estudiantes, los cuales cursan tercero y cuarto año de la carrera y en su mayoría han aprobado todos los cursos, o casi la totalidad de todos los cursos

42 La Práctica Profesional como área para potenciar las competencias pedagógicas necesarias para la enseñanza en Educación Infantil 
Algunos de sus resultados arrojaron que: a) en los planes de estudio, no se presentan las estrategias metodológicas, sino que se debe inferir a partir de la fundamentación teórica, del enfoque pedagógico del plan, de las actividades y criterios de evaluación; b) predominan tendencias pedagógicas tradicionales y cierta tendencia hacia el constructivismo, predomino de destrezas cognoscitivas, los lineamientos y orientaciones teórico-prácticas están presentes en el plan de estudio, pero se diluyen o no están presentes en los programas del curso; c) se evidencia un distanciamiento entre el discurso docente y su práctica, esto es reconocido por los estudiantes, no así por los profesores; d) la práctica pedagógica universitaria, se enriquece y diversifica con el empleo de diversas técnica y recursos didácticos por parte de los estudiantes.

El abordaje metodológico de esta investigación, guarda relación directa con nuestro estudio, ya que se considera tanto el análisis de documentos, como las opiniones de profesores universitarios y estudiantes. Entre las fortalezas, se aprecia que el autor indaga acerca de las estrategias didácticas, utilizando una muestra acorde con la metodología seleccionada, obteniendo hallazgos significativos: las diferencias de opiniones, las variaciones entre los planes y programas de curso, lo cual ayuda a tener otra mirada, de esta realidad especifica.

Por su parte, Salcedo, Forero, Callejas, Pardo y Oviedo (2005), desarrollaron una investigación titulada: “Los estilos pedagógicos y la Investigación-Acción. Implicaciones en el desarrollo profesional de los docentes universitarios." El propósito de este estudio fue determinar las implicaciones que tiene la visibilización, reflexión-crítica y toma de conciencia de los estilos pedagógicos desde los cuales cada profesor desarrolla su práctica pedagógica, mediante la investigación acción. La intencionalidad consistió en conformar grupos de Investigación-Acción y generar la problematización de las prácticas pedagógicas de los profesores de la Universidad Pedagógica Nacional de Colombia, a través de un proceso criticoreflexivo sobre los estilos pedagógicos y el desarrollo profesional docente.

Esta investigación se realizó teniendo como fundamento el paradigma critico-reflexivo, y se fundamenta en tres pilares: los participantes, el comportamiento de las personas y los métodos 43 La Práctica Profesional como área para potenciar las competencias pedagógicas necesarias para la enseñanza en Educación Infantil 
cualitativos. Los participantes en este estudio están conformados por: once profesores de la Universidad Pedagógica Nacional que pertenecen a las facultades de Ciencia y Tecnología, Educación y Bellas Artes; seis profesores que son estudiantes de primer semestre de la maestría en Educación. Entre las técnicas e instrumentos se tiene: observación de clases, registros que incluyen grabaciones de audio y video, cuestionarios para profesores y estudiantes, diarios de campo y entrevistas.

Con respecto a los resultados de esta investigación se destacan las siguientes ideas expresadas por los profesores: el desarrollo profesional docente se entiende como toda posibilidad de cualificación humana y profesional (docente y disciplinar) que redunda en el quehacer pedagógico, tales como: mejoramiento en competencias pedagógico-didácticas, capacidad en áreas específicas del conocimiento y mejoramiento en competencias investigativas. Para otros profesores es un proceso que apoya su crecimiento individual, en su formación educativapedagógica y en el desempeño docente en su campo disciplinar, entre otras. Las categorías que emergen de estas reflexiones son: el reconocimiento del estado actual y la identificación del estado deseado. Como conclusión se plantea que la diversidad de estilos pedagógicos que fueron encontrados en la identificación inicial, muestra la complejidad y riqueza de las diferentes alternativas que orientan los procesos de formación en la universidad, las cuales además de reconocidas, son susceptibles de cambio cuando se asume una perspectiva crítica y profesional que permita fortalecer de manera progresiva los procesos de formación de educadores.

Fortalezas del estudio de Salcedo, Forero, Callejas, Pardo y Oviedo (2005), la posibilidad de realizar colectivos de reflexión con los profesores universitarios, es un ejemplo a seguir por parte de quienes nos desempeñamos en este nivel educativo, ya que permite el abordaje de problemas comunes o no, que posibilitan la resolución conjunta y por tanto dan la oportunidad tanto a estudiantes como profesores de abordar proyectos de investigación consustanciados con el contexto en el cual se labora. La debilidad que se observa en este estudio es la falta de información para el lector, sobre las dificultades que se presentan en este tipo de estudio y 
además las formas en las cuales pudieron resolverlas, ya que es bien sabido la natural resistencia ante procesos de revisión de la propia práctica profesional de los formadores de docentes.

Siguiendo con los trabajos seleccionados, se tiene el estudio documental de Caballero (2005), titulado: La formación inicial del profesorado de Educación Infantil y Primaria, dentro del marco Europeo. La autora, parte de los basamentos legales previstos en el proceso de convergencia europea en Educación Superior, sobre la formación inicial y permanente del profesorado universitario, la cual se debe orientar a conseguir un profesorado competente y motivado por una docencia centrada en las actividades del estudiante, donde la enseñanza sea individualizada y en pequeños grupos; Así, el estudiante adquirirá habilidades de solución de problemas y desarrollará un pensamiento crítico y reflexivo que le permitirá progresar a su propio ritmo, usar sus propias estrategias y, en definitiva, aprender a aprender.

Desde este punto de partida, el profesorado tendrá que enfrentarse a nuevos retos y, por tanto, al desarrollo de nuevas competencias. Pasará de ser un expositor de contenidos a convertirse en orientador del aprendizaje de los alumnos. Es decir, lograr que los alumnos adquieran autonomía en sus aprendizajes Esta autonomía en el aprendizaje se hace además imprescindible en una estructura de mercado laboral variable que demanda profesionales que sepan adaptarse a las nuevas condiciones que van surgiendo, lo que, a su vez, fomenta el aprendizaje a lo largo de la vida, tan necesario para el desarrollo personal y para la actualización continua en el ámbito profesional. La autora concluye su ensayo afirmando que, la formación inicial debe recuperar la fuerza que ha ido perdiendo en las últimas décadas, ya que actualmente todos los esfuerzos parecen ponerse al servicio de la formación permanente o continua. También es preciso, por parte de las universidades, la elaboración de un plan de formación propio que ayude a los docentes y demás implicados a desarrollar las competencias necesarias para llevar a cabo una mejora de sus funciones.

A título de análisis del trabajo de Caballero (2005), se percibe una situación de cambios importantes en el proceso de formación inicial del profesorado, el cual requiere de grandes dosis 45 La Práctica Profesional como área para potenciar las competencias pedagógicas necesarias para la enseñanza en Educación Infantil 
de esfuerzo y voluntad para lograr el propósito de formar profesionales con autonomía y capacidad de toma de decisiones; no obstante, la piedra angular para lograr estas metas es el propio profesor universitario, a quien le corresponde asumir que, debe revisar su práctica e involucrarse en las propuestas de cambio, lo cual resultaría ideal si se llega a cumplir de manera satisfactoria.

En este orden de ideas, otro estudio que vale destacar, es el de Vivanco, Bravo, Torres y Cárcamo (2010) el cual tuvo como propósito conocer, cuales son las representaciones sociales que los estudiantes de pedagogía de enseñanza media de la Universidad del Bio-Bio, tienen acerca del saber pedagógico y el saber disciplinar, y cuál es su visión de las debilidades y fortalezas de su proceso de formación docente. Utilizaron entrevistas estructuradas, para describir la opinión de los alumnos de pedagogía, respecto de la construcción de su saber pedagógico y disciplinario recibido durante su formación inicial, identificar, desde la perspectiva de los estudiantes, las debilidades y fortalezas que reconocen en su proceso de formación docente y contrastar la representación social que los estudiantes tienen de la formación pedagógica con la disciplinaria.

Entre los resultados de este estudio, se tiene: la opinión de los entrevistados sobre la didáctica, expresa en forma evidente, la falta de preparación previa y específica de cada clase por parte de los profesores, además plantean como fundamental la necesidad de unir la especialidad (el qué enseñar) con la didáctica, determinada en el cómo enseñar los contenidos de manera fusionada, lo que permitiría una mayor internalización del rol docente desde los primeros años de formación y además el tipo de clase que predomina en la formación inicial docente, es la clase expositiva; los docentes tanto de pedagogía como de la especialidad, tienden a presentar los contenidos de manera tal que el profesor es el centro activo dentro de la sala de clases; Las practicas pedagógicas fueron también un punto neurálgico en la evaluación del currículo, se hace latente la necesidad de tener más contacto con los alumnos en años previos a la práctica profesional. 
En el trabajo de Vivanco, Bravo, Torres y Cárcamo (2010), se confirma que la opinión de los alumnos sobre la práctica profesional es semejante a la de otras investigaciones; además la evaluación que le hacen a la didáctica empleada por los profesores revela que no ha sido la mejor y que se requiere de cambios importantes en estos procesos de formación inicial de docentes.

\section{Cuadro resumen investigaciones previas sobre Formación inicial de docentes}

\begin{tabular}{|c|c|c|c|c|c|}
\hline Titulo & Autor & Año & Muestra & Método & Resultados \\
\hline $\begin{array}{l}\text { La formación de } \\
\text { profesores, desafíos } \\
\text { y prioridades en el } \\
\text { Chile de hoy }\end{array}$ & $\mathrm{Zu}$ & 1995 & 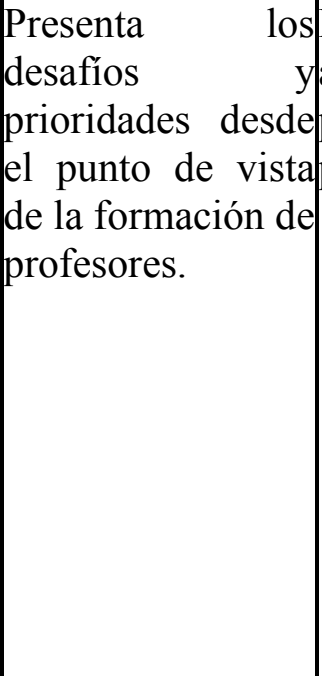 & $\begin{array}{l}\text { Documental, } \\
\text { análisis } \\
\text { planes } \\
\text { programas }\end{array}$ & 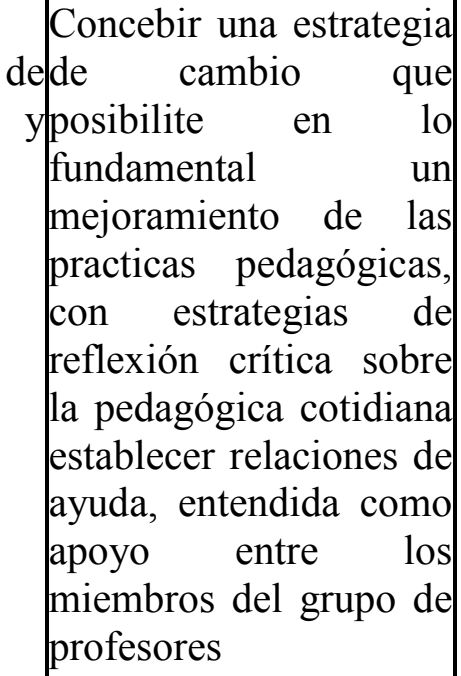 \\
\hline $\begin{array}{|lrr|}\text { Las } & \text { estrategias } \\
\text { didácticas } & \text { en } & \text { la } \\
\text { formación } & & \text { de } \\
\text { docentes } & & \text { de } \\
\text { educación } & & \\
\text { primaria } & & \\
\end{array}$ & & 2005 & $\begin{array}{|lr|}\text { Se consideraron } \\
\text { como fuente } \\
\text { información: } \\
\text { profesores, } \\
\text { estudiantes. }\end{array}$ & & \begin{tabular}{llr|} 
Tendencia & pedagógica \\
tradicional & y & cierta \\
tendencia & hacia & el \\
constructivismo, & \\
predominio & de \\
destrezas cognoscitivas.
\end{tabular} \\
\hline \begin{tabular}{|l|} 
Los estilos \\
pedagógicos y la \\
investigación \\
acción. \\
Implicaciones en el \\
campo profesional.
\end{tabular} & $\begin{array}{l}\text { Salcedo L., } \\
\text { Forero, F., } \\
\text { Callejas } \\
\text { M., Pardo } \\
\text { A. y } \\
\text { Oviedo P. }\end{array}$ & 2005 & $\begin{array}{l}\text { Participantes: } \\
\text { once profesores } \\
\text { de la universidad } \\
\text { pedagógica } \\
\text { nacional, } \\
\text { profesores } \\
\text { estudiantes del } \\
\text { primer semestre }\end{array}$ & $\begin{array}{l}\text { Investiga } \\
\text { acción. }\end{array}$ & 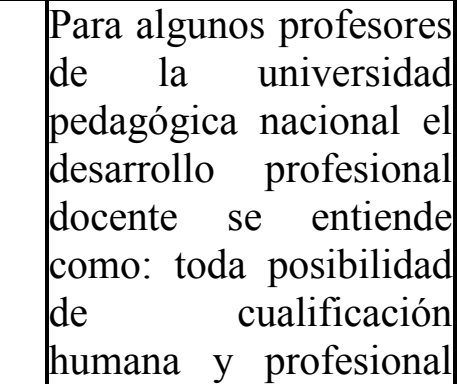 \\
\hline
\end{tabular}




\begin{tabular}{|c|c|c|c|c|c|}
\hline & & & $\begin{array}{l}\text { de la maestría en } \\
\text { educación. }\end{array}$ & & $\begin{array}{l}\text { (docente y disciplinar } \\
\text { que redunde en } \\
\text { quehacer pedagógico }\end{array}$ \\
\hline \begin{tabular}{|l|} 
La formación \\
inicial del \\
profesorado de \\
Educación Infantil \\
y Primaria, dentro \\
del marco Europeo
\end{tabular} & $\begin{array}{l}\text { Caballero, } \\
\text { K. }\end{array}$ & 2005 & 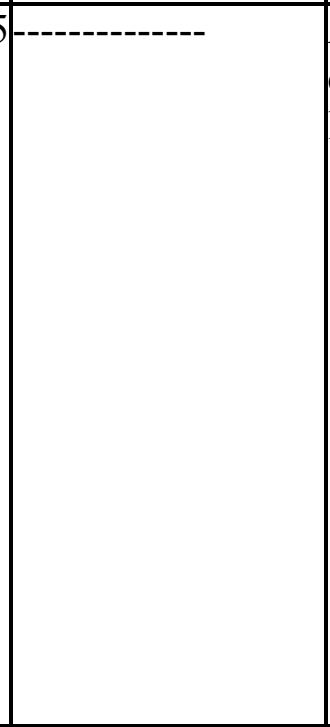 & $\begin{array}{l}\text { Análisis } \mathrm{d} \\
\text { documentos } \\
\text { legales }\end{array}$ & $\begin{array}{l}\text { de calidad en la } \\
\text { formación inicial de } \\
\text { profesorado } \\
\text { Educación Infantil y } \\
\text { Primaria, dentro de un } \\
\text { Espacio Europeo de } \\
\text { Educación Superior } \\
\text { supone desplazar e } \\
\text { centro de atención de } \\
\text { sujeto que enseña a } \\
\text { sujeto que aprende, de } \\
\text { modo que el trabajo de } \\
\text { los estudiantes se } \\
\text { constituya como eje } \\
\text { central de su formación }\end{array}$ \\
\hline \begin{tabular}{|l|} 
Representaciones \\
sociales \\
estudiantes acerca \\
de su formación \\
inicial docente
\end{tabular} & $\begin{array}{l}\text { Vivanco, } \\
\text { M., Bravo, } \\
\text { C., Torres, } \\
\text { M. y } \\
\text { Cárcamo } \\
\text { H. }\end{array}$ & 2010 & 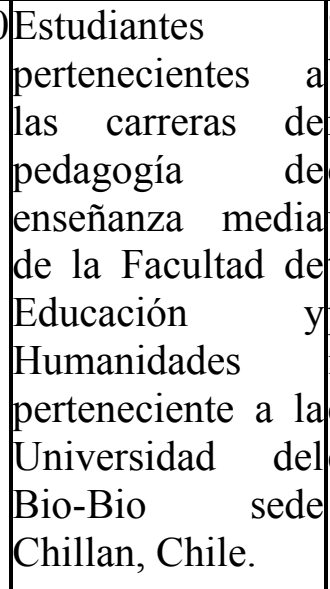 & $\begin{array}{l}\text { Se trabajo e } \\
\text { base a } \\
\text { metodología } \\
\text { cualitativa, } \\
\text { a utilizando com } \\
\text { técnica d } \\
\text { producción d } \\
\text { información 1 } \\
\text { antrevista semi } \\
\text { estructurada. }\end{array}$ & $\begin{array}{l}\text { en } \\
\text { lapedagógica se vación } \\
\text { desplazada por } \\
\text { formación entregada en } \\
\text { no el área disciplinar, tanto } \\
\text { de en el énfasis curricula } \\
\text { de como en la atención } \\
\text { lapuesta por profesores y } \\
\text { ni-estudiantes. }\end{array}$ \\
\hline
\end{tabular}

Cuadro $n^{\circ} 2$. Resumen investigaciones previas sobre formación inicial de docentes. Fuente: elaboración propia.

\subsubsection{Antecedentes sobre la Práctica Profesional}

En relación con los estudios referidos a práctica profesional, tenemos el de Pérez Martina (1997), titulado: Las prácticas de enseñanza a debate: opinión de los alumnos, los profesores de las escuelas universitarias y los maestros de la EGB en ejercicio. Para esta autora, el interés 
investigativo estuvo centrado en la formación práctica de los futuros maestros en las escuelas universitarias, conocer la finalidad que se persigue durante el desarrollo de las prácticas, los pasos metodológicos y el papel que juegan las personas que participan en este proceso. Así mismo, afirma que las escuelas de formación de maestros siguen aplicando (con algunas variaciones) un modelo formativo clásico, el cual está apoyado en tres vertientes: cultura general, teoría pedagógica y prácticas docentes, por lo cual sugiere que en la actualidad este proceso debe orientarse hacia la comprensión global de los principios que subyacen el comportamiento docente.

En este orden de ideas, para este estudio se utilizó el método cuantitativo, apoyado en un instrumento tipo cuestionario de opinión, sobre los aspectos metodológicos, didácticos y pedagógicos relacionados con las prácticas de enseñanza. Se aplicó a una muestra de 2.166 alumnos de las escuelas universitarias del estado español, 320 profesores supervisores de escuelas universitarias y 764 maestros de EGB, tutores de los alumnos durante sus prácticas docentes.

Entre sus principales resultados se destacan: los encuestados afirman que el plan de estudios es inadecuado; del mismo modo, opinan que faltan prácticas de enseñanza y además quieren que se refuercen las ciencias pedagógicas y psicológicas. Respecto al tiempo que debería ocupar las prácticas de enseñanza, los alumnos opinan que entre un $40 \%$ y $50 \%$ del tiempo total de la carrera, por su parte los profesores consideran que es suficiente con un 30\% y los maestros piensan que debería ser un $40 \%$ del total.

Fortalezas del estudio de Pérez (1997) Como puede observarse, existe un total acuerdo en que se debe aumentar el tiempo de las prácticas, también es necesario destacar que en este estudio se consideraron las opiniones de los principales actores de este proceso, lo cual le da mayor validez a sus resultados. Como una desventaja, puede señalarse, que la autora pudo realizar algunas entrevistas a estos mismos informantes con el fin de profundizar en detalles como, el desarrollo o metodología de esas prácticas, con el fin de extraer los aspectos positivos y minimizar los negativos de esta amplia muestra en estudio. 
De igual forma, Gonzales (2006), en su investigación titulada: Evaluación y mejora del practicum en las titulaciones de ciencias de la educación de la UPVIEHU, cuyo objetivo primordial fue realizar una evaluación sobre los programas de práctica, en el cual se pretende definir un procedimiento metodológico para su evaluación, que permita aproximarse a la situación actual de la formación práctica de alumnos universitarios. Este trabajo es de corte cuantitativo-cualitativo, como instrumento se utilizó un cuestionario, el cual fue aplicado a 590 estudiantes de practicum, 13 coordinadores y 100 tutores. Entre sus principales resultados: a) la formación previa y específica para el practicum se revela necesaria e imprescindible, tanto para alumnos como para tutores; b) el enriquecimiento por el practicum se produce, pero de forma más autónoma que pautada, debido a la escasa conjunción entre teoría-práctica y al factor "suerte" en la asignación de tutores; c) los criterios de evaluación son conocidos por los alumnos pero, dudan de su eficacia aquellos que no han sido tutorizados y orientados coherentemente; d) existe desproporción entre las expectativas iniciales (altas) y la satisfacción final (media-baja).

El trabajo de González (2006), aporta en gran medida al presente estudio, por cuanto, se evidencia como fortaleza, la imperiosa necesidad de brindar a los alumnos un proceso de tutoría y acompañamiento desde el inicio, desarrollo y cierre de la práctica profesional; se observa como debilidad, la ausencia de datos sobre las opiniones por separado, de cada uno de los grupos de informantes, ya que evidentemente no deben ser las mismas experiencias.

Seguidamente tenemos el trabajo documental de Sayago y Chacón (2007): Las prácticas profesionales en la formación docente: hacia un nuevo diario de ruta. Aquí las autoras intentan colocar al lector en el debate, la reflexión crítica y propositiva sobre el componente práctico, el cual amerita ser repensado a la luz de las orientaciones paradigmáticas del momento, para que así pueda ayudar a estudiantes y profesores a explicar y comprender su trascendencia en el trayecto de formación inicial.

En este orden de ideas, la disertación de este trabajo documental, refiere algunos obstáculos que las autoras ponen en evidencia al analizar las debilidades que encontraron al usar un modelo de prácticas basados en talleres, luego de los cuales el alumno podría cursar la pasantía. De 50

La Práctica Profesional como área para potenciar las competencias pedagógicas necesarias para la enseñanza en Educación Infantil 
acuerdo con sus propias palabras estos talleres se caracterizan por tener, un funcionamiento fragmentado en asignaturas excesivamente desconectadas entre sí, apoyadas en contenidos dispersos sin posibilidad de generar procesos de articulación. Así, se tienen talleres funcionando como pequeñas unidades aisladas dentro del plan de estudio de la carrera.

Como resultado de estos razonamientos se propone redimensionar las Prácticas Profesionales de la Carrera de Educación Básica Integral como el elemento medular del proceso de formación docente, en el cual se centra el análisis de las problemáticas educativas, apoyado en la transdisciplinariedad, y además, incorporar dentro del currículo, prácticas profesionales reales desde el comienzo de la carrera.

Este trabajo, presenta como fortalezas la propuesta de redimensionar las prácticas profesionales apoyadas en la transdisciplinariedad y en ambientes reales desde el inicio de la carrera.

En el año 2007, Escobar publicó un trabajo interpretativo, titulado: La práctica profesional docente desde la perspectiva de los estudiantes practicantes y los tutores. El mismo, tuvo como propósito conocer sobre las perspectivas que tienen los estudiantes practicantes y sus tutores en relación con la Práctica Profesional docente en el pregrado de la Universidad Pedagógica Experimental Libertador (UPEL), Instituto de Mejoramiento Profesional del Magisterio (IMPM) del Núcleo Académico Táchira. Para efectos de la presente investigación se consideró a los estudiantes practicantes (los cuales son docentes en ejercicio) y tutores de las especialidades de Educación Integral y Pedagogía Social, que cursaban la fase de Docencia Integrada, por ser la última fase del componente de Práctica Profesional. Para ello, se aplicó una encuesta referida a los mismos tópicos con seis preguntas abiertas a estudiantes y tutores, de la última fase de las carreras de educación y pedagogía social, en total 42 sujetos de investigación, de los cuales seis son tutores de las fases. En cuanto a sus resultados se tiene que, los problemas referidos por los futuros docentes permiten inferir que sus dificultades mayormente se suscitaron en aspectos personales más que propios de su desempeño docente; contrariamente a los señalados por los tutores quienes refieren limitaciones en competencias esenciales como la escritura, lectura, 
trabajo grupal, entre otros; además, se aprecia en las respuestas referidas, el predominio de la angustia, el nerviosismo y el miedo, como sentimientos que genera el desarrollo de las prácticas en los alumnos.

El trabajo de Escobar (2007), revela como fortaleza, que aun y cuando las prácticas profesionales se estén realizando con docentes en ejercicio (los cuales necesitan el título universitario), éstos también manifiestan sentimientos de miedo, angustia y nerviosismo ante la experiencia de práctica. Del mismo, modo, los profesores observan fallas en estos alumnos, lo cual también ocurre con estudiantes sin ningún tipo de experiencia previa.

Recientemente, Ríos, Lagos y Walker (2011), realizaron un trabajo de investigación, titulado: El efecto de las experiencias de práctica en el desarrollo del sentido de auto eficacia en la formación inicial de educadoras de párvulos. El propósito de la investigación fue conocer la evolución del sentido de auto eficacia de los estudiantes de pedagogía en educación parvularia, hipotetizando que éste debiera fortalecerse a medida que los estudiantes avanzan en su formación y se ven inmersos en una mayor cantidad de experiencias prácticas de aula. Para ello se aplicó a los estudiantes de cada semestre de la carrera de Educación Parvularia una escala de auto eficacia, con el fin de comparar su rendimiento de acuerdo al semestre de carrera que cursaban. Los resultados encontrados, permitieron concluir que se apoya parcialmente la hipótesis del aumento del sentido de auto eficacia a medida que se avanza en la formación inicial y se cuenta con una mayor experiencia de práctica pedagógica.

El trabajo de Ríos, Lagos y Walker (2011), pone especial acento, en un contacto precoz e intensivo con la realidad educativa durante el transcurso de la formación, es decir el eje de prácticas esté presente de manera transversal a lo largo de toda la formación. Este significado que se le otorga a la experiencia es, el que justamente se puede acompañar desde una práctica profesional reflexiva, bien diseñada. Como debilidad se percibe, la forma particular de administrar estas prácticas, no puede extrapolarse sus resultados a otros contextos educativos.

52

La Práctica Profesional como área para potenciar las competencias pedagógicas necesarias para la enseñanza en Educación Infantil 
Cuadro resumen investigaciones previas sobre práctica profesional

\begin{tabular}{|c|c|c|c|c|c|}
\hline Titulo & Autor & Año & Muestra & Método & Resultados \\
\hline $\begin{array}{l}\text { Las prácticas de } \\
\text { enseñanza a } \\
\text { debate: opinión } \\
\text { desde los alumnos, } \\
\text { los profesores de } \\
\text { las escuelas } \\
\text { universitarias y los } \\
\text { maestros en } \\
\text { servicio. }\end{array}$ & Pérez, M. & 1997 & \begin{tabular}{|l|} 
Se aplico a una \\
muestra de 2.166 \\
alumnos, 320 \\
profesores \\
supervisores de \\
escuelas \\
universitarias y 764 \\
maestros de EGB.
\end{tabular} & $\begin{array}{l}\text { Cuantitativo, } \\
\text { apoyado en un } \\
\text { instrumento tipo } \\
\text { cuestionario de } \\
\text { opinión. }\end{array}$ & $\begin{array}{l}\text { Plan de estudios } \\
\text { inadecuado; del mismo } \\
\text { modo, opinan que faltan } \\
\text { prácticas de enseñanza y } \\
\text { además quieren que se } \\
\text { refuercen las ciencias } \\
\text { pedagógicas y psicológicas. }\end{array}$ \\
\hline \begin{tabular}{|lrr} 
Evaluación & & y \\
mejora & & del \\
practicum en & las \\
titulaciones & de \\
ciencias de & la \\
educación de & la \\
UPV/EHU & &
\end{tabular} & $\begin{array}{l}\text { Natalia } \\
\text { González }\end{array}$ & 2006 & $\begin{array}{|lr|}590 \text { estudiantes } & \text { de } \\
\text { practicum, r } & 100 \\
\text { tutores } & \text { de } \\
\text { practicum y } & 13 \\
\text { coordinadores } & \text { de } \\
\text { practicum } & \end{array}$ & 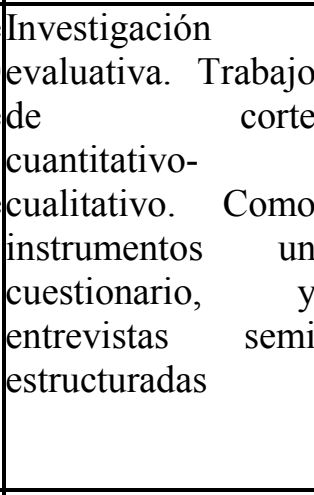 & $\begin{array}{l}\text { Adecuación, coherencia y } \\
\text { utilidad del diseño del } \\
\text { practicum, es satisfactoria } \\
\text { para los coordinadores y } \\
\text { discutible para los tutores. } \\
\text { Desproporción entre las } \\
\text { expectativas iniciales (altas) } \\
\text { la satisfacción final } \\
\text { (media-baja) identificable } \\
\text { entre los diferentes } \\
\text { colectivos implicados }\end{array}$ \\
\hline $\begin{array}{l}\text { Las prácticas } \\
\text { profesionales en la } \\
\text { formación docente: } \\
\text { hacia un nuevo } \\
\text { diario de ruta. }\end{array}$ & $\begin{array}{l}\text { Sayago, } \\
\text { Z. y } \\
\text { Chacón } \\
\text { M. }\end{array}$ & 2007 & & \begin{tabular}{|l} 
Documental, \\
análisis de modelos \\
de \\
profesional
\end{tabular} & $\begin{array}{l}\text { Se sugiere estructurar el Eje } \\
\text { de Prácticas Profesionales } \\
\text { teniendo presente los } \\
\text { planteamientos del enfoque } \\
\text { hermenéutico-reflexivo, } \\
\text { por cuanto supone su } \\
\text { construcción como objeto } \\
\text { de estudio y campo de } \\
\text { intervención en la compleja } \\
\text { situación de la cultura } \\
\text { escolar }\end{array}$ \\
\hline $\begin{array}{|lrr|}\text { La } & \text { práctica } \\
\text { profesional } & \text { docente } \\
\text { desde } & & \text { la } \\
\text { perspectiva } & \text { de } & \text { los } \\
\text { estudiantes } & & \\
\text { practicantes } & \text { y } & \text { los } \\
\text { tutores } & & \\
\end{array}$ & $\begin{array}{l}\text { Escobar } \\
\text { Nancy }\end{array}$ & 2007 & 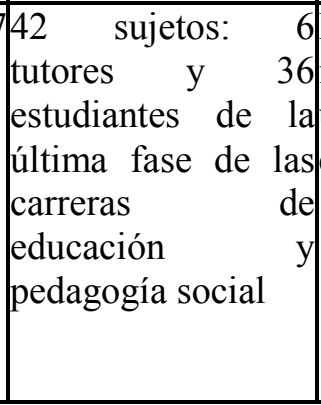 & $\begin{array}{l}\text { Enfoque } \\
\text { interpretativo, } \\
\text { uso la entrevi } \\
\text { estructurada. }\end{array}$ & $\begin{array}{l}\text { El dilema es una constante } \\
\text { en el desarrollo de la } \\
\text { práctica, los estudiantes le } \\
\text { dan importancia a la } \\
\text { práctica profesional, } \\
\text { angustia, nerviosismo y } \\
\text { miedo son los sentimientos } \\
\text { que les genera la práctica, } \\
\text { se requiere enfatizar en el }\end{array}$ \\
\hline
\end{tabular}

53

La Práctica Profesional como área para potenciar las competencias pedagógicas necesarias para la enseñanza en Educación Infantil 


\begin{tabular}{|c|c|c|c|c|c|}
\hline & & & & & $\begin{array}{l}\text { desarrollo de la capacidad } \\
\text { de aprender a aprender }\end{array}$ \\
\hline $\begin{array}{l}\text { El efecto de las } \\
\text { experiencias de } \\
\text { práctica en el } \\
\text { desarrollo del } \\
\text { sentido de auto } \\
\text { eficacia en la } \\
\text { formación inicial de } \\
\text { educadoras de } \\
\text { párvulos. }\end{array}$ & $\begin{array}{l}\text { Rio, M., } \\
\text { Lagos, C., } \\
\text { Walker, } \\
\text { H. }\end{array}$ & 2011 & $\begin{array}{l}\text { La primera } \\
\text { medición se llevó a } \\
\text { cabo en abril de } \\
2008, \text { a un grupo de } \\
76 \text { alumnos de los } \\
\text { semestres I, III, V y } \\
\text { VII. En la segunda } \\
\text { medición } \\
\text { participaron } 62 \\
\text { alumnos, que en } \\
\text { esa fecha cursaban } \\
\text { los semestres II, } \\
\text { IV, VI } \\
\text { y VIII }\end{array}$ & $\begin{array}{l}\text { Aplicación de la } \\
\text { versión de } 24 \text { ítems } \\
\text {-traducida al } \\
\text { castellano- de la } \\
\text { Escala de Sentido } \\
\text { de Auto eficacia de } \\
\text { los Profesores de } \\
\text { Tschannen-Moran } \\
\text { \& Woolfolk Hoy } \\
(2001)\end{array}$ & $\begin{array}{l}\text { Los resultados muestran } \\
\text { que el sentido de auto } \\
\text { eficacia tiende a fluctuar } \\
\text { durante la formación } \\
\text { pedagógica inicial, } \\
\text { observándose } \\
\text { especialmente desafiado } \\
\text { cuando las alumnas se } \\
\text { enfrentan a contextos } \\
\text { educativos más complejos, } \\
\text { como es el caso de los de } \\
\text { dependencia municipal. }\end{array}$ \\
\hline
\end{tabular}

Cuadro $n^{\circ} 3$. Resumen investigaciones previas sobre práctica profesional. Fuente: elaboración propia.

Tal como puede observarse, los estudios e investigaciones presentados como antecedentes se consideran de gran utilidad, ya que constituyen un punto referencial para la presente investigación, pues contienen elementos relacionados directamente con la formación inicial de profesores y la práctica profesional, sus características, problemas comunes y variadas propuestas de mejorar. En tal sentido, la problemática de la práctica profesional en la formación inicial de profesores ha sido estudiada en distintos países latinoamericanos, cuyo interés investigativo revela que si existe una problemática común, tanto para la formación inicial, como para la práctica profesional.

A título ilustrativo, en esta revisión se demostró que en relación a la Formación inicial, los autores: Zurita (1995), Gonzaga (2005), Salcedo, Forero, Callejas, Pardo y Oviedo (2005), Caballero (2005), Vivanco, Bravo, Torres y Cárcamo (2010), coinciden en una misma problemática: a) predominio de tendencias pedagógicas tradicionales, b) distanciamiento entre el discurso docente y su práctica; c) la necesidad de reflexión-critica y toma de conciencia de los estilos pedagógicos desde los cuales cada profesor desarrolla su práctica pedagógica, d) la falta de preparación previa y específica de cada clase por parte de los profesores, e) el tipo de clase 
que predomina en la formación inicial docente, es la clase expositiva; es decir que, la piedra angular en todos estos estudios la constituye el propio profesor universitario, a quien le corresponde asumir que, debe revisar su práctica e involucrarse en las propuestas de cambio, tales como, la posibilidad de realizar colectivos de reflexión entre los profesores universitarios, ya que permite el abordaje de problemas comunes o no, que posibilitan la resolución conjunta

En cuanto a los estudios sobre la Práctica profesional, los trabajos realizados por : Pérez Martina (1997), Gonzales (2006), Sayago y Chacón (2007), Escobar (2007), y Ríos, Lagos y Walker (2011), revelan como necesario e imprescindible : a) aumentar el tiempo de las prácticas b) necesidad de formación previa y específica para el practicum tanto para alumnos como para tutores; c) escasa conjunción entre teoría-práctica y d) prácticas profesionales reales desde el comienzo de la carrera,

Lo anterior, indica que esta temática representa un tema de gran importancia y que en la actualidad ha tomado mayor auge, además, con este pequeño arqueo documental se deja en evidencia que no existen estudios previos sobre la práctica profesional en educación preescolar de la Universidad Pedagógica Experimental Libertador, instituto Rafael Alberto Escobar Lara, de Maracay; Así, no queda duda de que las experiencias de práctica son importantes para los alumnos en formación, pues son esas experiencias las que les entregan el recurso más relevante de la competencia pedagógica, la sensación de ser capaz de asumir el importante rol de educador infantil, la que proviene justamente de la interacción y experiencia de trabajar con niños y niñas y enseñar en aulas reales.

\subsection{Descripción General de la Investigación y objetivos perseguidos}

La presente investigación se estructuró en dos partes. La primera, corresponde al marco teórico y comprende seis capítulos; el primero de ellos se refiere a la Introducción General, en la que se expusieron cuatro aspectos de gran importancia: en primer lugar se desarrollan ideas generales e introductorias sobre el hecho de emprender una investigación de la práctica profesional, como

55

La Práctica Profesional como área para potenciar las competencias pedagógicas necesarias para la enseñanza en Educación Infantil 
factor de interés constante en la comunidad científica de las Ciencias de la Educación. De acuerdo con la referencias al respecto, la práctica profesional es uno de los componentes de la formación pedagógica de mayor transcendencia e importancia para la construcción del conocimiento profesional de los futuros docentes, (González 2006; Latorre, 2007). Luego, en segundo lugar, se aborda la relevancia del tema sobre la formación de maestros, la cual se ha convertido en una de las prioridades más defendidas tanto en el proceso de convergencia europea (Declaración de Bolonia 1999) como en las instituciones de Educación Superior en América Latina (Proyecto Tuning 2002); así como, el proceso de transformación curricular de las universidades y entre ellas la UPEL. En tercer lugar, se presenta la justificación, es decir los motivos que impulsaron la realización de esta tesis; el primero, es de carácter personal y profesional, donde se asume el compromiso que los docentes tenemos con la profesión y con los alumnos de educación superior, ya que éste es el ámbito laboral en el que se desempeña la investigadora y por tanto el acceso a la información e impacto es de mayor contribución. Además, en estudios previos (Galindo, 2008, 2009) se indicó que tanto el egresado, como el estudiante en formación de UPEL IPMAR, demuestran serias debilidades en cuanto a conocimientos y habilidades prácticas referidas a la didáctica del nivel inicial. El segundo motivo, responde al compromiso de carácter académico y social, al estudiar un aspecto de la realidad de la Universidad Pedagógica Experimental Libertador, Instituto Rafael Alberto Escobar Lara, ya que permite presentar una mirada crítica y auto crítica respecto a ella misma y sus principales actores (estudiantes y profesores) como objeto de investigación, para generar información que le permita identificar fortalezas y debilidades, de modo de potenciar las primeras y fortalecer las segundas. En cuarto lugar, se presenta la revisión de investigaciones realizadas sobre el tema, cuyas conclusiones permiten revelar coincidencias con este estudio, así como los aspectos que no han sido tratados y que además contribuyen a justificar aún más la presente investigación; además, con este pequeño arqueo documental se deja en evidencia que no existen estudios previos sobre la práctica profesional en educación preescolar de la Universidad Pedagógica Experimental Libertador, instituto Rafael Alberto Escobar Lara, de Maracay.

56

La Práctica Profesional como área para potenciar las competencias pedagógicas necesarias para la enseñanza en Educación Infantil 
En el segundo capítulo, se conceptualiza la Educación Superior, en su importante función de formar, educar y realizar investigaciones, así como de su capacidad para transformarse y propiciar el cambio y el progreso de la humanidad. También se abordó la Formación Superior del Profesorado, considerando como referente los planteamientos de UNESCO (1998), al alertar sobre la necesidad de reformular los planes de estudio y utilizar métodos nuevos y adecuados que permitan superar el énfasis en el dominio cognitivo de las disciplinas. En este mismo orden de ideas, se hizo un breve análisis sobre la Formación del Docente en América Latina y Europa, para dejar claro que en la mayoría de los países, la formación docente inicial se realiza en institutos superiores pedagógicos y en universidades, con un proceso académico de una duración entre tres y cinco años. Así mismo, fue ineludible revisar la Formación Superior del Profesorado en Venezuela, y en especifico a la Universidad Pedagógica Experimental Libertador y su Diseño Curricular, el cual presenta una organización lineal o por asignaturas, es decir, una concepción y orientación centrada en el Plan de Estudios y sus contenidos más que el aprendizaje, lo que limita las posibilidades de éxito e impacto que tendrá el egresado. El cierre de este capítulo, se concreto en el Compromiso Profesional de la Universidad con la Sociedad, en consonancia con los planteamientos de Freire (2004:88), para este autor, la primera condición para que un ser pueda ejercer un acto comprometido, está en que sea capaz de actuar y reflexionar, es decir, ser capaz de alejarse de su contexto para objetivarlo y transformarlo.

En el tercer capítulo, se presenta la conceptualización en Educación infantil, apoyado en los planteamientos de autores como Peralta (2002), Zabalza (2006), Gassó, (2004), para quienes la educación infantil procura potenciar y fortalecer todas las oportunidades de desarrollo de los niños, así como de proporcionarles de competencias, habilidades, hábitos, aptitudes y actitudes que puedan contribuir a hacer más placentera, práctica, efectiva y feliz su vida personal y escolar. Así mismo, se consideraron los Acuerdos Mundiales para la educación infantil, ya que este marco legal representa un principio importante para profundizar y ampliar los estudios relacionados con la educación infantil. Estos compromisos internacionales, son una expresión del consenso de los países sobre la importancia de los seis primeros años de vida del niño así como la 
notable labor que cumple la familia y la sociedad; así, las declaraciones emitidas por organizaciones internacionales como UNESCO, ONU, OEA, entre otros, reconocen y ratifican la importancia de la educación infantil y de un jerarquizado desarrollo profesional de los educadores infantiles. En este mismo capítulo se encuentra la evolución curricular de la Educación Infantil Venezolana, presentando brevemente una historia de la atención al niño preescolar en este contexto; la cual, tiene su antecedente más importante en el año 1879, cuando surgen los asilos para huérfanos; luego, en 1948 la ley de educación, considera la educación preescolar para niños de tres a siete años, y en 1969, se edita, el primer programa oficial para educación preescolar. Desde el año 2005, la atención integral a la población infantil en Venezuela, es denominada como educación inicial, donde se considera la atención integral al ser humano, en la etapa fundamental de la vida, desde el nacimiento (aún antes de la concepción) hasta los seis años de edad, privilegiando el desarrollo de la persona. Dentro de la descripción de este nivel educativo, también se consideró, el tema del profesional para Educación Infantil, el cual debe poseer dominio de muchas disciplinas tales como: desarrollo físico, salud, psicología, lenguaje y muchos aspectos de psicología del desarrollo, y además la competencia de cuidar y educar niños de cero a seis años de edad, en instituciones educacionales, en complementación a la acción de la familia (Katz, 2005, Didonet, 2007).

El cuarto capítulo, denominado Didáctica del nivel de Educación Infantil, explica en primer lugar, la conceptualización de la Didáctica como una disciplina que estudia, desde la propia práctica, los modos de ser y de enseñar del docente a fin de provocar en sus alumnos un aprendizaje útil y placentero (Ribot y Varguillas ,2008). Luego en segundo lugar, se presenta la evolución histórica de la Didáctica en Educación Infantil, en la cual se distinguen tipologías que surgen desde diferentes criterios y que aportan en función de conocer la construcción del saber pedagógico en este nivel. Algunos autores la distinguen como un antes y un después, en la escuela de la infancia. El antes, como un periodo pedagógicamente oscuro, y el después, como el periodo de la alternativa, en la que se derriba la lógica custodial-asistencial y se construye la idea del derecho de toda la infancia a la educación (Frabboni, 1996); por su parte, Fernández, 
González, Requena y Vicuña, (1994), la organizan atendiendo a grupos de autores que son asociados de acuerdo con el movimiento, o momento histórico en el que sus producciones se dieron a conocer: Los precursores de la educación temprana, Movimiento Escuela Nueva, Movimiento Psicoanalítico, la escuela de Ginebra, la escuela soviética. Esta reflexión permitió distinguir los vacíos y también los aportes que podrían continuar enriqueciendo este campo educativo, en el cual hay muchas contribuciones que aún siendo conocidas, no se han llevado a la práctica de una manera reflexiva, critica y principalmente, contextualizada a los diferentes espacios y culturas del mundo. Finalmente, en este capítulo se describen por separado los principales elementos de la Didáctica en Educación infantil: Organización del ambiente y los recursos, planificación, evaluación, articulación con la familia y la comunidad, como elementos básicos que permiten hacer operativa la acción didáctica en el nivel inicial.

Luego, en el capitulo cinco, se trabaja en el tema de la formación profesional basada en competencias, donde se muestra un breve análisis de los constructos teóricos que respaldan el término competencias, luego se incluyen modelos teóricos, metodología y resultados, derivados de la experiencia de algunos países pioneros, en incluir en sus procesos formativos las competencias. También, se presentan algunas consideraciones generales sobre educación, enseñanza y aprendizaje. Términos muy relacionados con el tema de las competencias pedagógicas, resaltando la concepción de educación, como un proceso de configuración y construcción que capacita al hombre para el cambio; para ello, es importante la conjugación del desarrollo personal, en la puesta en acción de los aprendizajes, considerando la interrelación con contexto en el cual el sujeto en formación se desenvuelve, (Martínez, 2008). Ésta y otras consideraciones, permiten apreciar la tendencia constructivista subyacente en los planteamientos que se asumen en esta investigación. Todo lo anterior, conlleva a considerar a la actuación humana, como un hecho constructivo y creativo, por cuanto, las personas en situación de aprendizaje, construyen activamente un conocimiento personal y subjetivo de la realidad que orienta sus acciones y actuaciones. Comprender esta problemática y sus consecuencias, implica considerar que el mejoramiento de los métodos de enseñanza no debe ser considerado un fin en sí 
mismo, sino como un importante medio para que las universidades cumplan sus funciones sociales, situar el papel de la enseñanza como función de la universidad, en relación con la sociedad, en la que al analizar la realización de las funciones clásicas de la universidad, tales como, enseñanza- investigación - extensión, sugieren una formación docente orientada hacia la investigación de las competencias pedagógicas, es decir, la problemática que envuelve su acción, asumiendo que esta acción tiene impacto tanto en un nivel micro social, como macro social. A manera de cierre, en este capítulo se analizan distintas posturas sobre el término competencias pedagógicas; tenemos que para Zabalza (2003) y Tejada (2009) son competencias docentes; por su parte, Ribot, Varguillas y Báez (2008) las identifican como competencias didácticas; finalmente, Valdés, Mujica, Roque y Darin (2007) y Arboleda (2011), las consideran como competencias pedagógicas. Este análisis, conlleva a considerar las competencias pedagógicas desde un amplio marco de referencia o guía en la formación inicial y continua de futuro profesor de educación infantil, pues permite ilustrar los contenidos, actitudes, orientaciones a desarrollar en este importante proceso de formación de la carrera docente

Finalmente en el capítulo seis, trata el tema de la Formación Superior del Profesorado de Educación Preescolar, para intentar dar conocer la situación referida a la formación de profesionales en este nivel educativo, en las universidades e institutos venezolanos, las cuales tienen la responsabilidad de formar al licenciado en educación preescolar, o profesor especialidad: educación preescolar, estos profesionales tienen como compromiso fundamental facilitar el desarrollo integral del niño (social, afectivo, cognoscitivo, motriz, físico-biológico) en edad preescolar, fomentando la participación de la familia en el proceso evolutivo integral del niño. Luego, en segundo lugar se describen las Instituciones de Educación Superior en Venezuela, cada una con una organización curricular particular o específica; al respecto, en Venezuela existen universidades e institutos universitarios (públicos y privados) responsables de la formación de profesionales para la educación infantil, entre las públicas, pueden mencionarse: Universidad Nacional Abierta (UNA), Universidad Nacional Experimental Simón Rodríguez (UNERSR), Universidad de Carabobo (UC), Universidad del Zulia (LUZ), Universidad 60 La Práctica Profesional como área para potenciar las competencias pedagógicas necesarias para la enseñanza en Educación Infantil 
Pedagógica Experimental Libertador (UPEL), Universidad Bolivariana de Venezuela (UBV). En tercer lugar, se trata sobre la formación de profesores de educación preescolar en la UPEL donde se describe la organización curricular y sus componentes: Formación General, Formación Pedagógica, Formación Especializada y Práctica Profesional; otros factores de importancia para la administración del currículo, tales como: el número de cursos y fases, la unidad crédito, el semestre o período académico, la duración de la carrera, el nivel de los cursos y las prelaciones. En cuarto lugar, se desarrolla ampliamente el tema de la práctica profesional: se repasa brevemente los conceptos relacionados; además, se considera la práctica profesional en la formación de docentes de educación inicial, para luego analizar esta temática a la luz de las aplicaciones que en la actualidad se está realizando en la UPEL, específicamente en el Instituto Pedagógico Rafael Alberto Escobar Lara, contexto académico en el que se realiza la investigación.

En la segunda parte de esta investigación, se presenta el capítulo referido al estudio empírico que tiene como objetivo general: Diseñar un programa de práctica profesional, que potencie las competencias pedagógicas necesarias para la enseñanza en Educación Infantil. Para alcanzar este objetivo nos propusimos los siguientes objetivos específicos:

1.- Analizar la valoración sobre la práctica profesional del programa de Educación Preescolar de la UPEL - IPMAR, desde el punto de vista de profesores y alumnos.

2.- Conocer cuáles son las características pedagógicas presentes en los planes y programas de estudio del área de práctica profesional, de la especialidad Educación Preescolar de la UPELMaracay.

3.- Indagar sobre las fortalezas y debilidades que distinguen los alumnos y los profesores de la especialidad de Educación Preescolar en el proceso de administración de la práctica profesional

4.- Establecer los lineamientos para la propuesta del plan de mejora, a partir de los resultados encontrados, con los elementos teóricos- prácticos necesarios a incluir en el diseño de un 61 La Práctica Profesional como área para potenciar las competencias pedagógicas necesarias para la enseñanza en Educación Infantil 
programa de práctica profesional que potencie las competencias pedagógicas necesarias para la enseñanza en Educación Infantil

A tal fin, se dividió en dos fases. La primera fase está dirigida a conocer las valoraciones que expresan los estudiantes y profesores acerca de la práctica profesional en educación preescolar de la UPEL Maracay, mediante la utilización de un cuestionario elaborado expresamente para esta investigación, sobre la opinión o valoración que tanto estudiantes como profesores hacen de la práctica profesional que se lleva a cabo en la UPEL-IPMAR. El cuestionario contiene 103 ítems y fue aplicado a 72 estudiantes y 06 profesores, para tener una evaluación de lo que hasta ahora se ha hecho y de lo que aún falta por hacer. Esta doble valoración, permitió discriminar las opiniones de los alumnos, frente a la de sus profesores, lo cual arrojo datos interesantes para este estudio.

En la segunda fase, se muestra el estudio detallado de dos procedimientos empleados; Por una parte, el análisis a documentos oficiales, referidos a los planes de estudio del área de Práctica Profesional, para un conocimiento más profundo de la realidad académica y visualizar la determinación de propuestas que permitan atacar debilidades y convertirlas en oportunidades. Por otra parte, la realización de talleres reflexivos, efectuados con dos grupos distintos: 09 profesores que administran práctica profesional de educación preescolar, de la UPEL Maracay, y 10 estudiantes de Educación Preescolar que cursan el último semestre de la carrera, los cuales estuvieron dispuestos a compartir su conocimiento, experiencia y sus prácticas docentes. Finalmente, se muestra una discusión general que completa analíticamente los resultados obtenidos con las principales aproximaciones conceptuales presentadas en el marco teórico. Asimismo, se presentan las conclusiones centrales, y nuevas vías para contribuir a la mejora de esta importante área de formación académica y propuesta de un programa de práctica profesional que potencie las competencias pedagógicas necesarias para la enseñanza en educación infantil, que surgió como producto del análisis general.

A continuación grafico explicativo de la metodología de este estudio:

La Práctica Profesional como área para potenciar las competencias pedagógicas necesarias para la enseñanza en
Educación Infantil




\section{GRÁFICO EXPLICATIVO DEL DISEÑO}

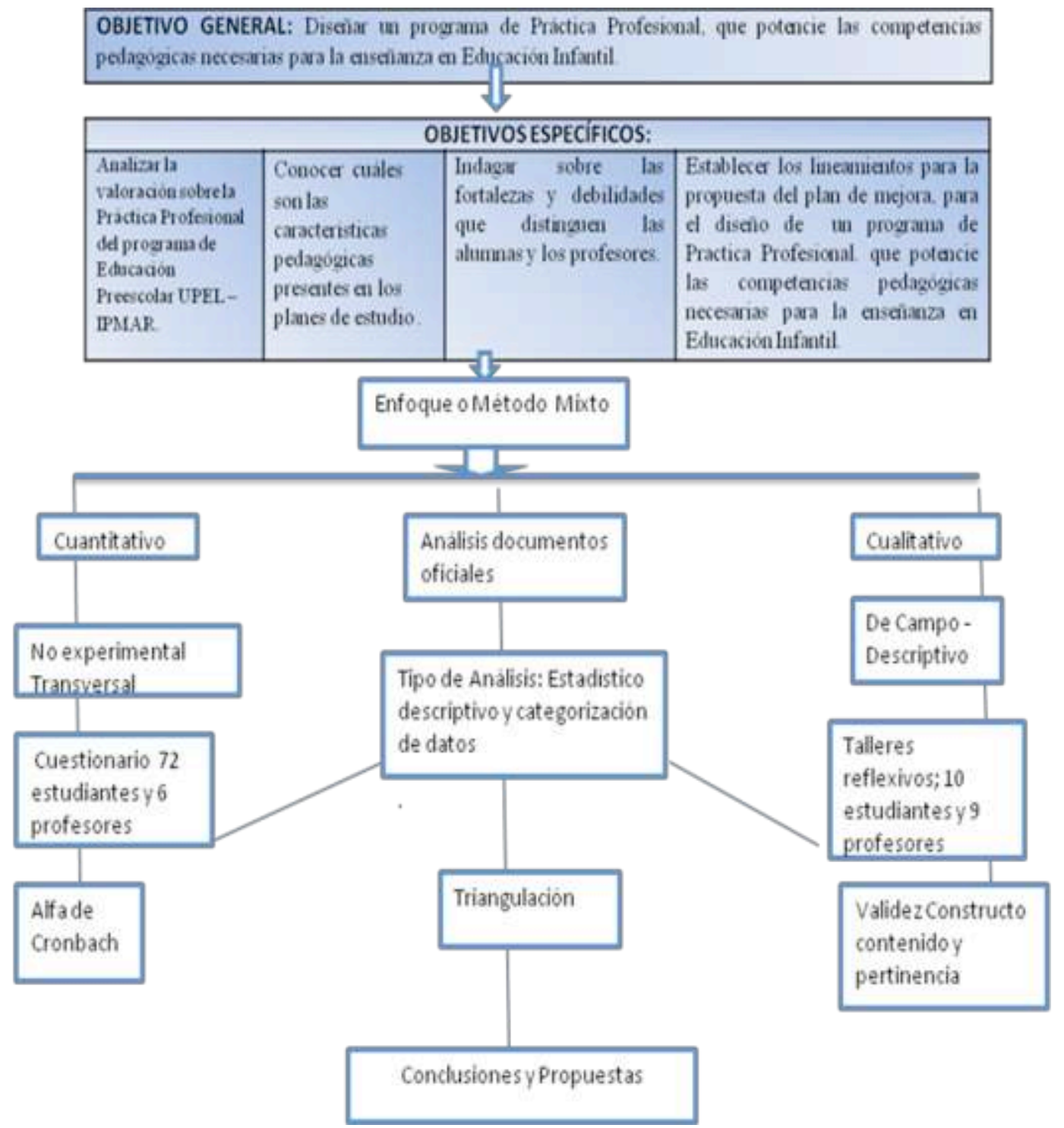

Grafico $n^{\circ} 1$. Diseño de la investigación. Fuente: Elaboración propia

63

La Práctica Profesional como área para potenciar las competencias pedagógicas necesarias para la enseñanza en Educación Infantil 


\section{Capítulo 2. La Formación Superior del Profesorado}

> Conceptualización de la educación superior

$>$ La formación superior del profesorado

$>$ La formación del docente en América Latina y Europa

$>$ La formación del profesorado en España

$>$ La formación superior del profesorado en Venezuela

$>$ La Universidad Pedagógica Experimental Libertador (UPEL)

> Misión y visión de la Universidad Pedagógica

$>$ Diseño curricular de la UPEL

$>$ El compromiso profesional de la Universidad con la sociedad

$>$ Resumen de formación superior del profesorado 


\section{CAPITULO 2. LAFORMACION SUPERIOR DEL PROFESORADO}

\subsection{Conceptualización de la Educación Superior.}

Para la UNESCO (1998:1), la Educación Superior comprende "todo tipo de estudios de formación o de formación para la investigación en el nivel post secundario, impartidos por una universidad u otros establecimientos de enseñanza que estén acreditados por las autoridades competentes del estado, como centros de enseñanza superior”.

Además y siguiendo con el mismo documento, la Educación Superior, tiene la misión y función de educar, formar y realizar investigaciones; Esto implica, reforzar y fomentar aún más sus valores fundamentales, particularmente la misión de contribuir al desarrollo sostenible y al mejoramiento del conjunto de la sociedad.

Esta contribución, conlleva a la necesaria revisión de sus ofertas académicas a la luz de los avances de los tiempos modernos, lo cual comprende ofrecer capacitación profesional en la que se combinen los conocimientos teóricos y prácticos de alto nivel, asumir los retos que implica la tecnología como oportunidad para mejorar la manera de producir, organizar, difundir y controlar el saber y el acceso al mismo, adaptados a las necesidades presentes y futuras de la sociedad.

La educación superior ha dado abundantes pruebas de su viabilidad a lo largo del tiempo y de su capacidad para transformarse y propiciar el cambio y el progreso de la humanidad. Los aportes de la investigación, que en ella se produce, constituyen parte fundamental del desarrollo cultural, socioeconómico y ecológico de los individuos, las comunidades y las naciones. En consideración a su misión, la educación superior debe dar respuesta a los desafíos que la sociedad contemporánea le plantea; para ello requiere emprender sus propios procesos de transformación y renovación, para transcender las consideraciones técnicas a dimensiones más humanas y sostenibles en el tiempo.

Un antecedente importante, en relación con los procesos de evaluación de la educación superior, lo constituye el proyecto Tuning - América Latina, el cual en términos teóricos "remite implícitamente a un marco reflexivo-critico, producto de una multi-referencialidad tanto

65

La Práctica Profesional como área para potenciar las competencias pedagógicas necesarias para la enseñanza en Educación Infantil 
pedagógica como disciplinaria" (Beneitone y otros, 2007:12), en este documento se aclara que el proyecto no puede tomarse como una "receta", sino como una metodología que procede de una perspectiva, cuya finalidad es incorporar los diferentes aspectos de la diversidad de los países que en el intervienen e interactúan.

La idea de aplicar este proyecto en Latinoamérica, se inicia en Europa, pero planteada por latinoamericanos, luego de escuchar los resultados de la primera fase de Tuning-Europa. Por tanto, Tuning Latinoamérica es un trabajo conjunto que tiene como propósito, la búsqueda de lenguajes y mecanismos, que faciliten los procesos de reconocimiento de los sistemas de enseñanza superior a nivel transnacional y transregional, que cuenta con la participación de 182 universidades provenientes de 18 países de América Latina (Argentina, Brasil, Bolivia, Colombia, Costa Rica, Cuba, Chile, Ecuador, El Salvador, Guatemala, Honduras, México, Nicaragua, Panamá, Perú, Uruguay, Venezuela), más tarde Republica Dominicana, solicita su inclusión al grupo, quedando en definitiva 19 países y 190 universidades latinoamericanas.

Para Beneitone y otros (2007:31), la experiencia del proyecto está dada por la búsqueda de puntos comunes de referencia, centrados en las competencias. Además la metodología propia de Tuning-América Latina, tiene cuatro líneas de trabajo: a) Competencias genéricas y específicas de las áreas temáticas; b) enfoque de enseñanza, aprendizajes y evaluación de estas competencias; c) créditos académicos y d) calidad de los programas.

Estas cuatro líneas de trabajo están muy relacionadas entre ellas, ya que al definir las competencias genéricas, se busca compartir criterios que puedan generarse en cualquier titulación y que son consideradas importantes por ciertos grupos sociales. Las competencias específicas difieren de disciplina a disciplina, cuya responsabilidad de definición recae en los académicos, en consulta con otros grupos interesados en el tema. Con respecto a la segunda línea, se busca desarrollar una combinación novedosa de enfoques de enseñanza y aprendizaje, lo cual implica también modificaciones en los métodos y criterios de evaluación, en función no solo de contenidos, sino de habilidades, destrezas y valores. En la tercera línea, se inicia una reflexión 66 La Práctica Profesional como área para potenciar las competencias pedagógicas necesarias para la enseñanza en Educación Infantil 
sobre los siguientes temas; el papel de los créditos, la asignación de los créditos a los cursos, el cálculo de los créditos en base al trabajo del estudiante, entre otros. Finalmente, el tema de la calidad articula las tres líneas anteriores, para garantizar una metodología común y contrastada de evaluación de la calidad.

En síntesis, el énfasis colocado en el desarrollo de competencias, responde a un enfoque de educación centrado en el estudiante y en la posibilidad de potenciar sus habilidades para aprender, la asunción de sus propias responsabilidades, como actor principal en el hecho educativo; así mismo, ha brindado ciertos lineamientos y reflexiones sobre temas de interés común, tales como:

- Un sistema centrado en el estudiante y basado en competencias.

- Nuevos paradigmas en el campo educativo.

- El reconocimiento de titulaciones entre los países latinoamericanos

- La construcción conjunta de un espacio para dialogar sobre educación superior, con una mirada centrada en la calidad y buscando soluciones concretas y accesibles a problemas compartidos.

\subsubsection{La Formación Superior del Profesorado.}

Aun cuando es un hecho frecuentemente reconocido por los autores dedicados al análisis del proceso educativo, no existe una definición única de educación (Peñalver, 2000:3), esta situación implica reconocer el hecho de que el proceso educativo no tiene lugar solamente en una situación claramente definida, formal, como lo es la escuela y la universidad; tiene lugar también, en todas las instituciones sociales tales como la familia, los grupos de amigos, las situaciones de trabajo, entre otros. Vista de esta forma, la educación puede ser adquirida de manera formal e informal y constituye un proceso al que se está expuesto durante toda la vida (Ciclo Vital, Martí, 1991).

67

La Práctica Profesional como área para potenciar las competencias pedagógicas necesarias para la enseñanza en Educación Infantil 
En este orden de ideas, conviene señalar que entre las misiones y funciones de la Educación Superior, planteados por UNESCO (2009), se destaca el artículo 1, referido a : la misión de educar, formar y realizar investigaciones, en el cual se reafirma la necesidad de preservar, reforzar y fomentar aún más la misión de contribuir al desarrollo sostenible y el mejoramiento del conjunto de la sociedad, a saber: formar diplomados altamente cualificados y ciudadanos responsables, capaces de atender a las necesidades de todos los aspectos de la actividad humana, ofreciéndoles cualificaciones que estén a la altura de los tiempos modernos, comprendida la capacitación profesional, en las que se combinen los conocimientos teóricos y prácticos de alto nivel mediante cursos y programas que estén constantemente adaptados a las necesidades presentes y futuras de la sociedad.

Para ello y considerando lo anteriormente planteado, la UNESCO (1998), propone las siguientes recomendaciones relativas a las condiciones del personal docente de la enseñanza superior, aprobada en la conferencia general de noviembre 1997:

Artículo 5. Promoción del saber mediante la investigación en los ámbitos de la ciencia, el arte y las humanidades y la difusión de sus resultados: incrementar la investigación en todas las disciplinas; Artículo 6. Orientación a largo plazo fundada en la pertinencia: aumentar su contribución al desarrollo del conjunto del sistema educativo, sobre todo mejorando la formación del personal docente, la elaboración de los planes de estudio y la investigación sobre la educación. Artículo 7. Reforzar la cooperación con el mundo del trabajo y el análisis y la previsión de las necesidades de la sociedad: mediante la participación de sus representantes en los órganos rectores de las instituciones, la intensificación de la utilización por los docentes y los estudiantes, en los planos nacional e internacional, de las posibilidades de aprendizaje profesional y de combinación de estudios y trabajo, el intercambio de personal entre el mundo del trabajo y las instituciones de educación superior y la revisión de los planes de estudio para que se adapten mejor a las prácticas profesionales. Artículo 9. Métodos educativos innovadores: pensamiento crítico y creatividad: formar a los estudiantes para que se conviertan en ciudadanos bien 68 La Práctica Profesional como área para potenciar las competencias pedagógicas necesarias para la enseñanza en Educación Infantil 
informados y profundamente motivados, provistos de un sentido crítico y capaces de analizar los problemas de la sociedad.

Desde este marco referencial, y en concordancia con los planteamientos de UNESCO (1998), es necesario reformular los planes de estudio y utilizar métodos nuevos y adecuados que permitan superar el énfasis en el dominio cognitivo de las disciplinas, para ello es ineludible facilitar el acceso y fomento de nuevos planteamientos pedagógicos y didácticos, que propicien la adquisición de conocimientos prácticos, competencias y aptitudes para la comunicación, el análisis creativo y crítico, la reflexión independiente y el trabajo en equipo en contextos multiculturales, en los que la creatividad exige combinar el saber teórico y práctico, tradicional o local, con la ciencia y la tecnología de vanguardia. Así mismo, los nuevos métodos pedagógicos también supondrán materiales didácticos y métodos, que pongan a prueba no sólo la memoria sino también las facultades de comprensión, la aptitud para las labores prácticas y la creatividad.

Más, al actuar en la transformación de los individuos concretos, la educación se corresponde entonces como una estrategia más amplia de cambio social, que la hace una práctica política y cultural. Así, la docencia se manifiesta en resumen, como una práctica dinámica, profesional, educativa y social. Por lo que la teoría aislada, o la sola actividad, no podrían catalogarse como docencia, sino como un proceso que requiere mediaciones en el que el momento teórico debe materializarse en una actividad que se ejerce sobre una realidad que es independiente de la conciencia, utilizando medios e instrumentos objetivos y dando lugar a un resultado concreto.

Por lo tanto, y de acuerdo con Melograno (2003:152):

No basta el conocimiento científico-técnico para ejercer la docencia, y mucho menos para la formación de educadores. Sobre todo considerando que un educador es la única persona que se forma para una actividad (el proceso de enseñanza aprendizaje), mediante esa misma actividad. Por eso, no se trata solamente de un proceso en el que lo subjetivo (concretado en el 69 La Práctica Profesional como área para potenciar las competencias pedagógicas necesarias para la enseñanza en Educación Infantil 
proyecto del docente) se inserta en lo objetivo (la actividad que este realiza para transformar al educando), sino de una actividad que no sólo trasforma al educando al cual se dirige su acción sino al sujeto mismo que actúa como agente de esa transformación (el docente).

Es por eso que, la docencia es una expresión de la dialéctica sujeto- objeto y cuando esa dialéctica no se cumple o se vuelve una acción sin un propósito definido, o cuando se relega a la pura teoría que no conlleva una acción transformadora, la docencia deja de ser tal. En este orden de ideas, se destaca la importancia al fomento de las capacidades de investigación, en los establecimientos de enseñanza superior con funciones de investigación puesto que, cuando la educación superior y la investigación se llevan a cabo en un alto nivel dentro de la misma institución se logra una potenciación mutua de la calidad.

\subsubsection{La Formación del Docente en América Latina y Europa}

La formación docente en América Latina es heterogénea y la información sobre ella es algo difusa, pues en la mayoría de los casos no se explicita el contenido de las asignaturas y en otros sólo se mencionan las áreas de formación en forma muy general, situación que impide realizar comparaciones o análisis para identificar los puntos de encuentro y desencuentro en relación a este importante proceso de formación profesional.

De acuerdo con la revisión sobre el tema, las primeras formas institucionalizadas de educación primaria se inician en el siglo XIX, es la escuela normal, institución que operaba a nivel del ciclo diversificado de educación secundaria, además rigió la formación inicial de los maestros durante casi un siglo y subsiste aún en algunos países. Posteriormente, desde mediados del siglo XX las escuelas normales se fueron convirtiendo gradualmente, en los institutos de formación superior no universitaria o institutos superiores pedagógicos (post secundaria).

En el caso de Europa, específicamente en España, es posible distinguir cuatro tipos de docentes: el profesorado de educación infantil y primaria, el profesorado de educación 70 La Práctica Profesional como área para potenciar las competencias pedagógicas necesarias para la enseñanza en Educación Infantil 
secundaria, el profesorado técnico de formación profesional y el profesorado universitario. Cada uno de ellos tiene una formación inicial y unos requisitos de acceso a la función docente diferenciados. Para desempeñar labores docentes en educación infantil y educación primaria, la normativa exige que se tenga el título de maestro con la especialidad correspondiente. Este título se obtiene tras cursar los estudios universitarios de primer ciclo (diplomatura, de tres años de duración) en los planes aún vigentes aunque en vías de extinción. Con el Plan de Bolonia estos planes se están sustituyendo por los estudios de Grado que contemplan cuatro años de duración para cada una de las etapas educativas.

A continuación, se presentan algunas características de la formación inicial de los docentes en los países latinoamericanos y en algunos países de Europa, destacando especialmente la de los docentes de educación infantil o preescolar (según la denominación de cada país), en función de la información recogida en ese sentido.

Cuadro resumen: Formación inicial de los docentes de preescolar en América Latina y Europa.

\begin{tabular}{|c|c|}
\hline América Latina & uropa \\
\hline $\begin{array}{l}\text { Argentina: Los contenidos básicos } \\
\text { comunes para la formación docente se } \\
\text { organizan en tres campos: formación } \\
\text { general (común y obligatorio a todos } \\
\text { los niveles); formación especializada } \\
\text { (para niveles y regímenes especiales); y } \\
\text { formación de orientación (comprende la } \\
\text { formación y profundización centrada en } \\
\text { ciclos/áreas o disciplinas curriculares). } \\
\text { Bolivia: En los institutos normales } \\
\text { superiores, se obtiene el título de } \\
\text { maestro normalista. A nivel } \\
\text { universitario se obtiene el título de } \\
\text { licenciado. } \\
\text { El currículo de formación considera las }\end{array}$ & $\begin{array}{l}\text { En todos los países europeos, con el fin de } \\
\text { convertirse en un maestro de escuela de calidad, } \\
\text { los candidatos están obligados a realizar } \\
\text { estudios académicos, incluyendo un curso de } \\
\text { estudio en la educación que les proporciona los } \\
\text { conocimientos teóricos y prácticos (incluidas } \\
\text { prácticas de la escuela) que se necesita para } \\
\text { unirse a la enseñanza profesional. } \\
\text { Hay dos modelos de formación inicial del } \\
\text { profesorado. Bajo el modelo simultáneo, el } \\
\text { componente profesional de educación se } \\
\text { proporciona desde el principio, junto con la } \\
\text { educación general y / o estudio del sujeto (s), que } \\
\text { el futuro maestro tiene la intención de enseñar. } \\
\text { Bajo el modelo consecutivo, los estudiantes } \\
\text { continúan sus estudios académicos y toman un }\end{array}$ \\
\hline
\end{tabular}


siguientes áreas: (i) realidad nacional y educación, (ii) análisis y desarrollo curricular, (iii) gestión educativa, y (iv) pedagógica.

Brasil: La formación docente a nivel de licenciatura se desarrollan en las universidades e institutos superiores de educación para profesores de educación infantil y los primeros grados de educación fundamental

Chile: La formación docente se brinda en las universidades y en los institutos profesionales.

La duración de los estudios oscila entre tres y cinco años.

El currículo comprende las siguientes áreas de formación: (i) general, (ii) profesional, (iii) especialidad, y (iv) práctica.

Colombia: forma docentes para la educación de niños/as desde el nacimiento a los ocho años, tendiendo un puente entre el preescolar y la básica. El currículo considera formación: (i) pedagógica, (ii) disciplinaria específica, (iii) científica e investigativa, y (iv) deontológica y en valores humanos.

México: Las escuelas normales de educación superior ofrecen licenciatura en educación preescolar y primaria, $\mathrm{La}$ duración de los estudios es de cuatro años y el plan de estudios comprende las líneas: (i) psicológica, (ii) formación social, (iii) pedagógica, (iv) instrumental, y (v) otras áreas de curso profesional después de completar su programa académico. Desde el lanzamiento del proceso de Bolonia, la formación inicial del profesorado ha visto muchos cambios, por lo tanto, las comparaciones históricas tienen que hacerse con cautela. Con esto en mente, cabe señalar que desde 2002/03, el número de países que ofrecen el modelo consecutivo de la formación docente, además del modelo simultáneo, se ha incrementado para todos los niveles de educación. En casi todos los países europeos, los maestros de los niveles pre-primario y primario de la educación están capacitados bajo el modelo simultáneo. En Bulgaria, Irlanda, Polonia, Portugal y el Reino Unido (Inglaterra, País de Gales e Irlanda del Norte), tanto el concurrente y las rutas están disponibles. Sin embargo, mientras que Irlanda y Polonia, informan de que el modelo simultáneo es el modelo más común de la intención los maestros de pre-primaria y primaria, en el Reino Unido (Inglaterra) el modelo consecutivo es más habitual. El modelo simultáneo es la única opción posible en Bélgica, Dinamarca, Alemania, Eslovaquia y Turquía. Sin embargo, en Estonia, España, Francia, Italia, Chipre, Luxemburgo y Hungría, el modelo consecutivo es el disponible de la formación. En la mayoría de todos los otros países donde existen los dos modelos, el modelo simultáneo es la vía más generalizada para este nivel de educación. Para desempeñar labores docentes en educación infantil y educación primaria, la normativa exige que se tenga el título de maestro con la especialidad correspondiente. 


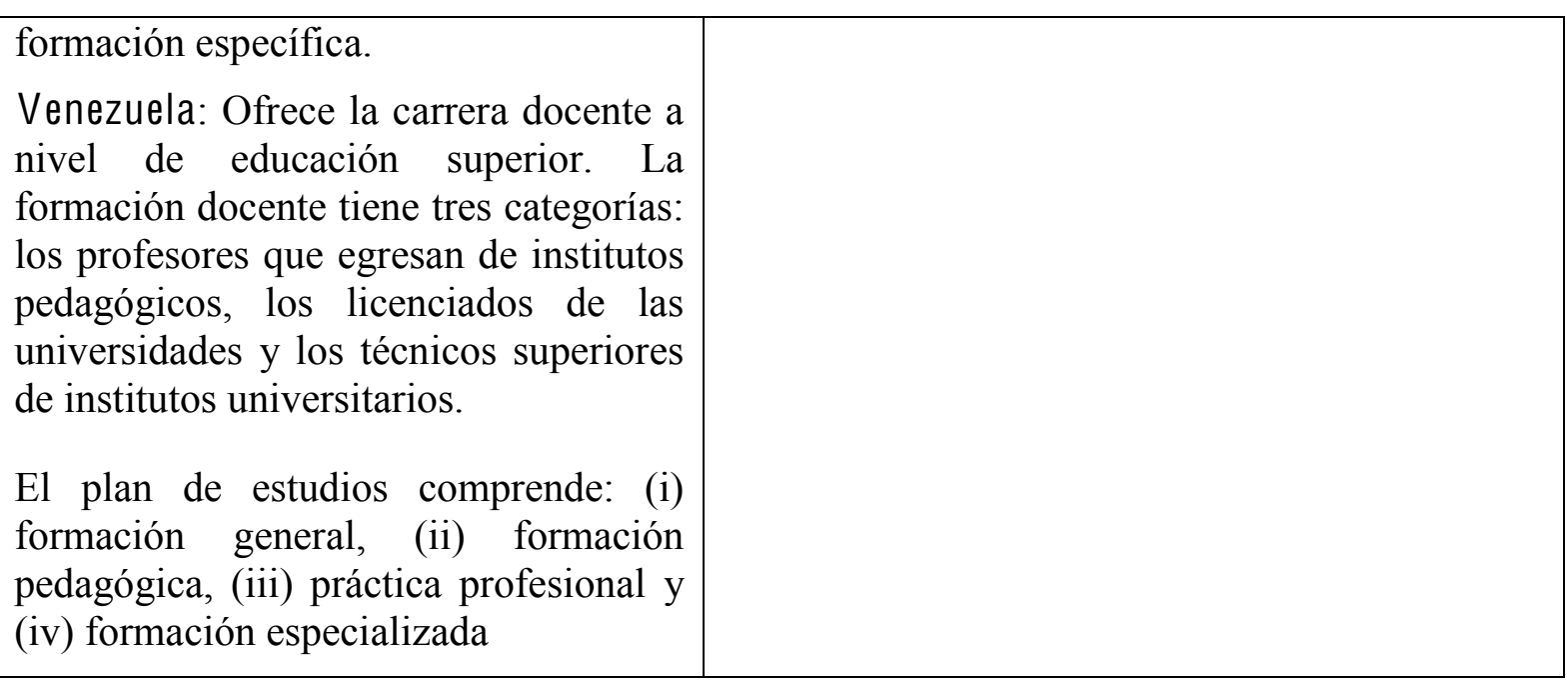

Cuadro $\mathrm{n}^{\circ}$ 4. Formación inicial y continua de los docentes de preescolar en América Latina y Europa. Fuente: Organización de Estados Iberoamericanos (2003) / Education, Audiovisual and Culture Executive Agency (2012).

El análisis de este cuadro admite asegurar que en la mayoría de los países, la formación docente inicial se realiza en institutos superiores pedagógicos y en universidades. Éste proceso académico tiene una duración entre tres y cinco años. En relación al currículo, se observa grandes similitudes en todos los países, con algunas diferencias de organización especialmente al comparar con el modelo europeo, que ofrece dos modelos alternativos: simultáneo y consecutivo. En el caso de los países latinoamericanos, la mayoría coincide en componentes de formación pedagógica, especializada y práctica profesional.

Así mismo, ésta formación de docentes responde a determinadas tendencias o enfoque pedagógicos, en este sentido, Gonzaga (2005:5) presenta una conceptualización de Pérez y Hernández (1999), las cuales lo denominan como: tradicional, tecnocrática, constructivista y crítica; la caracterización de acuerdo con estas autoras se presenta a continuación en el cuadro comparativo. 


\begin{tabular}{|c|c|c|c|c|}
\hline Tendencias & Tradicional & Tecnocrática & Constructivista & Crítica \\
\hline Característica & $\begin{array}{lr}\text { Centrada en la } \\
\text { trasmisión de } \\
\text { contenidos. } \\
\text { Predomina el uso } \\
\text { de métodos } \\
\text { expositivos y de } \\
\text { actividades que } \\
\text { promueven la } \\
\text { memorización y } \\
\text { repetición de } \\
\text { contenidos }\end{array}$ & $\begin{array}{l}\text { Caracterizada por el } \\
\text { uso de diversos } \\
\text { medios } \\
\text { audiovisuales, } \\
\text { multimedia y otros } \\
\text { relacionados con la } \\
\text { tecnología } \\
\text { informática }\end{array}$ & $\begin{array}{lr}\text { Propicia } & \text { la } \\
\text { participación activa } \\
\text { del sujeto que } \\
\text { aprende en la } \\
\text { construcción } \\
\text { apropiación y } \\
\text { conocimiento }\end{array}$ & $\begin{array}{l}\text { El contexto, } \\
\text { como un todo, } \\
\text { se constituye } \\
\text { en el espacio } \\
\text { en el cual el } \\
\text { conocimiento } \\
\text { adquiere } \\
\text { significado. }\end{array}$ \\
\hline Enseñanza & $\begin{array}{l}\text { Fundamentada en } \\
\text { la autoridad del } \\
\text { profesor; él posee } \\
\text { el conocimiento, } \\
\text { toma decisiones y } \\
\text { define estrategias } \\
\text { de enseñanza y } \\
\text { de evaluación }\end{array}$ & $\begin{array}{lr}\text { Incorporada } & \text { a } \\
\text { equipos } & \\
\text { interdisciplinarios } \\
\text { que preparan } \\
\text { materiales } \\
\text { educativos } \\
\text { elaborados } \\
\text { sofisticados. }\end{array}$ & 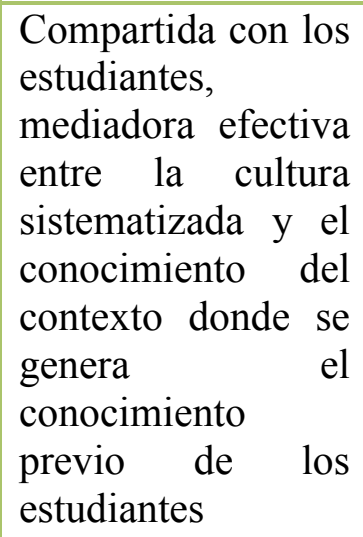 & $\begin{array}{l}\text { Articulada con } \\
\text { los problemas } \\
\text { educativos } \\
\text { reales que se } \\
\text { espera sean } \\
\text { analizados. }\end{array}$ \\
\hline Aprendizaje & Pasivo-receptivo & $\begin{array}{l}\text { Con acceso a } \\
\text { múltiples medios. }\end{array}$ & $\begin{array}{l}\text { Activo, dinámico y } \\
\text { creativo }\end{array}$ & $\begin{array}{l}\text { Analizar, } \\
\text { comprender y } \\
\text { transformar esa } \\
\text { realidad en } \\
\text { beneficio de la } \\
\text { comunidad } \\
\text { afectada. }\end{array}$ \\
\hline Evaluación & $\begin{array}{l}\text { Orientada hacia } \\
\text { la comprobación } \\
\text { "mecánica" de } \\
\text { los aprendizajes, } \\
\text { mediante una } \\
\text { devolución de los } \\
\text { contenidos }\end{array}$ & $\begin{array}{l}\text { Orientada hacia la } \\
\text { comprobación }\end{array}$ & $\begin{array}{l}\text { Orientada hacia los } \\
\text { procesos de } \\
\text { aprendizaje de cada } \\
\text { estudiante. }\end{array}$ & $\begin{array}{lr}\text { Orientada } & \\
\text { hacia } & \text { los } \\
\text { procesos } & \text { de } \\
\text { aprendizaje. } & \end{array}$ \\
\hline
\end{tabular}

La Práctica Profesional como área para potenciar las competencias pedagógicas necesarias para la enseñanza en Educación Infantil 
\begin{tabular}{|l|l|l|l|l|}
\hline & aprendidos & & \\
\hline
\end{tabular}

Cuadro n ${ }^{\circ}$ 5. Caracterización de tendencias o enfoques pedagógicos. Fuente: Gonzaga, 2005

Como puede apreciarse, el análisis del cuadro anterior, permite constatar que todas estas tendencias, se encuentran vigentes y en uso en muchos centros de formación superior de profesores y además puede afirmarse que, es el tradicional el que se ubica con mayor tendencia en estos procesos de formación.

\subsubsection{La Formación Superior del Profesorado en España.}

Los objetivos generales para el Grado en Educación Infantil, marcados por la Orden ECI/3854/2007, de 27 de diciembre, son:

1. Conocer los objetivos, contenidos curriculares y criterios de evaluación de la Educación Infantil.

2. Promover y facilitar los aprendizajes en la primera infancia, desde una perspectiva globalizadora e integradora de las diferentes dimensiones cognitiva, emocional, psicomotora y volitiva.

3. Diseñar y regular espacios de aprendizaje en contextos de diversidad que atiendan a las singulares necesidades educativas de los estudiantes, a la igualdad de género, a la equidad y al respeto a los derechos humanos.

4. Fomentar la convivencia en el aula y fuera de ella y abordar la resolución pacífica de conflictos. Saber observar sistemáticamente contextos de aprendizaje y convivencia y saber reflexionar sobre ellos. 
5. Reflexionar en grupo sobre la aceptación de normas y el respeto a los demás. Promover la autonomía y la singularidad de cada estudiante como factores de educación de las emociones, los sentimientos y los valores en la primera infancia.

6. Conocer la evolución del lenguaje en la primera infancia, saber identificar posibles disfunciones y velar por su correcta evolución. Abordar con eficacia situaciones de aprendizaje de lenguas en contextos multiculturales y multilingües. Expresarse oralmente y por escrito y dominar el uso de diferentes técnicas de expresión.

7. Conocer las implicaciones educativas de las tecnologías de la información y la comunicación y, en particular, de la televisión en la primera infancia.

8. Conocer fundamentos de dietética e higiene infantiles. Conocer fundamentos de atención temprana y las bases y desarrollos que permiten comprender los procesos psicológicos, de aprendizaje y de construcción de la personalidad en la primera infancia.

9. Conocer la organización de las escuelas de educación infantil y la diversidad de acciones que comprende su funcionamiento. Asumir que el ejercicio de la función docente ha de ir perfeccionándose y adaptándose a los cambios científicos, pedagógicos y sociales a lo largo de la vida.

10. Actuar como orientador de padres y madres en relación con la educación familiar en el periodo 0-6 y dominar habilidades sociales en el trato y relación con la familia de cada estudiante y con el conjunto de las familias.

11. Reflexionar sobre las prácticas de aula para innovar y mejorar la labor docente. Adquirir hábitos y destrezas para el aprendizaje autónomo y cooperativo y promoverlo en los estudiantes. 
12. Comprender la función, las posibilidades y los límites de la educación en la sociedad actual y las competencias fundamentales que afectan a los colegios de educación infantil y a sus profesionales. Conocer modelos de mejora de la calidad con aplicación a los centros educativos.

Además de estos objetivos, los principios generales que deben inspirar el diseño de los nuevos planes de grado, están definidos en el artículo 3.5 del RD 1393/2007, debiendo incluirse en estos nuevos planes enseñanzas relacionadas con valores los valores relativos a los derechos fundamentales y de igualdad entre hombres y mujeres; principios de accesibilidad universal y diseño para todos; valores de una cultura de paz; de sensibilización y prevención de la violencia de género.

\section{Competencias Generales.}

Son competencias comunes para todos los graduados españoles, independientemente del Grado que hayan cursado y de la Universidad en que hayan realizado sus estudios. Están marcadas por ley, en el RD 1393/2007, que regula las enseñanzas oficiales de Grado y Máster.

- Que los estudiantes hayan demostrado poseer y comprender conocimientos en un área de estudio que parte de la base de la educación secundaria general, y se suele encontrar a un nivel que, si bien se apoya en libros de texto avanzados, incluye también algunos aspectos que implican conocimientos procedentes de la vanguardia de su campo de estudio.

- Que los estudiantes sepan aplicar sus conocimientos a su trabajo o vocación de una forma profesional y posean las competencias que suelen demostrarse por medio de la elaboración y defensa de argumentos y la resolución de problemas dentro de su área de estudio.

- Que los estudiantes tengan la capacidad de reunir e interpretar datos relevantes (normalmente dentro de su área de estudio) para emitir juicios que incluyan una reflexión sobre temas relevantes de índole social, científica o ética. 
- Que los estudiantes puedan transmitir información, ideas, problemas y soluciones a un público tanto especializado como no especializado.

Competencias Transversales.

Son competencias comunes que no tienen que ver tanto con los aspectos concretos de las titulaciones como con habilidades más genéricas

- Nivel C1 en Lengua Castellana

- Nivel B1 en una lengua extranjera

- Expresión escrita: saber expresarse con claridad en la redacción de escritos adecuando el estilo del lenguaje al interlocutor y utilizando vocabulario específico y relevante

- Expresión oral: saber expresarse con claridad en conversaciones o debates adecuando el estilo del lenguaje al interlocutor y utilizando vocabulario específico y relevante

- Trabajo en equipo: Capacidad de compromiso con un equipo, hábito de colaboración y trabajo solucionando conflictos que puedan surgir

- Liderazgo: capacidad para liderar grupos de trabajo, reuniones, supervisar personas...

- Toma de decisiones y solución de problemas: localización del problema, identificar causas y alternativas de solución, selección y evaluación de la más idónea

- Pensamiento crítico: capacidad de analizar, sintetizar y extraer conclusiones de un artículo (ya sea de opinión o científico) 
- Razonamiento cotidiano: capacidad de buscar argumentos de sentido contrario a la propia opinión (marco teórico, ideología, valores, conflictos sociales...)

- Creatividad: capacidad de innovación, iniciativa, fomento de ideas e inventiva

- Habilidad para el aprendizaje

- Capacidad reflexiva sobre su propio trabajo

- Gestión: capacidad de gestionar tiempos y recursos: desarrollar planes, priorizar actividades, identificar las críticas, establecer plazos y cumplirlos

- Habilidad de documentación: consulta de bases de datos relevantes en el campo profesional, consulta de revistas específicas, navegación "experta" por Internet...

- Capacidad de análisis y síntesis: descomponer situaciones complejas en partes para su análisis y reunir información disgregada para analizarla como un todo

- Habilidades de relación interpersonal: capacidad para relacionarse adecuadamente con los demás

- Adaptación a nuevas situaciones.

- Conocimientos de informática relativos al ámbito de estudio.

Competencias Específicas.

Son las competencias necesarias para acceder a la profesión para la que capacita el título. En este caso, las necesarias para ser maestro. En el caso de profesiones reguladas, como es la de Maestro, estas competencias vienen marcadas por ley, en las órdenes ECI. Se agrupan en función de los 3 módulos de los títulos: Bloque de Formación Básica, Bloque Didáctico Disciplinar y Practicum.

Bloque de Formación Básica

79

La Práctica Profesional como área para potenciar las competencias pedagógicas necesarias para la enseñanza en Educación Infantil 
- Comprender los procesos educativos y de aprendizaje en el periodo 0-6, en el contexto familiar, social y escolar. Conocer los desarrollos de la psicología evolutiva de la infancia en los periodos 0-3 y 3-6. Conocer los fundamentos de atención temprana. Reconocer la identidad de la etapa y sus características cognitivas, psicomotoras, comunicativas, sociales, afectivas. Saber promover la adquisición de hábitos en torno a la autonomía, la libertad, la curiosidad, la observación, la experimentación, la imitación, la aceptación de normas y de límites, el juego simbólico y heurístico. Conocer la dimensión pedagógica de la interacción con los iguales y los adultos y saber promover la participación en actividades colectivas, el trabajo cooperativo y el esfuerzo individual.

- Identificar dificultades de aprendizaje, disfunciones cognitivas y las relacionadas con la atención. Saber informar a otros profesionales especialistas para abordar la colaboración del centro y del maestro en la atención a las necesidades educativas especiales que se planteen. Adquirir recursos para favorecer la integración educativa de alumnos con dificultades.

- Crear y mantener lazos de comunicación con las familias para incidir eficazmente en el proceso educativo. Conocer y saber ejercer las funciones de tutor y orientador en relación con la educación familiar. Promover y colaborar en acciones dentro y fuera de la escuela, organizadas por familias, ayuntamientos y otras instituciones con incidencia en la formación ciudadana. Analizar e incorporar de forma crítica las cuestiones más relevantes de la sociedad actual que afectan a la educación familiar y escolar: impacto social y educativo de los lenguajes audiovisuales y de las pantallas; cambios en las relaciones de género e intergeneracionales; multiculturalidad e interculturalidad; discriminación e inclusión social y desarrollo sostenible. Conocer la evolución histórica de la familia, los diferentes tipos de familias, de estilos de vida y educación en el contexto familiar. 
- Conocer los principios básicos de un desarrollo y comportamiento saludables. Identificar trastornos en el sueño, la alimentación, el desarrollo psicomotor, la atención y la percepción auditiva y visual. Colaborar con los profesionales especializados para solucionar dichos trastornos. Detectar carencias afectivas, alimenticias y de bienestar que perturben el desarrollo físico y psíquico adecuado de los alumnos.

- Comprender que la dinámica diaria en educación infantil es cambiante en función de cada alumno, grupo y situación y saber ser flexible en el ejercicio de la función docente. Valorar la importancia de la estabilidad y la regularidad en el entorno escolar, los horarios y los estados de ánimo del profesorado como factores que contribuyen al progreso armónico e integral de los alumnos. Saber trabajar en equipo con otros profesionales de dentro y fuera del centro en la atención a cada alumno, así como en la planificación de las secuencias de aprendizaje y en la organización de las situaciones de trabajo en el aula y en el espacio de juego, identificando las peculiaridades del periodo $0-3 \mathrm{y}$ del periodo 3-6. Atender las necesidades de los alumnos y transmitir seguridad, tranquilidad y afecto.

- Comprender que la observación sistemática es un instrumento básico para poder reflexionar sobre la práctica y la realidad, así como contribuir a la innovación y a la mejora en educación infantil. Dominar las técnicas de observación y registro. Abordar análisis de campo mediante metodología observacional utilizando tecnologías de la información, documentación y audiovisuales. Saber analizar los datos obtenidos, comprender críticamente la realidad y elaborar un informe de conclusiones.

- Situar la escuela infantil en el sistema educativo español, en el contexto europeo y en el internacional. Conocer experiencias internacionales y ejemplos de prácticas de innovadoras en educación infantil. Valorar la importancia del trabajo en equipo. Participar en la elaboración y seguimiento de proyectos educativos de educación 81

La Práctica Profesional como área para potenciar las competencias pedagógicas necesarias para la enseñanza en Educación Infantil 
infantil en el marco de proyectos de centro y en colaboración con el territorio y con otros profesionales y agentes sociales. Conocer la legislación que regula las escuelas infantiles y su organización. Valorar la relación personal con cada alumno y su familia como factor de calidad de la educación.

\section{Bloque Didáctico Disciplinar}

- Conocer los fundamentos científicos, matemáticos y tecnológicos del currículo de esta etapa así como las teorías sobre la adquisición y desarrollo de los aprendizajes correspondientes. Conocer estrategias didácticas para desarrollar representaciones numéricas y nociones espaciales, geométricas y de desarrollo lógico. Comprender las matemáticas como conocimiento sociocultural. Conocer la metodología científica y promover el pensamiento científico y la experimentación. Adquirir conocimientos sobre la evolución del pensamiento, las costumbres, las creencias y los movimientos sociales y políticos a lo largo de la historia. Conocer los momentos más sobresalientes de la historia de las ciencias y las técnicas y su trascendencia. Elaborar propuestas didácticas en relación con la interacción ciencia, técnica, sociedad y desarrollo sostenible. Promover el interés y el respeto por el medio natural, social y cultural a través de proyectos didácticos adecuados. Fomentar experiencias de iniciación a las tecnologías de la información y la comunicación.

- Conocer el currículo de lengua y lectoescritura de esta etapa así como las teorías sobre la adquisición y desarrollo de los aprendizajes correspondientes. Favorecer las capacidades de habla y de escritura. Conocer y dominar técnicas de expresión oral y escrita. Conocer la tradición oral y el folklore. Comprender el paso de la oralidad a la escritura y conocer los diferentes registros y usos de la lengua. Conocer el proceso de aprendizaje de la lectura y la escritura y su enseñanza. Afrontar situaciones de aprendizaje de lenguas en contextos multilingües. Reconocer y 
valorar el uso adecuado del lenguaje verbal y no verbal. Conocer y utilizar adecuadamente recursos para la animación a la lectura y a la escritura. Adquirir formación literaria y en especial conocer la literatura infantil. Ser capaz de fomentar una primera aproximación a una lengua extranjera.

- Conocer los fundamentos musicales, plásticos y de expresión corporal del currículo de esta etapa así como las teorías sobre la adquisición y desarrollo de los aprendizajes correspondientes. Conocer y utilizar canciones para promover la educación auditiva, rítmica y vocal. Saber utilizar el juego como recurso didáctico, así como diseñar actividades de aprendizaje basadas en principios lúdicos. Elaborar propuestas didácticas que fomenten la percepción y expresión musicales, las habilidades motrices, el dibujo y la creatividad. Analizar los lenguajes audiovisuales y sus implicaciones educativas. Promover la sensibilidad relativa a la expresión plástica y a la creación artística.

\section{Practicum}

- Adquirir un conocimiento práctico del aula y de la gestión de la misma. Conocer y aplicar los procesos de interacción y comunicación en el aula, así como dominar las destrezas y habilidades sociales necesarias para fomentar un clima que facilite el aprendizaje y la convivencia. Controlar y hacer el seguimiento del proceso educativo $\mathrm{y}$, en particular, de enseñanza y aprendizaje mediante el dominio de técnicas y estrategias necesarias. Relacionar teoría y práctica con la realidad del aula y del centro. Participar en la actividad docente y aprender a saber hacer, actuando y reflexionando desde la práctica. Participar en las propuestas de mejora en los distintos ámbitos de actuación que se puedan establecer en un centro. Regular los procesos de interacción y comunicación en grupos de alumnos de 0-3 años y de 3-6 años. Conocer formas de colaboración con los distintos sectores de la comunidad educativa y del entorno social. 


\subsubsection{La Formación Superior del Profesorado en Venezuela.}

En Venezuela, la ley de Universidades (1970:1) en el artículo primero, define a la Universidad como una comunidad de intereses espirituales que reúne a profesores y estudiantes en la tareas de buscar la verdad y afianzar los valores trascendentales del hombre; así mismo en los artículos segundo y tercero, la referida ley destaca que las universidades deben colaborar con el país mediante la contribución doctrinaria en el esclarecimiento de los problemas nacionales y además realizar una función rectora en la educación, la cultura y la ciencia mediante actividades dirigidas a crear, asimilar y difundir el saber mediante la investigación y la enseñanza, a completar la formación integral iniciada en los ciclos educacionales anteriores y a formar los equipos profesionales o técnicos que necesite la nación para su desarrollo y progreso.

En la actualidad, el órgano rector de las políticas de este nivel educativo es el Ministerio del Poder Popular para la Educación Superior (MPPES), creado el 08 de enero de 2007, según Decreto Presidencial $N^{\circ}$ 5.103, publicado en Gaceta Oficial Extraordinaria $N^{\circ}$ 5.836; éste órgano rector, está conformado por un Despacho de Viceministro (a) de Políticas Académicas y un Despacho de Viceministro (a) de Políticas Estudiantiles (MPPES, 2010). Las competencias del MPPES están orientadas a planificar, dirigir y coordinar actividades inherentes a la asesoría, ejecución, seguimiento, evaluación, control y difusión de las políticas académicas y estudiantiles a fin de fortalecer la calidad, equidad y pertinencia social de la educación superior, en concordancia con las políticas del estado venezolano.

Es necesario destacar algunos de los principios orientadores que guían las acciones del MPPES: a) La educación y el conocimiento como bienes públicos al servicio de todas y todos; b) inclusión y justicia social; c) Diversidad e interculturalidad; d) Cooperación solidaria; e) Calidad; f) Pertinencia; g) Formación integral; h) Ejercicio del pensamiento crítico y creativo; i) Educación a lo largo de toda la vida; j) Autonomía responsable; k) Cooperación internacional. Como puede observarse constituyen principios globales enmarcados en los acuerdos mundiales a

84

La Práctica Profesional como área para potenciar las competencias pedagógicas necesarias para la enseñanza en Educación Infantil 
los cuales Venezuela está suscrita, lo que implica para las instituciones universitarias, un gran compromiso que tienen que cumplir y por tanto dar respuesta a los ciudadanos.

Para conocer un poco más acerca de la historia de la evolución de las universidades en Venezuela, Rojas (2005) presenta un cuadro general desde sus inicios en 1721, hasta el año 2005, contando para esta fecha con 6 universidades autónomas, 16 universidades nacionales experimentales, 24 universidades privadas, 09 colegios universitarios y 99 institutos universitarios entre públicos y privados. En este sentido, Rojas describe la evolución del subsistema de educación superior, tomando como criterio la periodización histórica de las principales reformas sufridas por la institución, desde la fundación de la Real y Pontificia universidad de Santiago de León en Caracas (1721), hasta la fecha, cuando el país es escenario de un debate dirigido a elaborar una nueva ley de Educación superior, a tono con los cambios que ha sufrido el sistema educativo en general y en el marco de una nueva constitución de la República Bolivariana de Venezuela (1999).

En este sentido, puede señalarse que en estos casi trescientos años de historia universitaria, y de acuerdo con Rojas (2005), se aprecia que en las primeras tres décadas del siglo XX, hubo muy poca actividad académica y científica en las universidades venezolanas; luego en el llamado periodo de transición (1936-1958), en el país solo se contaba con dos universidades (Universidad Central de Venezuela, UCV y la Universidad de los Andes, ULA), así mismo, se destaca la iniciativa de apertura de otras universidades tanto públicas como privadas. En el año 1958, se elaboró un anteproyecto de Ley de Universidades donde se reconoce el principio de autonomía y se creó como órgano único nacional, destinado a coordinar al sector universitario, al Consejo Nacional de Universidades (CNU).

En ese mismo año, el subsistema de educación superior ya dividido en universidades públicas y privadas, sufre una nueva división, la creación de las Universidades Nacionales Experimentales, con autonomía restringida y totalmente dependientes del gobierno a través del Ministerio de Educación, entre las que se cuenta la Universidad Pedagógica Experimental 85 La Práctica Profesional como área para potenciar las competencias pedagógicas necesarias para la enseñanza en Educación Infantil 
Libertador (UPEL) en el año 1983, la cual surge a partir de la integración de los antiguos institutos pedagógicos de Caracas, Barquisimeto, Maracay, Rubio, Maturín, el Mácaro, y Siso Martínez del Estado Miranda.

Entre 1970 y 2005, ocurre la expansión y crisis del sistema educativo universitario, el cual ha "rebasado los marcos de su propia legislación y ha alcanzado niveles de masificación que han puesto en cuestión su calidad y pertinencia" (ob. cit. p.79). Como puede observarse, la historia de la Educación Superior en Venezuela, es relativamente joven, con un crecimiento acelerado en los últimos 20 años, en los que se destaca la búsqueda de la calidad por medio del desarrollo de la investigación y la lucha por continuar mejorando en su desarrollo y expansión.

En este orden de ideas, Parra (2010) describe dos etapas en el proceso de cambios recientes (10 últimos años). La primera de 1999 a 2002, y la segunda de 2003 a 2009, las cuales marcaron un impacto en la educación superior. La primera fase se caracteriza por la implementación de los siguientes criterios para orientar las políticas de atención de las áreas críticas en educación superior, las cuales se enuncian a continuación:

- Educación superior como servicio publico

- Calidad e innovación

- Ejercicio del pensamiento critico

- Fortalecimiento de lo académico

- Equidad

- Pertinencia social

- Formación integral

- Autonomía

- Articulación vertical y horizontal

- Cooperación internacional

En este sentido, y siguiendo con la autora anteriormente señalada, estos criterios de formularon con el amparo y confirmación establecidos en la carta magna de 1999, donde se establece la 86 La Práctica Profesional como área para potenciar las competencias pedagógicas necesarias para la enseñanza en Educación Infantil 
educación como un derecho humano y un deber del estado, obligado así a garantizar la gratuidad de la educación superior.

Otro rasgo importante de señalar, es el referido a las políticas definidas desde el vice ministerio de educación superior, las cuales apuntan hacia: a) Estructurar el sistema de educación superior, en tanto no había articulación entre la heterogeneidad de instituciones existentes, con misiones, organización y modelos de gestión diferentes; b) Elevar la calidad académica de las instituciones, a partir del fortalecimiento de las funciones de docencia, investigación y extensión, dado el evidente deterioro que presentaban muchas de las instituciones oficiales; c) Mejorar la equidad en el acceso y en el desempeño de los estudiantes; d) Lograr una mayor pertinencia social de las instituciones, los programas y los currículos; e) Lograr una mayor interrelación con la sociedad y con los otros niveles educativos; f) Promover y fortalecer la cooperación nacional, regional e internacional (Ministerio de Educación, Cultura y Deporte, 2001: s/p).

En enero de 2002, se decreta la creación del Ministerio de Educación Superior como ente encargado de la dirección estratégica de la educación superior venezolana, la cual hasta ese momento era responsabilidad compartida entre el Ministerio de Educación, Cultura y Deportes (Vice-ministerio de Educación Superior) y el Consejo Nacional de Universidades (CNU), a través de la Oficina de Planificación del Sector Universitario (OPSU).

Estas políticas y acciones planteadas, durante el periodo 1999-2002, si bien estuvieron trazadas para atender los problemas más importantes que presentaba la educación superior en Venezuela, y de acuerdo con Parra (2010:11):

En muchos casos no lograron establecerse de manera definitiva ni producir las reformas deseadas; aparte de lograr el incremento en la cobertura y en el número de instituciones del sector oficial, no se llegó a constituir el sistema de educación superior, tampoco se logró elevar la calidad ni la pertinencia social, ni se implementó el sistema de evaluación ni el de 
carrera académica que hubiesen implicado un logro en el avance hacia la garantía de alcanzar la calidad.

\subsection{La Universidad Pedagógica Experimental Libertador.}

La Universidad Pedagógica Experimental Libertador, también conocida como UPEL, es la única casa de estudios universitarios para la formación de profesores en Venezuela. La UPEL, fue creada mediante el Decreto No.2176 de fecha 28 de Julio de 1983 del Ejecutivo Nacional como un homenaje a la memoria del Libertador Simón Bolívar en el Bicentenario de su nacimiento. Su reconocimiento como universidad se logró, a través de la unión de los Institutos Oficiales de Formación Docente conocidos como Institutos Pedagógicos, los cuales funcionaban de manera independiente, en todo el territorio nacional.

Desde su creación en 1983, la UPEL comenzó el proceso para la consecución de una estructura inicial que, en Noviembre de ese mismo año, se constituyó como Sede Rectoral con el nombramiento del Rector, del Vicerrector de Docencia y del Vicerrector de Investigación y Posgrado. Posteriormente, en 1984, se designó al Vicerrector de Extensión y al Secretario. Una vez designadas las autoridades rectorales, se incorporó un grupo interdisciplinario de profesionales para iniciar el proceso de reglamentación del funcionamiento de la Universidad, quienes se encargaron de originar vías para la integración de los Institutos Pedagógicos como un todo coherente e interrelacionado.

La incorporación de estos Institutos para la creación de la Universidad se estableció mediante Resolución No. 22 de fecha 28 de Enero de 1988 y se hizo efectiva el 27 de Junio del mismo año con la firma del Acta de Consolidación, en un hecho histórico y solemne realizado en la Iglesia San Francisco, de la Ciudad de Caracas. Este proceso de integración unió a todos los Institutos Oficiales de Formación Docente que para ese momento eran conocidos como los Institutos Pedagógicos : Caracas, creado en 1936, Barquisimeto, 1959, Maturín y "Rafael Alberto Escobar Lara" (Maracay), 1971; y el de Miranda "José Manuel Siso Martínez", en 1976. Igualmente se 88 La Práctica Profesional como área para potenciar las competencias pedagógicas necesarias para la enseñanza en Educación Infantil 
incorporó a la Universidad el Instituto de Mejoramiento Profesional del Magisterio con sus respectivos Núcleos Académicos, el Centro de Capacitación Docente "El Mácaro", creado en 1938 y el Gervasio Rubio, creado en 1952, como el "Centro Interamericano de Educación Rural" (CIER). En 1990, éstos últimos pasaron a formar parte de la Universidad como Institutos Pedagógicos independientes. En 1992, igualmente, se incorpora el Instituto Universitario Pedagógico "Monseñor Rafael Arias Blanco" en calidad de Instituto asociado a la Universidad.

\subsubsection{Misión y Visión de la Universidad Pedagógica}

De acuerdo con la planteado en el Reglamento General (s/f), la UPEL tiene como misión: formar, capacitar, perfeccionar y actualizar los recursos humanos, para la educación que se requiere en el país; asesorar al Estado venezolano en la formulación de políticas educativas y generar, aplicar y divulgar nuevos conocimientos, teorías y prácticas pedagógicas que contribuyan al desarrollo humanístico, científico, tecnológico y social del país a través de sus funciones de docencia, investigación y extensión. Así mismo en el citado documento, se afirma que la universidad tiene como visión, convertirse en una universidad de prestigio y cobertura nacional, líder en la formación y actualización docente promotora de los cambios necesarios del sector educativo, en concordancia con las transformaciones y exigencias del entorno y asesorar al Estado en la formulación de las políticas educativas nacionales y regionales, para contribuir al desarrollo y mejoramiento de la calidad de la educación, y en consecuencia de la calidad de vida del venezolano.

La UPEL, está constituida por siete institutos a nivel nacional: Instituto Pedagógico de Caracas, Instituto Pedagógico de Barquisimeto, Instituto Pedagógico de Maturín, Instituto Pedagógico de Maracay, Instituto Pedagógico de Miranda, Instituto de Mejoramiento Profesional del Magisterio (compuesto por: 13 Núcleos académicos, 11 Extensiones académicas, 20 centros de atención, en todo el territorio nacional), Instituto Pedagógico Rural "El Mácaro" y el Instituto Pedagógico Rural "Gervasio Rubio". A continuación, se presenta el mapa geográfico, que

La Práctica Profesional como área para potenciar las competencias pedagógicas necesarias para la enseñanza en Educación Infantil 
representa la ubicación de los institutos, núcleos y extensiones que conforman el contexto universitario UPEL en el territorio Venezolano.

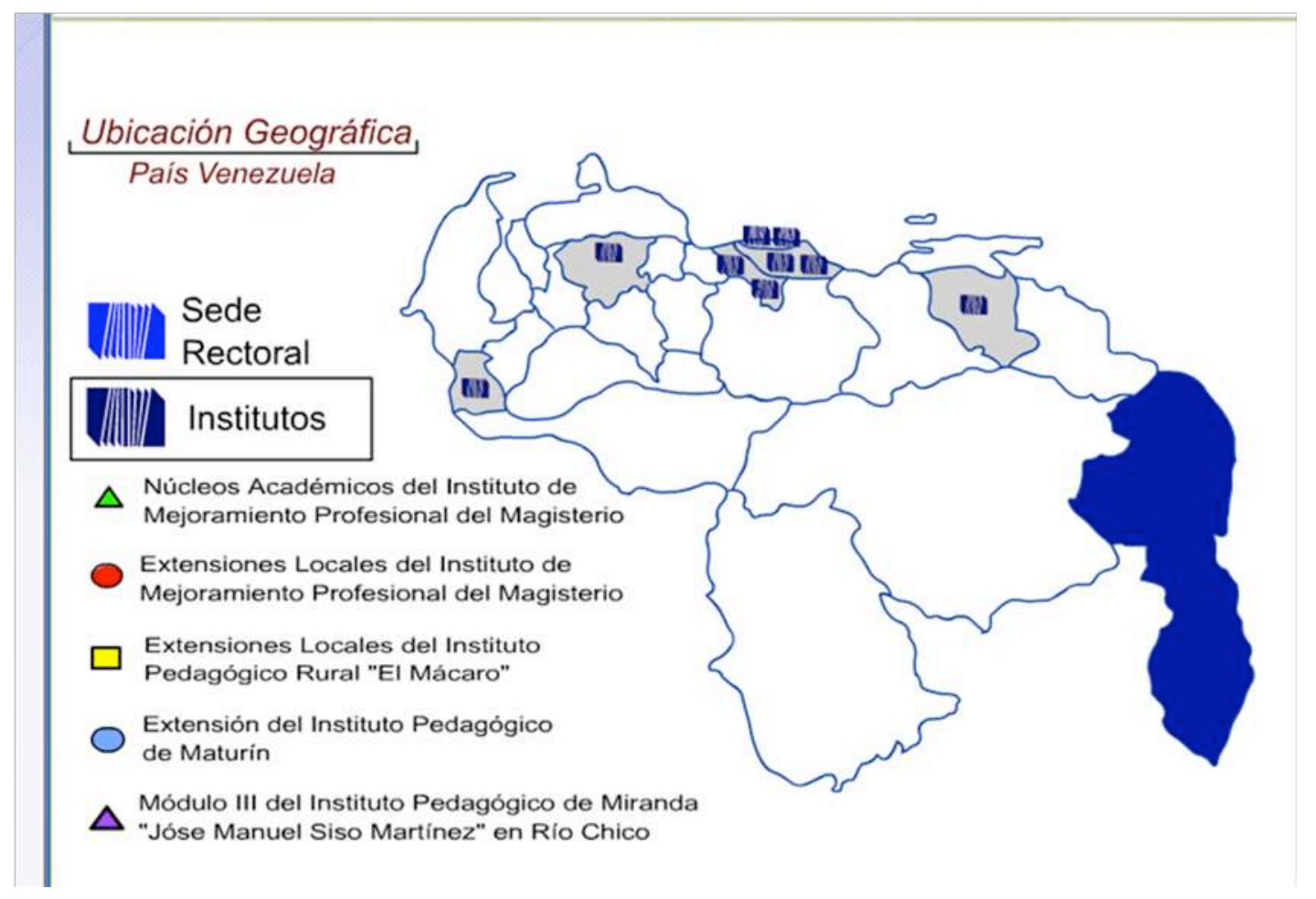

Grafico n ${ }^{\circ}$ 2. Mapa UPEL- nacional. Fuente UPEL. Documento en línea.

El contexto donde se realiza la presente investigación es la Universidad Pedagógica Experimental Libertador (UPEL), específicamente en el Instituto Pedagógico "Rafael Alberto Escobar Lara", de Maracay (UPEL-IPMAR) fue creado un 11 de noviembre de 1971, bajo el decreto presidencial No. 788 y ha formado, desde entonces, profesionales de la docencia en las diferentes áreas del conocimiento. En la actualidad la UPEL IPMAR, ofrece la formación de 
pregrado en las siguientes especialidades: matemática, castellano, inglés, informática, sociales, física, química, biología, preescolar, especial, educación física.

Así mismo, para atender la demanda de actualización y mejoramiento profesional de los egresados no sólo de esta Universidad, sino de otras casas de estudios superiores, la UPEL, ofrece a nivel de postgrado los subprogramas de maestría: enseñanza de la geografía, enseñanza de la educación física, enseñanza de la biología, enseñanza de la química, enseñanza de la matemática, enseñanza de la historia, educación superior, gerencia educacional, lingüística, literatura, orientación, educación infantiles y las especializaciones en preescolar, gestión comunitaria, educación inicial, educación para la integración de personas con discapacidad, estrategias didácticas para la educación básica. También ofrece estudios de doctorado en educación. De esta manera, la Universidad atiende la inminente demanda que a este nivel exige la región y los demás estados del centro del país.

Este servicio de formación abre la oportunidad de que la Universidad visualice nuevos escenarios para mejorar, que considere las exigencias de la nueva sociedad del conocimiento; para ello los profesionales de la docencia requieren competencias para afrontar los acelerados cambios tecnológicos, la aparición de diversas formas de cultura, el surgimiento de nuevos puestos de trabajo, las exigencias, y habilidades requeridas para el desempeño profesional, la actualización de los conocimientos, entre otros, los cuales provocan la necesidad de una formación y capacitación continua a lo largo de toda la vida.

En cuanto al personal docente de la UPEL, en el reglamento del personal académico se establecen una serie de normativas, para organizar y definir las funciones específicas de los docentes adscritos a los diversos departamentos, especialidades y programas que hacen vida en ella. En el mismo orden de ideas, para la Universidad Pedagógica Experimental Libertador y de acuerdo con el reglamento general de la UPEL (s/f), articulo 113, se considera como personal académico, a quienes ingresen por concurso de oposición y ostenten las categorías de profesores instructores, agregados, asociados y titulares.

91

La Práctica Profesional como área para potenciar las competencias pedagógicas necesarias para la enseñanza en Educación Infantil 


\subsubsection{Diseño Curricular de la Universidad Pedagógica Experimental Libertador (UPEL)}

En este espacio no se pretende analizar en profundidad el diseño curricular de la Universidad Pedagógica, pero es inevitable hacer referencia al diseño curricular con el cual se ha venido formando a los educadores del país, desde el año 1995. En este orden de ideas y de acuerdo con Rodríguez, Reyes y Peña (2009:5), el currículo puede considerarse como un proyecto prospectivo cuya implementación busca alcanzar determinados objetivos. Pero también el currículo en su estructura contiene los elementos que han de desarrollarse para cumplir con los propósitos establecidos. Al respecto, Díaz (1993:3) afirma que es frecuente encontrar en la literatura especializada en materia de diseño curricular, ciertas confusiones y ambigüedades, entre modelo curricular y los modelos de instrucción; para evitarlo es necesario tener presente que abordar lo curricular (nivel macro del proceso educativo), debe necesariamente conducirnos al estudio de lo instruccional (nivel micro del mismo proceso), por tanto, resulta útil presentar el siguiente cuadro resumen con los diferentes enfoques y corrientes teóricas en relación al currículo, para luego analizar brevemente el diseño curricular de la UPEL.

\begin{tabular}{|l|l|l|}
\hline Enfoque curricular & Abordaje metodológico & Autores \\
\hline Racionalidad & Metodológico curricular clásico. & $\begin{array}{l}\text { R. Tyler } \\
\text { H. Taba } \\
\text { M. Johnson }\end{array}$ \\
\hline Tecnológico & & R. Glasman \\
& & M. Ibarrola \\
& & J.A. Arnaz \\
\hline Socio político & Crítico & Stenhouse \\
\hline Reconceptualista & Constructivismo & C.Coll \\
\hline
\end{tabular}

Cuadro $n^{\circ}$ 6. Enfoques y corrientes teóricas en relación al currículo. Fuente: Díaz, (1993)

Como puede observarse en el cuadro $\mathrm{n}^{\circ} 6$, los enfoques presentan distintos énfasis asociados al desarrollo de la teoría y la metodología curricular; al respecto, podemos destacar que en el enfoque basado en la racionalidad, existe un énfasis en la función trasmisora y formadora de la 92 La Práctica Profesional como área para potenciar las competencias pedagógicas necesarias para la enseñanza en Educación Infantil 
escuela, con base a una concepción disciplinaria del conocimiento científico; en cuanto al segundo enfoque, el currículo se elabora desde una concepción tecnológica de la educación. Finalmente se destacan el enfoque sociopolítico y reconceptualista, donde el currículo es considerado como un conjunto de experiencias de aprendizaje y como una reconstrucción del conocimiento y propuesta de acción.

Por su parte Gundry (1998:27) refiere tres formas de saber, a partir de los postulados de Habermas, en los cuales se organiza el currículo según los intereses cognitivos básicos: técnico, práctico y emancipador:

- El interés técnico constituye un interés fundamental para el control del ambiente mediante la acción de acuerdo con reglas basadas en leyes con fundamento empírico. El interés cognitivo técnico informa el modelo curricular por objetivos, cuyo representante es Tyler; aquí está implícito el interés por el control del aprendizaje del alumno, de modo que al final del proceso de enseñanza, el producto se ajustará al “eidos” (intenciones o ideas) expresadas en los objetivos.

- El interés práctico, es un interés fundamental por comprender el ambiente, mediante la interacción, basado en una interpretación consensuada del significado. Sus conceptos claves son la comprensión y la interacción. El currículo informado por este interés se considera como un proceso donde el alumno y el profesor interactúan con el fin de dar sentido al mundo.

- El interés emancipador, se preocupa por la potenciación, o sea la capacitación del individuo y grupos para tomar las riendas de sus propias vidas de manera autónoma y responsable. El interés cognitivo emancipador se define como, un interés fundamental por la emancipación y la potenciación para comprometerse en una acción autónoma que surge de intuiciones auténticas, criticas, de la construcción social de la sociedad humana. Un currículo informado por este interés tenderá a la libertad de una serie de niveles, supone una acción recíproca entre auto reflexión y acción.

93

La Práctica Profesional como área para potenciar las competencias pedagógicas necesarias para la enseñanza en Educación Infantil 
Considerando las propuestas anteriores, puede afirmarse que la estructura curricular de la UPEL, presenta una organización lineal o por asignaturas, es decir, una concepción y orientación centrada en el Plan de Estudios y sus contenidos más que el aprendizaje, lo que limita las posibilidades de éxito e impacto que tendrán el egresado en un mundo inestable y cambiante, que posee una alta velocidad en la renovación del conocimiento; lo anterior coincide con lo que los autores identifican como un currículo con enfoque basado en la racionalidad o de interés cognitivo técnico, donde se especifica a tomar cada uno de los cuerpos organizados de conocimientos, habilidades y actividades, dividirlos y articularlos siguiendo una mayor lógica en cuanto al contenido y a las experiencias de aprendizaje, pasando de un tema a otro, según una jerarquización definida, y partiendo de un análisis, valoración y ordenamiento previos a la enseñanza.

Esta estructuración por asignaturas ha sido históricamente predominante en la elaboración de los planes de estudios, pues su producción es más fácil para el control administrativo de las instituciones educacionales. Estas asignaturas se agrupan en disciplinas, como anteriormente se ha señalado, lo que ha llevado a una variante de estructuración por disciplinas. No obstante ser el enfoque más difundido, a ésta estructuración lineal o por asignaturas se le han señalado críticas, tales como: 1.-contribuye de una manera particular a fragmentar la realidad y generar repetición constante de información muchas veces contradictoria, 2- son percibidas por el estudiante como opiniones o puntos de vista igualmente válidos, y no como concreciones de marcos teóricos diversos, 3.- que privilegia la exposición y tiende a convertir al alumno en espectador ante el objeto de estudio, 4.-que genera un gasto innecesario de energía psíquica por parte de alumnos y maestros como consecuencia de la atomización de contenidos.

En este sentido, a pesar de que esta concepción tiende a contemplar los nexos externos de las asignaturas y disciplinas y su evaluación esencialmente en términos de cantidad, actualmente se está elaborando un nuevo diseño curricular cuyo postulado principal responde a un enfoque curricular "basado en un modelo de desarrollo marcado por la cooperación, que exige 
capacidad para la interrelacionar saberes porque se caracteriza por una institucionalidad dialógica y multidimensionaf' (UPEL, 2005: 5).

\subsubsection{El Compromiso Profesional de la Universidad con la Sociedad.}

Las innovaciones tecnológicas, sociales y culturales de la actualidad asignan a los sistemas universitarios verdaderos desafíos que son necesarios reconocer y asumir si se quiere avanzar a tono con los cambios (Rodríguez, 2009:828). En este orden de ideas, y siguiendo a Rodríguez, se requiere que, las instituciones universitarias se constituyan en un elemento básico para generar mayores niveles de competitividad en el país; del mismo modo, están obligadas a convertirse en una fuente esencial de oportunidades de formación continua y movilidad social. También, las instituciones universitarias deben velar por la calidad y pertinencia de su oferta académica, cuestión de la mayor importancia para generar programas de formación e investigación que efectivamente impacten sobre la capacidad competitiva del país y permitan la inserción exitosa de jóvenes de familias vulnerables al mercado del trabajo. Bajo esta configuración, y para ilustrar los roles de las instituciones universitarias, su impacto directo e indirecto en la contribución y progreso de un país, se presenta el grafico $\mathrm{n}^{\circ} 3$ : 


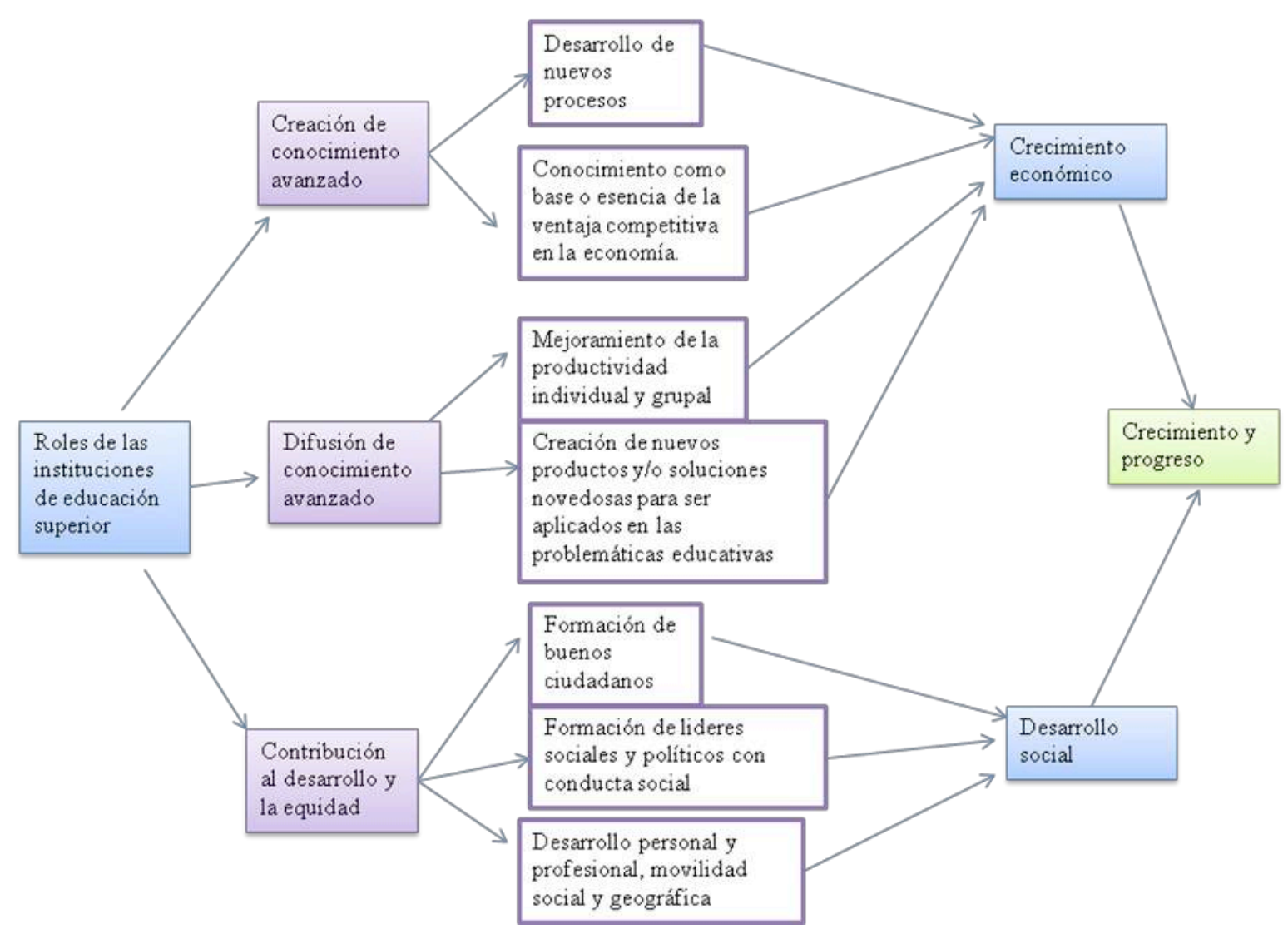

Grafico ${ }^{\circ} 3$. Roles de la educación universitaria. Fuente: Rodríguez (2009).

La profesión y el trabajo profesional tienen una dimensión social, materializada en las acciones y decisiones que los egresados de las instituciones de educación superior, deben manifestar en los contextos donde les corresponda ejercer su acción profesional. Ante esto es menester preguntarse ¿qué significa tener compromiso profesional con la sociedad?, ¿qué características deben desarrollar los egresados universitarios para poder comprometerse?

Al respecto, resulta valioso comentar las afirmaciones que Freire (2004:88), refiere sobre el compromiso del profesional con la sociedad; para este autor la primera condición para que un ser pueda ejercer un acto comprometido, está en que sea capaz de actuar y reflexionar, es decir, ser

La Práctica Profesional como área para potenciar las competencias pedagógicas necesarias para la enseñanza en Educación Infantil 
capaz de alejarse de su contexto para objetivarlo y transformarlo; además el verdadero compromiso es la solidaridad con los sujetos activos, en un encuentro dinámico de hombres solidarios. Así mismo, entre las características que debe manifestar los profesionales comprometidos con la sociedad, se destaca el reconocimiento al hecho de que antes de ser profesional es hombre, por lo tanto su primer encargo es consigo mismo, asumiéndose en un contexto histórico y social, así como el hecho de que el compromiso debe ser un acto de praxisacción-reflexión sobre la realidad, lo cual implica, indudablemente, un conocimiento crítico de la realidad.

En consideración a estas premisas, podemos referir que las instituciones universitarias formadoras de profesionales de la educación infantil, tienen una ineludible misión con la sociedad, la cual aspira poder contar con educadores que se desempeñen en este nivel educativo con características particulares tales como: abierto, dinámico, reflexivo de su quehacer, critico de su propia praxis y la de sus colegas y por supuesto investigador de todos los procesos relacionados con los niños y niñas, sus familias, el aula, la comunidad, es decir la realidad que le corresponda asumir, todo ello en un marco de permanente actualización.

Así mismo, este profesional egresado universitario, debe tener una solida base moral y ética que respete y promueva valores en la sociedad, con la suficiente preparación para enfrentar los diferentes retos que presenta el trabajar en diversos escenarios, poblaciones y regiones del país. (Ministerio de Educación Cultura y Deportes, 2002).

Ante este compromiso y de acuerdo con Thurler (2002:78) los profesores universitarios se enfrentan a dos grandes desafíos: reinventar la universidad como local de trabajo y de experiencias significativas de educación y reinventarse a sí mismos como personas, miembros de una profesión y ciudadanos en busca de la ciudadanía plena. Según esta autora, los profesores precisan examinar las prácticas pedagógicas que aprendieron y reorientarlas sobre las nuevas bases, así como revisar las relaciones profesionales con sus colegas y la organización del trabajo en el interior del claustro universitario. 
En este orden de ideas, es necesario repensar los modelos didácticos de aprender primero la teoría, para aplicarla algunos años después, ya que han demostrado su obsolescencia. El nuevo contexto de vida y aprendizaje, la dinámica social, las inmensas posibilidades de información, intercambio entre personas (expertos, estudiantes), las tecnologías de la información y comunicación, representan situaciones, información e iniciativas, frente a las cuales los alumnos encuentran desafíos, para hablar, investigar, reaccionar y actuar y los profesores universitarios requieren imponer otra dinámica a la vida y por tanto a la educación.

\subsection{Resumen de Formación Superior del Profesorado.}

En el presente apartado se realizó un acercamiento a la Educación Superior, en su indiscutible misión y función de educar, formar y realizar investigaciones, implica, particularmente en la misión de contribuir al desarrollo sostenible y al mejoramiento del conjunto de la sociedad. Así mismo se hizo mención a un antecedente importante, en relación con los procesos de evaluación de la educación superior, como lo es el proyecto Tuning - América Latina, el cual tiene como finalidad incorporar los diferentes aspectos de la diversidad de los países que en el intervienen e interactúan. En este orden de ideas, también se señala algunas de las misiones y funciones de la Educación Superior, planteados por UNESCO (2009), se destacan algunos artículos, referido a: la misión de educar, formar y realizar investigaciones, formar diplomados altamente cualificados y ciudadanos responsables, capaces de atender a las necesidades de todos los aspectos de la actividad humana, entre otros. Desde este marco referencial, y en concordancia con los planteamientos de UNESCO (1998), se asume como necesario reformular los planes de estudio y utilizar métodos nuevos y adecuados que permitan superar el énfasis en el dominio cognitivo de las disciplinas, para ello es ineludible facilitar el acceso y fomento de nuevos planteamientos pedagógicos y didácticos, que propicien la adquisición de conocimientos prácticos, competencias y aptitudes para la comunicación, el análisis creativo y crítico, la reflexión independiente y el trabajo en equipo en contextos multiculturales, en los que la creatividad exige combinar el saber teórico y práctico, tradicional o local, con la ciencia y la tecnología de vanguardia. Así mismo,

98

La Práctica Profesional como área para potenciar las competencias pedagógicas necesarias para la enseñanza en Educación Infantil 
los nuevos métodos pedagógicos también supondrán materiales didácticos y métodos, que pongan a prueba no sólo la memoria sino también las facultades de comprensión, la aptitud para las labores prácticas y la creatividad. En este sentido, se realizó un breve análisis a los modelos de formación profesoral en América Latina y Europa donde se encontró que en la mayoría de los países, la formación docente inicial se realiza en institutos superiores pedagógicos y en universidades, con un proceso académico de tres y cinco años de duración. Del mismo modo, y como una forma de ubicar al lector en el contexto de la presente investigación, se describe a la Universidad Pedagógica Experimental Libertador, también conocida como UPEL, es la única casa de estudios universitarios para la formación de profesores en Venezuela, la cual tiene como misión: formar, capacitar, perfeccionar y actualizar los recursos humanos, para la educación que se requiere en el país; asesorar al Estado venezolano en la formulación de políticas educativas y generar, aplicar y divulgar nuevos conocimientos, teorías y prácticas pedagógicas que contribuyan al desarrollo humanístico, científico, tecnológico y social del país a través de sus funciones de docencia, investigación y extensión. 


\section{Capítulo 3. Profesionales para la Educación Infantil}

$>$ Conceptualización educación infantil

$>$ Acuerdos mundiales para la educación infantil

$>$ Declaración de los Derechos del Niño 1959

$>$ Conferencia mundial Educación para Todos 1990

$>$ Informe Delors (UNESCO 1996)

$>$ Declaración de Salamanca (2005)

$>$ Declaración de Montevideo (2006)

$>$ Declaración de Valparaíso (2007)

$>$ Declaración de El Salvador (2008)

> XIX Conferencia de Portugal, Declaración de Lisboa (2009)

$>$ X Conferencia Iberoamericana de jefes de estado y presidentes de gobierno (2000).

> Evolución curricular de la educación infantil Venezolana

$>$ Cobertura nacional de la educación inicial

$>$ El profesional para educación infantil

$>$ Rol del profesional de educación infantil

$>$ Resumen profesionales para la educación infantil 


\section{CAPITULO 3. PROFESIONALES PARA LA EDUCACIÓN INFANTIL}

\subsection{Conceptualización Educación infantil}

Una de las características que tiene la educación infantil es su gran heterogeneidad conceptual y práctica. Desde el punto de vista de Peralta (2002: 28) en el caso especifico de Latinoamérica, las expresiones de "Educación Inicial, de la Primera Infancia y Parvularia", son las más adecuadas para identificar a la educación que se genera en función de los niños y niñas de cero a seis años; la cual se refiere a:

Los procesos educativos intencionados, oportunos y pertinentes, que se seleccionan a partir de sus necesidades, fortalezas y características, a fin de favorecer aprendizajes significativos que aporten a su desarrollo integral, dentro de una concepción de ellos y ellas como personas en continuo perfeccionamiento. (Ob.cit.:28).

Para Zabalza (2006:5) "la educación infantil es un conjunto de factores y agentes que intervienen coordinadamente en y desde la institución escolar, para lograr ciertos efectos educativos en niños de una determinada edad". También este autor distingue la escuela infantil como un recurso necesario para propiciar la equidad e igualdad de oportunidades entre todos los niños, sean cuales sean sus condiciones sociales, personales o culturales. De la cita anterior podemos destacar tres elementos a los cuales el autor hace referencia: a) condiciones sociales, de allí la importancia de las escuelas públicas; b) condiciones personales, es decir, mantener criterios de inclusión y atención a la diversidad; y c) condiciones culturales, como una vía para construir la identidad cultural desde la más temprana edad.

Por su parte, Gassó, (2004:13) sostiene que "el concepto de educación infantil en el siglo XXI, se fundamente en una formación integral de los niños que tiene en cuenta todos los ámbitos de la persona... y que se aleja del modelo tradicional de la "trasmisión" de conocimientos".

La Práctica Profesional como área para potenciar las competencias pedagógicas necesarias para la enseñanza en Educación Infantil 
También se considera que los saberes que el maestro debe enseñar deben incluir contenidos de procedimientos, actitudes y conceptos y que su papel es mas de "mediador" que el de "trasmisor".

Tenemos así que, la educación infantil procura potenciar y fortalecer todas las oportunidades de desarrollo de los niños, así como de proporcionarles de competencias, habilidades, los hábitos, aptitudes y actitudes que puedan contribuir a hacer más placentera, práctica, efectiva y feliz su vida personal y escolar.

\subsection{Acuerdos Mundiales para la Educación Infantil}

Los marcos legales son un principio importante para profundizar y ampliar los estudios relacionados con la educación infantil. Particularmente los acuerdos internacionales, respaldados por los países suscritos, resaltan evidencias que aportan información y que se convierten en la base para fundamentar investigaciones en beneficio de la población infantil.

Estos compromisos internacionales son una expresión del consenso de los países sobre la importancia de los seis primeros años de vida del niño así como la notable labor que cumple la familia y la sociedad. La relación en la aplicación práctica de dichos acuerdos, hace que los mismos reviertan en beneficios de mejor calidad de vida de los niños y sus familias.

Por lo general, en coherencia con los acuerdos emanados, cada país orienta sus propias políticas educativas, en consonancia con sus propias particularidades como región. Al respecto, la necesidad de una formación profesional de jerarquía, y la incorporación de la educación infantil en los sistemas educativos, es algo en lo que afortunadamente todos coinciden (Peralta y Fujimoto 1998:75): tanto la comunidad científica, como los especialistas involucrados en la preparación y desarrollo profesional docente, como los organismos internacionales abocados al tema de la educación, e incluso los gobiernos, al menos desde el punto de vista discursivo, aunque en líneas generales las políticas implementadas hasta el momento no hayan logrado alcanzar los cambios deseados.

102

La Práctica Profesional como área para potenciar las competencias pedagógicas necesarias para la enseñanza en Educación Infantil 
Las declaraciones emitidas por organizaciones internacionales como UNESCO, ONU, OEA, entre otros, reconocen y ratifican la importancia de la educación infantil y de un jerarquizado desarrollo profesional de los educadores infantiles. Valga como ejemplo, recorrer los siguientes documentos:

1. Declaración de los Derechos del Niño (ONU, 1959)

2. Conferencia Mundial Educación Para Todos (Tailandia, 1990)

3. Informe Delors (UNESCO, 1996)

4.- Declaración de Salamanca (2005),

5.- Declaración de Montevideo (2006).

6.- Declaración de Valparaíso (2007).

7.- Declaración de El Salvador (2008)

8.- XIX Conferencia de Portugal, (Declaración de Lisboa, 2009)

9.- X Conferencia Iberoamericana de Jefes de Estados y Presidentes de Gobiernos. (Panamá, 2000).

\subsubsection{Declaración de los Derechos del Niño 1959}

Exhorta a padres, organizaciones, autoridades y gobiernos a reconocer esos derechos y procuren su cumplimiento con medidas legislativas, a fin de que los niños /as, puedan tener una infancia feliz y gozar, en su propio bien y en bien de la sociedad, de los derechos y libertades que en ella se enuncian

Al respecto, se destacan:

103

La Práctica Profesional como área para potenciar las competencias pedagógicas necesarias para la enseñanza en Educación Infantil 
- El derecho que tienen todos los niños, sin distingo de ninguna índole, a disfrutar de todos los enunciados de la presente declaración (principio número 1).

- Se resalta el interés superior del niño, lo cual le garantiza el derecho a una protección especial, de oportunidades y servicios, que particularmente en las instituciones educativas y especialmente por sus maestros, le deben brindar para que pueda desarrollarse física, mental, moral espiritual y socialmente, en condiciones de libertad y dignidad (principio número 2).

- En esta misma línea, los principios 4 y 5, enuncian acerca de los beneficios de seguridad social: alimentación, vivienda, recreo y servicios médicos, así como del tratamiento, cuidado y educación a los niños física o mentalmente impedidos.

- En este mismo orden de ideas, el principio 6, destaca la obligación de la sociedad y las autoridades públicas de cuidar especialmente a los niños sin familia o que carezcan de medios adecuados de subsistencia.

- Y luego el número 7, establece el derecho a recibir una educación pública, gratuita y obligatoria, que permita, entre otras cosas, desarrollar actitudes y llegar a ser un miembro útil de la sociedad; realidad ésta que compromete aún más a las universidades responsables de la formación de profesionales para este nivel educativo, a garantizar que sus egresados, posean las competencias necesarias para cumplir y hacer cumplir el principio rector referido al interés suprior del niño, como factor fundamental del cual se desprenden todos los demás derechos, los cuales deberán estar orientados hacia los fines perseguidos por la educación; la sociedad y las autoridades públicas se esforzaran por promover el goce de este derecho.

\subsubsection{Conferencia Mundial Educación Para Todos (1990)}

La Declaración Final de esta Conferencia desarrollada en 1990 en Jomtien, Tailandia representó sin duda alguna una guía importante en el proceso de avance educativo y el lugar que ocupa en el diseño de las políticas de desarrollo humano; "El aprendizaje comienza con el 
nacimiento. Ello exige el cuidado temprano y la educación inicial de la infancia, lo que puede conseguirse mediante medidas destinadas a la familia, la comunidad o las instituciones, según convenga” (1990:11).

La unanimidad alcanzada por este acuerdo ha dado renovado impulso a la campaña mundial dirigida a proporcionar una enseñanza primaria universal y a erradicar el analfabetismo de los adultos. Además ha suscitado esfuerzos con vistas a mejorar la calidad de la educación básica y a dar con los medios más eficaces y baratos para satisfacer las necesidades básicas de aprendizaje de diversos grupos desasistidos. Más adelante, se resalta que "la sociedad debe proporcionar además un sólido ambiente intelectual y científico a la educación básica” (p.11). Ello requiere el mejoramiento de la enseñanza superior y el desarrollo de la investigación científica. En cada nivel de la educación debiera ser posible establecer un estrecho contacto con el conocimiento tecnológico y científico contemporáneo.

\subsubsection{Informe Delors (UNESC 0, 1996)}

El Informe de Comisión internacional sobre la Educación para el Siglo XXI, más conocido como informe Delors, presentado a la UNESCO en 1996, asigna a la educación inicial la connotación de "un pasaporte para toda la vida", subrayando la importancia de la educación de la primera infancia con estas frases:

Además del inicio de socialización que los centros y programas permiten efectuar, se ha podido comprobar que los niños a los que se imparte una educación destinada especialmente a la primera infancia están más favorablemente dispuestos hacia la escuela y es menos probable que la abandonen prematuramente que los que no han tenido esa posibilidad. Una escolarización iniciada tempranamente puede contribuir a la igualdad de oportunidades al ayudar a superar los obstáculos iníciales de la pobreza o de un entorno social o cultural desfavorecido. Puede facilitar considerablemente la integración escolar de los niños procedentes de familias inmigradas o de minorías culturales o lingüísticas. Además, la existencia de estructuras educativas que acogen a niños en edad preescolar facilita la participación de las mujeres en la vida social y económica.

105

La Práctica Profesional como área para potenciar las competencias pedagógicas necesarias para la enseñanza en Educación Infantil 


\subsubsection{Declaración de Salamanca (2005)}

Emanada en el marco de la XV Cumbre Iberoamericana, donde se señala el compromiso de avanzar en la creación de un Espacio Iberoamericano del Conocimiento, orientado a la necesaria transformación de la Educación Superior, y articulado en torno a la investigación, el desarrollo y la innovación, condición necesaria para incrementar la productividad brindando mejor calidad y accesibilidad a los bienes y servicios para nuestros pueblos así como la competitividad internacional de nuestra región.

\subsubsection{Declaración de Montevideo (2006).}

Realizada en la XVI Cumbre Iberoamericana en Uruguay, la cual afirma que se deben potenciar los esfuerzos y acciones que los gobiernos y redes regionales de instituciones de educación superior están desarrollando para la construcción de espacios comunes multilaterales, así como para la conformación de redes de cooperación e intercambio académico como un medio eficaz para la construcción del Espacio Iberoamericano del Conocimiento (EIC).

\subsubsection{Declaración de Valparaíso (2007)}

Se ratifica el deber ineludible del Estado de promover políticas educativas que refuercen la inclusión y cohesión social y el sentido de pertenencia, a través de la promoción de la calidad y equidad educativa, su vinculación con el sistema productivo, para lograr con ello sociedades más justas, con mejores oportunidades para todos, mayores niveles de bienestar y haciendo posible la construcción de ciudadanía.

\subsubsection{Declaración de El Salvador (2008)}

Efectuada en la XVIII Cumbre iberoamericana. Su principal propósito fue el fortalecimiento de las políticas educativas y culturales, tendientes a asegurar el derecho a la educación de calidad desde la primera infancia. 


\subsubsection{Conferencia de Portugal, Declaración de Lisboa, (2009)}

Se planteó la contribución a la mejora de la calidad de la educación en condiciones de equidad, a través de iniciativas de formación del profesorado, evaluación de la educación, prevención del fracaso escolar y fortalecer la formación del personal docente, en especial en materia de Tics e incorporarlas en los procesos educativos de los países en todos sus niveles

\subsubsection{Conferencia Iberoamericana de Jefes de Estados y Presidentes de Gobiernos (2000)}

Celebrada en Panamá, año 2000, eleva el acuerdo de los Ministros de Educación donde se insiste en que: la educación es un proceso social ininterrumpido que comienza desde el momento de la concepción y se extiende a lo largo de toda la vida y dentro de ella, la educación inicial (desde el nacimiento y hasta la educación primaria o básica, según las distintas acepciones en los países) es una etapa en sí misma, en la cual se sientan las bases para la formación de la personalidad, el aprendizaje, el desarrollo afectivo, la capacidad de diálogo y tolerancia en las relaciones interpersonales, así como el entendimiento entre pueblos y culturas

En la mencionada reunión de Ministros, se concluye, entre otras cuestiones en:

a) reafirmar una vez más el valor de la educación inicial, como una etapa fundamental para el desarrollo de la personalidad;

b) promover y fortalecer políticas públicas que conduzcan eficazmente a la ampliación de la cobertura y mejoramiento de calidad con equidad según sea apropiado para los tramos de edad correspondientes;

c) reconocer la necesidad de definir y desarrollar estrategias que tomen en cuenta la singularidad de cada grupo etario en los contextos nacionales, priorizando el papel básico de las familias en la atención de las edades más tempranas;

107

La Práctica Profesional como área para potenciar las competencias pedagógicas necesarias para la enseñanza en Educación Infantil 
d) promover acciones que tiendan al fortalecimiento y formación de los padres y madres como agentes educadores responsables;

e) fortalecer la especificidad y especialización del nivel inicial, en una estrategia de desarrollo articulado con los demás niveles del sistema educativo, en particular en el desarrollo de las competencias para un efectivo aprendizaje de la lectura y escritura en los momentos apropiados;

f) propiciar instancias de formación y actualización de personal docente y de apoyo para la educación inicial, a través de modalidades presenciales y no presenciales, utilizando los medios de comunicación al alcance y las redes académicas, sociales, institucionales, tecnológicas, culturales, de intercambio y cooperación iberoamericanas.

Estos acuerdos de los ministros de educación, revelan un claro diagnóstico, de la realidad de la educación infantil en ese momento histórico, realidad que luego de 10 años de promulgado, aun sigue demostrando evidencias de grandes debilidades, lo cual, impulsa a continuar promoviendo investigaciones y acciones que ayuden verdaderamente a garantizar la equidad y justicia en pos de la educación de la primera infancia, como uno de los factores estratégicos para garantizar la equidad, disminuir los efectos de la pobreza, la convivencia social, así como en el apoyo al desarrollo económico y a la competitividad de nuestros países. Visto de esta manera, en la propia Declaración de Panamá, nuevamente se distingue, el acceso a una educación superior de calidad, la formación de profesionales para la educación infantil, la capacitación de los docentes en servicio, como la piedra angular del proceso de búsqueda de soluciones.

Los acuerdos y políticas 1959 -2009, proponen en resumen:

1.- Garantizar el cumplimiento de los compromisos asumidos en los últimos eventos políticos y hacer un seguimiento a los acuerdos. Particularmente en el tema de la educación, 
2.- Cumplir con los compromisos frente al niño/a de 0 a 6 años, la familia y la comunidad, con prioridad la más pobre.

3.-. Mejorar las condiciones de vida: salud, educación, nutrición, entre otros, con prioridad para la población de 0 a 3 años.

4.-. Otorgar alta prioridad a la educación inicial y al desarrollo infantil.

5.- Impulsar políticas, planes, acciones y servicios orientados a crear condiciones que fortalezcan el rol de la familia.

6.- Redoblar e intensificar acciones para lograr no sólo la universalización de la educación básica con su concepto ampliado, desde que el niño nace, sino además cumplir con los criterios de calidad, equidad, pertinencia y diversidad.

\subsection{Evolución Curricular de la Educación Infantil Venezolana.}

La atención al niño preescolar en Venezuela, tiene sus antecedentes en el año 1879, con la creación del asilo de huérfanos de Caracas, que amparaba niños de ambos sexos, cuyas edades oscilaban entre los tres y siete años. Estas instituciones tenían carácter asistencial, pues en ningún momento atendían la parte pedagógica (Bravo, 1979:14). En el año 1913, se funda el primer jardín de infancia, anexo a la escuela normal de mujeres de caracas, que servía de centro de práctica y entrenamiento a las estudiantes inscritas en la referida escuela, allí se aplicaba el método froebeliano.

Es en el año de 1940 y luego en 1948, cuando la Ley de Educación, considera la educación preescolar para niños de tres a siete años. Más tarde en 1952, se inician los cursos de kindergarterina, para formar a los maestros con un mayor grado de conocimientos, para la educación de los niños en edad preescolar (Universidad Nacional Experimental Simón Rodríguez (UNERS), 2004:18).

109

La Práctica Profesional como área para potenciar las competencias pedagógicas necesarias para la enseñanza en Educación Infantil 
En el año 1966, se empieza a experimentar en el país con el primer programa-ensayo para el nivel preescolar; este programa se entrega a maestros de siete planteles que participaron, durante cuatro años, quienes propusieron modificaciones y ajustes a ese programa. De esta manera surge en 1969, el primer programa oficial para educación preescolar.

Continuando con la historia de la educación preescolar, en el V Plan de la Nación (1974) se manifestaba la idea de ofrecer nuevas oportunidades a la población, como un modo de avanzar, en la formación de la población, también darle oportunidad a la familia y en ello a la madre, para incorporarse al mercado de trabajo y poder contar con un centro de atención seguro que favoreciera el crecimiento y desarrollo de sus hijos.

Si bien la educación preescolar es considerada en la Ley Orgánica de Educación (1980) como el primer nivel obligatorio del sistema escolar venezolano, el Reglamento General de la Ley de Educación (1996) delimitó la obligatoriedad, con preferencia a los cinco años, sin embargo la idea de atención desde el nacimiento, siempre estuvo en el ánimo de los responsables de formular y gestionar las políticas públicas en educación. Es así como entraron en acción diferentes modalidades de atención denominados Programas Convencionales y No Convencionales.

Así mismo, es importante destacar que el nivel de educación preescolar ha experimentado algunos cambios en sus modelos pedagógicos. A mediados de la década de los ochenta entró en vigencia una propuesta curricular, fundamentado para ese tiempo en innovaciones filosóficas, psicológicas y pedagógicas con un enfoque de desarrollo integral, lo que reflejó nuevas orientaciones en la búsqueda de mayor calidad educativa para los niños y niñas más pequeños(as). El currículo de educación preescolar (1986) plantea que el niño y la niña son el centro y autores de su propio aprendizaje, con atención a las peculiaridades individuales y el respeto como seres únicos dentro de un contexto familiar y comunitario (Ministerio de Educación y Deportes, 2005:8).

\section{0}

La Práctica Profesional como área para potenciar las competencias pedagógicas necesarias para la enseñanza en Educación Infantil 
Vale resaltar la experiencia de programas desarrollados a partir de 1974, tales como: Atención pre-escolar a niños entre 3 y 5 años, Participación de la Comunidad en la Atención Integral del Niño Preescolar, Programa Familia, Centros del Niño y la Familia, Programa de Educación Preescolar Rural, El Maestro en Casa y en la actualidad el Programa Simoncito que expresa la política del Estado en educación inicial. Por otra parte, y siguiendo con lo planteado en el documento anteriormente citado, se plantea a partir de 1996, la revisión curricular del nivel preescolar, dados los cambios en el contexto social, económico y cultural donde se desarrolla el proceso educativo. Estos estudios coincidieron en señalar la necesidad de tomar decisiones a corto y mediano plazo con relación a la definición de lineamientos curriculares en el marco de una visión del sistema educativo en su conjunto como un verdadero continuo, así como hacer los ajustes pertinentes, en atención a los cambios ocurridos en el contexto social y educativo en los diez años de vigencia del currículo del nivel preescolar (Ob. Cit., 2005:10).

En este mismo contexto, la Constitución de la República Bolivariana de Venezuela (1999) determina la responsabilidad del Estado desde maternal. Siendo así, se concibe como obligatoria la atención en esta primera etapa de la vida. Por las características evolutivas de la población en este período de la vida hay que considerar que se trata de un sistema complejo de relaciones humanas que al integrarse conformarán el sub-sistema de educación inicial, del sistema escolar. Ello implica considerar la dimensión, psicológica, social y antropológica en el sector educativo para la atención integral de la población infantil, con participación de las familias y la comunidad.

Desde el año 2005, la atención integral a la población infantil en Venezuela, es denominada como educación inicial, lo cual fue un cambio en la denominación del primer nivel obligatorio del sistema escolar, en correspondencia con la normativa legal vigente. En este paradigma, la educación inicial se inserta en un enfoque de educación y desarrollo humano como un continuo, enfoque integral globalizado que vincula la educación inicial con la educación básica para darle

111

La Práctica Profesional como área para potenciar las competencias pedagógicas necesarias para la enseñanza en Educación Infantil 
continuidad y afianzamiento en ésta última a los vínculos afectivos que son la base de la socialización y de la construcción del conocimiento.

Cabe destacar que en los nuevos lineamientos (respecto a este nivel educativo) emitidos por el Ministerio de Educación y Deportes (2005) se asume a la educación inicial, como la atención integral al ser humano, en la etapa fundamental de la vida, desde el nacimiento (aún antes de la concepción) hasta los seis años de edad, privilegiando el desarrollo de la persona, lo cual conduce en sí mismo, a la formación integral para proseguir la escolaridad en educación básica. Para ello (desde el punto de vista formal) este nivel educativo está organizado en dos fases, a saber: educación maternal (de 0 a tres años de edad) y educación preescolar (de tres a seis años). Asimismo, la educación inicial privilegia a la familia como el primer escenario de socialización, donde se asegura la formación de la personalidad, de los valores y de la ciudadanía.

\subsubsection{Cobertura Nacional de la Educación Inicial.}

El informe de Educación para todos, entregado a la UNESCO por Venezuela (2000/sep.) contiene una sección descriptiva donde se analizan los principales índices sobre los altibajos en la expansión de la asistencia y de las actividades de la primera infancia, que incluye asistencia formal y no formal, así como la cobertura de los mismos, siendo ésta muy insuficiente en términos generales. También se analiza el proceso de ampliación del acceso a la educación primaria, así como la propuesta de mejoramiento de la calidad en educación primaria con las escuelas bolivarianas y el relanzamiento de las escuelas técnicas para la formación de técnicos medios. En este informe también se observa una sección destinada al análisis de los resultados estadísticos en cuanto a matrícula general, por grado, repitencia, prosecución escolar, rendimiento, distribución por género y por estados, donde se omiten los datos referidos a la atención y educación del nivel maternal y preescolar. Esta situación, da muestras de omisiones importantes con respecto a la información real o actualizada de este nivel educativo.

112

La Práctica Profesional como área para potenciar las competencias pedagógicas necesarias para la enseñanza en Educación Infantil 
Al respecto, en el mencionado informe, se encontró que la cobertura en sus distintas modalidades para la primera infancia entre 4 y 6 años de edad, pasó de 570.615 en el año escolar 1989-90 a 1.130.958 en 1998-99, sobre el total de la población de 1.656.396. Es decir, que sólo el $68,2 \%$ de los niños en esos niveles etarios recibía algún tipo de asistencia bien sea en

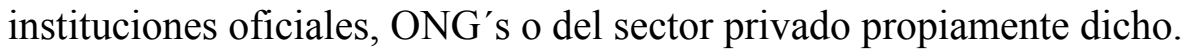

En el año escolar 1999-2000, con la política de "educación para todos", se abrieron cien mil nuevos cupos en preescolar en el sector oficial nacional, por lo que este nivel ha sido tomado por el gobierno como "Proyecto Bandera" para continuar ampliando la cobertura. En cuanto a la atención de la población de 0 a 3 años las cifras arrojan una situación realmente crítica. En esos niveles etarios se atienden sólo 108.879 niños, es decir el 4,89\%, quedando excluidos el 95,11\%; Cerca de un $94 \%$ de la matrícula escolar preescolar formal se ubica en las comunidades urbanas, el resto en las intermedias y rurales. En cuanto a los programas no formales, más del 97\% se ubican en comunidades urbanas (ob. Cit.).

En la actualidad, para ampliar la atención al niño se desarrollan varios programas y proyectos: programa familia, programa centro del niño y la familia, proyecto de atención integral a niños del sector rural y el proyecto maestro en casa. Así mismo, en el nivel preescolar se presentan varias modalidades de atención al niño:

a) Atención pedagógica formal con estrategias de aula y participación de la familia y la comunidad. Se caracteriza por ser una comunidad de aprendizaje estructurada dentro del contexto institucional, como preescolar independiente o anexo a una escuela básica, como ambiente de aprendizaje que considera la organización del tiempo (jornada diaria, de lunes a viernes) y el espacio (áreas de trabajo). Por lo general atiende niños de 4 a 6 años de edad. En esta modalidad los grupos de niños trabajan bajo la orientación de un docente quien organiza el ambiente para que puedan darse las interacciones entre niños y ambiente, a objeto de propiciar el aprendizaje y favorecer el desarrollo.

113

La Práctica Profesional como área para potenciar las competencias pedagógicas necesarias para la enseñanza en Educación Infantil 
b) Atención pedagógica no formal con estrategias de familias y estrategias de comunidades. Se desarrolla una atención directa o indirecta al niño. Por lo general atiende a niños entre 0 y 3 años y aquellos que por diversos motivos y razones no están escolarizados. En este contexto el marco de actuación del docente es directamente con los niños, con los padres y con la comunidad, en espacios comunitarios integrados al programa familia, centros del niño y la familia, proyecto de atención integral a niños del sector rural, niños de los multihogares, hogares de cuidado diario a través del proyecto el maestro en casa.

\subsection{El profesional para Educación Infantil}

A lo largo del tiempo, se ha demostrado que la educación infantil tiene muchas y variadas posibilidades de desarrollarse. Dentro de esta perspectiva surge la necesidad de una actitud cada vez más abierta a una revisión crítica de lo que se hace, con el propósito de generar una educación cada vez más liberadora, no solo de los educandos, sino también del propio educador (Peralta, 2002:101). Sobre el particular, cabe destacar como identifica Soltis (1994: 245) al educador propicio a los cambios, al que denomina "the new teacher"; este autor expresa que la enseñanza para el nuevo educador es una constante reorganización, reconstrucción y transformación de su propia experiencia. Es el desarrollo de su propia filosofía de la enseñanza y de la educación y es lo que hace la diferencia definitiva de la forma como se vive la vida profesional.

Dentro de este mismo orden de ideas, puede afirmarse que la educación inicial tiene el apoyo de un buen número de investigadores y docentes especializados tanto en la teoría como en la práctica, que proporcionan vitalidad a este importante nivel educativo.

Al respecto Katz (2005:29), realiza una clara distinción en cuanto al conocimiento que debe poseer un "profesor profesional preescolar", para esta autora éste profesional debe poseer dominio de muchas disciplinas tales como: desarrollo físico,, salud, psicología, lenguaje y muchos aspectos de psicología del desarrollo, más adelante señala que para una descripción más

La Práctica Profesional como área para potenciar las competencias pedagógicas necesarias para la enseñanza en Educación Infantil 
completa del trabajo de profesores preescolares, mostraría que deben poseer conocimientos avanzados en neurología, algunos aspectos de antropología y sociología.

Para Marín (2003:19) el concepto de formación del profesorado, es visto como

Un proceso sistemático y organizado mediante el cual los profesores en formación se implican, individual o colectivamente en un proceso formativo que, de forma crítica y reflexiva, propicia la adquisición de conocimientos, destrezas y disposiciones que contribuyan al desarrollo de su competencia profesional.

Por su parte Didonet (2007:34) sostiene que "el profesor de educación infantil es un profesional que tiene la competencia de cuidar y educar niños de cero a seis años, en instituciones educacionales, en complementación a la acción de la familia, según las directrices de las políticas educacionales”. Esta definición presenta los siguientes elementos: a) dice que es un profesional, es decir alguien con preparación adecuada y credencial que le ha dado una institución acreditada; b) que cuida y educa, por tanto, se ocupa de todo lo que tiene relación con el niño: sus necesidades físicas, cognitivas, sociales y afectivas; c) su espacio de actuación es la institución de educación inicial, sabiendo que es el lugar de su ejercicio profesional, por tanto, acogedor y heurístico; d) complementar la acción de la familia, lo cual resultaría imposible si no se conoce bien, como es la vida del niño, en su familia y comunidad.

Es, por tanto, un proceso de desarrollo profesional que implica un desarrollo global de categorías relacionadas con la actividad humana: tener, en el sentido de saber y recibir; hacer, como sinónimo de actuar y comportarse; ser, como expresión de desarrollo existencial; comunicar, como testimonio de cooperación y confrontación; y cambiar, en el sentido de adaptación y transformación (Marín, 2003:20).

115

La Práctica Profesional como área para potenciar las competencias pedagógicas necesarias para la enseñanza en Educación Infantil 
Desde el punto de vista de Uribe (2007:135) el profesional de educación parvularia, dentro del ejercicio de su quehacer educativo debe desarrollar un amplio sentido de receptividad frente a los cambios, el cual le permita liderar, gestionar y modificar en virtud de esas demandas; sin embargo estas características frente a los diversos contextos en los cuales este se desenvuelve, deben estar esencialmente basadas en el conocimiento del niño y de todos y cada uno de los rasgos que involucran su desarrollo integral. Solo de esta forma su capacidad de intervención dentro del espacio y la comunidad educativa, será producto de una reflexión continua de su práctica pedagógica y de los procesos investigativos que a partir de esta se puedan generar.

En este sentido, es evidente que la función de un profesional de la educación preescolar no puede ser realizada por cualquiera, y por tanto, la formación de las estudiantes de este nivel educativo, invita de manera apremiante a la adopción de estándares elevados de calidad.

Ubicándonos específicamente en el contexto latinoamericano, existen variados informes de investigación que señalan algunos elementos importantes a considerar en la formación del educador del nivel inicial. En este orden de ideas, Peralta (2002), señala que los grandes avances del siglo XXI, originan a su vez cambios en el desarrollo y en el aprendizaje de los niños y niñas; Para esta autora, existen diferentes factores que están incidiendo fuertemente en "repensar" la pedagogía de los infantes y por tanto se hace necesario revisar, actualizar y operacionalizar, los currículos educacionales que se diseñen para la Educación.

Así mismo, la autora resalta los nuevos aportes teóricos y de la investigación que enriquecen la pedagogía de los infantes, entre los que se destacan: aportes históricos situacional, filosóficos, antropológicos-culturales, ecológicos, desde el campo de las neurociencias, sicológicos y pedagógicos, los cuales se presentan de manera resumida, a continuación:

116

La Práctica Profesional como área para potenciar las competencias pedagógicas necesarias para la enseñanza en Educación Infantil 
Aportes que enriquecen la pedagogía Infantil

\begin{tabular}{|c|c|}
\hline APORTES & PRÓPOSITO RELEVANTE \\
\hline $\begin{array}{l}\text { Fundamento } \\
\text { Histórico-situacional }\end{array}$ & $\begin{array}{l}\text { Que la niña y el niño asuman su identidad histórica en función de la época } \\
\text { en que viven, sin desestimar las culturas específicas de pertenencia de las } \\
\text { cuales también se es parte por tradicionales que sean; los niños y las niñas } \\
\text { han demostrado en la práctica que se pueden mover desde ámbitos muy } \\
\text { particulares a otros más extensos sin problemas. }\end{array}$ \\
\hline $\begin{array}{l}\text { Fundamento } \\
\text { Filosófico }\end{array}$ & $\begin{array}{l}\text { Asumirse como sujeto- persona, protagonista de los destinos personales y } \\
\text { colectivos. El llamado a reflexionar sobre nosotros mismos a la luz de la } \\
\text { situación presente de América Latina y de sus proyecciones a futuro } \\
\text { aparece fundamental como base para definir quiénes somos, que queremos } \\
\text { de nosotros, de las nuevas generaciones, y de la educación. }\end{array}$ \\
\hline $\begin{array}{l}\text { Fundamento socio- } \\
\text { antropológico- } \\
\text { cultural }\end{array}$ & $\begin{array}{l}\text { Se considera al niño(a), un activo partícipe social y cultural desde su } \\
\text { perspectiva, valorando la necesidad de analizar la complejidad de los } \\
\text { tiempos, de las sociedades, de las comunidades y de las familias actuales } \\
\text { donde coexisten varias concepciones y tipos de ellas, con diferentes } \\
\text { dinámicas y valores culturales }\end{array}$ \\
\hline $\begin{array}{l}\text { Fundamentos desde } \\
\text { el ámbito de la } \\
\text { ecología }\end{array}$ & $\begin{array}{l}\text { Favorecer un rol activo de los niños en la conservación del medic } \\
\text { ambiente para una mejor calidad de vida. Ambientes más sanos } \\
\text { alimentación adecuada, actividades al aire libre, relación y sensibilidac } \\
\text { con la naturaleza y conservación del medio ambiente se visualizan como } \\
\text { propósitos importantes, para una pedagogía que pretende darle mayores } \\
\text { posibilidades a las niñas y niños del siglo XXI }\end{array}$ \\
\hline $\begin{array}{l}\text { Fundamentos desde } \\
\text { el campo de las } \\
\text { neurociencias }\end{array}$ & $\begin{array}{l}\text { Aprovechar las fantásticas posibilidades del cerebro infantil para su mejor } \\
\text { desarrollo y aprendizaje. Estas investigaciones implican un enorme } \\
\text { desafío, tanto para los padres como los encargados de generar políticas } \\
\text { educativas, y para los educadores que las implementan. Deben centrarse } \\
\text { los esfuerzos para diseñar y aplicar programas educativos, orientados a } \\
\text { impulsar el desarrollo cerebral de los párvulos, con situaciones oportunas } \\
\text { pertinentes y relevantes, que permitan desarrollar este enorme potencial. }\end{array}$ \\
\hline $\begin{array}{l}\text { Fundamentos de la } \\
\text { Sicología }\end{array}$ & $\begin{array}{l}\text { Las amplias y variadas posibilidades de desarrollo y aprendizaje de las } \\
\text { niñas y niños. Con los aportes de L. Vygotsky al desarrollo infantil; Los de } \\
\text { las inteligencias múltiples de Gardner; La inteligencia emocional } \\
\text { planteada por Goleman, y muchos otros fundamentos sicológicos que } \\
\text { desde comienzos del siglo XX, han sustentado fuertemente los currículos } \\
\text { de Educación Inicial. }\end{array}$ \\
\hline
\end{tabular}

117

La Práctica Profesional como área para potenciar las competencias pedagógicas necesarias para la enseñanza en Educación Infantil 
Fundamentos desde Avanzando hacia una pedagogía de las oportunidades para las niñas y la Pedagogía niños latinoamericanos, a partir del repensar y reconstruir la teoría y la práctica.

Cuadro $\mathrm{n}^{\circ}$ 7. Aportes que enriquecen la pedagogía infantil. Fuente: Peralta (2002).

En síntesis, los aportes para una pedagogía del siglo XXI, planteados por Peralta, reflejan su experiencia educativa en Latinoamérica, en la que su mayor proposición descansa en una Pedagogía de las oportunidades acorde a los fundamentos anteriormente expuestos, y como un proceso de construcción que debe realizar cada comunidad educativa en función a las necesidades y fortalezas de las niñas y niños, para aprovechar y generar cambios efectivos, donde el rol de educador infantil es clave, ya que debe partir por el análisis de su postura frente a la temática de plantearse como verdadero agente transformador.

Del mismo modo, Fornasari de Menegazzo (2007), presenta una propuesta de pedagogía de la escucha, en donde se resalta la importancia de considerar la comunicación humana como una acción múltiple, variada y cambiante. Nunca es lineal, se da simultáneamente implicando varios sentidos. Así por ejemplo, mientras se escucha a una persona se oyen sus palabras, se observa sus actitudes corporales y hasta impresionan sus gestos, cuando estos están transmitiendo emociones. Es decir, la posibilidad de esta captación está directamente relacionada con la capacidad de vincularnos.

Al respecto, la modalidad pedagógica que se desarrolla en Reggio Emilio, posee como fundamento de su labor, la creciente importancia que le asignan al "escuchar a la infancia". Esta propuesta, está relacionada con los principios de los "Cien lenguajes del niño" y lo relacional. La conciben como una invitación de respeto al niño competente, como un camino de mayor humanización en un mundo que avanza cada vez más hacia lo mediático, donde se pierde en forma creciente la comunicación “cara a cara”, los contactos genuinos y serenos.

Para Fornasari de Menegazzo, escuchar, no es solo oír; No obstante, la frase "pedagogía de la escucha" puede centrar la atención en un solo sentido y limitar la comprensión al "oír", sin 118

La Práctica Profesional como área para potenciar las competencias pedagógicas necesarias para la enseñanza en Educación Infantil 
embargo, escuchar no solo se centra en lo auditivo sino en todos los sentidos (vista, tacto, gusto). Mirar forma parte del escuchar. La observación puede ayudar a los adultos a comprender mejor la forma en que los niños reaccionan en su entorno, las opciones que toman y las conexiones que establecen.

Ahora bien, el tacto requiere especial atención por parte del educador, sobre todo con los niños que asisten al Maternal. Este constituye una función central del contacto y la bibliografía provenientes de corrientes tales como la Gestal, y la Neurolingüística ofrecen interesantes estudios sobre la influencia importante y benéfica que se ejerce sobre otra persona con un "sostener" amoroso, una caricia, un escuchar tomando de la mano al niño que transmite su mensaje, como puede.

En este sentido, el poder escuchar al otro implica el saber escucharse a sí mismo. Escuchar permite una mejor y mayor cercanía al mundo y por lo tanto a los niños.

Dentro de este orden de ideas, Fernández (2007), explica las evidencias experimentales sobre desarrollo cerebral y su aplicación en el desarrollo cognitivo de los niños, a sus lazos afectivos, a su percepción del mundo, estas evidencias demuestran que la capacidad cognitiva depende en gran medida del grado de riqueza que las relaciones que se establezcan con el medio circundante, por tanto, enfatiza que no se tienen excusas y que no hay tiempo que perder en aprovechar tan importantes evidencias.

Del mismo modo, Zuluaga (2009) en su conferencia sobre neurociencias, neurodesarrollo y educación: realidad y mitos, enfatiza que la socialización del conocimiento científico en general y en particular de las neurociencias, no solo es deseable, sino que se ha convertido para la sociedad moderna en un deber social vinculado al derecho de acceso a la información; Tal divulgación, asocia todos los riesgos interpretativos y de aplicaciones desviadas de todos los preceptos éticos y estéticos inherentes a lo humano.

119

La Práctica Profesional como área para potenciar las competencias pedagógicas necesarias para la enseñanza en Educación Infantil 
Este autor, señala que la aplicabilidad directa del conocimiento neurocientífico al aula y a los espacios de interacción para la educación y el desarrollo humano, debe hacerse teniendo en cuenta las premisas de vulnerabilidad y se auto regulará a través de dinámicas sociales transdisciplinarias y grupos colegiados, que involucren educadores, científicos, políticos, sociólogos y público en general, propiciando la incorporación crítica y plural del mismo.

En este orden de ideas, Zuluaga, alerta sobre los mitos que se generan alrededor del uso e implementación de los aportes de las neurociencias, de una manera acrítica e irresponsable, en donde la peor parte es para los niños, niñas y sus familias, pues se convierten en consumidores de la publicidad que se genera de estas acciones, es importante aclarar que los planteamientos de fondo de estos conceptos, son reconocidos como valiosos para su aplicabilidad en educación, el peligro radica en lo que ya se ha señalado anteriormente; Entre los neuromitos que este autor señala, se destacan: (a) sobre-interpretación de la plasticidad y los períodos críticos del desarrollo, (b) asumir el ser humano con una visión parcializada por las especializaciones de los hemisferios cerebrales, los estilos cognitivos y gimnasia cerebral, dejando de lado la importante visión de manera integral y (c) los neuro nutrientes.

De igual modo, plantea algunas recomendaciones y estrategias que implican a la familia, sociedad, salud y educación, entre las que se destacan: (a) implementación temprana, (b) involucrar al núcleo familiar, (c) amplia cobertura, (d) recalcar la importancia de las políticas aplicadas, (e) crear instituciones líderes, (f) asegurar una nutrición adecuada, (g) identificar estrategias exitosas, (h) evaluar el impacto de las políticas a corto plazo.

Para finalizar, es sumamente valioso que un docente de educación inicial, asuma que la formación recibida y sus experiencias son un instrumento poderoso para desempeñarse en su diaria labor, no obstante, el tiempo no se detiene, y los niños de ayer ya no son los mismos, éstos exigen mayores oportunidades y están dispuestos a conseguirlas con el apoyo amoroso, y atento de sus familias y maestros, por ello no pueden los docentes conformarse, y las universidades

\section{0}

La Práctica Profesional como área para potenciar las competencias pedagógicas necesarias para la enseñanza en Educación Infantil 
descuidar la invaluable labor de estar a la vanguardia en la formación de los docentes del siglo XXI.

\subsection{Rol del profesional de Educación Infantil}

La identidad y profesionalidad del educador, descansa en investigar, saber, comprender y valorar qué, porqué y para qué enseñar. Todo educador del nivel de Educación Inicial, debe ser capaz de responder con claridad y precisión a preguntas básicas relacionadas con su profesión: ¿Cómo aprenden los niños?, ¿qué y cómo enseñar en educación inicial?, ¿cómo potenciar las habilidades y destrezas de los infantes?, entre otras. Así mismo, un profesional de la Educación Inicial, debe analizar las concordancias y discrepancias entre lo que piensa, dice y hace en su práctica cotidiana, ya que sus niños/as, padres y representantes, estarán muy atentos a sus orientaciones.

López de Maturana (2008), afirma que la diferencia entre lo que un educador hace y dice en el jardín de infantil, genera diversa tensiones, lo cual afecta el sentido y la trascendencia de las acciones educativas. Por su parte Gimeno (1999), recomienda que la praxis del docente, deba ser una acción transformadora y consciente. Esta acción transformadora, le permitirá al educador leer y re leer la cultura escolar, lo cual le facilitara la construcción de nuevos ajustes cognitivos, sociales y metodológicos para mejorar su cotidianidad. Al respecto:

Existe una creencia generalizada incluso en el ámbito pedagógico, que enseñar a los niños y niñas en edades tempranas, lo puede hacer cualquier persona, esto implica desconocimiento de las especificidades pedagógicas, ya que enseñar profesionalmente exige habilidades, destrezas y conocimientos específicos, que solo se logran en el estudio profesional" (López de M. 2008: $61)$. 
Siguiendo a Gil. Contreras y Gómez, (2006), el profesional de esta etapa educativa debe ser competente en su dimensión personal (paciencia, amabilidad, ayuda, cortesía, dedicación, entusiasmos, honestidad), en su dimensión educativa (pensar acerca de lo que enseña y como lo enseña, por lo tanto planificar, evaluar e informar), en su dimensión pública ( comprometido con las responsabilidades en los programas profesionales y de colaboración con las familias y con otros colegas) y en su dimensión formativa ( estudio permanente sobre el conocimiento teórico práctico de la infancia, trabajador en equipo, trabajador con los alumnos que tiene a su cargo y con las familias de estos e involucrado en los procesos de cambios).

En este punto, resulta interesante presentar el análisis que Ríos (1998:29) presenta sobre el rol del educador infantil. Para este autor es necesario distinguir entre las distintas denominaciones que se utilizan para identificar a estos profesionales, a saber: educador, facilitador o mediador. En el siguiente cuadro resumen se presentan sus principales características.

\begin{tabular}{|l|l|l|l|}
\hline Denominación & Significado & Fundamento teórico & Aporte del autor \\
\hline Educador & $\begin{array}{l}\text { Origen en el término } \\
\text { latino Educere, expresa } \\
\text { la acción de sacar a la } \\
\text { luz. }\end{array}$ & $\begin{array}{l}\text { Sócrates utiliza el } \\
\text { dialogo, el arte de la } \\
\text { dialéctica. Piaget retoma } \\
\text { este planteamiento para } \\
\text { destacar el conflicto } \\
\text { cognitivo }\end{array}$ & $\begin{array}{l}\text { Se busca el desarrollo de } \\
\text { ciertas capacidades, el } \\
\text { descubrimiento de las } \\
\text { potencialidades del alumno, } \\
\text { más que la reproducción o } \\
\text { memorización de contenidos. }\end{array}$ \\
\hline Facilitador & $\begin{array}{l}\text { Tiene dos acepciones } \\
\text { básicas que son } \\
\text { proporcionar y allanar. }\end{array}$ & $\begin{array}{l}\text { El concepto se impuso } \\
\text { desde la psicoterapia } \\
\text { humanística y según } \\
\text { Roger las cualidades } \\
\text { esenciales del maestro } \\
\text { facilitador son } \\
\text { autenticidad, cordialidad } \\
\text { empatía. }\end{array}$ & $\begin{array}{l}\text { Si bien este enfoque tiene gran } \\
\text { validez y aplicabilidad en } \\
\text { psicoterapia, también es cierto } \\
\text { que su aplicación en el proceso } \\
\text { educativo se ha visto } \\
\text { distorsionada en el sentido de } \\
\text { limitar el rol del docente a una } \\
\text { especie de conductor de } \\
\text { dinámicas de grupos, en un } \\
\text { ambiente generalmente } \\
\text { permisivo, donde su función se } \\
\text { ve minimizada. }\end{array}$ \\
\hline
\end{tabular}

122

La Práctica Profesional como área para potenciar las competencias pedagógicas necesarias para la enseñanza en Educación Infantil 


\begin{tabular}{|l|l|l|l|}
\hline Mediador & $\begin{array}{l}\text { Agente mediador que } \\
\text { actúa como apoyo, se } \\
\text { interpone entre el } \\
\text { aprendiz y su entorno } \\
\text { para ayudarle a } \\
\text { organizar y a desarrollar } \\
\text { su sistema de } \\
\text { pensamiento y facilitar } \\
\text { la aplicación de las } \\
\text { nuevas capacidades a } \\
\text { los problemas que se le } \\
\text { presenten. }\end{array}$ & $\begin{array}{l}\text { Feuerstein considera que } \\
\text { la modificabilidad } \\
\text { cognitiva y la superación } \\
\text { de las deficiencias } \\
\text { cognitivas se producen } \\
\text { gracias a la acción } \\
\text { deliberada, intencional yo de mediación } \\
\text { sistemática de agentes } \\
\text { mediadores. }\end{array}$ & $\begin{array}{l}\text { y } \\
\text { alado por el adulto, concede al } \\
\text { lumo la posibilidad de } \\
\text { alerse de un conjunto de } \\
\text { capacidades que aún no puede } \\
\text { hacer por sí mismo. De este } \\
\text { modo el mediador dará } \\
\text { importancia a los contenidos, a } \\
\text { los medios empleados para } \\
\text { enseñarlos y a las } \\
\text { aracterísticas particulares del } \\
\text { alumno. }\end{array}$ \\
\hline
\end{tabular}

Cuadro ${ }^{\circ} 8$ Rol del educador infantil. Ríos (1998)

Tomando como referencia los planteamientos de Ríos, es posible considerar que dentro del rol de un profesional de educación infantil, lo importante no es enseñar, en el sentido tradicional del término, sino guiar el proceso de aprendizaje, adaptar contenidos académicos a sus estudiantes a sus intereses, su nivel de desarrollo o su estilo cognitivo.

Por su parte Katz (2005:47) expone sobre las etapas de desarrollo de los profesores, la autora afirma que nadie puede comenzar un rol social como si tuviera experiencia, y en la mayoría de los casos, la habilidad mejora con la experiencia y la práctica adjunta, por tanto considera que los profesores tienen secuencias o etapas de desarrollo en los patrones de crecimiento profesional. De este modo, sugiere las tareas y las necesidades de entrenamiento asociado a cada etapa de desarrollo, para ello se presentan en el siguiente cuadro resumen sus principales características.

\begin{tabular}{|c|c|c|}
\hline Etapas & Tarea de desarrollo & Necesidad de perfeccionamiento \\
\hline Supervivencia & $\begin{array}{l}\text { Puede durar a través de todo su primer } \\
\text { año de trabajo. La principal } \\
\text { preocupación del profesor es si podrá o } \\
\text { no subsistir a los desafíos diarios de ser } \\
\text { el responsable de un grupo de niños y } \\
\text { de su aprendizaje. Esto provoca gran } \\
\text { ansiedad y sentimientos de ser }\end{array}$ & $\begin{array}{l}\text { El profesor necesita apoyo, comprensión, } \\
\text { estimulo, confianza, comodidad, y } \\
\text { asesoramiento. Necesita ayuda directa con } \\
\text { técnicas específicas. Se debe brindar } \\
\text { capacitación en forma constante e } \\
\text { inmediata por alguien que conozca al } \\
\text { profesor novel y al contexto d enseñanza, } \\
\text { que disponga de tiempo y flexibilidad, }\end{array}$ \\
\hline
\end{tabular}




\begin{tabular}{|c|c|c|}
\hline & inadecuado y no estar preparado. & $\begin{array}{l}\text { con horarios de visita periódicas, que han } \\
\text { sido organizadas por adelantado. }\end{array}$ \\
\hline Consolidación & $\begin{array}{l}\text { Al final del primer año el profesor se } \\
\text { siente más seguro y está listo para } \\
\text { consolidar lo aprendido en forma } \\
\text { global durante la primera etapa y } \\
\text { diferenciar las tareas específicas y } \\
\text { técnicas que debe dominar. En esta } \\
\text { etapa los profesores generalmente } \\
\text { comienzan a poner atención en los } \\
\text { niños problema y en las situaciones } \\
\text { problemáticas individualmente. }\end{array}$ & $\begin{array}{l}\text { Durante esta etapa la capacitación en } \\
\text { terreno continua siendo valiosa. } \\
\text { instructor puede ayudar al profesor } \\
\text { haciendo una evaluación en conjunto de } \\
\text { un caso problema. Sin embargo es el } \\
\text { profesor quien debe poseer un } \\
\text { conocimiento directo sobre el niño y su } \\
\text { contexto, para que el intercambio de } \\
\text { información entre profesor e instructor } \\
\text { pueda ser de la mejor manera y el } \\
\text { profesor reciba la ayuda para interpretar } \\
\text { su experiencia y solucionar los } \\
\text { problemas. También se recomienda la } \\
\text { consulta a otros especialistas. }\end{array}$ \\
\hline $\begin{array}{l}\text { lll } \\
\text { Renovación }\end{array}$ & $\begin{array}{l}\text { Frecuentemente el profesor suele } \\
\text { cansarse de hacer las mismas } \\
\text { actividades y celebrando las mismas } \\
\text { secuencias de feriados, durante el } \\
\text { tercer o cuarto año de enseñanza. En } \\
\text { consecuencia comienza a consultar } \\
\text { sobre los avances en los distintos } \\
\text { procesos de aprendizaje de los niños. }\end{array}$ & $\begin{array}{l}\text { En esta etapa los profesores están } \\
\text { particularmente receptivos a participar en } \\
\text { conferencias y talleres locales, regionales } \\
\text { y nacionales y beneficiarse al pertenecer a } \\
\text { asociaciones profesionales y participar en } \\
\text { sus encuentros. Es particularmente útil } \\
\text { proporcionar temas de lectura, invitarlos a } \\
\text { filmar sus propios videos, visitar otras } \\
\text { clases, programas y demostraciones de } \\
\text { proyectos. }\end{array}$ \\
\hline IV Madurez & $\begin{array}{l}\text { La madurez puede ser alcanzada por } \\
\text { los profesores dentro de tres, cinco o } \\
\text { más años. En esta etapa la persona ha } \\
\text { llegado a aceptarse como profesor y ha } \\
\text { alcanzado un cómodo nivel de } \\
\text { confianza en su propia capacidad. } \\
\text { Ahora tiene suficiente perspectiva para } \\
\text { comenzar a hacerse preguntas } \\
\text { profundas y abstractas, como búsqueda } \\
\text { más significativa para comprender sus } \\
\text { propias emociones, tener perspectiva y } \\
\text { realismo. }\end{array}$ & $\begin{array}{l}\text { Los profesores se benefician de } \\
\text { oportunidades para participar en } \\
\text { conferencias y seminarios y tal vez en un } \\
\text { postgrado. Estos profesores agradecen la } \\
\text { oportunidad de leer extensamente y de } \\
\text { interactuar con profesores que trabajen en } \\
\text { varias áreas problemáticas en diferentes } \\
\text { niveles. }\end{array}$ \\
\hline
\end{tabular}

Cuadro $n^{\circ} 9$ Etapas de desarrollo de los profesores. Katz (2005)

124

La Práctica Profesional como área para potenciar las competencias pedagógicas necesarias para la enseñanza en Educación Infantil 
Como puede observarse, de la tabla anterior se desprende que resulta beneficioso pensar que el desarrollo de los profesores ocurre en etapas generalmente ligadas a la experiencia lograda a través del tiempo, así mismo, las necesidades de perfeccionamiento que la autora plantea ayudan a tener una mejor comprensión del contexto y sus responsables. Sin embargo, estas etapas también pueden servir de alerta para que las universidades responsables de la formación docente, colaboren en mejorar sus propios procesos de enseñanza y también se articulen con las escuelas para orientar y apoyar a los profesores noveles en su desarrollo como profesional.

\subsection{Resumen Profesionales para la Educación Infantil.}

En el presente apartado se intentó presentar en primer lugar un acercamiento a la conceptualización que se tiene acerca de la educación infantil, destacándose que una de sus principales características es su gran heterogeneidad conceptual y práctica. Desde el punto de vista de Peralta (2002: 28) en el caso específico de Latinoamérica, las expresiones de "Educación Inicial, de la Primera Infancia y Parvularia", son las más adecuadas para identificar a la educación que se genera en función de los niños y niñas de cero a seis años; la cual se refiere a, los procesos educativos intencionados, oportunos y pertinentes, que se seleccionan a partir de sus necesidades, fortalezas y características, a fin de favorecer aprendizajes significativos que aporten a su desarrollo integral, dentro de una concepción de ellos y ellas como personas en continuo perfeccionamiento.

Más adelante, se comentan algunos acuerdos y declaraciones que los países del mundo reconocen y lo dejan manifiestan en sus políticas educativas; tal como el reconocimiento que la educación es la clave para el fortalecimiento de las instituciones democráticas, la promoción del desarrollo del potencial humano, y que influye positivamente en el crecimiento económico y la reducción de la pobreza. En tal sentido, se comprometen a promover el acceso de todos a una educación básica de calidad, apoyar el aprendizaje permanente, fortalecer los sistemas educativos, y realzar el desempeño de los docentes. 
También asumieron el apoyo y promoción del aprendizaje permanente, realzar el desempeño de los docentes mediante el mejoramiento de sus condiciones de servicio, elevar el perfil de la profesión dándoles, además de una formación inicial sólida, oportunidades de perfeccionamiento profesional permanente. Se deja evidencia del reconocimiento al papel fundamental de los docentes, y la priorización de su formación profesional como factor clave para el desarrollo de la sociedad, por lo que se constituye en una exhortación permanente, a los países y a sus universidades en la adopción de mecanismos que ayuden a mejorar la formación inicial y permanente de los docentes. Los acuerdos y políticas 1959 -2009, proponen en resumen: 1.Garantizar el cumplimiento de los compromisos asumidos y hacer un seguimiento a los acuerdos, particularmente en el tema de la educación; 2.- Cumplir con los compromisos frente al niño de 0 a 6 años, la familia y la comunidad, con prioridad la más pobre; 3.-. Mejorar las condiciones de vida: salud, educación, nutrición, entre otros, con prioridad para la población de 0 a 3 años; 4.-. Otorgar alta prioridad a la educación inicial y al desarrollo infantil; 5.- Impulsar políticas, planes, acciones y servicios orientados a crear condiciones que fortalezcan el rol de la familia; 6.Redoblar e intensificar acciones para lograr no sólo la universalización de la educación básica con su concepto ampliado, desde que el niño nace, sino además cumplir con los criterios de calidad, equidad, pertinencia y diversidad.

Del mismo modo, en este apartado se realizo un breve recorrido histórico sobre la educación infantil en Venezuela, en donde se dibuja una memoria breve de apenas 130 años, y que además tiene un origen muy parecido a otros países. Se encontró que en Venezuela la educación preescolar se inicia en la forma de guardería o asilo infantil (1876) y que de manera muy lenta fue ganando interés y respeto como nivel educativo. Del mismo, modo, se presentan los tres modelos curriculares que desde aproximadamente, 44 años se han venido utilizando como guías orientadoras para el trabajo educativo con niños de cero a seis años. Al respecto en el año 1966 se presento a los maestros de la época un programa de educación preescolar, organizado en contenidos y en áreas académicas, luego en el año 1986 surge la guía práctica para actividades con niños preescolar, como un gran aporte para la educación de los niños en edad preescolar 126

La Práctica Profesional como área para potenciar las competencias pedagógicas necesarias para la enseñanza en Educación Infantil 
(tres a seis años) y más recientemente el diseño curricular de educación inicial (2005) donde se considera la educación maternal (0 a 3 años) y la educación preescolar ( 3 a 6 años).

Más adelante, consideramos el tema de los profesionales para la educación infantil, donde encontramos que los autores consultados coinciden en afirmar que todo proceso de desarrollo profesional implica un desarrollo global de categorías relacionadas con la actividad humana: tener, en el sentido de saber y recibir; hacer, como sinónimo de actuar y comportarse; ser, como expresión de desarrollo existencial; comunicar, como testimonio de cooperación y confrontación; y cambiar, en el sentido de adaptación y transformación (Marín, 2003:20).

En este sentido, es evidente que la función de un profesional de la educación preescolar no puede ser realizada por cualquiera, y por tanto, la formación de las estudiantes de este nivel educativo, invita de manera apremiante a la adopción de estándares elevados de calidad; es sumamente valioso que un docente de educación inicial, asuma que la formación recibida y sus experiencias son un instrumento poderoso para desempeñarse en su diaria labor, no obstante, el tiempo no se detiene, y los niños de ayer ya no son los mismos, éstos exigen mayores oportunidades y están dispuestos a conseguirlas con el apoyo amoroso, y atento de sus familias y maestros, por ello no pueden los docentes conformarse, y las universidades descuidar la invaluable labor de estar a la vanguardia en la formación de los docentes del siglo XXI .

Finalmente, destacamos algunos aspectos relacionados con el rol profesional de un educador infantil, el cual debe ser capaz de responder con claridad y precisión a preguntas básicas relacionadas con su profesión: ¿Cómo aprenden los niños?, ¿qué y cómo enseñar en educación inicial?, ¿cómo potenciar las habilidades y destrezas de los infantes?, entre otras. Así mismo, un profesional de la Educación Inicial, debe analizar las concordancias y discrepancias entre lo que piensa, dice y hace en su práctica cotidiana, ya que sus niños, padres y representantes, estarán muy atentos a sus orientaciones. 


\section{Capítulo 4. Didáctica del Nivel de Educación Infantil.}

\section{Conceptualización de la didáctica}

$>$ Evolución histórica de la didáctica en educación infantil

$>$ Didáctica en educación infantil

$>$ Organización del ambiente y los recursos

$>$ La planificación

$>$ La evaluación

$>$ La articulación con la familia y la comunidad.

$>$ Resumen didáctica del nivel de educación infantil 


\section{CAPITULO 4. DIDÁCTICA DEL NIVEL DE EDUCACIÓN INFANTIL}

\subsection{Conceptualización de la Didáctica.}

En el diccionario de pedagogía, la didáctica es conceptualizada como instrucciones metodológicas que, recordando al maestro los fines que se persiguen, le proporciona los datos necesarios para su aplicación práctica (2000:41).

En la actualidad, la didáctica representa un tema de frecuentes debates dentro de las ciencias de la educación, al respecto Carretero (2009) desde el enfoque didáctico constructivista, afirma que:

Aprender es sinónimo de comprender. Por ello, lo que se comprende es lo que se aprende y lo que luego se recordará mejor, porque queda integrado en la estructura de conocimientos. Por tanto, resulta fundamental para el profesor no sólo conocer las representaciones que poseen los alumnos sobre lo que se les va a enseñar, sino también analizar el proceso de interacción entre el conocimiento nuevo y el que ya poseen. De esta manera, no es tan importante el producto final que emite el alumno como el proceso que lo lleva a dar una determinada respuesta. (p.32).

De esta manera, el aprendizaje de conceptos, leyes, valores, actitudes o normas, descansa en las experiencias y conocimientos previos y la necesidad de superar obstáculos mediante el aprendizaje y además el papel del docente se enfocará en mediar las condiciones para que surja el problema de conocer como algo necesario, y así hacer posible que el alumno o alumna se enfrente al desafío de romper el conflicto cognitivo. Esta perspectiva didáctica, con sólidos respaldos en la psicología genética y la psicología del aprendizaje, hace hincapié en el protagonismo del estudiante, para cumplir con logros de desarrollo en mejorar la calidad de los aprendizajes y recuperar la valoración del conocimiento por los actores que lo construyen. 
Es significativo destacar lo expuesto por Ribot, Varguillas y Báez (2008:47) al plantear a la didáctica como una disciplina que estudia, desde la propia práctica, los modos de ser y de enseñar del docente a fin de provocar en sus alumnos un aprendizaje útil y placentero, esta afirmación invita a meditar, sobre la realidad de la práctica profesional, en las aulas del contexto universitario, en la búsqueda de superar actitudes pasivas, por la de profesores comprometidos, que asuman el desarrollo integral de sus estudiantes. Tal como lo expresa Díaz (2001:64), "en la actualidad se requiere de docentes universitarios con un amplio perfil, que abarque sus habilidades como pedagogo, investigador y mediador, tanto de su propia práctica, como de la promoción de aprendizajes significativos en sus estudiantes”.

Vista de este modo, la didáctica es una disciplina emergente, que se incluye en el campo de las ciencias de la educación, que tiene en su haber un amplio proceso de integración y reelaboración epistemológica, psicológica y pedagógica, está plenamente integrada al conjunto de disciplinas que se interesan por los problemas educativos y se encarga de estudiar el proceso docenteeducativo, lo cual en el contexto de la educación superior, comprende la formación de un profesional capaz de tomar decisiones de manera autónoma, pero con solida fundamentación científica, para resolver las cuestiones generales y específicas que se le presenten en sus distintos ámbitos de actuación.

\subsection{Evolución Histórica de la Didáctica en Educación Infantil}

Las ciencias auxiliares de la Pedagogía, representan un papel primordial en la formación de los profesionales de educación Infantil, ya que ellas proporcionan el fundamento del modo de actuar de los educadores. No obstante, para Castro (2007:23) el problema es que los educadores nos engolosinamos con la novedad o variedad de contenidos que nos ofrece la investigación en disciplinas auxiliares, así mismo Kamii y De Vries (1991:13), opinan que para los educadores este punto de vista es muy limitado y puede conducir a una equivocada aplicación de la teoría, para estos autores es importante tener presente la óptica epistemológica en la que dichas investigaciones fueron realizadas, y que al aplicarlas sin ningún tipo de criterio en la docencia de 
aula, se tiende a saturar a los alumnos con contenidos poco prácticos y de escaso relieve, para atender las demandas prioritarias del desempeño en un centro de educación infantil.

En la formación de profesionales de educación infantil es preciso tener presente la actualización de contenidos, la mayoría provenientes de las ciencias auxiliares, las cuales apoyan a la pedagogía en la resolución de las diversas situaciones en las que se debe organizar y llevar a cabo el acto educativo; Sin embargo, es fundamental valorar y no descuidar el hecho de que, si bien la pedagogía es subsidiaria de todas las ciencias auxiliares, ella también posee un espacio epistemológicamente demarcado de conocimientos teóricos propios. La situación de acentuación y aplicación de manera acrítica de los aportes teóricos de otras disciplinas en el campo de la pedagogía, representa un indicador de la desatención de la didáctica, lo cual afecta el espacio concreto donde se resuelven las posibilidades de actos efectivamente formadores, y por tanto, la calidad del desempeño del profesional de este importante nivel educativo.

La Didáctica proporciona los principios y criterios para resolver en cada situación, la manera en que el educador debe relacionarse con los niños. Es aquí, donde adquiere sentido el saber extraído de las ciencias auxiliares. En el acto didáctico se descubre el sentido formativo de las múltiples teorías, por ejemplo la del apego de Bowlby, el aprendizaje significativo de Ausubel, la condición de resiliencia, la hora del silencio planteada por Montessori, entre otras.

En las últimas décadas, los docentes de Educación Inicial han estado preocupados y ocupados del como aprenden los niños preescolares. El enfoque constructivista, brinda la posibilidad de ampliar la información, respecto a cómo construye el conocimiento el infante menor de seis años, así como la oportunidad de profundizar acerca de la características del desarrollo en esta etapa. Sin embargo, no se ha avanzado lo suficiente en algunos aspectos de la práctica docente, tales como la actualización en cuanto a los referentes teóricos y prácticos que sustentan el proceso didáctico, así como algunos de los métodos más utilizados en el aula preescolar, que posibiliten evolucionar hacia una educación infantil de calidad. 
En relación con la historia de la didáctica de la educación infantil, en la literatura especializada se distinguen tipologías que surgen desde diferentes criterios y que aportan en función de conocer la construcción del saber pedagógico en este nivel.

Al respecto, Frabboni (1996: 62), señala una breve revisión de los hitos fundamentales de la historia del niño y de sus relaciones con el universo adulto, para ello hace referencia al trabajo de un historiador francés: Philippe Ares, quien establece un "mapa de fronteras, para describir un tortuoso y doloroso sendero que lleva a la liberación- emancipación de la infancia"; Frabboni, plantea tres momentos en la historia de la infancia:

a) Primera identidad: el niño-adulto o la infancia negada. La ubica en la Edad Media, donde ser niño, significo convertirse en el compañero natural del adulto, y aún más, a los siete años recibe un carnet de identidad jurídica de adulto y es el momento en que es reconocido como capaz de entender y de querer.

b) Segunda identidad: el niño-alumno o la infancia institucionalizada. Este momento está ubicado en una fase avanzada de la Edad Moderna, la infancia se convierte en el epicentro del interés educativo de los adultos; la familia comienza a valerse de la escuela como una agencia unida a ella y que la complementa. Se reconoce ya que el niño no está maduro para la vida y que es necesario someterlo a un régimen especial. En este proceso a la infancia le es negada la posibilidad de situarse autónomamente frente a la realidad y a lo social al hallarse cercado entre el ámbito familiar y escolar de maneras sumamente delimitadas.

c) Tercera Identidad: el niño sujeto social o la infancia reencontrada. Esta etapa fuertemente connotada por la transformación tecnológica-científica y por el cambio ético-social, cumple (a juicio del autor) todos los requisitos para hacer efectiva la conquista del último salto en la educación del niño, legitimándolo como figura social, como sujeto de derechos.

Para Frabboni, la existencia de los periodos de escolarización de niños y niñas, permite distinguir un antes y un después, en la escuela de la infancia. El antes, como un periodo 132 La Práctica Profesional como área para potenciar las competencias pedagógicas necesarias para la enseñanza en Educación Infantil 
pedagógicamente oscuro, y el después, como el periodo de la alternativa, en la que se derriba la lógica custodial-asistencial y se construye la idea del derecho de toda la infancia a la educación

Otra forma de presentar la evolución histórica es la que muestra, Fernández, González, Requena y Vicuña (1994), al organizarla atendiendo a grupos de autores que son asociados de acuerdo con el movimiento, o momento histórico en el que sus producciones se dieron a conocer. De este modo, tenemos:

a) Los precursores de la educación temprana: en este grupo, se encuentran autores como: Rousseau, Pestalozzi, Froebel, quienes demostraron con sus trabajos y su compromiso por la primera infancia, que los primeros años de vida son los más significativos para la acción educativa. Sus postulados han tenido tanta repercusión, que luego de casi dos siglos, han llegado a la actualidad y aún siguen vigentes.

b) Búsqueda de método científico: Movimiento Escuela Nueva. Sus principales representantes: Hermanas Agazzi, Montessori y Decroly. Este movimiento pedagógico, denominado Escuela Nueva, acoge a pensadores, pedagogos y psicólogos. Que tienen en común la creencia en el niño como un ser capaz y lleno de posibilidades. Este movimiento también es denominado "escuela activa", por su clara oposición a la escuela tradicional en la que niños y maestros pasaban la jornada sentados y casi exclusivamente escuchando al maestro(a). El mayor aporte de este movimiento está en las orientaciones didácticas, ya que proporciono métodos y modelos didácticos, fundamentados en principios como: individualización, socialización, globalización, actividad y autoeducación.

c) Movimiento Psicoanalítico. Las autoras presentan este grupo de científicos: Freud, Spitz, Klein, Erikson, como los representantes de este movimiento. Para la didáctica, el movimiento psicoanalítico ha tenido repercusiones muy importantes en la atención a los niños en edad maternal, desde la consideración a la vida sexual y afectiva, hasta la significación de conductas como el apego. 
d) La escuela de Ginebra: Los aportes a la didáctica, están especialmente representados por Jean Piaget. Su método de investigación se aparta del laboratorio, para acercarse al niño, con quien habla, juega, dialoga a través de pequeños problemas para buscar soluciones y observa como el niño las resuelve. De esta manera, Piaget demuestra que los conocimientos se adquieren mediante dos procesos complementarios: acomodación y asimilación.

e) La escuela soviética, representada por Vygotsky. De acuerdo con este autor, la educación deja de ser un campo de aplicación experimental de la psicología, para convertirse en un hecho consustancial al propio desarrollo humano, tanto desde la perspectiva individual, como desde el de la evolución histórica cultural, considera que la formación de la inteligencia y el desarrollo de los procesos psicológicos superiores, no pueden comprenderse al margen de la vida social. Así mismo, acentúa el papel del educador como mediador social, en el que adquiere especial relieve los procesos de comunicación.

Desde el punto de vista de Peralta (2008) es vital para los educadores reconocer los aportes de los diversos currículos, los cuales presenta agrupados atendiendo al principio de innovación curricular. De este modo, se encuentran tres generaciones: a) los fundantes, donde se identifican a los pedagogos clásicos de la educación preescolar; b) los de segunda generación, como el reconocido currículo Reggio Emilia, y c) los de tercera generación, que configuran un saber pedagógico diversificado, para llegar a la propuesta de construcción de currículo en una línea postmoderna y post-estructuralista. Siendo aportadoras estas agrupaciones para enfocar mejor los cambios producto de la evolución de la didáctica infantil. Esta organización, propuesta por Peralta, se analiza a continuación.

En primer lugar se encuentra el grupo denominado currículos fundantes, o de primera generación, los cuales tienen el merito de que tanto su teoría como práctica han construido la base de todo el desarrollo curricular posterior. En este grupo Peralta, destaca los siguientes: Robert Owen, Federico Froebel, Rosa y Carolina Agazzi, Ovidio Decroly, María Montessori, el gran aporte de ellos ha sido el ser modelos de creación con gran coherencia entre su teoría y su 134

La Práctica Profesional como área para potenciar las competencias pedagógicas necesarias para la enseñanza en Educación Infantil 
desarrollo curricular, además de constituirse en el "piso" teórico-práctico curricular sobre el cual pueden establecerse los avances innovadores.

En segundo lugar, se encuentran los currículos elaborados principalmente en la primera mitad del siglo XX, de acuerdo con lo expresado por Peralta, este grupo posee ciertas características propias y otras compartidas con los representantes del primer grupo. Entre los autores de los currículos infantiles de segunda generación se encuentran: R, Steiner, A.S. Neill (Summerhill), Celestine Freinet, P. Fauré, y Loris Malaguzzi (Reggio Emilia). Para el momento histórico en el cual estos autores producen sus propuestas para la educación infantil, donde lo bélico ocupaba un lugar central, es merecedor de especial atención, ya que están sumamente fundamentadas en el humanismo y totalmente definidas dentro del movimiento de escuelas activas, es decir la línea de escuelas "anti autoritarias", "auto gestionarías o libertarias". Esta denominación la reciben por oponerse abiertamente a los sistemas existentes, no solo en el plano educativo, sino que conllevan una visión política y social. Estas modalidades continúan aplicándose a nivel mundial.

En tercer lugar, y siguiendo con Peralta, se presentan los currículos de educación infantil de tercera generación, ubicados en la segunda mitad del siglo XX. Este tercer grupo de modalidades curriculares, surgen no solo de Europa, se incorpora Estados Unidos y Latinoamérica, con algunos aportes, en un intento de otorgar mayor pertinencia social y cultural a sus propuestas curriculares. Así mismo es importante destacar que, se incorporan nuevos fundamentos en la base de estos currículos como las neurociencias, la ecología, la tecnología, entre otros, y hay una fuerte renovación de los fundamentos más clásicos como la psicología y la propia pedagogía, sin separarse de la educación activa que sigue siendo el paradigma esencial.

En este grupo, la autora reseña solo algunos, que representan y aportan aspectos interesantes, a saber: Currículo Cognitivo High Scope, Filosofía para niños, Pedagogía del buen humor, Proyecto Spectrum, La Escuela Nueva, Currículos Culturalmente Pertinentes.

135

La Práctica Profesional como área para potenciar las competencias pedagógicas necesarias para la enseñanza en Educación Infantil 
En síntesis, las agrupaciones presentadas por Peralta (2008), permiten develar las condiciones que dieron lugar a la creación, sus etapas, los factores que cada una de las innovaciones curriculares, considero en su momento, como importantes para la didáctica en educación infantil. La reflexión está dirigida hacia aquellos vacíos o aportes que podrían continuar enriqueciendo este campo educativo, en el cual hay muchas contribuciones que aun siendo conocidas, no se han llevado a la práctica de una manera reflexiva, critica y principalmente, contextualizada a los diferentes espacios y culturas del mundo.

En relación a lo anterior, es urgente considerar entre unirse a la creación de nuevas propuestas para este nivel o centrar la atención en tratar de develar todo lo que subyace detrás de las teorías y prácticas que están vigentes, con el fin de aportar soluciones a las muchas urgencias que tiene nuestros niños y familias en Latinoamérica.

\subsection{Didáctica en Educación infantil}

"Desde la representación postmoderna, no existe el niño o la infancia, un ser y un estado esenciales que aguardan a ser descubiertos, definidos y realizados..., existen, por el contrario, múltiples niños y múltiples infancias” (Simonstein, 2006:48), desde esta perspectiva, las diferentes interpretaciones de la infancia y de lo que, lo que los niños son y deben ser, está sujeto a las construcciones que de éste significado realicen los docentes y las instituciones de atención, cuidado y educación para los niños y niñas.

En la educación infantil, siempre se ha planteado como pilar fundamental, los intereses de los niños y niñas, como forma de buscar que aprendizajes tienen más sentido para sus vidas, sin embargo, en la realidad se percibe que la práctica que se lleva a cabo está saturada de actividades que solo tienen sentido para el educador: rellenar con color, bolitas de papel o plastilina un dibujo ya realizado por el adulto, en el que la única ganancia para el infante consiste en el desarrollo de su motricidad fina, y la percepción de una educación sumamente aburrida y sin ningún desafío.

\section{6}

La Práctica Profesional como área para potenciar las competencias pedagógicas necesarias para la enseñanza en Educación Infantil 
Una realidad muy diferente, es aquella donde cada día el niño, se le plantean desde el ambiente de aprendizaje, los recursos, y el dialogo con los compañeros y adultos proposiciones atractivas, así como también se les escucha y respeta algún proyecto que el infante tenga en mente, entonces sus dibujos, pinturas, construcciones, obras modeladas con plastilina, resultan más interesantes, llenas de significados, y por tanto con múltiples aprendizajes para ellos.

En este punto, resulta importante señalar que antes de referir algunos de los elementos que conforman la didáctica en educación inicial, es necesario presentar la conceptualización que presenta Peralta (1996:6), del currículo de educación infantil:

Todas las vivencias y aprendizajes significativos que han sido experienciados por los párvulos y adultos, como resultado de la selección y organización consistente de un conjunto de factores humanos, materiales, y técnicos que han sido generados por una comunidad educativa, desde el jardín infantil como institución educativa sistemática.

Esta proposición de currículo infantil, considera no solo los aprendizajes de los infantes sino también las vivencias y significados, ya que en muchas ocasiones son desvalorizados los encuentros con personas, lugares, animales u objetos los cuales pueden estar llenos de significado y sentido para la vida del niño; del mismo modo, en esta conceptualización se considera tanto al niño como a los adultos, como una postura de educación integradora y permanente donde ambos están creciendo. Otro factor presente en la proposición anterior, es el referido al conjunto de factores humanos, materiales y técnicos que han sido seleccionados y organizados en forma consistente, lo cual implica tener claro que siempre hay una intencionalidad pedagógica en función de la cual surgen los criterios para seleccionarlos y organizarlos.

Todo lo anterior, conlleva a reflexionar sobre la didáctica en educación inicial, es decir cómo debe enseñarse en este nivel educativo; En este punto surgen infinidad de planteamientos, tal como lo expresa Delval (1988:185) "Enseñar es algo extremadamente difícil pues no sabemos 
cómo se produce y no tenemos ninguna seguridad en que los métodos que empleamos sean eficaces; sin embargo, delante de nosotros tenemos continuamente sujetos que aprenden, sin que sepamos muy bien cómo".

Afortunadamente, autores como Baldwin, Wallon, Vygotsky, Piaget, entre otros, han dejado un legado sobre cómo se construye la inteligencia, las etapas del pensamiento del niño, así como también una visión de la formación de conocimientos en la que el infante tiene un papel activo y construye sus estructuras intelectuales al mismo tiempo que sus representaciones del mundo.

En este orden de ideas, y para efectos del presente trabajo se adoptara el concepto de didáctica para la educación infantil, presentado por Galindo (2007: 6):

Proceso dirigido a la mediación de los aprendizajes de los niños (as), de una manera integral, con la participación reflexiva y activa, que llevan a cabo los docentes, en permanente comunicación con la familia y comunidad en la cual se desarrolla, planificada en el tiempo, considerando la rutina diaria, la evaluación permanente y los recursos presentes en el aula y el entorno.

Desde este punto de vista, se pueden distinguir los siguientes elementos: Organización del ambiente y los recursos, planificación, evaluación, articulación con la familia y la comunidad, como elementos básicos que permiten operacionalizar la acción didáctica en el nivel inicial. A continuación se describen pos separado, cada uno de ellos;

\subsubsection{O rganización del Ambiente y los Recursos.}

Los factores ambientales integran una serie de elementos importantes, si se consideran las características de la etapa en las que se encuentran los niños (as) de 0 a 6 años, en la cual los aprendizajes son especialmente activos, fruto de su interacción con un ambiente pleno de

La Práctica Profesional como área para potenciar las competencias pedagógicas necesarias para la enseñanza en Educación Infantil 
posibilidades de investigación y descubrimientos. De este modo, se debe considerar tanto el ambiente físico del preescolar, como el entorno natural y cultural, que aporta significado en la vida del niño.

En relación con la organización interna del aula, y de acuerdo con Peralta (1996) hay ciertos criterios comunes que responden a una lógica, los cuales sería interesante puntualizar. En primer lugar considerar el grupo- edad, para el cual se ambienta el aula, es un requisito fundamental diferenciar la organización de un espacio para lactantes, o para niños de cuatro a seis años. El tener presente las características de desarrollo y físicas de grupo, es esencial por las implicaciones que tiene en: (a) la selección del mobiliario en cuanto a dimensiones, tipo y ubicación de éste; (b) la determinación de las áreas de trabajo, en cuanto a su tipo y cantidad; (c) la selección de los materiales, y por tanto su ordenación y ubicación; (d) la ambientación o decoración general del aula.

En este orden de ideas, el Ministerio de Educación, Cultura y Deportes (MECD,2005), a través del Diseño Curricular de Educación Inicial, ofrece un conjunto de orientaciones que unido al criterio profesional del docente, permitirían ofrecer al infante un ambiente escolar lleno de significados, no solo en el plano intelectual, sino también en lo afectivo, considerando las inmensas oportunidades que brinda el entorno social y cultural de la comunidad y región en la que se encuentra ubicado el centro preescolar, tales como: áreas verdes, plazas, locales, zonas de esparcimiento, museos, entre otros.

\subsubsection{La Planificación.}

El MECD (2005: 88), plantea que la planificación en este nivel educativo, se considera un proceso dinámico que parte de la necesidad de una mediación educativa activa, planificada e intencional, con el objeto de garantizar los aprendizajes significativos para el desarrollo integral del niño y la niña ; Del mismo modo, invita al docente a transitar de una planificación centrada 
exclusivamente en el niño, a una planificación por planes y proyectos didácticos donde, el niño, la niña, el docente y la familia son actores y autores del hecho educativo.

De acuerdo con Lavanchy y Suzuqui (2000: 71), antes de hacer su planificación general, el educador debe buscar aquella información que le permita circunscribirla a las características de sus niños, esta información proviene de varias fuentes, a saber: (a) las orientaciones definidas en los fines y objetivos educativos de cada país, (b) las bases teóricas que caracteriza a los niños de esta edad, (c) la base real que entregan las características, necesidades e intereses del grupo de niños, (d) el conocimiento del contexto familiar y comunitario del grupo de niños.

Al poseer los diagnósticos de los niños, de la familia, del propio docente y realizar la triangulación con los fundamentos teóricos, permiten el análisis de datos y de la toma de decisiones para planificar. Luego la reflexión de los resultados al evaluar permite validar los logros, limitaciones e implicaciones para futuras planificaciones.

Al aplicar estos conceptos al esquema de planificación por proyectos, podemos darnos cuenta que siempre está presente el rol del docente como investigador.

Entre las características recomendadas por Galindo y Gómez (2009:32), para realizar una planificación por proyectos tenemos: (a) Realizar el diagnóstico triangulado a: los niños, para conocer sus características, necesidades, e intereses tanto individuales como grupales. A los padres, para conocer sus expectativas, debilidades y potencialidades con respecto a la formación de sus hijos, y las del docente como eje integrador de los procesos pedagógicos y conocedor de los fundamentos teóricos que caracterizan a los niños en edad preescolar. (b) Compartir los hallazgos con todos los involucrados y con el equipo de trabajo, para la toma de decisiones, teniendo como norte los fines y objetivos de la educación inicial. (c) Selección de objetivos, actividades, estrategias, y los procedimientos de evaluación.

Lo antes expuesto, significa planificar con libertad, desde la reflexión permanente, orientada hacia la diversidad de características que posee el ser humano impregnado íntimamente de su 
cultura, tradición e idiosincrasia. En cuanto al formato para realizar el proyecto, es útil para el docente asumir, que la planificación, cualquiera que esta sea, se debe registrar por escrito, donde lo recomendable, es que exprese la explicación de lo que debe hacer, de acuerdo con sus alumnos y el contexto, porque y como se va a lograr. De este modo se evita la improvisación, que tanto daño hace a nuestros niños y al sistema educativo en general.

\subsubsection{La Evaluación}

En Educación Infantil, la evaluación se ha destacado por su carácter cualitativo, sin embargo, en algunos casos esta actividad ha consistido en chequear conductas aplicando un test de desarrollo al inicio del año y en algunos casos al finalizar el período lectivo o, marcar el logro de conductas en una lista de cotejo o, en registrar procesos de aprendizaje de un modo cualitativo denominado registro anecdótico o, apreciar la calidad en el logro de ciertos objetivos o conductas en una escala. No obstante, es apremiante preguntarse si la información que se entrega en el informe dirigido a la familia, ayuda o sirve de algo a ese niño, o también si durante ese proceso evaluativo se aplicó un análisis científico de los datos.

Consideremos el concepto de evaluación, presentado por Peralta (1996: 146): "proceso constante, sistemático, dinámico, que pretende la objetividad, a través del cual se emite un juicio valorativo que ayuda a la determinación de nuevas alternativas de decisión, en relación a los diferentes agentes y elementos del currículo".

Del concepto anterior es necesario destacar que la objetividad es un requisito deseable, pero que es difícil lograrlo plenamente, por más previsiones que se tomen al respecto, ya que siempre estará presente algún rasgo de subjetividad, por cuanto es una actividad humana, lo cual no debe ser visto como una desventaja, al contrario, al hacerlo consciente es posible disminuir su efecto en los juicios emitidos;

Del mismo modo, se considera la evaluación como un proceso constante, en efecto, para que esto se cumpla es necesario ejecutar tres etapas: medición, la evaluación, y la formulación de 
sugerencias para futuras decisiones. A continuación y siguiendo con Peralta (1996), se describen cada una de ellas:

1. La medición, tiene como propósito constatar, registrar y llegar a cuantificar el nivel de desarrollo de un determinado aspecto del niño, a través de la observación y de la aplicación de diferentes instrumentos de medición, tales como: listas de control, escalas de estimación, entre otros; Esta información no es suficiente en sí misma, pues es necesario pronunciarse valorativamente sobre la significación de la conducta medida, por tanto se justica la siguiente etapa.

2. La evaluación propiamente tal, para que la valorización tenga sentido, es necesario tomar algún punto de referencia, tales como: (a) hacerla en función de un deber ser que se obtiene de un marco teórico general de tipo sicológico, sobre lo esperable en educandos en esa etapa, (b) que se haga en función al comportamiento que evidencian los niños que componen el grupo en el que participa en niño, y que conforman el grupo de iguales, y (c) en base a los antecedentes que se tienen del propio niño, considerando mediciones anteriores. Es importante señalar que estas posibilidades no son excluyentes entre sí y que pueden combinarse.

3. Respecto a las sugerencias, éstas son las resultantes de todo el proceso anterior y deben ser el aporte concreto a tener presente en la planificación de las futuras líneas de acción

Si bien la evaluación se puede considerar como un tipo de conocimiento técnico, es conveniente tener presente que cuando se habla de evaluación en educación no lo se hace respecto de una actividad que se aplica a maquinas u objetos inanimados. Se hace referencia a una actividad científica en la cual participan seres humanos, los juicios que se emiten son respecto a ellos o a su quehacer.

Desde ésta perspectiva de no olvidar lo humano, de considerar el impacto que esta actividad aparentemente tan neutra como es la evaluación, tiene en la Educación Infantil (y también la de 
los restantes niveles), Reveco (2007) presenta tres principios que se deben tener presente en todo acto evaluativo:

1. Evaluación y Ética: se debe tener presente la responsabilidad ética respecto del juicio que se emite. Un juicio negativo, inadecuadamente sustentado puede generar graves efectos en niños, profesionales, decidores o familiares. Por ejemplo, señalar a un grupo de padres y madres que el $60 \%$ de sus niños están bajo el nivel de desarrollo en el área de lenguaje, puede potenciar el apoyo en el hogar, sin embargo también puede hacer creer que ello es producto de un grave trastorno, o, hacer creer que la escuela o el jardín de Niños no enseña lo suficiente.

2. Evaluación y Formación: La evaluación no es sólo una actividad técnica, en el sentido de exigir un excelente manejo de técnicas, instrumentos y metodologías para llegar a emitir un juicio. Como toda actividad científica requiere de una sólida formación profesional, acerca de "lo técnico", y también de lo que está detrás de ello, el paradigma que funda cada tipo de diseño, por ende la visión de persona y de sociedad que está detrás. En suma, pasar de consumidores de la evaluación, o de ella en cuanto "moda", a educadores profesionales de ella: diseñadores, analizadores, críticos.

3. Evaluación una Exigencia: Conocer los procesos, los fenómenos que acontecen en el contexto de la educación, el efecto de nuestro hacer, la visión auto evaluativa de los niños, de sus familias y también nuestra, entre muchas otras es un requisito para la Educación Infantil. No podemos mantenernos en el activismo del sólo hacer, aunque ello sea creativo e innovador. Necesitamos saber que sucede, con nosotros en cuando educadores, con los niños en cuanto aprendices y descubridores, con el currículum en cuanto cultura seleccionada y organizada, con el Programa Educativo en cuanto oferta a niños/as y familias, entre mucho otros.

En este orden de ideas, es importante destacar un nuevo enfoque de evaluación de los aprendizajes que se ha venido utilizando en las últimas décadas, se trata de la evaluación dinámica planteada por el Dr. Feuerstein. La evaluación dinámica, por su intencionalidad y

143

La Práctica Profesional como área para potenciar las competencias pedagógicas necesarias para la enseñanza en Educación Infantil 
características, responde a muchas de las limitaciones de los procesos evaluativos, al constituirse en un sistema de apoyo para el docente y para el alumno.

De acuerdo con Fuentes (2006:16), este tipo de evaluación recoge información respecto al evaluado en todos los aspectos que inciden en su desempeño ( afectivo, cognitivo y social), lo que posibilita enriquecer el conocimiento del profesor respecto a sus alumnos, además, dado que se sustenta en el modelo de análisis del mapa cognitivo planteado por el Dr. Feuerstein, permite apreciar las diferencias individuales de los estudiantes al enfrentar una tarea cognitiva y, por ende, comprender sus diferentes estilos de procesamiento de la información y de pensamiento .

El alcance educativo de este enfoque, radica al admitir que una de las metas centrales de la educación es provocar cambios, lo que se necesita saber de un sujeto dado es hasta qué punto es posible lograr en él el cambio deseado y como se puede lograr. A este proceso Feuerstein lo denomina Experiencia de Aprendizaje Mediado (EAM), la cual según Fuentes (2006:18), se refiere a un proceso interaccional del sujeto con el medio, en el cual el adulto, usualmente los padres o el educador, se interpone entre el niño y el mundo y modifica ciertos estímulos afectándolos en frecuencia, orden, intensidad y contexto.

Este tipo de mediación permite al niño adquirir funciones cognitivas, sistemas de aprendizaje, lo cual le permite a él ser modificado cognitivamente y beneficiarse de las oportunidades de aprendizaje tanto formal como informal. Además, Feuerstein, citado por Fuentes (ob. Cit.), señala que para que exista experiencia de aprendizaje mediado, esta interacción entre mediado y mediador debe sustentarse en parámetros, de los cuales resalta como imprescindibles para que cualquier interacción sea clasificada como interacción mediada: (a) Mediación de Intencionalidad y Reciprocidad, se refiere a los esfuerzos intencionales del mediador por producir en el sujeto un estado de alerta con el fin de ayudarlo a registrar cierta información y la reciprocidad, es un aspecto esencial para el desarrollo de sentimientos de competencia y auto- determinación; (b) Mediación de Trascendencia. El objetivo de la EAM, es trascender las necesidades inmediatas que pueden no tener nada que ver con las actividades originales, proyectándose hacia el futuro a 
través de generaciones y principios aplicados también a diversas instancias de la vida; y (c) Mediación de Significado: se refiere a aquellas interacciones en las cuales los estímulos presentados plantan una significación afectiva motivacional y orientada hacia ciertos valores, el mediador no muestra una actitud neutral hacia los estímulos, sino más bien les confiere importancia y significado.

Estas características, brevemente expuestas establecen que la mediación sea un fuerte aliado para lograr que los infantes desarrollen su modificabilidad cognitiva, o estrategias que les permitan aprender a aprender y a desarrollar su capacidad de pensar, en forma eficaz y efectiva

\subsubsection{La Articulación con la Familia y la Comunidad.}

Uno de los desafíos más complejos a los que se enfrentan los docentes de educación inicial, es el de garantizar la proyección de los aprendizajes de sus niños, al ambiente del hogar y de la comunidad de donde proviene. Así mismo, este docente debe apoyar el desarrollo temprano de la identidad cultural, el sentido de pertenencia a su comunidad, como fuente de valores y normas.

Para Katz (2005) no se trata solo de enseñar y aprender sobre comidas, festividades y bailes, del mismo modo, Peralta (2002), indica que hay que tener presente el carácter mixto de las sociedades latinoamericanas, donde se entremezclan diferentes culturas, implica considerar que existen diferentes ámbitos culturales, algunos más cercanos y específicos (culturas locales, regionales) y otros más amplios (nacional, latinoamericano, occidental, global)

Cuando se trata de articular el trabajo pedagógico con las familias y la comunidad, necesariamente hay que conocer su cultura, sus costumbres, las características particulares de cada familia, respetar y orientar sus prácticas de crianza. En este sentido, es importante construir lazos afectivos con las familias, para sí apoyarse mutuamente en el proceso educativo de las niñas y niños. En la medida en que se logre una mayor colaboración mutua, se beneficia la formación integral del infante.

\section{5}

La Práctica Profesional como área para potenciar las competencias pedagógicas necesarias para la enseñanza en Educación Infantil 
El compartir los objetivos educativos evitará, en lo posible contradicciones criterios de valoración opuestos. Para ello el docente tiene la obligación de brindar información sobre los objetivos que se persiguen en educación inicial, de esta manera se abrirán los espacios para la participación.

En este orden de ideas, las prácticas de articulación entre la escuela-familia-comunidad, se pueden concretar en reuniones para padres, clases abiertas en la comunidad, experiencias de visitas a los hogares de los niños, talleres, encuestas, entre otros.

De igual manera, el docente debe favorecer el conocimiento, la comunicación y el vínculo entre las familias de los pequeños. Uno de los temas importantes a ser tratado, es el referido a la lectura y escritura, pues la participación de los padres es fundamental en este proceso; es necesario concienciar a los padres acerca de su papel en la adquisición y desarrollo del lenguaje, entre otros aprendizajes fundamentales de esta edad.

En esta misma línea de organización de los procesos didácticos en educación Infantil, se presenta un cuadro resumen, elaborado por Malagón y Montes (2006:10) en el cual se representan los principales elementos, que a juicio de sus autoras, deben ser considerados en este importante nivel educativo, y que además coinciden ampliamente con lo que hasta ahora se ha venido desarrollando en el presente apartado.

146

La Práctica Profesional como área para potenciar las competencias pedagógicas necesarias para la enseñanza en Educación Infantil 


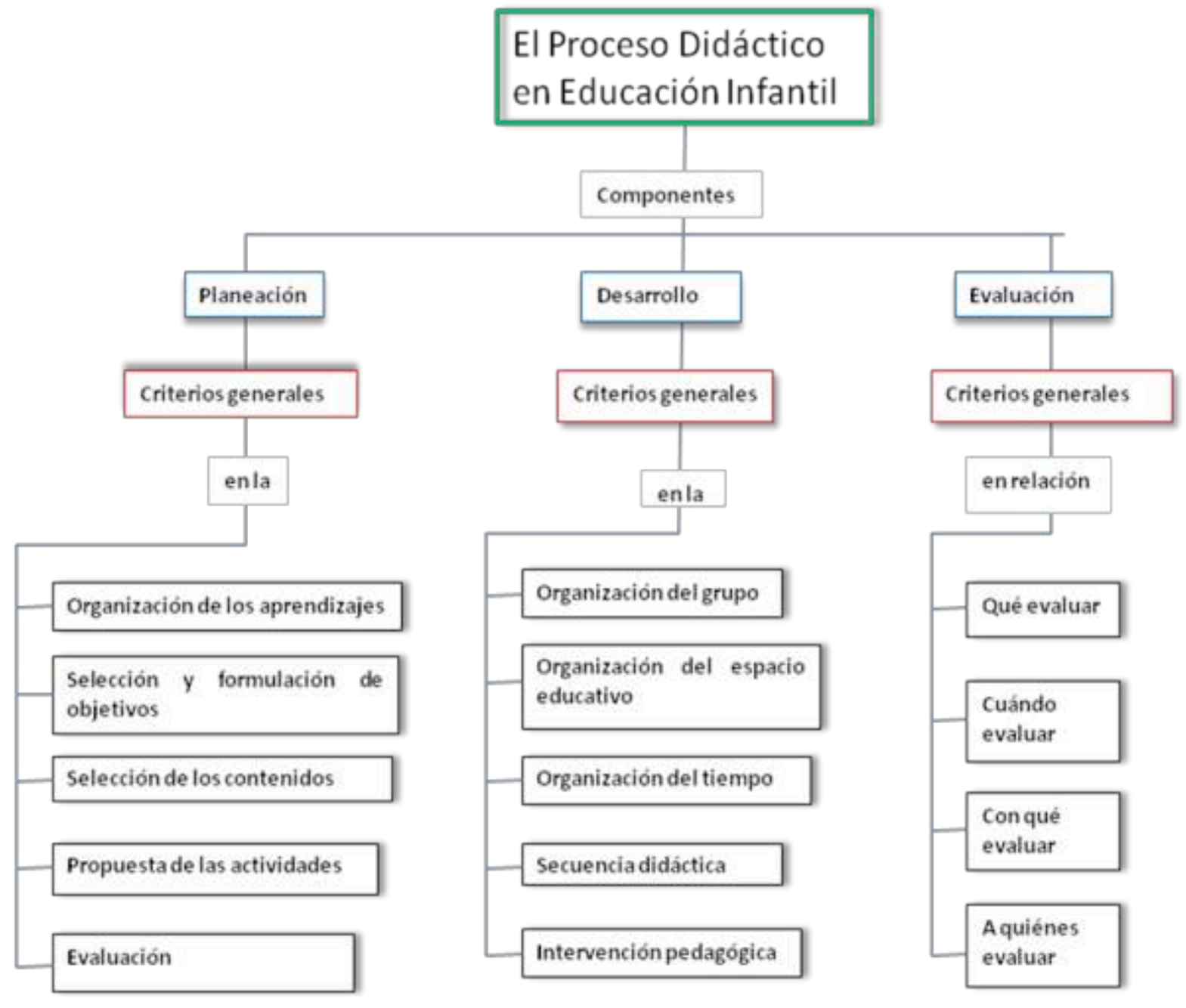

Gráfico No 4. El proceso didáctico en Educación Infantil. Fuente, Malagón y Montes 2006.

Por tanto, se considera que, en principio no hay metodologías buenas ni malas por ellas mismas, sino que dependen de cómo se apliquen, de la capacidad de observar, evaluar sus efectos y su utilidad según muestren los alumnos, y los resultados que se consiguen en el aula. Por su parte, Solé, en Coll, Martín, Mauri, Miras, Onrubia y Zabala (1999:28) manifiesta que la explicación constructivista no admite propuestas en las que los alumnos tengan que supeditarse a las características de la enseñanza, es ésta la que debe adaptarse a las características de ellos y se consideran las siguientes premisas:

147

La Práctica Profesional como área para potenciar las competencias pedagógicas necesarias para la enseñanza en Educación Infantil 
- Considerar el cómo enseñar desde un enfoque globalizador, que posibilite la relación del niño con contenidos de diversa naturaleza, que a su vez estén relacionados con varios campos de desarrollo.

- Potenciar todas las capacidades de los niños para el logro de competencias.

- Partir de los intereses, las necesidades, las motivaciones y los aprendizajes significativos.

- Cuando sea posible proponer aprendizajes concretos que los alumnos han de realizar, con el fin de que la docente tenga un referente inmediato para evaluar.

- Respetar la diversidad de los alumnos, entendida como origen étnico, género, nivel socioeconómico, capacidad para el aprendizaje, lengua, entre otros.

- Favorecer los procesos de observación, manipulación, experimentación, descubrimiento e investigación por parte de los alumnos.

- Llevar a cabo el proceso didáctico en la práctica cotidiana: planeación, desarrollo o ejecución evaluación.

En síntesis, en Educación Infantil se requiere promover cambios significativos y de calidad tanto en sus educadores, las instancias administrativas, como en las instituciones formadoras. Los cambios que se han de imprimir requieren de una reconceptualización del sujeto de la educación a este nivel, que es el niño de cero a seis años, así como una actitud crítica respecto de las prácticas pedagógicas, conocer los requerimientos de aprendizaje y el potencial de los alumnos, así como una revisión de su rol.

\subsection{Resumen Didáctica del Nivel de Educación Infantil.}

En este apartado se reseñan los aspectos teóricos relacionados con la didáctica, considerada como una disciplina emergente, que se incluye en el campo de las ciencias de la educación, que tiene en su haber un amplio proceso de integración y reelaboración epistemológica, psicológica y pedagógica, está plenamente integrada al conjunto de disciplinas que se interesan por los problemas educativos y se encarga de estudiar el proceso docente- educativo, lo cual en el contexto de la educación superior, comprende la formación de un profesional capaz de tomar decisiones de manera autónoma, pero con solida fundamentación científica, para resolver las 
cuestiones generales y especificas que se le presenten en sus distintos ámbitos de actuación. Luego se abordo específicamente la didáctica en Educación Inicial, que el caso del presente trabajo se adoptó el concepto de didáctica para la educación infantil, presentado por Galindo (2007). Desde ese punto de vista, se pueden distinguir los siguientes elementos: a) Organización del ambiente y los recursos, donde se debe considerar tanto el ambiente físico del preescolar, como el entorno natural y cultural, que aporta significado en la vida del niño. En relación con la organización interna del aula, y de acuerdo con Peralta (1996) hay ciertos criterios comunes que responden a una lógica, los cuales sería interesante puntualizar. En primer lugar considerar el grupo- edad, para el cual se ambienta el aula, es un requisito fundamental diferenciar la organización de un espacio para lactantes, o para niños de cuatro a seis años; b) la planificación, considerada por el MECD (2005: 88), como un proceso dinámico que parte de la necesidad de una mediación educativa activa, planificada e intencional, con el objeto de garantizar los aprendizajes significativos para el desarrollo integral del niño y la niña; c) la evaluación, vista como un proceso constante, sistemático, dinámico, que pretende la objetividad, a través del cual se emite un juicio valorativo que ayuda a la determinación de nuevas alternativas de decisión, en relación a los diferentes agentes y elementos del currículo, (Peralta 1996: 146); y d) la articulación con la familia y la comunidad, para construir lazos afectivos con las familias y apoyarse mutuamente en el proceso educativo de las niñas y niños. En la medida en que se logre una mayor colaboración mutua, se beneficia la formación integral del infante. 


\section{Capítulo 5. Formación Profesional Basada en Competencias Pedagógicas}

$>$ Construcciones teóricas que respaldan el término competencias

$>$ Competencias básicas definidas por la Unión Europea.

$>$ Consideraciones generales Sobre educación, enseñanza y aprendizaje.

$>$ Competencias pedagógicas

$>$ Resumen formación profesional basada en competencias pedagógicas 


\section{CAPITULO 5. FORMACIÓN PROFESIONAL BASADA EN COMPETENCIAS PEDAGÓGICAS.}

\subsection{Construcciones Teóricas que Respaldan el Término Competencias.}

Las múltiples definiciones que el termino competencias posee, plantea en sí mismo desacuerdos y vacíos, especialmente para la estructuración de programas educativos, con base en este enfoque. Estas definiciones, presentan distintos matices en relación con la orientación que se le quiera dar; Por ejemplo: las competencias sociales, son vistas como diferentes de las competencias técnicas, por su carácter de intangibles (las primeras) o tangibles (las segundas).

El significado de competencia según el Diccionario de la Real Academia Española (2009) proviene del latín competentia; y lo significa como: 1.f. Incumbencia, 2. f. Pericia, aptitud, idoneidad para hacer algo o intervenir en un asunto determinado y 3. f. Ámbito legal de atribuciones que corresponden a una entidad pública o a una autoridad judicial o administrativa. En la revisión documental, se encuentra que para Gil (2000, citado en Tobón 2004) el término competencia es un concepto confuso en la cultura organizacional actual, en la medida en que no está claro si las competencias se refieren a lo que las personas son capaces de hacer, deben ser capaces de hacer, tienen que hacer o realmente hacen para alcanzar el éxito en un puesto de trabajo o una organización.

Siguiendo con Tobón (2004) el término competencias cada vez aparece más en el discurso cotidiano y su uso se hace con múltiples significaciones, lo cual indica que es un concepto altamente polisémico que facilita el acomodamiento del discurso a los propósitos de quien habla. A continuación se muestra un resumen de los distintos significados que se han adjudicado para el término desde lo social. 


\begin{tabular}{|c|c|}
\hline Uso & Descripción \\
\hline $\begin{array}{l}\text { 1.- } \quad \text { La competencia como } \\
\text { autoridad }\end{array}$ & Se refiere al poder de mando que puede tener un determinado cargo \\
\hline $\begin{array}{l}\text { 2.- La competencia como } \\
\text { capacitación }\end{array}$ & $\begin{array}{l}\text { Se refiere al grado en el cual las personas están preparadas para } \\
\text { desempeñar determinados oficios }\end{array}$ \\
\hline $\begin{array}{l}\text { 3.- La competencia como } \\
\text { función laboral }\end{array}$ & $\begin{array}{l}\text { Se refiere a las responsabilidades y actividades que debe desempeñar toda } \\
\text { persona en un determinado puesto de trabajo }\end{array}$ \\
\hline $\begin{array}{l}\text { 4.- La competencia como } \\
\text { idoneidad }\end{array}$ & $\begin{array}{l}\text { Se refiere al calificativo de apto y no apto, con respecto al desempeño en } \\
\text { un puesto de trabajo }\end{array}$ \\
\hline $\begin{array}{lll}5 .- & \text { La competencia como } \\
\text { rivalidad empresarial } & \end{array}$ & $\begin{array}{l}\text { Expresa un eje esencial en el ámbito empresarial, como lo es la necesidad } \\
\text { de toda empresa de sobresalir en la producción de bienes y servicios, } \\
\text { sobre otras en determinados aspectos(precio, calidad, oportunidad y } \\
\text { beneficios) }\end{array}$ \\
\hline $\begin{array}{l}\text { 6.- La competencia como } \\
\text { competición entre personas }\end{array}$ & $\begin{array}{l}\text { Se refiere a la lucha de los empleados por competir entre sí por sobresalir } \\
\text { en su desempeño y buscar con ello posibilidades de ascenso, mejores } \\
\text { ingresos y reconocimientos }\end{array}$ \\
\hline $\begin{array}{l}\text { 7.- La competencia como } \\
\text { requisito para desempeñar } \\
\text { un puesto de trabajo. }\end{array}$ & $\begin{array}{l}\text { Se refiere a las habilidades, capacidades, destrezas, conocimientos, valore } \\
\text { y actitudes que un candidato a un determinado puesto de trabajo deb } \\
\text { tener para poder ser vinculado a la empresa }\end{array}$ \\
\hline $\begin{array}{l}\text { 8.- } \quad \text { La } \text { competencia como } \\
\text { actividad deportiva }\end{array}$ & \\
\hline
\end{tabular}

Cuadro $n^{\circ} 10$. Usos de las competencias en lo social. Fuente Tobón (2004)

Tal como puede observarse, la noción de competencia que se emplea actualmente en educación, no proviene de un único paradigma teórico, sino que tiene múltiples fuentes (psicología, lingüística, sociología, educación para el trabajo y filosofía). Al respecto, Tobón (Ob. cit.: 43) afirma que "la multiplicidad de perspectivas y la transposición del concepto de una disciplina a otra, es en donde está su mayor fortaleza"; el autor agrega que el bajo nivel de limites disciplinares, coloca al concepto por encima de enfoques como: las inteligencias múltiples, el desempeño comprensivo, la modificabilidad cognitiva, entre otros. Más adelante señala, que la construcción de un enfoque riguroso de competencias desde la academia, viene dado por la orientación del pensamiento complejo, donde a partir de la transdisciplinariedad puede llegar a la 
elaboración de un tejido conceptual riguroso con conciencia de sus límites y posibilidades, a fin de tener en cuenta la variedad de orientaciones y constructos relacionados con este enfoque.

En esta misma exploración documental se encontró que, Alles (2001) la define como las habilidades, destrezas, conocimientos y operaciones que un individuo debe ser capaz de desempeñar y aplicar en distintas situaciones de su vida.

Por su parte, Salas (2004) considera una competencia como el conjunto de comportamientos socio-afectivos y habilidades cognitivas sensoriales y motoras que permiten llevar a cabo adecuadamente un papel, una función, una actividad o una tarea. En esta misma línea se adscribe el planteamiento de Canquis e Inciarte (2007) al conceptualizar las competencias como atributos socio afectivo, cognoscitivo y motor que permiten cumplir adecuadamente una función o una actividad, incorporando la ética y los valores.

De la Herrán y Paredes (2008:95), en su libro didáctica general, las define como "la forma en que una persona utiliza todos sus recursos personales para resolver una tarea del contexto”, y más adelante afirma que "objetivos y contenidos son aspectos principales del diseño curricular, las competencias son un aspecto que atraviesa ambos elementos" (2008: 88). Para estos autores, los objetivos, las competencias combinadas con el trabajo educativo y los contenidos adquiridos, parecen ser el principal capital que los estudiantes sacan de su paso por las instituciones formadoras, por tanto se estaría hablando del núcleo de la enseñanza.

En este orden de ideas, Asensio, Cerezo, Valbuena y Rodríguez (2009: 1), consideran que, la adquisición de competencias puede hacer viable la profesionalización del estudiante mediante la capacitación y cualificación que actualmente demanda la sociedad emergente. Las competencias son resultados del aprendizaje por lo que no solo es necesario el identificar las competencias en los programas, también se deben establecer las reglas que permitan conocer como el estudiante evoluciona en su formación en competencias

153

La Práctica Profesional como área para potenciar las competencias pedagógicas necesarias para la enseñanza en Educación Infantil 
Atendiendo a las ideas antes señaladas, lograr competencias para el desarrollo personal y profesional, implica que los equipos docentes deben realizar, a partir de su experiencia y criterio, una adaptación del currículo a los procesos didácticos del aula, donde se tome en consideración las características de lo que se adapta, al espacio, tiempo y personas con las que se hace, todo ello con la idea de favorecer el aprendizaje más completo para los estudiantes.

Evidentemente, las competencias son las unidades del currículo más reconocidos por su carácter social, pues al definirlos, se está puntualizando el modo de relación de la universidad y la sociedad, se está identificando que es válido y valioso para los futuros profesionales y para qué se están preparando en la educación superior. Es decir, a partir de una selección cultural, se procura incluir actividades de aula, más allá de lo conceptual, siendo posible explorar también lo referido al procedimiento, actitudes, emociones.

En palabras de Tobón las competencias entraron en la educación por influencia en gran medida de factores externos, tales como la competencia empresarial, la globalización y la internacionalización de la economía, con un bajo grado de estudio, análisis crítico y discusión por parte de la comunidad educativa. Así mismo, este autor advierte que "lo esencial es que cada docente asuma una perspectiva reflexiva sobre las competencias, considerando el proceso histórico que ha tenido este concepto, dado por la confluencia de aportes, de múltiples escenarios” (2004: 35)

Por lo tanto, es un reto para cada educador continuar avanzando, sin tener la pretensión de construir un término único, pero sí de configurar la construcción de un concepto con limites básicos, que demuestren la apropiación critica de la comunidad educativa.

Tal como puede observarse, las distintas definiciones de competencias nos refieren hacia el desarrollo de las potencialidades que posee el individuo de manera innata, donde es posible vincular procesos formativos y de desempeño, sin perder de vista que las competencias no aparecen de un momento a otro, al contrario se van desarrollando progresivamente, en un proceso 
que abarca las experiencias previas, hasta pensamientos, hechos y fenómenos que suceden en otros lugares y en otros tiempos.

Visto de este modo, ser competente es la posibilidad que tiene una persona para investigar y resolver, tanto situaciones de la vida cotidiana, como otras novedosas o complejas, a partir de habilidades, conocimientos, estrategias, actitudes y valores que se disponen y se enriquecen de manera permanente.

\subsection{Competencias Básicas Definidas por la Unión Europea}

En el ámbito de la Unión Europea, el interés creciente por las competencias educativas es consecuencia de la influencia de su utilización en el mercado laboral, pero de forma más concreta de las evaluaciones realizadas por la Internacional Association for Educational Achievement (IEA) de Estados Unidos y de las evaluaciones PISA en la Organización para la Cooperación y Desarrollo Económico (OCDE). El resultado ha sido la generalización del currículo por competencias tanto en la educación obligatoria, como en la educación superior, así como en la formación permanente.

De acuerdo con la OCDE, (2002:3), en su definición y selección de competencias, (Deseco), afirma que "ser competente" es ser capaz de responder a demandas complejas y llevar a cabo tareas diversas de forma adecuada"; más adelante, indica que la Comisión Europea, determina que ser competente supone "utilizar de forma combinada los conocimientos, destrezas, aptitudes y actitudes en el desarrollo personal, la inclusión y el empleo" (p.5).

Por su parte el Programa para la evaluación internacional de los alumnos (PISA 2006:9) indica que la competencia se demuestra cuando "se aplican los conocimientos adquiridos a las tareas y retos cotidianos y a los entornos extraescolares, previa valoración de distintas opciones y toma de decisiones". De esta situación se desprende que, la unión europea ha propuesto un conjunto de competencias básicas, orientadas al desarrollo personal y profesional, la participación ciudadana y el aprendizaje a lo largo de la vida. Estas competencias se deben haber adquirido por 155

La Práctica Profesional como área para potenciar las competencias pedagógicas necesarias para la enseñanza en Educación Infantil 
un joven al finalizar la enseñanza obligatoria para poder lograr su realización personal, ejercer la ciudadanía activa, incorporarse a la vida adulta de manera satisfactoria y ser capaz de desarrollar aprendizajes a lo largo de su vida.

El origen de estos postulados puede señalarse, que fue en la Declaración de Bolonia (1999:3), cuyos principales objetivos consisten en: facilitar el intercambio de titulados y adaptar el contenido de los estudios universitarios a las demandas sociales mejorando su calidad y competitividad a través de una mayor transparencia y un aprendizaje basado en el estudiante cuantificado a través de los créditos. Con relación a la educación superior, en el marco del Espacio Europeo de Educación Superior (EEES) se establece un sistema de competencias como lenguaje común para describir objetivos de los planes de estudio. De tal modo que la educación basada en competencias se ha convertido en uno de los pilares fundamentales del nuevo modelo europeo de universidad.

\subsection{Consideraciones Generales sobre Educación, Enseñanza y Aprendizaje.}

Desde hace algún tiempo se ha establecido en el sector educativo la necesidad de vincular la educación con las competencias; los resultados de las pruebas al rendimiento escolar, demuestran la urgencia de incorporar en los pensum de estudios una modalidad educativa más acorde a las necesidades reales del entorno, donde la educación tenga mayor presencia no solo con los contenidos institucionales y pedagógicos, sino también en la evaluación de los resultados, teniendo como base el desempeño que demuestren los individuos una vez que hayan concluido su formación en el sistema educativo y que a su vez le permita la demostración de los saberes, sus competencias y su desempeño.

Al respecto, Tobón (2008:2) afirma que "las competencias se vienen abordando en la educación y en el mundo organizacional desde diferentes enfoques, como por ejemplo el conductismo, el funcionalismo, el constructivismo y el sistémico-complejo". 
En este punto resulta cardinal, definir algunos términos que están implicados en este análisis (sin pretender un tratado profundo de estos) y que ayudan a definir con mayor claridad los supuestos teóricos de esta investigación:

La Real Academia de la Lengua (2009) define a la educación, por un lado, como crianza, enseñanza y doctrina que se da a los niños y a los jóvenes, y, por otro, como instrucción a través de la acción docente. Teniendo en cuenta esto, resulta necesario diferenciar la instrucción de la educación.

Según Bruner (1972), la instrucción implica organizar sistemáticamente el conocimiento didáctico desde dos componentes. A saber:

- El componente normativo, aquel que formula criterios y condiciones para la práctica de la enseñanza.

- El componente prescriptivo, aquel que expone reglas para el logro eficaz de los conocimientos y destrezas. Dichas reglas deben ser el resultado de la estructura sistemática mencionada y deben tener la posibilidad de generalización a situaciones didácticas concretas.

Por su parte, Zavala Miguel (2000) citado por Cejas, (2005:118) considera que la educación está más vinculada al desarrollo personal a la adquisición de nuevas capacidades a la incorporación al mundo de la cultura y lo que es la formación algo mucho más puntual y funcional dirigida a la adquisición de habilidades específica y vinculada al mundo del trabajo.

Puede afirmarse que, la instrucción se limita a transmitir criterios normativos y prescriptivos, destrezas técnicas o teorías científicas y que la educación es un proceso más complejo que tiende a capacitar al individuo para actuar conscientemente frente a situaciones nuevas y aprovechando la experiencia anterior.

En cuanto a la concepción de educación que en este trabajo se apoya, se suscribe la afirmación de Martínez (2008:28) al definirla como

Una experiencia social y cultural por la que desarrollamos nuestra personalidad plena, adquirimos autonomía, aprendemos a pensar y a ejercitar la crítica, reconocemos al otro o a la

La Práctica Profesional como área para potenciar las competencias pedagógicas necesarias para la enseñanza en Educación Infantil 
otra en su particularidad y diferencia, valoramos el territorio en que vivimos, adquirimos y ampliamos competencias para la vida y construimos un saber de emancipación.

Es decir, un proceso de configuración y construcción que capacita al hombre para el cambio; para ello, es importante la conjugación del desarrollo personal, en la puesta en acción de los aprendizajes, considerando la interrelación con el contexto en el cual el sujeto en formación se desenvuelve. De este modo, el hombre progresivamente va construyéndose o configurándose de una manera, y no de otra, lo que le permite definirse como un ser humano único; estas consideraciones permiten apreciar la tendencia constructivista subyacente en los planteamientos que se asumen en esta investigación.

En este sentido, la educación incluye dos conceptos paralelos y complementarios que son necesarios distinguir: la enseñanza y el aprendizaje. Mientras que enseñar es mostrar algo a los demás, el aprendizaje sería su proceso complementario, su efecto.

A tal efecto, la actividad de aprender se compone de una secuencia de acciones encaminadas a la construcción del conocimiento, al desarrollo de habilidades, a la adquisición de hábitos y la formación de actitudes, originando una transformación en la conducta del alumno.

Este orden de ideas, conlleva a considerar a la actuación humana, como un hecho constructivo y creativo, por cuanto, las personas en situación de aprendizaje, construyen activamente un conocimiento personal y subjetivo de la realidad que orienta sus acciones y actuaciones.

En concordancia con lo anterior, surge la noción de enseñanza,(Alfaro, 2006:83) entendida como un proceso de interrelación entre personas: una que planifica, orienta, apoya, dirige y evalúa el aprendizaje, y otra (s) que escucha, interpreta, actúa, critica, crea, se autoevalúa y evalúa a los demás, es decir, una actividad intencional, compleja, impregnada de componentes éticos, morales y normativos, que ocurre en un medio psicosocial de intercambios donde sus principales actores (docentes y estudiantes) interpretan y proyectan sus significados particulares, donde el docente tiene la responsabilidad de intervenir en la construcción y reformulación de los 158

La Práctica Profesional como área para potenciar las competencias pedagógicas necesarias para la enseñanza en Educación Infantil 
esquemas de pensamiento de sus alumnos, desde una posición de mediador consciente de los aprendizajes.

Los diversos problemas analizados con relación al cómo enseñar, destaca la oposición de dos tipos de educación: la educación bancaria o convergente y la educación "problematizadora" o divergente. Comprender esta problemática y sus consecuencias, implica considerar que el mejoramiento de los métodos de enseñanza no debe ser considerado un fin en sí mismo, sino como un importante medio para que las universidades cumplan sus funciones sociales. Tal como lo expresa Luzuriaga (1991:218) "el método es el instrumento principal de que se sirve el educador para conseguir sus fines".

Los métodos pedagógicos tienen es su haber la misma evolución que los fines u objetivos de la educación. Comenzaron en su forma más simple, la exposición de la materia a enseñar, siguió el dialogo y la interrogación basada en la palabra, luego la mostración de los objetos, la intuición y por fin se llegó a la participación directa del alumno, a los métodos activos de la educación. En general se pueden resumir de la siguiente manera:

\begin{tabular}{|l|l|l|l|}
\hline Método & Papel del profesor & Características & Tipos \\
\hline Didácticos & $\begin{array}{l}\text { La actividad principal es la del } \\
\text { educador, quien asume todo el } \\
\text { trabajo de la clase, dejando al } \\
\text { alumno en un papel receptivo y } \\
\text { pasivo. }\end{array}$ & $\begin{array}{l}\text { Aquel método en el que } \\
\text { predomina la instrucción y la } \\
\text { enseñanza }\end{array}$ & $\begin{array}{l}\text { 1)Expositivo } \\
\text { 2) Interrogativo }\end{array}$ \\
\hline Activos & $\begin{array}{l}\text { La actividad principal está en la } \\
\text { ayuda y acompañamiento guiado } \\
\text { del profesor, el cual debe } \\
\text { organizar el trabajo del alumno. }\end{array}$ & $\begin{array}{l}\text { Prevalece el aspecto creador, } \\
\text { activo del alumno, pueden } \\
\text { tener como predomino la } \\
\text { actividad sensorial, o la } \\
\text { actividad intelectual, también } \\
\text { pueden ser individuales o }\end{array}$ & $\begin{array}{l}\text { Montessori } \\
\text {-método } \\
\text { Decroly } \\
\text { proyectodo } \\
\text {-plan Dalton }\end{array}$ \\
\hline
\end{tabular}




\begin{tabular}{|c|c|c|c|}
\hline & & colectivos. & \\
\hline Especiales & $\begin{array}{l}\text { Papel activo en la búsqueda de } \\
\text { complementos que le permita } \\
\text { poner a sus alumnos en contacto } \\
\text { con todas las manifestaciones } \\
\text { artísticas, culturales, históricas, } \\
\text { sociales de acuerdo con sus fines } \\
\text { didácticos. }\end{array}$ & 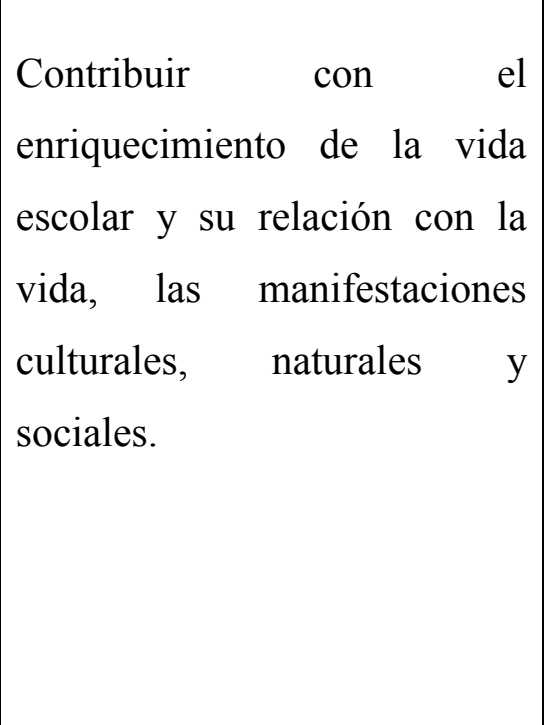 & $\begin{array}{l}\text { Paseos } \\
\text { excursiones } \\
\text { Proyecciones y } \\
\text { cine escolar; } \\
\text { radio escolar. } \\
\text { Periódico y la } \\
\text { imprenta } \\
\text { Exposiciones y } \\
\text { museos } \\
\text { escolares. }\end{array}$ \\
\hline
\end{tabular}

Cuadro ${ }^{\circ}$ 11. Métodos didácticos. Fuente Luzuriaga 1991

Al respecto, el resumen de los métodos presentados en el aparte anterior, permite captar la evolución que ha tenido en varios aspectos: su orientación desde lo objetivo, hasta lo subjetivo, desde la preocupación por las cosas al interés por el sujeto; no obstante, Díaz y Martins (1982: 11) afirman que "la modernización de los métodos no garantiza por sí misma que la universidad se integre a su medio, se identifique con sus problemas e influya en la transformación de la sociedad".

Por consiguiente, es necesario situar el papel de la enseñanza como función de la universidad, en relación con la sociedad, en la que al analizar la realización de las funciones clásicas de la universidad, tales como, enseñanza- investigación - extensión, puede evidenciarse paralelismo y desvinculación entre las tres funciones, de tal forma que, ni la investigación alimenta la enseñanza, ni la extensión mantiene una relación significativa con ambas (Díaz, 1982), una situación diferente, sería si se procura reformular estas relaciones, a fin de establecer una interacción más dinámica y armónica entre la enseñanza, investigación y extensión. 
En este sentido, si en las universidades se deciden a revisar y actualizar la ejecución de sus tres funciones clásicas, la metodología de enseñanza, no podrá conservar sus modelos actuales, de este modo, el estilo de enseñanza, donde el profesor trasmite sus conocimientos a sus alumnos pasivos, debe confrontarse con la realidad y sustituirse por la necesidad de que el profesor revise constantemente sus conocimientos, a la luz de la producción investigativa propia y de la sociedad científica, para que la investigación se convierta en un instrumento de la enseñanza y la evaluación del aprendizaje no termine en lo que el alumno "sabe", sino también en la referencia de lo que conoce, hace y valora.

Estos planteamientos, sugieren una formación docente orientada hacia la investigación de las competencias pedagógicas, es decir, la problemática que envuelve su acción, asumiendo que esta acción tiene impacto tanto en un nivel micro social (aula de clases), como macro social (institución-comunidad). En el siguiente apartado, intentaremos realizar un acercamiento a lo que hasta ahora se ha considerado como competencias pedagógicas.

\subsection{Competencias Pedagógicas}

No es fácil abordar el tema de las competencias pedagógicas, dada la variedad de acepciones en las que se ubican estos vocablos, como ocurre con otros términos educativos. Por una parte, es necesario ubicarse en el amplio campo conceptual de las competencias (ya tratado anteriormente) que en la actualidad posee alta relevancia; por otra parte, el término pedagógico como parte de las competencias, obliga a delimitar detalladamente el campo de acción, o dicho de otro modo, asumir una posición teórico-práctico concreta.

El escenario o contexto de acción profesional, en el cual se ubican estos términos es de la educación superior, específicamente los responsables de la formación de profesores en educación preescolar; ante esto, se plantea nuevamente una doble mirada, por una parte las competencias pedagógicas que los formadores de profesores deben poseer, y por otra parte, las que los futuros profesores deben aprender para su desempeño como profesionales de educación infantil. 
En relación con las competencias pedagógicas, que los formadores de formadores deben poseer, se cuenta con los aportes de algunos autores, teniendo en cuenta la denominación y caracterización que cada uno le concede al termino; Así tenemos que para Zabalza (2003) y Tejada (2009) son competencias docentes; por su parte, Ribot, Varguillas y Báez (2008) las identifican como competencias didácticas; finalmente, Valdés, Mujica, Roque y Darin (2007) y Arboleda (2011), las consideran como competencias pedagógicas.

Al respecto, Zabalza (2003), presenta el perfil del docente universitario, desde una óptica funcional, donde destaca 10 competencias docentes:

- Planificar el proceso enseñanza-aprendizaje,

- Seleccionar y preparar los contenidos disciplinares,

- Ofrecer informaciones y explicaciones comprensibles y bien organizadas,

- Manejo de las nuevas tecnologías,

- Diseñar metodología y organizar actividades,

- Comunicarse-relacionarse con los alumnos,

- Tutorizar,

- Evaluar,

- Reflexionar e investigar sobre la enseñanza,

- Identificarse con la institución y trabajar en equipo.

En esta misma línea, Tejada (2009) determina que al ubicar la formación en competencias, en el ámbito estrictamente didáctico, el profesional de la docencia universitaria, además de ser un experto en la disciplina académica correspondiente, deberá tener una amplia gama de competencias profesionales básicas entre las cuales se destacan:

- Conocimiento del proceso de aprendizaje del estudiante en contextos académicos y naturales.

- $\quad$ Planificación de la enseñanza y de la interacción didáctica.

- Utilización de métodos y técnicas didácticas pertinentes.

162

La Práctica Profesional como área para potenciar las competencias pedagógicas necesarias para la enseñanza en Educación Infantil 
- Gestión de interacción didáctica y de las relaciones con los alumnos.

- $\quad$ Evaluación, control y regulación de la propia docencia y del aprendizaje.

- Conocimiento de normas legales e institucionales reguladoras de derechos y deberes del profesor y del estudiante.

- Gestión de su propio desarrollo profesional como docente.

- Diagnóstico e identificación de necesidades y objetivos de innovación y mejora de su docencia y de su formación.

Por su parte Ribot, Varguillas y Báez, conceptualizan el término competencias didácticas, como el desarrollo de las funciones inherentes a la tarea docente, ejercidas de manera efectiva dentro o fuera del aula, con el fin de transferir a otros, saberes útiles su desenvolvimiento en la vida (2008:54)

Desde otro punto de vista, Valdés, Mujica, Roque y Darin (2007: 6), presentan un cambio de perspectiva en comparación con los modos de enfocar tradicionalmente los programas, que tenían la tendencia a considerar el campo disciplinario como el principio organizador de la formación. Para ello, sustituyen el enfoque disciplinario por el de competencias, donde se destaca la necesidad de poner la aplicación de conocimientos y habilidades en primer plano antes que la adquisición de conocimientos y habilidades. Es decir, la competencia como principio organizador de la formación. Su contenido es práctico y permite a cada alumno construir su proceso de aprendizaje a partir de la experiencia personal, la reflexión activa y la interacción en grupo; en otras palabras, coloca al estudiante en el centro del proceso de aprendizaje ofreciéndole más importancia a las actividades de aprendizaje que a las de enseñanza.

Estos autores, en la determinación de las competencias pedagógicas establecieron la correlación entre ellas, la identificación y el desarrollo de disposiciones estables que permiten:

- Articular conocimientos nuevos con conocimientos ya adquiridos previamente (constitución de aprendizajes significativos).

163

La Práctica Profesional como área para potenciar las competencias pedagógicas necesarias para la enseñanza en Educación Infantil 
- Aplicar conocimientos adquiridos en un espacio y tiempo determinados en contextos distintos a los que lo originaron inicialmente (capacidad de transferencia de conocimiento).

- Explicar las propias operaciones que emergen en el ejercicio de los procesos de pensamiento (capacidad de metacognición).

- Diseñar explicaciones de los fenómenos producidos como resultados del aprendizaje (formalización).

- Aplicación de conocimientos en forma espontánea para el desenvolvimiento de la vida cotidiana (" uso " y "actuación" del aprendizaje).

- El desarrollo de aprendizajes en procesos de interacción y trabajo en grupo (aprendizaje como negociación cultural).

- Atender la configuración de saberes a partir de redes de comunicación y proyectos comunes, propio del mundo globalizado (inteligencias colectivas).

- Adaptarse y responder a los cambios producidos por la dinámicas de la vida humana y la realidad social, de modo que le permitan no solo aprender sino también "desaprender" y volver aprender (auto reorganización).

Del mismo modo, tenemos la conceptualización que ofrece Arboleda (2011:2) sobre las competencias pedagógicas como: la serie de conocimientos, capacidades, habilidades, destrezas, actitudes y disposiciones que alguien debe poseer para intervenir en la formación integral de un individuo. No obstante el carácter de la competencia lo define la naturaleza del entorno en el que el mediador realice su intervención; hay unos mínimos que todo docente debería poseer para asumir su tarea en el complejo entorno de los aprendizajes y las comprensiones que deben construir los estudiantes. Para este autor, todo docente debe conocer la naturaleza de la acción pedagógica y del aprendizaje, apropiarse de los conceptos básicos y actualizados de las disciplinas desde las cuales intervienen. Igualmente, de los insumos metodológicos para la mediación didáctica, tanto como del discurso sobre la enseñanza, que permanece habitualmente en un nivel restringido. 
Desde el punto de vista de este estudio y en correspondencia con los aportes de los autores citados, las competencias pedagógicas deben considerarse desde un amplio marco de referencia o guía en la formación inicial y continua de futuro profesor de educación infantil, pues permite ilustrar los contenidos, actitudes, orientaciones a desarrollar en este importante proceso de formación de la carrera docente. Por tanto, las competencias pedagógicas que se requieren para la práctica profesional, debe ser considerada en sus múltiples dimensiones y direcciones, tanto del profesor formador, como del estudiante en formación. Es decir, no puede dejarse de lado, a ninguno de los actores, como tampoco el contexto, el conocimiento científico, práctico y didáctico de la educación infantil, los procesos de enseñanza aprendizaje, las experiencias previas, Ios contenidos en el cual se realice esta acción; por ello las competencias pedagógicas en esta investigación son consideradas como un ciclo concéntrico, en el que se incluyen factores de tipo epistemológicos, axiológicos, teleológicos, metodológicos propios de la profesión, para que profesores y alumnos asuman sus competencias de manera autónoma, participativa, que se permita investigar, planificar, asumir acciones reflexivas y evaluarse a sí mismo, a sus compañeros e institución donde le corresponda ejercer su práctica. Este ciclo puede representarse gráficamente del siguiente modo.

165

La Práctica Profesional como área para potenciar las competencias pedagógicas necesarias para la enseñanza en Educación Infantil 


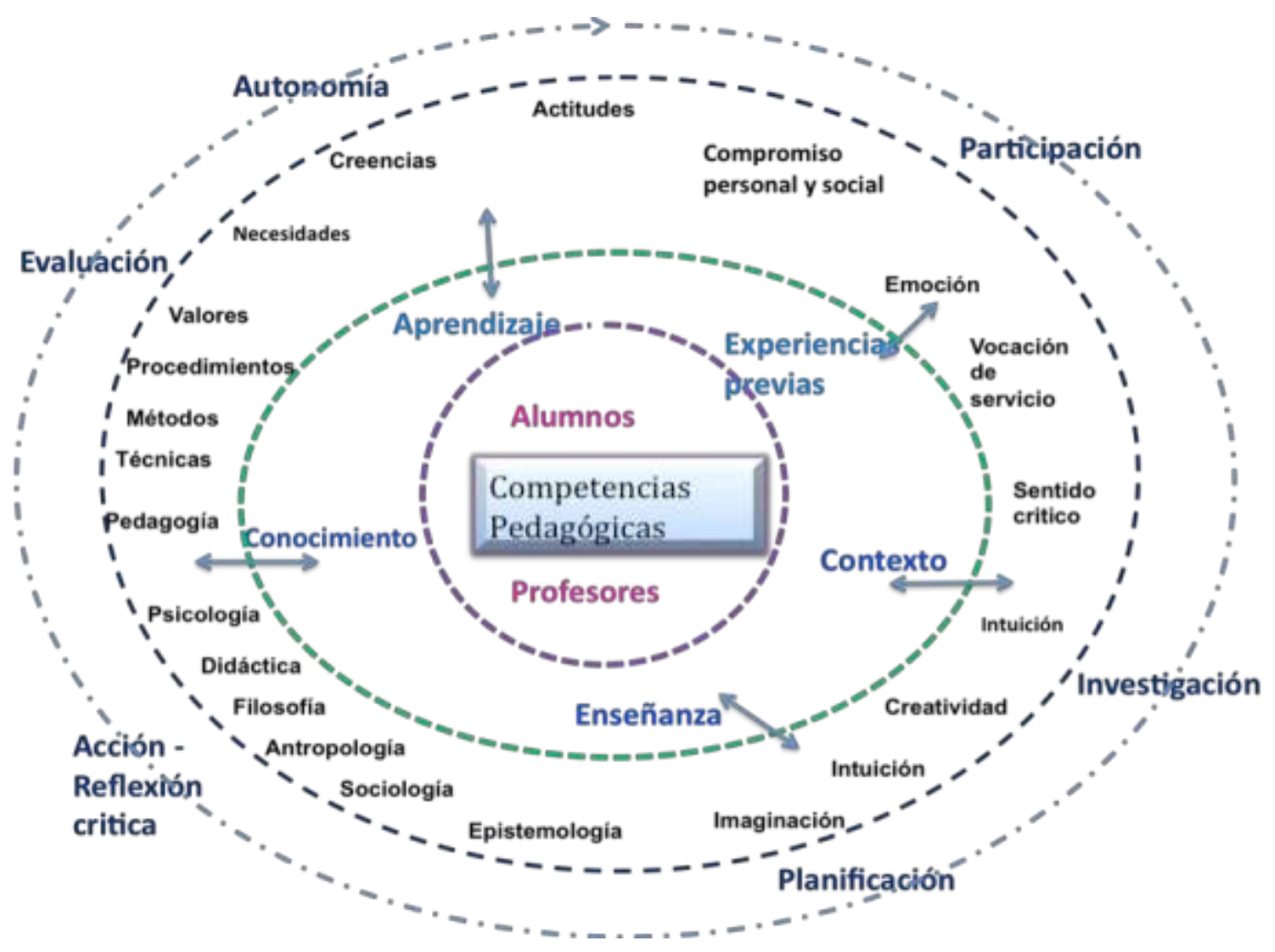

Grafico $n^{\circ} 5$ Competencias Pedagógicas. Fuente: Elaboración propia

\subsection{Resumen Formación Profesional Basada en Competencias Pedagógicas}

En este capítulo, se comenzó explicando el término competencias, el cual cada vez aparece más, en el discurso cotidiano y su uso se hace con múltiples significaciones, lo que indica que es un concepto altamente polisémico que facilita el acomodamiento del discurso a los propósitos de quien habla. En este mismo orden, la noción de competencia que se emplea actualmente en educación, no proviene de un único paradigma teórico, sino que tiene múltiples fuentes teóricas

La Práctica Profesional como área para potenciar las competencias pedagógicas necesarias para la enseñanza en Educación Infantil 
(psicología, lingüística, sociología, educación para el trabajo y filosofía). Al respecto, Tobón (2004: 43) afirma que "la multiplicidad de perspectivas y la transposición del concepto de una disciplina a otra, es en donde está su mayor fortaleza", lograr competencias para el desarrollo personal y profesional, implica que los equipos docentes deben realizar, a partir de su experiencia y criterio, una adaptación del currículo a los procesos didácticos del aula, donde se tome en consideración las características de lo que se adapta, al espacio, tiempo y personas con las que se hace, todo ello con la idea de favorecer el aprendizaje más completo para los estudiantes. Más adelante y en concordancia con esta línea expositiva, se presentan algunas consideraciones generales sobre educación, enseñanza y aprendizaje, términos que están implicados en este análisis (sin pretender un tratado profundo de éstos) y que ayudan a definir con mayor claridad los supuestos teóricos de esta investigación. Por tanto, se asume que la educación es una experiencia social y cultural, que posibilita un desarrollo pleno de la personalidad, con autonomía, ejercicio del pensamiento crítico, el reconocimiento al otro o a la otra en su particularidad y diferencia, y la adquisición y ampliación de competencias para la vida. Es decir, un proceso de configuración y construcción que capacita al hombre para el cambio; estas consideraciones permiten apreciar la tendencia constructivista subyacente en los planteamientos que se asumen en esta investigación.

Finalmente y como aporte importante de este capítulo, se hizo reseña a las competencias pedagógicas, haciendo la aclaratoria que cada autor le incorpora el matiz que a su juicio debe considerarse en su abordaje; de este modo se tiene que para Zabalza (2003) y Tejada (2009) son competencias docentes; por su parte, Ribot, Varguillas y Báez (2008) las identifican como competencias didácticas; Valdés, Mujica, Roque y Darin (2007) y Arboleda (2011), las consideran como competencias pedagógicas.

Al respecto, en esta investigación se asume que las competencias pedagógicas, deben atenderse desde un amplio marco de referencia o guía en la formación inicial y continua de futuro profesor de educación infantil, pues permite ilustrar los contenidos, actitudes,

167

La Práctica Profesional como área para potenciar las competencias pedagógicas necesarias para la enseñanza en Educación Infantil 
orientaciones a desarrollar en este importante proceso de formación de la carrera docente. Por tanto, las competencias pedagógicas que se requieren para la práctica profesional, debe ser considerada en sus múltiples dimensiones y direcciones, tanto del profesor formador, como del estudiante en formación. Es decir, no puede dejarse de lado, a ninguno de los actores, como tampoco el contexto, el conocimiento científico, práctico y didáctico de la educación infantil, los procesos de enseñanza - aprendizaje, las experiencias previas, los contenidos en el cual se realice esta acción; por ello las competencias pedagógicas en esta investigación son consideradas como un ciclo concéntrico (se inserta gráfico $\mathrm{N}^{\circ}$ 5) en el que se incluyen factores de tipo epistemológicos, axiológicos, teleológicos, metodológicos propios de la profesión, para que profesores y alumnos desplieguen sus competencias de manera autónoma, participativa, que se permita investigar, planificar, asumir acciones reflexivas y evaluarse a sí mismo, a sus compañeros e institución donde le corresponda ejercer su práctica.

168

La Práctica Profesional como área para potenciar las competencias pedagógicas necesarias para la enseñanza en Educación Infantil 
169

La Práctica Profesional como área para potenciar las competencias pedagógicas necesarias para la enseñanza en Educación Infantil 


\section{Capítulo 6. Formación del Profesorado en Educación Preescolar.}

Formación de profesores de educación preescolar en Venezuela

$>$ Instituciones de educación superior en Venezuela

$>$ Formación de profesores de educación preescolar en la UPEL

$>$ Propósitos del currículo

$>$ Organización curricular

$>$ Práctica profesional: conceptos, propósitos, fines

$>$ La Práctica profesional en la formación del docente: enfoques y criterios

$>$ Práctica profesional en la formación del docente de educación inicial en Venezuela

$>$ La práctica profesional en la formación del docente de educación inicial en la UPEL

$>$ Resumen de formación de profesionales para educación preescolar 


\section{CAPITULO 6. FORMACIÓN DEL PROFESORADO DE EDUCACION PREESCOLAR}

\subsection{Formación de Profesores de Educación Preescolar en Venezuela}

En la conferencia mundial de Educación para Todos (Jomtien, 1990), los representantes mundiales asumen el reto de luchar contra la exclusión educativa, y lo más importante, es el reconocimiento de que el aprendizaje comienza desde el nacimiento. Esto implica que es en la educación infantil, inicial o preescolar, donde se asientan las bases de la formación del individuo. Más adelante, en el Foro Mundial de Educación Para Todos (Dakar, 2000) se ratifica el compromiso con los objetivos de Jomtien, lo cual forma parte del basamento político- educativo de Venezuela, como país suscriptor de estos acuerdos.

En este sentido, resulta interesante conocer más de cerca la situación referida a la formación de profesionales en educación preescolar, en las universidades e institutos venezolanos. Al respecto, el sistema de educación superior en Venezuela está representado por:

Universidades Nacionales Autónomas (públicas u oficiales).

Universidades Nacionales Experimentales (públicas u oficiales).

Universidades Privadas y

Institutos y Colegios Universitarios, públicos u oficiales y privados.

Estas instituciones están regidas por la Ley de universidades (1970:1) que entre sus principales disposiciones se destacan:

Artículo 1.- La universidad es fundamentalmente una comunidad de intereses espirituales que reúne a profesores y estudiantes en la tarea de buscar la verdad y afianzar los valores trascendentales del hombre.

Artículo 2.- Las Universidades son instituciones al servicio de la Nación y a ellas corresponde colaborar en la orientación de la vida del país mediante su contribución doctrinaria en el esclarecimiento de los problemas nacionales.

Artículo 3.- Las Universidades deben realizar una función rectora en la educación, la cultura y la ciencia. Para cumplir esta misión, sus actividades se dirigirán a crear, asimilar y difundir el saber

La Práctica Profesional como área para potenciar las competencias pedagógicas necesarias para la enseñanza en Educación Infantil 
mediante la investigación y la enseñanza; a completar la formación integral iniciada en los ciclos educacionales anteriores, y a formar los equipos profesionales y técnicos que necesita la Nación para su desarrollo y progreso.

Artículo 4.- La enseñanza universitaria se inspirará en un definido espíritu de democracia, de justicia social y de solidaridad humana, y estará abierta a todas las corrientes del pensamiento universal, las cuales se expondrán y analizarán de manera rigurosamente científica.

Artículo 5.- Como parte integral del sistema educativo, especialmente del área de estudios superiores, las Universidades se organizarán y funcionarán dentro de una estrecha coordinación con dicho sistema.

Artículo 6.- La finalidad de la Universidad, tal como se define en los artículos anteriores, es una en toda la Nación. Dentro de este concepto se atenderá a las necesidades del medio donde cada Universidad funciones y se respetará la libertad de iniciativa de cada institución.

En este sentido, y siguiendo con la Ley de Universidades (1970: 3) en su Título II, Artículo 18, el Consejo Nacional de Universidades (CNU)

Es el organismo encargado de asegurar el cumplimiento de la presente Ley por las Universidades, de coordinar las relaciones de ellas entre sí y con el resto del sistema educativo, de armonizar sus planes docentes, culturales y científicos y de planificar su desarrollo de acuerdo con las necesidades del país. Este Consejo, con sede en Caracas, tendrá un Secretario Permanente y una Oficina de Planificación del Sector Universitario (Ob. cit.)

El CNU, está integrado por el Ministro de Educación quien lo preside; los Rectores de las Universidades Nacionales y Privadas; tres representantes de los profesores escogidos en la siguiente forma: uno por los profesores de las Universidades Nacionales no experimentales, uno por los profesores de las Universidades Nacionales Experimentales, y uno por los profesores de las Universidades Privadas, entre los profesores de ellas con rango no inferior al de asociado; tres representantes de los estudiantes, escogidos igualmente a razón de uno por cada grupo de Universidades; dos profesores universitarios de alto rango académico, elegidos de fuera de su seno, por el Congreso de la República o por la Comisión Delegada; y un representante del Consejo Nacional de Investigaciones Científicas y Tecnológicas (Artículo 19, 1970:4).

La Práctica Profesional como área para potenciar las competencias pedagógicas necesarias para la enseñanza en Educación Infantil 
Por su parte en el Plan de Desarrollo Estratégico Social de la Nación (2004), se recomienda atender las exigencias de la construcción de una nueva visión de sociedad y de una nueva república, desde estas perspectivas queda señalado el logro de un profesional para el nivel inicial, que garanticen la puesta en marcha del proyecto del país, quedando proyectado como un docente comprometido con los cambios, con conciencia crítica, autónomo, humanista, investigador, reflexivo, creativo, solidario, participativo, consustanciado con la realidad socio económica política y cultural de los diversos contextos local, regional, nacional e internacional.

Partiendo de este principio, las universidades e institutos universitarios tienen la responsabilidad de formar al licenciado en educación preescolar, o profesor especialidad: educación preescolar, el cual tiene como compromiso fundamental facilitar el desarrollo integral del niño (social, afectivo, cognoscitivo, motriz, físico-biológico) en edad preescolar, para lo que aplica técnicas y procedimientos adecuados al proceso didáctico, cultivando la sensibilidad para lograr cambios sociales positivos en los niños y en los familiares; fomentando la participación de la familia en el proceso evolutivo integral del niño. Este profesional además está capacitado para estudiar la problemática propia del nivel y planificar, programar y organizar la administración de soluciones al problema detectado, así como también está en capacidad de organizar centros preescolares.

El campo de trabajo de estos profesionales, está delimitado por Instituciones de educación Preescolar y ler grado de la escuela básica; oficinas de planificación educativa, grandes empresas que ofrezcan servicios de guardería a sus empleados, entre otros.

En resumen, la formación de profesionales para la educación preescolar en Venezuela, le plantea a las universidades el reto de formar un docente proactivo, crítico, reflexivo, con capacidad para apropiarse del conocimiento y mantener un aprendizaje permanente, con autonomía para actuar en una diversidad de ambientes y comunidades de aprendizaje, con habilidades, destrezas, valores y actitudes que le permitan tomar decisiones, innovar y dar respuesta a la diversidad de problemas que se le presentan y a las múltiples inquietudes que pueden tener sus alumnos.

173

La Práctica Profesional como área para potenciar las competencias pedagógicas necesarias para la enseñanza en Educación Infantil 


\subsection{Instituciones de Educación Superior en Venezuela.}

De acuerdo con Madrid y Lucero (1999:2) "las instituciones de formación del profesorado tienen dos funciones claras y específicas: primera, formar profesores enfocada a distintos niveles de educación y segunda, proponer alternativas para continuar la formación permanente del profesorado".

Cada una de estas instituciones tiene una organización curricular particular o específica, al respecto en Venezuela existen universidades e institutos universitarios (públicos y privados) responsables de la formación de profesionales para la educación infantil, entre las públicas, pueden mencionarse: Universidad Nacional Abierta (UNA), Universidad Nacional Experimental Simón Rodríguez (UNERSR), Universidad de Carabobo (UC), Universidad del Zulia (LUZ), Universidad Pedagógica Experimental Libertador (UPEL), Universidad Bolivariana de Venezuela (UBV).

Al respecto, estas instituciones tienen la responsabilidad de formar al recurso humano necesario para que responda a las múltiples y variadas expectativas que la Venezuela de hoy plantea, específicamente para la formación de profesionales responsables de la educación de los infantes de 0 a 6 años, los cuales, de acuerdo con los requerimientos que plantea el diseño curricular del nivel deben brindar una educación de alta calidad, fortaleciendo el papel educativo de las familias y demás adultos responsables.

El régimen de estudio de estas universidades es diverso y al mismo tiempo compatible entre algunas universidades, por ejemplo la UNERS y la UNA poseen un ciclo introductorio, luego un ciclo general, seguido del ciclo profesional y los cursos electivos; pos su parte la UC, LUZ está organizado en semestres, con tres oportunidades de práctica profesional en los semestres octavo, noveno y décimo.

Todas ellas con el propósito de preparar un docente para que preste servicios en el ámbito de la Educación Preescolar, correspondiente a la educación formal y no formal, con estrategias convencionales y no convencionales.

174

La Práctica Profesional como área para potenciar las competencias pedagógicas necesarias para la enseñanza en Educación Infantil 
En el siguiente cuadro resumen, puede observarse las características particulares del régimen de estudio, que ofrecen estas instituciones públicas de educación superior en el país.

\begin{tabular}{|c|c|c|c|c|}
\hline Institución & Modalidad & Horario & Duración & Título que otorga \\
\hline $\begin{array}{l}\text { Universidad del Zulia } \\
\text { LUZ }\end{array}$ & Semestral & $\begin{array}{l}\text { Diurno- } \\
\text { Nocturno }\end{array}$ & 5 años & $\begin{array}{l}\text { Licenciado en Educación } \\
\text { Preescolar }\end{array}$ \\
\hline $\begin{array}{ll}\text { Universidad } & \text { Nacional } \\
\text { Abierta UNA } & \end{array}$ & Semestral & Diurno & 5 años & $\begin{array}{l}\text { Licenciado en Educación } \\
\text { Preescolar }\end{array}$ \\
\hline $\begin{array}{lr}\text { Universidad } & \text { Nacional } \\
\text { Experimental } & \text { Simón } \\
\text { Rodríguez } & \\
\text { UNESR } & \end{array}$ & Semestral & Diurno & 5 años & $\begin{array}{l}\text { Licenciado en Educación } \\
\text { Preescolar }\end{array}$ \\
\hline $\begin{array}{l}\text { Universidad Bolivariana } \\
\text { de Venezuela UBV }\end{array}$ & Semestral & $\begin{array}{l}\text { Diurno- } \\
\text { Nocturno }\end{array}$ & 4 años. & $\begin{array}{l}\text { Licenciado en Educación } \\
\text { Preescolar }\end{array}$ \\
\hline $\begin{array}{ll}\text { Universidad } & \text { de } \\
\text { Carabobo UC } & \end{array}$ & Semestral & Diurno & 5 años. & $\begin{array}{l}\text { Licenciado en Educación: } \\
\text { mención Educación Inicial y I } \\
\text { etapa de Educación Básica. }\end{array}$ \\
\hline $\begin{array}{l}\text { Universidad Pedagógica } \\
\text { Experimental Libertador } \\
\text { UPEL }\end{array}$ & Semestral & Diurno & 5 años & Profesor Educación Preescolar \\
\hline
\end{tabular}

Cuadro $n^{\circ}$ 12. Universidades Públicas con la carrera de educación preescolar en Venezuela. Fuente: elaboración propia.

La formación de profesionales para la educación preescolar en Venezuela, fue analizada por una comisión nacional de formación docente en preescolar, bajo la dirección del Ministerio de Educación, para la reorientación de los perfiles profesionales de las carreras de docencia en educación preescolar e infantil. 
$\mathrm{Al}$ respecto, el reto, que tenían y aún tienen las Universidades, institutos, Tecnológicos y Colegios Universitarios, es la formación de un recurso humano de calidad, actualizado, que tome en cuenta la investigación como recurso para estudiar y satisfacer los problemas y necesidades que surjan en torno a la atención del niño pequeño, dado los problemas sociales, económicos y los cambios en las políticas educativas, curriculares y de atención al niño menor de seis años, que se vienen produciendo en el País, precisan la formación de un docente capaz de establecer una relación con el entorno cultural comunitario en el cual se inserte una justa valoración del papel que desempeñan los padres y otros adultos significantes en la educación de los niños. (Díaz y Mayz, 2004:3).

En este orden de ideas, la referida comisión, pudo constatar que los perfiles y planes de estudio no se correspondían con las nuevas políticas y tendencias nacionales e internacionales en materia de formación para la Educación Superior, no tomaban en cuenta los pilares de la UNESCO y tampoco respondían a las políticas internacionales de Latinoamérica y el Caribe para la Educación Inicial (ob. cit.: 9).

Todo esto le confirmo a la comisión, que debía evaluar la carrera de Educación Preescolar en el ámbito nacional para llegar a acuerdos y unificar criterios en torno a los parámetros que debían orientar la formación del profesional de la docencia para la Educación Inicial y Preescolar. A partir de allí, y en correspondencia con los resultados de este y otros estudios, en el país de inicia el llamado a la transformación curricular de los diseños en las universidades del país.

De acuerdo con Valdivieso (2011) En el caso específico de Venezuela,

El inicio de las revisiones curriculares en las Instituciones Educativas venezolanas, han traído como consecuencia la reducción en algunos casos el tiempo de graduación en las licenciaturas de 5 a 4 años, como ocurre en muchos país de mundo, la creación de programas a distancia y basados en el aprendizaje virtual en algunas universidades, entre ellas la Universidad Nacional Experimental Simón Rodríguez (UNESR), la Universidad Simón Bolívar (USB),Universidad Central de Venezuela (UCV), la flexibilización de los planes de estudio al incorporar en ellos 176

La Práctica Profesional como área para potenciar las competencias pedagógicas necesarias para la enseñanza en Educación Infantil 
la unidades curriculares electivas y el empleo de diversas modalidades y estrategias formativas.

Sin embargo, en la actualidad, se continúa sin unificación de criterios para realizar estas revisiones curriculares, a pesar de las directrices dadas por los organismos rectores de sector de educación superior en el país. A este particular la referida autora señala que el currículo de las Universidades venezolanas está caracterizado de la siguiente manera: a) Rígido: a los estudiantes sólo le es permitido el transitar dentro del plan de estudios para la obtención del grado académico, b) Poca pertinencia social: el proceso educativo en las universidades no responden a las necesidades de la juventud y de la sociedad, c) énfasis en la formación especializada: lo que se interpone en la formación de un ciudadano integral, que pueda comprender el complejo mundo que le rodea desde diversas perspectivas, d) frondosidad curricular: que lleva a que los planes de estudio estén sobrecargado de unidades curriculares, que en muchos casos repiten contenidos y e) tradicionalidad del proceso de enseñanza-aprendizaje: en el que se manifiesta la autoridad docente en el aula de clase.

Tal como puede evidenciarse, aún hay mucho por hacer en cuanto a los procesos formativos de profesionales para la educación infantil en Venezuela.

\subsection{Formación de Profesores de Educación Preescolar en la UPEL}

El currículo de la UPEL, tiene una vigencia de dieciséis (16) años, en la actualidad se está desarrollando un proceso de transformación curricular, al cual se hará referencia más adelante; para efectos de esta investigación se analizara el currículo vigente, el cual Asume aportes de diferentes corrientes del pensamiento y los integra con una visión holística para generar un diseño curricular prospectivo, equilibrado, ajustable, comprehensivo, multidisciplinario y perfectible, el cual responde a los cambios de paradigma producidos en las ciencias, la tecnología, las artes, las humanidades y la sociedad en general, que han impactado a la Pedagogía y en consecuencia a los

177

La Práctica Profesional como área para potenciar las competencias pedagógicas necesarias para la enseñanza en Educación Infantil 
procesos orientadores del "prever" y el hacer" currículo en escenarios permeables donde las realidades se construyen y reconstruyen sobre acontecimientos menos predecibles, donde las fórmulas, y los esquemas se ubican en un segundo plano para dar cabida a quehaceres creativos y diversos. (Diseño curricular UPEL, 1996: 12)

\subsubsection{Propósitos del Currículo.}

En atención a la concepción del currículo la Universidad Pedagógica Experimental Libertador ha asumido los siguientes propósitos:

- Responder a las necesidades de Formación Docente dentro del marco general que plantean las políticas del Estado Venezolano en esta materia.

- Favorecer la identidad de los procesos académicos que se desarrollen en la Universidad.

- Constituir el eje integrador de la academia Universitaria.

- Garantizar una formación integral general y pedagógica básica, y una formación especializada equilibrada, con los aportes de los diferentes campos del conocimiento.

- Contribuir al enriquecimiento, consolidación y exaltación del acervo cultural, local, regional y nacional, y propiciar el desarrollo de una conciencia nacional.

- Permitir la incorporación de contenidos y experiencias educativas que se correspondan con las especificidades institucionales y regionales.

- Organizar los saberes tanto en función de su estructura, como de su relación dinámica interdisciplinaria con la problemática que enfrenta el hombre en su interacción con el medio natural y cultural.

- Promover el desarrollo de habilidades y actitudes para el ejercicio ético, racional, reflexivo, crítico y eficiente de la docencia en el marco de la política nacional de Formación Docente.

- Estimular procesos que impulsen la cooperación, el trabajo en grupo, la responsabilidad. Propiciar en el estudiante el desarrollo social, intelectual y afectivo, orientándolo hacia la búsqueda de su bienestar y mejoramiento cualitativo. 
- Propiciar la adquisición de competencias que permitan al estudiante educarse permanentemente.

- Promover los procesos de investigación a fin de permitir la adquisición de variadas formas de indagación e interpretación de la realidad, que conduzcan al diseño y aplicación de estrategias propias para la transformación de la misma.

- Propiciar la evaluación y retroalimentación permanente del currículo a fin de garantizar la calidad del egresado.

\subsubsection{Organización Curricular.}

Siguiendo con el diseño curricular UPEL, donde expresa que su organización curricular responde a los principios y lineamientos de la política de formación docente del Estado, a las políticas de docencia de la Universidad Pedagógica Experimental Libertador, los propósitos del currículo y al perfil del egresado. En consecuencia,

El currículo se constituye dentro de una estructura conformada por cuatro componentes curriculares articulados: definiéndose el componente como el conjunto de actividades y experiencias que se agrupan en cursos, fases y actividades de extensión. Se organizan en atención a los propósitos, niveles, áreas, prelaciones, bloques homologados e institucionales, tipo de curso o fase y otras estrategias definidas en los proyectos de cada instituto, con el fin de desarrollar en el individuo los conocimientos, habilidades, destrezas y actitudes requeridas por la profesión docente. (1996:14).

Estos componentes son: Formación General, Formación Pedagógica, Formación Especializada y Práctica Profesional. A continuación procederemos a explicar cada uno de ellos: Tabla: Componentes curriculares UPEL

\begin{tabular}{|l|l|}
\hline Componentes & Descripción \\
\hline $\begin{array}{l}\text { Formación } \\
\text { General }\end{array}$ & $\begin{array}{l}\text { Propicia actividades y experiencias de aprendizaje que contribuyen al } \\
\text { desarrollo integral de la personalidad del estudiante, a la comunicación }\end{array}$ \\
\hline
\end{tabular}

La Práctica Profesional como área para potenciar las competencias pedagógicas necesarias para la enseñanza en Educación Infantil 


\begin{tabular}{|l|l|}
\hline & $\begin{array}{l}\text { interpersonal y grupal, a la comprensión del hombre y de las realidades } \\
\text { sociales, entre otros. }\end{array}$ \\
\hline Pormación & $\begin{array}{l}\text { Proporciona las experiencias vitales de aprendizaje que enfatizan los valores } \\
\text { éticos y las actitudes propias del ejercicio docente, permite la adquisición de } \\
\text { enfoques, conocimientos, métodos y tecnologías que aseguran su capacitación } \\
\text { para cumplir con sus funciones básicas: planificación de las tareas docentes, } \\
\text { la comprensión del proceso evolutivo y la dinámica de desarrollo personal del } \\
\text { educando; la selección, producción y uso de las estrategias y tecnologías y } \\
\text { evaluación de los aprendizajes, así como uso de los resultados de las } \\
\text { investigaciones para reformular o construir nuevos conocimientos y } \\
\text { metodologías aplicables al hecho pedagógico. }\end{array}$ \\
\hline $\begin{array}{l}\text { Formación } \\
\text { Especializada }\end{array}$ & $\begin{array}{l}\text { Ofrece las experiencias de aprendizaje que permiten el dominio teórico y } \\
\text { práctico de los contenidos y la metodología de las disciplinas científicas del } \\
\text { nivel, en el que actuará como docente, así como también de las estrategias } \\
\text { para la enseñanza y el aprendizaje de dichas disciplinas y de la aplicación de } \\
\text { estos conocimientos. }\end{array}$ \\
\hline $\begin{array}{l}\text { Práctica } \\
\text { Profesional }\end{array}$ & $\begin{array}{l}\text { Se concibe como un eje de integración y de confrontación teórico-práctica de } \\
\text { la formación docente, distribuido a lo largo de la carrera, en torno al cual los } \\
\text { objetivos de los componentes de Formación General, Formación Pedagógica y } \\
\text { Formación Especializada se integran en función del perfil profesional del } \\
\text { egresado. }\end{array}$ \\
\hline $\begin{array}{l}\text { Se desarrolla sobre la base de un conjunto de experiencias de aprendizaje } \\
\text { integradoras de carácter sistemático, progresivo y acumulativo que en su } \\
\text { conjunto le permite al sujeto en formación la intervención pedagógica de la } \\
\text { realidad educativa, a fin de validar teorías y construir una praxis que consolide } \\
\text { el perfil profesional. }\end{array}$ \\
\hline
\end{tabular}

Cuadro nº 13. Componentes Curriculares. Fuente: Diseño Curricular UPEL 1996

Siguiendo con la descripción al modelo de formación que actualmente posee la UPEL, dentro de cada uno de los componentes curriculares descritos anteriormente, se agrupan los cursos, fases y actividades de extensión, en dos categorías: el bloque homologado y el bloque institucional. El bloque homologado de cursos de formación general y pedagógica y la fase homologada del componente de práctica profesional son comunes para todas las especialidades de la Universidad. Mientras que, el bloque institucional responde a las características particulares

180

La Práctica Profesional como área para potenciar las competencias pedagógicas necesarias para la enseñanza en Educación Infantil 
de cada uno de los institutos (siete) que componen la Universidad Pedagógica en todo el territorio nacional.

En cuanto al componente de práctica profesional, se tiene que, la fase de observación pertenece a la fase homologada, las restantes son del bloque institucional y también son obligatorias. Ellas son: Ensayo Didáctico, Integración Docencia-Administración y Ejecución de Proyectos Educativos. Sin embargo, en esta última fase se atiende al criterio de flexibilidad, en el sentido de que el estudiante asume la responsabilidad de construir o desarrollar su formación profesional, ya que la fase plantea, que el futuro docente escoge la opción de acuerdo con las líneas de proyectos educativos factibles estipulados por los programas o departamentos involucrados. Los proyectos optativos a elegir son tres: proyectos de investigación en áreas de su especialidad o de su quehacer educativo, proyectos comunitarios o institucionales o prácticas no convencionales.

En este diseño curricular se plantea la posibilidad de que el estudiante opte por una salida de intermedia, que le permita ingresar al mercado laboral, con el título de Maestro en Educación Preescolar; en este caso, se considera una fase específica, no incluida en la carrera larga, denominada Fase Docencia Integrada; no obstante, en la actualidad esta opción de salida intermedia fue eliminada, debido al excedente de profesionales sin posibilidad de acceso al mercado laboral.

Además de los elementos considerados en la descripción de la organización curricular de la Universidad, existen otros factores de importancia para la administración del currículo: el número de cursos y fases, la unidad crédito, el semestre o período académico, la duración de la carrera, el nivel de los cursos y las prelaciones.

Con respecto a la unidad crédito, ésta equivale a una hora teórica presencial de clases a dos o tres horas de práctica o de laboratorio por semana, durante un semestre o período académico, en regímenes presenciales. Para los estudios a distancia o de carácter mixto la unidad crédito equivale a ocho (8) horas de asesoría o taller durante un semestre o período académico, o a 16 horas de práctica, o laboratorio en un período académico, con excepción de las actividades de extensión en ambos casos. 
En la Práctica Profesional la unidad-crédito equivale a 8 horas de asesoría y confrontación individual o grupal durante un semestre o período académico, independientemente del régimen de estudio.

El total de unidades créditos distribuidos entre los componentes es de 165. .El semestre o período académico es una estimación del tiempo que se asume para la administración de los cursos, fases o actividades de extensión. Tiene una duración de dieciséis a dieciocho semanas. La carrera tiene una duración de diez períodos académicos.

Para la ubicación y distribución de los cursos y fases en los semestres o períodos académicos se establecen tres niveles: fundamentación, integración y profundización, que tienen la función de graduar la complejidad de los cursos y fases de práctica profesional en secuencia vertical y horizontal, que garantice la prosecución regular de los estudios y el logro del perfil profesional en el tiempo estimado para el desarrollo de la carrera. En atención a esto, los cursos de fundamentación se ubican entre el primer y cuarto semestre o período académico; los de integración entre el cuarto y séptimo; y los de profundización entre el séptimo y el décimo.

Nivel de Fundamentación: Comprende los cursos, fases y experiencias formativas, dirigidas a proporcionar los conocimientos y habilidades fundamentales para la formación integral básica, el refuerzo de la vocación docente, la identificación de las funciones del docente y el crecimiento personal.

Nivel de Integración: Abarca los cursos, fases y experiencias formativas orientadas a la articulación de la teoría y la práctica en las disciplinas de la especialidad, en las disciplinas pedagógicas, el manejo de la didáctica aplicada a su especialidad, el inicio en la praxis docente y el compromiso ético-profesional.

Nivel de Consolidación y Profundización: Constituyen los cursos, fases y experiencias formativas que permiten la profundización y aplicación de conocimientos y habilidades en la investigación educativa en la práctica docente y en el área de conocimiento de la especialidad. 
El ordenamiento de los cursos, fases o actividades correspondientes a una especialidad, se presenta en planes de estudio. Cada plan de estudio se identifica con el código, la denominación y el total de unidades crédito de la especialidad correspondiente. El resto de la información se refiere a los cursos y sus códigos de identificación, el componente al que pertenecen, las horas teóricas o prácticas, de asesoría, taller, prácticas o de laboratorio, las prelaciones sugeridas y el semestre o período académico en el que se ofrecen.

\subsection{Práctica Profesional: Conceptos, Propósito, Fines}

La práctica profesional representa el espacio ideal para que la teoría se exprese en la práctica y viceversa, es decir la vinculación y aproximación a la acción de aprender a enseñar, ya que constituye uno de los elementos de la formación inicial de extraordinaria significación para la construcción del conocimiento profesional de los aspirantes al ejercicio de la profesión docente.

En la revisión de la literatura, se tiene que, Schön (1992:45), la denomina "practicum reflexivo", y la considera como un proceso de aprendizaje de la práctica en el sitio a través de la acción; es decir, del ejercicio preconcebido y puesto en situación de trabajo con el auxilio de un tutor, preceptor u orientador; así el practicum es una situación pensada y dispuesta para la tarea de aprender una práctica.

Por su parte Rodríguez (2006:20) conceptualiza la práctica pedagógica como reconstrucción del conocimiento pedagógico, que brinda la posibilidad de replantear los supuestos teóricos, de reconsiderar los principios o criterios, relacionados con la educación y el maestro, así como de hallar relaciones entre los supuestos teóricos y la cotidianidad de los maestros. Esta autora, enfatiza el rescate de lo que le pertenece al maestro desde la constitución histórica de su oficio: la enseñanza. Por eso prefiere el término de práctica pedagógica. Asume la interdisciplinariedad no como la simple convergencia de disciplinas en el tratamiento de un problema o temática, sino como la responsabilidad del equipo docente en la práctica, además, propone la búsqueda de una tercera vía: la práctica y la teoría como un instante de un continuum que reproduce y aplica una lógica de reconstrucción constante de la realidad.

183

La Práctica Profesional como área para potenciar las competencias pedagógicas necesarias para la enseñanza en Educación Infantil 
En este orden de ideas, García (2004:263) conceptualiza al practicum, como experiencias orientadas que permiten que el alumno, futuro profesor, utilice de manera crítica y reflexiva, los conocimientos teóricos-prácticos apropiados a las circunstancias concretas que se le puedan presentar en el proceso enseñanza-aprendizaje y en el contexto escolar. Propone entre otras ideas, la de realizar el practicum como un trabajo de colaboración entre los profesionales de la institución escolar y los profesionales de la universidad, no solo para realizar las prácticas, sino que debería estar integrada en la cultura formativa de ambas instituciones, a través de la realización de seminarios de investigación acción, donde participen los alumnos, profesores tutores y los profesores del centro de aplicación, como un medio para vincular la teoría y la práctica, estimular la reflexión, en unión estrecha con la práctica docente y la investigación.

En la misma línea, Tallaferro (2006:4) concibe las prácticas pedagógicas como un eje que atraviese transversalmente toda la formación profesional, constituyéndose en el elemento que articule el saber teórico con el saber práctico. Un componente de prácticas profesionales que sea el eje estructurador del currículum y les permita a los alumnos reflexionar desde sus prácticas reales de aula al participar en la realidad educativa. Tal como lo considera, Álvarez (2007:271) quien sostiene que el proceso formativo en la educación tiene que ser fundamentalmente prácticolaboral e investigativo, puesto que el estudiante se forma como resultado de su preparación para trabajar, ejercitando la metodología de la investigación científica, como sustento básico para hacer más eficiente su labor práctica, y a su vez ésta determina cómo dirigir esa labor de investigación.

De la revisión anterior se desprende que, la práctica profesional es considerada como: proceso de aprendizaje de la práctica en el sitio a través de la acción (Shön, 1992), reconstrucción del conocimiento pedagógico (Rodríguez, 2006), oportunidad de utilizar de manera crítica y reflexiva los conocimientos teóricos y de sus propias prácticas (García 2004, Tallaferro 2006 y Álvarez 2009), lo cual nos indica que esta acción formativa, debe implicar experiencias previas por parte de los tutores o profesores universitarios, dominio teórico de contenidos relacionados con la

184

La Práctica Profesional como área para potenciar las competencias pedagógicas necesarias para la enseñanza en Educación Infantil 
didáctica en educación infantil, tanto de profesores como alumnos, disponibilidad de centros educativos donde se puedan realizar las prácticas y actitud permanente de reflexión sobre la acción.

\subsection{La Práctica Profesional en la Formación del Docente: Enfoques y Criterios}

La práctica profesional como actividad esencial en la formación del docente ha sido objeto de estudio, de abundante discusión, y de diferente aplicación. Esta multiplicidad de aplicaciones no solamente ha dependido del desarrollo científico, sino también de las necesidades sociales y técnicas, que han impuesto criterios para la búsqueda de soluciones científicas a partir de condiciones particulares.

En este orden de ideas, los cambios permanentes en la organización administrativa, tanto de las universidades como de las escuelas, afectan notablemente los períodos de oportunidad de aplicación práctica por parte de los estudiantes, los cuales se ven reflejados en disminución de horas de práctica en los planes de estudios de las asignaturas prácticas de la UPEL. La velocidad de estos cambios es tal, que determina una gran incertidumbre respecto a las tareas que desempeñarán los futuros profesionales; de lo que se deriva que, hoy día se requiera de estos egresados una gran capacidad de enfrentar las incertidumbres, de estar abiertos al cambio, de promover estos cambios, y de identificar y resolver problemas valorando entre diversas alternativas.

Esto implica que la formación del profesional tiene que estar organizada para dar respuesta a los nuevos desafíos. En esta situación, inciden factores que determinan esta realidad, y que dependen de cómo se ha estado concibiendo la formación en los últimos años, lo cual, se refleja de modo particular en la institución objeto en estudio, cuya única dedicación es formar profesionales para la docencia.

Desde el punto de vista de Melograno (2003: 202), la reflexión para el mejoramiento de la calidad en la formación de los docentes ha de estar centrada en la reflexión de su práctica, en la

185

La Práctica Profesional como área para potenciar las competencias pedagógicas necesarias para la enseñanza en Educación Infantil 
elaboración de conocimientos a partir de la misma, y en su actualización. A partir del concepto de actividad, como categoría que designa el modo de existencia y transformación del hombre en su mundo, la misma se concibe en tres sub categorías o dimensiones de la forma existencial de la realidad social, que son la actividad práctica, la actividad cognoscitiva o gnoseológica y la actividad valorativa o axiológica. Al respecto, podemos visualizar cada dimensión en el siguiente cuadro resumen:

\begin{tabular}{|l|l|}
\hline $\begin{array}{l}\text { Categoría: } \\
\text { Actividad }\end{array}$ & Modo de existencia y transformación del hombre en su mundo \\
\hline $\begin{array}{l}\text { Subcategoría: } \\
\text { actividad práctica }\end{array}$ & $\begin{array}{l}\text { Dado su carácter integrador, cumple la función de núcleo estructurador } \\
\text { del sistema de actividades que media la relación sujeto-objeto, a tal } \\
\text { punto que su propia definición implica la determinación del sistema. La } \\
\text { práctica, es una relación esencial entre el sujeto y el objeto, donde lo } \\
\text { ideal y lo material interactúan recíprocamente, deviniendo en la actividad } \\
\text { humana principal. }\end{array}$ \\
\hline $\begin{array}{l}\text { Subcategoría: } \\
\text { actividad } \\
\text { cognoscitiva } \\
\text { gnoseológica }\end{array}$ & $\begin{array}{l}\text { La actividad cognoscitiva o gnoseológica, derivada de la actividad } \\
\text { práctica y condicionada por ella. A través de esta forma especial de } \\
\text { actividad se produce un reflejo activo y creador de la realidad en forma } \\
\text { de conocimiento, que se expresa en teorías, leyes, categorías, entre otras. } \\
\text { Desde este enfoque, la aprehensión de la realidad que se da a través del } \\
\text { conocimiento, transcurre de lo sensorialmente concreto a lo psíquico } \\
\text { abstracto, y de este a lo concreto pensado, en un movimiento de } \\
\text { interrelación mutua inseparable. }\end{array}$ \\
\hline $\begin{array}{l}\text { Subcategoría: } \\
\text { actividad valorativa } \\
\text { 0 axiológica }\end{array}$ & $\begin{array}{l}\text { La actividad valorativa o axiológica, representa las relaciones } \\
\text { valorativas, en la que el sujeto aborda el objeto a partir de la concesión } \\
\text { de un valor, es decir, de su significado moral, cultural, ético, estético, } \\
\text { etc. Así, el sujeto actúa de acuerdo con sus necesidades, y en la misma } \\
\text { medida, evalúa su realidad, discrimina lo negativo de lo que no lo es, y } \\
\text { en este sentido todo conocimiento está siempre implícito en una } \\
\text { actividad valorativa. }\end{array}$ \\
\hline
\end{tabular}

Cuadro n¹4 Actividad práctica del estudiante. Fuente Melograno (2003)

Siguiendo con Melograno, esta práctica laboral, en cualquiera de sus variantes, ha de tener las siguientes condiciones: a) Carácter problematizado de la teoría y la práctica, es decir, asignarle a la práctica su lugar correspondiente, a partir de problemas previamente determinados para darles una solución integrada; b) Carácter investigativo: la práctica ha de ser un proceso de 186 La Práctica Profesional como área para potenciar las competencias pedagógicas necesarias para la enseñanza en Educación Infantil 
planteamiento y solución de problemas con las alternativas que se pueden utilizar en un momento dado el nivel de conocimientos del estudiante; c) Carácter investigativo-laboral, para ser utilizado como fuente para el diagnóstico, buscando alternativas en la solución de problemas educativos y la evaluación de sus resultados; d) Carácter sistémico: la práctica ha de ser concebida como un sistema, lo cual implica considerarla como un conjunto íntegro de actividades para mejorar la calidad de la preparación del futuro educador bajo determinadas condiciones; e) Carácter flexible y diferenciado: la identificación de las tareas prácticas del estudiante ha de posibilitar su adecuación a la realidad, lo que implica una mejora constante y una aceptación de lo particular dentro de lo general; f) Carácter auto controlado y autor regulado: implica que cada estudiante pueda elaborar su programa de trabajo en cada período a partir de la orientación básica del profesor. La acción de valoración se forma sobre la base del control y permite determinar la calidad alcanzada, y el grado de correspondencia entre las exigencias y los resultados; g) Carácter integrador: dado por la unidad de las áreas de formación de la educación de la personalidad del profesional, de los factores del proceso docente-educativo, y de los contenidos de las diferentes asignaturas, módulos o disciplinas, en función de problemas formativos determinados. Parte de un enfoque integral de la realidad, su desmembramiento para su comprensión, y de ahí nuevamente a su integración.

Lo anterior implica que, para la ejecución de la práctica profesional, es importante establecer que el diseño de la programación, posea una organización didáctica integrada y sistemática. La misma, debe determinar previamente cuales son las situaciones educativas a las que ha de enfrentarse el estudiante de acuerdo con el contexto social y cultural, para que recorra de manera eficaz, variadas experiencias que le permitan avanzar desde ejecutor de tareas, hasta un profesional crítico, reflexivo e investigador de los retos y desafíos con los cuales le corresponda actuar. Así mismo, el referido diseño programático de la práctica, debe poseer una metodología integradora, es decir articulado con las demás asignaturas de la formación académica de la especialidad, con el fin de que, desde el punto de vista metodológico, el estudiante se enfrente a

187

La Práctica Profesional como área para potenciar las competencias pedagógicas necesarias para la enseñanza en Educación Infantil 
las diferentes experiencias en múltiples dimensiones, para lo cual tendrá que echar mano de toda la información y conocimientos que le provean todas las asignaturas.

En este orden de ideas, se presentan algunas propuestas para el diseño de tipos de práctica profesional, las cuales se describen, destacando cual es el punto de vista de sus autores, que proponen y además considerando sus fortalezas:

Martínez y Watts (1997:45), la denomina práctica profesional y le asigna las siguientes características: Inicial, gradual y progresivo, organizado por talleres pedagógicos. Fundamentado en la investigación- acción. Esta propuesta tiene como fortaleza que posibilita que el alumno reflexione, analice y evalué sus experiencias previas, como parte de su formación académica en contacto directo con la realidad escolar en la que ejercerá su profesión.

Por su parte Zabalza (1998), la identifica como practicum, en el cual se identifiquen los contenidos y competencias a desarrollar durante las prácticas, así como la responsabilidad y tarea de la universidad y el centro de práctica, esta postura presenta como fortaleza, la tarea de una planificación precisa de las acciones y responsabilidades de todos los involucrados en el practicum.

Desde el punto de vista de Redon (2007:154), considera que las prácticas deben graduarse desde el primer semestre del plan de estudios, ya que la práctica generada a partir de la experiencia juega un papel crucial como espacio para la construcción, consolidación, creación del conocimiento pedagógico (Stenhouse, 1998; Shön, 1992; Kemmis, 1998; Carr, Gundry, 1993; Elliot, 1993). Esta autora concibe un eje de práctica docente que propicia un nuevo modelo de aprendizaje, según el cual los estudiantes de pedagogía deben vincular o articular necesariamente teoría y práctica, acción y reflexión, realidad escolar y universitaria. Para ello se deben escalonar las prácticas en base al logro o demostración de competencias de "observación", "sistematización", "problematización”, "reflexión sobre la acción” y "transformación de la 
práctica", sobre la base de notas de campo, diarios, bitácoras, portafolios, protocolos de evaluación y coevaluación en un colectivo específico de tutoras que acompañan dicho proceso.

Melograno (2003: 204) considera la actividad práctica como la actividad transformadora, adecuada a fines, en la cual se produce la interrelación dialéctica entre lo objetivo y lo subjetivo, y dentro de la cual el trabajo, o actividad laboral, se destaca como la principal acción del hombre encaminada a un fin productivo. Esta actividad práctico-laboral se expresa en formas organizativas propias de esta área de formación y asume una tipología que puede reflejarse y definir estas formas a partir de cinco criterios fundamentales:

\begin{tabular}{|c|c|c|c|}
\hline & CRITERIO & CARACTERISTICAS & TIPOS \\
\hline & Temporal & $\begin{array}{l}\text { Relación existente entre las formas } \\
\text { y el tiempo que se dedica a las } \\
\text { mismas. }\end{array}$ & $\begin{array}{l}\text { Sistemática, que se establece por determinados } \\
\text { periodos breves de tiempo, que se realizar } \\
\text { repetidamente y distribuyen a lo largo de } \\
\text { trimestre, cuatrimestre, semestre o curso, de } \\
\text { acuerdo con la estructura del plan de formación. } \\
\text { Concentrada, aquella que transcurre en lapso } \\
\text { más largos y continuados, y que se distribuyen de } \\
\text { acuerdo con los propósitos más amplios de los } \\
\text { objetivos pedagógicos. }\end{array}$ \\
\hline & Asimilación & $\begin{array}{l}\text { Expresa una relación entre el } \\
\text { contenido y la forma organizativa } \\
\text { que se adopta }\end{array}$ & $\begin{array}{l}\text { Familiarización: propiciar un acercamientc } \\
\text { afectivo, cognitivo instrumental y ético de } \\
\text { estudiante a los problemas propios del objeto de st } \\
\text { profesión. } \\
\text { Reproductiva: ejercitación de modos de } \\
\text { actuación de la profesión a partir de determinado } \\
\text { modelos. }\end{array}$ \\
\hline
\end{tabular}

189

La Práctica Profesional como área para potenciar las competencias pedagógicas necesarias para la enseñanza en Educación Infantil 


\begin{tabular}{|c|c|c|c|}
\hline & & & $\begin{array}{l}\text { Productiva: independencia creativa e integración } \\
\text { de los aprendizajes en los modos de actuación del } \\
\text { profesional que se forma. }\end{array}$ \\
\hline 3 & Actuación & $\begin{array}{l}\text { Expresa una relación forma- } \\
\text { método-medio, dada en la } \\
\text { interacción espacio y objeto de } \\
\text { influencia }\end{array}$ & $\begin{array}{l}\text { Institucional, referida a la práctica que se realiza } \\
\text { No un centro infantil como tal. } \\
\text { cuando se lleva a cabo en las condiciones de las } \\
\text { vías no convencionales de la educación de la } \\
\text { primera infancia. } \\
\text { Familiar, enfocada a una relación de influencia } \\
\text { sobre el medio familiar, con los padres y demás } \\
\text { miembros del hogar. } \\
\text { Comunitaria, caracterizada por acciones en la } \\
\text { comunidad, para coordinar relaciones de influencia } \\
\text { y apoyo. }\end{array}$ \\
\hline 4 & $\begin{array}{l}\text { Socio- } \\
\text { participativo }\end{array}$ & $\begin{array}{l}\text { El abordaje y solución de tareas } \\
\text { con ayuda y mediación del } \\
\text { individuo y el grupo. }\end{array}$ & $\begin{array}{l}\text { Individual, que se ejecuta de manera } \\
\text { independiente por el estudiante } \\
\text { Grupal, donde se establece una relación de } \\
\text { colaboración entre el individuo y el grupo social. }\end{array}$ \\
\hline j & $\begin{array}{l}\text { Carácter de la } \\
\text { Actividad }\end{array}$ & $\begin{array}{l}\text { Referida a la naturaleza de las } \\
\text { acciones, siendo una expresión de } \\
\text { la relación forma-método. }\end{array}$ & $\begin{array}{l}\text { Observación valorativa, que se caracteriza por } \\
\text { una relación externa entre el estudiante en su } \\
\text { práctica y su objeto de la profesión. } \\
\text { Interventora, que se distingue por la ejecución de } \\
\text { acciones en función de la solución total o parcial }\end{array}$ \\
\hline
\end{tabular}

190

La Práctica Profesional como área para potenciar las competencias pedagógicas necesarias para la enseñanza en Educación Infantil 


\begin{tabular}{|l|l|l|}
\hline & & de determinados problemas \\
\hline
\end{tabular}

Cuadro n¹5 Criterios actividad Práctica. Fuente: Melograno (2003).

Estos cinco criterios no se excluyen, sino que funcionan interrelacionados para permitir la variedad de condiciones que puede asumir la organización de la actividad práctico-laboral, partiendo del supuesto del rol activo del estudiante dentro del proceso educativo, y del reconocimiento de que, el proceso educativo práctico-laboral requiere de una estructuración didáctica.

Las diferentes propuestas presentadas permiten concretar la imperiosa necesidad de reorganizar las prácticas profesionales de la formación de profesoras en educación preescolar de la UPEL Maracay, de acuerdo a los resultados que arroje este estudio y en consonancia a los aportes innovadores de los autores que ya han trabajado este tema. Así mismo, puede afirmarse que la práctica profesional, en esta investigación, se asume como un proceso dinámico de orientación, acompañamiento, asesoría y aplicación de las actividades de formación inicial, que se desarrolla en variados contextos sociales, culturales y educacionales, donde el futuro profesional obtiene aprendizajes significativos sobre la realidad educativa, mediante la asunción de responsabilidades, experimentación e intervención didáctica de situaciones educativas, como investigador crítico y reflexivo, de los retos y desafíos inherentes al quehacer pedagógico.

191

La Práctica Profesional como área para potenciar las competencias pedagógicas necesarias para la enseñanza en Educación Infantil 


\subsection{Práctica Profesional en la Formación del Docente de Educación Inicial en Venezuela}

La práctica profesional ha sido poco estudiada en cuanto a sus aspectos organizativos y particularmente la referida a la formación de docentes para la primera infancia. Como ya se ha afirmado, el diseño del área de formación práctica profesional ha de estar vinculado de manera sistémica con los objetivos generales de la formación del educador, y no es posible concebir una formación apropiada del mismo si no se parte del contexto al cual va dirigida.

Al respecto, Pérez (1995:398), tomando en cuenta las diferentes propuestas y enfoques alternativos que se han desarrollado en la teoría o en la práctica, presenta un análisis de cuatro perspectivas básicas usadas en los programas de formación, y además establece dentro de ellas corrientes o enfoques que las enriquecen, a saber: perspectiva académica, perspectiva técnica, perspectiva práctica y perspectiva de reconstrucción social. Para efectos de este trabajo destaremos ésta última. En la perspectiva de reconstrucción social se agrupan aquellas posiciones que con matices diferentes, conciben la enseñanza como una actividad crítica y dentro de ellas de destaca el enfoque de investigación acción y formación del profesorado para la comprensión, cuyos principales representantes son; Stenhouse, McDonald y Elliot, para estos autores el profesor no puede ser un simple técnico que aplica las estrategias y rutinas de aprendizaje aprendidas en los años de su formación académica, debe necesariamente convertirse en un investigador en el aula, en el ámbito natural donde se desarrolla la práctica, donde aparecen los problemas definidos de manera singular y donde deben experimentarse estrategias de intervención también singulares y adecuadas al contexto y a la situación.

El caso de la educación de la primera infancia, es quizás uno de los más agudos en esta problemática. Por una parte, la utilización frecuente de personal sin formación profesional especializada, con solo buenas intenciones y afecto hacia los niños, pero sin ninguna preparación eficaz, ha sido uno de los problemas vigentes en la práctica pedagógica profesional, y por otra parte, el estancamiento y la falta de capacitación de los profesionales en servicio, ha sido una constante dentro de muchos de los sistemas educacionales.

192

La Práctica Profesional como área para potenciar las competencias pedagógicas necesarias para la enseñanza en Educación Infantil 
Se ha dicho que, desde el punto de vista educacional, la eficiencia de los programas de la primera infancia no está directamente relacionada con la teoría curricular que se utilice ni con el tipo, la escasez o la abundancia de los recursos y materiales que se usan, sino que la misma está ligada a la calidad del profesional responsable. Al respecto, se requiere que los cursos de formación docente establezcan coherencia entre los paradigmas, para no someter al profesor al dilema de quedarse con la teoría sin la práctica, o con una práctica que se opone a la concepción teórica (Didonet, 2007:27); además los expertos en psicología evolutiva han ido elaborando un marco teórico que ve el desarrollo infantil, como un proceso cultural, tal como el enfoque de Super (1982:178) quien recomienda considerar tres elementos (del ambiente donde habitan los niños) que influyen en su desarrollo: a) los entornos físicos y sociales donde viven; b) las costumbres reglamentadas por la cultura y las prácticas de crianza; c) las convicciones o etnoteorías de los padres. En resumen, es evidente que una concepción universal o prescriptiva según la cual los programas para la educación infantil sean considerados como lineales y aplicables a todos los contextos resulta inadecuada para reflejar las complejas realidades relacionadas con este nivel educativo.

Al respecto, Peralta y Fujimoto (1998:96) plantean que la metodología de los programas formativos para los docentes ha de estar caracterizada por la flexibilidad y apertura del proceso educativo, la integración teórico-práctica, la posibilidad de aplicación del conocimiento en contextos reales, y de generar conocimientos desde la reflexión sobre procesos prácticos, la contextualización social económica, social y cultural del aprendizaje y la autodeterminación de los participantes en el proceso.

Desde este punto de vista, la preocupación para el mejoramiento de la calidad en la formación de los docentes ha de estar centrada en la reflexión de su práctica, en la elaboración de conocimientos a partir de la misma, y en su actualización. Considerar que la docencia es una práctica que tiene formas y modos de recolección particulares equivale a definirla como actividad, cuyos actos tienen que estar dirigidos a un objeto para transformarlo, a partir de fines

193

La Práctica Profesional como área para potenciar las competencias pedagógicas necesarias para la enseñanza en Educación Infantil 
o resultados que terminan con un producto efectivo y real. En resumen, entender a la docencia como praxis significa para concebirla como una actividad consciente, conforme a fines y dirigida a transformar objetivamente la realidad.

La práctica docente, asume diversas formas en este proceso, a partir de que es una práctica profesional, en tanto que:

- Se realiza en un ámbito laboral determinado

- Requiere determinados conocimientos y habilidades para poder realizarla

- Se ejerce públicamente

Pero además, es una práctica educativa, lo cual significa que el conjunto de actos que conforman la docencia se inscriben en un concepto más amplio, el de educación, cuyo propósito fundamental es formar al ser humano como persona.

Fundamentalmente, todo este proceso implica en pasar de un conocimiento práctico más bien inconsciente, conocimiento práctico que, como dice Shön, es un proceso de reflexión en la acción o conversación reflexiva con la situación problemática (1987:65), a un conocimiento crítico y teórico construido a través del dialogo y la interacción con todos los actores.

Esto se justifica dada la consideración de la práctica como fuente del conocimiento y comprobación de la validez de la teoría, en la cual los estudiantes tienen la oportunidad de ejercitar tareas propias de su ámbito de actuación y por tanto, apropiarse gradualmente de variados modos de acción de su quehacer profesional, al vincular las actividades de la institución, la familia y la comunidad. Esta síntesis refleja una concepción de la práctica profesional, que se corresponde con las necesidades presentes en la formación del educador de la primera infancia.

En el caso especifico de Venezuela, López (1995:50) realizó un estudio acerca del perfil del especialista de educación preescolar, el cual representa información ajustada a ese momento histórico, que permite ser objeto de reflexión y análisis en la actualidad, a la hora de 
redimensionar los planes de formación; al respecto, se consultaron a 42 docentes de preescolar, que laboraban en centros educativos convencionales y no convencionales, ubicados en la región capital de Venezuela. Entre los resultados sobre la formación recibida por las informantes, las prácticas profesionales, aparecen reseñadas como el momento de mayor aprendizaje dentro de la formación universitaria; del mismo modo, se presenta información acerca de los aprendizajes obtenidos por las maestras en las prácticas (información que será útil para poder proponer mejoras en el diseño existente en las universidad): a) las informantes (57,63\%), dicen haber obtenido aprendizajes educativos en la evaluación de los niños, planificación de actividades, jornada diaria, manejo de grupo; b) en proporción un poco menor $(42,37 \%)$ dicen haber obtenido aprendizajes no educativos, básicamente afectivos, paciencia, cariño, cuidado y trato hacia los niños. Actitudes que evidentemente no pueden ser enseñadas dentro de un aula de clases y que sin embargo son parte importante del oficio.

En este orden de ideas, es importante destacar un diagnostico realizado durante los años 1997 al 2000, con el fin de consultar a profesionales del área de educación infantil, que provenían de todas las regiones del país, en relación con el perfil del profesional encargado de la atención cuidado y educación de los niños y niñas de 0 a 6 años. Sus recomendaciones, permitieron el desarrollo de una propuesta consensuada, con relación a los aportes de cada una de las regiones incorporadas y se buscaba con ello una mayor pertinencia socio cultural en los currículos de formación. Tal como lo refieren Díaz y Mayz (2004:172), entre los años 2000 al 2004, se continuó trabajando en la preparación de una plataforma para la sensibilización hacia una cultura de evaluación, control y ajuste permanente de los diseños curriculares existentes para formar profesionales en Educación Inicial.

El propósito del proyecto consistió en iniciar un proceso de reflexión-acción dirigido a los líderes y formadores de las instituciones que formaban profesionales de la docencia para la Educación Preescolar en Venezuela, en cuanto a la visión y misión de la carrera, los valores de la misma, el perfil del egresado que se requiere formar para el siglo XXI, el pensum de la carrera

195

La Práctica Profesional como área para potenciar las competencias pedagógicas necesarias para la enseñanza en Educación Infantil 
en cada una de las instituciones existentes, el impacto de la formación docente en el aula infantil y principalmente, definir el alcance de la carrera de Educación Preescolar con relación a las nuevas tendencias y exigencias para la atención integral de niños y niñas de 0 a 6 años. En este proyecto, participaron, algunas instituciones de Educación Superior (institutos y colegios universitarios) y universidades responsables de formar el recurso humano para la docencia en el nivel de Educación Preescolar.

Los participantes de este proyecto, decidieron construir, en primera instancia, una aproximación al perfil que respondiera a las nuevas tendencias latinoamericanas y mundiales, en el campo de la docencia infantil, considerando como principal sustento, los pilares del conocimiento planteados por la UNESCO, y algunas resoluciones educativas, propias del contexto venezolano, que representan avances en lo atinente a la educación de los niños y niñas entre cero y seis años de edad.

En este sentido, la referida comisión elaboró una aproximación al perfil del docente para la educación inicial, el cual fue sustanciado por todas las instancias respectivas del Ministerio de Educación y los representantes de las universidades que ofertan la carrera de Educación Preescolar con salida intermedia ( tres años de duración) y con salida extendida (cinco años de duración). Por tanto, contaba con la validación de amplios sectores responsables de la Educación Infantil venezolana. La propuesta se dirigió hacia la reorientación de los perfiles profesionales, de las carreras de Docencia en Educación Preescolar e Infantil, y por ende de los Diseños Curriculares de las distintas instituciones formadoras, lo cual implicaba a su vez un pase del docente academicista al docente crítico, reflexivo y transformador, considerando en este perfil como un "recurso humano de calidad, actualizado, con valores éticos y morales, que tome en cuenta la investigación como recurso para estudiar y satisfacer los problemas y necesidades que surjan en torno a la atención del niño pequeño" (Díaz y Mayz, 2004:172)

Al respecto, los planes de estudio de algunas universidades del país, permiten poner en evidencia algunas tendencias en cuanto a prioridades y a la organización de las oportunidades de 196

La Práctica Profesional como área para potenciar las competencias pedagógicas necesarias para la enseñanza en Educación Infantil 
prácticas otorgadas por dichas instituciones para la formación de un profesional para la educación infantil.

En este punto, vamos a detenernos en los análisis de varios programas de formación, vigentes en algunas instituciones de nivel superior; al respecto vale destacar que las prácticas profesionales incluyen todo tipo de prácticas, pero lo que interesa a los fines de este estudio, es la oportunidad de interacción directa con niños en centros preescolares o en contextos comunitarios. A continuación se presentan las asignaturas agrupadas en las cuatro áreas comunes (materias teóricas, asignaturas pedagógicas, cursos y asignaturas prácticas, cursos y asignaturas generales) presentes en cinco instituciones de educación superior que cubren el mayor número de estudiantes de preescolar en el país.

\begin{tabular}{|c|c|c|c|}
\hline Universidad & Prácticas & $\mathbb{N}^{\circ}$ & Temporalidad \\
\hline \multirow[t]{5}{*}{$\begin{array}{l}\text { Universidad Nacional Abierta } \\
\text { UN A }\end{array}$} & $\begin{array}{l}\text { Práctica I: desarrollo del niño de } 0 \text { a } 3 \\
\text { años }\end{array}$ & 06 & IV semestre \\
\hline & $\begin{array}{l}\text { Práctica II: Desarrollo cognoscitivo, } \\
\text { socioemocional y del lenguaje. }\end{array}$ & 06 & VI semestre \\
\hline & Práctica III: El maestro en aula & 06 & VII semestre \\
\hline & $\begin{array}{l}\text { Práctica IV: Procesos administrativos } \\
\text { en centros de educación inicial }\end{array}$ & 06 & VIII semestre \\
\hline & Práctica Profesional & 08 & X semestre \\
\hline \multirow[t]{4}{*}{$\begin{array}{l}\text { Universidad Nacional } \\
\text { Experimental Simón Rodríguez } \\
\text { UNERS }\end{array}$} & Pasantías Fase I & 04 & II semestre \\
\hline & Pasantías Fase II & 04 & IV semestre \\
\hline & Pasantías Fase III & 04 & VI semestre \\
\hline & Pasantías Fase IV & 04 & VII semestre \\
\hline
\end{tabular}




\begin{tabular}{|c|c|c|c|c|}
\hline & & Pasantías Fase V & 04 & IX semestre \\
\hline \multirow[t]{4}{*}{$\begin{array}{l}\text { Universidad } \\
\text { Experimental } \\
\text { UPE L }\end{array}$} & $\begin{array}{l}\text { Pedagógica } \\
\text { Libertador }\end{array}$ & Fase Observación & 05 & III semestre \\
\hline & & Fase Ensayo Didáctico & 07 & IV semestre \\
\hline & & Fase Ejecución proyectos educativos & 06 & VIII semestre \\
\hline & & $\begin{array}{l}\text { Fase Integración docencia } \\
\text { administración }\end{array}$ & 07 & X semestre \\
\hline \multirow[t]{7}{*}{$\begin{array}{l}\text { Universidad } \\
\text { Venezuela } \\
\text { UBV }\end{array}$} & Bolivariana & Vinculación Profesional Educativa & 02 & II \\
\hline & & Vinculación Profesional Educativa & 05 & III \\
\hline & & Vinculación Profesional Educativa & 05 & IV \\
\hline & & Vinculación Profesional Educativa & 05 & $\mathrm{~V}$ \\
\hline & & Vinculación Profesional Educativa & 05 & VI \\
\hline & & Vinculación Profesional Educativa & 05 & VII \\
\hline & & Vinculación Profesional Educativa & 05 & VIII \\
\hline
\end{tabular}

Cuadro ${ }^{\circ} 16$ Práctica profesional Universidades Venezolanas. Elaboración Propia

Del análisis al cuadro anterior, se observa que las prácticas profesionales, para la formación docente en educación preescolar presentan gran diversidad y diferencias en su organización; también ofrece algunos puntos en común que representan tendencias en el enfoque de un programa de prácticas profesionales que se desea lograr. De este grupo de universidades se destaca la Universidad Bolivariana de Venezuela, UBV, la cual ofrece prácticas o vinculaciones, desde el segundo semestre de la carrera de manera continua hasta su culminación, lo cual pudiera representar un ejemplo a seguir, desde el punto de vista de número de horas prácticas; no obstante, en la revisión de este diseño, no se pudo evidenciar cual es el propósito u objetivo a lograr en cada una de las prácticas lo cual representa una gran debilidad desde el punto de vista metodológico e investigativo. También es importante destacar que, la UPEL como única 
universidad pedagógica del país, posee el agravante de tener, cuatro prácticas profesionales en su diseño, lo que significa una tremenda desventaja en la formación práctica de sus egresados.

Al respecto, Freire (2004:24), considera que la práctica de la enseñanza se torna una exigencia de la relación teoría-práctica, "sin la cual la teoría puede convertirse en palabrería y la práctica en activismo", lo cual puede interpretarse como la importancia que tiene para el estudiante en formación de dominar los saberes fundamentales de las teorías educativas, los cuales debe ir fortaleciendo con la práctica formadora, con el convencimiento que enseñar no es transferir conocimientos, sino crear las posibilidades de su producción o de su construcción. Más adelante, el autor señala que si se "transforma la experiencia educativa en puro adiestramiento técnico es despreciar lo que hay de fundamentalmente humano en el ejercicio educativo: su carácter formador" (p.34)

Siguiendo con Freire (2004:40), resulta importante destacar que, la práctica docente critica, implícita en el pensar acertadamente, encierra el movimiento dinámico, dialectico, entre el hacer y el pensar sobre el hacer. Es por eso por lo que el momento fundamental en la formación permanente de los profesores, es el de la reflexión crítica sobre la práctica. Es pensando críticamente sobre la práctica de hoy o la de ayer, como se puede mejorar la próxima. El propio discurso teórico necesario a la reflexión crítica, tiene que ser tan concreto que casi se confunda con la práctica.

Así mismo, se trasluce la formación de un docente capaz de establecer una relación con el entorno cultural comunitario, en el cual se inserte una justa valoración del papel que desempeñan los padres y otros adultos significantes en la educación de los niños. A partir del citado documento de aproximación, el Ministerio de Educación Superior decide emprender el proceso de sensibilización para el cambio en la formación docente, en las distintas instituciones de educación superior, que administran la carrera de Educación Preescolar en el país. Para tal efecto se realizó un evento con mesas de trabajo que permitió contrastar el perfil propuesto por el Ministerio de Educación y algunos de los perfiles de egresado de los institutos participantes. 
Los resultados de este evento, permiten destacar el acuerdo de revisar las competencias de los formadores de formadores para fortalecer este perfil; existía una gran debilidad en las prácticas profesionales de los institutos en relación con las exigencias del perfil presentado por el Ministerio de Educación. Del mismo modo, los participantes observaban dos grandes fortalezas en el perfil oficial presentado: reflejaba un alcance orientado a la atención integral del futuro educador y defendía la atención a la diversidad, al incorporar áreas y competencias relacionadas con la integración de los niños con necesidades educativas especiales al aula regular, así como las modalidades no convencionales. Entre las dimensiones del perfil propuesto se organizaron, sobre la base de los plantados por la UNESCO (1996) con relación a cuatro pilares de conocimiento que apuntan hacia una formación integral profundamente humana que reúne tanto aspectos personales (afectivos, actitudinales, intelectuales y habilidades) como aquellos relativos a la relación con los demás. Además dichos pilares, guardan una estrecha relación con las tres dimensiones del perfil que la comisión propuso, a saber: a) Dimensión Personal, b) Dimensión Pedagógica -Profesional, c) Dimensión Socio - Cultural.

\subsection{La Práctica Profesional en la Formación del Docente de Educación Inicial en la UPE L}

En concordancia con lo planteado en el aparte anterior, vamos a realizar un pequeño análisis del diseño curricular UPEL (1996), de la especialidad de Educación Preescolar, lo cual permite formular algunos indicadores que son relevantes de considerar en materia de la formación de docentes en sentido general y que en virtud o en el marco de los cambios actuales, dejan de ser aplicables para la formación de los educadores para la primera infancia en particular.

En este sentido, se observa que el currículo de la Universidad, asume aportes de diferentes corrientes del pensamiento y los integra con una visión holística, lo que se puede interpretar como un currículo prospectivo, equilibrado, ajustable, multidisciplinario y perfectible, para responder a los cambios de paradigma producidos en las ciencias, que impactan a la pedagogía. En síntesis, este diseño posee rigor científico en su concepción para la formación de los 
docentes, en las que se incluyen teorías que fundamentan los fenómenos educativos y el transcurso histórico de los mismos.

Así mismo, se destacan como principales propósitos del currículo: responder a las necesidades de formación docente, dentro del marco general que plantean las políticas educativas del estado venezolano; garantizar una formación integral general y pedagógica básica y una formación especializada equilibrada con los aportes de diferentes áreas del conocimiento; propiciar en el estudiante el desarrollo social, intelectual y afectivo orientándolo hacia la búsqueda de su bienestar y mejoramiento cualitativo; propiciar la adquisición de competencias que permitan al estudiante educarse permanentemente; promover procesos de investigación a fin de permitir la adquisición de variadas formas de indagación e interpretación de la realidad; propiciar la evaluación y retroalimentación permanente del currículo a fin de garantizar la calidad del egresado.

Del análisis al extracto anterior es factible asumir que en la actualidad y luego de 14 años de estar en vigencia este diseño, los propósitos anteriores carecen de fundamento, por cuanto, la universidad ha tardado demasiado tiempo en revisar y actualizar aportes, que realmente le permitan su retro alimentación, y que si bien es cierto, muchos de sus docentes se han preocupado por implementar o introducir algunos cambios, no es menos cierto que desde la promulgación por vía ministerial del proceso de transformación curricular, aún hoy día no se observan los cambios que den respuesta a tal evolución.

Otro factor que es necesario analizar es el referido a la organización curricular. En éste diseño UPEL, se presenta una estructura conformada por cuatro componentes curriculares articulados, la definición de componente según la UPEL (1996: 16) "es el conjunto de actividades y experiencias que se agrupan en cursos, fases... con el fin de desarrollar en el individuo los conocimientos, habilidades, destrezas y actitudes requeridas para la profesión docente". Estos componentes son los siguientes: Formación general, Formación pedagógica, Formación Especializada y Práctica Profesional. Este tipo de organización curricular es definida por los 
alumnos de la universidad como "cursos que hay que aprobar, y que no tiene articulación entre ellos" (Galindo 2009:59), más aun en el caso de la relación teoría práctica, esta es escasa, porque el tiempo que se dedica a la práctica profesional es muy limitado (solo tres fases de acercamiento e intervención en la realidad y una de ejecución de proyectos educativos), así como se observa una falta de comprensión del contenido principal de la misma.

Esta situación de falta de equilibrio entre la formación académica y la profesional, produce ausencia o escasa capacidad de respuesta ante las necesidades y requerimientos que en la práctica profesional se encuentra el egresado. Este modelo de formación, centrado en las asignaturas, implica un énfasis excesivo en la dimensión teórica de la profesión y que responde al criterio de que el egresado posea herramientas y saberes de utilidad indiscutible para comprender e interpretar al niño, su desarrollo, sus procesos, sus necesidades, de manera integral, pero también se requiere que este profesional, sea capaz de enfrentar la solución de los problemas que se planteen en su área de trabajo, y pueda actuar de acuerdo con las necesidades de la práctica y demandas sociales con la mayor efectividad y eficiencia posibles. Esto hace que este énfasis en un área sobre otra, conlleve aparejada una subvaloración de otros aspectos importantes de la formación, como son, por ejemplo, la concepción de la profesión, de su cosmovisión y ética, del sentido de pertenencia y de la identidad profesional.

En relación con la duración de los estudios, el diseño plantea una carrera de cinco años de duración, organizada en diez (10) semestres, para obtener el título de Profesor en Educación Preescolar. Es importante destacar, que al inicio de la carrera de Educación Preescolar y en atención a la demanda educativa en el mercado laboral, existía una oportunidad de salida intermedia (seis semestres) y el egresado obtenía el título de Maestro en Educación Preescolar, con la misma oportunidad de continuar sus estudios y acceso a puestos de trabajo. Esta modalidad fue suspendida hace cuatro años, ya que otros institutos se sumaron a formar técnicos superiores en Educación Preescolar, lo cual ocasiono un exceso de profesionales y pocas oportunidades de trabajo.

202

La Práctica Profesional como área para potenciar las competencias pedagógicas necesarias para la enseñanza en Educación Infantil 
Otra característica de este diseño curricular es la referida a la formación inicial y permanente así como la investigación, en pocas oportunidades se promueven actividades de extensión que impliquen la formación permanente de estudiantes y docentes, en la mayoría de los casos, se realizan en instituciones ajenas al instituto, lo que impide su adecuada interrelación. En cuanto a la investigación, en el plan de estudio se ofertan dos cursos relacionada con esta temática y una práctica que se supone los estudiantes deben poner en acción lo aprendido en dichos cursos; Esto se concibe como una estrategia formativa, es decir, que sirva al estudiante no para convertirse en un investigador, sino que sea capaz de organizar las experiencias de aprendizaje y adquiera las competencias de los conceptos, métodos y técnicas de la investigación como formas de aproximación al saber con fines de aprendizaje. Visto de esta manera, tanto estudiante, como profesor, asumen una visión alejada de la investigación como parte fundamental de la práctica pedagógica.

Estas son algunas regularidades que caracterizan el plan de formación de la UPEL, que quizás coincide en muchos aspectos con otros sistemas educacionales de formación de profesionales para la educación, y que se ven reflejadas con particular dimensión en la correspondiente a la de los educadores para la primera infancia.

\subsection{Resumen de Formación de Profesionales para Educación Preescolar.}

En este apartado se hizo una revisión acerca de la formación de profesionales para la educación preescolar en Venezuela, haciendo un breve recorrido por la situación de las universidades públicas y privadas del país, responsables de formar un docente proactivo, crítico, reflexivo, con capacidad para apropiarse del conocimiento y mantener un aprendizaje permanente, con autonomía para actuar en una diversidad de ambientes y comunidades de aprendizaje. Por tanto, se describe el diseño curricular de algunas Universidades, especialmente el de la UPEL, como la única universidad pedagógica que existe en Venezuela responsable la formación de un recurso humano de calidad, actualizado, que tome en cuenta la investigación como recurso para estudiar y satisfacer los problemas y necesidades que surjan en torno a la atención del niño pequeño, dado 
los problemas sociales, económicos y los cambios en las políticas educativas, curriculares y de atención al niño menor de seis años, que se vienen produciendo en el País,

Más adelante, se presentan algunos conceptos de la práctica profesional, la cual es considerada como: proceso de aprendizaje de la práctica en el sitio a través de la acción (Shön, 1992), reconstrucción del conocimiento pedagógico (Rodríguez, 2006), oportunidad de utilizar de manera crítica y reflexiva los conocimientos teóricos y de sus propias prácticas (García 2004, Tallaferro 2006 y Álvarez 2007), lo cual nos indica (hasta este momento) que esta acción formativa, debe implicar experiencias previas por parte de los tutores o profesores universitarios, dominio teórico de contenidos relacionados con la didáctica en educación infantil, tanto de profesores como alumnos, disponibilidad de centros educativos donde se puedan realizar las prácticas y actitud permanente de reflexión sobre la acción. Así mismo se presentaron diferentes propuestas para la organización y administración de la práctica profesional, lo cual permitió concretar la imperiosa necesidad de reorganizar las prácticas profesionales de la formación de profesoras en educación preescolar de la UPEL Maracay, de acuerdo a los resultados que arroje este estudio y en consonancia a los aportes innovadores de los autores que ya han ensayado este tema. Por tanto, la práctica profesional, en esta investigación, se asume como un proceso dinámico de orientación, acompañamiento, asesoría y aplicación de las actividades de formación inicial, que se desarrolla en variados contextos sociales, culturales y educacionales, donde el futuro profesional obtiene aprendizajes significativos sobre la realidad educativa, mediante la asunción de responsabilidades y experimentación de situaciones educativas, como investigador crítico y reflexivo, de los retos y desafíos inherentes al quehacer pedagógico. En este orden de ideas, se encontró que este tema ha sido poco estudiado en Venezuela, específicamente, en cuanto a sus aspectos organizativos y particularmente la referida a la formación de docentes para la primera infancia. Finalmente se abordaron algunas regularidades que caracterizan el plan de formación de la UPEL, que quizás coincide en muchos aspectos con otros sistemas educacionales de formación de profesionales para la educación, y que se ven reflejadas con particular dimensión en la correspondiente a la de los educadores para la primera infancia.

La Práctica Profesional como área para potenciar las competencias pedagógicas necesarias para la enseñanza en Educación Infantil 
La Práctica Profesional como área para potenciar las competencias pedagógicas necesarias para la enseñanza en Educación Infantil 


\section{Capítulo 7. Planteamiento y Desarrollo de la Investigación.}

El problema

$>$ Objetivos del estudio

$>$ Metodología

$>$ Instrumentos de recogida de datos

$>$ Proceso de construcción, validación y fiabilidad del cuestionario

$>$ Planes y programas oficiales de práctica profesional de educación preescolar de la UPEL Maracay

$>$ Talleres reflexivos

$>$ Población y muestra. 


\section{PARTE EMPIRICA}

\section{CAPITULO 7. PLANTEAMIENTO Y DESARROLLO DE LA INVESTIGACIÓN}

\subsection{Introducción}

El objetivo general que pretendo con este trabajo, es diseñar un programa de práctica profesional para la universidad Pedagógica Experimental Libertador, instituto "Rafael Alberto Escobar Lara" de Maracay (Venezuela) que desarrolle las competencias profesionales necesarias para ejercer la función docente en la etapa de Educación Infantil A tal fin se ha diseñado la presente investigación que comprende dos fases, a saber:

Fase 1: dirigida a conocer, las valoraciones que expresan los estudiantes y profesores acerca de la práctica profesional en Educación Preescolar en la UPEL Maracay, mediante la utilización de un cuestionario elaborado expresamente para esta investigación. El tema de la práctica profesional resulta interesante abordarlo desde la opinión de las estudiantes y sus profesores, porque aporta dos visiones distintas que al final se afectan mutuamente, por cuanto lo que opinen los profesores será visto o confrontado con lo expresado por las estudiantes, lo cual resultara en una valiosa oportunidad para clarificar algunos elementos que ayuden a redefinir la administración de este importante componente de la formación de profesionales para la Educación Infantil. En la fundamentación teórica de la presente tesis, se procuró explicar los principales aspectos relacionados con la práctica profesional y la responsabilidad que, desde la universidad se asume. Así mismo, se describe la situación que ocurre cuando no se da correctamente oportunidades de práctica, la postura o énfasis de cada profesor, los procesos de aprendizaje de los estudiantes. Esta fase del estudio se planteó a partir de la formulación de varias interrogantes: ¿Cuáles son las opiniones de los alumnos y profesores acerca de la administración de la práctica profesional del programa de Educación Preescolar?, ¿Cuáles son las competencias pedagógicas que poseen los alumnos de la especialidad de Educación Preescolar, para la realización de sus prácticas profesionales?, ¿Cómo se pueden mejorar?, para responder

La Práctica Profesional como área para potenciar las competencias pedagógicas necesarias para la enseñanza en Educación Infantil 
estas y otras interrogantes que se puedan ir presentando, diseñamos este estudio que consiste fundamentalmente en la elaboración y aplicación de un cuestionario de recolección de datos con 103 preguntas, el cual fue adaptado tanto para estudiantes, como para profesores de práctica profesional. Los datos obtenidos permitirán describir las opiniones que conformen la experiencia de los informantes que subyacen a la propia acción y práctica docente.

Fase 2: Para este momento del estudio y con el objetivo de indagar en la realidad de los principales actores (profesores y alumnos), sobre las fortalezas y debilidades que distinguen en el proceso de administración de la práctica profesional, esta fase se organizó en dos momentos; en primer lugar se realizó el análisis documental de los planes y programas que componen el área de práctica profesional, con el fin de conocer a profundidad sus principales características. Luego en un segundo momento se realizaron los talleres reflexivos, en la forma de encuentros presenciales, por separado; es decir tres sesiones con los profesores y tres sesiones con los alumnos, en los cuales los asistentes se sintieran con libertad de expresar sus experiencias, debilidades y fortalezas, así como propuestas de acción. La razón de realizar dichos encuentros por separado, responde a lo recomendado por Buendía, Colás y Hernández "en la muestra interesa que queden representadas determinadas relaciones sociales existentes" (1995:254), de este modo se estaría garantizando la simetría en las relaciones de los grupos. Concretamente interesa encontrar respuesta a las siguientes preguntas: ¿En qué medida se corresponde las competencias pedagógicas que las estudiantes manifiestan haber alcanzado, la valoración de sus docentes tutores y el perfil del egresado de la especialidad de Educación Preescolar de la UPEL Maracay? ¿Cuáles serían las características de un programa de práctica profesional, que potencie las competencias pedagógicas necesarias para la enseñanza en Educación Infantil?

En esta parte del estudio se busca profundizar en los procesos reflexivos, no solamente del referido a la enseñanza y aprendizaje o al conocimiento que poseen sobre la práctica profesional; se pretende valorar la investigación reflexiva sobre su propia práctica (como estudiante o profesor) y el entorno en el cual se desarrolla. Con estos resultados se harán análisis intragrupos, 
los cuales conducirán consecuentemente a un posterior análisis intergrupos, que permitirá obtener un detallado estudio comparativo de las opiniones de cada grupo, para poder constatar las semejanzas y diferencias de sus apreciaciones. Debido a la complejidad de lograr agrupar en un solo espacio y momento a los dos conjuntos, se optó por hacer talleres, que permitieran obtener la información lo más exhaustiva posible. Así mismo, se consideró conveniente que el estudio se llevara a cabo con informantes claves pertenecientes a los dos grupos: estudiantes del último semestre de la carrera de Educación Preescolar y profesores de práctica profesional, para poder encontrar así una mayor variabilidad de relaciones. Por este motivo se invitaron a los alumnos y profesores que ya habían participado en la aplicación del cuestionario y que estuvieran dispuestos a participar en dos o más sesiones de trabajo colectivo. Como instrumentos en esta parte: la cámara fotográfica, los registros de observación y las producciones graficas de los participantes.

\subsection{Planteamiento del Problema.}

En los últimos años, el tema de la práctica profesional de los universitarios aspirantes al ejercicio de la profesión docente, se ha convertido en un factor de interés constante en la comunidad científica de las Ciencias de la Educación. De acuerdo con la referencias al respecto, la práctica profesional es uno de los componentes de la formación pedagógica de mayor transcendencia e importancia para la construcción del conocimiento profesional de los futuros docentes, (González 2006; Latorre, 2007). El tema de la mejora de la calidad en la Educación Superior, y por tanto la formación de maestros excelentes, se ha convertido en una de las prioridades más defendidas tanto en el proceso de convergencia europea (Declaración de Bolonia 1999) como en las instituciones de Educación Superior en América Latina (Proyecto Tuning 2002).

Entre las razones que impulsan a centrar la atención sobre la práctica profesional, se pueden destacar las siguientes: inicialmente el interés surgió de la preocupación sobre el valor y transcendencia formativa de la práctica profesional, a partir de la experiencia como profesora de esta área en la especialidad de Educación Preescolar. En segundo lugar, al participar en el

La Práctica Profesional como área para potenciar las competencias pedagógicas necesarias para la enseñanza en Educación Infantil 
diseño y elaboración de programas, supervisar las prácticas en los centros de aplicación y participar como coordinadora de las fases de Ensayo didáctico y de integración docencia administración, lo que permite tener una visión interna y global de los procesos relacionados con la práctica profesional. Del mismo modo, otra razón que motiva a realizar este estudio sobre la práctica profesional en la Especialidad de Educación Preescolar, es la inquietud por conocer la valoración que le hacen las estudiantes y los profesores a este importante bloque de la formación pedagógica. En este sentido, en estudios anteriores (Galindo 2008), se pudo evidenciar que los docentes en servicio activo del ejercicio docente en educación infantil, presentaban serias debilidades en los conocimientos referidos a la didáctica de acuerdo con los planteamientos del diseño curricular del nivel, y que además la auto valoración que le asignan a su praxis didáctica, no coincide con las observaciones realizadas. El proceso de revisión de la literatura muestra la existencia de estudios de análisis sobre la práctica como periodo clave para el aprendizaje, desarrollo y/o potenciación de las competencias profesionales necesarias para la enseñanza ( Arregui, Bilbatua y Sagasta, 2004; Zabalza 2003; Jiménez, 2007; Latorre 2007), sin embargo, se comprueba ausencia de investigaciones referidas a la evaluación del programa de formación de la práctica profesional en Educación Preescolar de la Universidad Pedagógica Experimental Libertador, instituto "Rafael Alberto Escobar Lara" de Maracay .

En este estudio se indagará la formación que reciben los estudiantes de Educación Preescolar, desde el análisis a los diferentes cursos (cuatro fases) que componen el área de práctica profesional, al considerar que esta área es cardinal en la construcción del marco de acción que fundamentará su práctica educativa. Del mismo modo, se identificaran formas en que el currículo se desarrolla, privilegiando el abordaje en dos dimensiones: lo previsto para su ejecución en los planes y programas de estudio y la manera en que estos son llevados a la práctica. En este sentido, se plantea como interrogante general: ¿Cuáles son la opiniones o valoraciones que tienen los estudiantes y profesores, acerca de la administración de la práctica profesional del programa de Educación Preescolar de la Universidad Pedagógica Experimental Libertador instituto "Rafael Alberto Escobar Lara", de Maracay? 
El propósito de esta investigación se centrara en constatar las particularidades de la situación actual de la formación práctica de alumnos universitarios, conocer sus competencias pedagógicas, referidas a la enseñanza para la Educación Infantil, adquiridas en este proceso de formación, así como la valoración que de ellas realizan, los profesores tutores, para posteriormente diseñar un programa de formación, pertinente con los avances y propuestas locales, nacionales e internacionales, referidas a las competencias pedagógicas requeridas para un profesional responsable de la educación, cuidado y atención a los niños y niñas de 0 a 6 años de edad.

\subsection{Objetivos del Estudio.}

Considerando todo lo explicado con anterioridad, en esta investigación se planteó el siguiente objetivo general: Diseñar un programa de práctica profesional que potencie las competencias pedagógicas necesarias para la enseñanza en Educación Infantil.

En este orden de ideas, y con el propósito de alcanzar este objetivo nos propusimos los siguientes objetivos específicos:

1.- Analizar la valoración sobre la práctica profesional del programa de Educación Preescolar de la UPEL - IPMAR, desde el punto de vista de profesores y alumnos.

2.- Conocer cuáles son las características pedagógicas presentes en los planes y programas de estudio del área de práctica profesional, de la especialidad Educación Preescolar de la UPELMaracay.

3.- Indagar sobre las fortalezas y debilidades que distinguen los alumnos y los profesores de la especialidad de Educación Preescolar en el proceso de administración de la práctica profesional

4.- Establecer los lineamientos para la propuesta del plan de mejora, a partir de los resultados encontrados, con los elementos teóricos- prácticos necesarios a incluir en el diseño de un 
programa de práctica profesional que potencie las competencias pedagógicas necesarias para la enseñanza en Educación Infantil.

\subsection{Metodología}

En este capítulo se aborda la descripción del proceso metodológico seguido en la investigación, la cual pretende, como se ha señalado, diseñar un programa de práctica profesional, que potencie las competencias pedagógicas necesarias para la enseñanza en Educación Infantil. El contexto de este estudio fue el programa de Educación Preescolar de la Universidad Pedagógica Experimental Libertador, Instituto Pedagógico de Maracay, mediante un proceso participativo y reflexivo de sus principales actores.

Para llevar a cabo el propósito establecido se describe y analiza el camino metodológico seguido en la investigación, es decir, se trata de orientar los planteamientos tal y como lo afirma Morín (1999:91) y McMillan y Schumacher (2005: 125-145) quienes sugieren conducir por orden los pensamientos, comenzando por las ideas más simples y más fáciles de conocer para luego subir poco a poco hasta niveles más avanzados.

En primera instancia se presenta una descripción de los diferentes enfoques o perspectivas posibles, para realizar un trabajo de investigación, haciendo especial énfasis sobre la dicotomía entre el enfoque cualitativo y cuantitativo, para de este modo, justificar el enfoque asumido en este estudio.

Considerando esta perspectiva, se especifica el diseño, las estrategias metodológicas y las decisiones que se asumen en la investigación. Así mismo, se describen las características esenciales de cada una de sus fases de la investigación, señalando a los sujetos (población y muestra) que intervienen. Más adelante, se presenta todo lo referido al proceso de recogida de datos, donde se describen las técnicas e instrumentos utilizados. 
Finalmente, encontraran el análisis de los datos, la modalidad asumida, vinculada con los objetivos y los sujetos participantes.

\subsubsection{Modelo y diseño de investigación}

La investigación educativa viene de una larga tradición e influencia y práctica eminentemente positivista, razón por la cual la aceptación de otros paradigmas, encontró y encuentra resistencia para aceptarlo en un plano de igualdad científica (Martínez, 1997:64). Desde esta perspectiva, éste autor, afirma que el "todo polisistémico" que constituye la naturaleza global, nos obliga a adoptar una metodología interdisciplinaria, para poder captar la riqueza de la interacción entre los diferentes subsistemas que estudian las disciplinas particulares. Más adelante, el autor advierte que la interdisciplinariedad exige respetar la interacción entre los sujetos de estudio de las diferentes disciplinas y lograr la integración de sus aportes respectivos en un todo coherente y lógico. Por tanto, se trata de un paradigma emergente, es decir, un paradigma que brota de la dinámica y dialéctica histórica de la vida humana y se impone con más fuerza y poder convincente a nuestra mente inquisitiva, (1997:118).

A manera de entrada, es necesario explicitar que en el desarrollo de toda investigación educativa, se utilizan los términos de metodología, método y técnicas, por lo cual es necesario en este momento, realizar una breve descripción de los mismos, conscientes de que existen diferentes modos de asumirlos.

Al respecto, la metodología, según Buendía, Colás y Hernández (1995:6) “se ocupa de los componentes objetivos de la ciencia, puesto que en cierto modo es la filosofía del proceso de investigación"; Así mismo, se refiere a la descripción, análisis y valoración crítica de los métodos. Por lo tanto la metodología de la investigación se refiere al estudio de los métodos de investigación (Rodríguez, 2001).

Por su parte, el método podría quedar definido como el conjunto de procedimientos que permiten abordar un problema de investigación, con el fin de lograr unos objetivos determinados;

La Práctica Profesional como área para potenciar las competencias pedagógicas necesarias para la enseñanza en Educación Infantil 
por tanto, se consideran como estrategias o conjunto de procedimientos para alcanzar los objetivos (ob. cit.).

En relación con la técnica es considerada parte del método, que consiste en un procedimiento o conjunto de procedimientos, regulado y previsto de una determinada eficacia; se relaciona con el cómo de la investigación, es decir, es el procedimiento particular, reflexivo y confiable aplicado al empleo del instrumento, al uso del material, en este sentido, pueden encontrarse numerosas técnicas para obtener información acerca del problema de investigación, entre las más utilizadas se tiene: la recopilación documental, la observación, la entrevista y la encuesta. (Palella y Martins, 2004:75, Rodríguez, 2001: 70).

\subsubsection{Enfoque Mixto o Complementario}

En el caso del presente estudio, el método seleccionado es de tipo mixto, en el cual se combinarán los métodos cualitativo y cuantitativo, no obstante se hará mayor énfasis en el método cualitativo. Lo cual, se perfila como lo más aceptable ya que al considerar el contexto, los participantes y la dinámica misma del ambiente universitario, es necesario acercarse lo más posible para comprender los distintos puntos de vista. Además la investigadora forma parte de la situación objeto en estudio, ya que pertenece al grupo de profesores responsables de la administración de la práctica profesional de la especialidad de Educación Preescolar. Lo anterior tiene sustento en la sugerencia de adoptar la complementariedad, por parte de autores como: Keves (1986); Gage (1989); Martínez (1997); Rodríguez (2001); Dos Santos y Sánchez (2001); y McMillan y Schumacher (2005), Peña y Valdivieso (2007), entre otros, los cuales, en líneas bien generales, afirman que la tesis de la incompatibilidad estaba simplemente errada y que las diferencias paradigmáticas no requerían necesariamente un conflicto paradigmático. A propósito, es válido citar las palabras de Cook y Reichard (1979:26) citado por Dos Santos y Sánchez (2001:47): "los vacíos de un paradigma son las virtudes del otro, un vínculo tan vital y necesario como lo es la luz en relación a la oscuridad" 
Por lo antes expuesto y en relación directa con el paradigma cuantitativo se hizo un primer estudio empírico que se corresponde con una metodología no experimental, con un diseño transeccional, el cual permite recolectar datos en un solo momento, en un tiempo único (Palella y Martins, 2004, Hernández, Fernández y Baptista, 1991). Este diseño permitió investigar la opinión que los estudiantes del último semestre de la carrera de Educación Preescolar y sus profesores, tenían sobre la administración de la práctica profesional;

Los datos obtenidos con la aplicación del cuestionario, se analizaron mediante la aplicación de un programa informático SPSS, lo cual permitió realizar análisis estadístico descriptivo y presentar los resultados en tablas y gráficas de distribución de frecuencias.

En cuanto al segundo estudio, se adoptó el paradigma cualitativo, representado en los talleres reflexivos, con los estudiantes y los profesores. En esta metodología participan los siguientes principios (Gee, Michaels y O'connor, 1992:228, citado por Buendía y colaboradores 1995: 253):

a) El discurso humano es gobernado por reglas y estructurado internamente;

b) Es generado por hablantes, que están situados en un contexto socio histórico, en los que la realidad cultural, política, social y personal configura el discurso;

c) El discurso por sí mismo incorpora elementos de los contextos socio histórico en el cual se desarrolla.

Para el análisis cualitativo se utilizó el procedimiento de categorización y codificación propuesto por Martínez (1997:75) el cual consiste en examinar los datos para identificar determinados componentes temáticos que nos permitan clasificarlos en una u otra categoría de contenido. 


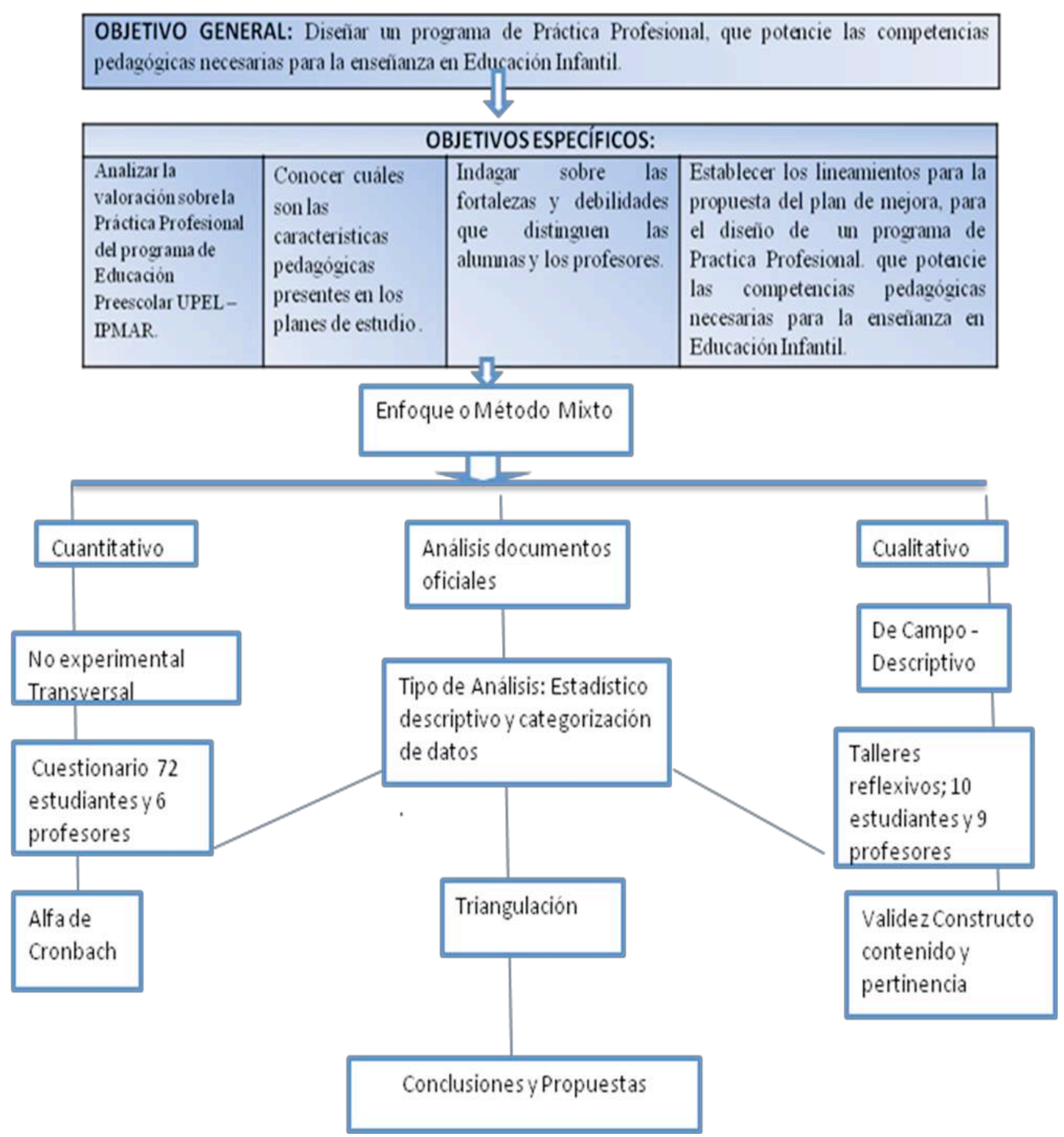

Grafico ${ }^{\circ}$ 6- Diseño de la investigación. 


\subsection{Instrumentos de Recogida de Datos.}

Los instrumentos de recogida de la información son aquellos medios impresos, dispositivos, herramientas o aparatos que se utilizan para registrar las observaciones o facilitar el tratamiento experimental (Rodríguez 2001:71); Palella y Martins (2004:113) los reconocen como cualquier recurso del cual pueda valerse el investigador para acercarse a los fenómenos y extraer de ellos información. Por su parte Buendía, Colás y Hernández (1995:32) consideran a los instrumentos como el dispositivo que utiliza el investigador (papel y lápiz, el cuestionario, escala); al respecto estas autoras ofrecen una clasificación de los instrumentos, que resulta didáctica para profundizar en el tema, la cual está centrada en tres aspectos: a) quien suministra la información, b) de donde proviene los instrumentos, c) que acciones realizan los participantes al suministrar la información. En el caso del presente estudio se presenta a continuación un cuadro resumen que representa el momento o fase de la investigación con sus respectivas técnicas e instrumentos:

\begin{tabular}{lll}
\hline FASE DE & TÉCNICAS & \\
INVESTIGACIÓN &
\end{tabular}

\begin{tabular}{lll}
\hline $\begin{array}{l}\text { Fase I: Valoración de la } \\
\text { Práctica Profesional }\end{array}$ & Encuesta & \\
$\begin{array}{l}\text { Fase II primera parte: } \\
\text { Conocer las características } \\
\text { pedagógicas de los planes de } \\
\text { estudio }\end{array}$ & Análisis de documentos & Matriz de análisis \\
$\begin{array}{l}\text { Fase II segunda parte: } \\
\text { Fortalezas y debilidades de } \\
\text { la implementación de la } \\
\text { Práctica Profesional }\end{array}$ & Talleres reflexivos & \\
& & Cuaderno de notas \\
& & Fotografías \\
\hline
\end{tabular}

Cuadro $n^{\circ} 17$ - Técnicas e instrumentos utilizados en la investigación. Fuente: elaboración propia. 


\subsubsection{El cuestionario}

\subsubsection{Proceso de construcción, validación y fiabilidad del cuestionario}

La técnica más habitual en los estudios de identificación de necesidades, resulta ser el cuestionario. Esta técnica de fácil aplicación permite recoger la opinión de sectores de la población bastante amplios, a la vez que proporciona datos críticos y útiles siempre que la secuencia de aplicación sea la correcta. (Buendía, Colás y Hernández, 1998:123) por ello la encuesta ha sido la metodología utilizada para recoger la información necesaria que se planteó en el objetivo específico número uno: Analizar la valoración sobre la práctica profesional del programa de Educación Preescolar de la UPEL - IPMAR, desde el punto de vista de profesores y alumnas.

El cuestionario fue seleccionado porque su aplicación puede ofrecer una visión extensa de la población estudiantil y profesoral que cursa y administra (según sea el caso) la práctica profesional de educación preescolar en la UPEL Maracay; no obstante, aunque este instrumento posee una serie de ventajas, también incluye algunas debilidades; entre sus principales ventajas aludiremos las puntualizadas por Buendía, Pilar y Hernández (1998:127), las cuales son:

- Puede abarcar mayor cantidad de individuos de una población.

- Las respuestas pueden ser más meditadas al no exigirse tiempo en la realización, además de existir mayor libertad de expresión, al no estar presionado por colocar su identificación.

- Al no existir una relación directa entre el encuestador y el encuestado, existe menos riesgo de distorsión de las respuestas.

En cuanto a las desventajas, Rodríguez (2001:70) comenta lo siguiente: 
- Se corre el riesgo de que muchas de las preguntas no sean respondidas.

- La construcción de las preguntas puede incidir en las respuestas, ya que llevan consigo una serie de supuestos, creencias ya concebidas por el investigador.

- Al no existir relación directa encuestador encuestado existe mayor riesgo porcentaje de cuestionarios no devueltos.

Partiendo de las ventajas antes indicadas y considerando principalmente la perspectiva ampliada del objeto de estudio, se procuro minimizar las debilidades de la siguiente manera:

- Se utilizará el cuestionario acompañado de otros instrumentos para la recogida de la información.

- Para la construcción de las preguntas se considera la opinión de otros profesionales del área, además del apoyo teórico de las fuentes consultadas.

- Su aplicación debe realizarse con el mayor acercamiento a los sujetos participantes, para ello se fijaron acuerdos entre encuestador y grupos de profesores y estudiantes cursantes de práctica profesional.

El instrumento un cuestionario dirigido tanto a los alumnos como a los profesores, está compuesto por 103 preguntas relacionadas con el proceso de formación docente universitaria, Éste cuestionario fue elaborado a partir de los aportes presentados en el marco teórico y de la consulta a trabajos empíricos realizados con anterioridad, relacionados con la temática. Se presentan 103 ítems, divididos en cuatro unidades de análisis correspondientes con la variable en estudio: Práctica Profesional.

En cada uno de los ítems, se solicitó la valoración tanto a profesores como a estudiantes con relación al grado de acuerdo, sobre los aspectos que componen la administración de la práctica profesional en Educación Preescolar: Dimensión procesos de aprendizaje, Dimensión didáctica 219

La Práctica Profesional como área para potenciar las competencias pedagógicas necesarias para la enseñanza en Educación Infantil 
especifica de Educación Inicial, Dimensión de enseñanza universitaria, Dimensión académico estudiantil. Las opciones de respuesta representan una escala de 1 a 4 de menor a mayor grado de acuerdo concedido al criterio. (Ver anexos $\mathrm{N}^{\circ} 1$ y 2 ).

Descripción y estructura del cuestionario

\begin{tabular}{|lll|}
\hline$N^{\circ}$ & Dimensión & $N^{\circ}$ de ítems \\
\hline 1 & Procesos de aprendizaje & 10 \\
\hline 2 & Didáctica especifica de Educación Inicial & 26 \\
\hline 3 & Enseñanza universitaria & 41 \\
\hline 4 & Académico estudiantil & 18 \\
\hline
\end{tabular}

Cuadro $n^{\circ} 18$ - Dimensiones del cuestionario y cantidad de ítems. Fuente elaboración propia.

Siguiendo con la descripción del cuestionario, en la primera parte del mismo, se decidió colocar ocho (8) preguntas que permitan obtener información complementaria de los informantes, tales como: sexo, estado civil, número de asignaturas aprobadas en su carrera (o nivel académico, en el caso de los profesores), entre otras. Ya en la segunda parte se organizaron las preguntas en el mismo orden de las categorías e indicadores elaborados para tal fin (en anexo 3). Así mismo, resulta importante destacar que, además de las preguntas, el cuestionario incluye, una parte explicativa relacionada con lo siguiente: quién solicita la información, porque se solicita, la confidencialidad en el tratamiento de los datos y el agradecimiento a quiénes respondan con sinceridad, dedicación y tiempo. Además se incorporan, las instrucciones que indican como contestarlo.

El cuestionario responde a las características de una escala tipo Likert, la cual consiste en un conjunto de ítems presentados en forma de afirmaciones o juicios, ante los cuales se pide la reacción de los sujetos a quienes se administran (Palella y Martins, 4004:139). En este caso en particular se presenta la afirmación y se le solicitó a los sujetos que expresaran su respuesta

La Práctica Profesional como área para potenciar las competencias pedagógicas necesarias para la enseñanza en Educación Infantil 
eligiendo uno de los cuatro puntos de la escala. A cada punto se le asigno un valor numérico, al final se obtiene una puntuación total sumando las obtenidas en cada una de las afirmaciones, a saber: 4.- Totalmente de acuerdo (T-A). 3.- Bastante de acuerdo (B-A).2.- Poco de acuerdo $(P-A)$. 1.- En Desacuerdo (E-D). Como puede observarse las afirmaciones tienen una dirección positiva, lo cual permite saber cómo se codificaran las alternativas de respuesta. Finalmente, se aclara que este modelo de cuestionario fue adaptado en la mayoría de sus ítems, para el uso tanto de los estudiantes de Educación Preescolar, como de los profesores del área de Práctica Profesional.

\subsubsection{Fiabilidad y Validez}

La mayoría de los autores coinciden en afirmar que toda medición o instrumento de medición debe reunir dos requisitos esenciales: la confiabilidad y la validez. La confiabilidad de un instrumento es el "grado en que la aplicación repetida al mismo sujeto u objeto produce iguales resultados" (Hernández y Col, 1991:242) Este grado de confiabilidad se expresa mediante un coeficiente de correlación. Existen varios métodos para hallar dichos coeficientes. Los más usuales son: Person, test-retest, formas paralelas, dos mitades, y consistencia interna. Éste último es un análisis estadístico que utiliza el coeficiente Alfa de Cronbach o las formulas de Kuderr Richarson (Kerlinger, 1989: Ary y otros, 1990).

De acuerdo con, Hernández, Fernández y Baptista (1991:248) los coeficientes que resultan de este cálculo pueden oscilar entre 0 y 1 . Donde un coeficiente de 0 significa nula confiabilidad y 1 representa un máximo de confiabilidad. En el caso del cuestionario utilizado en este estudio se aplico el coeficiente Alfa de Cronbach (tanto al cuestionario aplicado a los estudiantes, como al de los profesores), el cual requiere una sola administración del instrumento de medición y produce valores que oscilan entre 0 y 1; además, Palella y Martins (2004:154) afirman que es una de las técnicas que permite establecer el nivel de confiabilidad que es, junto con la validez, un requisito mínimo de un buen instrumento de medición presentado con una escala tipo Likert. Para hacer este cálculo, se utilizo el software llamado SPSS, en el cual se ingreso la información 
proveniente del número de ítems de cada instrumento por separado y las respuestas obtenidas de una muestra de sujetos. En el anexo 4 se presenta el cuadro con los criterios de decisión para la confiabilidad del instrumento

Análisis de fiabilidad al cuestionario

$$
\begin{aligned}
& \text { Estudiantes } \\
& \text { Alfa }=\left(\begin{array}{cc}
95 & 58,21 \\
- \hdashline 94 & (1-1038,77
\end{array}\right.
\end{aligned}
$$

$A L F A=0,954$

\section{Profesores}

$$
\text { Alfa }=\left(\begin{array}{cc}
88 & 73,77 \\
----) & (1----)
\end{array}\right.
$$

$A L F A=0,853$

\begin{tabular}{|c|c|}
\hline Resultado Profesores & Resultado Estudiantes \\
\hline 0.853 & 0.954 \\
\hline
\end{tabular}

Cuadro ${ }^{\circ} 19$ - Valores del Alfa de Cronbach para los dos cuestionarios. Fuente: elaboración propia

Una vez realizadas todas las operaciones, se puede afirmar que los resultados de .853 para el cuestionario de los profesores y .954 para el cuestionario a los alumnos, todos ellos por encima de 0.8 , y por tanto, según la prueba Alfa de Cronbach, demuestran que los instrumentos son de muy alta confiabilidad, es decir en cada instrumento existe alta correlación interna de sus ítems. Así mismo, es importante aclarar que aunque se aplico el mismo instrumento a los dos grupos de informantes, los resultados son diferentes atendiendo a sus características particulares referidas a las características propias de cada sujeto.

222

La Práctica Profesional como área para potenciar las competencias pedagógicas necesarias para la enseñanza en Educación Infantil 
En relación con la validez, la han definido como la ausencia de sesgos, representa la relación entre lo que se mide y aquello que realmente se quiere medir, captar de manera significativa y en un grado de exactitud suficiente y satisfactorio, aquello que es objeto de medición (Ander Egg, 1992:273; Rodríguez 2001:72; Palella y Martins. 2004:146). Así mismo, existe consenso entre los autores en cuanto a los tipos de validez: constructo, contenido y criterio. En el caso que nos ocupa, se determino la validez mediante la técnica del juicio de expertos, que consistió en entregarle a tres expertos, un ejemplar del instrumento con su respectiva matriz, acompañada de los objetivos de la investigación, el sistema de variables y los criterios anteriormente mencionados para cualificar las preguntas. Del mismo modo se incluyo un espacio abierto para que los validadores escriban las sugerencias o aclaratorias que consideren necesario (anexo 5)

\begin{tabular}{|l|l|}
\hline Contenido & $\begin{array}{l}\text { El contenido es claro y permite entender toda la afirmación de la misma } \\
\text { forma. Marque (SI) o (NO) }\end{array}$ \\
\hline Pertinencia & $\begin{array}{l}\text { Si la afirmación sirve para aclarar lo que se pregunta y se corresponde con } \\
\text { ello. Marque (SI) o (NO) }\end{array}$ \\
\hline Relevancia & $\begin{array}{l}\text { Se refiere a la importancia del tema. Marque (1) muy importante, (2) } \\
\text { Importante, (3) Nada importante }\end{array}$ \\
\hline
\end{tabular}

Cuadro ${ }^{\circ}$ 20. Criterios de evaluación del instrumento. Fuente: elaboración propia, a partir de Palella y Martins (2004)

Una vez elaborado el instrumento, El grupo de expertos seleccionados estaba conformado por:

- Dos profesoras en educación infantil, con grado académico de postgrado y amplia experiencia en el área de práctica profesional de la UPEL.

- Una profesora especialista en metodología y construcción de instrumentos de investigación, con grado académico de doctora.

- Una profesora especialista en lingüística con grado académico de magister. 
Cada uno de los expertos seleccionados emitió sus propias observaciones, las cuales giraban en torno a lo siguiente: a) reducción del número de preguntas, ya que algunas se repetían o trataban el mismo asunto (ambigüedad); b) corrección o modificación en la redacción de algunos ítems; c) organización interna del instrumento en cuanto a categorías.

A la hora de considerar la opinión del grupo de expertos en el proceso de validación del cuestionario, se considero por separado los aspectos analizados. Por una parte, el criterio de contenido, y por otra el de pertinencia y relevancia.

En cuanto al criterio de contenido, se reformularon algunas afirmaciones, otras se eliminaron, específicamente las que estaban marcadas con un NO, por dos o más validadores; entre ellas las que se repetían o estaban redactadas de tal manera que indicaban tendencia hacia respuestas positivas. En relación con la pertinencia y relevancia, se encontró que había coincidencia en las que ya se había encontrado debilidad en el criterio contenido, por lo que el instrumento definitivo fue modificado y aplicado a la población seleccionada.

\subsubsection{Planes y Programas Oficiales de Práctica Profesional Educación Preescolar de la UPEL-Maracay.}

El análisis de documentos oficiales constituyo otra de las fuentes de información y recogidas de datos, que permitió extraer y recopilar la información relevante y necesaria que atañe a la realidad investigada, de manera más especifica permitió encontrar contestaciones al segundo objetivo propuesto: Conocer cuáles son las características pedagógicas presentes en los planes y programas de estudio del área de práctica profesional, de la especialidad Educación Preescolar de la UPEL- Maracay. Tal y como lo exponen Rodríguez (2001:65) y Hernández, Fernández y Baptista, (1991:23), es el estudio de problemas, con el propósito de ampliar y profundizar el conocimiento de su naturaleza, con apoyo, principalmente, en fuentes bibliográficas y documentales. 
En el caso del presente estudio, en primer lugar, se hizo la consulta al diseño curricular de pregrado, de la Universidad Pedagógica Experimental Libertador (UPEL, 1996), el cual posee una organización curricular que responde a los principios y lineamientos de la Política de Formación Docente del Estado, a las Políticas de Docencia de la Universidad Pedagógica Experimental Libertador, los propósitos del currículo y al Perfil del Egresado. En consecuencia, el currículo se constituye dentro de una estructura conformada por cuatro componentes curriculares articulados: definiéndose el componente como el conjunto de actividades y experiencias que se agrupan en cursos, fases y actividades de extensión. Se organizan en atención a los propósitos, niveles, áreas, prelaciones, bloques homologados e institucionales, tipo de curso o fase y otras estrategias definidas en los proyectos de cada instituto, con el fin de desarrollar en el individuo los conocimientos, habilidades, destrezas y actitudes requeridas por la profesión docente. Estos componentes son: Formación General, Formación Pedagógica, Formación Especializada y Práctica Profesional.

Al respecto el cuadro $n^{\circ} 21$, permite apreciar la organización en término de tipos de cursos o fases (obligatorios homologados, obligatorios institucionales, optativos y actividades de extensión electivas).

\begin{tabular}{|c|c|c|c|c|}
\hline COMPONENTES & $\begin{array}{c}\text { OBLIGATORIOS } \\
\text { HOM OLOGADOS }\end{array}$ & $\begin{array}{c}\text { OBLIGATORIOS } \\
\text { INSTITUCIONALES }\end{array}$ & OPTATIVAS & TOTALES \\
\hline formación general & 04 & 02 & 02 & $08+1^{*}$ \\
\hline formación pedagógica & 09 & 03 & 03 & 15 \\
\hline $\begin{array}{c}\text { formación } \\
\text { especializada }\end{array}$ & $09-10$ & 08 & $03-04$ & 21 \\
\hline práctica profesional & 01 & $02+1 * *$ & 01 & $04-05$ \\
\hline Totales & $23-24$ & $15-16$ & $09-10$ & $49-50$ \\
\hline
\end{tabular}

Cuadro no 21. Distribución por tipos de curso o fase. Fuente UPEL, 1996

Además de los elementos considerados en la descripción de la organización curricular de la Universidad, existen otros factores de importancia para la administración del currículo: el número 
de cursos y fases, la unidad crédito, el semestre o período académico, la duración de la carrera, el nivel de los cursos y las prelaciones.

Siguiendo con UPEL, (1996:21), la unidad crédito equivale a una hora teórica presencial de clases a dos o tres horas de práctica, durante un semestre o período académico, en regímenes presenciales. Para los estudios a distancia o de carácter mixto la unidad crédito equivale a ocho (8) horas de asesoría o taller durante un semestre o período académico, o a 16 horas de práctica, o laboratorio en un período académico, con excepción de las actividades de extensión en ambos casos. En la Práctica Profesional la unidad-crédito equivale a 8 horas de asesoría y confrontación individual o grupal durante un semestre o período académico, independientemente del régimen de estudio.

La unidad crédito es el factor de valorización de los planes de estudio, de los componentes y de los cursos, fases y actividades. Pero además, permite apreciar o estimar la prosecución estudiantil a lo largo de la carrera. Este factor es de vital importancia en un currículo que se ha diseñado en atención al criterio de flexibilidad entendido básicamente como la oportunidad que se le da al estudiante para que construya o desarrolle su formación profesional, es decir, donde los patrones de prosecución estudiantil son variables.

El total de unidades créditos distribuidos entre los componentes es de 165 . Se prevé salidas intermedias con un total de unidades crédito entre 100 y 110 . En el cuadro $\mathrm{N}^{\circ} 22$ se puede visualizar la distribución de las unidades crédito entre los diferentes cursos y fases por componente. 


\begin{tabular}{|c|c|c|c|c|c|c|}
\hline \multirow{2}{*}{$\begin{array}{c}\text { Organización } \\
\text { del Currículo }\end{array}$} & \multicolumn{2}{|c|}{ Homologados } & \multicolumn{2}{c|}{ Institucionales } & \multicolumn{2}{c|}{ Totales } \\
\hline Componentes: & Cursos & $\mathrm{U} / \mathrm{C}$ & Cursos & $\mathrm{U} / \mathrm{C}$ & Cursos & $\mathrm{U} / \mathrm{C}$ \\
\hline Formación General & 04 & 12 & 05 & 14 & 09 & 26 \\
\hline Formación Pedagógica & 09 & 30 & 06 & 18 & 15 & 48 \\
\hline Formación Especializada & $09-10$ & 30 & $11-12$ & 36 & 21 & 66 \\
\hline Práctica Profesional & 01 & 05 & $03+01$ & 20 & $04-05$ & 25 \\
\hline Totales: & $23-24$ & 77 & $25-27$ & 88 & $49-50$ & 165 \\
\hline
\end{tabular}

Cuadro n²2. Distribución de las unidades crédito por curso y componentes. Fuente UPEL 1996

El semestre o período académico es una estimación del tiempo que se asume para la administración de los cursos, fases o actividades de extensión. Tiene una duración de dieciséis a dieciocho semanas. La carrera larga tiene una duración de diez períodos académicos y la etapa intermedia de egreso (Salida Intermedia) una duración de seis períodos académicos. Sin embargo, este estimado es ideal ya que varía según las necesidades o intereses del estudiante.

Para la ubicación y distribución de los cursos y fases en los semestres o períodos académicos se establecen tres niveles: fundamentación, integración y profundización, que tienen la función de graduar la complejidad de los cursos y fases de Práctica Profesional en secuencia vertical y horizontal, que garantice la prosecución regular de los estudios y el logro del perfil profesional en el tiempo estimado para el desarrollo de la carrera. En atención a esto, los cursos de fundamentación se ubican entre el primer y cuarto semestre o período académico; los de integración entre el cuarto y séptimo; y los de profundización entre el séptimo y el décimo.

Con respecto a los contenidos, metodología y sistema de evaluación de las materias, más adelante se ofrecerá una descripción detallada, al presentar el análisis a los programas de cada una de las fases que componen el área de práctica profesional en la UPEL, Maracay. 
Todo lo anteriormente referido sobre la organización, permite definir al diseño curricular de la Universidad como un sistema interrelacionado de cursos o fases obligatorias u optativas y actividades de extensión electiva, distribuidos de manera armónica en cuatro componentes curriculares. Con el fin de obtener una visión general de la organización curricular y con el propósito de ofrecer una visión panorámica de este documento, se incluye en el anexo 6 la matriz de ubicación y secuencia de los cursos y fase

Del mismo modo y continuando con el análisis al diseño curricular UPEL 1996, se hizo la exploración a los programas oficiales y programas en uso, del área de práctica profesional de la especialidad de Educación Preescolar. Concretamente se analizaron los programas de la fase de observación (FO), fase de ensayo didáctico (FED), fase ejecución de proyectos educativos (FEPE), y fase integración docencia administración (FIDA).

En estos documentos se encontraron datos correspondientes a:

- Denominación del curso o fase.

- Tipo de curso y nivel.

- Componente curricular al cual pertenece el curso o fase.

- Unidades de crédito.

- Prelaciones.

- Propósitos del curso o fase.

- Objetivos generales.

- Contenidos fundamentales.

- Estrategias pedagógicas sugeridas.

- Tipo de centro de aplicación.

La estrategia seleccionada para este trabajo de análisis fue la matriz FODA, como herramienta esencial que provee los insumos necesarios al proceso de planeación estratégica, proporcionando la información necesaria para la implantación de acciones y medidas correctivas

La Práctica Profesional como área para potenciar las competencias pedagógicas necesarias para la enseñanza en Educación Infantil 
y la generación de nuevos proyectos (Serna, 2008:73) Entre los principales objetivos de análisis FODA, se pueden destacar:

- Conocer las características básicas de los programas de práctica profesional, en Educación Preescolar, UPEL, Maracay.

- Visualizar panoramas para la determinación de estrategias, con el propósito de detectar debilidades y convertirlas en oportunidades.

En este mismo orden de ideas, la representación de éste análisis FODA, se realizó de la siguiente manera:

\begin{tabular}{|c|c|}
\hline $\begin{array}{l}\text { Fortalezas(Referidas a variables internas): } \\
\text { Experiencias de los recursos humanos } \\
\text { Procesos administrativos para alcanzar los } \\
\text { objetivos } \\
\text { Cualidades del servicio }\end{array}$ & $\begin{array}{l}\text { Debilidades (referidas a variables internas): } \\
\text { Capital de trabajo mal utilizado } \\
\text { Deficiencias en habilidades gerenciales } \\
\text { Falta de capacitación }\end{array}$ \\
\hline $\begin{array}{l}\text { Oportunidades (referidas variables externas): } \\
\text { Políticas educativas } \\
\text { Regulaciones del Ministerio de Educación } \\
\text { Superior }\end{array}$ & $\begin{array}{l}\text { Amenazas (referidas a variables externas): } \\
\text { Cambios en la legislación } \\
\text { Tendencias educativas del país. }\end{array}$ \\
\hline
\end{tabular}

Cuadro $n^{\circ} 23-$ Matriz análisis FODA. Fuente elaboración propia.

A partir de este examen, se construyo una matriz de estrategias para el planteamiento de posibles soluciones que contribuyan a minimizar las debilidades para lograr oportunidades y emplear las fortalezas para evitar las amenazas. 


\begin{tabular}{|l|l|l|} 
F. Externos & Lista de fortalezas & Lista de debilidades \\
\hline Lista de oportunidades & $\begin{array}{l}\text { FO: estrategias para } \\
\text { maximizar las F y las O. }\end{array}$ & $\begin{array}{l}\text { DO: estrategias para } \\
\text { minimizar las D y maximizar } \\
\text { las O }\end{array}$ \\
\hline Lista de amenazas & $\begin{array}{l}\text { FA: Estrategias para } \\
\text { maximizar las F y minimizar } \\
\text { las A }\end{array}$ & $\begin{array}{l}\text { DA: estrategias para } \\
\text { minimizar las D y las A. }\end{array}$
\end{tabular}

Cuadro ${ }^{\circ}$ 24- Matriz de estrategias. Fuente elaboración propia.

\subsubsection{Talleres Reflexivos.}

En este apartado vamos a presentar la explicación de los instrumentos seleccionados para el estudio cualitativo de esta investigación. La especificación conceptual del instrumento seleccionado resulta necesaria, ya que existen numerosas técnicas para recolectar la información, es decir las técnicas y procedimientos que actualmente se aplican en investigaciones educativas adquieren su pleno sentido cuando se comprenden las bases conceptuales que las orientan.

De acuerdo con Teppa (2006: 35) las técnicas cualitativas se centran en el lenguaje, base fundamental de la comunicación, como fuente clave para captar los hechos personales, grupales, educativos y sociales. En este sentido, en el presente estudio se decidió utilizar los Talleres Reflexivos, los cuales de acuerdo con la autora antes mencionada, son una modalidad de la técnica círculos de acción docente propuesta por Elliot (1993), pero que la autora propone como Talleres Reflexivos. Estos talleres se propician a manera de discusiones grupales en reuniones participativas con los colaboradores. En este contexto, tanto los participantes como el investigador tienen un rol activo en el proceso deliberativo. La tarea del investigador será, sobre todo, la de acompañar, coordinar y desencadenar (cuando esto no suceda espontáneamente) procesos cognitivos, utilizando para ello el diálogo y el debate (Perkins, 1995:56).

La Práctica Profesional como área para potenciar las competencias pedagógicas necesarias para la enseñanza en Educación Infantil 
Siguiendo esta línea, consideramos útil abordar los rasgos principales de dos tendencias educativas fundantes de la modalidad taller: el constructivismo y la perspectiva crítico reflexiva. Desde este marco, el aporte de la escuela constructivista permite plantear el aprendizaje como proceso de elaboración a partir de problemas, antes que como transmisión de conocimientos, en consonancia con marcos teóricos-metodológicos de corte cualitativo. Por tanto, se busca abarcar los aspectos subjetivos y no manifiestos del comportamiento humano en los procesos educativos en general. En este mismo orden de ideas, los talleres reflexivos, también tienen sustento en la perspectiva crítico-reflexiva, en referencia a la contribución de la investigación-acción, la cual aparece admitida en los nuevos conceptos de desarrollo profesional que tienen lugar en la actualidad, con expresiones como: "profesores como investigadores en la acción" (Stenhouse, 1987; Elliot; 1993; Schön, 1987), y la de "profesores como prácticos reflexivos" (Carr y Kemmis, 1988)

Estas perspectivas presentan algunas coincidencias que permiten denominar a los talleres reflexivos, como un procedimiento metodológico que permite interrelacionar la teoría con la práctica, y que además vincula procesos reflexivos acerca del hacer de cada uno de los participantes y su modificación o mejora a partir de la práctica Tanto la teoría como la práctica son componentes necesarios del conocimiento por cuanto los sujetos no pueden conocer separadamente de su acción, de su vivencia como tampoco pueden accionar sin reflexión.

Al respecto, Calsamiglia y Tusón (2002:15) opinan que hablar de discurso es, ante todo, hablar de una práctica social. De una forma de acción entre las personas, que se articula a partir del uso lingüístico contextualizado, ya sea oral o escrito, por tanto, abordar los talleres reflexivos implicó adentrarse en el entramado de las relaciones sociales, de las identidades y de los conflictos, para intentar entender cómo se expresan los dos grupos participantes.

En este orden de ideas, se realizaron dos grupos de trabajo, con el mismo propósito de investigación, es decir, dar respuesta al tercer objetivo del estudio: Indagar las fortalezas y debilidades que distinguen los alumnos y los profesores de la especialidad de Educación 231

La Práctica Profesional como área para potenciar las competencias pedagógicas necesarias para la enseñanza en Educación Infantil 
Preescolar en el proceso de administración de la práctica profesional. Por una parte, se invito a un grupo de estudiantes cursantes del último semestre de su carrera universitaria y que además ya habían participado como informantes en la aplicación del cuestionario, pues estaban terminando de cursar la fase de integración docencia administración. El grupo estaba compuesto por 10 estudiantes, los cuales fueron seleccionados de forma intencional. Por otra parte, se invito a la totalidad de los profesores (ordinarios y contratados) que en ese momento, administran la práctica profesional en Educación Preescolar (15 en total) de los cuales asistieron 09 en la primera y segunda sesión y 05 en la tercera sesión.

Cada una de las sesiones programadas tuvo una duración de cuatro (04) horas con un intervalo de realización de una semana. Por lo que en ambos grupos se trabajo durante tres semanas consecutivas (o sea, seis semanas). El procedimiento seguido para esta actividad, fue construido siguiendo algunas recomendaciones de Buendía, Colás y Hernández (1995:254), el cual se presenta a continuación:

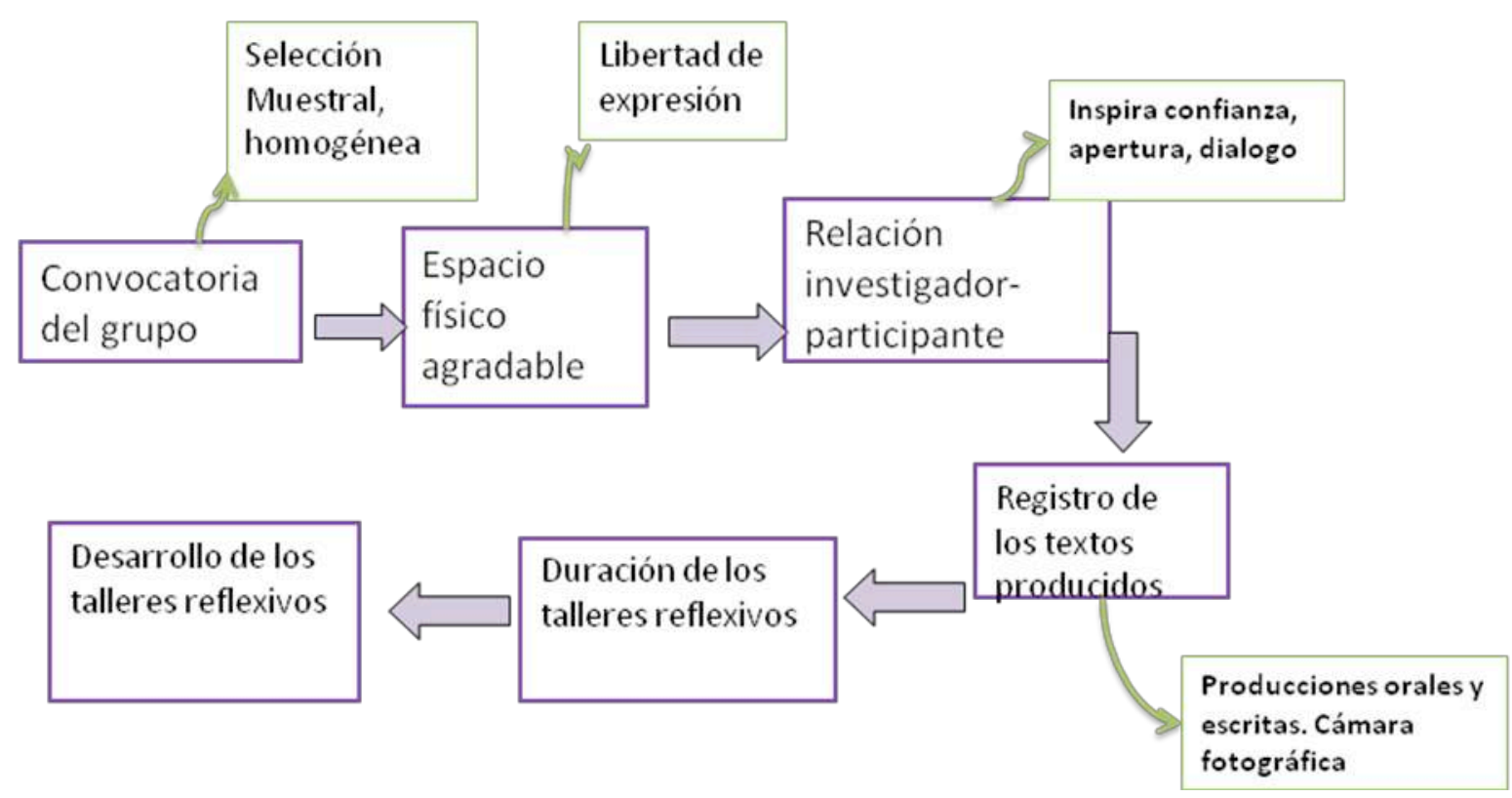

Gráfico ${ }^{\circ} 7$ - Esquema talleres reflexivos Fuente: Buendía, Colás y Hernández (1995:255)

232

La Práctica Profesional como área para potenciar las competencias pedagógicas necesarias para la enseñanza en Educación Infantil 


\subsubsection{Diseño General de los Talleres Reflexivos.}

Dentro de este marco, se diseñaron tres encuentros, tipo taller, de alrededor cuatro (04) horas por semana. Las experiencias de esta naturaleza, deben ser flexibles, por lo que cada sesión de trabajo estuvieron sujetas a modificaciones, dependiendo de las características que no se pueden controlar, entre las que se pueden destacar: movilizaciones estudiantiles, lo cual ocasiona cierre de las instalaciones universitarias, cambios climáticos (lluvia), que impide la asistencia de algunos miembros del grupo, factores personales. El método principal fue la observación participante de la investigadora, en cuanto a las respuestas conductuales y actitudinales de las participantes, del mismo modo, se sistematizaron todas las producciones escritas de los grupos.

\subsection{Descripción de los Talleres Dirigidos a los Profesores:}

En el siguiente cuadro se presenta un resumen de las sesiones realizadas con los profesores.

\begin{tabular}{|c|c|c|c|}
\hline Taller/ dimensiones & Contenido & Actividad & Recursos \\
\hline \multirow{6}{*}{$\begin{array}{l}\text { Primer Taller } \\
\text { dimensión didáctica } \\
\text { universitaria (DEU) } \\
\text { dimensión procesos } \\
\text { de aprendizaje } \\
\text { (DPA) }\end{array}$} & \multirow{6}{*}{$\begin{array}{l}\text { Representación } \\
\text { gráfica de su práctica } \\
\text { pedagógica }\end{array}$} & \multirow{6}{*}{$\begin{array}{l}\text { Charla introductoria } \\
\text { Producción escrita } \\
\text { Valorar su práctica } \\
\text { pedagógica en la } \\
\text { formación de futuros } \\
\text { profesionales para la } \\
\text { educación infantil. }\end{array}$} & \multirow{2}{*}{$\begin{array}{l}\text { Sobre con } \\
\text { afirmaciones }\end{array}$} \\
\hline & & & \\
\hline & & & Laptop. \\
\hline & & & Video beam. \\
\hline & & & $\begin{array}{l}\text { Papel bond. } \\
\text { Marcadores. }\end{array}$ \\
\hline & & & Cámara fotográfica \\
\hline \multirow{4}{*}{$\begin{array}{l}\text { Segundo Taller } \\
\text { dimensión didáctica } \\
\text { especifica educación } \\
\text { infantil (DDEEI) } \\
\text { dimensión } \\
\text { académico } \\
\text { estudiantil }\end{array}$} & \multirow{4}{*}{$\begin{array}{l}\text { Revisión y análisis de } \\
\text { los planes de estudio, } \\
\text { programas didácticos, } \\
\text { rendimiento } \\
\text { estudiantil, apoyo } \\
\text { institucional (UPEL, } \\
\text { centros de aplicación), } \\
\text { numero de prácticas, }\end{array}$} & \multirow{4}{*}{$\begin{array}{l}\text { Preguntas generadoras } \\
\text { Evaluar programas de } \\
\text { fase y comparar con } \\
\text { lo vivido }\end{array}$} & \multirow{3}{*}{$\begin{array}{l}\text { Producciones gráficas } \\
\text { del primer taller. } \\
\text { Formatos de planes y } \\
\text { programas. }\end{array}$} \\
\hline & & & \\
\hline & & & \\
\hline & & & $\begin{array}{l}\text { Formato para } \\
\text { sistematizar las ideas. } \\
\text { Cámara fotográfica }\end{array}$ \\
\hline
\end{tabular}

La Práctica Profesional como área para potenciar las competencias pedagógicas necesarias para la enseñanza en Educación Infantil 
\begin{tabular}{ll}
\hline (DAE) & $\begin{array}{l}\text { duración, ubicación } \\
\text { dentro del currículo } \\
\text { de formación }\end{array}$
\end{tabular}

Tercer Taller Propuestas de mejora
Elaborar Propuesta de Papel Bond. mejora

Presentación oral y Marcadores.

Cuadro $\mathrm{n}^{\circ} 25-$ Talleres dirigidos a los profesores. Fuente: elaboración propia.

\section{a) 1er Taller:}

Este taller estuvo dirigido a lograr un primer desafío de los profesores con su práctica pedagógica, más específicamente con el ejercicio de pensar analíticamente su desempeño profesional, de manera de poder diseñar un esquema inicial de la misma. En este sentido, la actividad consistió en entregar a cada uno de los profesores asistentes, un papelógrafo, marcadores, una barra de goma y un sobre con tarjetas escritas y en blanco, donde aparecen ciertas afirmaciones sobre la práctica profesional, algunas muy relacionadas con la práctica misma y otras más bien con el ambiente generado en torno a ellas.

Es preciso señalar que, estas afirmaciones, tienen su origen en un trabajo efectuado por Ramiro (2001:11) en el cual realizó talleres denominados practicum reflexivo, así mismo, se agregaron otras aseveraciones producto de la experiencia de la investigadora, acerca de los aspectos importantes de considerar a la hora del desempeño laboral, cuidando que existan tanto afirmaciones relevantes desde el punto de vista pedagógico, como otras no tanto. Del mismo modo, y con el propósito de mantener los criterios científicos de orden, secuencia, consistencia interna, se utilizaron dos de las dimensiones que conforman el cuestionario, las cuales responden a las siguientes siglas: DPA: Dimensión: Procesos de Aprendizaje, DEU: Dimensión Enseñanza Universitaria, las otras dos dimensiones restantes se ejecutaron en el siguiente taller.

234

La Práctica Profesional como área para potenciar las competencias pedagógicas necesarias para la enseñanza en Educación Infantil 


\begin{tabular}{|c|c|c|}
\hline Tarjeta & $\begin{array}{l}\text { Dimensión relacionada } \\
\text { con cuestionario }\end{array}$ & Afirmaciones \\
\hline 1 & \multirow{14}{*}{$\begin{array}{l}\text { Dimensión Enseñanza } \\
\text { Universitaria }\end{array}$} & Alcanzar los objetivos del programa. \\
\hline 2 & & Puntualidad en la entrega de planificaciones y evaluaciones \\
\hline 3 & & Diseño permanente de actividades \\
\hline 4 & & Conexión con el coordinador de la fase \\
\hline 5 & & Presentación personal \\
\hline 6 & & Trabajo integrado con otros colegas \\
\hline 7 & & Cumplimiento de contenidos programados \\
\hline 8 & & Apego al reglamento de la institución \\
\hline 9 & & Puntualidad en la hora de llegada \\
\hline 10 & & Planificación anticipada de actividades \\
\hline 11 & & Preparación de material \\
\hline 12 & & Claridad y dominio de los contenidos entregados \\
\hline 13 & & $\begin{array}{l}\text { Perfeccionamiento continúo acerca de los avances de la } \\
\text { Educación Inicial. }\end{array}$ \\
\hline 14 & & Revisión permanente de bibliografía actualizada \\
\hline 15 & \multirow{9}{*}{$\begin{array}{l}\text { Dimensión Procesos de } \\
\text { Aprendizaje }\end{array}$} & Hacerse respetar \\
\hline 16 & & Buena comunicación con los alumnos \\
\hline 17 & & Claridad en los valores que deseo transmitir \\
\hline 18 & & $\begin{array}{l}\text { Cuestionamiento personal sobre problemáticas vividas en } \\
\text { clase }\end{array}$ \\
\hline 19 & & Ambiente grato \\
\hline 20 & & Buena relación con los alumnos \\
\hline 21 & & Consideración de los intereses de los alumnos \\
\hline 22 & & Consideración de las necesidades de los alumnos \\
\hline 23 & & Reflexión sobre mi desempeño \\
\hline
\end{tabular}

Cuadro ${ }^{\circ}$ 26- Afirmaciones primer taller reflexivo con los profesores. Fuente elaboración propia, a partir de Ramiro 2001.

Con este material, cada profesor debe construir la representación gráfica de su práctica pedagógica, pensando en que es lo más importante que le sirve de sustento y fundamento a su desempeño y que, por lo tanto, debe estar en la base de la misma y de ahí edificar, hacia arriba, la construcción que representa su práctica. En otras palabras, cada tarjeta semejará la base de su construcción, que ayudara a sostener el muro, por lo que, los más importantes, más sólidos deben estar en la base de la construcción. Además de las tarjetas con afirmaciones, se entregaron

235

La Práctica Profesional como área para potenciar las competencias pedagógicas necesarias para la enseñanza en Educación Infantil 
algunas tarjetas en blanco, donde los profesores puedan escribir nuevas afirmaciones, que no hayan sido consideradas y que sean fundamentales para ellos.

Este trabajo será individual y una vez terminado, cada profesor explicara ante el grupo, el por qué de la distribución elegida, es decir su propia realidad pedagógica. Esto también permitirá conocer cuáles son las fundamentaciones o explicaciones que los profesores le asignan a situaciones como: su acción didáctica, implícita en su práctica cotidiana, las afirmaciones que decide para la base de la enseñanza universitaria, entre otras.

Ahora bien, en caso de que algún profesor considere que, algunas afirmaciones no tienen nada que ver con su desempeño, la devolverá como desechable o también puede considerar la posibilidad de integrarlas o agruparlas.

Como orientación para el desarrollo de la actividad es necesario tener en cuenta:

- Comprensión de las instrucciones dadas, si existió alguna dificultad o duda, anotar.

- Tiempo de desarrollo de la actividad. (40 minutos máximo)

- Fotografiar las etapas de la actividad y las representaciones gráficas construidas, por cada uno de ellos.

- Nivel de reflexión en sus exposiciones, conocimiento o confusión de términos o conceptos, fundamentación teórica de apoyo en sus explicaciones.

- Escribir las frases, opiniones, gestos, comportamiento de los asistentes en un diario o cuaderno de notas.

- Que frases fueron desechadas, ¿por qué?

- Que frases fueron agrupadas, ¿por qué?

- Que frases fueron agregadas.

- Principales conclusiones y apreciaciones de los participantes.

En lo referente a los instrumentos, se tienen las notas de campo, las cuales permitieron el registro de la observación de la realidad en la que se llevo a cabo la actividad; al respecto,

La Práctica Profesional como área para potenciar las competencias pedagógicas necesarias para la enseñanza en Educación Infantil 
Martínez (1997:64) recomienda que se deba escribir una descripción detallada de los acontecimientos y la interpretación de estos con base a un marco teórico referencial. En esta investigación las notas de campo constituyeron un instrumento de indagación y evaluación del proceso grupal; así mismo, permitió también la reflexión y el análisis del proceso de formación (praxis del profesorado), la descripción, valoración y explicación de los niveles de significación de la práctica profesional.

Finalmente el otro recurso utilizado fue la cámara fotográfica, valiosa herramienta científica capaz de registrar los más fugaces acontecimientos o dar continuidad a situaciones que se desarrollan a lo largo de días o meses. Éste instrumento constituyo una herramienta de apoyo para registrar cada una de las acciones desarrolladas y tuvo como norte conformar evidencia tangible del trabajo efectuado, por cuanto las fotografías son consideradas herramientas científicas y documentales de primera importancia.

\section{b) Segundo Taller}

A continuación, se presenta el segundo taller, que estuvo dirigido a trabajar con los profesores sobre la base de las reflexiones de los diseños creados durante la primera sesión, por lo tanto tiene como propósito analizar y repensar los aspectos relacionados con la práctica pedagógica, en relación a la realidad que la experiencia contextualizada refiere, acerca de aspectos como: planes de estudio, programas didácticos, rendimiento estudiantil, apoyo institucional (UPEL, centros de aplicación), numero de prácticas, duración, ubicación dentro del currículo de formación, otros.

Lo que se pretende con esta actividad es que los profesores puedan expresar lo que han vivido, al administrar cada una de las prácticas profesionales.

Para ello se les entregó un formato con preguntas generadoras las cuales se redactaron tomando en consideración dos de las dimensiones del cuestionario: Dimensión Didáctica Especifica Educación Inicial (DDEEI) y Dimensión Académico Estudiantil (DAE), con el fin de completar todas las dimensiones ya valoradas en el cuestionario. Luego se les solicitó

La Práctica Profesional como área para potenciar las competencias pedagógicas necesarias para la enseñanza en Educación Infantil 
compartir oralmente sus escritos, para invitarlos a formar grupos, con el fin de que unifiquen criterios semejantes y diferentes. Para la conformación de estos grupos se les sugirió varias propuestas: a) atendiendo al criterio de ordinarios y contratados; b) por fase (observación, ensayo didáctico, integración docencia administración); c) de libre decisión; Las participantes decidieron agruparse con las personas a las cuales conocían con anterioridad.

Al mismo tiempo, se les entrego a los profesores, los planes de las fases, su ubicación dentro del currículo, los formatos para que reflejen su opinión individual y papel bond para las conclusiones grupales, todo ello como material de apoyo para el desarrollo pleno de la actividad planificada.

\begin{tabular}{|l|l|} 
Dimensión Cuestionario & Preguntas generadoras. \\
\hline $\begin{array}{l}\text { Dimensión didáctica } \\
\text { especifica educación inicial } \\
\text { (DDEEI) }\end{array}$ & $\begin{array}{l}\text { ¿Cómo debería ser la enseñanza en Educación Infantil? } \\
\text { ¿Exprese su opinión acerca de la planificación y la evaluación } \\
\text { en E.I? } \\
\text { ¿Qué opinión le merece las habilidades procedimentales de las } \\
\text { estudiantes en el desarrollo de sus PP? }\end{array}$ \\
\hline $\begin{array}{l}\text { Dimensión Académico } \\
\text { Estudiantil (DAE) }\end{array}$ & $\begin{array}{l}\text { ¿Cuál es su opinión acerca de la organización curricular de la } \\
\text { P.P? } \\
\text { ¿Cuál es su opinión acerca de los planes y programas de la } \\
\text { P.P? }\end{array}$ \\
\hline
\end{tabular}

Cuadro ${ }^{\circ} 27$ - Segundo taller, relación dimensiones- preguntas generadoras. Fuente: elaboración propia

c) Tercer Taller

El tercer taller estuvo destinado a formular propuestas que mantuvieran relación con las evaluaciones realizadas en el primer y segundo taller. Con el propósito de elaborar proposiciones que pudieran ser aplicadas a corto, mediano y largo plazo.

La Práctica Profesional como área para potenciar las competencias pedagógicas necesarias para la enseñanza en Educación Infantil 
Entre los indicadores que se presentaron como guías para esta actividad se tiene:

- Número de prácticas profesionales para Educación Inicial

- Duración de cada una de ellas

- Centros de aplicación: acuerdos, convenios, normas

- Competencias de entrada para cada fase

- Competencias de salida en cada fase.

Para la realización de esta actividad se tomo como requisito, que haya transcurrido una semana luego del segundo taller, con el fin de que los profesores tengan la oportunidad de reflexionar. La metodología utilizada fue parecida a la del segundo taller, donde los asistentes trabajaron individualmente y luego en pequeños grupos, para finalmente llegar a consenso en grupo grande.

\subsection{Descripción de los Talleres Dirigidos a los Alumnos:}

a) 1er Taller

Esta parte del estudio se estructuró de la misma manera que la realizada con los profesores. Para ello se invitaron a participar a quince (15) estudiantes del programa de Educación Preescolar, de las cuales solo participaron diez (10). Los patrones asumidos para invitarlos fueron los siguientes: a) haber cursado todas sus Prácticas Profesionales, b) haber participado como informantes en la aplicación del cuestionario; c) disposición y tiempo para participar en los tres talleres. Estos estudiantes fueron informados de esta actividad el mismo día en que se les aplico el cuestionario, en donde se les indico que los interesados se dirigieran a la coordinación de Práctica Profesional, para tomar sus datos y elaborar por escrito su invitación formal. En relación con el criterio de selección de participantes, se determino siguiendo las sugerencias de Buendía, Colás y Hernández (1995: 254), en la que recomiendan que debe ser mayor de cinco (05) y menos de quince (15) y además mantener mínimos de homogeneidad y mínimo de heterogeneidad entre los participantes, para mantener la simetría de la relación de los componentes del grupo y asegurar la diferencia necesaria en todo proceso del habla respectivamente. 
En el primer taller se realizo una dinámica tipo lluvia de ideas, en la que se les solicito a los estudiantes que expresaran su opinión sobre la formación recibida en la UPEL. Específicamente se les pregunto sobre las estrategias didácticas utilizadas en la práctica profesional, los conocimientos previamente adquiridos en planificación, evaluación, estrategias y recursos y su utilidad en la realización de sus prácticas; Al igual que en los talleres de los profesores, se utilizo como criterio de análisis dos dimensiones del cuestionario: dimensión procesos de aprendizaje (DPA), y dimensión enseñanza universitaria (DEU). Para ello se les presento una introducción al tema, utilizando presentaciones power point; al final se les plantea tres preguntas generadoras. Los estudiantes debían responder de manera individual por escrito en sus cuadernos y luego hacer pública sus respuestas, usando la estrategia de representación gráfica.

\section{b) Segundo Taller:}

Luego de una semana, se realizó el segundo encuentro con los alumnos, para ello se les invitó que publicaran sus producciones del encuentro anterior. Luego, se les solicitó que en parejas revisaran los programas de: FO, FED, FEPE y FIDA, con el fin de que realicen comparaciones con lo vivido. Al igual que en el segundo taller de los profesores, en éste encuentro se busco confrontar las dos dimensiones restantes: dimensión didáctica especifica educación inicial (DDEEI) y dimensión académico estudiantil (DAE), en aspectos: planes de estudio, programas didácticos, rendimiento estudiantil, apoyo institucional (UPEL, centros de aplicación), número de prácticas, duración, ubicación dentro del currículo de formación, entre otros. La metodología de trabajo fue la expresión oral y escrita de sus ideas, juicios y opinión, el instrumento de recogida de datos fue el reporte escrito, llevado a cabo por una estudiante auxiliar que pertenece al Centro de Investigación en Educación Infantil (CIEDIN), la cual fue preparada para llevar a cabo esta tarea . 


\section{c) Tercer Taller:}

Del mismo modo y como parte de la dinámica planificada se realizó el tercer encuentro; en esta oportunidad, se les planteo el reto de presentar propuestas de mejora, sobre la base de toda la evaluación realizada en los talleres anteriores. Esta producción fue elaborada en forma general, es decir todas participaron, con el fin de promover la discusión y reflexión.

\begin{tabular}{|c|c|c|c|}
\hline Taller/ dimensiones & Contenido & Actividad & Recursos \\
\hline $\begin{array}{l}\text { Primer Taller } \\
\text { DEU } \\
\text { DPA }\end{array}$ & $\begin{array}{l}\text { Formación recibida en } \\
\text { práctica profesional } \\
\text { UPEL, } \\
\text { específicamente las } \\
\text { estrategias didácticas } \\
\text { y su utilidad en la } \\
\text { realización de sus } \\
\text { practicas }\end{array}$ & $\begin{array}{l}\text { Charla introductoria } \\
\text { Producción escrita } \\
\text { Valorar las } \\
\text { estrategias didácticas } \\
\text { y su utilidad en la } \\
\text { realización de sus } \\
\text { practicas }\end{array}$ & $\begin{array}{l}\text { Preguntas generadoras } \\
\text { Laptop. } \\
\text { Video beam. } \\
\text { Papel bond. } \\
\text { Marcadores. } \\
\text { Cámara fotográfica }\end{array}$ \\
\hline $\begin{array}{l}\text { Segundo Taller } \\
\text { DDEEI } \\
\text { DAE }\end{array}$ & $\begin{array}{l}\text { Revisión y análisis de } \\
\text { los planes de estudio, } \\
\text { programas didácticos, } \\
\text { rendimiento } \\
\text { estudiantil, apoyo } \\
\text { institucional (UPEL, } \\
\text { centros de aplicación), } \\
\text { numero de prácticas, } \\
\text { duración, ubicación } \\
\text { dentro del currículo } \\
\text { de formación }\end{array}$ & $\begin{array}{l}\text { Evaluar programas de } \\
\text { fase y comparar con } \\
\text { lo vivido }\end{array}$ & $\begin{array}{l}\text { Producciones gráficas } \\
\text { del primer taller. } \\
\text { Formatos de planes y } \\
\text { programas. } \\
\text { Formato para } \\
\text { sistematizar las ideas. } \\
\text { Cámara fotográfica }\end{array}$ \\
\hline Tercer Taller & Propuestas de mejora & $\begin{array}{l}\text { Elaborar Propuesta de } \\
\text { mejora } \\
\text { Presentación oral y } \\
\text { escrita }\end{array}$ & $\begin{array}{l}\text { Papel Bond. } \\
\text { Cámara Fotográfica } \\
\text { Marcadores. } \\
\text { Tirro }\end{array}$ \\
\hline
\end{tabular}

Cuadro $\mathrm{n}^{\circ} 28$ - Resumen talleres reflexivos con los estudiantes. Fuente: elaboración propia. 


\subsection{Población y Muestra}

El contexto de esta investigación es el pedagógico de Maracay, ubicado en la ciudad del mismo nombre en el estado Aragua. Este Instituto fue creado el 11 de Noviembre de 1971, luego, el 13 de Julio de 1973, recibe el nombre de Instituto Pedagógico Experimental "Rafael Alberto Escobar Lara".

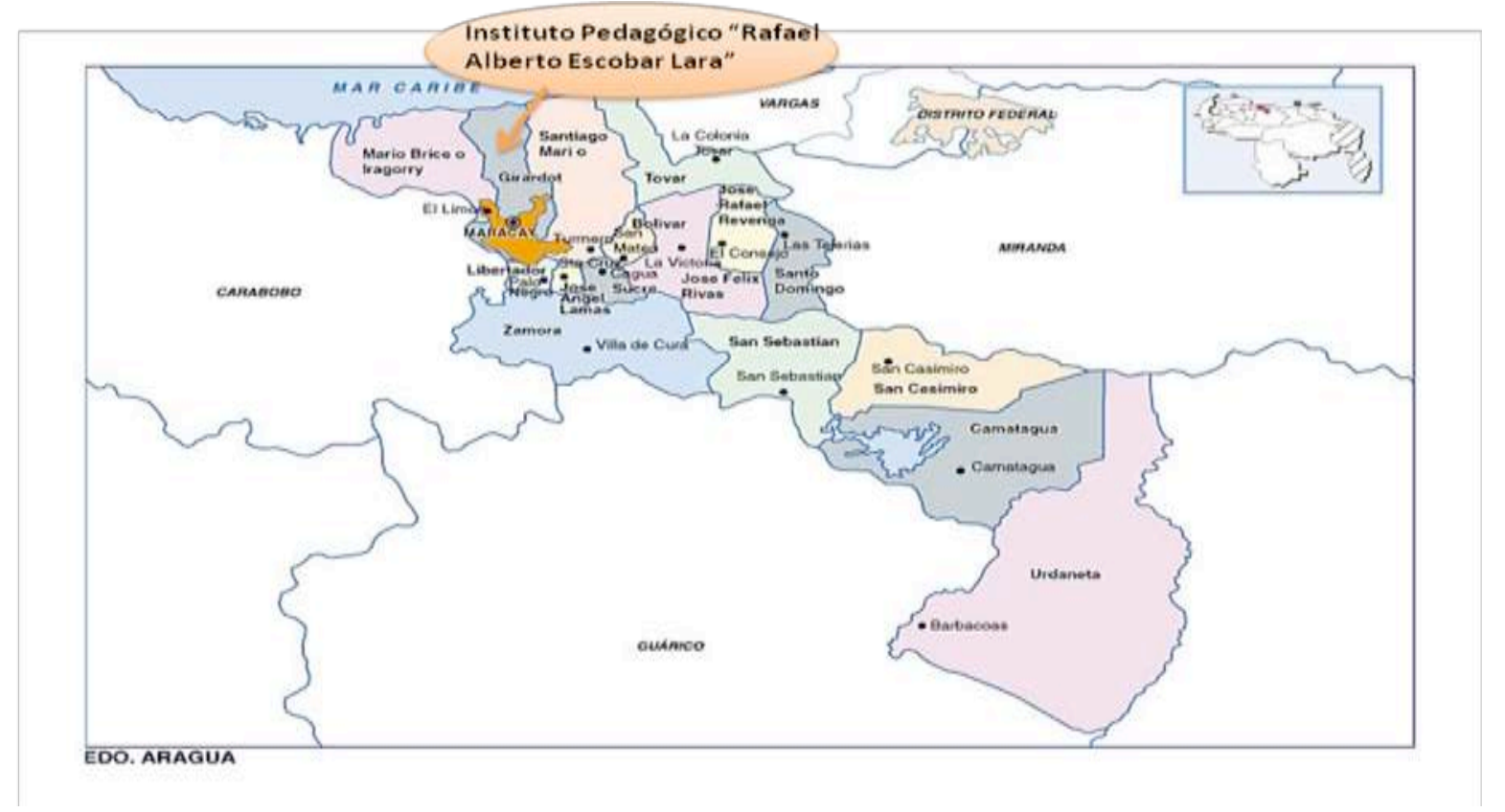

Grafico ${ }^{\circ} 8$ - Mapa geográfico ubicación UPEL IPMAR.

Desde el punto de vista académico este instituto tiene una estructura organizativa conformada por la dirección del instituto, las subdirecciones de Docencia, Extensión, Investigación y Postgrado y la Secretaría. De la subdirección de docencia, dependen los departamentos, específicamente el departamento de componente docente, donde está ubicada el área de práctica profesional. De un modo más detallado, podemos presentar la organización en la que se ubica nuestra inquietud investigativa. 


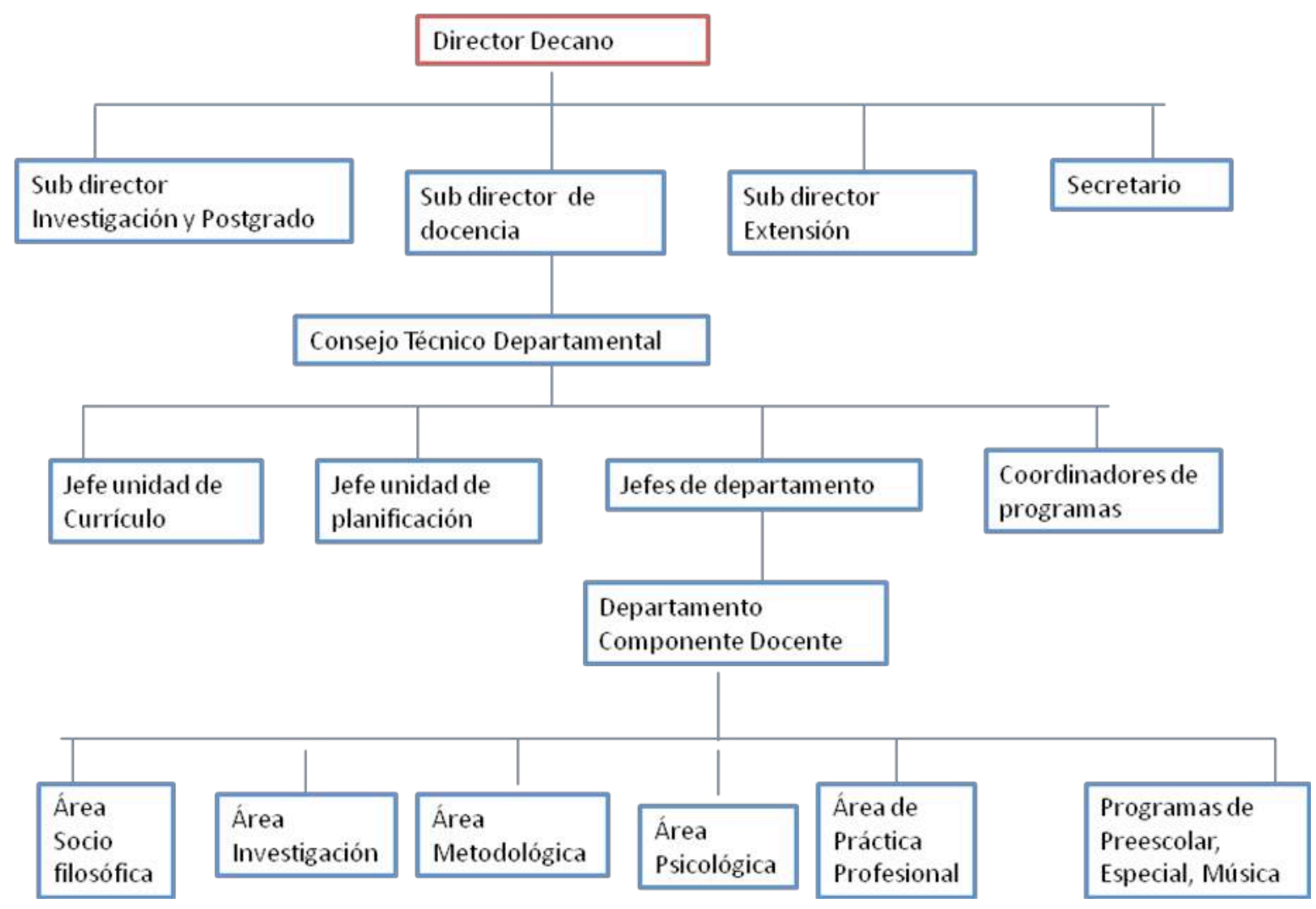

Grafico nº 9- Estructura Organizativa UPEL-IPMAR. Fuente UPEL 1996

En lo que respecta a la decisión de seleccionar la población y la muestra, con quienes se llevó a cabo éste estudio, puede afirmarse que se constituyo como una acción relevante para el investigador. Para ello se hizo necesario concretar el ámbito de cada una de las fases de esta investigación, con el fin de definir en cada caso, la población y muestra específica a ser estudiada.

En cuanto a los profesores podemos señalar algunos aspectos característicos: En la UPEL, se distinguen a los profesores en torno a su condición de ordinario y contratado. Los profesores contratados ejercen sus funciones en tiempo convencional o medio tiempo. Los profesores ordinarios ejercen sus funciones de acuerdo a la condición y categoría académica que posea, lo cual está determinado en el reglamento para el personal docente de la UPEL

La Práctica Profesional como área para potenciar las competencias pedagógicas necesarias para la enseñanza en Educación Infantil 
De acuerdo con el citado reglamento existen cinco escalafones: instructor, asistente, agregado, asociado y titular; en cuanto al tiempo de dedicación: tiempo convencional, medio tiempo, dedicación exclusiva. El área de Práctica Profesional, cuenta actualmente con seis (06) profesores ordinarios que han concursado para ejercer sus funciones en la especialidad de Educación Preescolar. El resto de los profesores son contratados. La contratación en cada semestre varía de acuerdo con la oferta académica. A titulo ilustrativo, puede representarse de la siguiente manera:

\begin{tabular}{|l|l|l|l|l|}
\hline Profesores & Medio tiempo & $\begin{array}{l}\text { Tiempo } \\
\text { completo }\end{array}$ & $\begin{array}{l}\text { Dedicación } \\
\text { exclusiva }\end{array}$ & Total \\
\hline Ordinario & 02 & 03 & 01 & 06 \\
\hline Contratado & 12 & - & - & 12 \\
\hline Total & 14 & 03 & 01 & 18 \\
\hline
\end{tabular}

Cuadro n 29-Tiempo de dedicación profesores práctica profesional. Fuente UPEL 1996.

Según la condición laboral del total de 18 profesores, tenemos que un 33\% está representado por los profesores ordinarios y un $67 \%$ por los contratados.

Con respecto al escalafón los profesores están distribuidos de la siguiente manera:

\begin{tabular}{|l|l|l|l|l|}
\hline Profesores & Instructor & Asistentes & Agregados & Total \\
\hline Ordinarios & - & 05 & 01 & 06 \\
\hline Contratados & 12 & - & - & 12 \\
\hline Total & 12 & 05 & 01 & 18 \\
\hline
\end{tabular}

Cuadro ${ }^{\circ}$ 30. Escalafón docente. Fuente UPEL 1996.

Según el cuadro anterior, se tiene que: 12 profesores en la categoría de instructor representan un $67 \%, 5$ profesores en la categoría de asistente equivalen a $28 \%$ y 01 en la categoría de agregado representa un 5\%. 
En relación con los estudiantes del Programa de Educación Preescolar, puede afirmarse que, un 99, $9 \%$ está representado por mujeres y solo un 1\% está representado por hombres; de acuerdo con las requisitos de ingreso, cada aspirante a cursar la especialidad de Educación Preescolar, debe cumplir con los siguientes requisitos de ingreso, de acuerdo con el reglamento especial de admisión de la UPEL : Poseer título de bachiller, resultado de la prueba de aptitud académica del Consejo Nacional de Universidades (CNU), los requisitos de salud física y mental que se establecen para el ejercicio de la profesión docente y las cuotas de ingreso que determinen los consejos directivos de cada instituto.

Atendiendo a lo anteriormente expuesto, en este punto podemos presentar la conceptualización de la población de una investigación "es el conjunto de unidades de las que se desea obtener información y sobre las que se van a generar conclusiones" (Palella y Martins, 2004:93); Por su parte, Hernández , Fernández y Baptista (1991:210) la consideran como el conjunto de todos los casos que concuerdan con una serie de especificaciones, por lo que, la población objeto de estudio está formada por los siguientes grupos de individuos:

- Total de estudiantes de la carrera de Educación Preescolar que estuvieran cursando la fase de integración docencia administración (última fase de Práctica Profesional), en el semestre 2010-II (72 en total).

- Total profesores (ordinarios y contratados) que estuvieran administrando, cualquiera de las cuatro fases que componen la práctica profesional en Educación Preescolar (12 en total).

Con respecto a la selección de la muestra, los autores consultados asumen diversas posturas, en este sentido, Buendía, Colás y Hernández, la consideran como "un conjunto de individuos extraído de la población, a partir de un procedimiento especifico" (1995:28); Así mismo, Hernández Fernández y Baptista (1991:212) afirman que la muestra es en esencia un sub grupo de la población, pero además, agregan que el uso de la palabra "representativa", resulta inútil, ya 
que todas las muestras deben ser representativas. Así mismo estos autores, recomiendan que se categorice a las muestras en dos grandes ramas: las muestras probabilísticas y las muestras no probabilísticas; por tanto, en este estudio, se opto por las técnicas de muestreo no probabilístico, denominada también muestras dirigidas, que consiste en seleccionar la muestra de forma deliberada porque los sujetos poseen las características necesarias para la investigación; en este tipo de muestreo el procedimiento depende del proceso de toma de decisiones de una persona o grupo de personas. (ob. Cit.), aunque algunos autores proponen diferentes criterios para la selección de la muestra, optamos por esta modalidad dada la dificultad para contactar una buena parte de la población.

Como consecuencia, la selección de los sujetos participantes para la primera fase de este estudio, es decir la aplicación de cuestionarios, quedó constituida de la siguiente manera: se contacto a todos los profesores que estuvieran administrando práctica profesional en Educación Preescolar durante el semestre 2010-II, de los cuales se logró ubicar a 6 profesores junto a sus estudiantes (54 en total); Éste resultado se desprende de la imposibilidad de ubicar a los profesores contratados, ya que asisten solo el tiempo necesario y a la inasistencia de algunas estudiantes. Más adelante se puede apreciar la constitución de la muestra para la aplicación del cuestionario.

Con respecto a la segunda fase de la investigación, referida a los talleres reflexivos, se consideraron las recomendaciones de los autores expertos en la materia y se decidió de manera intencional la constitución de los informantes claves. De este modo, se invitaron a participar a un grupo de 15 profesores y 15 estudiantes, los cuales tenían que cumplir con los mismos requisitos usados para la aplicación del cuestionario.

La conformación definitiva de los talleres reflexivos resultó con 09 profesores y 10 estudiantes. 
7.6.1. Selección de la Muestra No Probabilística Intencional.

\begin{tabular}{|l|l|l|l|}
\hline Sujetos & Población & \multicolumn{2}{|c|}{ Muestra } \\
\cline { 3 - 4 } & & $N^{\circ}$ & $\%$ \\
\hline Profesores & 12 & 06 & $50 \%$ \\
\hline Estudiantes & 72 & 54 & $80 \%$ \\
\hline
\end{tabular}

Cuadro $n^{\circ} 31$ - Sujetos primera fase investigación

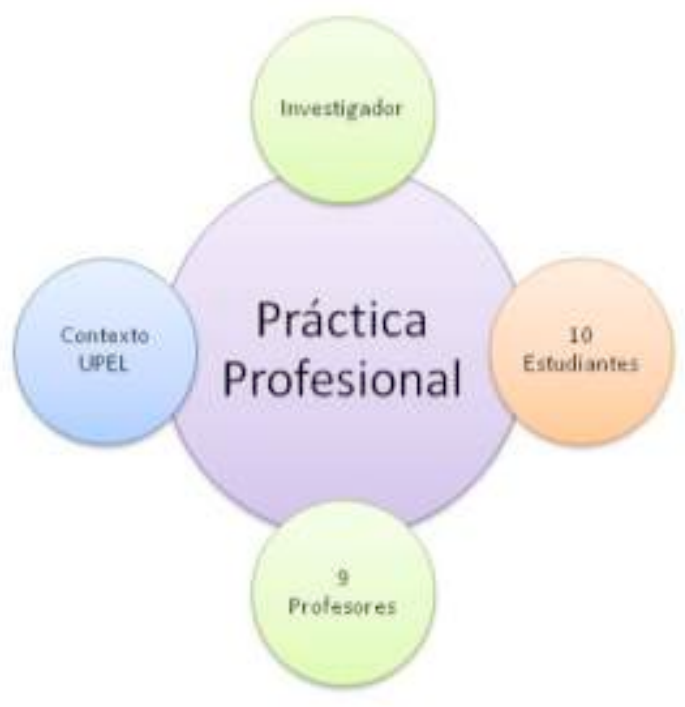

Grafico $\mathrm{n}^{\circ} 10$. Informantes segunda fase investigación 


\section{Capítulo 8. Análisis de los Resultados.}

Descripción del análisis de las fases de la investigación.

$>$ Resultados cuestionario aplicado a los alumnos.

$>$ Resultado cuestionario aplicado a los profesores.

$>$ Conclusiones del análisis de los cuestionarios.

$>$ Análisis documental planes oficiales de práctica profesional educación preescolar

$>$ Conclusiones análisis programas práctica profesional

$>$ Análisis de los talleres reflexivos

$>$ Taller reflexivo realizado con los profesores

$>$ Taller reflexivo realizado con los alumnos

$>$ Conclusiones generales de los talleres reflexivos con los alumnos y profesores

> Triangulación de los resultados

$>$ Limitaciones de la investigación

$>$ Conclusiones y propuesta

$>$ Lineamientos para la propuesta del plan de mejora

$>$ Consideraciones finales

$>$ Nuevas líneas de investigación sugeridas por los hallazgos 


\section{CAPITULO 8. ANÁLISIS DE LOS RESULTADOS}

\section{1.- Introducción.}

Una de las etapas sobresalientes del proceso investigativo, está en analizar e interpretar los resultados obtenidos. El análisis consiste en separar un conocimiento o un objeto de las partes que lo estructuran; es decir, hallar los principios y las relaciones, las dependencias que existen en un todo. (Rodríguez, 2001:80). Este autor, distingue los procesos básicos del pensamiento que conducen al análisis y la síntesis correspondiente, al respecto se presenta el grafico 12.

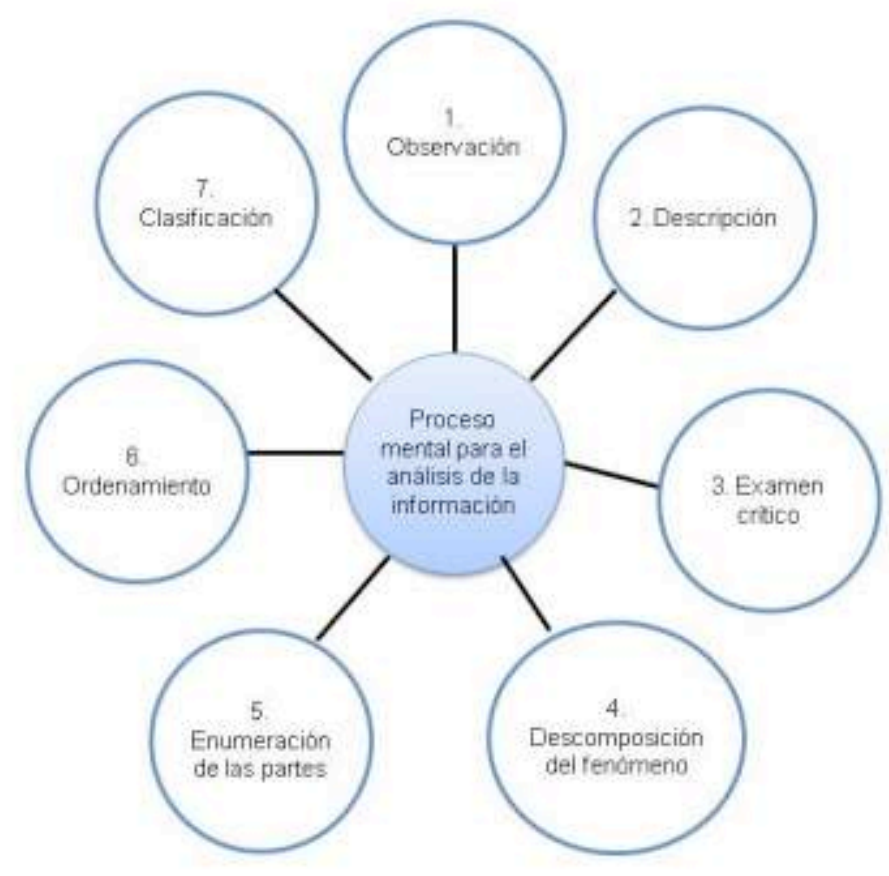

Grafico $\mathrm{n}^{\circ}$ 11. Procesos del pensamiento que participan en el análisis de la información (Rodríguez, 2001:80)

La Práctica Profesional como área para potenciar las competencias pedagógicas necesarias para la enseñanza en Educación Infantil 
De tal manera que, en el proceso de análisis es necesario reestructurar un todo en forma concentrada, a través de un proceso continuo y sistemático. Siguiendo con este orden de ideas, en esta fase de la investigación se explica el uso de las estrategias de análisis utilizadas, con el fin de aportar soluciones a la situación que por una parte, presentan los estudiantes de Educación Preescolar, en la UPEL- Maracay, como lo son sus competencias pedagógicas al abordar la práctica profesional, y por otra parte, la opinión y propuesta de los profesores de práctica profesional responsables de la formación de estos estudiantes, todo esto con el fin de impulsar y mejorar los procesos formativos en esta área, lo cual va a permitir la elaboración de un diseño de programa de práctica profesional que va a incidir en el proceso de enseñanza- aprendizaje universitario y en el futuro desempeño profesional de los estudiantes.

Sustentado en las afirmaciones anteriores, se procede a explicar el proceso de análisis tomando en cuenta que este estudio se realizo en dos fases y dentro de cada una se emplearon varias técnicas e instrumentos para recolectar la información, por lo tanto se realizará el análisis e interpretación de resultado por separado. No obstante y de acuerdo con lo planteado por Palella y Martins, al interpretar los resultados es necesario tener en cuenta que se debe ofrecer una discusión para cada uno de los objetivos y/o hipótesis planteados (2004:171), además recomiendan que para facilitar la discusión de los resultados se utilice la triangulación, la cual según Martínez (1997:199) consiste en determinar ciertas intersecciones o coincidencias a partir de varios puntos de vista del mismo fenómeno. En la lectura a estos autores se encontró que se pueden realizar varias triangulaciones, combinando diversas maneras, técnicas y procedimientos cualitativos y cuantitativos. En el caso de esta investigación, se contrasto la información obtenida en el trabajo de campo (cuestionario, talleres reflexivos), la posición teórica y la posición del investigador; en función de las dimensiones del estudio.

En cuanto al procesamiento y análisis de los datos cuantitativos provenientes de la primera fase, a través del cuestionario, se realizo en un ordenador personal mediante el programa de 
análisis estadístico SPSS. Se efectuó análisis descriptivo de las opiniones, diferencias en las medias, medianas, máximos y mínimos.

Para el análisis de los datos cualitativos, utilizamos el procedimiento de categorización y codificación propuesto por Martínez (1997) el cual consiste en examinar los datos para identificar determinados componentes temáticos que nos permitan clasificarlos en una u otra categoría de contenido. Según Dilthey citado por Martínez, se pueden establecer tres condiciones para emprender mejor el significado que tienen las expresiones de la vida de otras personas, sentido solo en forma implícita y luego se va haciendo explicito con la aparición de signos verbales en nuestra conciencia:

- Es necesario familiarizarse con los procesos mentales mediante los cuales se vive y se expresa el significado; esto constituye la vida cotidiana de todo ser humano, pero el investigador debe ser más riguroso, sistemático y critico de ello. En cada revisión del material disponible es útil ir haciendo las anotaciones, para valorar las expresiones más significativas y que tienen mayor poder descriptivo, elaborando esquemas de interpretación posibles, diseñando y rediseñando los conceptos de manera constante.

- Se necesita un conocimiento particular del contexto concreto en que tiene lugar una expresión: una palabra se entiende en el contexto de una frase, una acción humana en el contexto de una situación.

- Es necesario conocer también los sistemas sociales y culturales que proveen el significado de la mayoría de las expresiones de la vida: para comprender una frase hay que conocer la lengua; para comprender el comportamiento de una persona hay que conocer su formación, medio cultural, entre otros.

Una buena categorización debe ser tal que exprese y precise con propiedades adecuadas lo más valioso y rico de los contenidos protocolares, de tal manera que facilite el proceso. 


\subsection{Descripción del Análisis de las Fases de la Investigación}

\subsubsection{Descripción de la Fase I.}

En el apartado anterior se explico sobre la organización de este estudio. Al respecto, en este punto vamos a presentar el análisis producto de la aplicación del cuestionario, tanto a profesores del área de práctica profesional, como a los estudiantes cursantes de la última fase de esta área. En este sentido, los resultados del cuestionario están representados en forma numérica, es decir, son datos cuantitativos. El objetivo de este análisis no es reducir la información a valores numéricos, sino presentar dichos datos lo más exhaustivo posible.

La información obtenida en esta fase, está representada en una escala que indica la cantidad presente de la variable medida, por lo que en primer lugar se efectúa análisis de estadística descriptiva, para cada una de las variables y luego se describe la relación entre éstas (Hernández y col. 1991:350).

Por tanto, el análisis de los datos se efectuó sobre la matriz de datos, utilizando un programa de computadora denominado SPSS, el cual ayudo a organizar los resultados con las medidas de tendencia central.

\subsection{1.- Cuestionario aplicado a los alumnos.}

\subsubsection{Introducción.}

Como se ha señalado en el objetivo de esta fase, se pretende analizar la valoración sobre la práctica profesional del programa de Educación Preescolar de la UPEL - IPMAR, desde el punto de vista de profesores y alumnos. Para lograrlo se realizó un proceso de consulta tanto a profesores como estudiantes de la especialidad de Educación Preescolar de la UPEL de Maracay.

En esta parte, vamos a explicar los resultados de las opiniones de los estudiantes, acerca de la práctica profesional, la modalidad de consulta que se utilizó es el cuestionario, con una escala que

La Práctica Profesional como área para potenciar las competencias pedagógicas necesarias para la enseñanza en Educación Infantil 
va de 1 a 4, en donde uno (1) es la mínima valoración y cuatro (4) es la máxima, según la importancia que los sujetos le asignen; en cuanto al tipo de análisis se utilizó el programa SPSS.

\subsubsection{Resultados Cuestionario Aplicado a los Alumnos.}

\subsection{Análisis de los Datos Socio- Académicos de los Alumnos.}

En la primera parte del instrumento, se considero importante realizar algunas preguntas que nos permitiera conocer un poco más acerca de la realidad social personal y académica de los informantes. Para ello se les plantearon las siguientes cuestiones: a) edad, b) sexo, c) estado civil, d) tiempo en semestres en la universidad, e) número de asignaturas aprobadas, f) número de eventos académicos a los que ha asistido, g) tiempo dedicado al estudio (fuera de clases), h) actividades de formación complementarias.

Con estos datos se presenta cada uno de las respuestas, en la representación del cuadro, luego el gráfico de barra y también el cuadro resumen, que permite ver de manera global, las características más resaltantes de los alumnos que participaron en la aplicación del cuestionario

\section{Edad.-}

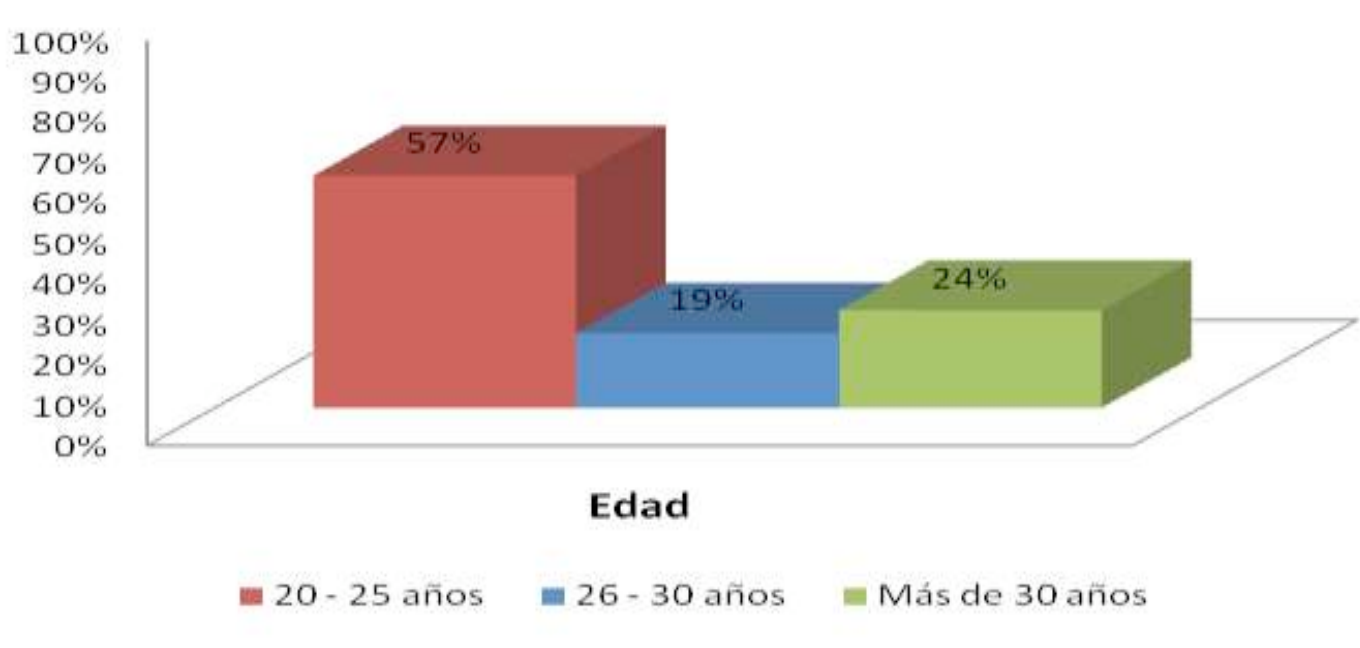

Grafico $n^{\circ} 12$. Distribución de los alumnos por edad. 
31 alumnos están en el rango de 20 a 25 años (57,4\%), Considerando que están cursando la última fase, podemos apreciar que más de la mitad de los alumnos egresan de la universidad en un rango de edad de 25 años.

Sexo.-

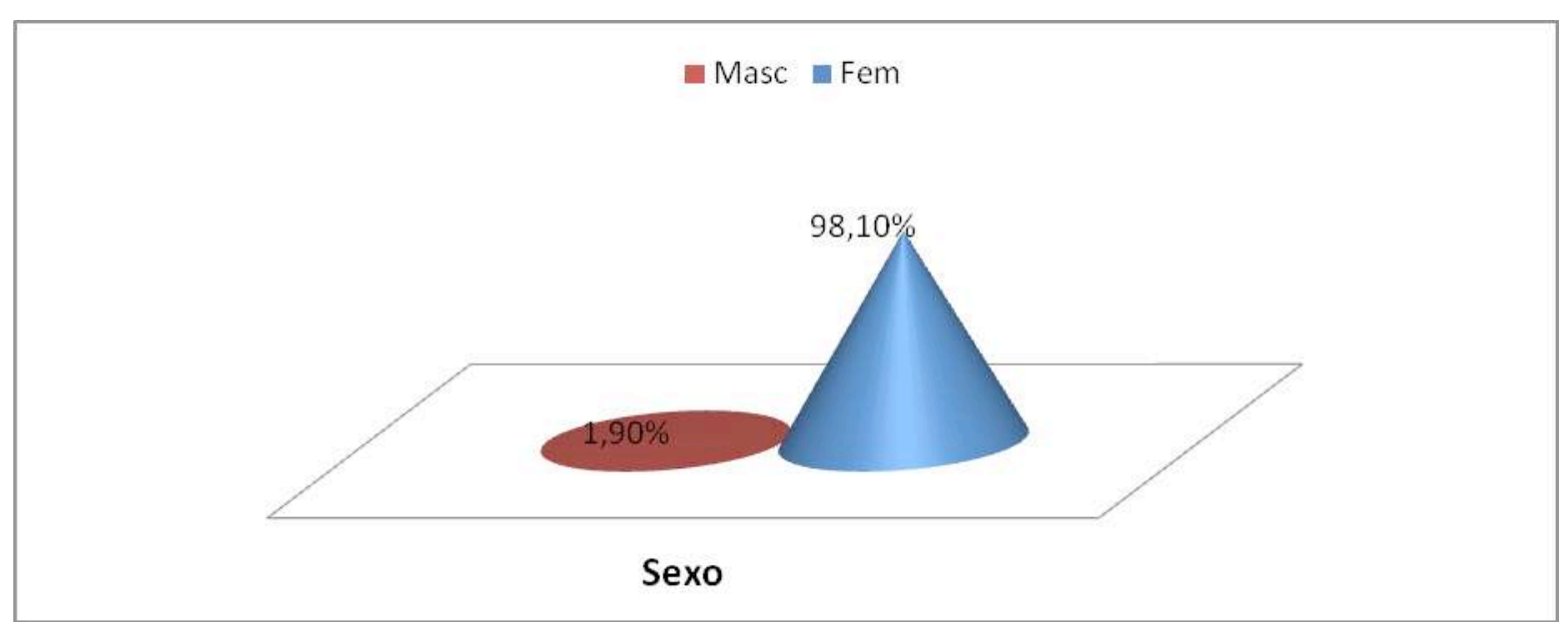

Grafico $n^{\circ} 13$. Distribución de los alumnos por sexo.

En esta información, se encontró que, de los alumnos de Educación Preescolar, existe un solo alumno de sexo masculino, el resto es del sexo contrario. Esta cifra es un indicador importante de que, en educación la mayor cantidad de estudiantes es de sexo femenino y más aun en Educación Preescolar. 
Estado civil.

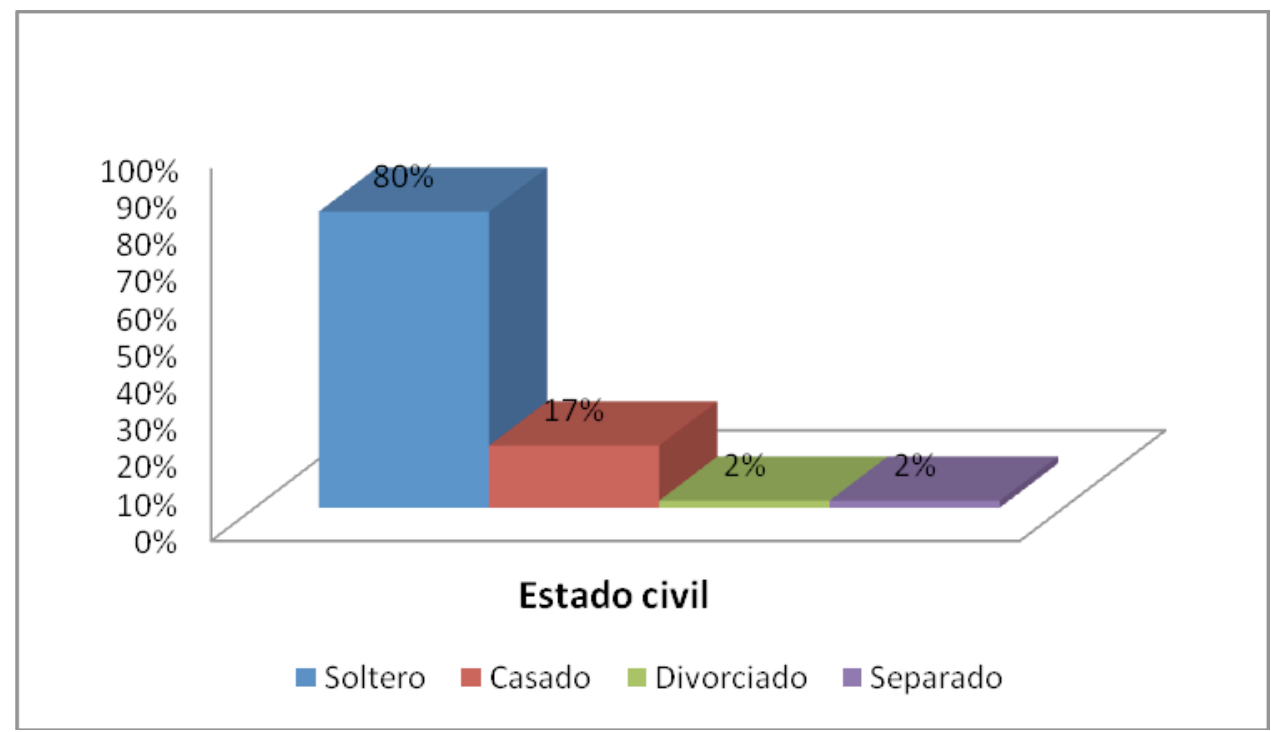

Grafico $\mathrm{n}^{\circ}$ 14. Distribución de los alumnos por estado civil

43 alumnos están solteros (79,6\%). 9 están casados (16,7\%). 1 divorciado y 1 separado. Este aspecto es bien valioso, ya que la mayoría de los alumnos están jóvenes y solteros, lo cual permite afirmar que tienen mayores posibilidades de dedicarse a sus estudios. 
Tiempo en semestres en la universidad.

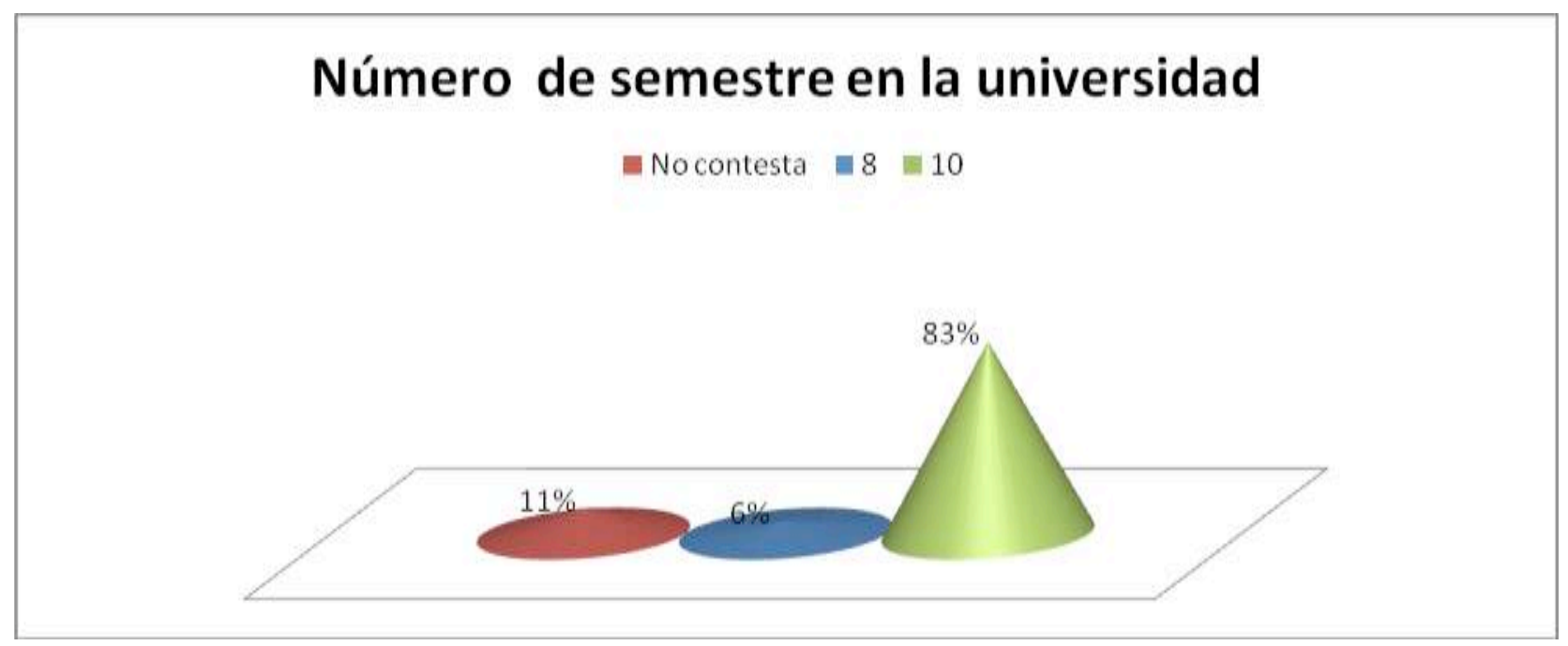

Grafico $n^{\circ} 15$. Distribución de los alumnos por número de semestres cursados en la universidad.

45 alumnos (83,3\%), están cursando su 10mo semestre. 3 alumnos están el 8vo semestre y 6 no contestan. En este aspecto tenemos que la mayoría de los alumnos, están efectivamente en el último semestre de su carrera, para sorpresa observamos que un $3(6 \%)$ afirman estar en el 8 semestre, lo cual nos da un dato importante acerca de las prelaciones para cursar la última fase del componente de práctica profesional, en donde resulta apremiante que los alumnos hayan aprobado y posean suficientes conocimientos para asumir esta exigente práctica; así mismo, se observa que 6 alumnos, no responde a la pregunta, lo cual pudiera pensarse que no están seguros acerca del número de semestres en la universidad o tienen temor a responder. 
Número de Asignaturas Aprobadas.

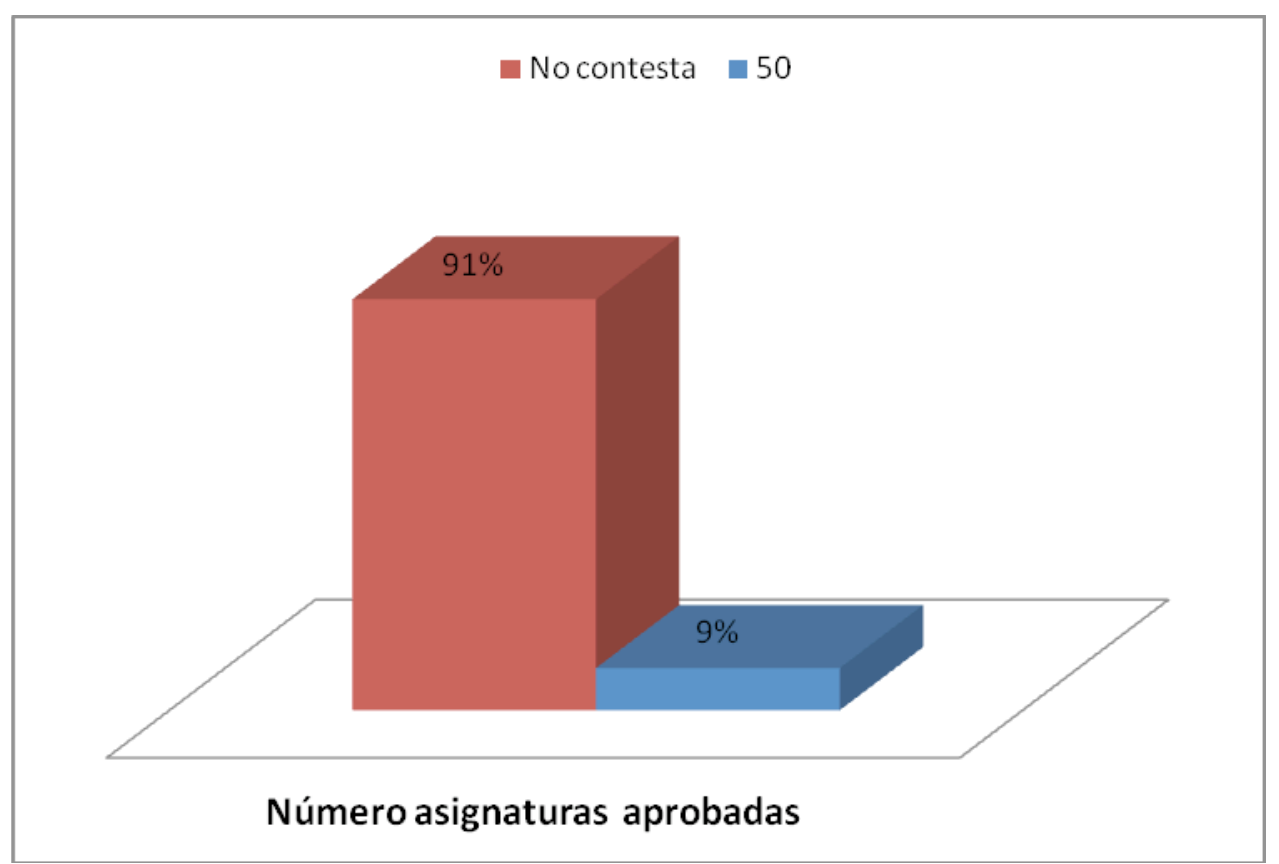

Grafico $\mathrm{n}^{\circ}$ 16. Distribución de los alumnos por número de asignaturas aprobadas.

5 alumnos (9,3\%), responden que tienen 50 asignaturas aprobadas, el resto $(90,7 \%)$ no contesta. Este aspecto resulta interesante, ya que sorprendentemente los alumnos en su gran mayoría (90,7\%), desconocen cuantas asignaturas tienen aprobadas, solo cinco estudiantes, están pendientes de sus avances y control académico 


\section{Asistencia a Eventos Académicos.}

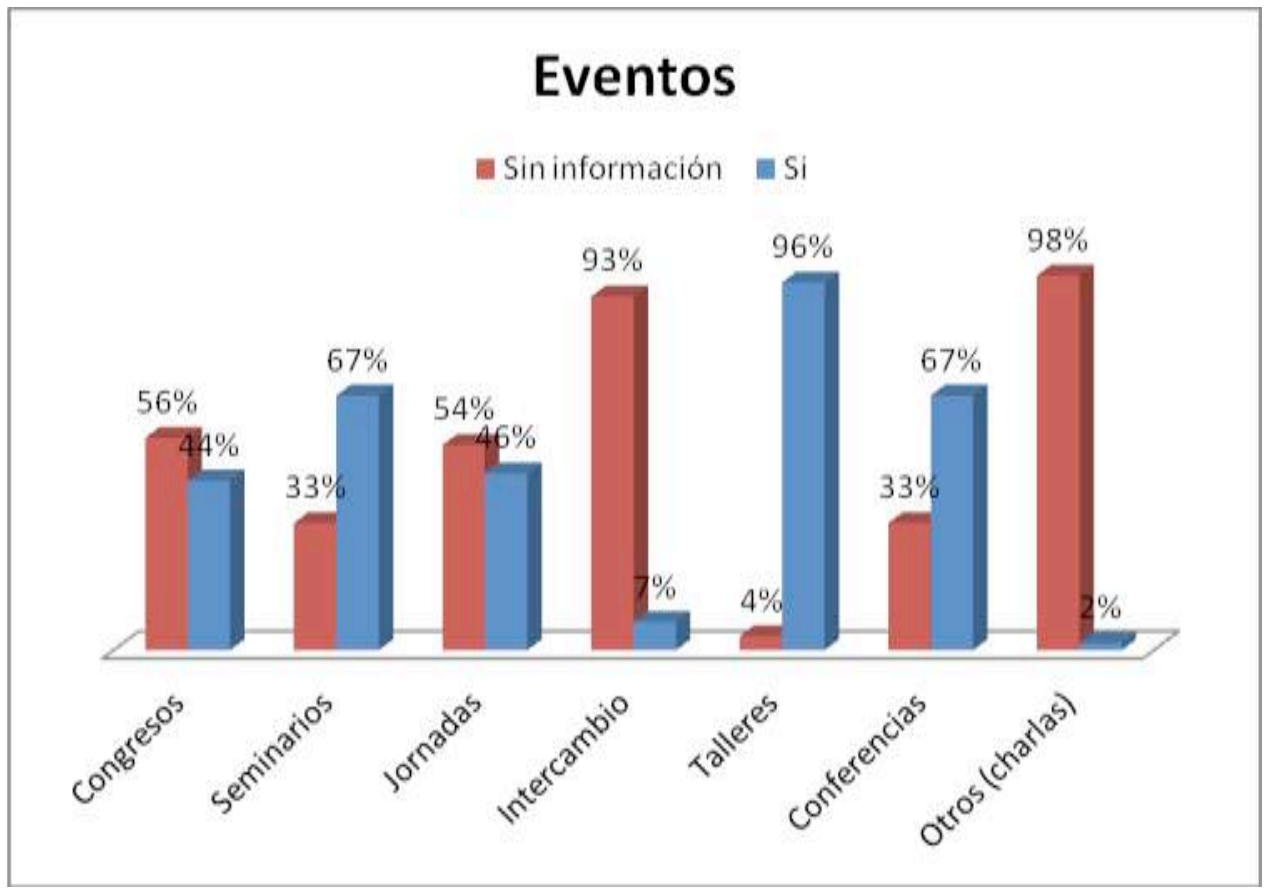

Grafico $\mathrm{n}^{\circ}$ 17. Distribución de los alumnos por asistencia a eventos.

- Congresos: 24 alumnos (44,4\%) responden afirmativamente. El resto no responde.

- Jornadas: 25 alumnos (46,3\%) responden haber asistido, el resto no responde.

- Seminarios: 36 alumnos $(66,7 \%)$, han asistido a seminarios. El resto no.

- Talleres: 52 alumnos responden que si han asistido a talleres, esto equivale a un 96, $3 \%$ del total.

- Conferencias: 36 alumnos (66,7\%) afirman haber asistido, el resto no.

Se puede apreciar que los alumnos, tienen un record modesto en cuanto a su procesos de formación permanente o complementario con su formación en la UPEL, se observa mayor participación en asistencia a talleres, conferencias, y seminarios, en el resto de los eventos que se 258

La Práctica Profesional como área para potenciar las competencias pedagógicas necesarias para la enseñanza en Educación Infantil 
le consultan se observa un número bastante bajo, en asistencia.

\section{Tiempo Dedicado al Estudio}

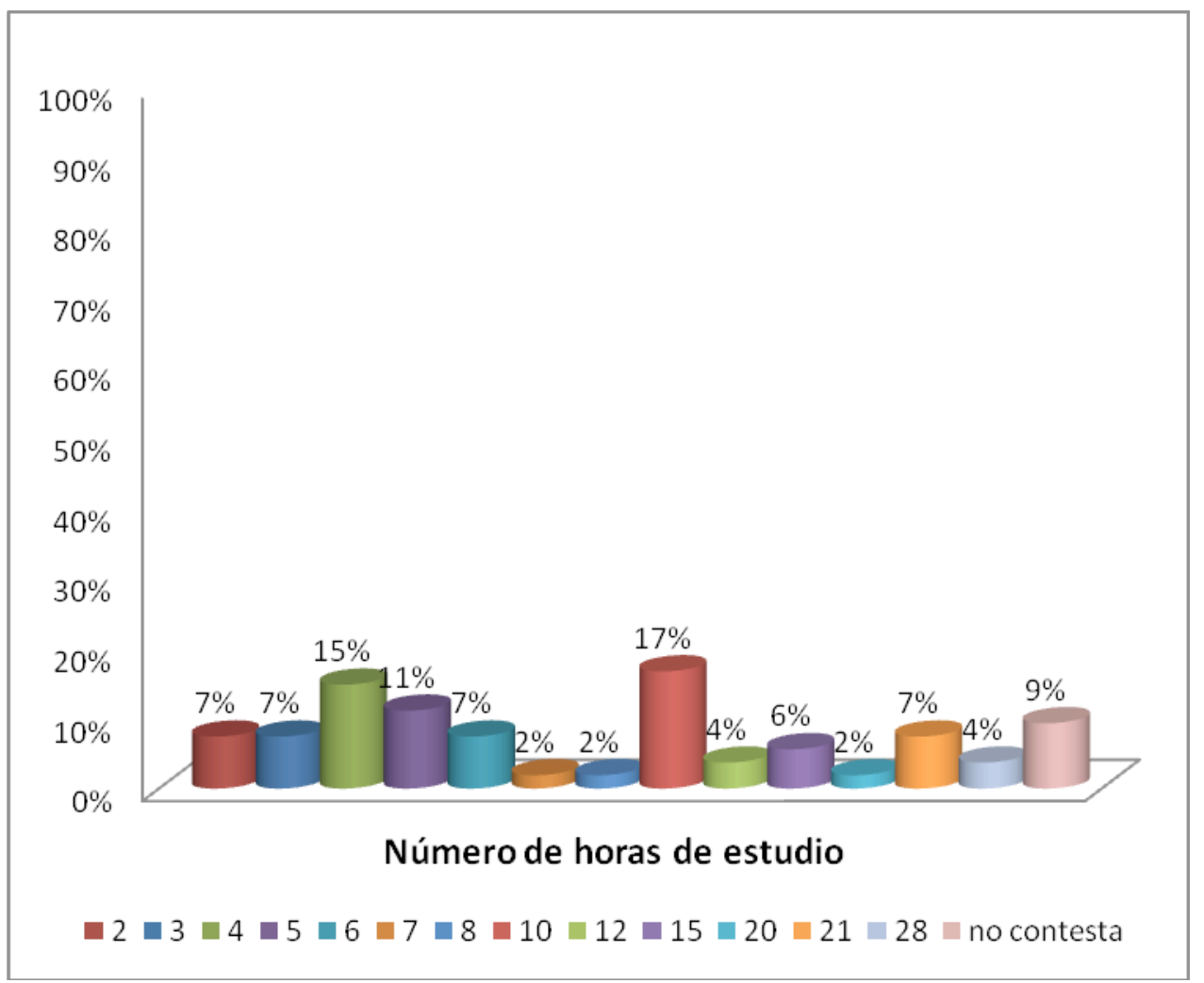

Grafico ${ }^{\circ} 18$. Distribución de los alumnos por número de horas dedicadas al estudio.

Del total de informantes responden que dedican de 2 a 20 horas semanales al estudio, siendo 10 horas la de mayor frecuencia (17\%). En las respuestas de los alumnos a esta pregunta, se observa gran variedad, lo cual es normal considerando las diferencias individuales, solo 5 estudiantes no contestan.

259

La Práctica Profesional como área para potenciar las competencias pedagógicas necesarias para la enseñanza en Educación Infantil 


\section{Actividades de Formación Complementaria}

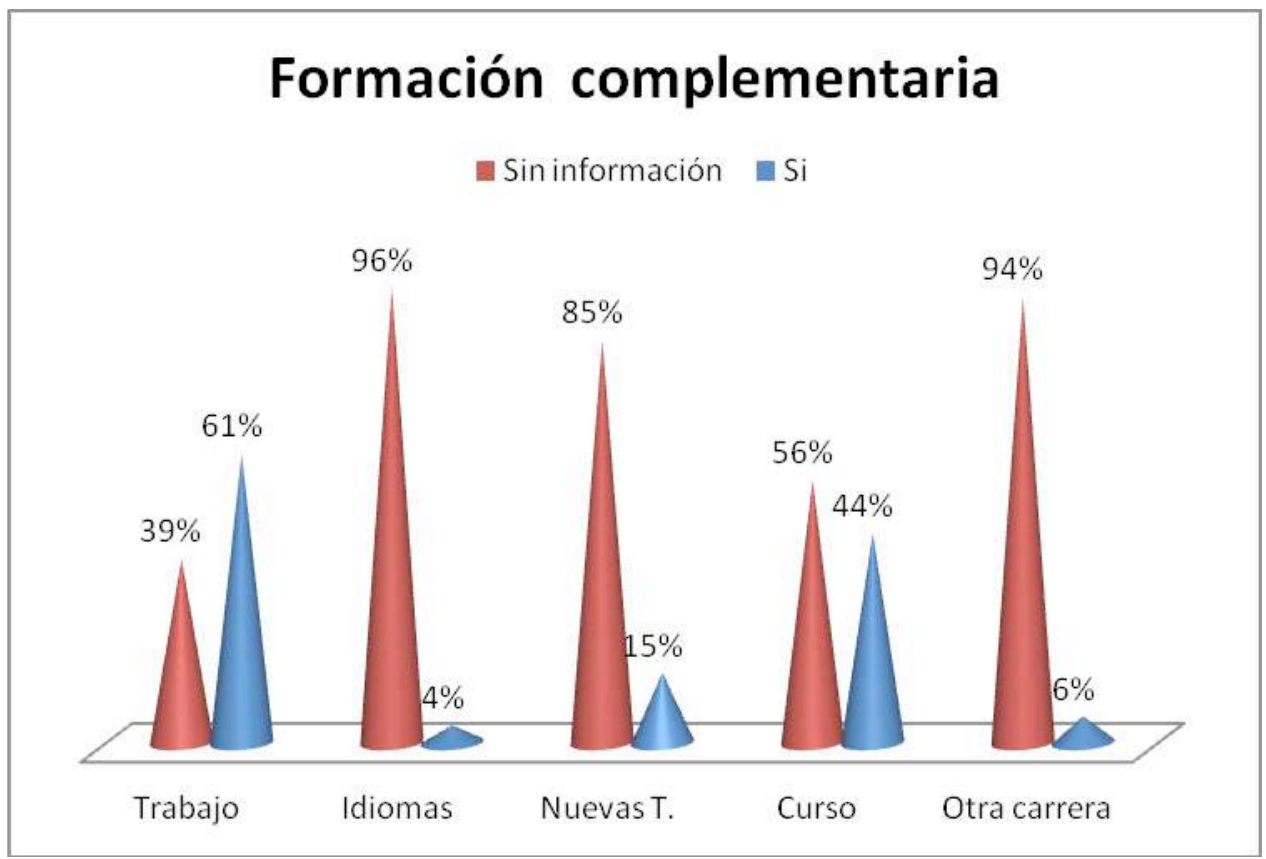

Grafico ${ }^{\circ} 19$. Distribución de los alumnos por formación complementaria.

Este aspecto referido a la formación complementaria que los alumnos poseen, resulta claro el poco interés o motivación por complementar su formación, lo cual coincide con su baja asistencia a eventos académicos.

Seguidamente se muestran las respuestas de los alumnos a cada una de las cuatro dimensiones e indicadores, en las que se dividió el cuestionario: Dimensión procesos de aprendizaje (DPA), dimensión didáctica especifica educación inicial (DDEEI), dimensión enseñanza universitaria (DEU), y dimensión académico estudiantil (DAE).

En cada una de ellas presentamos un cuadro que resume todos los ítems y sus valoraciones, así como un gráfico de barras con las puntuaciones medias de cada una de las cuestiones. Luego se muestra un análisis fundamentado de cada dimensión. 


\subsection{Dimensión Procesos de Aprendizaje}

Categoría: aprender a aprender

\begin{tabular}{|c|c|c|c|c|c|c|c|c|c|c|}
\hline & \multicolumn{2}{|c|}{ En desacuerdo } & \multicolumn{2}{|c|}{ Poco de acuerdo } & \multicolumn{2}{|c|}{$\begin{array}{l}\text { Bastante de } \\
\text { acuerdo }\end{array}$} & \multicolumn{2}{|c|}{$\begin{array}{l}\text { Totalmente de } \\
\text { acuerdo }\end{array}$} & \multirow[b]{2}{*}{ Media } & \multirow[b]{2}{*}{$\begin{array}{l}\text { Desv } \\
\text { típ }\end{array}$} \\
\hline & Frec & $\%$ & frec & $\%$ & frec & $\%$ & frec & $\%$ & & \\
\hline $\begin{array}{l}\text { 09. Integrar las nuevas tendencias } \\
\text { científicas a la práctica } \\
\text { pedagógica. }\end{array}$ & 1 & 1.9 & 10 & 18.5 & 26 & 48.1 & 17 & 31.5 & 3.09 & .76 \\
\hline $\begin{array}{l}\text { 10. Integrar las nuevas tendencias } \\
\text { tecnológicas a la práctica } \\
\text { pedagógica. }\end{array}$ & 0 & .0 & 5 & 9.3 & 20 & 37.0 & 29 & 53.7 & 3.44 & .66 \\
\hline $\begin{array}{l}\text { 11. Desarrollar habilidades para la } \\
\text { resolución de problemas }\end{array}$ & 0 & .0 & 0 & .0 & 14 & 25.9 & 40 & 74.1 & 3.74 & .44 \\
\hline $\begin{array}{l}\text { 12. Aprender a partir de tus } \\
\text { propias experiencias }\end{array}$ & 0 & .0 & 0 & .0 & 5 & 9.3 & 49 & 90.7 & 3.91 & .29 \\
\hline 13. Aprender a partir de los errores & 0 & .0 & 1 & 1.9 & 13 & 24.1 & 40 & 74.1 & 3.72 & .49 \\
\hline
\end{tabular}

Cuadro $n^{\circ}$ 32. Categoría Aprender a aprender (alumnos)

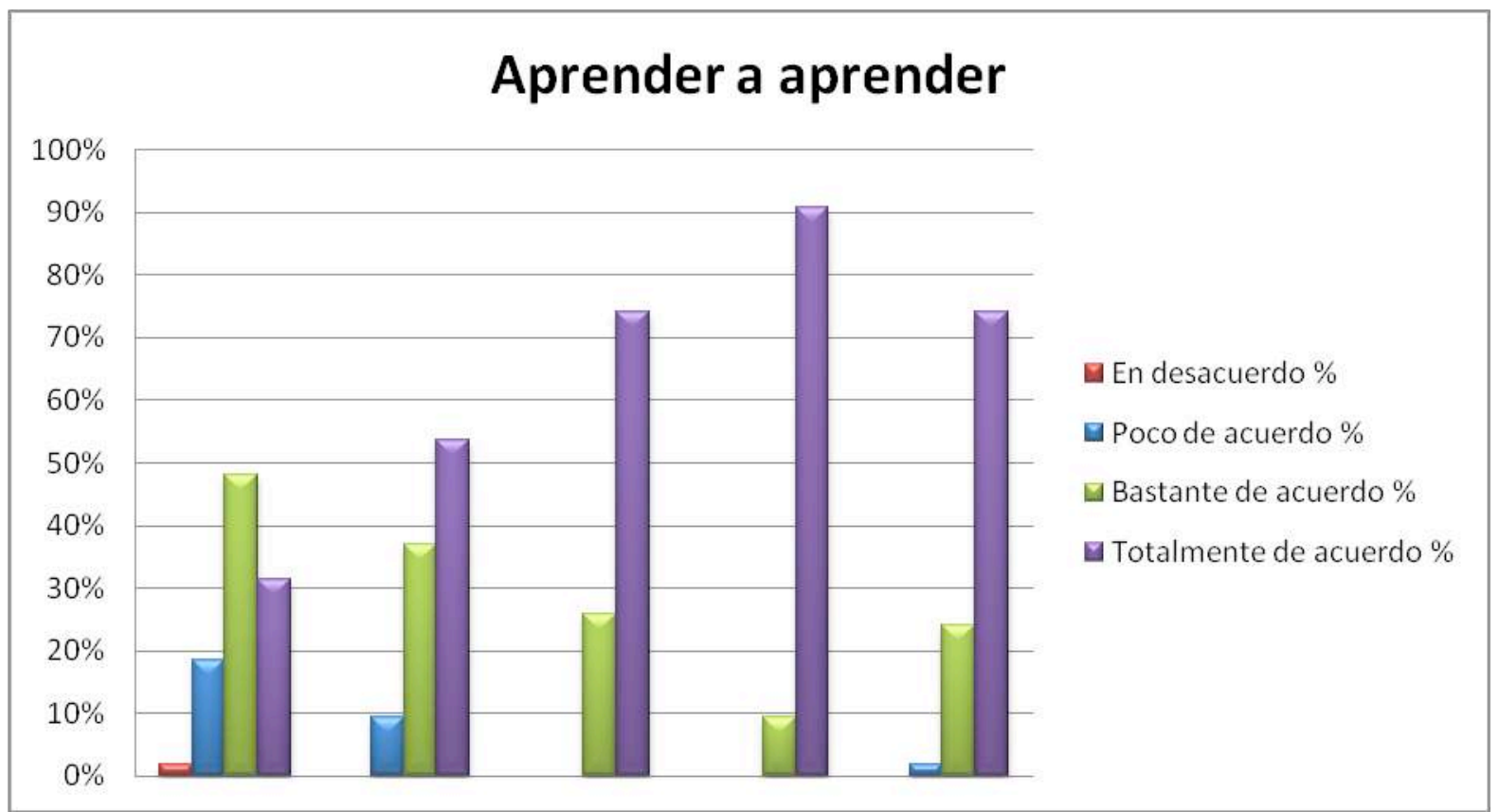

Grafico ${ }^{\circ}$ 20. Categoría aprender a aprender (alumnos) 
Como se observa en el cuadro 32, gráfico 21, donde se representa la primera categoría referida a aprender a aprender, se aprecia que menos de la mitad de los alumnos (31\%) están totalmente de acuerdo en haber aprendido a integrar las nuevas tendencias científicas a la práctica pedagógica; Con respecto al resto de los ítems, la gran mayoría de los encuestados (90,7\%) están totalmente y bastante de acuerdo con haber aprendido habilidades para integrar la tecnología, resolución de problemas, la habilidad de aprender a partir de sus propias experiencias.

\section{Categoría: actualización permanente}

\begin{tabular}{|c|c|c|c|c|c|c|c|c|}
\hline & \multicolumn{2}{|c|}{ Poco de acuerdo } & \multicolumn{2}{|c|}{$\begin{array}{l}\text { Bastante de } \\
\text { acuerdo }\end{array}$} & \multicolumn{2}{|c|}{$\begin{array}{l}\text { Totalmente de } \\
\text { acuerdo }\end{array}$} & \multirow[b]{2}{*}{ Media } & \multirow[b]{2}{*}{$\begin{array}{l}\text { Desv } \\
\text { típ }\end{array}$} \\
\hline & frec & $\%$ & Frec & $\%$ & frec & $\%$ & & \\
\hline $\begin{array}{l}\text { 14. Ampliar y complementar los } \\
\text { conocimientos adquiridos }\end{array}$ & 1 & 1.9 & 15 & 27.8 & 38 & 70.4 & 3.69 & .51 \\
\hline $\begin{array}{l}\text { 15. Asistir a clases con materiales } \\
\text { leídos/ preparados }\end{array}$ & 1 & 1.9 & 15 & 27.8 & 38 & 70.4 & 3.69 & .51 \\
\hline
\end{tabular}

Cuadro $n^{\circ} 33$. Categoría actualización permanente (alumnos). 


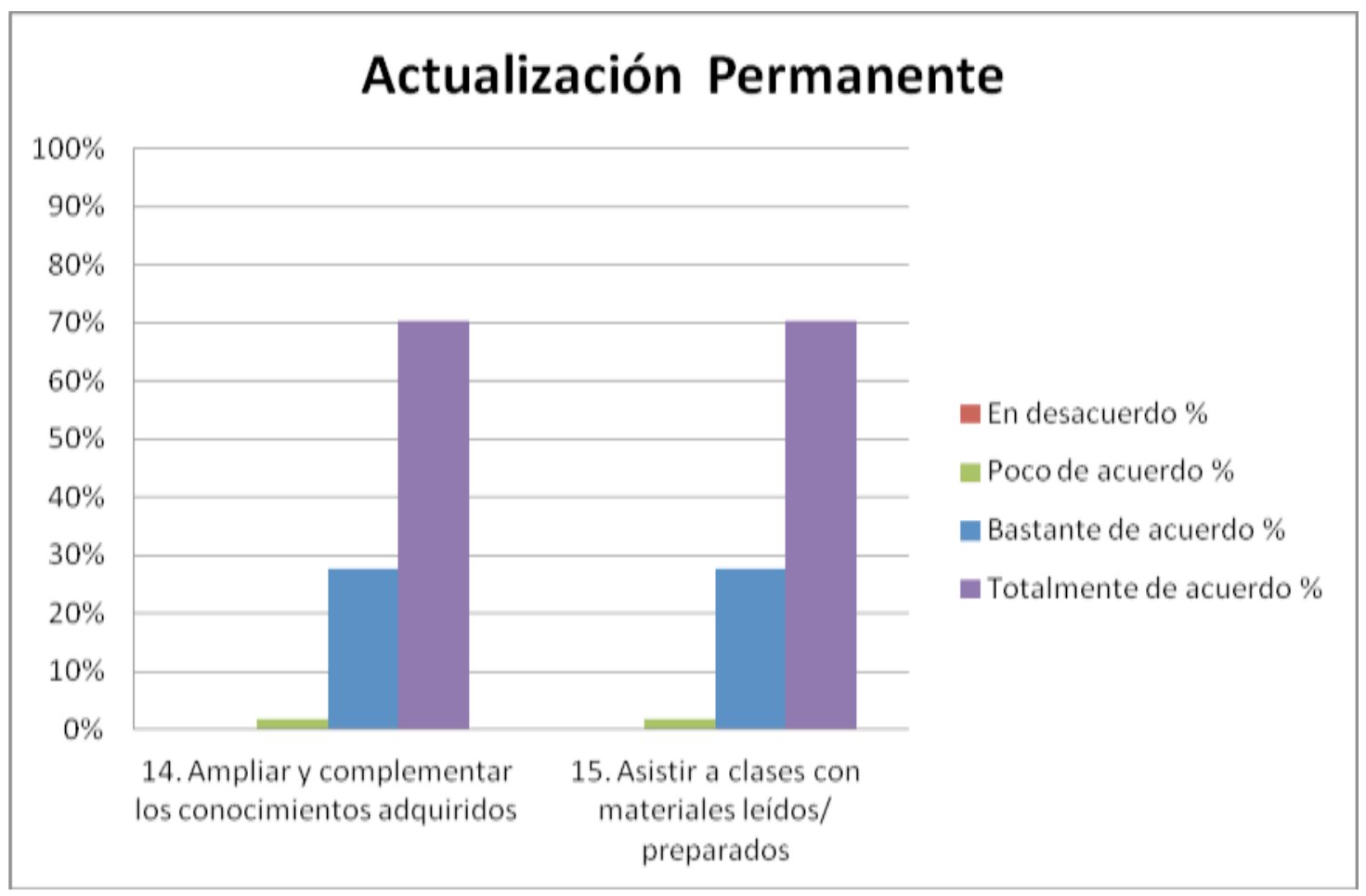

Grafico $\mathrm{n}^{\circ} 21$. Categoria actualización permanente (alumnos)

En esta categoría, se aprecia que los informantes ubican sus respuestas en las opciones positivas de estar bastante $(27,8 \%)$ y totalmente de acuerdo $(70,4 \%)$, con haber desarrollado habilidades de ampliar y complementar los conocimientos adquiridos y asistir a clases con materiales leídos y preparados, solo un pequeña porción $(1,9 \%)$, asume que esta poco de acuerdo en haber aprendido o desarrollado esta cualidad de ampliar y profundizar los conocimientos adquiridos.

Categoría: capacidad de autoevaluar sus aprendizajes

\begin{tabular}{|c|c|c|c|c|c|c|c|c|c|c|}
\hline & \multicolumn{2}{|c|}{ En desacuerdo } & \multicolumn{2}{|c|}{$\begin{array}{l}\text { Poco de } \\
\text { acuerdo }\end{array}$} & \multicolumn{2}{|c|}{$\begin{array}{c}\text { Bastante de } \\
\text { acuerdo }\end{array}$} & \multicolumn{2}{|c|}{$\begin{array}{l}\text { Totalmente de } \\
\text { acuerdo }\end{array}$} & \multirow{2}{*}{\multicolumn{2}{|c|}{$\begin{array}{c}\text { Desv } \\
\text { típ }\end{array}$}} \\
\hline & frec & $\%$ & frec & $\%$ & Frec & $\%$ & frec & $\%$ & & \\
\hline $\begin{array}{l}\text { 16. Trasladar a otras } \\
\text { situaciones los aprendizajes } \\
\text { teóricos/prácticos }\end{array}$ & 0 & .0 & 3 & 5.6 & 13 & 24.1 & 38 & 70.4 & 3.65 & .59 \\
\hline
\end{tabular}

263

La Práctica Profesional como área para potenciar las competencias pedagógicas necesarias para la enseñanza en Educación Infantil 
17. Integrar actividades de docencia con investigación

18. Comprobar la relación de las asignaturas cursadas con la puesta en práctica de tus prácticas profesionales

Cuadro $n^{\circ}$ 34. Categoría capacidad de autoevaluar sus aprendizajes (alumnos)

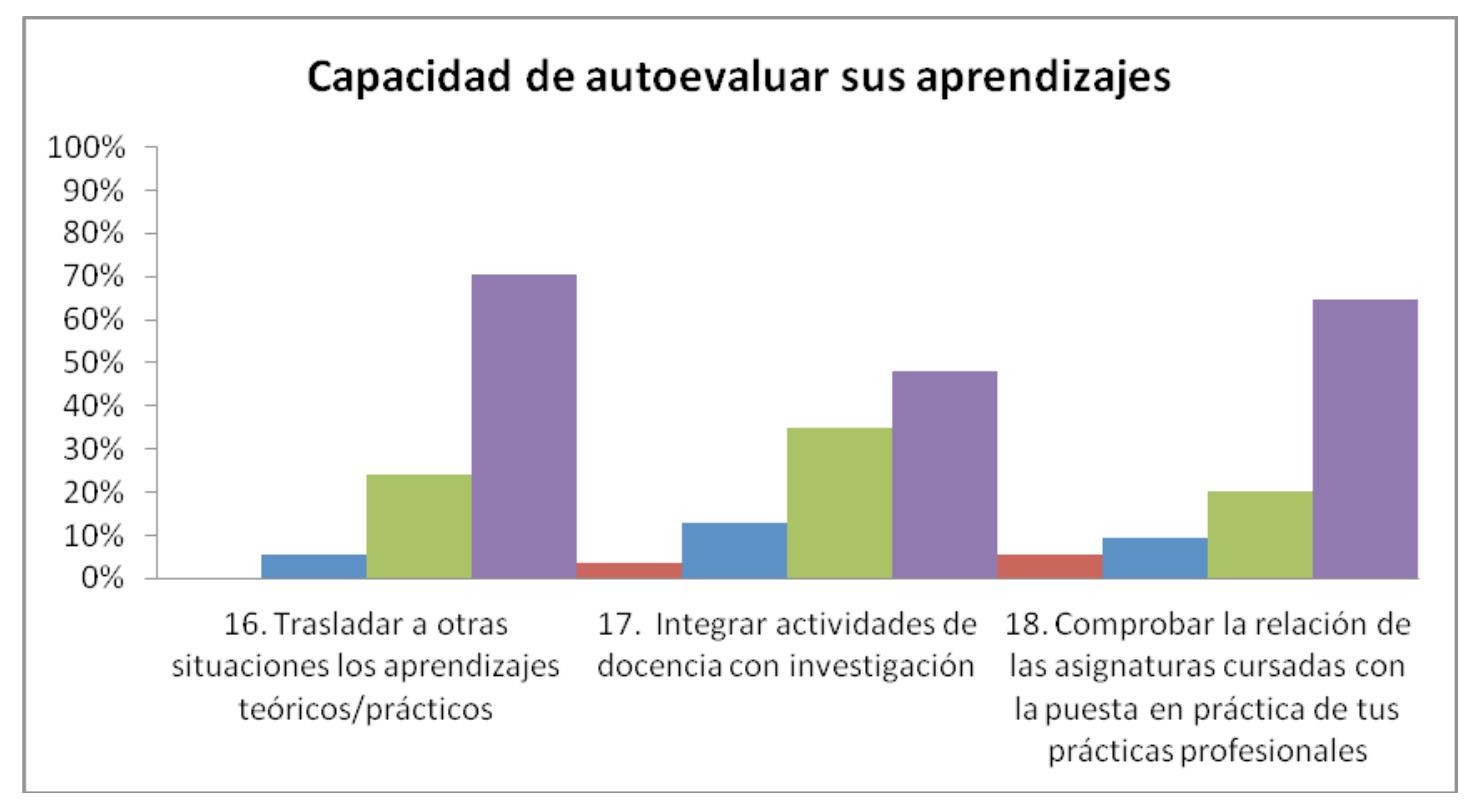

Grafico $\mathrm{n}^{\circ}$ 22. Categoría capacidad de autoevaluar sus aprendizajes (alumnos)

En la categoría denominada capacidad de autoevaluar sus aprendizajes, se pudo apreciar que en el ítem $\mathrm{N}^{\circ} 16$, el $70 \%$ de los alumnos está totalmente de acuerdo en haber aprendido a trasladar a otras situaciones los aprendizajes teóricos prácticos, el 30\% restante no parece estarlo; Luego en el ítem $\mathrm{N}^{\circ} 17$, se evidencia una variada gama de respuestas que demuestra mucho desacuerdo en sus propios logros para integrar las actividades de docencia con la investigación; caso muy parecido ocurre en el ítem $\mathrm{N}^{\circ} 18$, referido a la oportunidad de comprobar la relación de las asignaturas cursadas con la experiencia de sus prácticas profesionales 


\subsection{Dimensión Didáctica Específica Educación Inicial}

\section{Categoría: organización de la situación enseñanza-ap rendizaje}

\begin{tabular}{|c|c|c|c|c|c|c|c|c|}
\hline & En des & erdo & \multicolumn{2}{|c|}{$\begin{array}{c}\text { Bastante de } \\
\text { acuerdo }\end{array}$} & \multicolumn{2}{|c|}{$\begin{array}{l}\text { Totalmente de } \\
\text { acuerdo }\end{array}$} & \multirow[b]{2}{*}{ Media } & \multirow[b]{2}{*}{$\begin{array}{l}\text { Desv } \\
\text { típ }\end{array}$} \\
\hline & frec & $\%$ & frec & $\%$ & frec & $\%$ & & \\
\hline $\begin{array}{l}\text { 19. Crear ambientes que motiven } \\
\text { a los niños al descubrimiento de } \\
\text { sus propias capacidades, } \\
\text { limitaciones, intereses y } \\
\text { necesidades }\end{array}$ & 0 & .0 & 6 & 11.1 & 48 & 88.9 & 3.89 & .32 \\
\hline $\begin{array}{l}\text { 20. Elaborar material didáctico } \\
\text { adecuado a los requerimientos de } \\
\text { las actividades planificadas y de } \\
\text { los aprendizajes esperados }\end{array}$ & 0 & .0 & 7 & 13.0 & 47 & 87.0 & 3.87 & .34 \\
\hline $\begin{array}{l}\text { 21. Crear ambientes de } \\
\text { aprendizaje, respondiendo a las } \\
\text { exigencias del Diseño Curricular } \\
\text { Educación Inicial }\end{array}$ & 1 & 1.9 & 11 & 20.4 & 42 & 77.8 & 3.74 & .56 \\
\hline $\begin{array}{l}\text { 22. Diseñar recursos para el } \\
\text { aprendizaje }\end{array}$ & 0 & .0 & 9 & 16.7 & 45 & 83.3 & 3.83 & .38 \\
\hline
\end{tabular}

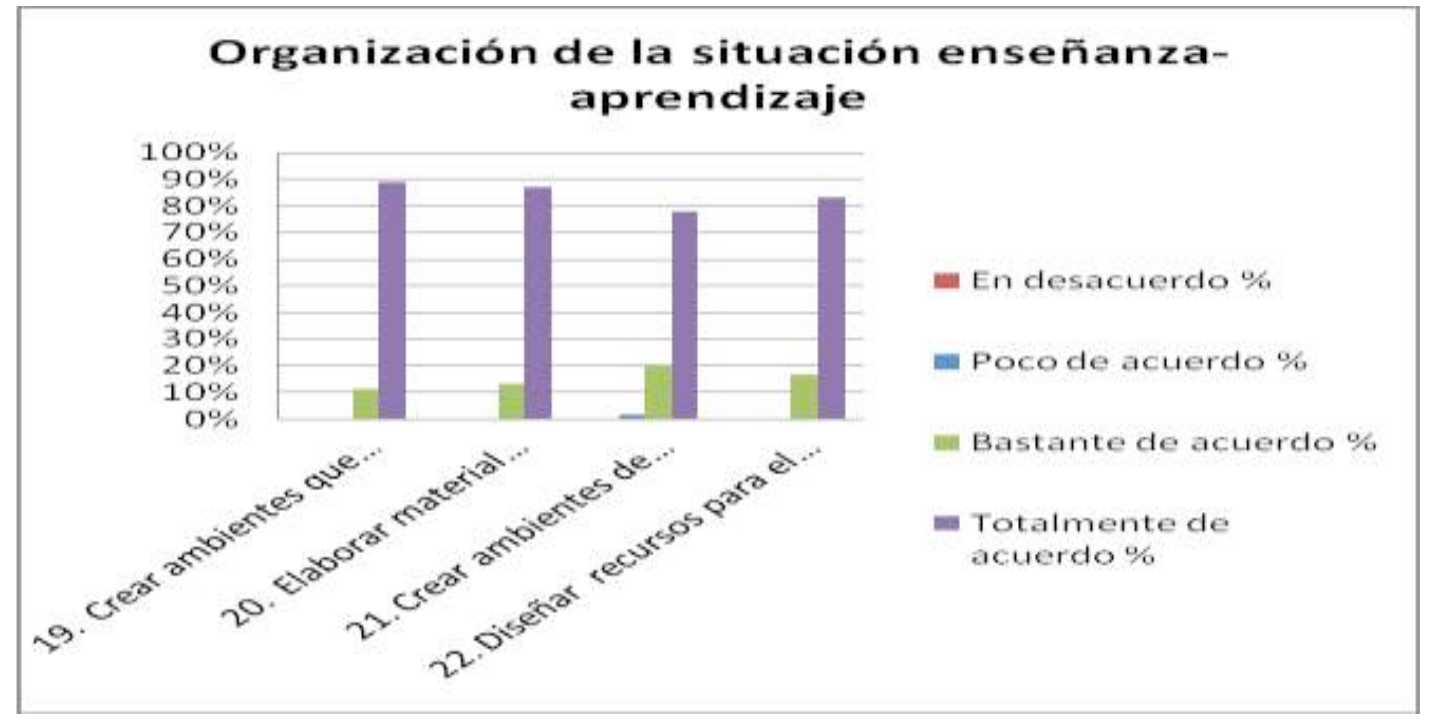

Grafico $\mathrm{n}^{\circ}$ 23.Categoría organización situación enseñanza aprendizaje (alumnos)

265

La Práctica Profesional como área para potenciar las competencias pedagógicas necesarias para la enseñanza en Educación Infantil 
En esta dimensión, tenemos la primera categoría referida a la organización de la situación enseñanza aprendizaje, en la cual los alumnos afirman poseer conocimientos para crear recursos para el aprendizaje y además organizar los ambientes de enseñanza. Las cifras indican que todas las respuestas están por encima de la media.

\section{Categoría: proceso de planificación.}

\begin{tabular}{|c|c|c|c|c|c|c|c|c|c|c|}
\hline & \multicolumn{2}{|c|}{ En desacuerdo } & \multicolumn{2}{|c|}{ Poco de acuerdo } & \multicolumn{2}{|c|}{$\begin{array}{l}\text { Bastante de } \\
\text { acuerdo }\end{array}$} & \multicolumn{2}{|c|}{$\begin{array}{l}\text { Totalmente de } \\
\text { acuerdo }\end{array}$} & \multirow[b]{2}{*}{ Media } & \multirow{2}{*}{$\begin{array}{l}\text { Desv } \\
\text { típ }\end{array}$} \\
\hline & Frec & $\%$ & frec & $\%$ & frec & $\%$ & frec & $\%$ & & \\
\hline $\begin{array}{l}\text { 23. Planificar actividades en virtud } \\
\text { del logro de los aprendizajes } \\
\text { esperados }\end{array}$ & 0 & .0 & 1 & 1.9 & 13 & 24.1 & 40 & 74.1 & 3.72 & .49 \\
\hline $\begin{array}{l}24 . \quad \text { Planificar proyectos } \\
\text { involucrando activamente a niños y } \\
\text { niñas, sus familias, personal, } \\
\text { comunidad circundante }\end{array}$ & 1 & 1.9 & 2 & 3.7 & 15 & 27.8 & 36 & 66.7 & 3.59 & .66 \\
\hline $\begin{array}{l}\text { 25. Diseñar, administrar y ejecutar } \\
\text { proyectos educativos }\end{array}$ & 1 & 1.9 & 2 & 3.7 & 20 & 37.0 & 31 & 57.4 & 3.50 & .67 \\
\hline $\begin{array}{l}\text { 26. Planificar experiencias de } \\
\text { orientación a la comunidad sobre } \\
\text { temas pedagógicos }\end{array}$ & 3 & 5.6 & 9 & 16.7 & 15 & 27.8 & 27 & 50.0 & 3.22 & .92 \\
\hline $\begin{array}{l}\text { 27. Planificar experiencias de } \\
\text { desarrollo personal para las } \\
\text { familias }\end{array}$ & 2 & 3.7 & 10 & 18.5 & 18 & 33.3 & 24 & 44.4 & 3.19 & .87 \\
\hline $\begin{array}{l}\text { 28. Coordinar y correlacionar } \\
\text { objetivos contenidos y actividades }\end{array}$ & 0 & .0 & 3 & 5.6 & 24 & 44.4 & 27 & 50.0 & 3.44 & .60 \\
\hline $\begin{array}{l}\text { 29. Transferir el diagnóstico a sus } \\
\text { planificaciones }\end{array}$ & 0 & .0 & 1 & 1.9 & 7 & 13.0 & 46 & 85.2 & 3.83 & .42 \\
\hline $\begin{array}{l}\text { 30. Diseñar y ejecutar actividades } \\
\text { para cada una de las áreas de } \\
\text { aprendizaje }\end{array}$ & 0 & .0 & 1 & 1.9 & 9 & 16.7 & 44 & 81.5 & 3.80 & .45 \\
\hline
\end{tabular}

Cuadro $\mathrm{n}^{\circ} 36$. Categoría proceso de planificación (alumnos) 


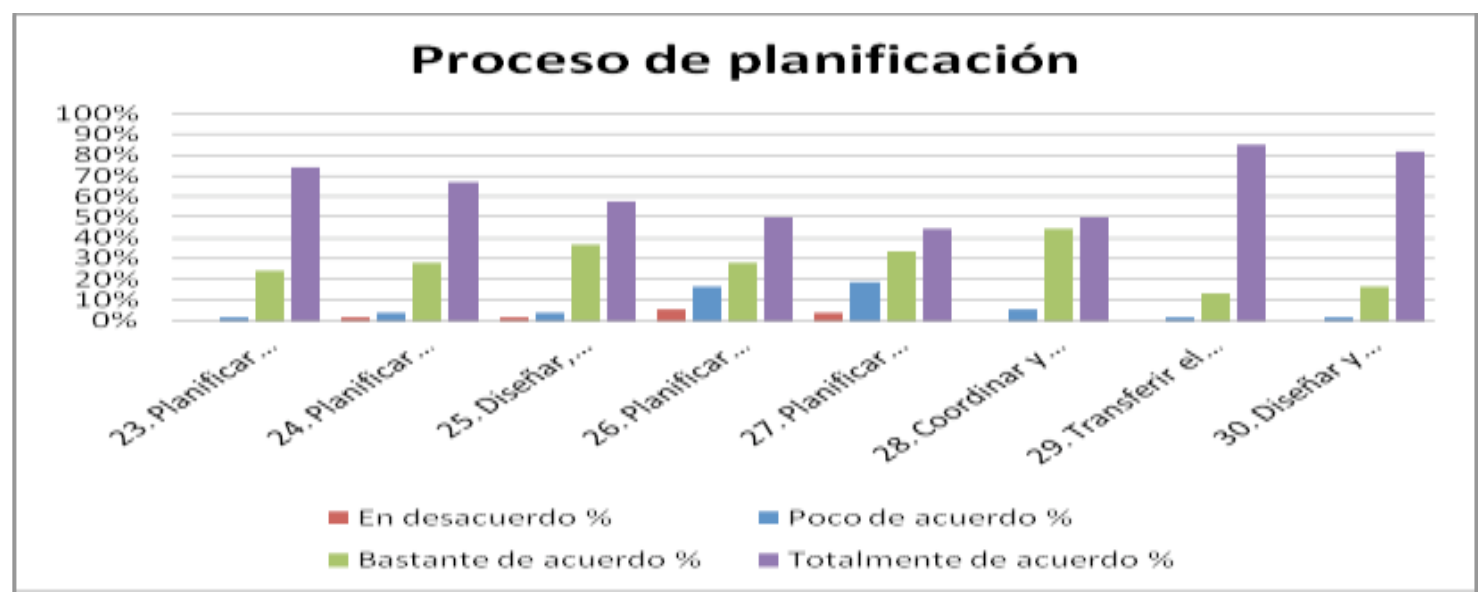

Grafico n 24 .Categoría proceso de planificación (alumnos).

En la categoría denominada proceso de planificación, se observa que la opinión de los informantes califica de manera positiva $(81,5 \%)$ todas las cuestiones referidas a su proceso de aprendizaje en el diseño, administración y ejecución de planificaciones. No obstante, llama la atención que en los ítems 24, 25, 26 y 27, hubo cierto porcentaje de respuestas negativas (18,5\% en desacuerdo) referido a aquellas acciones relacionadas con el trabajo comunitario y/o familiar, en las los alumnos hayan tenido la oportunidad de interactuar directamente en sus procesos formativos.

Categoría: proceso de evaluación

\begin{tabular}{|c|c|c|c|c|c|c|c|c|c|c|}
\hline & \multicolumn{2}{|c|}{ En desacuerdo } & \multicolumn{2}{|c|}{ Poco de acuerdo } & \multicolumn{2}{|c|}{$\begin{array}{l}\text { Bastante de } \\
\text { acuerdo }\end{array}$} & \multicolumn{2}{|c|}{$\begin{array}{l}\text { Totalmente de } \\
\text { acuerdo }\end{array}$} & \multirow[b]{2}{*}{ Media } & \multirow[b]{2}{*}{$\begin{array}{l}\text { Desv } \\
\text { típ }\end{array}$} \\
\hline & frec & $\%$ & frec & $\%$ & Frec & $\%$ & frec & $\%$ & & \\
\hline $\begin{array}{l}\text { 31. Diseñar instrumentos de } \\
\text { evaluación adecuados a los } \\
\text { requerimientos de los aprendizajes } \\
\text { esperados }\end{array}$ & 0 & .0 & 3 & 5.6 & 14 & 25.9 & 37 & 68.5 & 3.63 & .59 \\
\hline $\begin{array}{l}32 \text { Utilizar técnicas y } \\
\text { procedimientos de observación de } \\
\text { conductas de entrada, en } \\
\text { situaciones de aprendizaje }\end{array}$ & 1 & 1.9 & 3 & 5.6 & 16 & 29.6 & 34 & 63.0 & 3.54 & .69 \\
\hline $\begin{array}{l}\text { 33. Usar y dominar los } \\
\text { procedimientos de administración } \\
\text { de escalas sociométricas simples. }\end{array}$ & 5 & 9.3 & 15 & 27.8 & 23 & 42.6 & 11 & 20.4 & 2.74 & .89 \\
\hline $\begin{array}{l}\text { 34. Evaluar los procesos de } \\
\text { aprendizaje de los niños }\end{array}$ & 0 & .0 & 3 & 5.6 & 6 & 11.1 & 45 & 83.3 & 3.78 & .54 \\
\hline
\end{tabular}

La Práctica Profesional como área para potenciar las competencias pedagógicas necesarias para la enseñanza en Educación Infantil 


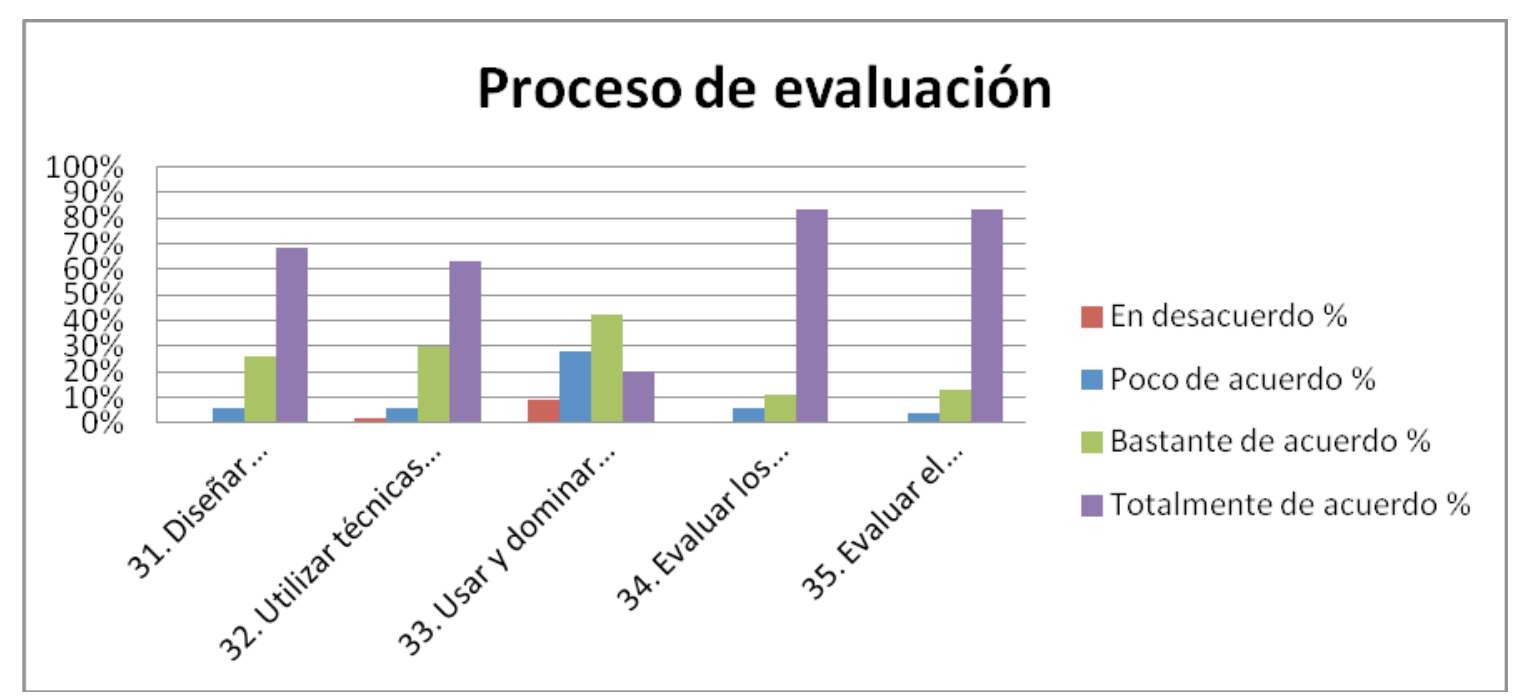

Grafico $n^{\circ} 25$. Categoria proceso de evaluación (alumnos).

Seguidamente tenemos la categoría referida a los procesos de evaluación en la educación infantil, aquí podemos verificar que los alumnos están totalmente de acuerdo (83,3\%), al considerar haber aprendido a evaluar el desarrollo evolutivo de los niños, sin embargo en relación al diseño y aplicación de técnicas e instrumentos de evaluación, su opinión varia en niveles de desacuerdo a poco de acuerdo, $(27,8 \%)$, lo que pudiera indicarnos que su conocimiento es más bien teórico y que existen algunas debilidades en la metodología o puesta en práctica de los mismos. 


\section{Categoría: interacción pedagógica}

\begin{tabular}{|c|c|c|c|c|c|c|c|c|c|c|}
\hline & \multicolumn{2}{|c|}{ En desacuerdo } & \multicolumn{2}{|c|}{ Poco de acuerdo } & \multicolumn{2}{|c|}{ Bastante de acuerdo } & \multicolumn{2}{|c|}{$\begin{array}{c}\text { Totalmente de } \\
\text { acuerdo }\end{array}$} & \multirow[b]{2}{*}{ Media } & \multirow[b]{2}{*}{ Desv típ } \\
\hline & Frec & $\%$ & frec & $\%$ & Frec & $\%$ & frec & $\%$ & & \\
\hline $\begin{array}{l}\text { 36. Realizar intercambio pedagógico } \\
\text { con otros profesionales }\end{array}$ & 1 & 1.9 & 4 & 7.4 & 11 & 20.4 & 38 & 70.4 & 3.59 & .71 \\
\hline $\begin{array}{l}\text { 37. Desarrollar habilidades para el } \\
\text { manejo grupal de niños durante la } \\
\text { rutina diaria. }\end{array}$ & 0 & .0 & 0 & .0 & 8 & 14.8 & 46 & 85.2 & 3.85 & .36 \\
\hline $\begin{array}{l}\text { 38. Realizar procesos de mediación en } \\
\text { el área afectiva }\end{array}$ & 0 & .0 & 3 & 5.6 & 10 & 18.5 & 41 & 75.9 & 3.70 & .57 \\
\hline 39. Favorecer la estimulación temprana & 0 & .0 & 2 & 3.7 & 7 & 13.0 & 45 & 83.3 & 3.80 & .49 \\
\hline $\begin{array}{l}\text { 40. Impulsar a los niños en los procesos } \\
\text { de lectoescritura }\end{array}$ & 0 & .0 & 2 & 3.7 & 10 & 18.5 & 42 & 77.8 & 3.74 & .52 \\
\hline $\begin{array}{l}\text { 41. Impulsar a los niños en el proceso } \\
\text { lógico-matemático }\end{array}$ & 0 & .0 & 4 & 7.4 & 11 & 20.4 & 39 & 72.2 & 3.65 & .62 \\
\hline 42. Fortalecer la autoestima del niño & 0 & .0 & 0 & .0 & 5 & 9.3 & 49 & 90.7 & 3.91 & .29 \\
\hline 43. Fomentar la educación para la salud & 0 & .0 & 1 & 1.9 & 7 & 13.0 & 46 & 85.2 & 3.83 & .42 \\
\hline $\begin{array}{l}\text { 44. Desarrollar habilidades para la } \\
\text { resolución de situaciones dificiles de } \\
\text { resolver: preguntas sobre sexualidad, } \\
\text { agresividad infantil }\end{array}$ & 5 & 9.3 & 1 & 1.9 & 14 & 25.9 & 34 & 63.0 & 3.43 & .92 \\
\hline
\end{tabular}

Cuadro $n^{\circ} 38$. Categoría interacción pedagógica (alumnos)

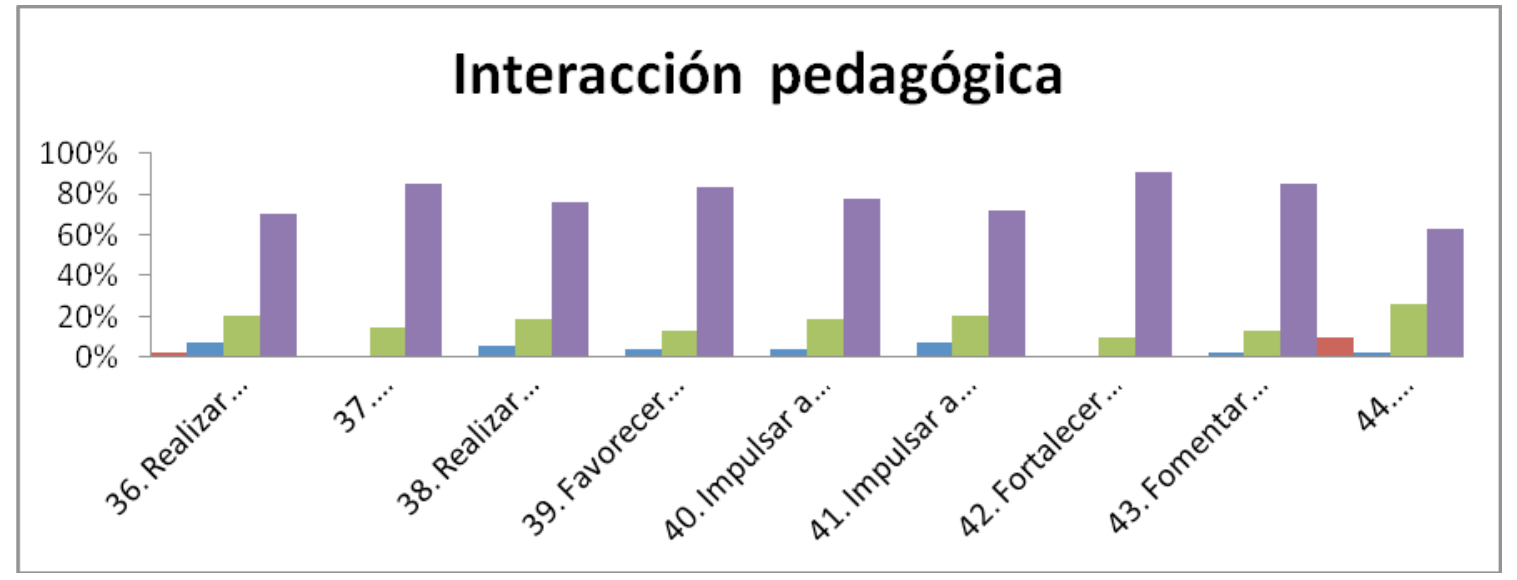

Grafico $n^{\circ}$ 26. Categoría interacción pedagógica (alumnos)

En esta categoría encontramos opinión favorable sobre las habilidades aprendidas por los alumnos para la interacción pedagógica con niños y niñas y otros adultos responsables del proceso educativo, la media más alta es de 3,91; no obstante se debe resaltar en el ítem $\mathrm{N}^{\circ} 44$, 
hubo un 9.3\% que opinó estar en desacuerdo con su aprendizaje para la resolución de situaciones difíciles en el aula de educación infantil.

\subsection{Dimensión Enseñanza Universitaria}

Categoría: didáctica universitaria.

\begin{tabular}{|c|c|c|c|c|c|c|c|c|c|c|}
\hline & En des & & Poco d & erdo & Bastante & cuerdo & $\begin{array}{r}\text { Totaln } \\
\text { act }\end{array}$ & & & \\
\hline & Frec & $\%$ & frec & $\%$ & frec & $\%$ & frec & $\%$ & Media & Desv típ \\
\hline $\begin{array}{l}\text { 45. Proporcionaron fuentes } \mathrm{de} \\
\text { información y recursos a los estudiantes }\end{array}$ & 0 & .0 & 10 & 18.5 & 26 & 48.1 & 18 & 33.3 & 3.15 & .71 \\
\hline $\begin{array}{l}\text { 46. Los motivaron a preparar actividades } \\
\text { de aprendizaje }\end{array}$ & 0 & .0 & 8 & 14.8 & 23 & 42.6 & 23 & 42.6 & 3.28 & .71 \\
\hline $\begin{array}{l}\text { 47. Inician los temas contextualizándolos } \\
\text { previamente }\end{array}$ & 0 & .0 & 7 & 13.0 & 28 & 51.9 & 19 & 35.2 & 3.22 & .66 \\
\hline $\begin{array}{l}\text { 48. Realizan asociación de temas con los } \\
\text { objetivos planteados }\end{array}$ & 1 & 1.9 & 6 & 11.1 & 22 & 40.7 & 25 & 46.3 & 3.31 & .75 \\
\hline 49. Aportan conocimientos actualizados & 0 & .0 & 10 & 18.5 & 20 & 37.0 & 24 & 44.4 & 3.26 & .76 \\
\hline $\begin{array}{l}\text { 50. Dominan los aspectos teóricos de los } \\
\text { contenidos de las asignaturas }\end{array}$ & 0 & .0 & 5 & 9.3 & 24 & 44.4 & 25 & 46.3 & 3.37 & .65 \\
\hline $\begin{array}{l}\text { 51. Dominan los aspectos prácticos de } \\
\text { los contenidos de las asignaturas }\end{array}$ & 1 & 1.9 & 6 & 11.1 & 25 & 46.3 & 22 & 40.7 & 3.26 & .73 \\
\hline $\begin{array}{l}\text { 52. Relacionan la asignatura con otras } \\
\text { ciencias o conocimientos }\end{array}$ & 1 & 1.9 & 9 & 16.7 & 25 & 46.3 & 19 & 35.2 & 3.15 & .76 \\
\hline
\end{tabular}

Cuadro $\mathrm{n}^{\circ} 39$. Categoría didáctica universitaria (alumnos)

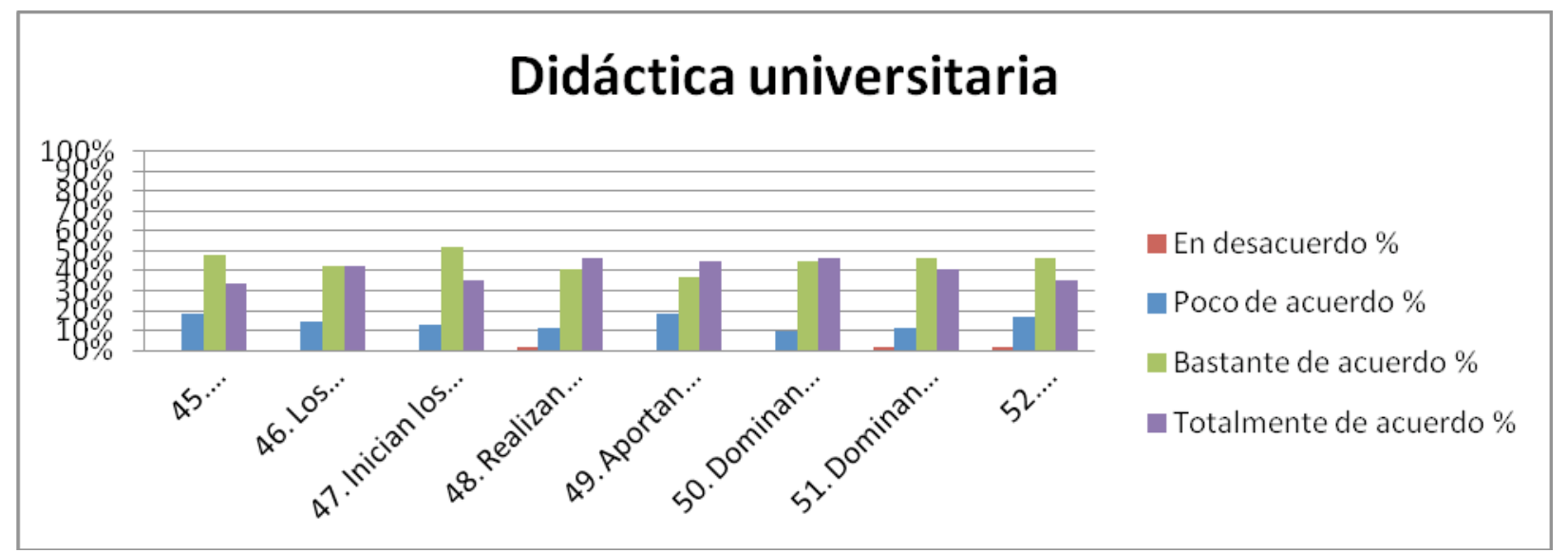

Grafico $n^{\circ} 27$. Categoría didáctica universitaria (alumnos) 
En cuanto a la categoría didáctica universitaria, los alumnos, en un rango de bastante a totalmente de acuerdo (46,3\%), consideran que sus profesores les proporcionaron habilidades y estrategias para el aprendizaje; sin embargo llama la atención la forma como están repartidas las opiniones, ya que también existen opiniones desfavorables que indican desacuerdo $(18,5 \%)$ con la aportación de fuentes actualizadas, asociación de temas y objetivos, aplicabilidad y transferencia de los contenidos

\section{Categoría: metodología universitaria}

\begin{tabular}{|c|c|c|c|c|c|c|c|c|c|c|}
\hline & \multicolumn{2}{|c|}{ En desacuerdo } & \multicolumn{2}{|c|}{ Poco de acuerdo } & \multicolumn{2}{|c|}{$\begin{array}{l}\text { Bastante de } \\
\text { acuerdo }\end{array}$} & \multicolumn{2}{|c|}{$\begin{array}{l}\text { Totalmente de } \\
\text { acuerdo }\end{array}$} & \multirow[b]{2}{*}{ Media } & \multirow[b]{2}{*}{$\begin{array}{l}\text { Desv } \\
\text { típ }\end{array}$} \\
\hline & Frec & $\%$ & frec & $\%$ & frec & $\%$ & frec & $\%$ & & \\
\hline $\begin{array}{l}\text { 53. Exposiciones magistrales del } \\
\text { profesor. }\end{array}$ & 8 & 14.8 & 14 & 25.9 & 16 & 29.6 & 16 & 29.6 & 2.74 & 1.05 \\
\hline $\begin{array}{l}\text { 54. Exposiciones orales de los } \\
\text { estudiantes }\end{array}$ & 0 & .0 & 0 & .0 & 16 & 29.6 & 38 & 70.4 & 3.70 & .46 \\
\hline $\begin{array}{l}\text { 55. Comentarios de actualidad, } \\
\text { relacionados con la educación } \\
\text { infantil }\end{array}$ & 0 & .0 & 4 & 7.4 & 15 & 27.8 & 35 & 64.8 & 3.57 & .63 \\
\hline $\begin{array}{l}\text { 56. Practicas colectivas en el aula } \\
\text { de recursos }\end{array}$ & 2 & 3.7 & 13 & 24.1 & 14 & 25.9 & 25 & 46.3 & 3.15 & .92 \\
\hline $\begin{array}{l}\text { 57. Debates y análisis colectivo de } \\
\text { documentos }\end{array}$ & 3 & 5.6 & 10 & 18.5 & 15 & 27.8 & 26 & 48.1 & 3.19 & .93 \\
\hline $\begin{array}{l}\text { 58. Trabajos individuales y } \\
\text { cooperativos fuera del horario de } \\
\text { clases }\end{array}$ & 4 & 7.4 & 12 & 22.2 & 15 & 27.8 & 23 & 42.6 & 3.06 & .98 \\
\hline 59. Comentarios de textos & 1 & 1.9 & 8 & 14.8 & 16 & 29.6 & 29 & 53.7 & 3.35 & .80 \\
\hline $\begin{array}{l}\text { 60. Presentaciones públicas de } \\
\text { trabajos }\end{array}$ & 4 & 7.4 & 12 & 22.2 & 18 & 33.3 & 20 & 37.0 & 3.00 & .95 \\
\hline $\begin{array}{l}\text { 61. Evaluación de materiales } \\
\text { didácticos }\end{array}$ & 1 & 1.9 & 4 & 7.4 & 19 & 35.2 & 30 & 55.6 & 3.44 & .72 \\
\hline $\begin{array}{l}\text { 62. Realización de proyectos } \\
\text { educativos }\end{array}$ & 1 & 1.9 & 8 & 14.8 & 20 & 37.0 & 25 & 46.3 & 3.28 & .79 \\
\hline $\begin{array}{l}\text { 63. Diseño y ejecución de } \\
\text { intervenciones educativas }\end{array}$ & 3 & 5.6 & 13 & 24.1 & 18 & 33.3 & 20 & 37.0 & 3.02 & .92 \\
\hline $\begin{array}{l}\text { 64. Ejecuciones prácticas con } \\
\text { simulaciones }\end{array}$ & 3 & 5.6 & 6 & 11.1 & 15 & 27.8 & 30 & 55.6 & 3.33 & .89 \\
\hline 65. Trabajos de investigación & 3 & 5.6 & 5 & 9.3 & 18 & 33.3 & 28 & 51.9 & 3.31 & .86 \\
\hline 66. Tutorías. & 9 & 16.7 & 16 & 29.6 & 12 & 22.2 & 17 & 31.5 & 2.69 & 1.10 \\
\hline $\begin{array}{l}\text { 67. Visitas a centros educativos de } \\
\text { diferentes modalidades (públicos, } \\
\text { privados, no convencional, } \\
\text { maternal) }\end{array}$ & 3 & 5.6 & 6 & 11.1 & 14 & 25.9 & 31 & 57.4 & 3.35 & .89 \\
\hline $\begin{array}{l}\text { 68. Actividades prácticas en los } \\
\text { centros educativos }\end{array}$ & 3 & 5.6 & 6 & 11.1 & 13 & 24.1 & 32 & 59.3 & 3.37 & .90 \\
\hline 69. Seminarios & 1 & 1.9 & 3 & 5.6 & 20 & 37.0 & 30 & 55.6 & 3.46 & .69 \\
\hline 70. Conferencias & 2 & 3.7 & 5 & 9.3 & 18 & 33.3 & 29 & 53.7 & 3.37 & .81 \\
\hline
\end{tabular}

Cuadro $\mathrm{n}^{\circ}$ 40. Categoría metodología universitaria (alumnos) 


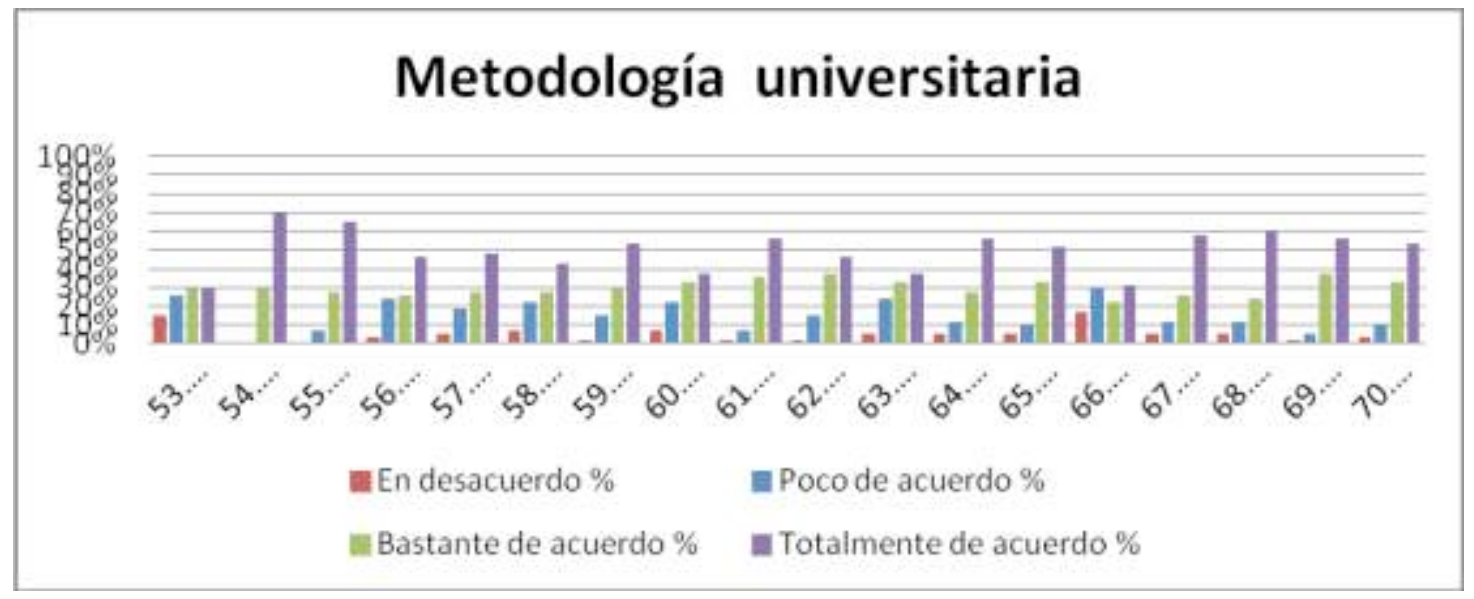

Grafico $n^{\circ}$ 28. Categoría metodología universitaria (alumnos)

En esta categoría se les preguntó a los informantes acerca de las oportunidades de participar en distintas estrategias de enseñanza durante su proceso de formación. Sus respuestas reflejan una variedad llamativa, por cuanto opinan estar en desacuerdo con las oportunidades de escuchar exposiciones magistrales de sus profesores $(25,9 \%)$, con las prácticas colectivas en el aula de recursos para el aprendizaje (24,1\%), el diseño y ejecución de intervenciones pedagógicas (24; 1\%), así como las tutorías (29.6\%); en contraposición se observa que el resto de las estrategias fueron valoradas de manera positiva.

Categoría: contextos de aprendizaje.

\begin{tabular}{|c|c|c|c|c|c|c|c|c|c|c|c|}
\hline & & \multicolumn{2}{|c|}{ En desacuerdo } & \multicolumn{2}{|c|}{ Poco de acuerdo } & \multicolumn{2}{|c|}{$\begin{array}{l}\text { Bastante de } \\
\text { acuerdo }\end{array}$} & \multicolumn{2}{|c|}{$\begin{array}{l}\text { Totalmente de } \\
\text { acuerdo }\end{array}$} & \multirow[b]{2}{*}{ Media } & \multirow[b]{2}{*}{$\begin{array}{c}\text { Desv } \\
\text { típ }\end{array}$} \\
\hline & & Frec & $\%$ & frec & $\%$ & Frec & $\%$ & frec & $\%$ & & \\
\hline $\begin{array}{l}\text { 71. Aula de clases } \\
\text { Universidad }\end{array}$ & la & 0 & .0 & 2 & 3.7 & 8 & 14.8 & 44 & 81.5 & 3.78 & .50 \\
\hline 72. Aula de recursos múltiples & & 11 & 20.4 & 10 & 18.5 & 11 & 20.4 & 22 & 40.7 & 2.81 & 1.18 \\
\hline $\begin{array}{l}\text { 73. Biblioteca/ salas } \\
\text { documentación }\end{array}$ & de & 5 & 9.3 & 11 & 20.4 & 11 & 20.4 & 27 & 50.0 & 3.11 & 1.04 \\
\hline 74. Centros maternales & & 10 & 18.5 & 19 & 35.2 & 5 & 9.3 & 20 & 37.0 & 2.65 & 1.17 \\
\hline $\begin{array}{l}\text { 75. Centros educativos } \\
\text { convencionales }\end{array}$ & no & 15 & 27.8 & 16 & 29.6 & 6 & 11.1 & 17 & 31.5 & 2.46 & 1.21 \\
\hline 76. Centros preescolares & & 2 & 3.7 & 5 & 9.3 & 10 & 18.5 & 37 & 68.5 & 3.52 & .82 \\
\hline 77. Contextos comunitarios & & 13 & 24.1 & 10 & 18.5 & 8 & 14.8 & 23 & 42.6 & 2.76 & 1.24 \\
\hline
\end{tabular}

Cuadro $\mathrm{n}^{\circ}$ 41. Categoría contextos de aprendizaje (alumnos) 


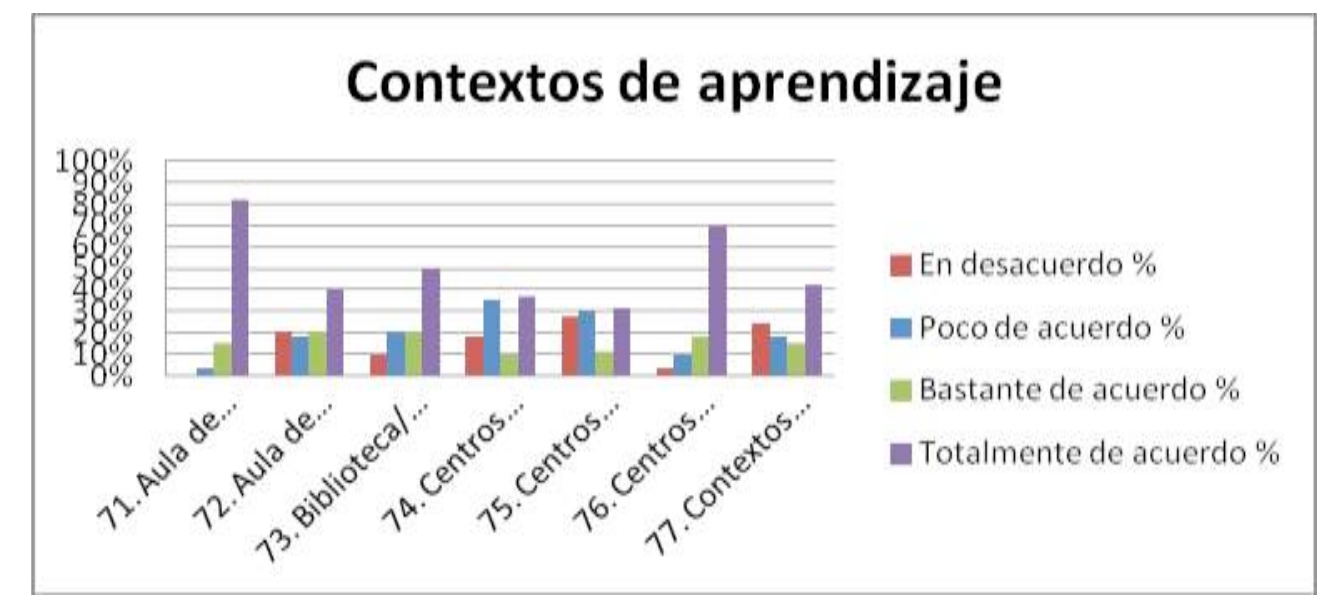

Grafico $\mathrm{n}^{\circ} 29$. Categoría contextos de aprendizaje (alumnos)

La categoría contextos de aprendizaje refleja que la totalidad de las actividades se realizaron en el aula de clases de la UPEL (81,5\%), mientras que hubo muy poca oportunidad de construir sus experiencias en el aula de recursos (20,4\%), en centros maternales $(35,2 \%)$, en centros educativos no convencionales $(29,6 \%)$ y en contextos comunitarios (18,5\%). Esto indica la urgente necesidad de revisar y mejorar las oportunidades de práctica por parte de los alumnos en otros espacios educativos.

Categoría: métodos y criterios de evaluación.

\begin{tabular}{|c|c|c|c|c|c|c|c|c|c|c|}
\hline & \multicolumn{2}{|c|}{ En desacuerdo } & \multicolumn{2}{|c|}{ Poco de acuerdo } & \multicolumn{2}{|c|}{ Bastante de acuerdo } & \multicolumn{2}{|c|}{$\begin{array}{l}\text { Totalmente de } \\
\text { acuerdo }\end{array}$} & \multirow[b]{2}{*}{ Media } & \multirow[b]{2}{*}{ Desv típ } \\
\hline & frec & $\%$ & frec & $\%$ & Frec & $\%$ & frec & $\%$ & & \\
\hline $\begin{array}{l}\text { 78. Trabajos grupales } \\
\text { e individuales }\end{array}$ & 0 & .0 & 1 & 1.9 & 5 & 9.3 & 48 & 88.9 & 3.87 & .39 \\
\hline $\begin{array}{l}\text { 79. Proyectos de } \\
\text { investigación }\end{array}$ & 3 & 5.6 & 6 & 11.1 & 9 & 16.7 & 36 & 66.7 & 3.44 & .90 \\
\hline 80. Informes escritos & 0 & .0 & 0 & .0 & 6 & 11.1 & 48 & 88.9 & 3.89 & .32 \\
\hline 81. Debates & 2 & 3.7 & 3 & 5.6 & 11 & 20.4 & 38 & 70.4 & 3.57 & .77 \\
\hline 82. Exposiciones & 0 & .0 & 0 & .0 & 6 & 11.1 & 48 & 88.9 & 3.89 & .32 \\
\hline 83. Pruebas orales & 4 & 7.4 & 4 & 7.4 & 10 & 18.5 & 36 & 66.7 & 3.44 & .92 \\
\hline $\begin{array}{l}84 . \quad \text { Seguimientos } \\
\text { desde la tutoría }\end{array}$ & 7 & 13.0 & 8 & 14.8 & 14 & 25.9 & 25 & 46.3 & 3.06 & 1.07 \\
\hline $\begin{array}{l}\text { 85. Realización de } \\
\text { trabajos en grupo }\end{array}$ & 0 & .0 & 0 & .0 & 8 & 14.8 & 46 & 85.2 & 3.85 & .36 \\
\hline
\end{tabular}

Cuadro $\mathrm{n}^{\circ} 42$. Categoría métodos y criterios de evaluación (alumnos)

273

La Práctica Profesional como área para potenciar las competencias pedagógicas necesarias para la enseñanza en Educación Infantil 


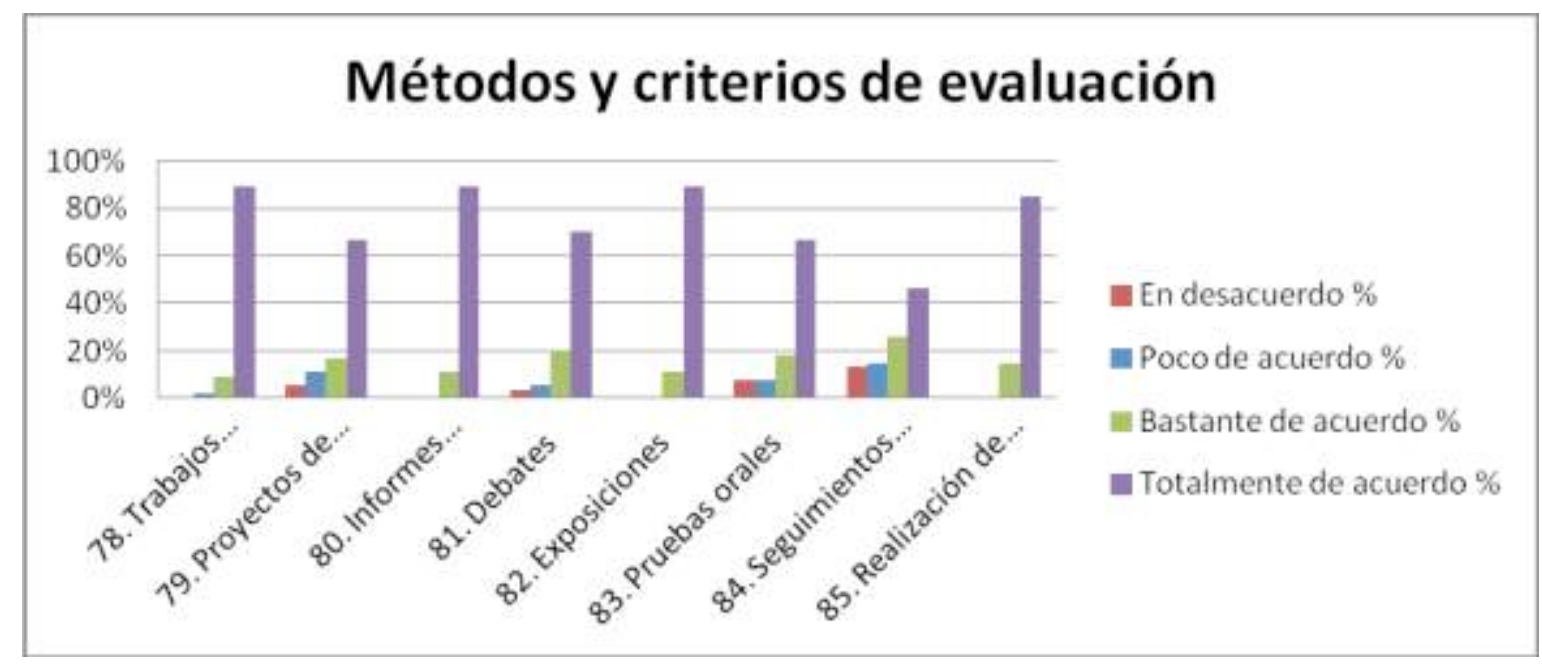

Grafico $\mathrm{n}^{\circ}$ 30. Categoría métodos y criterios de evaluación (alumnos)

En la categoría expresada sobre los métodos y criterios de evaluación, los informantes opinan que están totalmente de acuerdo en que los métodos más utilizados fueron los trabajos grupales, informes escritos, exposiciones y trabajos en grupos $(88,9 \%)$; y los debates, pruebas orales y seguimiento desde la tutoría fueron ponderados como los menos utilizados (14,8\%).

\subsection{Dimensión Académico Estudiantil.}

Categoría: créditos académicos.

\begin{tabular}{|c|c|c|c|c|c|c|c|c|c|c|}
\hline & \multicolumn{2}{|c|}{ En desacuerdo } & \multicolumn{2}{|c|}{ Poco de acuerdo } & \multicolumn{2}{|c|}{$\begin{array}{l}\text { Bastante de } \\
\text { acuerdo }\end{array}$} & \multicolumn{3}{|c|}{$\begin{array}{l}\text { Totalmente de } \\
\text { acuerdo }\end{array}$} & \multirow[b]{2}{*}{$\begin{array}{l}\text { Desv } \\
\text { típ }\end{array}$} \\
\hline & frec & $\%$ & frec & $\%$ & Frec & $\%$ & frec & $\%$ & Media & \\
\hline 86. Normativa (reglamento) & 0 & .0 & 1 & 1.9 & 17 & 31.5 & 36 & 66.7 & 3.65 & .52 \\
\hline $\begin{array}{l}\text { 87. Ubicación en el plan de } \\
\text { estudios }\end{array}$ & 3 & 5.6 & 3 & 5.6 & 16 & 29.6 & 32 & 59.3 & 3.43 & .84 \\
\hline 88. Apoyo institucional & 5 & 9.3 & 8 & 14.8 & 15 & 27.8 & 26 & 48.1 & 3.15 & 1.00 \\
\hline $\begin{array}{l}\text { 89. Apoyo de los centros de } \\
\text { aplicación }\end{array}$ & 1 & 1.9 & 6 & 11.1 & 20 & 37.0 & 27 & 50.0 & 3.35 & .76 \\
\hline 90. Recursos para el aprendizaje & 0 & .0 & 12 & 22.2 & 9 & 16.7 & 33 & 61.1 & 3.39 & .83 \\
\hline 91. Evaluación & 1 & 1.9 & 1 & 1.9 & 19 & 35.2 & 33 & 61.1 & 3.56 & .63 \\
\hline
\end{tabular}

Cuadro $\mathrm{n}^{\circ}$ 43. Categoría créditos académicos (alumnos) 


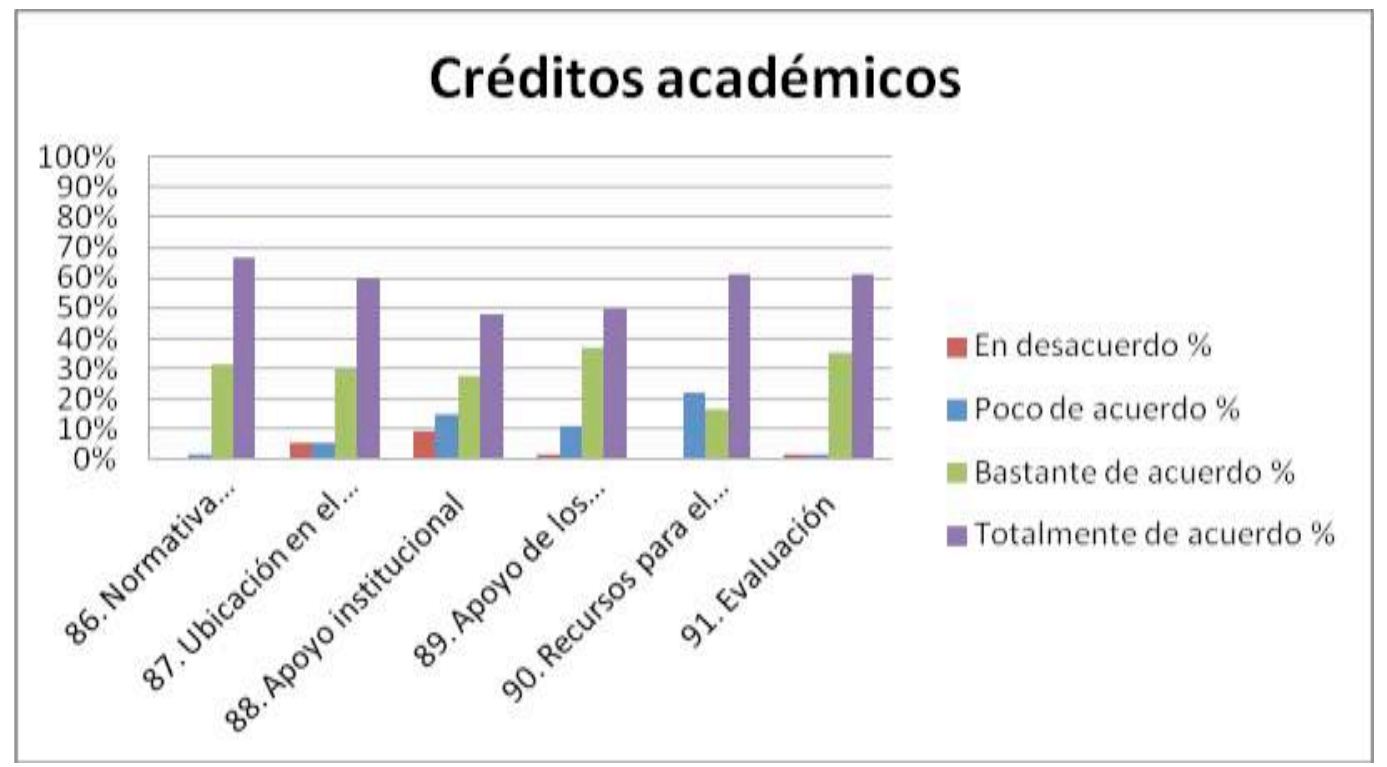

Grafico $\mathrm{n}^{\circ} 31$. Categoría créditos académicos (alumnos).

En la dimensión académica estudiantil, se les consulto la opinión a los informantes sobre la categoría créditos académicos, aquí se obtuvo una opinión favorable acerca de la normativa de la práctica profesional y el reglamento de evaluación, $(66,7 \%)$, las opiniones que expresaban desacuerdo estuvieron en la ubicación de las prácticas en el plan de estudio, el apoyo institucional (UPEL), los recursos para el aprendizaje y el apoyo en los centros de aplicación $(22,2 \%)$

Categoría: planes y programas.

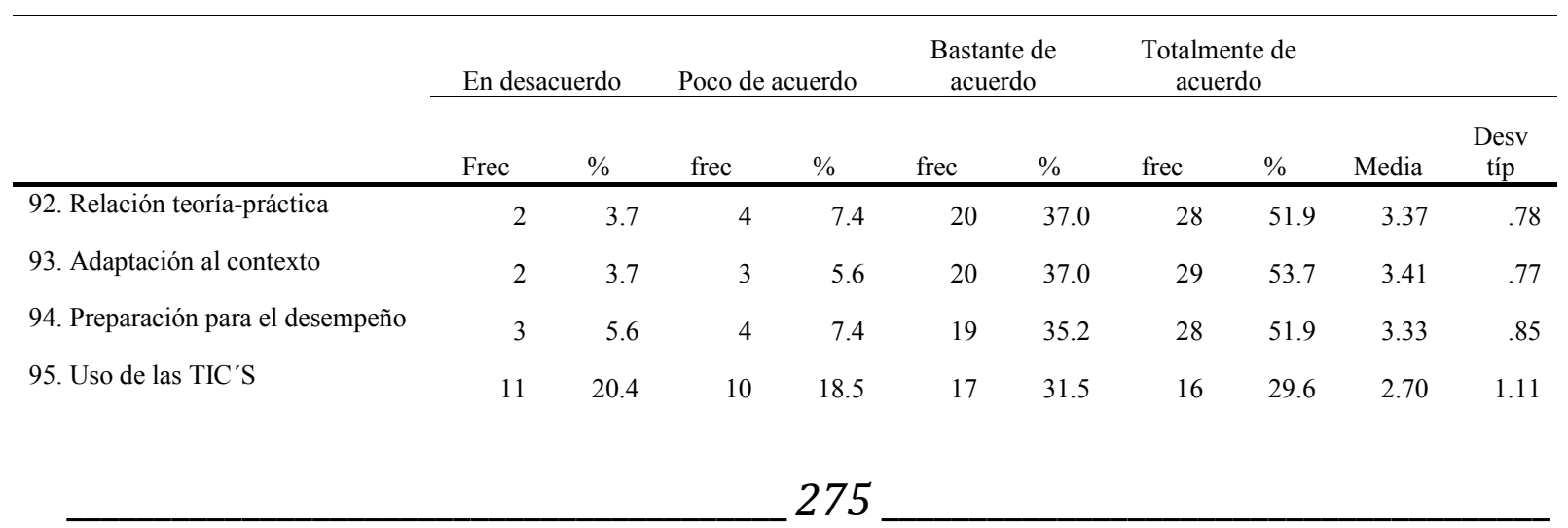

La Práctica Profesional como área para potenciar las competencias pedagógicas necesarias para la enseñanza en Educación Infantil 


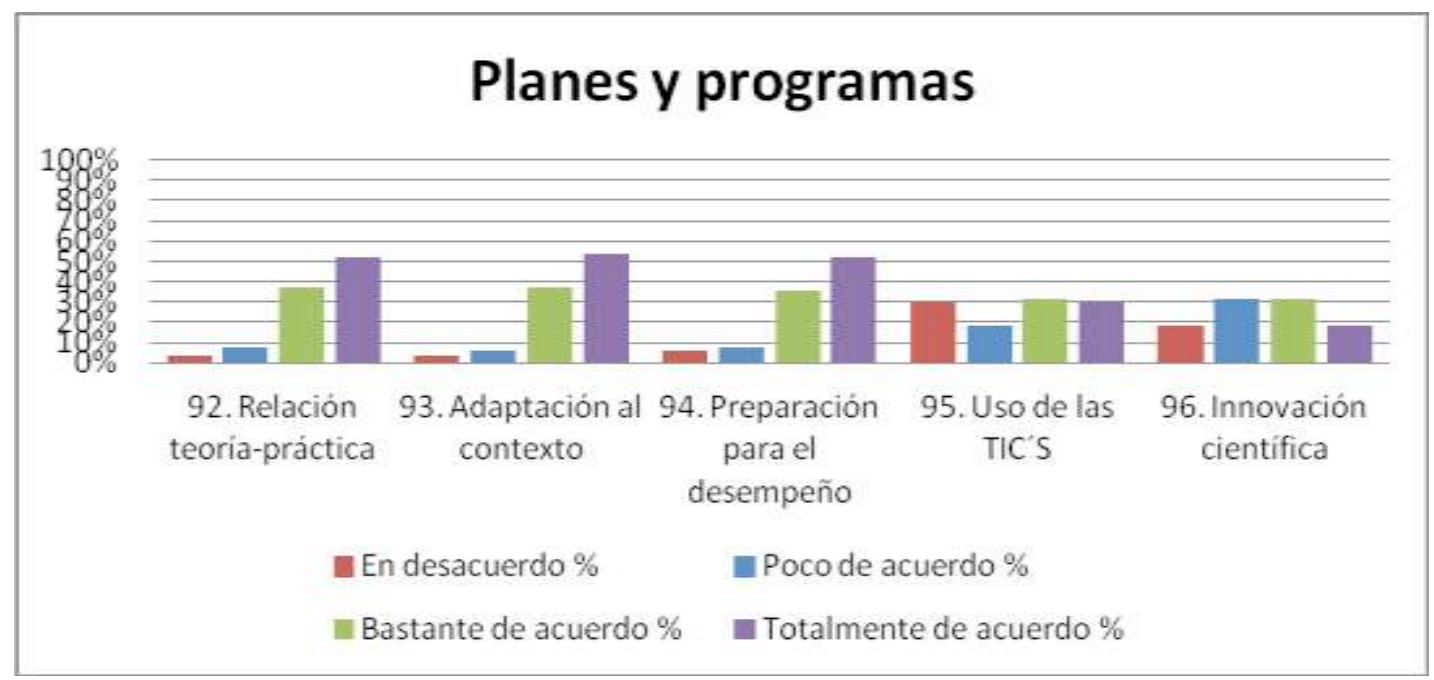

Grafico $n^{\circ} 32$. Categoría planes y programas (alumnos)

En relación con la categoría planes y programas los alumnos consideran estar en total acuerdo con la relación teoría práctica, la adaptación al contexto y la preparación para el desempeño (53\%) que se evidencia en el proceso académico de la práctica profesional; así mismo opinan desacuerdo con el uso de las tics y las innovaciones científicas $(31,5 \%$

Categoría: servicios estudiantiles.

\begin{tabular}{|c|c|c|c|c|c|c|c|c|c|c|c|}
\hline & & \multicolumn{2}{|c|}{ En desacuerdo } & \multicolumn{2}{|c|}{ Poco de acuerdo } & \multicolumn{2}{|c|}{$\begin{array}{l}\text { Bastante de } \\
\text { acuerdo }\end{array}$} & \multicolumn{2}{|c|}{$\begin{array}{l}\text { Totalmente de } \\
\text { acuerdo }\end{array}$} & \multirow[b]{2}{*}{ Media } & \multirow[b]{2}{*}{$\begin{array}{l}\text { Desv } \\
\text { típ }\end{array}$} \\
\hline & & frec & $\%$ & frec & $\%$ & Frec & $\%$ & frec & $\%$ & & \\
\hline 97. Becas de estudio & & 20 & 37.0 & 9 & 16.7 & 9 & 16.7 & 16 & 29.6 & 2.39 & 1.27 \\
\hline $\begin{array}{l}\text { 98. Beca/ Trabajo } \\
\text { ayudantía }\end{array}$ & o & 17 & 31.5 & 10 & 18.5 & 8 & 14.8 & 19 & 35.2 & 2.54 & 1.27 \\
\hline 99. Biblioteca & & 2 & 3.7 & 5 & 9.3 & 16 & 29.6 & 31 & 57.4 & 3.41 & .81 \\
\hline
\end{tabular}

La Práctica Profesional como área para potenciar las competencias pedagógicas necesarias para la enseñanza en Educación Infantil 


\begin{tabular}{|c|c|c|c|c|c|c|c|c|c|c|c|}
\hline 100. Transporte & & 6 & 11.1 & 9 & 16.7 & 12 & 22.2 & 27 & 50.0 & 3.11 & 1.06 \\
\hline 101. Comedor & & 5 & 9.3 & 9 & 16.7 & 11 & 20.4 & 29 & 53.7 & 3.19 & 1.03 \\
\hline 102. Cafetín & & 2 & 3.7 & 5 & 9.3 & 13 & 24.1 & 34 & 63.0 & 3.46 & .82 \\
\hline $\begin{array}{l}\text { 103. Áreas } \\
\text { esparcimiento }\end{array}$ & de & 7 & 13.0 & 6 & 11.1 & 12 & 22.2 & 29 & 53.7 & 3.17 & 1.08 \\
\hline
\end{tabular}

Cuadro $\mathrm{n}^{\circ}$ 45. Categoría servicios estudiantiles (alumnos)

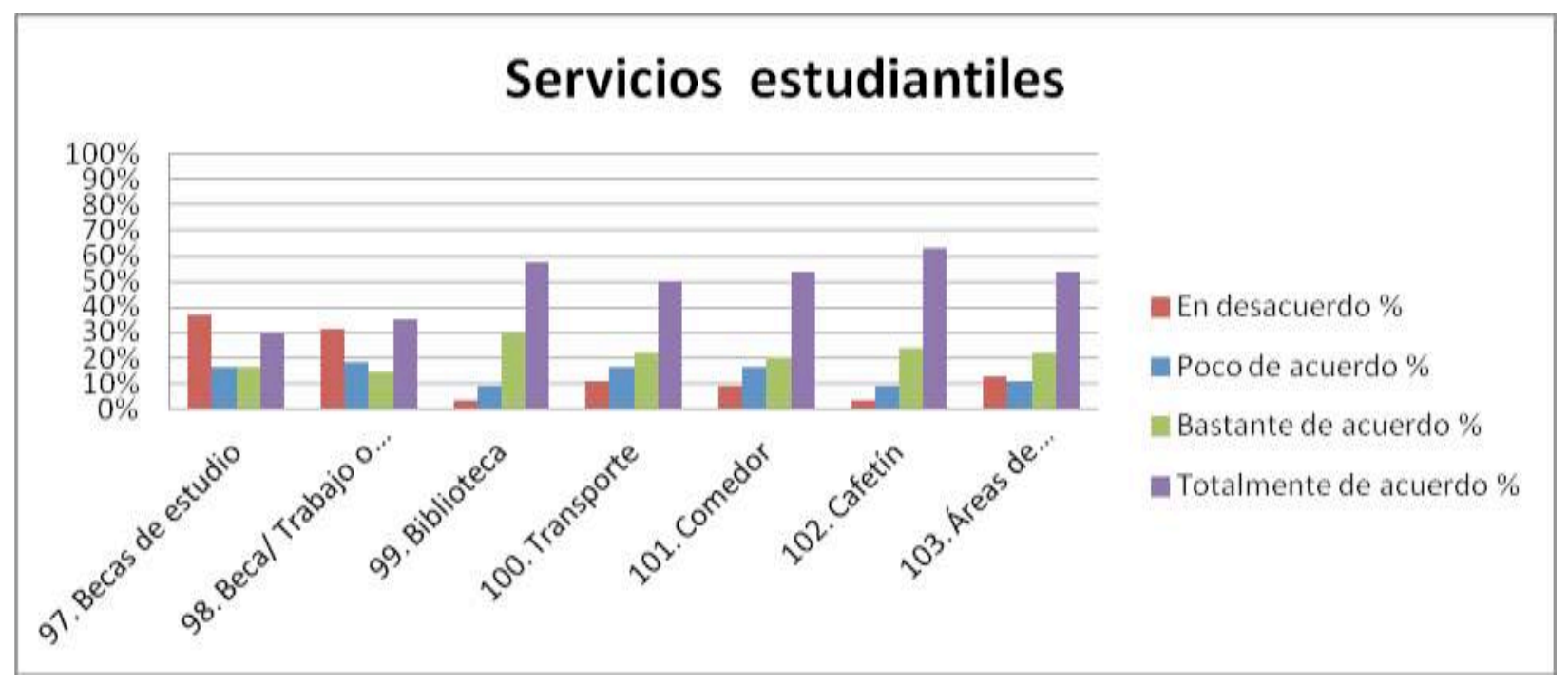

Grafico $\mathrm{n}^{\circ}$ 33. Categoría servicios estudiantiles (alumnos)

En esta categoría se observa que existe una opinión desfavorable para con las becas de estudio, beca trabajo y el transporte que se les brinda en la universidad (37\%); en relación con el resto de los servicios la opinión es positiva.

\subsubsection{Cuestionario Aplicado a los Profesores.}

\subsection{Introducción}

En este apartado corresponde conocer la valoración sobre la práctica profesional del programa de Educación Preescolar de la UPEL - IPMAR, desde el punto de vista de los profesores. Para lograrlo se realizó un proceso de consulta a seis profesores que administran la práctica profesional en la especialidad de Educación Preescolar de la UPEL de Maracay.

277

La Práctica Profesional como área para potenciar las competencias pedagógicas necesarias para la enseñanza en Educación Infantil 
A manera de recordatorio se aclara que para esta consulta se utilizó el cuestionario, con una escala que va de 1 a 4, en donde uno (1) es la mínima valoración y cuatro (4) es la máxima, según la importancia que los sujetos le asignen; en cuanto al tipo de análisis se utilizaron cuadros, gráficas y la opinión del investigador. En relación al orden de presentación se presenta en primer lugar los datos socio académicos de los informantes y luego las respuestas acerca de la práctica profesional.

\subsection{Resultados Cuestionario Aplicado a Profesores.}

\subsection{Análisis de los datos socio- académicos de los profesores}

\section{Edad.-}

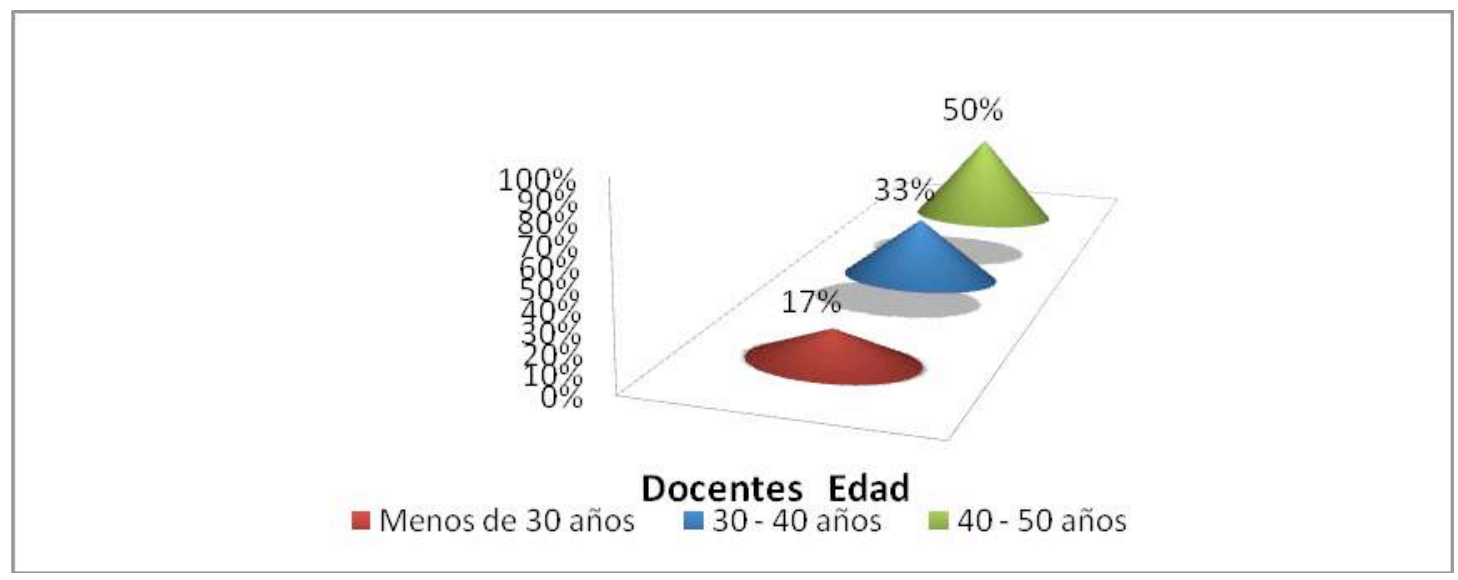

Grafico $n^{\circ} 34$. Distribución de los profesores por edad

Al observar la gráfica se puede apreciar que 50\% de los informantes esta en el rango de 40 a 50 años, 33\% se encuentra en el rango de 30 a 40 años. El resto 17\% está en el orden de menos de 30 años.

278

La Práctica Profesional como área para potenciar las competencias pedagógicas necesarias para la enseñanza en Educación Infantil 
Sexo.-

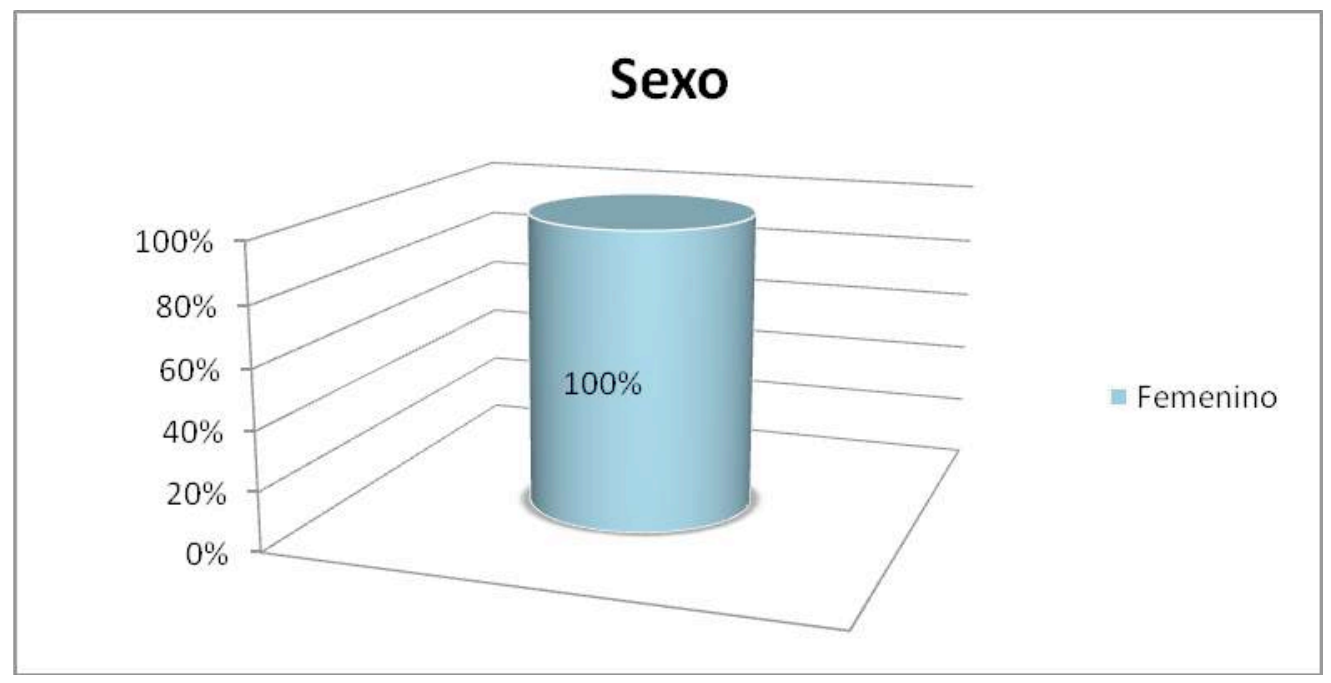

Grafico $n^{\circ} 35$. Distribución de los profesores por sexo.

En este aspecto tenemos que la totalidad de las informantes son del sexo femenino.

\section{Estado Civil}

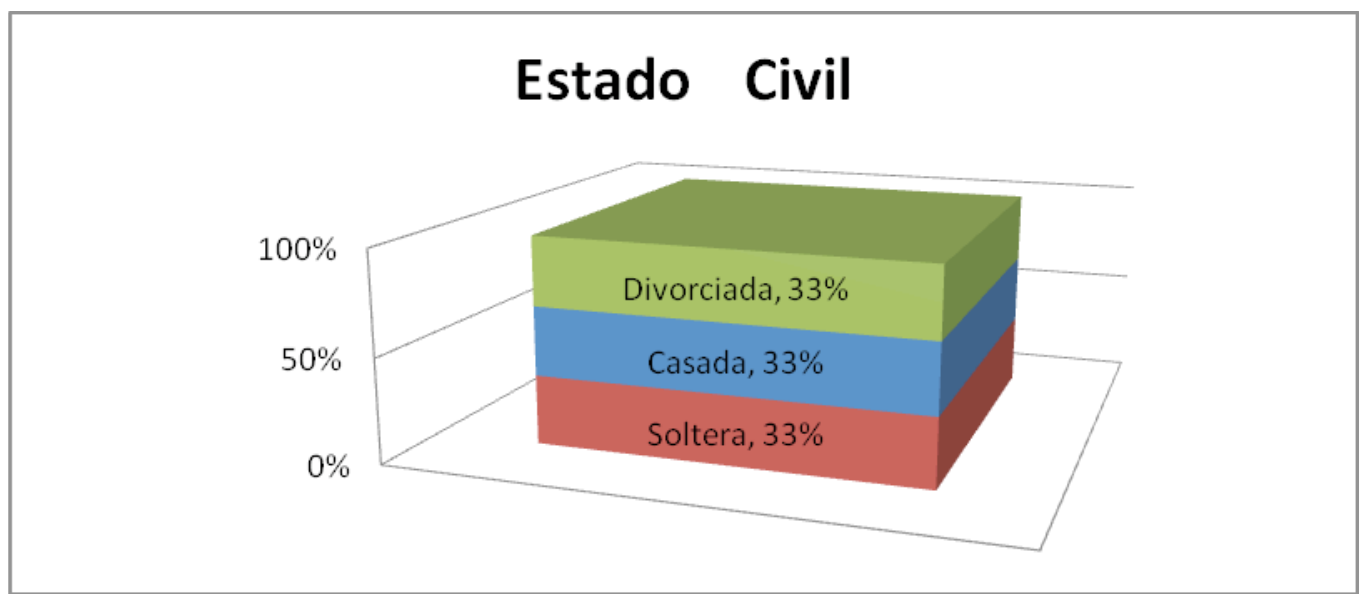

Grafico $\mathrm{n}^{\circ}$ 36. Distribución de los profesores por estado civil

La Práctica Profesional como área para potenciar las competencias pedagógicas necesarias para la enseñanza en Educación Infantil 
Con respecto al estado civil de las profesoras se observa que existen dos profesoras solteras, dos profesoras casadas, y dos divorciadas.

\section{Años en la Universidad.-}

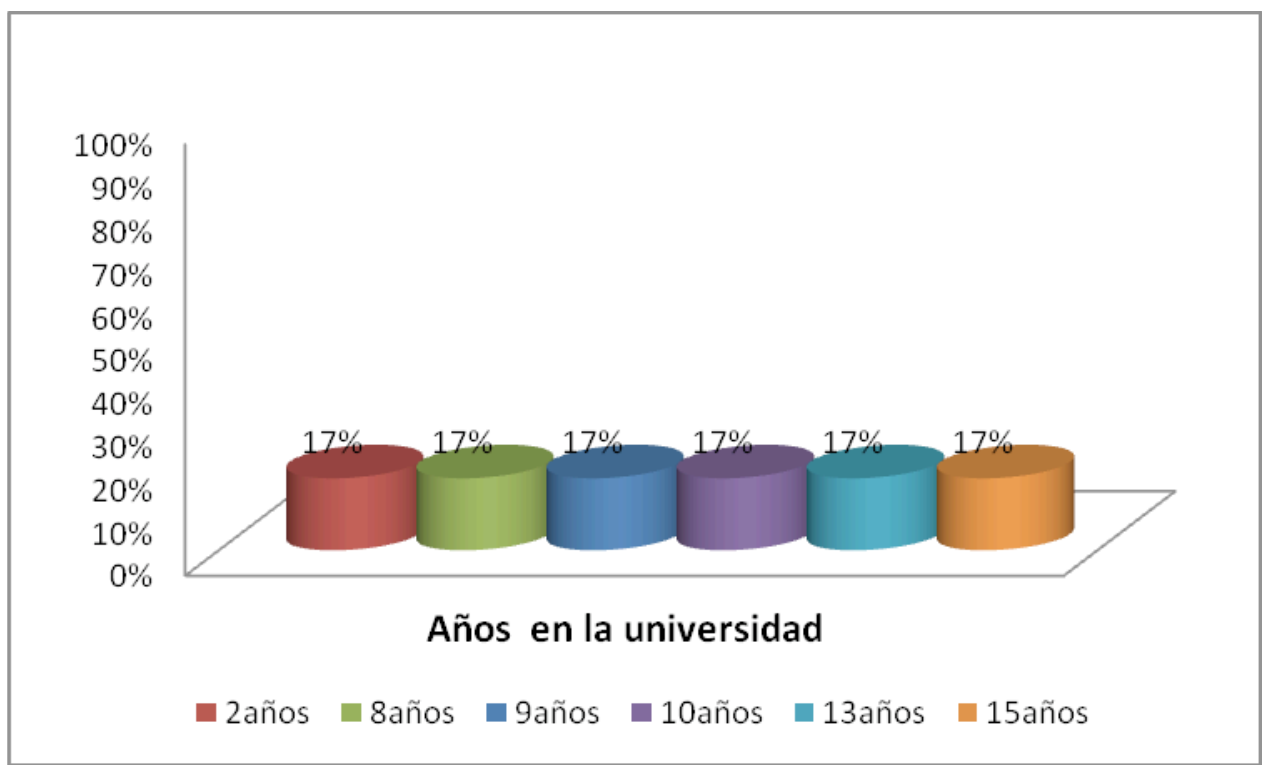

Grafico $n^{\circ} 37$. Distribución de los profesores por años de servicio en la universidad.

Existe una gran variedad en cuanto al tiempo de permanencia de las informantes en la universidad, se percibe que el menor tiempo es de dos años, frente a una informante que tiene 15 años de estar laborando en la UPEL. 


\section{Condición}

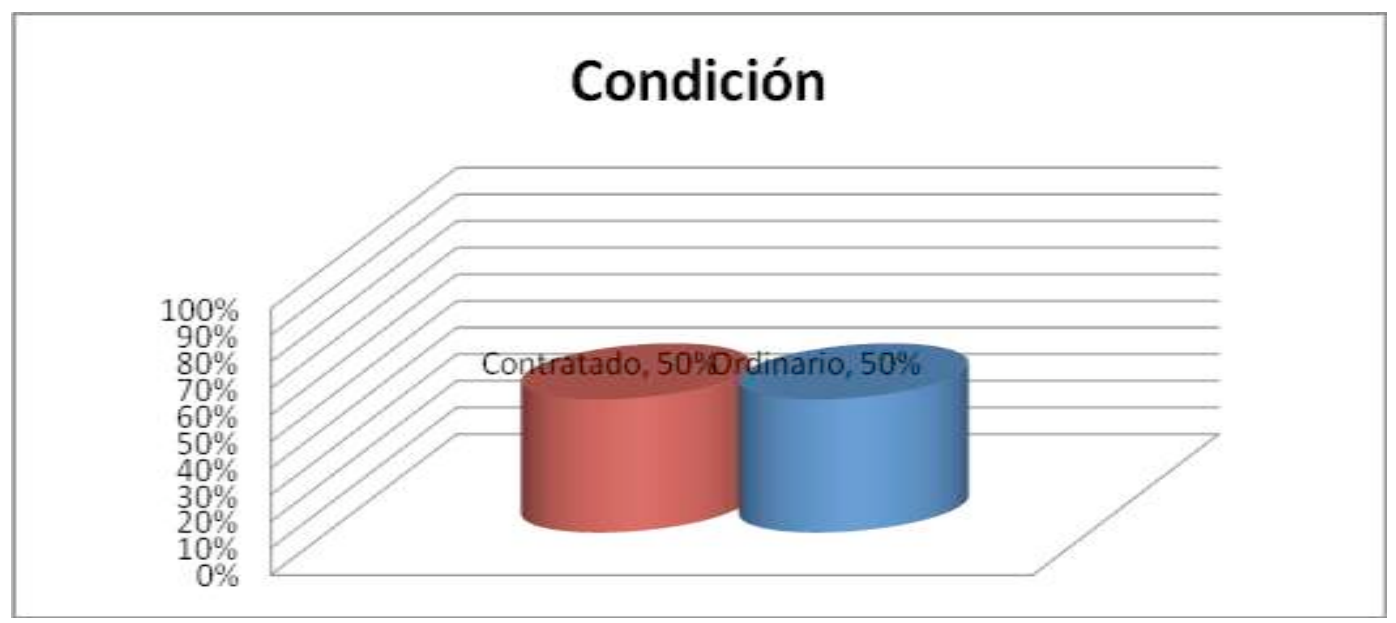

Grafico $n^{\circ} 38$. Distribución de los profesores por condición.

Se observa que tres profesores son ordinarios y tres son contratados, esto permite apreciar la importancia que tienen los profesores contratados en la gestión académica de la UPEL. 


\section{Escalafón.-}

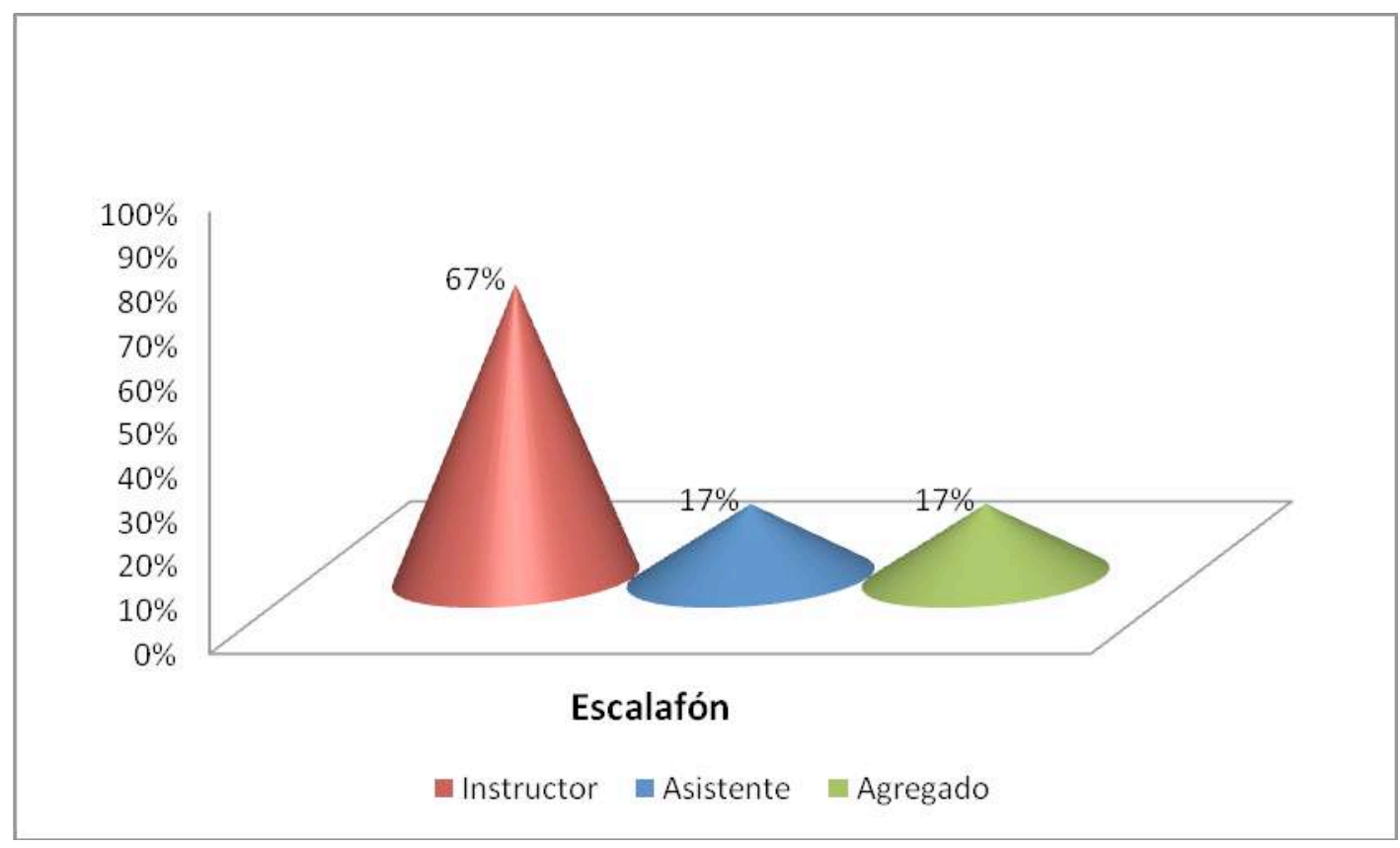

Grafico $n^{\circ} 39$. Distribución de los profesores por escalafón.

Tal como se puede estimar que, una profesora está en la categoría académica de asistentes. Una en la de agregado. El resto de los informantes (4 de ellas) se ubica en la categoría de instructor, lo cual coincide con el hecho de que a los profesores contratados se les asigna la categoría de instructor sin gozar del derecho a ser evaluado y ubicado en la categoría correspondiente. 


\title{
Titulo de Pregrado.-
}

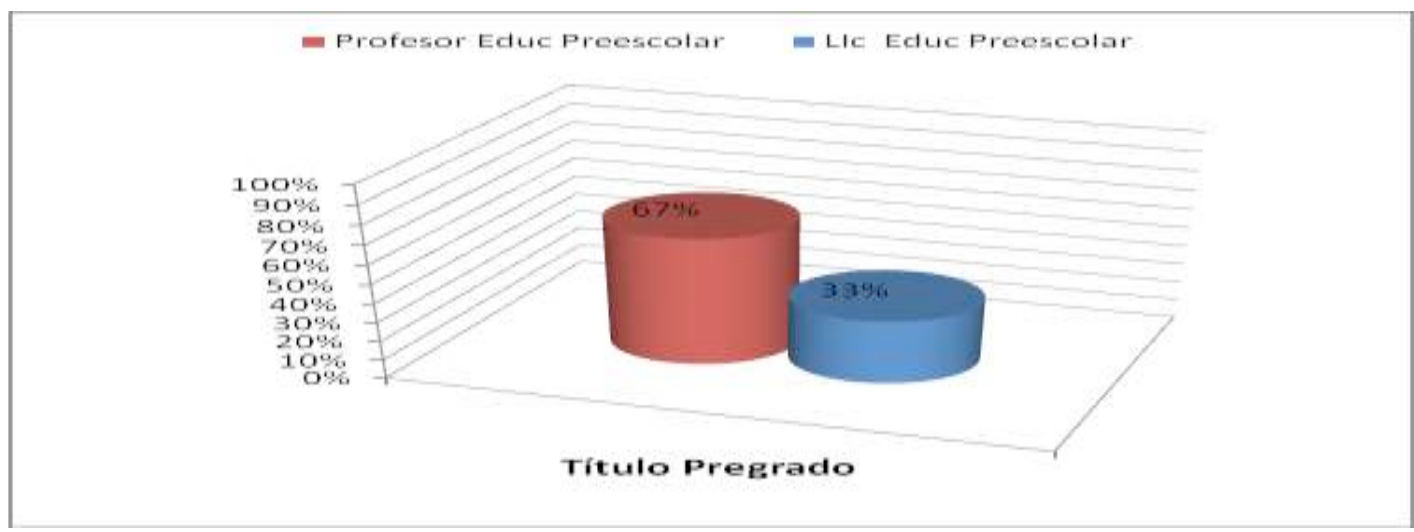

Grafico $n^{\circ} 40$. Distribución de los profesores por titulo de pregrado.

En cuanto al título que poseen las profesoras se observa que cuatro de ellas son egresadas de una universidad pedagógica ya que tienen el titulo de profesoras en educación preescolar y tres de ellas son egresadas de otras universidades que otorgan el titulo de licenciada en educación preescolar.

\section{Titulo de Postgrado.-}

\section{Título postgrado}

\author{
Especialista Educ Preescolar Magister Educ Infantil \\ - Magister Educ Superior Magister Gerencia Educativa
}

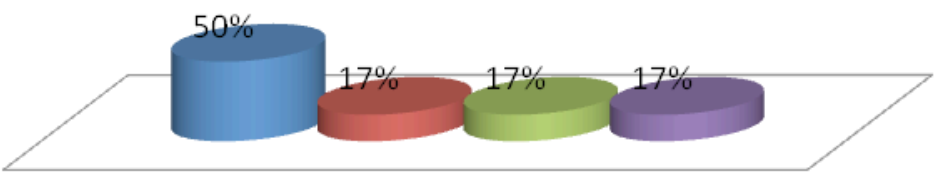

Grafico $n^{\circ} 41$. Distribución de los profesores por titulo de postgrado.

283

La Práctica Profesional como área para potenciar las competencias pedagógicas necesarias para la enseñanza en Educación Infantil 
Todas las informantes poseen estudios de cuarto nivel. Se tiene que tres de ellas tienen una especialización en educación preescolar, una profesora tiene una maestría en gerencia educativa, otra tiene maestría en educación superior y la última tiene maestría en educación infantil.

\subsection{Dimensión Procesos de Aprendizaje}

Categoría: aprender a aprender.

\begin{tabular}{|c|c|c|c|c|c|c|c|c|}
\hline & \multicolumn{2}{|c|}{ Poco de acuerdo } & \multicolumn{2}{|c|}{$\begin{array}{l}\text { Bastante de } \\
\text { acuerdo }\end{array}$} & \multicolumn{2}{|c|}{$\begin{array}{l}\text { Totalmente de } \\
\text { acuerdo }\end{array}$} & \multirow[b]{2}{*}{ Media } & \multirow[b]{2}{*}{$\begin{array}{c}\text { Desv } \\
\text { típ }\end{array}$} \\
\hline & frec & $\%$ & Frec & $\%$ & frec & $\%$ & & \\
\hline $\begin{array}{l}\text { 09. Integrar las nuevas tendencias } \\
\text { científicas a la práctica pedagógica. } \\
\text { 10. Integrar las nuevas tendencias }\end{array}$ & 1 & 16.7 & 4 & 66.7 & 1 & 16.7 & 3.00 & .63 \\
\hline $\begin{array}{l}\text { tecnológicas a la práctica } \\
\text { pedagógica. }\end{array}$ & 5 & 83.3 & 0 & .0 & 1 & 16.7 & 2.33 & .82 \\
\hline $\begin{array}{l}\text { 11. Desarrollar habilidades para la } \\
\text { resolución de problemas }\end{array}$ & 1 & 16.7 & 2 & 33.3 & 3 & 50.0 & 3.33 & .82 \\
\hline $\begin{array}{l}\text { 12. Aprender a partir de tus propias } \\
\text { experiencias }\end{array}$ & 0 & .0 & 3 & 50.0 & 3 & 50.0 & 3.50 & .55 \\
\hline 13. Aprender a partir de los errores & 0 & .0 & 3 & 50.0 & 3 & 50.0 & 3.50 & .55 \\
\hline
\end{tabular}

Cuadro ${ }^{\circ}$ 46. Categoría aprender a aprender (profesores)

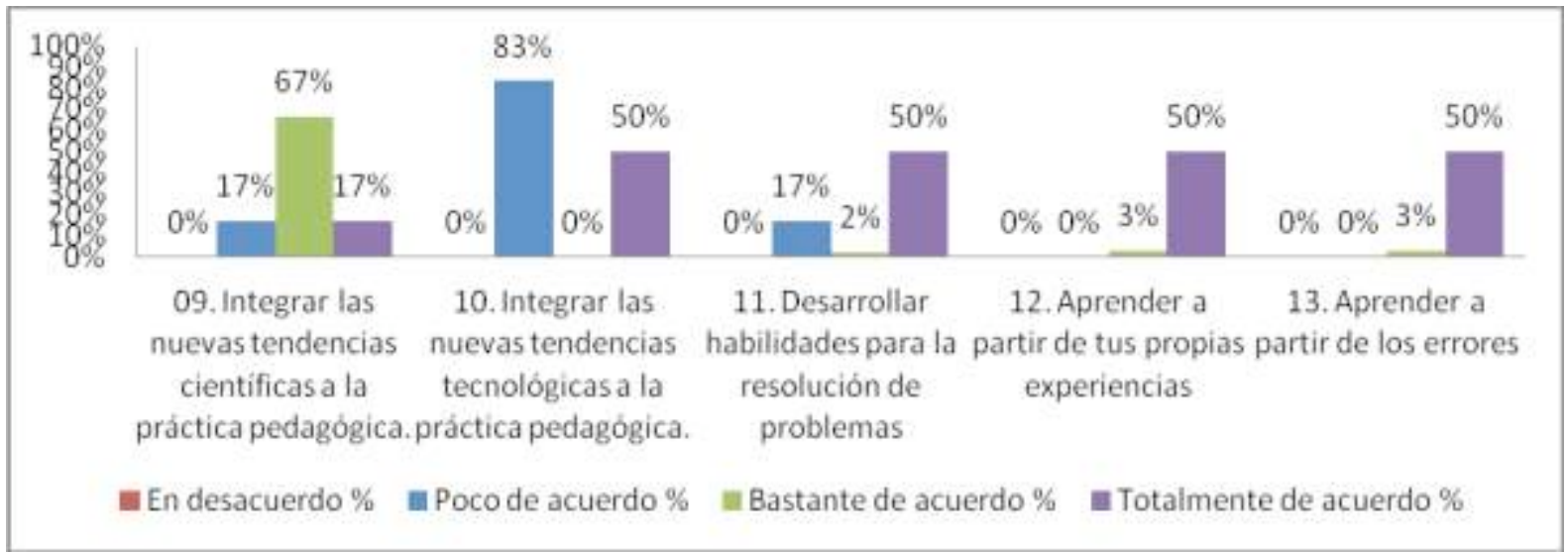

Grafico $n^{\circ} 42$. Categoría aprender a aprender (profesores) 
Como se distingue en la categoría de aprender a aprender, las profesoras encuestadas coinciden en estar bastante de acuerdo $(66,7 \%)$ en que sus alumnos aprendieron a integrar las nuevas tendencias científicas a la práctica pedagógica; así mismo, un 50\% de las informantes está totalmente de acuerdo en los aprendizajes sobre: habilidades para resolución de problemas, aprender a partir de sus propias experiencias y a partir de los errores. Se destaca que el 83,3\% de las profesoras esta poco de acuerdo con el aprendizaje de sus alumnos en la integración de las nuevas tecnologías a la práctica pedagógica.

\section{Categoría: actualización permanente}

Poco de acuerdo $\begin{array}{cc}\text { Bastante de } \\ \text { acuerdo }\end{array} \quad \begin{gathered}\text { Totalmente de } \\ \text { acuerdo }\end{gathered}$

14. Ampliar y complementar los

frec

$\% \quad$ Frec

$\% \quad$ frec

$\% \quad$ Desv

conocimientos adquiridos

16.7

16.7

4

66.7

3.50

.84

15. Asistir a clases con materiales leídos/ preparados

$\begin{array}{llll}2 & 33.3 & 3 & 500\end{array}$

$\begin{array}{lll}1 & 16.7 & 2.83\end{array}$

.75

Cuadro $\mathrm{n}^{\circ}$ 47. Categoría actualización permanente (profesores)

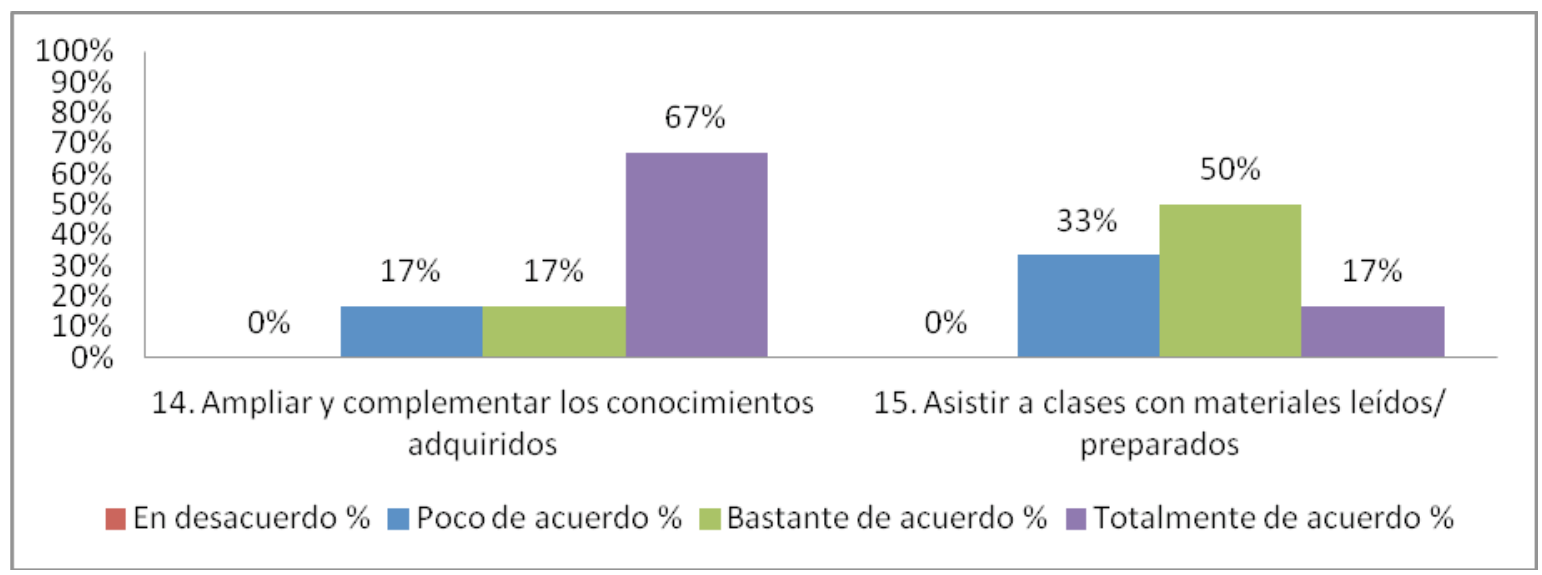

Grafico n ${ }^{\circ} 43$. Categoría actualización permanente (profesores)

285

La Práctica Profesional como área para potenciar las competencias pedagógicas necesarias para la enseñanza en Educación Infantil 
En relación a la categoría sobre actualización permanente, se tiene que hay una tendencia favorable por parte de las profesoras a estar totalmente de acuerdo con el hecho de que sus alumnos se muestran dispuestos a ampliar y complementar sus conocimientos; no ocurre lo mismo al preguntarle si sus alumnos asisten a clases con materiales leidos y preparados, ya que las opiniones tiene una tendencia negativa, a estar poco de acuerdo (33\%) y bastante de acuerdo $(50 \%)$ con esta caracteristica de sus alumnos.

\section{Categoría: capacidad de autoevaluar sus ap rendizajes.}

\begin{tabular}{|c|c|c|c|c|c|c|c|c|}
\hline & \multicolumn{2}{|c|}{ Poco de acuerdo } & \multicolumn{2}{|c|}{$\begin{array}{c}\text { Bastante de } \\
\text { acuerdo }\end{array}$} & \multicolumn{2}{|c|}{$\begin{array}{l}\text { Totalmente de } \\
\text { acuerdo }\end{array}$} & \multirow[b]{2}{*}{ Media } & \multirow[b]{2}{*}{$\begin{array}{l}\text { Desv } \\
\text { típ }\end{array}$} \\
\hline & frec & $\%$ & frec & $\%$ & frec & $\%$ & & \\
\hline $\begin{array}{l}\text { 16. Trasladar a otras situaciones los } \\
\text { aprendizajes teóricos/prácticos }\end{array}$ & 0 & .0 & 5 & 83.3 & 1 & 16.7 & 3.17 & .41 \\
\hline $\begin{array}{l}\text { 17. Integrar actividades de } \\
\text { docencia con investigación }\end{array}$ & 3 & 50.0 & 2 & 33.3 & 1 & 16.7 & 2.67 & .82 \\
\hline $\begin{array}{l}\text { 18. Comprobar la relación de las } \\
\text { asignaturas cursadas con la puesta } \\
\text { en práctica de sus prácticas } \\
\text { profesionales }\end{array}$ & 2 & 33.3 & 3 & 50.0 & 1 & 16.7 & 2.83 & .75 \\
\hline
\end{tabular}

Cuadro $\mathrm{n}^{\circ} 48$. Categoría capacidad de autoevaluar sus aprendizajes (profesores)

\section{Capacidad de autoevaluar sus aprendizajes}

—En desacuerdo \% — Poco de acuerdo \% Bastante de acuerdo \% - Totalmente de acuerdo \%
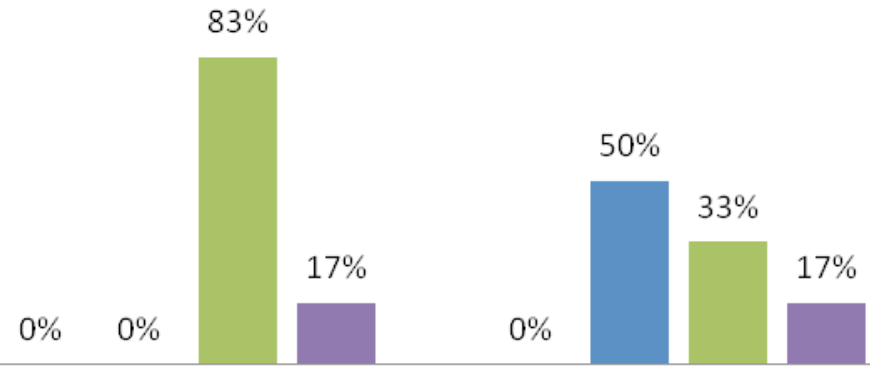

16. Trasladar a otras situaciones

17. Integrar actividades de

los aprendizajes teóricos/prácticos

docencia con investigación

18. Comprobar la relación de las asignaturas cursadas con la puesta

en práctica de tus prácticas profesionales

Grafico $n^{\circ} 44$. Categoría capacidad de autoevaluar sus aprendizajes (profesores)

286

La Práctica Profesional como área para potenciar las competencias pedagógicas necesarias para la enseñanza en Educación Infantil 
En la categoría capacidad de autoevaluar sus aprendizajes, las profesoras afirman que estan bastante de acuerdo $(83,3 \%)$ en que sus alumnos demuestran que trasladan a otras situaciones sus aprendizajes teóricos practicos; De manera impactante se tiene que el 50\% de las informantes considera que estan poco de acuerdo con los aprendizajes de los alumnos en cuestiones relacionadas con la integración de actividades de docencia e investigación. 


\subsection{Dimensión Didáctica Especifica Educación Inicial}

\section{Categoría: organización de la situación enseñanza aprendizaje}

\begin{tabular}{|c|c|c|c|c|c|c|c|c|}
\hline & \multicolumn{2}{|c|}{ Poco de acuerdo } & \multicolumn{2}{|c|}{$\begin{array}{l}\text { Bastante de } \\
\text { acuerdo }\end{array}$} & \multicolumn{2}{|c|}{$\begin{array}{l}\text { Totalmente de } \\
\text { acuerdo }\end{array}$} & \multirow[b]{2}{*}{ Media } & \multirow[b]{2}{*}{$\begin{array}{l}\text { Desv } \\
\text { típ }\end{array}$} \\
\hline & frec & $\%$ & frec & $\%$ & frec & $\%$ & & \\
\hline $\begin{array}{l}\text { 19. Crear ambientes que motiven } \\
\text { a los niños al descubrimiento de } \\
\text { sus propias capacidades, } \\
\text { limitaciones, intereses y } \\
\text { necesidades }\end{array}$ & 0 & .0 & 1 & 16.7 & 5 & 83.3 & 3.83 & .41 \\
\hline $\begin{array}{l}20 \text {. Elaborar material didáctico } \\
\text { adecuado a los requerimientos de } \\
\text { las actividades planificadas y de } \\
\text { los aprendizajes esperados }\end{array}$ & 0 & .0 & 1 & 16.7 & 5 & 83.3 & 3.83 & .41 \\
\hline $\begin{array}{l}\text { 21. Crear ambientes de } \\
\text { aprendizaje, respondiendo a las } \\
\text { exigencias del Diseño Curricular } \\
\text { Educación Inicial }\end{array}$ & 2 & 33.3 & 1 & 16.7 & 3 & 50.0 & 3.17 & .98 \\
\hline $\begin{array}{l}\text { 22. Diseñar recursos para el } \\
\text { aprendizaje }\end{array}$ & 0 & .0 & 3 & 50.0 & 3 & 50.0 & 3.50 & .55 \\
\hline
\end{tabular}

Cuadro $n^{\circ} 49$. Categoría organización de la situación enseñanza aprendizaje (profesores)

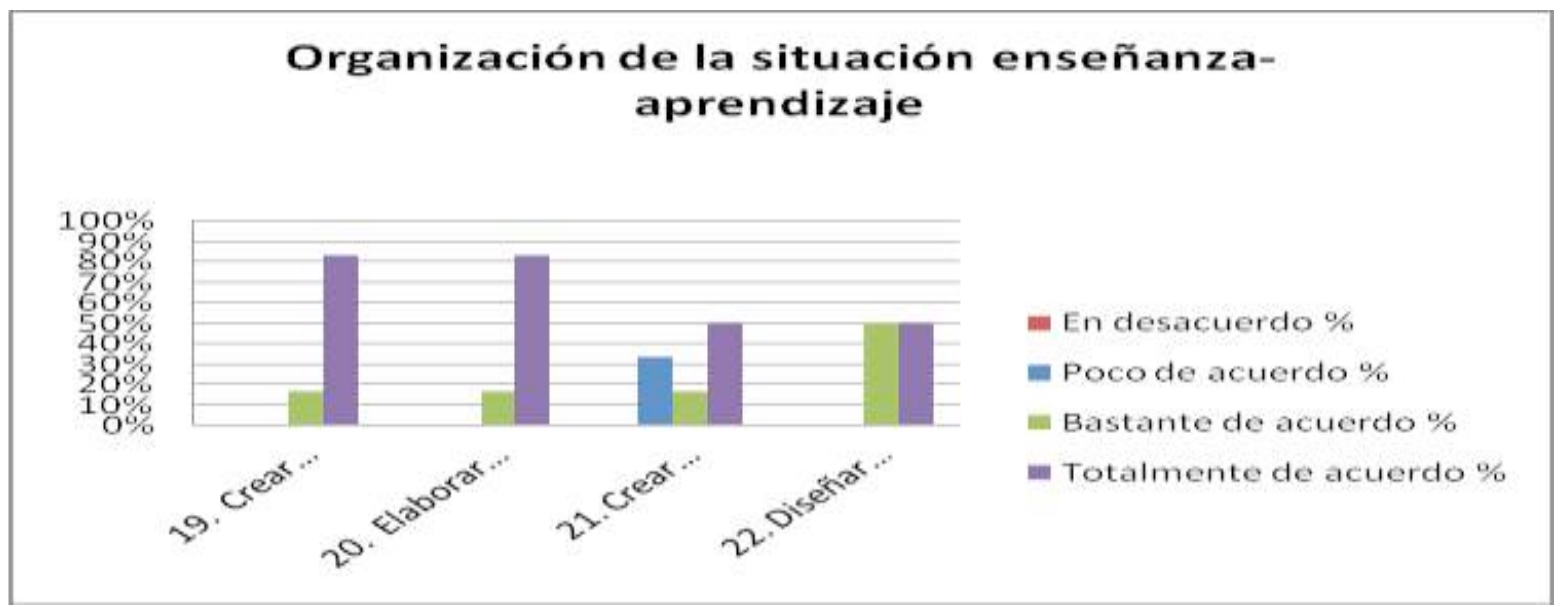

Grafico $n^{\circ}$ 45.Categoría organización de la situación enseñanza aprendizaje (profesores)

288

La Práctica Profesional como área para potenciar las competencias pedagógicas necesarias para la enseñanza en Educación Infantil 
En referencia a la categoría organización de la situación enseñanza aprendizaje, las profesoras expresaron una tendencia bastante favorable al opinar sobre las habilidades de sus alumnos para crear, elaborar, diseñar, recursos y ambientes de aprendizaje para la educación inicial.

\section{Categoría: proceso de planificación}

\begin{tabular}{|c|c|c|c|c|c|c|c|c|c|c|}
\hline & \multicolumn{2}{|c|}{ En desacuerdo } & \multicolumn{2}{|c|}{ Poco de acuerdo } & \multicolumn{2}{|c|}{$\begin{array}{l}\text { Bastante de } \\
\text { acuerdo }\end{array}$} & \multicolumn{2}{|c|}{$\begin{array}{l}\text { Totalmente de } \\
\text { acuerdo }\end{array}$} & \multirow[b]{2}{*}{ Media } & \multirow[b]{2}{*}{$\begin{array}{l}\text { Desv } \\
\text { típ }\end{array}$} \\
\hline & Frec & $\%$ & frec & $\%$ & frec & $\%$ & Frec & $\%$ & & \\
\hline $\begin{array}{l}\text { 23. Planificar actividades en } \\
\text { virtud del logro de los } \\
\text { aprendizajes esperados }\end{array}$ & 0 & .0 & 2 & 33.3 & 3 & 50.0 & 1 & 16.7 & 2.83 & .75 \\
\hline $\begin{array}{l}\text { 24. Planificar proyectos } \\
\text { involucrando activamente a } \\
\text { niños y niñas, sus familias, } \\
\text { personal, } \\
\text { circundante }\end{array}$ & 0 & .0 & 3 & 50.0 & 1 & 16.7 & 2 & 33.3 & 2.83 & .98 \\
\hline $\begin{array}{l}\text { 25. Diseñar, administrar y } \\
\text { ejecutar proyectos educativos }\end{array}$ & 0 & .0 & 4 & 66.7 & 0 & .0 & 2 & 33.3 & 2.67 & 1.03 \\
\hline $\begin{array}{l}\text { 26. Planificar experiencias de } \\
\text { orientación a la comunidad } \\
\text { sobre temas pedagógicos }\end{array}$ & 0 & .0 & 3 & 50.0 & 2 & 33.3 & 1 & 16.7 & 2.67 & .82 \\
\hline $\begin{array}{l}\text { 27. Planificar experiencias de } \\
\text { desarrollo personal para las } \\
\text { familias }\end{array}$ & 1 & 16.7 & 2 & 33.3 & 2 & 33.3 & 1 & 16.7 & 2.50 & 1.05 \\
\hline $\begin{array}{l}\text { 28. Coordinar y correlacionar } \\
\text { objetivos contenidos y } \\
\text { actividades }\end{array}$ & 0 & .0 & 1 & 16.7 & 4 & 66.7 & 1 & 16.7 & 3.00 & .63 \\
\hline $\begin{array}{l}\text { 29. Transferir el diagnóstico a } \\
\text { sus planificaciones }\end{array}$ & 0 & .0 & 2 & 33.3 & 3 & 50.0 & 1 & 16.7 & 2.83 & .75 \\
\hline $\begin{array}{l}30 . \quad \text { Diseñar y ejecutar } \\
\text { actividades para cada una de las } \\
\text { áreas de aprendizaje }\end{array}$ & 0 & .0 & 3 & 50.0 & 2 & 33.3 & 1 & 16.7 & 2.67 & .82 \\
\hline
\end{tabular}

289

La Práctica Profesional como área para potenciar las competencias pedagógicas necesarias para la enseñanza en Educación Infantil 


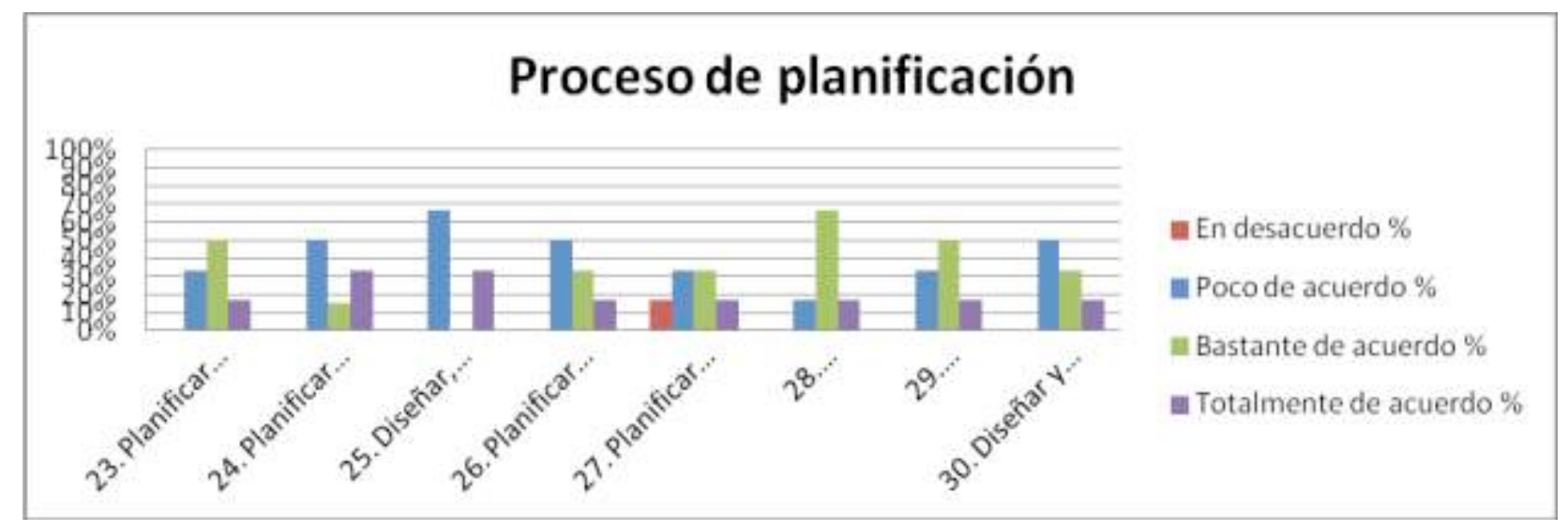

Grafico n 46. Categoría proceso de planificación (profesores).

En esta categoría las profesoras estan bastante de acuerdo en que sus alumnas demuestran aprendizajes en aspectos como: planificar actividades (50\%), correlacionar los objetivos, contenidos y actividades $(66,7 \%)$ y transferir el diagnostico a sus planificaciones ( $50 \%)$. Por otra parte, su opinión cambia al considerar estar poco de acuerdo con todos los aspectos relacionados con la planificación por proyectos.

\section{Categoría: proceso de evaluación}

\begin{tabular}{|c|c|c|c|c|c|c|c|c|c|c|}
\hline & \multicolumn{2}{|c|}{ En desacuerdo } & \multicolumn{2}{|c|}{ Poco de acuerdo } & \multicolumn{2}{|c|}{$\begin{array}{l}\text { Bastante de } \\
\text { acuerdo }\end{array}$} & \multicolumn{2}{|c|}{$\begin{array}{l}\text { Totalmente de } \\
\text { acuerdo }\end{array}$} & \multirow[b]{2}{*}{ Media } & \multirow[b]{2}{*}{$\begin{array}{l}\text { Desv } \\
\text { típ }\end{array}$} \\
\hline & frec & $\%$ & frec & $\%$ & frec & $\%$ & frec & $\%$ & & \\
\hline $\begin{array}{l}\text { 31. Diseñar instrumentos de } \\
\text { evaluación adecuados a los } \\
\text { requerimientos de los aprendizajes } \\
\text { esperados }\end{array}$ & 0 & .0 & 3 & 50.0 & 2 & 33.3 & 1 & 16.7 & 2.67 & .82 \\
\hline $\begin{array}{l}32 \text { Utilizar técnicas y } \\
\text { procedimientos de observación de } \\
\text { conductas de entrada, en } \\
\text { situaciones de aprendizaje }\end{array}$ & 0 & .0 & 2 & 33.3 & 3 & 50.0 & 1 & 16.7 & 2.83 & .75 \\
\hline $\begin{array}{l}\text { 33. Usar y dominar los } \\
\text { procedimientos de administración } \\
\text { de escalas sociométricas simples. }\end{array}$ & 2 & 33.3 & 2 & 33.3 & 1 & 16.7 & 1 & 16.7 & 2.17 & 1.17 \\
\hline $\begin{array}{l}\text { 34. Evaluar los procesos de } \\
\text { aprendizaje de los niños }\end{array}$ & 1 & 16.7 & 2 & 33.3 & 1 & 16.7 & 2 & 33.3 & 2.67 & 1.21 \\
\hline $\begin{array}{l}\text { 35. Evaluar el desarrollo evolutivo } \\
\text { de los niños }\end{array}$ & 1 & 16.7 & 2 & 33.3 & 1 & 16.7 & 2 & 33.3 & 2.67 & 1.21 \\
\hline
\end{tabular}

Cuadro $\mathrm{n}^{\circ} 51$. Categoría proceso de evaluación (profesores) 


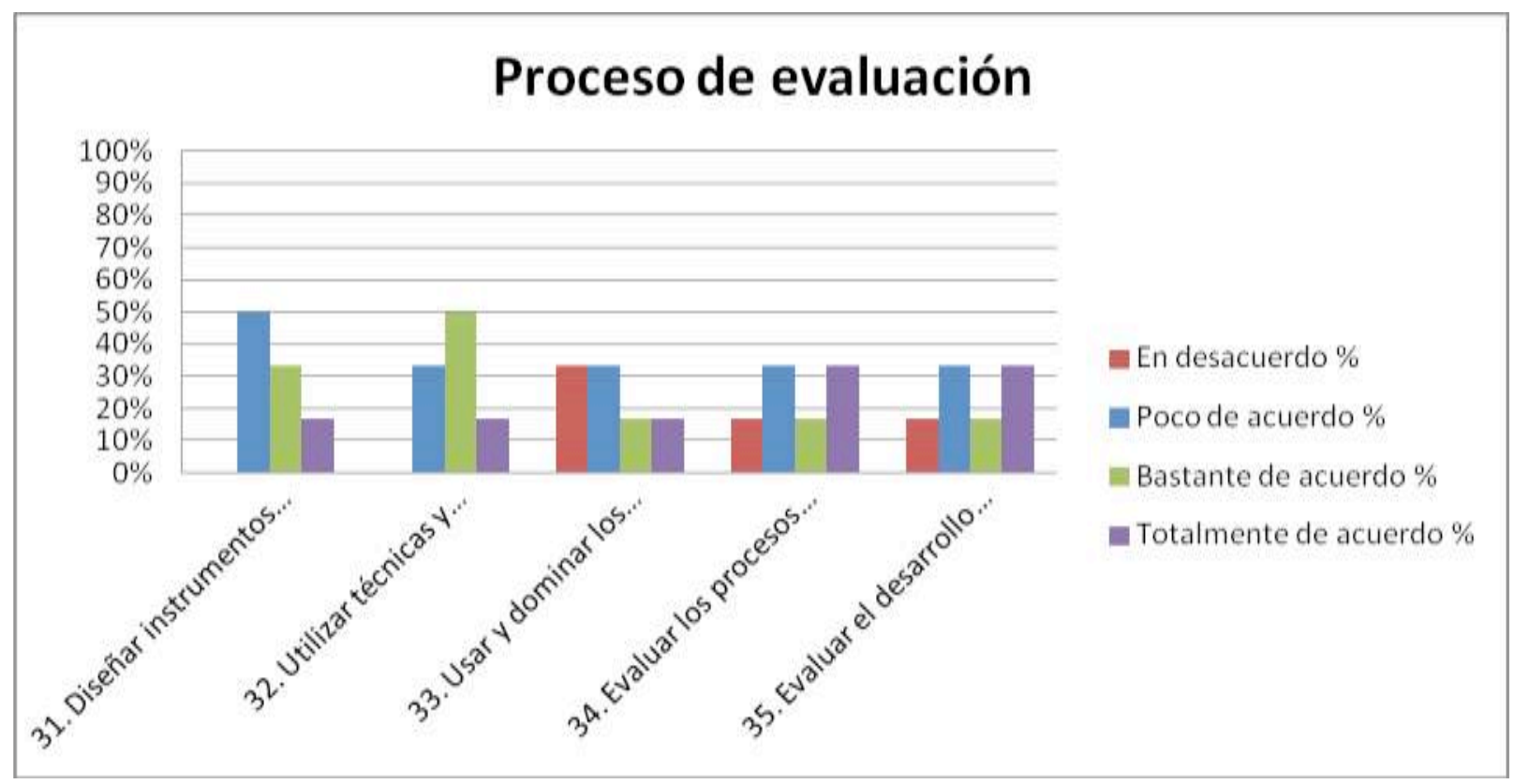

Grafico $n^{\circ} 47$. Categoría proceso de evaluación (profesores)

Al apreciar esta categoría, el 50\% de las profesoras, estan poco de acuerdo, con las destrezas de los alumnos en el diseño de instrumentos de evaluación; Así mismo existe una tendencia importante al valorar negativamente el aspecto referido al uso y dominio de escalas sociometricas simples. En líneas generales las opiniones de las profesoras sobre el proceso de evalución en educación inicial, tienen una tendencia negativa.

Categoría: interacción pedagógica

\begin{tabular}{|c|c|c|c|c|c|c|c|c|c|c|}
\hline & \multicolumn{2}{|c|}{ En desacuerdo } & \multicolumn{2}{|c|}{ Poco de acuerdo } & \multicolumn{2}{|c|}{$\begin{array}{l}\text { Bastante de } \\
\text { acuerdo }\end{array}$} & \multicolumn{2}{|c|}{$\begin{array}{l}\text { Totalmente de } \\
\text { acuerdo }\end{array}$} & \multirow[b]{2}{*}{ Media } & \multirow{2}{*}{$\begin{array}{l}\text { Desv } \\
\text { típ }\end{array}$} \\
\hline & frec & $\%$ & frec & $\%$ & frec & $\%$ & frec & $\%$ & & \\
\hline $\begin{array}{l}36 . \quad \text { Realizar } \\
\text { intercambio } \\
\text { pedagógico con otros } \\
\text { profesionales }\end{array}$ & 0 & .0 & 2 & 33.3 & 3 & 50.0 & 1 & 16.7 & 2.83 & .75 \\
\hline $\begin{array}{l}37 . \quad \text { Desarrollar } \\
\text { habilidades para el } \\
\text { manejo grupal de } \\
\text { niños durante la rutina }\end{array}$ & 0 & .0 & 1 & 16.7 & 2 & 33.3 & 3 & 50.0 & 3.33 & .82 \\
\hline & & & & & & & & & & \\
\hline
\end{tabular}


diaria.

38. Realizar procesos de mediación en el área afectiva

39. Favorecer la estimulación temprana 40. Impulsar a los niños en los procesos de lectoescritura

41. Impulsar a los niños en el proceso lógico-matemático

42. Fortalecer la autoestima del niño 43. Fomentar la educación para la salud 44. Desarrollar habilidades para la resolución de situaciones difíciles de resolver: preguntas sobre sexualidad, agresividad infantil

Cuadro $n^{\circ} 52$. Categoría interacción pedagógica (profesores)

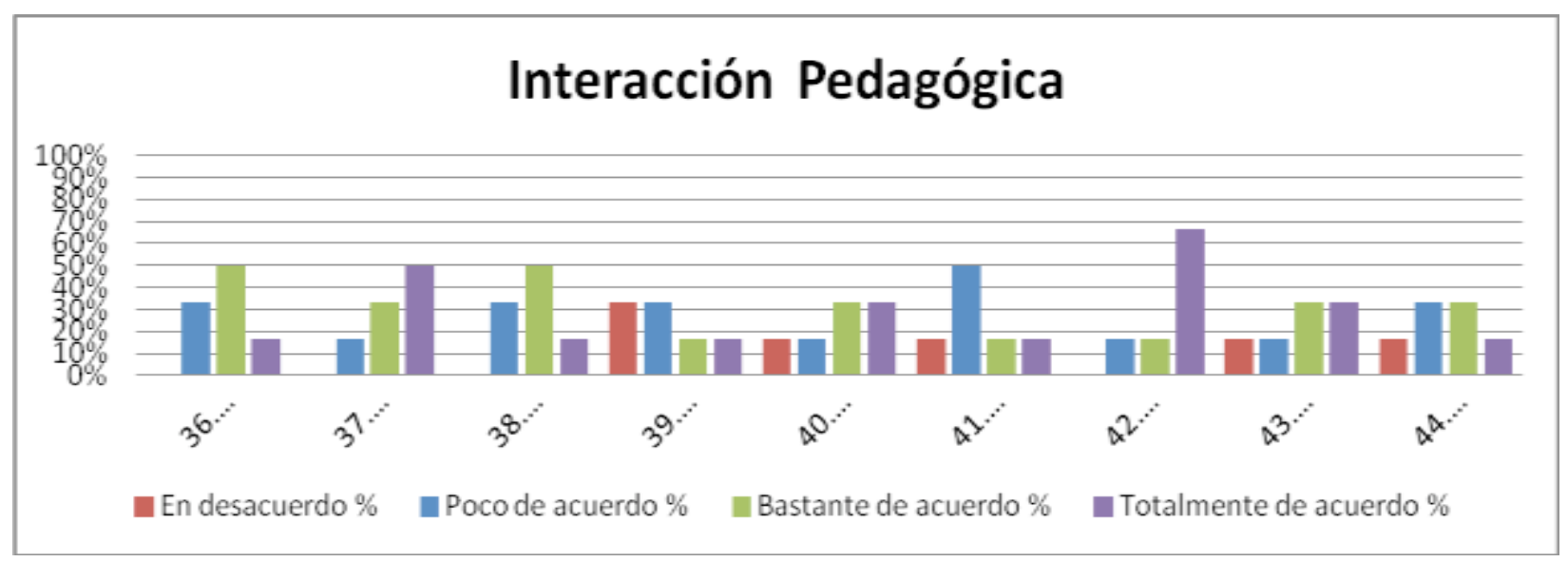

Grafico $n^{\circ}$ 48. Categoría interacción pedagógica (profesores).

En la categoría referida a la interacción pedagógica se estima una tendencia bastante positiva por parte de las profesoras al valorar los aprendizajes de los alumnos, no obstante, las opiniones sobre estimulación temprana, procesos logico matematicos y resolución de situaciones dificiles, presentan una tendencia negativa. 


\subsection{Dimensión Enseñanza Universitaria}

\section{Categoría: didáctica universitaria}

\begin{tabular}{|c|c|c|c|c|c|c|}
\hline & \multicolumn{2}{|c|}{ Bastante de acuerdo } & \multicolumn{2}{|c|}{ Totalmente de acuerdo } & \multirow[b]{2}{*}{ Media } & \multirow[b]{2}{*}{ Desv típ } \\
\hline & frec & $\%$ & frec & $\%$ & & \\
\hline $\begin{array}{l}\text { 45. Proporcionaron fuentes de información y } \\
\text { recursos a los estudiantes }\end{array}$ & 3 & 50.0 & 3 & 50.0 & 3.50 & .55 \\
\hline $\begin{array}{l}\text { 46. Los motivaron a preparar actividades de } \\
\text { aprendizaje }\end{array}$ & 1 & 16.7 & 5 & 83.3 & 3.83 & .41 \\
\hline $\begin{array}{l}\text { 47. Inician los temas contextualizándolos } \\
\text { previamente }\end{array}$ & 1 & 16.7 & 5 & 83.3 & 3.83 & .41 \\
\hline $\begin{array}{l}\text { 48. Realizan asociación de temas con los } \\
\text { objetivos planteados }\end{array}$ & 3 & 50.0 & 3 & 50.0 & 3.50 & .55 \\
\hline 49. Aportan conocimientos actualizados & 2 & 33.3 & 4 & 66.7 & 3.67 & .52 \\
\hline $\begin{array}{l}\text { 50. Dominan los aspectos teóricos de los } \\
\text { contenidos de las asignaturas }\end{array}$ & 1 & 16.7 & 5 & 83.3 & 3.83 & .41 \\
\hline $\begin{array}{l}\text { 51. Dominan los aspectos prácticos de los } \\
\text { contenidos de las asignaturas }\end{array}$ & 2 & 33.3 & 4 & 66.7 & 3.67 & .52 \\
\hline $\begin{array}{l}\text { 52. Relacionan la asignatura con otras } \\
\text { ciencias o conocimientos }\end{array}$ & 3 & 50.0 & 3 & 50.0 & 3.50 & .55 \\
\hline
\end{tabular}

Cuadro $\mathrm{n}^{\circ}$ 53. Categoría didáctica universitaria (profesores)

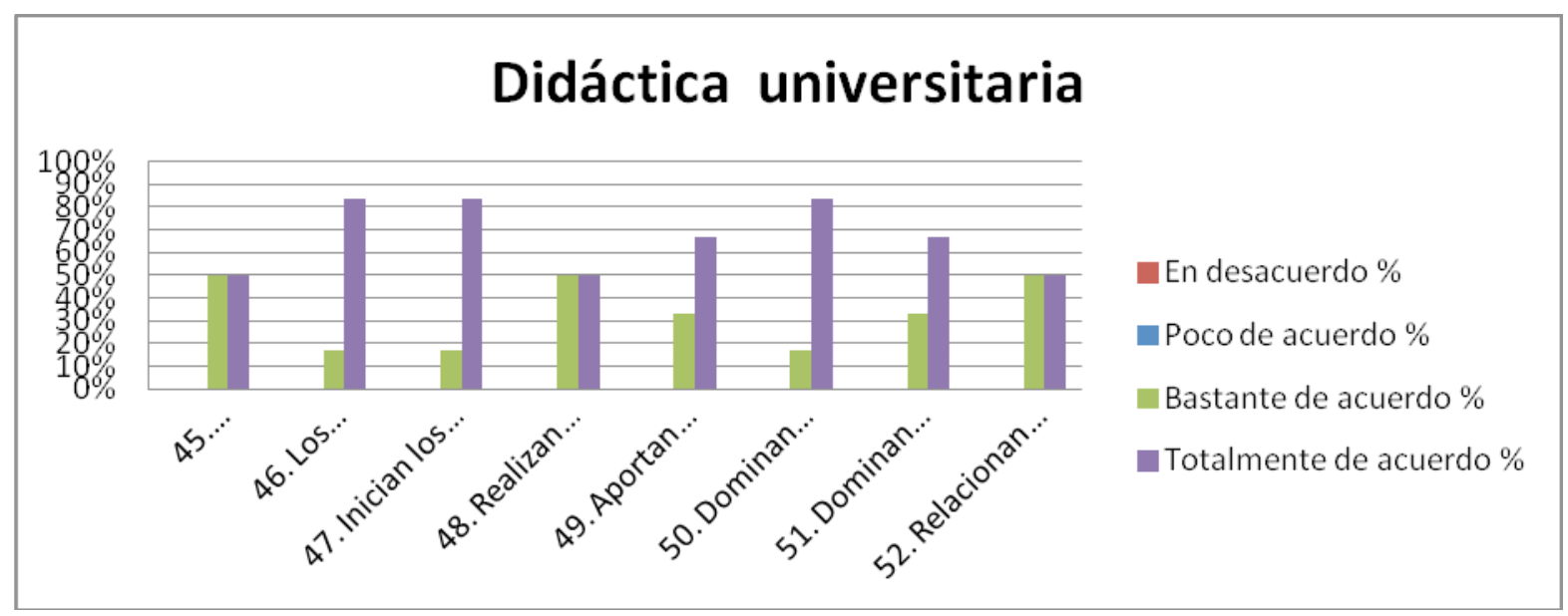

Grafico $n^{\circ} 49$. Categoría didáctica universitaria (profesores) 
En relación con la categoría didáctica universitaria, las profesoras se autoevaluan de manera bastante positiva en todos los ítems del cuestionario. Se aprecia que reconocen estar bastante y totalmente de acuerdo en haber proporcionado buenos procesos didácticos para favorecer los aprendizajes de sus alumnos.

\section{Categoría: metodología universitaria}

\begin{tabular}{|c|c|c|c|c|c|c|c|c|c|c|}
\hline & \multicolumn{2}{|c|}{ En desacuerdo } & \multicolumn{2}{|c|}{ Poco de acuerdo } & \multicolumn{2}{|c|}{ Bastante de acuerdo } & \multicolumn{2}{|c|}{$\begin{array}{l}\text { Totalmente de } \\
\text { acuerdo }\end{array}$} & \multirow[b]{2}{*}{ Media } & \multirow[b]{2}{*}{ Desv típ } \\
\hline & Frec & $\%$ & frec & $\%$ & frec & $\%$ & frec & $\%$ & & \\
\hline 53. Exposiciones magistrales del profesor. & 1 & 16.7 & 0 & .0 & 2 & 33.3 & 3 & 50.0 & 3.17 & 1.17 \\
\hline 54. Exposiciones orales de los estudiantes & 0 & .0 & 0 & .0 & 1 & 16.7 & 5 & 83.3 & 3.83 & .41 \\
\hline $\begin{array}{l}\text { 55. Comentarios de actualidad, } \\
\text { relacionados con la educación infantil }\end{array}$ & 0 & .0 & 0 & .0 & 1 & 16.7 & 5 & 83.3 & 3.83 & .41 \\
\hline $\begin{array}{l}\text { 56. Practicas colectivas en el aula de } \\
\text { recursos }\end{array}$ & 0 & .0 & 3 & 50.0 & 1 & 16.7 & 2 & 33.3 & 2.83 & .98 \\
\hline $\begin{array}{l}\text { 57. Debates y análisis colectivo de } \\
\text { documentos }\end{array}$ & 0 & .0 & 1 & 16.7 & 1 & 16.7 & 4 & 66.7 & 3.50 & .84 \\
\hline $\begin{array}{l}\text { 58. Trabajos individuales y cooperativos } \\
\text { fuera del horario de clases }\end{array}$ & 1 & 16.7 & 1 & 16.7 & 2 & 33.3 & 2 & 33.3 & 2.83 & 1.17 \\
\hline 59. Comentarios de textos & 1 & 16.7 & 1 & 16.7 & 2 & 33.3 & 2 & 33.3 & 2.83 & 1.17 \\
\hline 60. Presentaciones públicas de trabajos & 3 & 50.0 & 0 & .0 & 0 & .0 & 3 & 50.0 & 2.50 & 1.64 \\
\hline 61. Evaluación de materiales didácticos & 3 & 50.0 & 1 & 16.7 & 0 & .0 & 2 & 33.3 & 2.17 & 1.47 \\
\hline 62. Realización de proyectos educativos & 0 & .0 & 2 & 33.3 & 1 & 16.7 & 3 & 50.0 & 3.17 & .98 \\
\hline $\begin{array}{l}\text { 63. Diseño y ejecución de intervenciones } \\
\text { educativas }\end{array}$ & 0 & .0 & 0 & .0 & 2 & 33.3 & 4 & 66.7 & 3.67 & .52 \\
\hline 64. Ejecuciones prácticas con simulaciones & 0 & .0 & 0 & .0 & 1 & 16.7 & 5 & 83.3 & 3.83 & .41 \\
\hline 65. Trabajos de investigación & 0 & .0 & 0 & .0 & 3 & 50.0 & 3 & 50.0 & 3.50 & .55 \\
\hline 66. Tutorías. & 0 & .0 & 0 & .0 & 1 & 16.7 & 5 & 83.3 & 3.83 & .41 \\
\hline $\begin{array}{l}\text { 67. Visitas a centros educativos de } \\
\text { diferentes modalidades (públicos, privados, } \\
\text { no convencional, maternal) }\end{array}$ & 1 & 16.7 & 0 & .0 & 3 & 50.0 & 2 & 33.3 & 3.00 & 1.10 \\
\hline $\begin{array}{l}\text { 68. Actividades prácticas en los centros } \\
\text { educativos }\end{array}$ & 1 & 16.7 & 0 & .0 & 0 & .0 & 5 & 83.3 & 3.50 & 1.22 \\
\hline 69. Seminarios & 2 & 33.3 & 1 & 16.7 & 0 & .0 & 3 & 50.0 & 2.67 & 1.51 \\
\hline 70. Conferencias & 4 & 66.7 & 0 & .0 & 0 & .0 & 2 & 33.3 & 2.00 & 1.55 \\
\hline
\end{tabular}

Cuadro ${ }^{\circ} 54$. Categoría metodología universitaria (profesores) 


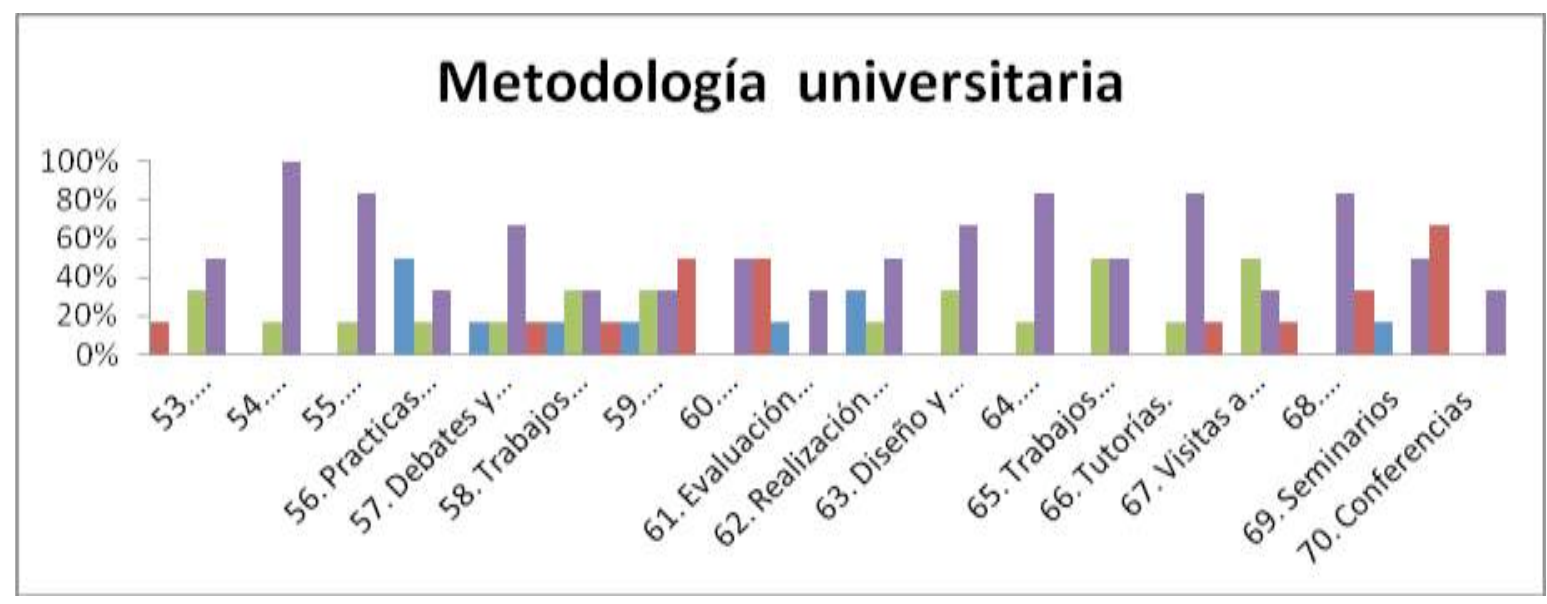

Grafico $\mathrm{n}^{\circ}$ 50. Categoría metodología universitaria (profesores)

En esta categoría, las profesoras admiten que los métodos que utilizaron con mayor frecuencia son: exposiciones de los alumnos, los comentarios sobre educación infantil, ejecuciones simuladas, tutorias y actividades prácticas en centros educativos $(83,3 \%)$. El resto de las opciones relacionadas con la metodología universitaria fue valorada como de muy poco uso por parte de los profesores.

\section{Categoría: contextos de aprendizaje.}

\begin{tabular}{|c|c|c|c|c|c|c|c|c|c|c|c|c|}
\hline & \multicolumn{2}{|c|}{ No contesta } & \multicolumn{2}{|c|}{ En desacuerdo } & \multicolumn{2}{|c|}{$\begin{array}{l}\text { Poco de } \\
\text { acuerdo }\end{array}$} & \multicolumn{2}{|c|}{$\begin{array}{l}\text { Bastante de } \\
\text { acuerdo }\end{array}$} & \multicolumn{2}{|c|}{$\begin{array}{l}\text { Totalmente de } \\
\text { acuerdo }\end{array}$} & \multirow[b]{2}{*}{ Media } & \multirow{2}{*}{$\begin{array}{l}\text { Desv } \\
\text { típ }\end{array}$} \\
\hline & frec & $\%$ & frec & $\%$ & frec & $\%$ & frec & $\%$ & frec & $\%$ & & \\
\hline $\begin{array}{l}\text { 71. Aula de clases de la } \\
\text { Universidad }\end{array}$ & 0 & .0 & 0 & .0 & 0 & .0 & 0 & .0 & 6 & 100.0 & 4.00 & .00 \\
\hline 72. Aula de recursos múltiples & 0 & .0 & 3 & 50.0 & 0 & .0 & 2 & 33.3 & 1 & 16.7 & 2.17 & 1.33 \\
\hline $\begin{array}{l}\text { 73. Biblioteca/ salas de } \\
\text { documentación }\end{array}$ & 0 & .0 & 3 & 50.0 & 2 & 33.3 & 0 & .0 & 1 & 16.7 & 1.83 & 1.17 \\
\hline 74. Centros maternales & 1 & 16.7 & 3 & 50.0 & 0 & .0 & 0 & .0 & 2 & 33.3 & 2.20 & 1.64 \\
\hline $\begin{array}{l}\text { 75. Centros educativos no } \\
\text { convencionales }\end{array}$ & 1 & 16.7 & 3 & 50.0 & 1 & 16.7 & 0 & .0 & 1 & 16.7 & 1.80 & 1.30 \\
\hline 76. Centros preescolares & 0 & .0 & 1 & 16.7 & 0 & .0 & 0 & .0 & 5 & 83.3 & 3.50 & 1.22 \\
\hline 77. Contextos comunitarios & 1 & 16.7 & 4 & 66.7 & 0 & .0 & 0 & .0 & 1 & 16.7 & 1.60 & 1.34 \\
\hline
\end{tabular}

Cuadro $n^{\circ} 55$. Categoría contextos de aprendizaje (profesores) 


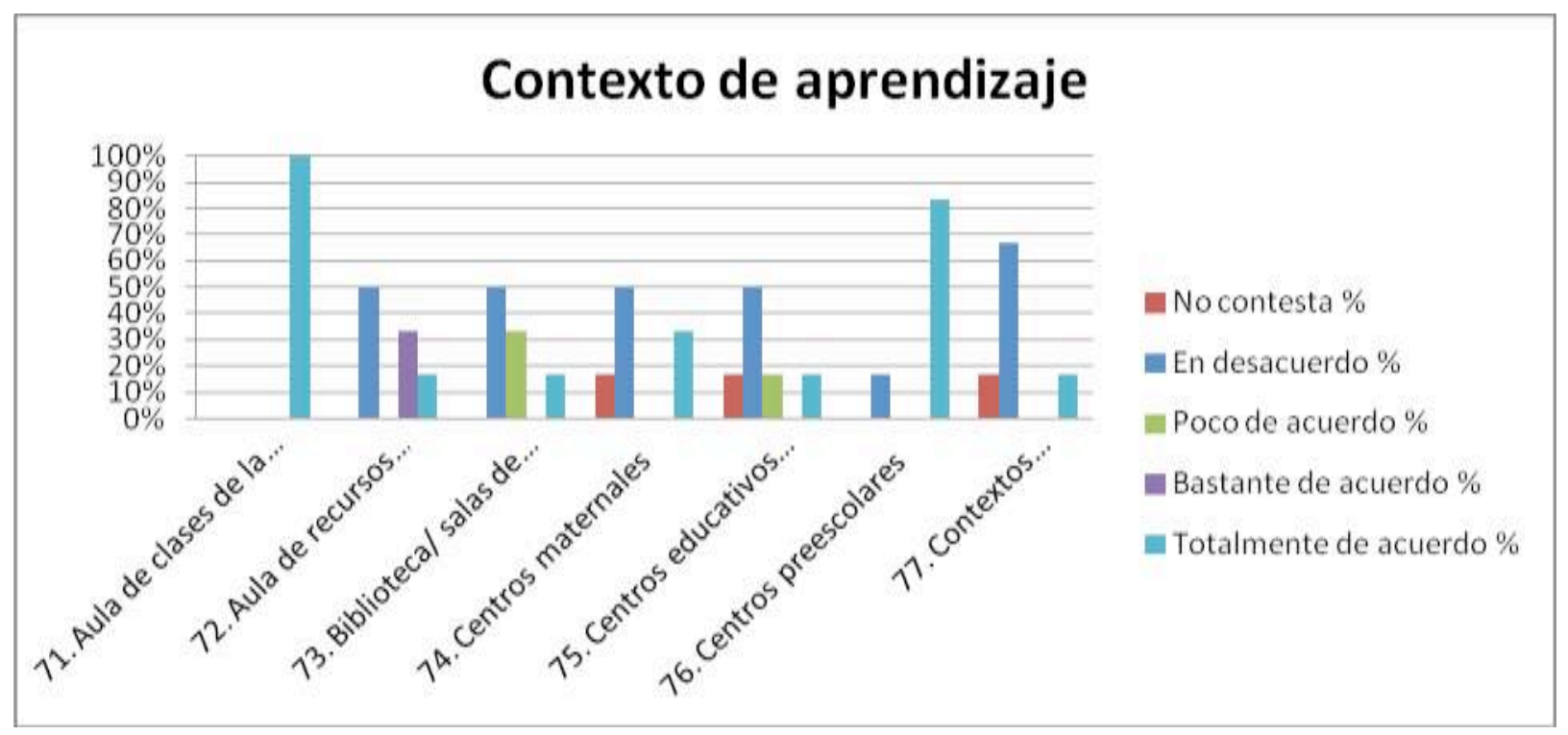

Grafico ${ }^{\circ} 51$. Categoría contextos de aprendizaje (profesores)

Las profesoras responden estar totalmente de acuerdo en haber utilizado las aulas de clases de la universidad, los centros preescolares, como los contextos de aprendizaje de práctica profesional. Por otra parte, admiten que no usaron el aula de recursos múltiples, la biblioteca, los centros maternales, los centros preescolars no convencionales y los contextos comunitarios $(50 \%)$. 
Categoría: métodos y criterios de evaluación.

\begin{tabular}{|c|c|c|c|c|c|c|c|c|c|c|}
\hline & \multicolumn{2}{|c|}{ En desacuerdo } & \multicolumn{2}{|c|}{ Poco de acuerdo } & \multicolumn{2}{|c|}{$\begin{array}{l}\text { Bastante de } \\
\text { acuerdo }\end{array}$} & \multicolumn{2}{|c|}{$\begin{array}{l}\text { Totalmente de } \\
\text { acuerdo }\end{array}$} & \multirow[b]{2}{*}{ Frec } & \multirow[b]{2}{*}{$\%$} \\
\hline & frec & $\%$ & frec & $\%$ & frec & $\%$ & frec & $\%$ & & \\
\hline $\begin{array}{l}78 . \quad \text { Trabajos } \\
\text { grupales } \quad \mathrm{e} \\
\text { individuales }\end{array}$ & 0 & .0 & 0 & .0 & 1 & 16.7 & 5 & 83.3 & 3.83 & .408 \\
\hline $\begin{array}{l}\text { 79. Proyectos } \\
\text { de investigación }\end{array}$ & 2 & 33.3 & 0 & .0 & 0 & .0 & 4 & 66.7 & 3.00 & 1.549 \\
\hline $\begin{array}{l}\text { 80. Informes } \\
\text { escritos }\end{array}$ & 1 & 16.7 & 0 & .0 & 0 & .0 & 5 & 83.3 & 3.50 & 1.225 \\
\hline 81. Debates & 1 & 16.7 & 1 & 16.7 & 3 & 50.0 & 1 & 16.7 & 2.67 & 1.033 \\
\hline $\begin{array}{l}82 . \\
\text { Exposiciones }\end{array}$ & 1 & 16.7 & 0 & .0 & 1 & 16.7 & 4 & 66.7 & 3.33 & 1.211 \\
\hline $\begin{array}{l}83 . \quad \text { Pruebas } \\
\text { orales } \\
84 .\end{array}$ & 3 & 60.0 & 0 & .0 & 0 & .0 & 2 & 40.0 & 2.20 & 1.643 \\
\hline $\begin{array}{l}\text { Seguimientos } \\
\text { desde la tutoría }\end{array}$ & 0 & .0 & 0 & .0 & 2 & 40.0 & 3 & 60.0 & 3.60 & .548 \\
\hline $\begin{array}{l}\text { 85. Realización } \\
\text { de trabajos en } \\
\text { grupo }\end{array}$ & 1 & 16.7 & 0 & .0 & 0 & .0 & 5 & 83.3 & 3.50 & 1.225 \\
\hline
\end{tabular}

Cuadro $\mathrm{n}^{\circ}$ 56. Categoría métodos y criterios de evaluación (profesores)

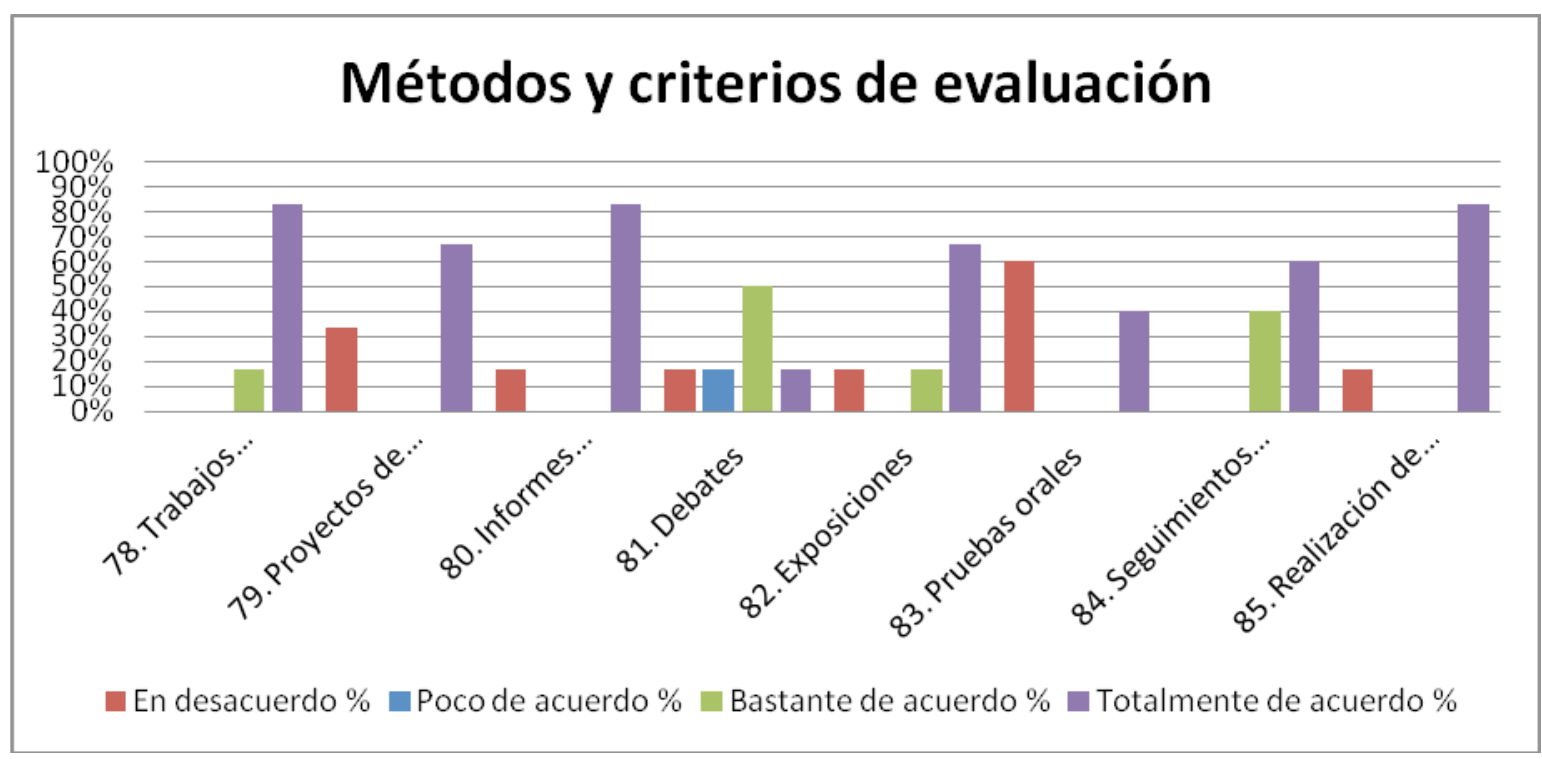

Grafico $\mathrm{n}^{\circ}$ 52. Categoría métodos y criterios de evaluación (profesores)

297

La Práctica Profesional como área para potenciar las competencias pedagógicas necesarias para la enseñanza en Educación Infantil 
Con relación a la categoría métodos y criterios de evaluación utilizados por las profesoras durante el proceso de formación, se observa que existe una tendencia positiva al considerar que hicieron uso de la mayoría de las opciones presentadas, solo resultan con baja valoración los métodos referidos al uso de pruebas orales

\subsection{Dimensión Académico Estudiantil}

\section{Categoría: créditos académicos}

\begin{tabular}{|c|c|c|c|c|c|c|c|c|c|c|}
\hline & \multicolumn{2}{|c|}{ En desacuerdo } & \multicolumn{2}{|c|}{$\begin{array}{l}\text { Poco de } \\
\text { acuerdo }\end{array}$} & \multicolumn{2}{|c|}{$\begin{array}{c}\text { Bastante de } \\
\text { acuerdo }\end{array}$} & \multicolumn{2}{|c|}{$\begin{array}{l}\text { Totalmente de } \\
\text { acuerdo }\end{array}$} & \multirow{2}{*}{\multicolumn{2}{|c|}{$\begin{array}{c}\text { Desv } \\
\text { típ } \\
\end{array}$}} \\
\hline & frec & $\%$ & frec & $\%$ & frec & $\%$ & frec & $\%$ & & \\
\hline 86. Normativa (reglamento) & 0 & .0 & 2 & 33.3 & $\overline{2}$ & 33.3 & 2 & 33.3 & 3.00 & .89 \\
\hline $\begin{array}{l}\text { 87. Ubicación en el plan de } \\
\text { estudios }\end{array}$ & 0 & .0 & 2 & 33.3 & 1 & 16.7 & 3 & 50.0 & 3.17 & .98 \\
\hline 88. Apoyo institucional & 0 & .0 & 4 & 66.7 & 1 & 16.7 & 1 & 16.7 & 2.50 & .84 \\
\hline $\begin{array}{l}\text { 89. Apoyo de los centros de } \\
\text { aplicación }\end{array}$ & 1 & 16.7 & 1 & 16.7 & 2 & 33.3 & 2 & 33.3 & 2.83 & 1.17 \\
\hline $\begin{array}{l}\text { 90. Recursos para el } \\
\text { aprendizaje }\end{array}$ & 1 & 16.7 & 2 & 33.3 & 0 & .0 & 3 & 50.0 & 2.83 & 1.33 \\
\hline 91. Evaluación & 0 & .0 & 0 & .0 & 3 & 50.0 & 3 & 50.0 & 3.50 & .55 \\
\hline
\end{tabular}




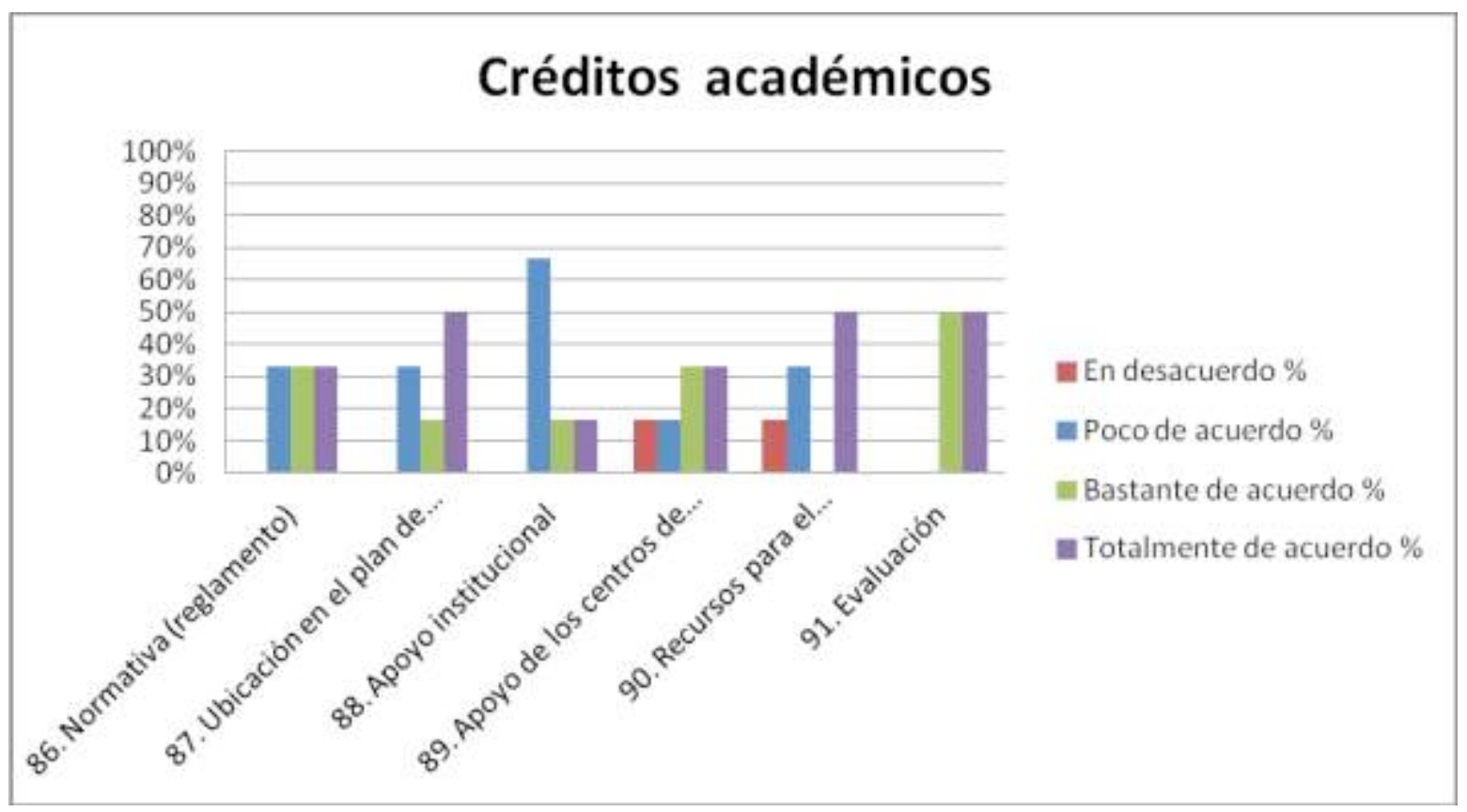

Grafico $n^{\circ} 53$. Categoría créditos académicos (profesores)

En esta categoría se aprecia que las profesoras estan bastante y totalmente de acuerdo con los aspectos referidos a la normativa UPEL, ubicación de las fases en el plan de estudios, el apoyo en los centros de aplicación y el reglamento de evaluación (50\%); en lo tocante al apoyo institucional y los recursos para el aprendizaje, la evaluación de las profesoras se ubicó en poco de acuerdo (66\%). 
Categoría: planes y programas

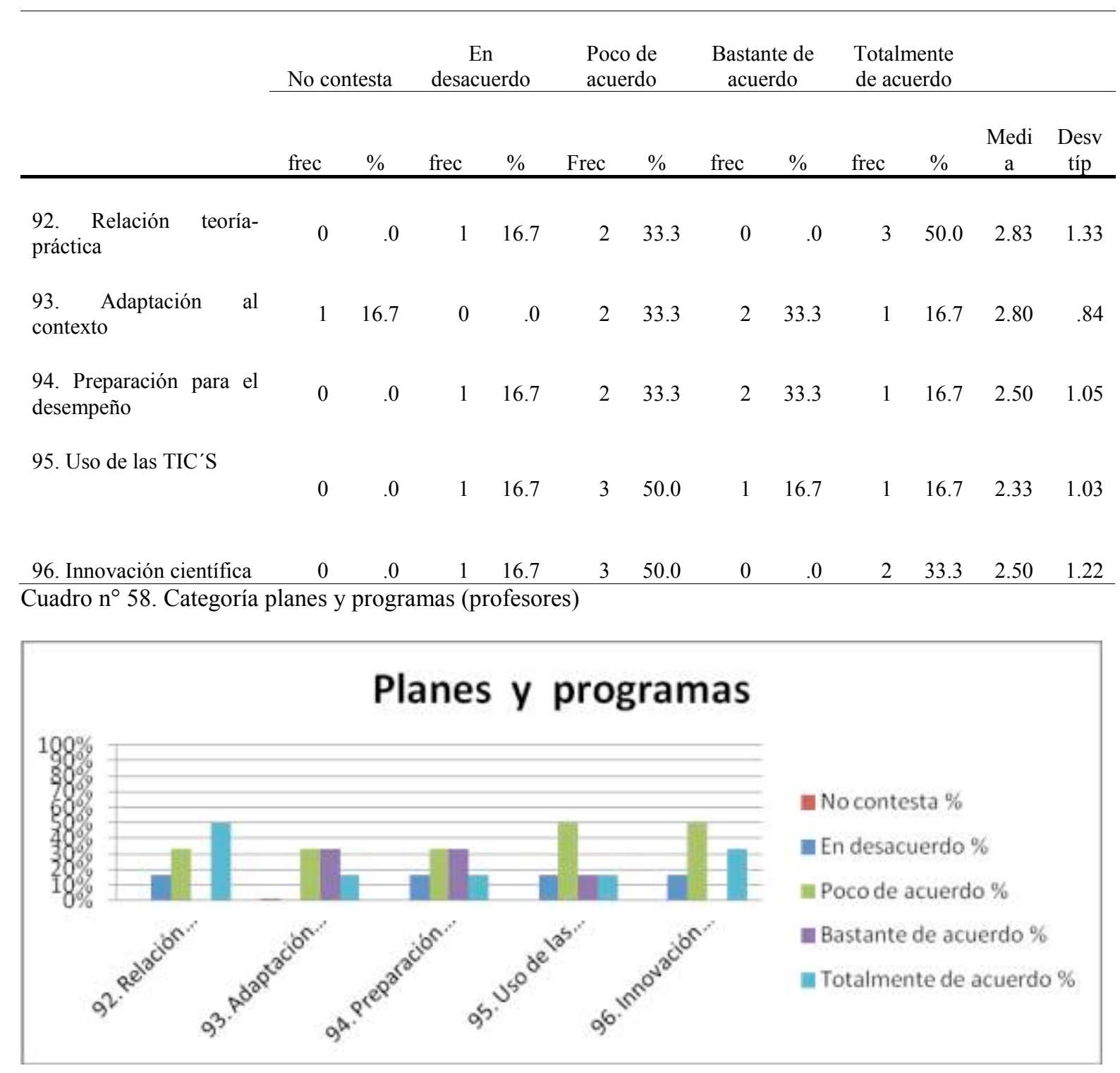

Grafico ${ }^{\circ} 54$. Categoría planes y programas (profesores)

Al observar la categoría planes y programas las profesoras se situan en un plano negativo al opinar sobre los ítems que indagan sobre la actualización, utilidad, prácticidad de los programas de práctica profesional. 
Servicio estudiantiles.

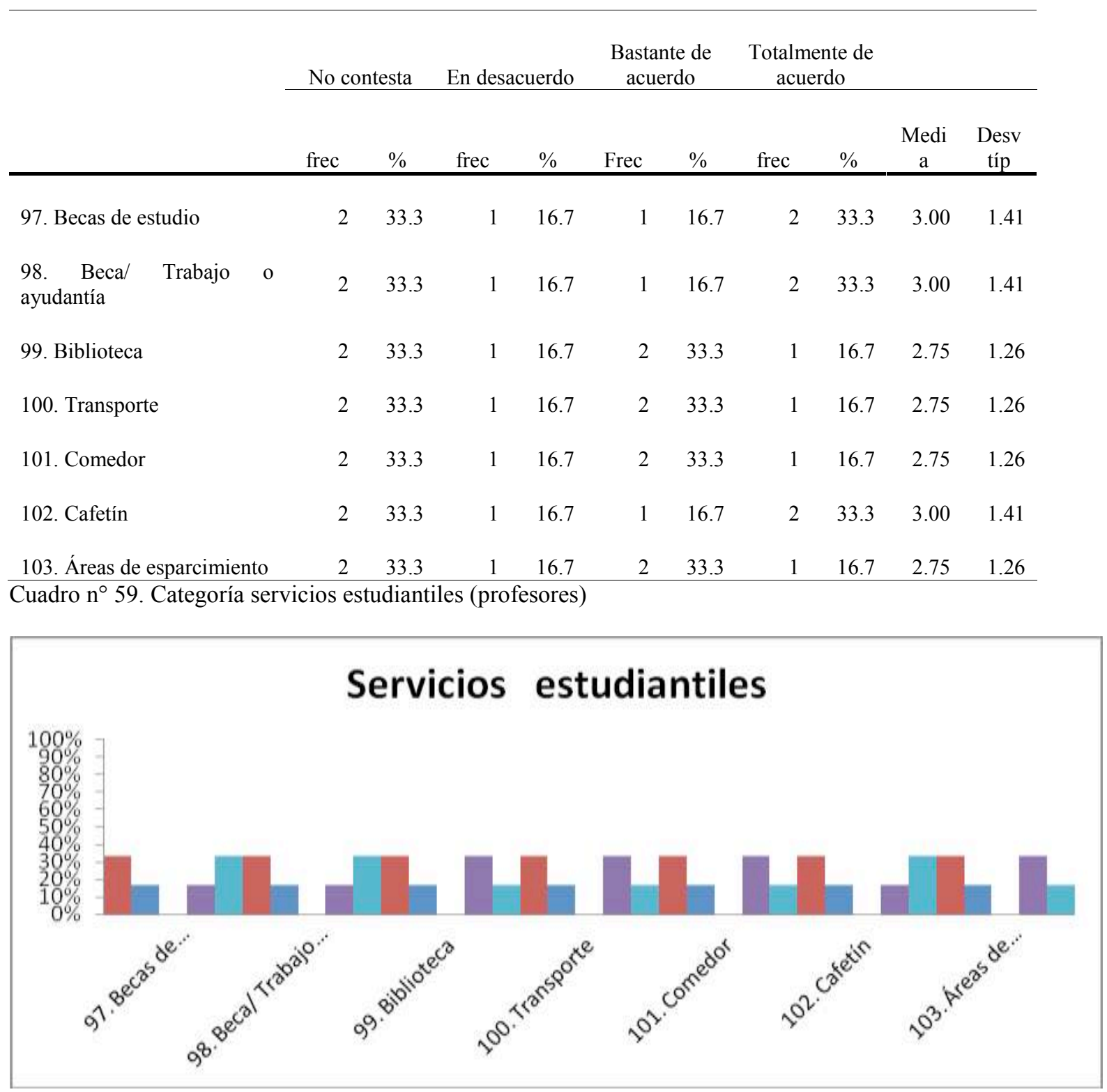

Grafico $n^{\circ} 55$. Categoría servicios estudiantiles (profesores)

Con relación a los servicios estudiantiles existe gran variedad en las opiniones de las profesoras. Se observa que un 33\% de ellas prefiere no responder en estos ítems, lo cual pudiera 
indicar cierto desconocimiento sobre la utilidad de los mismos en la formación del futuro profesional.

\subsubsection{Conclusiones del Análisis de los Cuestionarios}

La consulta de opiniones que se obtuvo de las alumnas y profesores de práctica profesional de la especialidad de educación preescolar de la UPEL, Maracay, permitió llegar a la descripción de su situación actual, además, representó un ejercicio participativo de reflexión de todos sus miembros.

A partir de este proceso, es posible mostrar una visión valorativa de las fortalezas y debilidades del área de práctica profesional y la proyección de las futuras acciones pertinentes para diseñar o rediseñar esta importante área de la universidad.

En este punto se integran las respuestas (agrupadas en dimensiones presentes en el instrumento), de los dos grupos de informantes; más adelante se destacan algunos aspectos expresados en sus opiniones, así como el respectivo sustento teórico.

\begin{tabular}{|c|c|c|}
\hline Dimensión & Alumnos & Profesores \\
\hline \multirow[t]{2}{*}{$\begin{array}{l}\text { Dimensión } \\
\text { procesos de } \\
\text { aprendizaje } \\
\text { DPA }\end{array}$} & $\begin{array}{l}(31 \%) \text { están totalmente de } \\
\text { acuerdo en haber aprendido a } \\
\text { integrar las nuevas tendencias } \\
\text { científicas a la práctica } \\
\text { pedagógica; }(90,7 \%) \text { están } \\
\text { totalmente y bastante de acuerdo } \\
\text { con haber aprendido habilidades } \\
\text { para integrar la tecnología, } \\
\text { resolución de problemas, la } \\
\text { habilidad de aprender a partir de } \\
\text { sus propias experiencias. }\end{array}$ & $\begin{array}{l}(66,7 \%) \text { consideran que sus alumnos } \\
\text { aprendieron a integrar las nuevas } \\
\text { tendencias científicas a la práctica } \\
\text { pedagógica; } 83,3 \% \text { de las profesoras } \\
\text { esta poco de acuerdo con el aprendizaje } \\
\text { de sus alumnos en la integración de las } \\
\text { nuevas tecnologías a la práctica } \\
\text { pedagógica. }\end{array}$ \\
\hline & $\begin{array}{l}(70,4 \%) \text {, está totalmente de } \\
\text { acuerdo con haber desarrollado } \\
\text { habilidades de ampliar y }\end{array}$ & $\begin{array}{l}\text { No ocurre lo mismo al preguntarle si sus } \\
\text { alumnos asisten a clases con materiales } \\
\text { leídos y preparados, ya que las }\end{array}$ \\
\hline
\end{tabular}

La Práctica Profesional como área para potenciar las competencias pedagógicas necesarias para la enseñanza en Educación Infantil 


\begin{tabular}{|c|c|c|}
\hline & $\begin{array}{l}\text { complementar los conocimientos } \\
\text { adquiridos y asistir a clases con } \\
\text { materiales leídos y preparados, }\end{array}$ & $\begin{array}{l}\text { opiniones tiene una tendencia negativa, } \\
\text { a estar poco de acuerdo }(33 \%) \text { y } \\
\text { bastante de acuerdo }(50 \%) \text { con esta } \\
\text { característica de sus alumnos. }\end{array}$ \\
\hline & $\begin{array}{l}7 \% \text { de las alumnas está } \\
\text { totalmente de acuerdo en haber } \\
\text { aprendido a trasladar a otras } \\
\text { situaciones los aprendizajes } \\
\text { teóricos prácticos, el } 30 \% \\
\text { restante no parece estarlo; }\end{array}$ & $\begin{array}{l}\text { Están bastante de acuerdo ( } 83,3 \% \text { ) en } \\
\text { que sus alumnos demuestran que } \\
\text { trasladan a otras situaciones sus } \\
\text { aprendizajes teóricos prácticos. El } 50 \% \\
\text { de las informantes considera que están } \\
\text { poco de acuerdo con los aprendizajes de } \\
\text { los alumnos en cuestiones relacionadas } \\
\text { con la integración de actividades de } \\
\text { docencia e investigación; }\end{array}$ \\
\hline \multirow[t]{3}{*}{$\begin{array}{l}\text { Dimensión } \\
\text { didáctica } \\
\text { especifica } \\
\text { educación } \\
\text { inicial } \\
\text { (DDEEI) }\end{array}$} & $\begin{array}{l}\text { Las alumnas afirman poseer } \\
\text { conocimientos para crear } \\
\text { recursos para el aprendizaje y } \\
\text { además organizar los ambientes } \\
\text { de enseñanza. Las cifras indican } \\
\text { que todas las respuestas están } \\
\text { por encima de la media. }\end{array}$ & $\begin{array}{l}\text { Tendencia bastante favorable al opinar } \\
\text { sobre las habilidades de sus alumnos } \\
\text { para crear, elaborar, diseñar, recursos y } \\
\text { ambientes de aprendizaje para la } \\
\text { educación inicial. }\end{array}$ \\
\hline & $\begin{array}{l}\text { Los informantes califican de } \\
\text { manera positiva }(81,5 \%) \text { todas } \\
\text { las cuestiones referidas a su } \\
\text { proceso de aprendizaje en el } \\
\text { diseño, administración } \\
\text { ejecución de planificaciones. }\end{array}$ & $\begin{array}{l}\text { Están bastante de acuerdo en que sus } \\
\text { alumnas demuestran aprendizajes en } \\
\text { aspectos como: planificar actividades } \\
(50 \%) \text {, correlacionar los objetivos, } \\
\text { contenidos y actividades }(66,7 \%) \text { y } \\
\text { transferir el diagnostico a sus } \\
\text { planificaciones }(50 \%) \text {. Por otra parte, su } \\
\text { opinión cambia al considerar estar poco } \\
\text { de acuerdo con todos los aspectos } \\
\text { relacionados con la planificación por } \\
\text { proyectos }\end{array}$ \\
\hline & $\begin{array}{l}\text { Las alumnas están totalmente de } \\
\text { acuerdo }(83,3 \%) \text {, al considerar } \\
\text { haber aprendido a evaluar el }\end{array}$ & $\begin{array}{l}\text { El } 50 \% \text { de las profesoras, estan poco de } \\
\text { acuerdo, con las destrezas de los } \\
\text { alumnos en el diseño de instrumentos de }\end{array}$ \\
\hline
\end{tabular}

La Práctica Profesional como área para potenciar las competencias pedagógicas necesarias para la enseñanza en Educación Infantil 


\begin{tabular}{|c|c|c|}
\hline & $\begin{array}{l}\text { desarrollo evolutivo de los } \\
\text { niños, sin embargo en relación al } \\
\text { diseño y aplicación de técnicas e } \\
\text { instrumentos de evaluación, su } \\
\text { opinión varia en niveles de } \\
\text { desacuerdo a poco de acuerdo, } \\
(27,8 \%) \text {, }\end{array}$ & $\begin{array}{l}\text { evaluación; Así mismo existe una } \\
\text { tendencia importante al valorar } \\
\text { negativamente el aspecto referido al uso } \\
\text { y dominio de escalas sociometricas } \\
\text { simples. En líneas generales las } \\
\text { opiniones de las profesoras sobre el } \\
\text { proceso de evalución en educación } \\
\text { inicial, tienen una tendencia negativa }\end{array}$ \\
\hline & $\begin{array}{l}\text { Opinión favorable sobre las } \\
\text { habilidades aprendidas por los } \\
\text { alumnos para la interacción } \\
\text { pedagógica con niños y niñas y } \\
\text { otros adultos responsables del } \\
\text { proceso educativo, la media más } \\
\text { alta es de } 3,91 \text {; no obstante hubo } \\
\text { un } 9.3 \% \text { que opinó estar en } \\
\text { desacuerdo con su aprendizaje } \\
\text { para la resolución de situaciones } \\
\text { difíciles en el aula de educación } \\
\text { infantil. }\end{array}$ & $\begin{array}{l}\text { Una tendencia bastante positiva por } \\
\text { parte de las profesoras al valorar los } \\
\text { aprendizajes de los alumnos, no } \\
\text { obstante, las opiniones sobre } \\
\text { estimulación temprana, procesos lógico } \\
\text { matemáticos y resolución de situaciones } \\
\text { difíciles, presentan una tendencia } \\
\text { negativa. }\end{array}$ \\
\hline \multirow[t]{2}{*}{$\begin{array}{l}\text { Dimensión } \\
\text { enseñanza } \\
\text { universitaria }\end{array}$} & $\begin{array}{l}\text { Un rango de bastante a } \\
\text { totalmente de acuerdo }(46,3 \%) \text {, } \\
\text { consideran que sus profesores } \\
\text { les proporcionaron habilidades } \\
\text { y estrategias para el aprendizaje; } \\
\text { indican desacuerdo }(18,5 \%) \text { con } \\
\text { la aportación de fuentes } \\
\text { actualizadas, asociación de } \\
\text { temas y objetivos, aplicabilidad } \\
\text { y transferencia de los contenidos }\end{array}$ & $\begin{array}{l}\text { Las profesoras se autoevalúan de } \\
\text { manera bastante positiva en todos los } \\
\text { ítems del cuestionario. Se aprecia que } \\
\text { reconocen estar bastante y totalmente de } \\
\text { acuerdo haber proporcionado buenos } \\
\text { procesos didácticos para favorecer los } \\
\text { aprendizajes de sus alumnos. }\end{array}$ \\
\hline & $\begin{array}{l}\text { Opinan estar en desacuerdo con } \\
\text { las oportunidades de escuchar } \\
\text { exposiciones magistrales de sus } \\
\text { profesores }(25,9 \%) \text {, con las } \\
\text { prácticas colectivas en el aula de } \\
\text { recursos para el aprendizaje } \\
(24,1 \%) \text {, el diseño y ejecución } \\
\text { de intervenciones pedagógicas }\end{array}$ & $\begin{array}{l}\text { Las profesoras admiten que los métodos } \\
\text { que utilizaron con mayor frecuencia } \\
\text { son: exposiciones de los alumnos, los } \\
\text { comentarios sobre educación infantil, } \\
\text { ejecuciones simuladas, tutorías y } \\
\text { actividades prácticas en centros } \\
\text { educativos }(83,3 \%) \text {. }\end{array}$ \\
\hline
\end{tabular}

304

La Práctica Profesional como área para potenciar las competencias pedagógicas necesarias para la enseñanza en Educación Infantil 


\begin{tabular}{|c|c|c|}
\hline & $\begin{array}{l}(24 ; 1 \%) \text {, así como las tutorías } \\
(29.6 \%) ;\end{array}$ & \\
\hline & $\begin{array}{l}\text { La totalidad de las actividades se } \\
\text { realizaron en el aula de clases de } \\
\text { la UPEL }(81,5 \%) \text {, mientras que } \\
\text { hubo muy poca oportunidad de } \\
\text { construir sus experiencias en el } \\
\text { aula de recursos }(20,4 \%) \text {, en } \\
\text { centros maternales }(35,2 \%) \text {, en } \\
\text { centros educativos no } \\
\text { convencionales }(29,6 \%) \text { y en } \\
\text { contextos comunitarios }(18,5 \%) \text {. }\end{array}$ & $\begin{array}{l}\text { Las profesoras responden estar } \\
\text { totalmente de acuerdo en haber utilizado } \\
\text { las aulas de clases de la universidad, los } \\
\text { centros preescolares, como los } \\
\text { contextos de aprendizaje de práctica } \\
\text { profesional. Por otra parte, admiten que } \\
\text { no usaron el aula de recursos múltiples, } \\
\text { la biblioteca, los centros maternales, los } \\
\text { centros preescolares no convencionales } \\
\text { y los contextos comunitarios }(50 \%) \text {. }\end{array}$ \\
\hline & $\begin{array}{l}\text { Los métodos más utilizados } \\
\text { fueron los trabajos grupales, } \\
\text { informes escritos, exposiciones } \\
\text { y trabajos en grupos }(88,9 \%) \text {; } \\
\text { los debates, pruebas orales y } \\
\text { seguimiento desde la tutoría } \\
\text { fueron ponderados como los } \\
\text { menos utilizados }(14,8 \%) \text {. }\end{array}$ & $\begin{array}{l}\text { Tendencia positiva al considerar que } \\
\text { hicieron uso de la mayoría de las } \\
\text { opciones presentadas, solo resultan con } \\
\text { baja valoración los métodos referidos al } \\
\text { uso de pruebas orales }\end{array}$ \\
\hline \multirow[t]{2}{*}{$\begin{array}{l}\text { Dimensión } \\
\text { académico } \\
\text { estudiantil }\end{array}$} & $\begin{array}{l}\text { Opinión favorable acerca de la } \\
\text { normativa de la práctica } \\
\text { profesional y su reglamento de } \\
\text { evaluación, }(66,7 \%) \text {, las } \\
\text { opiniones que expresaban } \\
\text { desacuerdo estuvieron en la } \\
\text { ubicación de las prácticas en el } \\
\text { plan de estudio, el apoyo } \\
\text { institucional (UPEL), los } \\
\text { recursos para el aprendizaje y el } \\
\text { apoyo en los centros de } \\
\text { aplicación }(22,2 \%)\end{array}$ & $\begin{array}{l}\text { Las profesoras están bastante y } \\
\text { totalmente de acuerdo con los aspectos } \\
\text { referidos a la normativa UPEL, } \\
\text { ubicación de las fases en el plan de } \\
\text { estudios, el apoyo en los centros de } \\
\text { aplicación y el reglamento de } \\
\text { evaluación }(50 \%) \text {; en lo tocante al } \\
\text { apoyo institucional y los recursos para } \\
\text { el aprendizaje, la evaluación de las } \\
\text { profesoras se ubicó en poco de acuerdo } \\
(66 \%) \text {. }\end{array}$ \\
\hline & $\begin{array}{l}\text { Las alumnas consideran estar en } \\
\text { total acuerdo con la relación } \\
\text { teoría práctica, la adaptación al }\end{array}$ & $\begin{array}{l}\text { Las profesoras se situan en un plano } \\
\text { negativo al opinar sobre los ítems que } \\
\text { indagan sobre la actualización, utilidad, }\end{array}$ \\
\hline
\end{tabular}

La Práctica Profesional como área para potenciar las competencias pedagógicas necesarias para la enseñanza en Educación Infantil 


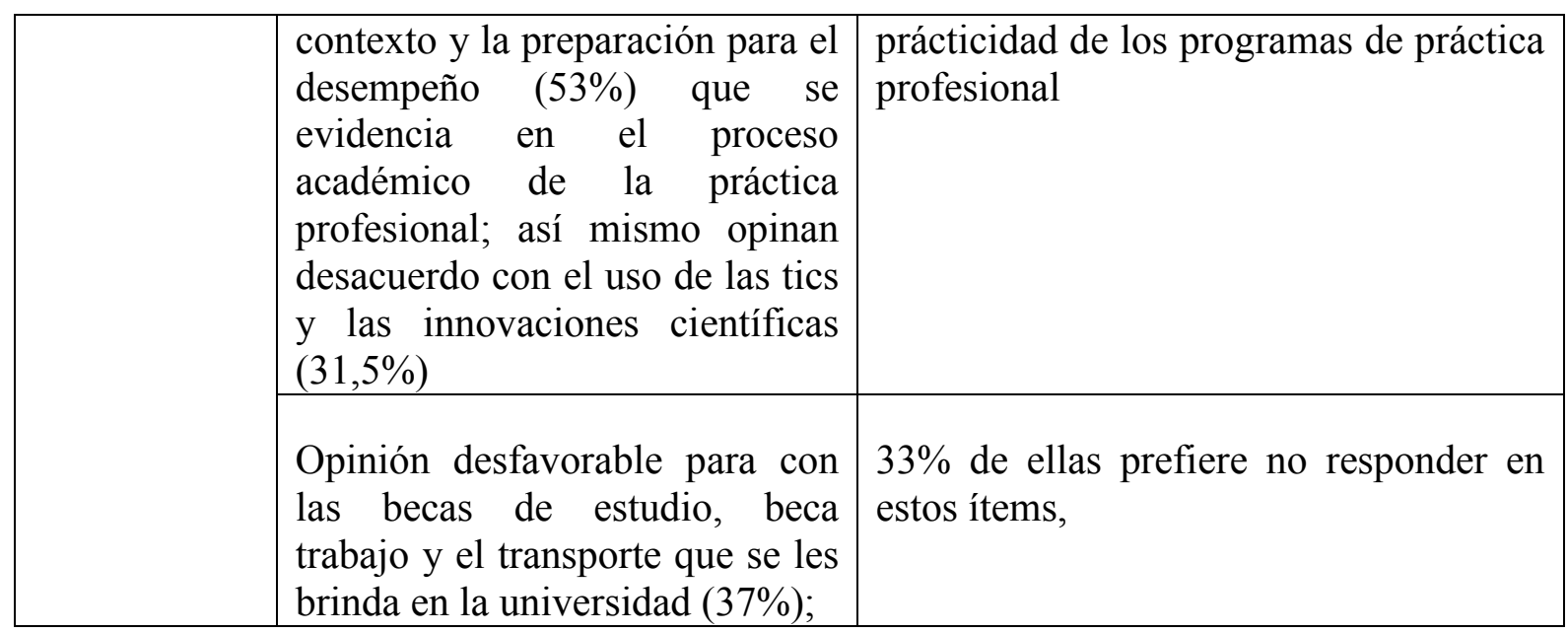

Cuadro $\mathrm{n}^{\circ} 60$. Respuestas de alumnos y profesores agrupadas por dimensiones.

\subsubsection{Análisis General a las Respuestas del Cuestionario.}

Tal como se ha señalado, en este punto vamos a presentar un análisis general de los datos recogidos en la aplicación del cuestionario a las alumnas cursantes de la última fase de la práctica profesional, así como a sus profesores. Para lograr este propósito se procedió a organizar la información obtenida, de acuerdo con las dimensiones del cuestionario y sus respectivas categorías, a manera de ofrecer una visión panorámica de esta matriz de opinión, fundamentada con algunos autores que ya se han ocupado en anteriores oportunidades de estudiar los temas relacionados; Tal es el caso de Cochran-Smith., Zeichner, y Fries (2006:96) al afirmar que:

Las investigaciones de este tipo dependen de una sucesión de datos causales en los que se registran diversos elementos críticos: a) datos empíricos que demuestran el nexo entre los programas de formación del profesorado y el aprendizaje adquirido por los futuros docentes (el aumento del conocimiento didáctico de los futuros docentes, habilidades y disposiciones); b) datos empíricos que demuestran el nexo entre el aprendizaje adquirido por los futuros docentes y su práctica en el aula y c) datos empíricos que demuestran el nexo entre las 306

La Práctica Profesional como área para potenciar las competencias pedagógicas necesarias para la enseñanza en Educación Infantil 
prácticas de los graduados de los programas de formación del profesorado y lo que aprenden sus alumnos.

Estos indicadores complejos y difíciles de valorar puede implicar que algunas variables no sean consideradas o ignoradas en el proceso de análisis, no obstante existe la inquietud por la promoción de realizar más estudios diseñados de manera que puedan tener en cuenta la variabilidad de los contextos intelectuales, organizativos y sociales, de este modo, y cuidando el logro de los objetivos propuestos, se obtendrán insumos valiosos que serán aprovechados para la propuesta de esta investigación.

Con respecto a la dimensión procesos de aprendizaje: Se observa diferencia de opinión en cuanto a las categorías aprender a aprender y habilidades en el manejo de las tics; las opiniones resultan contradictorias, Profesoras y alumnas coinciden en la disposición para ampliar y complementar los conocimientos, no así, en cuanto a la asistencia a clases con los materiales leídos y preparados. Las alumnas opinan no haber aprendido la habilidad de trasladar sus aprendizajes teóricos a la práctica, pero sus profesoras si lo creen. Existen algunas coincidencias en las debilidades por parte de las alumnas de integrar las actividades de docencia con investigación. Al respecto Morín (2001:38), advierte que los desarrollos propios de esta era planetaria nos enfrentan cada vez más, y de manera cada vez más ineluctable, a los desafíos de la complejidad, en consecuencia la educación debe utilizar los conocimientos existentes, superar las antinomias provocadas por el progreso en los conocimientos especializados, a la vez que identificar la falsa racionalidad.

Por su parte Ríos (2004:24) opina que participamos de un sistema educativo que intenta capacitarnos para desenvolvernos dentro de una sociedad, aprovechándonos del conocimiento acumulado, y que además en las dificultades de los estudiantes, seguramente incide una serie de factores, en los cuales se pueden mezclar cuestiones personales, familiares, sociales y del propio sistema educativo, sin embargo, la zona de influencia tiene sus límites y no podemos hacer

307

La Práctica Profesional como área para potenciar las competencias pedagógicas necesarias para la enseñanza en Educación Infantil 
mucho por cambiar el sistema educativo, pero donde sí se puede intervenir y producir transformaciones y rectificaciones es con respecto a nosotros mismos.

En referencia a la dimensión didáctica especifica de Educación Inicial, En esta dimensión relacionada directamente con la educación infantil y sus principios metodológicos, es importante plantearse cuál es el su objetivo fundamental; objetivo que consiste en potenciar el desarrollo en todas las capacidades físicas afectivas, intelectuales y sociales de los infantes. Para ello los alumnos en proceso de formación docente, deben aprender a organizar adecuadamente las actividades e interacciones, facilitando experiencias y dotando de un medio adecuado con espacios y materiales necesarios para lograr este desarrollo integral.

Como resultado a este aspecto se tiene que: los dos grupos de informantes coinciden en afirmar que las alumnas poseen habilidades para diseñar recursos y ambientes de aprendizaje, Existe consenso en evaluar positivamente los aspectos referidos a la planificación, no así en aquellas acciones relacionadas con el trabajo comunitario y/o familiar y la planificación por proyectos, Mientras que las alumnas consideran que saben evaluar, las profesoras opinan lo contrario; coinciden en afirmar que aun requieren aprender sobre diseño y aplicación de técnicas e instrumentos. Ambos grupos opinan favorablemente sobre las habilidades que demuestran las alumnas para interacciones pedagógicas con niños y niñas; no obstante, las alumnas consideran que necesitan aprender a resolver situaciones difíciles en el aula de educación infantil. Como puede apreciarse las diferencias de opinión resultan importantes, ya que estos informantes están indicando fallas y fortalezas presentes en el proceso de enseñanza aprendizaje, que lo más probable no solo este afectando a la práctica profesional, sino que pueda proyectarse a todo el componente de formación de la universidad. Además, y tomando como referencia las debilidades manifestadas por los dos grupos de informantes, García, Castañón, Domingo y Palou (1998:9) argumentan que para educar a un niño no basta el simple hecho de cuidar y atender sus necesidades elementales. Es preciso conocer las etapas de la evolución infantil, tanto física como

308

La Práctica Profesional como área para potenciar las competencias pedagógicas necesarias para la enseñanza en Educación Infantil 
psíquica, para favorecer oportuna e integralmente su desarrollo y lograr la incorporación paulatina de este ser humano al ámbito de la sociedad y la cultura.

Dimensión enseñanza universitaria: resulta valido partir de las consideraciones de Onrubia (en Coll, Martín, Mauri, Miras, Solé y Zabala, 1999:101), sobre la enseñanza entendida desde una concepción constructivista, como ayuda necesaria al proceso de aprendizaje para que los alumnos lleguen a aprender, y a aprender de manera lo más significativamente posible, los conocimientos necesarios para su desarrollo personal y para su capacidad de comprensión de la realidad y de actuación en ella. Pero solo ayuda, porque la enseñanza no puede sustituir la actividad mental constructivista del alumno ni ocupar su lugar. En este sentido, y con respecto a la dimensión enseñanza aprendizaje, existe coincidencia en afirmar que en general los profesores proporcionaron habilidades y procesos didácticos cónsonos con la didáctica universitaria. Mientras las profesoras confirman el uso frecuente de algunos métodos, las alumnas los valoran de manera negativa (en desacuerdo), Ambos grupos coinciden en que el contexto de aprendizaje más utilizado fue el aula de clases de la universidad, reflejando muy pocas oportunidades de prácticas en otros contextos. Acuerdo en ambos grupos acerca de los métodos y criterios de evaluación. A propósito de lo anterior, autores como Coll 1990, Onrubia 1999 proponen la creación de zonas de desarrollo próximo y de asistencia en ellas, como una manera de conectar los esquemas de conocimiento de los alumnos y movilizar su reestructuración.

Finalmente tenemos la dimensión académica estudiantil: En este aspecto resulta que las alumnas están en desacuerdo con la ubicación de las prácticas en el plan de estudio, por el contrario, las profesoras si están de acuerdo con su ubicación. Los grupos valoran de modo diferente los aspectos referidos a los planes y programas, Solo las alumnas se expresan en este aspecto, las profesoras prefieren no contestar en algunos aspectos, lo cual pudiera evidenciar desconocimiento de este aspecto que influye grandemente en la calidad de la formación académica de las alumnas. Esta situación encuentra sustento en los aportes de Torres (2006:32) al afirmar que una gran mayoría de las profesoras y profesores experimentan un notable 
desconcierto acerca de las finalidades de las etapas educativas en las que está trabajando, además este autor, considera que en los planes de estudio prima la formación psicopedagógica, pero está completamente descuidada la información cultural relacionada con los contenidos que los profesores de educación infantil trabajará en sus aulas.

\subsubsection{Descripción de la Fase II.}

\subsubsection{Análisis Documental: Planes Oficiales de Práctica Profesional Educación Preescolar.}

El análisis del diseño curricular UPEL (1996), de la especialidad de Educación Preescolar, específicamente de los planes del área de práctica profesional, permitió formular algunos indicadores que son relevantes de considerar en materia de la formación de docentes y que en el marco de los cambios actuales, son aplicables para la formación de los educadores para la primera infancia.

\subsubsection{Resultados del Análisis al Diseño Curricular UPEL 1996.}

El diseño curricular de la UPEL fue elaborado en el año 1996, y es el que se está utilizando en la actualidad, por lo que se requiere tener presente la necesidad de situarse en el momento histórico en el que fue diseñado y además que, desde el año 2005, se está realizando del proceso de transformación curricular, atendiendo a los requerimientos que le plantean las nuevas políticas educativas del estado venezolano y de los organismos mundiales (UPEL, 2005). En este sentido, el presente análisis se realizará con el fin de tener una visión general del contexto y del diseño curricular objeto en estudio, específicamente nos centraremos en el plan de estudio y los programas de las fases que componen el área de práctica profesional de la especialidad Educación Preescolar.

En cuanto al diseño curricular se consideraron los siguientes elementos: a) Enfoque pedagógico, b) Propósito del currículo, c) Organización curricular, d) Duración de los estudios. 


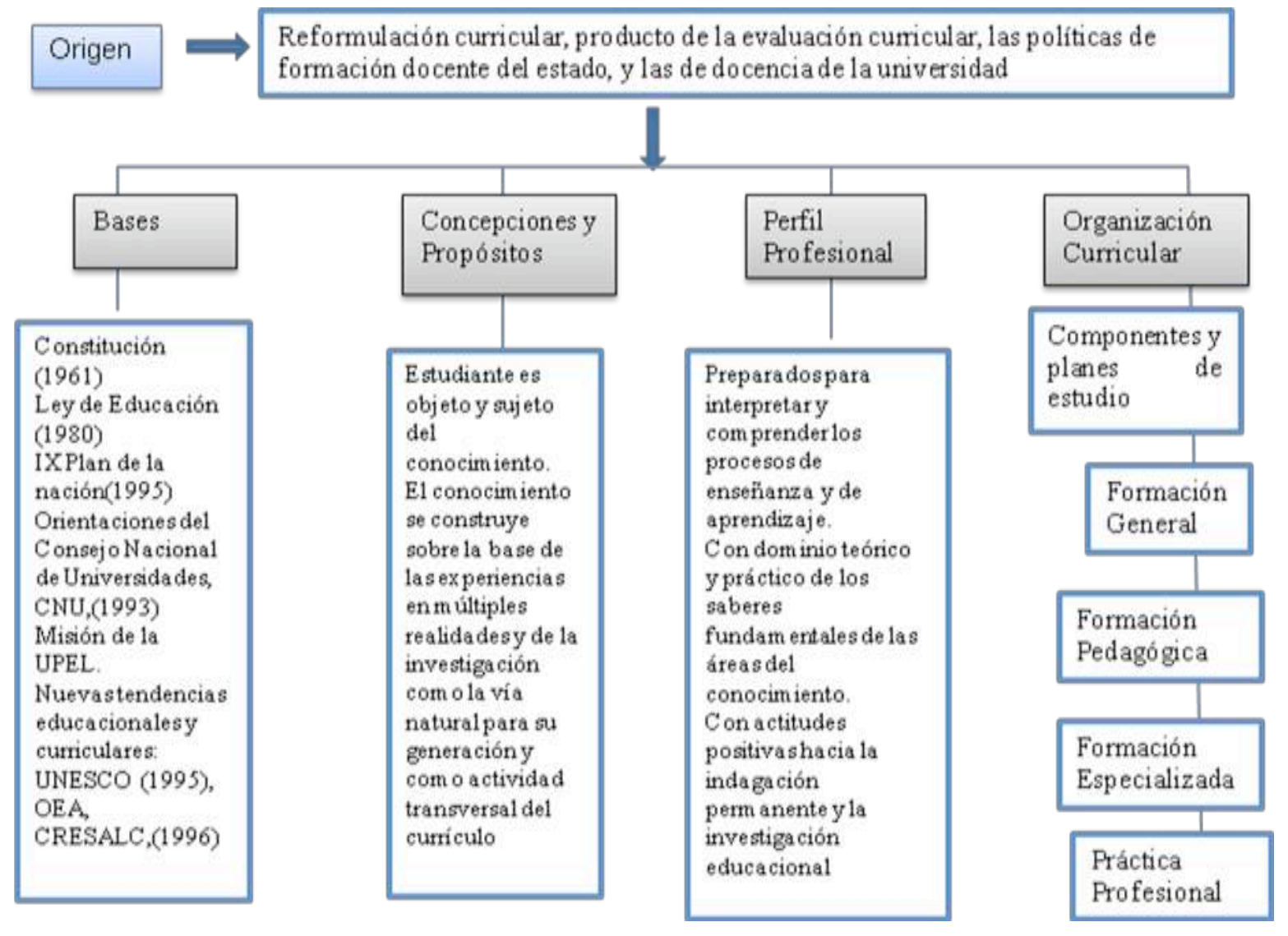

Grafico n 56. Diseño Curricular UPEL 1996, Visión General.

Se observa que el currículo de la Universidad, asume aportes de diferentes corrientes del pensamiento y los integra con una visión holística, lo que se puede interpretar como un currículo prospectivo, equilibrado, ajustable, multidisciplinario y perfectible, para responder a los cambios de paradigma producidos en las ciencias, que impactan a la pedagogía. En síntesis, este diseño posee rigor científico en su concepción para la formación de los docentes, en las que se incluyen teorías que fundamentan los fenómenos educativos y el transcurso histórico de los mismos. 
En este sentido, se destacan como principales propósitos del currículo: responder a las necesidades de formación docente, dentro del marco general que plantean las políticas educativas del estado venezolano; garantizar una formación integral general y pedagógica básica y una formación especializada equilibrada con los aportes de diferentes áreas del conocimiento; propiciar en el estudiante el desarrollo social, intelectual y afectivo orientándolo hacia la búsqueda de su bienestar y mejoramiento cualitativo; propiciar la adquisición de competencias que permitan al estudiante educarse permanentemente; promover procesos de investigación a fin de permitir la adquisición de variadas formas de indagación e interpretación de la realidad; propiciar la evaluación y retroalimentación permanente del currículo a fin de garantizar la calidad del egresado.

Otro factor que es necesario analizar es el referido a la organización curricular. Al respecto, existen factores de importancia para la administración del currículo, como lo son: los componentes que estructuran este diseño, los cursos o fases que lo representan, el número de cursos y fases, la unidad crédito, el semestre o período académico, la duración de la carrera, el nivel de los cursos y las prelaciones. La unidad crédito equivale a una hora teórica presencial de clases, a dos o tres horas de práctica o de laboratorio por semana, durante un semestre o período académico, en regímenes presenciales. En la práctica profesional la unidad-crédito equivale a 8 horas de asesoría y confrontación individual o grupal durante un semestre o período académico, independientemente del régimen de estudio. El semestre o período académico es una estimación del tiempo que se asume para la administración de los cursos, fases o actividades de extensión. Tiene una duración de dieciséis a dieciocho semanas.

Para ilustrar parte de lo dicho, podemos ver en el siguiente grafico: 


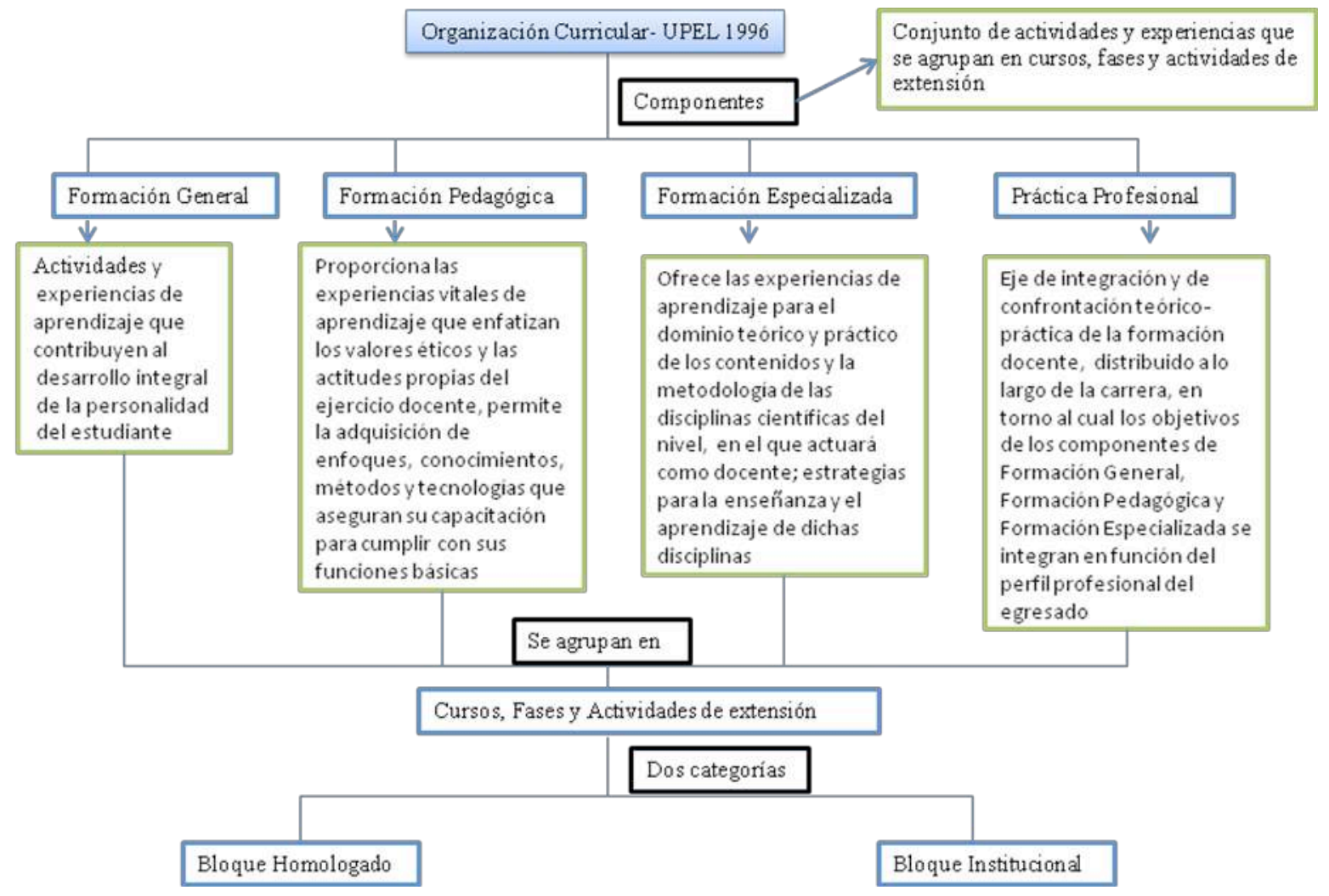

Grafico n 57. Organización Curricular UPEL. Elaboración propia, a partir de UPEL 1996

En éste diseño UPEL, se presenta una estructura conformada por cuatro componentes curriculares articulados, la definición de componente según la UPEL (1996: 16) "es el conjunto de actividades y experiencias que se agrupan en cursos, fases... con el fin de desarrollar en el individuo los conocimientos, habilidades, destrezas y actitudes requeridas para la profesión docente". Estos componentes son los siguientes: formación general, formación pedagógica, formación especializada y práctica profesional.

En relación con la duración de los estudios, el diseño plantea una carrera de cinco (5) años de duración, organizada en diez (10) semestres, para obtener el título de profesor en Educación Preescolar. Es importante destacar, que al inicio de la carrera de Educación Preescolar y en 313

La Práctica Profesional como área para potenciar las competencias pedagógicas necesarias para la enseñanza en Educación Infantil 
atención a la demanda educativa en el mercado laboral, existía una oportunidad de salida intermedia (seis semestres) y el egresado obtenía el título de maestro en Educación Preescolar, con la misma oportunidad de continuar sus estudios y accesar a puestos de trabajo. Esta modalidad fue suspendida hace cuatro años, ya que otros institutos se sumaron a formar técnicos superiores en Educación Preescolar, lo cual ocasiono un exceso de profesionales y pocas oportunidades de trabajo. La especialidad de Educación Preescolar, es afín en su estructura académica, con las otras especialidades que se ofrecen en el Instituto, para tal efecto se presenta el cuadro siguiente con las principales características de esta especialidad.

\section{Características Académicas Especialidad Educación Preescolar}

Titulo Profesor (a) Educación Preescolar

Duración $\quad 10$ semestres

Régimen lectivo Semestral

$N^{\circ}$ de créditos $\quad 165$

$\mathrm{N}^{\circ}$ de materias $\quad 49$

Requisitos de egreso Haber cursado y aprobado todos sus cursos.

Cuadro ${ }^{\circ}$ 61. Características académicas de la especialidad Educación Preescolar. Elaboración propia, a partir de UPEL 1996.

Otro atributo de este diseño curricular es el referido a la formación inicial y permanente así como la investigación. En cuanto a la investigación, en el plan de estudio se ofertan dos cursos relacionada con esta temática y una fase de ejecución de proyectos, práctica que se supone los

314

La Práctica Profesional como área para potenciar las competencias pedagógicas necesarias para la enseñanza en Educación Infantil 
estudiantes deben poner en acción lo aprendido en dichos cursos; Esto se concibe como una estrategia formativa, es decir, que sirva al estudiante no para convertirse en un investigador, sino que sea capaz de organizar las experiencias de aprendizaje y adquiera las competencias de los conceptos, métodos y técnicas de la investigación como formas de aproximación al saber con fines de aprendizaje. Visto de esta manera, tanto estudiante, como profesor, asumen una visión alejada de la investigación como parte fundamental de la práctica pedagógica.

Del análisis al resumen descriptivo, es factible asumir que en la actualidad y luego de 15 años de estar en vigencia este diseño, se requiere una actualización en sus fundamentos, por cuanto, la universidad ha tardado demasiado tiempo en revisar y renovar aportes, que realmente le permitan su retro alimentación, y que si bien es cierto, muchos de sus docentes se han preocupado por implementar o introducir algunos cambios, no es menos cierto que desde el año 2005, se promulgó por vía ministerial el proceso de transformación curricular y aún hoy día no se observan los cambios que den respuesta a tal proceso de transformación. Este tipo de organización curricular es definida por los alumnos de la universidad como "cursos que hay que aprobar, y que no tienen articulación entre ellos" (Galindo 2009:59), más aun en el caso de la relación teoría práctica, esta es escasa, porque el tiempo que se dedica a la práctica profesional es muy limitado (solo tres fases de acercamiento e intervención en la realidad y una de ejecución de proyectos educativos).

Esta situación de falta de equilibrio entre la formación académica y la profesional, produce ausencia o escasa capacidad de respuesta ante las necesidades y requerimientos que en la práctica profesional se encuentra el egresado. Este modelo de formación, a pesar de que en sus enunciados curriculares lo presentan como integrador, abierto y sensible, para asimilar los cambios que se susciten en la educación, la ciencia , la tecnología y la cultura (UPEL, 1996:8), en la actualidad se presenta como centrado en las asignaturas, lo cual implica un énfasis excesivo en la dimensión instrumental de la profesión y que responde al criterio de que, el egresado sea capaz de enfrentar

315

La Práctica Profesional como área para potenciar las competencias pedagógicas necesarias para la enseñanza en Educación Infantil 
la solución de los problemas que se planteen en su área de trabajo, y pueda actuar de acuerdo con las necesidades de la práctica y demandas sociales con la mayor efectividad y eficiencia posibles.

Esto hace que el énfasis en el área instrumental conlleve aparejada una subvaloración de otros aspectos importantes de la formación, como son, por ejemplo, la concepción de la profesión, de su cosmovisión y ética, del sentido de pertenencia y de la identidad profesional. En pocas oportunidades se promueven actividades de extensión que impliquen la formación permanente de estudiantes y docentes, en la mayoría de los casos, se realizan en instituciones ajenas al instituto, lo que impide su adecuada interrelación. Estas son algunas regularidades que caracterizan el plan de formación de la UPEL, que quizás coincide en muchos aspectos con otros sistemas educacionales de formación de profesionales para la educación, y que se ven reflejadas con particular dimensión en la correspondiente con los educadores para la primera infancia.

\subsubsection{Características Programas de Práctica Profesional Educación Preescolar, UPEL}

A continuación y como parte de este análisis se muestra un cuadro resumen con las principales características que aparecen en los programas oficiales de: fase observación (FO), fase ensayo didáctico (FED), fase ejecución de proyectos educativos (FEPE), fase integración docencia administración (FIDA), de la especialidad de Educación Preescolar. Seguidamente de este cuadro resumen, se analiza cada programa de fase a través de un estudio comparativo y por tanto más detallado, entre lo pautado en los programas oficiales y lo previsto en los programas elaborados por los profesores.

\begin{tabular}{|l|l|l|l|l|}
\hline \multicolumn{1}{|c|}{ Fase } & Observación & Ensayo didáctico & $\begin{array}{l}\text { Ejecución } \\
\text { Proyectos }\end{array}$ & $\begin{array}{l}\text { Integración docencia } \\
\text { administración }\end{array}$ \\
\hline Tipo de curso & $\begin{array}{l}\text { Obligatorio } \\
\text { Homologado. }\end{array}$ & Obligatorio. & Obligatorio & Obligatorio. \\
\hline $\begin{array}{l}\text { Componente } \\
\text { curricular }\end{array}$ & Práctica Profesional & Práctica Profesional & $\begin{array}{l}\text { Práctica } \\
\text { Profesional }\end{array}$ & Práctica Profesional \\
\hline $\begin{array}{l}\text { Unidades de } \\
\text { crédito. }\end{array}$ & Cinco (5) & Siete (7) & Seis (6) & Siete (7) \\
\hline
\end{tabular}

316

La Práctica Profesional como área para potenciar las competencias pedagógicas necesarias para la enseñanza en Educación Infantil 


\begin{tabular}{|c|c|c|c|c|}
\hline Prelaciones & $\begin{array}{l}\text { Introducción a la } \\
\text { investigación }\end{array}$ & $\begin{array}{l}\text { Planificación y } \\
\text { evaluación en } \\
\text { Preescolar }\end{array}$ & $\begin{array}{l}\text { Fase } \\
\text { Observación } \\
\text { Investigación } \\
\text { Educativa }\end{array}$ & $\begin{array}{l}\text { Fase de Ensayo didáctico, } \\
\text { Gerencia de la educación }\end{array}$ \\
\hline $\begin{array}{l}\text { Propósitos del } \\
\text { curso o fase }\end{array}$ & $\begin{array}{l}\text { Iniciar al estudiante } \\
\text { en el proceso de } \\
\text { identificación y } \\
\text { sensibilización con la } \\
\text { práctica docente. }\end{array}$ & $\begin{array}{l}\text { Desarrollar, } \\
\text { corregir y } \\
\text { consolidar } \\
\text { habilidades, } \\
\text { destrezas y } \\
\text { actitudes. }\end{array}$ & $\begin{array}{l}\text { Presenta } \\
\text { diferentes } \\
\text { modalidades } \\
\text { optativas. }\end{array}$ & $\begin{array}{l}\text { Propiciar la integración de } \\
\text { las funciones en el } \\
\text { quehacer docente- } \\
\text { administrativo. }\end{array}$ \\
\hline $\begin{array}{l}\text { Objetivos } \\
\text { generales }\end{array}$ & $\begin{array}{l}\text { Sensibilizar al } \\
\text { estudiante con la } \\
\text { profesión docente }\end{array}$ & $\begin{array}{l}\text { Demostración y } \\
\text { adquisición de las } \\
\text { habilidades, } \\
\text { destrezas, actitudes } \\
\text { y valores. }\end{array}$ & $\begin{array}{l}\text { De acuerdo al tipo } \\
\text { de proyecto } \\
\text { ofertado }\end{array}$ & $\begin{array}{l}\text { Desarrollar estrategias } \\
\text { interactivas, innovadoras y } \\
\text { transformadoras en las } \\
\text { áreas pedagógicas y } \\
\text { administrativas. }\end{array}$ \\
\hline $\begin{array}{l}\text { Contenidos } \\
\text { fundamentales }\end{array}$ & $\begin{array}{l}\text { Observación } \\
\text { sistemática y } \\
\text { pedagógica. } \\
\text { Concepción del } \\
\text { docente. Perfil } \\
\text { profesional del } \\
\text { docente. } \\
\text { Contrastación del } \\
\text { deber ser con la } \\
\text { realidad. }\end{array}$ & $\begin{array}{l}\text { Manejo y revisión y } \\
\text { aplicación de los } \\
\text { programas oficiales } \\
\text { del Ministerio de } \\
\text { Educación. }\end{array}$ & $\begin{array}{l}\text { De acuerdo al tipo } \\
\text { de proyecto } \\
\text { ofertado. }\end{array}$ & $\begin{array}{l}\text { Realizar observaciones } \\
\text { participativas en los } \\
\text { diferentes ambientes de la } \\
\text { escuela. Diseño y } \\
\text { aplicación de planes. } \\
\text { Aplicación de técnicas y } \\
\text { procedimientos } \\
\text { administrativos Desarrollo } \\
\text { de planes de acción donde } \\
\text { se involucren la familia y } \\
\text { la comunidad al proceso } \\
\text { educativo }\end{array}$ \\
\hline $\begin{array}{l}\text { Estrategias } \\
\text { pedagógicas } \\
\text { sugeridas. }\end{array}$ & $\begin{array}{l}\text { Observación, } \\
\text { dinámicas de grupo: } \\
\text { talleres, foros, } \\
\text { seminarios, videos. } \\
\text { Trabajo de campo, } \\
\text { círculos de estudio, } \\
\text { jornadas de reflexión, } \\
\text { plenarias, asesorías } \\
\text { individuales y } \\
\text { grupales }\end{array}$ & $\begin{array}{l}\text { Diagnóstico de } \\
\text { habilidades, } \\
\text { destrezas, } \\
\text { competencias a } \\
\text { través de } \\
\text { actividades } \\
\text { prácticas en el aula } \\
\text { taller. Asesorías } \\
\text { individuales y } \\
\text { grupales. Talleres. } \\
\text { Visitas guiadas. } \\
\text { Ejecuciones. } \\
\text { Presentación de } \\
\text { informe de } \\
\text { experiencias. }\end{array}$ & $\begin{array}{l}\text { De acuerdo al tipo } \\
\text { de proyecto }\end{array}$ & $\begin{array}{l}\text { Taller de inducción. Visita } \\
\text { guiada a las dependencias } \\
\text { administrativas de los } \\
\text { centros de aplicación. } \\
\text { Diseño y aplicación de } \\
\text { estrategias innovadoras } \\
\text { para la mejor } \\
\text { administración de los } \\
\text { recursos existentes en } \\
\text { cada dependencia. } \\
\text { Supervisiones en el aula. } \\
\text { Ejecución de planes. } \\
\text { Entrega de informes. } \\
\text { Seminario. Evaluación de } \\
\text { la fase }\end{array}$ \\
\hline $\begin{array}{l}\text { Tipo de centro } \\
\text { de aplicación }\end{array}$ & No lo indica. & $\begin{array}{l}\text { Aula taller. } \\
\text { Preescolares }\end{array}$ & $\begin{array}{l}\text { De acuerdo al tipo } \\
\text { de proyecto }\end{array}$ & $\begin{array}{l}\text { Centros de atención } \\
\text { convencionales y no } \\
\text { convencionales }\end{array}$ \\
\hline
\end{tabular}




\begin{tabular}{|l|l|l|l|l|}
\hline $\mathrm{N}^{\circ}$ de horas & 40 & 56 & 48 & 56 \\
\hline
\end{tabular}

Cuadro ${ }^{\circ}$ 62. Resumen Programas Oficiales de: FO, FED, FEPE, FIDA

La información presentada en el cuadro resumen, se constituye como el punto de partida para la elaboración y análisis de los cuadro comparativos y la matriz FODA, que se presentará más adelante.

\subsection{Análisis Comparativo de Cada Programa de Fase.}

En esta parte del estudio se detallara por separado cada uno de los programas de fase para ello se elaboran cuadros con algunos aspectos seleccionados de los cuatro programas aplicados por profesores de práctica profesional de Educación Preescolar y se compara con lo pautado en el programa oficial, detallando las principales elementos encontrados; luego se hará el análisis, procurando sustentarlo con la opinión de algunos autores.

La labor de hallar los programas aplicados por los profesores (ordinarios y contratados), fue una tarea sencilla, por cuanto al inicio de cada semestre cada coordinador de fase, se reúne con todos los profesores, con el fin de organizar académicamente las actividades a realizar en el semestre, dar información importante y agrupar a los profesores por especialidad con el propósito de que elaboren un único programa didáctico por especialidad; por tanto, el investigador acudió ante la coordinación de cada fase y solicitó un modelo de cada programa para ser usado solo con fines de análisis.

\subsection{Fase Observación}

La fase de observación es el primer acercamiento dele estudiante con el componente de práctica profesional. Desde el punto de vista académico, ya debe haber aprobado asignaturas que le proveen de herramientas básicas para comprender y demostrar sus habilidades como estudiante de la especialidad Educación Preescolar. De acuerdo con la malla curricular, esta fase se realiza una vez por semana durante el semestre, con una matrícula de 20 a 23 alumnos, a los cuales hay

318

La Práctica Profesional como área para potenciar las competencias pedagógicas necesarias para la enseñanza en Educación Infantil 
que vincular con centros de educación inicial, a razón de dos estudiantes por aula preescolar. A continuación se presenta el cuadro comparativo.

\begin{tabular}{|c|c|c|c|}
\hline Aspectos & Programa oficial & Programa aplicado & Observaciones \\
\hline Objetivos & $\begin{array}{l}\text { Sensibilizar al estudiante con la } \\
\text { profesión docente para la } \\
\text { afirmación de su vocación y } \\
\text { compromiso ético, a partir de la } \\
\text { aprehensión de la realidad socio } \\
\text { educativa en el nivel y modalidad } \\
\text { en la que se desempeñará }\end{array}$ & $\begin{array}{l}\text { Reflexión y discusión } \\
\text { sobre el perfil docente y } \\
\text { su concepción sobre el } \\
\text { nivel de Educación } \\
\text { Inicial. Análisis de leyes } \\
\text { que sustentan la } \\
\text { Educación Inicial. } \\
\text { Reflexión crítica sobre el } \\
\text { diseño curricular de } \\
\text { Educación Inicial. } \\
\text { Intercambiar } \\
\text { información teórica } \\
\text { sobre los elementos a } \\
\text { considerar en el proceso } \\
\text { de observación en el } \\
\text { contexto del nivel de } \\
\text { Educación inicial. } \\
\text { Observar y registrar la } \\
\text { realidad educativa en el } \\
\text { centro de aplicación } \\
\text { asignado. Generar } \\
\text { procesos de valoración } \\
\text { de la función docente a } \\
\text { partir de la contrastación } \\
\text { entre el deber ser y la } \\
\text { realidad observada. }\end{array}$ & $\begin{array}{l}\text { Se observa que los } \\
\text { objetivos en ambos } \\
\text { programas tienen énfasis } \\
\text { en el desarrollo de } \\
\text { competencias } \\
\text { conceptuales y } \\
\text { actitudinales y debilidad } \\
\text { en las procedimentales. } \\
\text { Muchos de los } \\
\text { contenidos pertenecen a } \\
\text { otras asignaturas de los } \\
\text { componentes de } \\
\text { formación general, } \\
\text { pedagógica y } \\
\text { especializada }\end{array}$ \\
\hline Contenidos & $\begin{array}{l}\text { Observación sistemática y } \\
\text { pedagógica. Concepción de } \\
\text { docente. Perfil Profesional } \\
\text { Docente. Profesión Docente. } \\
\text { Contrastación del deber ser del } \\
\text { profesional de la docencia con los } \\
\text { desempeños reales de un docente } \\
\text { en interacción con el contexto } \\
\text { socio-educativo. Realidades socio- } \\
\text { educativa. Situación pedagógica. } \\
\text { Contexto socio-histórico-cultural. } \\
\text { Diagnóstico educativo. Interacción: } \\
\text { Escuela-Comunidad, Docente- } \\
\text { Alumno, Docente-Institución, } \\
\text { Docente-Comunidad. Descripción } \\
\text { interpretativa de la realidad socio- } \\
\text { educativa observada. Autoestima. }\end{array}$ & $\begin{array}{l}\text { Perfil del docente de } \\
\text { Educación Inicial. Leyes } \\
\text { y artículos. Principales } \\
\text { postulados del Diseño } \\
\text { Curricular de Educación } \\
\text { Inicial. Observación } \\
\text { sistemática y } \\
\text { pedagógica, tipos de } \\
\text { observación, tipos de } \\
\text { registro, interacción con } \\
\text { los niños en edad } \\
\text { preescolar, rutina diaria, } \\
\text { recursos, instrumentos } \\
\text { de recolección de datos. } \\
\text { Diagnostico situacional } \\
\text { del centro de aplicación, } \\
\text { rol del docente, }\end{array}$ & $\begin{array}{l}\text { El mayor peso de los } \\
\text { contenidos se dirige } \\
\text { hacia temas propios de } \\
\text { otras asignaturas, los } \\
\text { cuales están muy } \\
\text { relacionados con la } \\
\text { práctica, en general se } \\
\text { observa desarrollo de los } \\
\text { contenidos previstos en } \\
\text { el programa oficial. }\end{array}$ \\
\hline
\end{tabular}

La Práctica Profesional como área para potenciar las competencias pedagógicas necesarias para la enseñanza en Educación Infantil 


\begin{tabular}{|c|c|c|c|}
\hline & $\begin{array}{l}\text { Valores. Creatividad. Interpretación } \\
\text { y valoración de las potencialidades } \\
\text { del estudiante como futuro } \\
\text { profesional de la docencia. Juicio } \\
\text { reflexivo en la decisión voluntaria } \\
\text { de actuación, frente a las } \\
\text { condiciones reales del contexto } \\
\text { socio-educativo. }\end{array}$ & $\begin{array}{l}\text { diagnostico pedagógico. } \\
\text { Descripción interactiva } \\
\text { de la realidad educativa, } \\
\text { juicios reflexivos del } \\
\text { contexto socio educativo } \\
\text { observado. }\end{array}$ & \\
\hline Estrategias & $\begin{array}{l}\text { Observación, dinámicas de grupo: } \\
\text { talleres, foros, seminarios, videos. } \\
\text { Trabajo de campo, círculos de } \\
\text { estudio, jornadas de reflexión, } \\
\text { plenarias, asesorías individuales y } \\
\text { grupales }\end{array}$ & $\begin{array}{l}\text { Lectura, discusión, } \\
\text { producción escrita. } \\
\text { Análisis de casos. } \\
\text { Jornada. Intervenciones, } \\
\text { análisis de instrumentos } \\
\text { de recolección de datos. } \\
\text { Observar y registrar el } \\
\text { contexto educativo } \\
\text { utilizando los } \\
\text { instrumentos discutidos } \\
\text { en clases, participar e } \\
\text { interactuar en el aula } \\
\text { preescolar. Descripción } \\
\text { y comparación de la } \\
\text { realidad observada y lo } \\
\text { previsto en los } \\
\text { documentos oficiales. } \\
\text { Autoevaluación. }\end{array}$ & $\begin{array}{l}\text { Énfasis en estrategias } \\
\text { cognitivas, no se } \\
\text { programan las } \\
\text { recomendadas en el } \\
\text { programa oficial }\end{array}$ \\
\hline $\begin{array}{l}\text { Tipo de } \\
\text { Centro de } \\
\text { aplicación }\end{array}$ & No lo indica. & $\begin{array}{l}6 \text { sesiones en centro } \\
\text { preescolar privado y } 7 \\
\text { sesiones en aulas UPEL }\end{array}$ & $\begin{array}{l}\text { Se observa que el } \\
\text { programa oficial no } \\
\text { indica la duración ni el } \\
\text { tipo de centro de } \\
\text { aplicación; mayor } \\
\text { tendencia a permanecer } \\
\text { en los espacios de la } \\
\text { universidad, en } \\
\text { desmedro del } \\
\text { acercamiento a la } \\
\text { realidad objeto en } \\
\text { estudio }\end{array}$ \\
\hline $\begin{array}{l}N^{\circ} \text { de horas } \\
\text { asesoría }\end{array}$ & $\begin{array}{l}20 \text { horas asesoría grupal } \\
20 \text { horas asesoría. Individual } \\
=40\end{array}$ & $\begin{array}{l}40 \text { horas de asesoría } \\
\text { grupal, no indica } \\
\text { asesorías individuales }\end{array}$ & $\begin{array}{l}\text { Predominio asesorías } \\
\text { grupales, no se cumple } \\
\text { lo sugerido en el } \\
\text { programa oficial }\end{array}$ \\
\hline
\end{tabular}

Cuadro $n^{\circ}$ 63. Comparación Fase de Observación 
Del análisis al cuadro comparativo del programa de fase de Observación, pueden indicarse los siguientes apuntes:

Énfasis en objetivos para el desarrollo de competencias conceptuales y actitudinales y debilidad en las procedimentales. Muchos de los contenidos pertenecen a otras asignaturas de los componentes de formación general, pedagógica y especializada, se observa desarrollo de los contenidos previstos en el programa oficial, Énfasis en estrategias cognitivas, no se programan las recomendadas en el programa oficial; en cuanto al tipo de centro de aplicación, el programa oficial no indica la duración ni el tipo de centro de aplicación, tendencia a permanecer en los espacios de la universidad, en desmedro del acercamiento a la realidad objeto en estudio; Predominio asesorías grupales, no se cumple lo sugerido de compartir asesorías grupales con individuales. Al respecto podemos afirmar que para mejorar este programa hace falta reflexionar sobre el hecho de que la práctica es elemento para lograr la consolidación del saber del estudiante, tal y como lo afirma Rodríguez (2006:20) "la practica pedagógica es un espacio para el aprendizaje de la enseñanza y desde este supuesto, alumnos y profesores esperan que el conocimiento declarativo, prescriptivo que se ofrece en las asignaturas, cursos y seminarios pueda resultar valido, útil y correcto para desempeñarse en la realidad”.

\subsection{Fase Ensayo Didáctico}

En relación con la fase de ensayo didáctico, podemos comentar que la oferta de este curso se realiza en el mismo momento en el que las estudiantes están cursando asignaturas claves para desarrollar con éxito algunos de los contenidos programáticos de esta fase. Así mismo es 
necesario señalar que se realiza una vez por semana, durante todo el semestre. Al respecto veamos el cuadro comparativo.

\begin{tabular}{|c|c|c|c|}
\hline Aspectos & Programa oficial & Programa aplicado & Observaciones \\
\hline Objetivos & $\begin{array}{l}\text { Demostración y adquisición de las } \\
\text { habilidades, destrezas, actitudes y } \\
\text { valores de comunicación o } \\
\text { interacción indispensables en el } \\
\text { proceso de aprendizaje en el nivel } \\
\text { preescolar, aplicando la didáctica de } \\
\text { procesos de los ejes transversales } \\
\text { contemplados en los programas } \\
\text { oficiales del Ministerio de } \\
\text { Educación. }\end{array}$ & $\begin{array}{l}\text { Analizar los contenidos } \\
\text { fundamentales } \\
\text { relacionados con la } \\
\text { educación Inicial } \\
\text { Analizar las nuevas } \\
\text { tendencias para la } \\
\text { enseñanza- aprendizaje } \\
\text { a este nivel. } \\
\text { Demostración de } \\
\text { habilidades y destrezas } \\
\text { al ejecutar de los planes } \\
\text { pedagógicos. }\end{array}$ & $\begin{array}{l}\text { Los dos programas } \\
\text { tienen similitudes. El } \\
\text { programa aplicado } \\
\text { presenta otros } \\
\text { contenidos: a) } \\
\text { contenidos } \\
\text { fundamentales } \\
\text { relacionados con la } \\
\text { educación Inicial } \\
\text { b) las nuevas tendencias } \\
\text { para la enseñanza- } \\
\text { aprendizaje a este nivel, }\end{array}$ \\
\hline Contenidos & $\begin{array}{l}\text { Manejo y revisión de los programas } \\
\text { oficiales del Ministerio de } \\
\text { Educación. Manejo y selección de } \\
\text { nuevas tendencias para el aprendizaje } \\
\text { a este nivel. Elaboración de } \\
\text { planificaciones centradas en el niño. } \\
\text { Elaboración de recursos pedagógicos. } \\
\text { Ejecución de planes pedagógicos. } \\
\text { Evaluación de su desempeño } \\
\text { profesional }\end{array}$ & $\begin{array}{l}\text { Manejo y revisión de los } \\
\text { programas oficiales del } \\
\text { Ministerio de Educación } \\
\text { para el nivel de } \\
\text { Preescolar. Manejo y } \\
\text { selección de las nuevas } \\
\text { tendencias para el } \\
\text { aprendizaje a este nivel. } \\
\text { Elaboración de } \\
\text { planificaciones } \\
\text { (considerando los } \\
\text { programas oficiales del } \\
\text { Ministerio de } \\
\text { Educación).Elaboración } \\
\text { de recursos pedagógicos } \\
\text { para la ejecución del } \\
\text { plan. Ejecución de los } \\
\text { planes pedagógicos en la } \\
\text { modalidad de Educación } \\
\text { Preescolar. Evaluación } \\
\text { de su desempeño } \\
\text { profesional }\end{array}$ & $\begin{array}{l}\text { No existen diferencias en } \\
\text { los contenidos de ambos } \\
\text { programas. }\end{array}$ \\
\hline Estrategias & $\begin{array}{l}\text { Diagnóstico de habilidades, } \\
\text { destrezas, competencias a través de } \\
\text { actividades prácticas en el aula taller. } \\
\text { Asesorías individuales y grupales. } \\
\text { Talleres. } \\
\text { Visitas guiadas. }\end{array}$ & $\begin{array}{l}\text { Diagnóstico de } \\
\text { habilidades, destrezas, } \\
\text { competencias. } \\
\text { Talleres } \\
\text { Ejecuciones } \\
\text { Presentación de recursos } \\
\text { en seminario final }\end{array}$ & $\begin{array}{l}\text { El programa aplicado } \\
\text { demuestra vacios en } \\
\text { algunas estrategias } \\
\text { recomendadas en el } \\
\text { programa oficial: a) } \\
\text { asesorías individuales, b) } \\
\text { visitas guiadas. }\end{array}$ \\
\hline
\end{tabular}

La Práctica Profesional como área para potenciar las competencias pedagógicas necesarias para la enseñanza en Educación Infantil 


\begin{tabular}{|c|c|c|c|}
\hline & Ejecuciones. & Seminario Integrador & \\
\hline & $\begin{array}{l}\text { Presentación de informe de } \\
\text { experiencias. }\end{array}$ & & \\
\hline Tipo de & Aula taller. & Aula taller. & Ambos programas \\
\hline $\begin{array}{l}\text { Centro de } \\
\text { aplicación }\end{array}$ & Preescolares & $\begin{array}{l}\text { Preescolar: publico } \\
\text { oficial, privados }\end{array}$ & coinciden. \\
\hline $\mathrm{N}^{\circ}$ de horas & 40 horas asesoría grupal & 60 horas asesoría grupal, & Se observa que existe \\
\hline asesoria & 16 horas asesoría individual $=56$ & $\begin{array}{l}\text { a razón de } 5 \text { horas por } \\
\text { semana. Solo un } \\
\text { programa indico } 1 \text { hora } \\
\text { de asesoría individual }\end{array}$ & $\begin{array}{l}\text { marcada preferencia poi } \\
\text { las asesorías grupales. }\end{array}$ \\
\hline
\end{tabular}

Cuadro $\mathrm{n}^{\circ} 64$. Comparación programa fase de ensayo didáctico

Del análisis al cuadro comparativo de la fase de ensayo, se encontró:

La FED, tiene la virtud de ser la primera oportunidad en que los estudiantes pongan en práctica lo que González (2001) citado en Latorre (2007:147) considera como desarrollo efectivo de sus tareas: "ver", "hacer", "ver hacer", y "hacer ver", lo cual requiere la puesta en marcha de competencias referidas a habilidades socialesrelacionales; habilidades técnico-funcionales; habilidades profesionales y habilidades reflexivas. En este sentido se encontró que: el programa aplicado presenta otros contenidos: a) contenidos fundamentales relacionados con la educación Inicial, b) las nuevas tendencias para la enseñanza- aprendizaje a este nivel, Esto indica que los profesores demuestran interés por ofrecer mayores oportunidades de confrontación teórico-práctica a sus alumnos; No existen diferencias en los contenidos de ambos programas; El programa aplicado demuestra vacios en algunas estrategias recomendadas en el programa oficial: a) asesorías individuales, b) visitas guiadas. Este hecho pudiera ser un factor de desventaja para los estudiantes por cuanto ambas estrategias enriquecen sus experiencias y por tanto aumentan sus potencialidades. En relación con el tipo de centro de aplicación: ambos programas coinciden. No obstante, es necesario mencionar que el número de horas de aplicación en las aulas UPEL es mayor al de aplicación o ejecución en los preescolares. Inclusive se da el caso en que algunos profesores deciden realizar todas las ejecuciones prácticas en las aulas UPEL, las cuales no posen los recursos mínimos para un verdadero ensayo didáctico, como lo son: cámaras de video, recursos y/o ambientación propia de un aula para niños y lo más importante niños y niñas en edad preescolar. Esta situación representa una seria debilidad en la administración de esta fase. Se observa que existe marcada preferencia por las asesorías grupales. 


\subsection{Fase Ejecución Proyectos Educativos}

Esta fase es la única del componente que presenta diferentes modalidades optativas, y se coordina a través de mecanismos que permiten controlar la oferta y la ejecución de los proyectos diseñados por los departamentos, los centros y núcleos de investigación del instituto, así como también de aquellos proyectos derivados de los acuerdos institucionales con organismos gubernamentales, no gubernamentales y centros de aplicación.

Los proyectos se ejecutan por grupos de alumnos, cuyo número estará establecido por el departamento u organismo oferente. Cada proyecto estará coordinado por un profesor del área de Práctica Profesional y el o los tutores que se designen para el proyecto. Tiene varias opciones: Ejecución proyectos de investigación, proyectos comunitarios o institucionales, práctica profesional no convencional. La modalidad, naturaleza y propósito de cada proyecto educativo determinará sus objetivos, contenidos y las estrategias para su ejecución. El estudiante tiene la obligación de cursar la fase y la libertad para seleccionar una de las opciones. Al respecto, en ocasiones no existe suficiente oferta de proyectos para el número de estudiantes de Educación Preescolar y estos seleccionan cualquier otro cuya disponibilidad de cupos les permita cursar y aprobar esta fase

En este sentido, se presentan dos proyectos de investigación ofertados por profesoras ordinarias de Educación Preescolar, con el fin de ofrecer dos visiones muy particulares de lo que implica esta importante fase, dentro de la formación integral de las futuras profesionales de Educación Infantil.

324

La Práctica Profesional como área para potenciar las competencias pedagógicas necesarias para la enseñanza en Educación Infantil 


\begin{tabular}{|c|c|c|c|}
\hline Aspectos & $\begin{array}{lll}\text { Programa } & \text { proyecto } & \text { de } \\
\text { investigación A }\end{array}$ & $\begin{array}{l}\text { Programa proyecto de } \\
\text { investigación } B\end{array}$ & Observaciones \\
\hline Objetivos & $\begin{array}{l}\text { Ejecutar una investigación } \\
\text { documental comparativa entre } \\
\text { Educación Preescolar y Educación } \\
\text { Especial. } \\
\text { Buscar información en centros de } \\
\text { documentación, internet, } \\
\text { bibliotecas. } \\
\text { Elaborar matrices de análisis. } \\
\text { Análisis y presentación de } \\
\text { resultados }\end{array}$ & $\begin{array}{l}\text { Ejecutar una } \\
\text { investigación de campo } \\
\text { referida a la praxis } \\
\text { pedagógica de los } \\
\text { docentes de Educación } \\
\text { Preescolar. } \\
\text { Evaluación y ensayo de } \\
\text { aplicación de los } \\
\text { instrumentos de } \\
\text { recolección de datos } \\
\text { Trabajo de campo: } \\
\text { observaciones y } \\
\text { aplicación de entrevistas } \\
\text { Análisis de los datos. } \\
\text { Presentación de } \\
\text { resultados. }\end{array}$ & $\begin{array}{l}\text { En ambos programas se } \\
\text { observa que los objetivos } \\
\text { tienen el énfasis en dos } \\
\text { modalidades } \\
\text { investigativas con } \\
\text { temáticas relacionadas } \\
\text { con la Educación } \\
\text { Infantil. }\end{array}$ \\
\hline Contenidos & $\begin{array}{l}\text { Investigación en educación, } \\
\text { Investigación documental, análisis } \\
\text { de programas oficiales de } \\
\text { Educación Preescolar y Educación } \\
\text { Especial, }\end{array}$ & $\begin{array}{l}\text { Revisión de la situación } \\
\text { objeto en estudio, } \\
\text { Técnicas e instrumentos } \\
\text { de recolección de datos, } \\
\text { estrategias para trabajo } \\
\text { de campo, análisis de } \\
\text { resultados, elaboración } \\
\text { de informe, presentación } \\
\text { oral de resultados. }\end{array}$ & $\begin{array}{l}\text { De acuerdo al tipo de } \\
\text { investigación cada } \\
\text { programa tiene } \\
\text { elementos pertinentes } \\
\text { con el aprendizaje del rol } \\
\text { de investigador, no } \\
\text { obstante, se observa } \\
\text { mayor riqueza en el } \\
\text { programa B, por cuanto } \\
\text { se perfila como } \\
\text { investigación de campo, } \\
\text { con todas sus etapas. }\end{array}$ \\
\hline Estrategias & $\begin{array}{l}\text { Fichaje, análisis de documentos, } \\
\text { debates, exposiciones, informes } \\
\text { escritos. }\end{array}$ & $\begin{array}{l}\text { Análisis de documentos, } \\
\text { ensayos, trabajo de } \\
\text { campo, observación } \\
\text { participante, aplicación } \\
\text { de entrevistas, } \\
\text { elaboración de matrices } \\
\text { de análisis, elaboración } \\
\text { de informe, presentación } \\
\text { pública de resultados. }\end{array}$ & $\begin{array}{l}\text { En el programa B se } \\
\text { observa mayor variedad } \\
\text { de estrategias propias de } \\
\text { una oportunidad de } \\
\text { práctica para los } \\
\text { estudiantes. }\end{array}$ \\
\hline $\begin{array}{l}\text { Tipo de } \\
\text { Centro de } \\
\text { aplicación }\end{array}$ & Aulas UPEL & $\begin{array}{l}\text { Aulas UPEL- variedad } \\
\text { de centros de Educación } \\
\text { Preescolar, de acuerdo al } \\
\text { contexto en el cual esta }\end{array}$ & $\begin{array}{l}\text { En el programa } \mathrm{B} \text {, los } \\
\text { estudiantes podrán } \\
\text { acercarse al contexto } \\
\text { educativo para el cual se }\end{array}$ \\
\hline
\end{tabular}

La Práctica Profesional como área para potenciar las competencias pedagógicas necesarias para la enseñanza en Educación Infantil 


\begin{tabular}{|c|c|c|c|}
\hline & & $\begin{array}{l}\text { residenciado el } \\
\text { estudiante. }\end{array}$ & $\begin{array}{l}\text { están formando, no así } \\
\text { en el programa } \mathrm{A}\end{array}$ \\
\hline $\begin{array}{l}N^{\circ} \text { de horas } \\
\text { asesoría }\end{array}$ & 48 horas asesoría grupal & $\begin{array}{l}48 \text { horas de asesoría } \\
\text { grupal, además señala un } \\
\text { horario extra en el cual } \\
\text { los estudiantes que así lo } \\
\text { requieran podrán } \\
\text { disponer de la asesoría } \\
\text { individual. }\end{array}$ & $\begin{array}{l}\text { El programa } B \\
\text { discrimina la atención } \\
\text { individual de la grupal }\end{array}$ \\
\hline
\end{tabular}

Cuadro $n^{\circ} 65$. Comparación fase de ejecución de proyectos.

Del análisis a los programas de FEDE se encontró:

Se observa que los objetivos tienen el énfasis en dos modalidades investigativas con temáticas relacionadas con la Educación Infantil. De acuerdo al tipo de investigación cada programa tiene contenidos pertinentes con el aprendizaje del rol de investigador, no obstante, se observa mayor riqueza en el programa $\mathrm{B}$, por cuanto se perfila como investigación de campo, con todas sus etapas. Las estrategias planteadas en ambos programas responden a la formación como investigadores, no obstante, se observa que la investigación de campo les brinda mayores oportunidades prácticas a los estudiantes. En relación al tipo de centro de aplicación ocurre igual situación, no resulta un reto para los estudiantes quedarse en las aulas universitarias, no así, al acercarse e involucrarse con otros contextos. De nuevo se evidencia ausencia en la discriminación de las asesorías. Al respecto, podemos afirmar que la FEPE, tiene que ver con el desarrollo de habilidades y competencias para el desarrollo de proyectos de investigación, y de acuerdo con Salcedo, Forero, Callejas, Pardo y Oviedo (2005:41) se propone un modelo de investigación- acción que articula la teoría y la práctica, dando un carácter educativo a la investigación, al integrar el conocimiento y la acción para desarrollar una práctica que este fundamentada y sobre la cual se reflexiona de manera crítica, se produce conocimiento y se reconoce que está comprometida con opciones valorativas y éticas.

326

La Práctica Profesional como área para potenciar las competencias pedagógicas necesarias para la enseñanza en Educación Infantil 


\subsection{Fase Integración Docencia Administración}

La fase de integración docencia administración constituye la última oportunidad de práctica en la formación de profesionales para la educación infantil. De acuerdo con la malla curricular los estudiantes pueden cursarla con dos asignaturas optativas, lo cual implica que debe asistir cuatro días de la semana al centro de aplicación de práctica y un día a la semana a las UPEL para cursar las otras asignaturas. Esta situación implica grandes dosis de organización, responsabilidad y capacidad de resolución de problemas, ya que las exigencias de esta fase son las mismas de un docente en servicio.

\begin{tabular}{|c|c|c|c|}
\hline Aspectos & Programa oficial & Programa aplicado & Observaciones \\
\hline Objetivos & $\begin{array}{l}\text { Desarrollar estrategias interactivas, } \\
\text { innovadoras y transformadoras en las } \\
\text { áreas pedagógicas y administrativas } \\
\text { consideradas en el contexto de la escuela, } \\
\text { familia y comunidad }\end{array}$ & $\begin{array}{l}\text { Diagnosticar en los } \\
\text { alumnos los conocimientos } \\
\text { teóricos-prácticos } \\
\text { adquiridos durante su } \\
\text { formación en la } \\
\text { especialidad, para orientar } \\
\text { la fase de integración } \\
\text { docencia-administración. } \\
\text { Los alumnos desarrollarán } \\
\text { y ejecutarán } \\
\text { planificaciones, elaborando } \\
\text { recursos de acuerdo a las } \\
\text { necesidades detectadas en } \\
\text { el grupo de niños, } \\
\text { aplicando las nuevas } \\
\text { tendencias educativas para } \\
\text { el nivel Inicial. } \\
\text { Diagnosticar necesidades } \\
\text { dentro del centro de } \\
\text { aplicación, para elaborar y } \\
\text { desarrollar un proyecto } \\
\text { pedagógico que contribuya } \\
\text { a satisfacer la necesidad } \\
\text { seleccionada. Reflexionar } \\
\text { acerca de las actividades } \\
\text { realizadas durante las } \\
\text { prácticas en el centro de } \\
\text { aplicación. }\end{array}$ & $\begin{array}{l}\text { Se observa congruencia } \\
\text { entre lo pautado en el } \\
\text { objetivo general del } \\
\text { programa oficial y lo } \\
\text { previsto por los profesores. }\end{array}$ \\
\hline Contenidos & $\begin{array}{l}\text { Realizar observaciones participativas en } \\
\text { los diferentes ambientes de la escuela. } \\
\text { Diseño y aplicación de planes. Aplicar la } \\
\text { didáctica de procesos de los ejes } \\
\text { transversales. Aplicación de técnicas y } \\
\text { procedimientos administrativos en las } \\
\text { diferentes dependencias del centro de }\end{array}$ & $\begin{array}{l}\text { Conceptualización teórica } \\
\text { fundamental para la } \\
\text { orientación de la fase } \\
\text { "integración, docencia y } \\
\text { administración". Rol del } \\
\text { docente preescolar. }\end{array}$ & $\begin{array}{l}\text { Se repiten algunos } \\
\text { contenidos de la fase de } \\
\text { observación. Ausencia de } \\
\text { algunos elementos } \\
\text { previstos en el programa } \\
\text { oficial: didáctica de } \\
\text { procesos de los ejes }\end{array}$ \\
\hline
\end{tabular}




\begin{tabular}{|c|c|c|c|}
\hline & $\begin{array}{l}\text { aplicación. Desarrollo de planes de } \\
\text { acción donde se involucren la familia y la } \\
\text { comunidad al proceso educativo }\end{array}$ & $\begin{array}{l}\text { Funciones de las } \\
\text { dependencias del centro de } \\
\text { investigación. Evaluación } \\
\text { en preescolar. Planificación } \\
\text { en preescolar. Normativa } \\
\text { del manual UPEL. } \\
\text { Instrumentos necesarios } \\
\text { para el desarrollo de la fase. } \\
\text { Diseño de actividades extra } \\
\text { cátedra y su aplicabilidad } \\
\text { en el centro preescolar. }\end{array}$ & $\begin{array}{l}\text { transversales, técnicas y } \\
\text { procedimientos } \\
\text { administrativos, planes de } \\
\text { acción donde se involucren } \\
\text { la familia y la comunidad } \\
\text { al proceso educativo }\end{array}$ \\
\hline Estrategias & $\begin{array}{l}\text { Taller de inducción. Visita guiada a las } \\
\text { dependencias administrativas de los } \\
\text { centros de aplicación. Diseño y } \\
\text { aplicación de estrategias innovadoras } \\
\text { para la mejor administración de los } \\
\text { recursos existentes en cada dependencia. } \\
\text { Supervisiones en el aula. Ejecución de } \\
\text { planes. Entrega de informes. Seminario. } \\
\text { Evaluación de la fase }\end{array}$ & $\begin{array}{l}\text { Dinámicas grupales } \\
\text { (integración). Elaborar el } \\
\text { diagnóstico pedagógico. } \\
\text { Elaborar proyectos y } \\
\text { planes. Elaborar y manejar } \\
\text { recursos. Ejecutar sus } \\
\text { proyectos y planes. } \\
\text { Elaborar un proyecto o } \\
\text { propuesta de solución. } \\
\text { Ejecución de proyecto. } \\
\text { Evaluación de los logros. } \\
\text { Confrontación de las } \\
\text { experiencias obtenidas en el } \\
\text { centro de aplicación. }\end{array}$ & $\begin{array}{l}\text { Existe congruencia entre } \\
\text { ambos programas. Solo } \\
\text { falto las visitas guiadas. }\end{array}$ \\
\hline $\begin{array}{l}\text { Tipo de } \\
\text { Centro de } \\
\text { aplicación }\end{array}$ & $\begin{array}{l}\text { Centros de atención convencionales y no } \\
\text { convencionales }\end{array}$ & $\begin{array}{l}\text { Centros preescolares } \\
\text { públicos y privados }\end{array}$ & Sin observaciones \\
\hline $\begin{array}{l}\mathrm{N}^{\circ} \text { de horas } \\
\text { asesoría }\end{array}$ & $\begin{array}{l}40 \text { horas asesoría grupal } \\
16 \text { horas asesoría individual }=56\end{array}$ & $\begin{array}{l}\text { No se discriminan las horas } \\
\text { de asesoría, no obstante se } \\
\text { observa que existen seis } \\
\text { sesiones de trabajo en aulas } \\
\text { UPEL y el resto (10 } \\
\text { sesiones) en contextos de } \\
\text { aplicación } \\
\text { preescolares) }\end{array}$ & Sin observaciones \\
\hline
\end{tabular}

Cuadro ${ }^{\circ}{ }^{66}$. Comparación Fase de integración docencia administración

328

La Práctica Profesional como área para potenciar las competencias pedagógicas necesarias para la enseñanza en Educación Infantil 
Del análisis a los programas de FIDA, se encontró:

Congruencia entre lo pautado en el objetivo general del programa oficial y los objetivos previstos por los profesores. Se repiten algunos contenidos de la fase de observación. Ausencia de algunos elementos previstos en el programa oficial: didáctica de procesos de los ejes transversales, técnicas y procedimientos administrativos, planes de acción donde se involucren la familia y la comunidad al proceso educativo. En cuanto a los últimos tres elementos: estrategias, tipo de centro, y asesorías existe congruencia entre ambos programas. Solo falto las visitas guiadas. Este programa de fase implica para los estudiantes la demostración o dominio de conocimientos, habilidades y destrezas necesarias para la enseñanza, lo cual a juicio de muchos investigadores es objeto de interés común; Al respecto, La torre (2007:142), refiere a varios autores entre los cuales citaremos a Martín del Pozo, quien afirma que existen cuatro componentes del conocimiento profesional que habrían de construir los futuros profesores: a) conocimiento profesionalizado del contenido (formación sobre las disciplinas, no en las disciplinas), b) conocimiento pedagógico general y del contexto, c) conocimiento didáctico especifico, supone una transposición didáctica del contenido para que sea objeto de enseñanza y aprendizaje en el contexto escolar, d) conocimiento práctico: proviene de la experiencia del profesor y es el conocimiento que de hecho utilizan y reflejan en su actuación en el aula.

\subsubsection{Análisis FODA Programas Practica Profesional.}

En esta parte del proceso de estudio documental al plan de estudio y los programas de práctica profesional de Educación Preescolar, se presenta el trabajo realizado con el apoyo estratégico que provee la herramienta denominada matriz FODA. Para esta labor se utilizaron indicadores internos de fortalezas y debilidades y los indicadores externos de amenazas y oportunidades. En el cuadro n67, puede observarse los resultados de su aplicación.

\begin{tabular}{|c|c|}
\hline Fortalezas (Referidas a variables internas): & Debilidades (referidas a variables internas): \\
\hline $\begin{array}{l}\text { La UPEL, actualmente se encuentra en el } \\
\text { proceso de transformación y actualización }\end{array}$ & $\begin{array}{l}\text { Los programas oficiales de prá } \\
\text { profesional, no responden a las polí }\end{array}$ \\
\hline
\end{tabular}


curricular.

Los programas son actualizados cada semestre, sobre la base de los aportes de algunos profesores.

Existe el apoyo por parte de los coordinadores a las innovaciones que los profesores quieran agregar a los programas de las fases, los cuales deben estar ajustados a las políticas educativas vigentes.

Los propósitos, objetivos y estrategias presentes en cada uno de los programas se perfilan aceptables en atención a las innovaciones en materia de Educación Infantil educativas del estado venezolano.

La FO, al ser homologada, ocasiona que cualquier profesional con mínimos conocimientos en el área de Educación Infantil, la administre. En esta fase hay marcado énfasis en objetivos conceptuales y actitudinales.

Las prelaciones de FED y FIDA, no responden a los requerimientos exigidos en los planes.

En FO y FEPE, se repiten contenidos de otras asignaturas.

Los contenidos Fundamentales de FO, FED, FEPE, FIDA, no están acordes a la realidad educativa del nivel.

La FO no indica centros de aplicación, esto induce a seleccionar centros de aplicación con poca variedad.

En FO, FED y FEPE existe un marcado predominio a permanecer mayor tiempo en las aulas universitarias.

En todos los programas que aplican los profesores se observa ausencia de asesorías individuales.

El número de horas a cada una de las fases no es suficiente.

No se cuenta con aulas y/o equipos tecnológicos que permitan grabar las ejecuciones prácticas de los alumnos.

No existe programas de formación permanente entre el profesorado.

El número de profesores contratados supera a los profesores ordinarios: 12 / 6 .
Oportunidades (referidas a variables externas):
Amenazas (referidas a variables externas):

Otras universidades poseen una administración

La Práctica Profesional como área para potenciar las competencias pedagógicas necesarias para la enseñanza en Educación Infantil 


\begin{tabular}{ll}
\hline Los profesores contratados se muestran & de sus prácticas, donde incorporan a sus \\
dispuestos a participar y producir & alumnos en los centros de aplicación desde el \\
Posibilidad de solicitar la participación y & inicio de la carrera. \\
apoyo de parte de representantes del Ministerio & Cambios en la legislación: Carta Magna \\
de Educación, para integrar sus aportes a la & $(1990)$, Ley Orgánica de Educación () \\
actualización de los planes & $\begin{array}{l}\text { Tendencias educativas del país: Sistema } \\
\text { Educación Bolivariano }\end{array}$ \\
\hline
\end{tabular}

Cuadro $n^{\circ}$ 67. Matriz FODA plan y programas práctica profesional Educación Preescolar.

\subsubsection{Análisis Estrategias FODA}

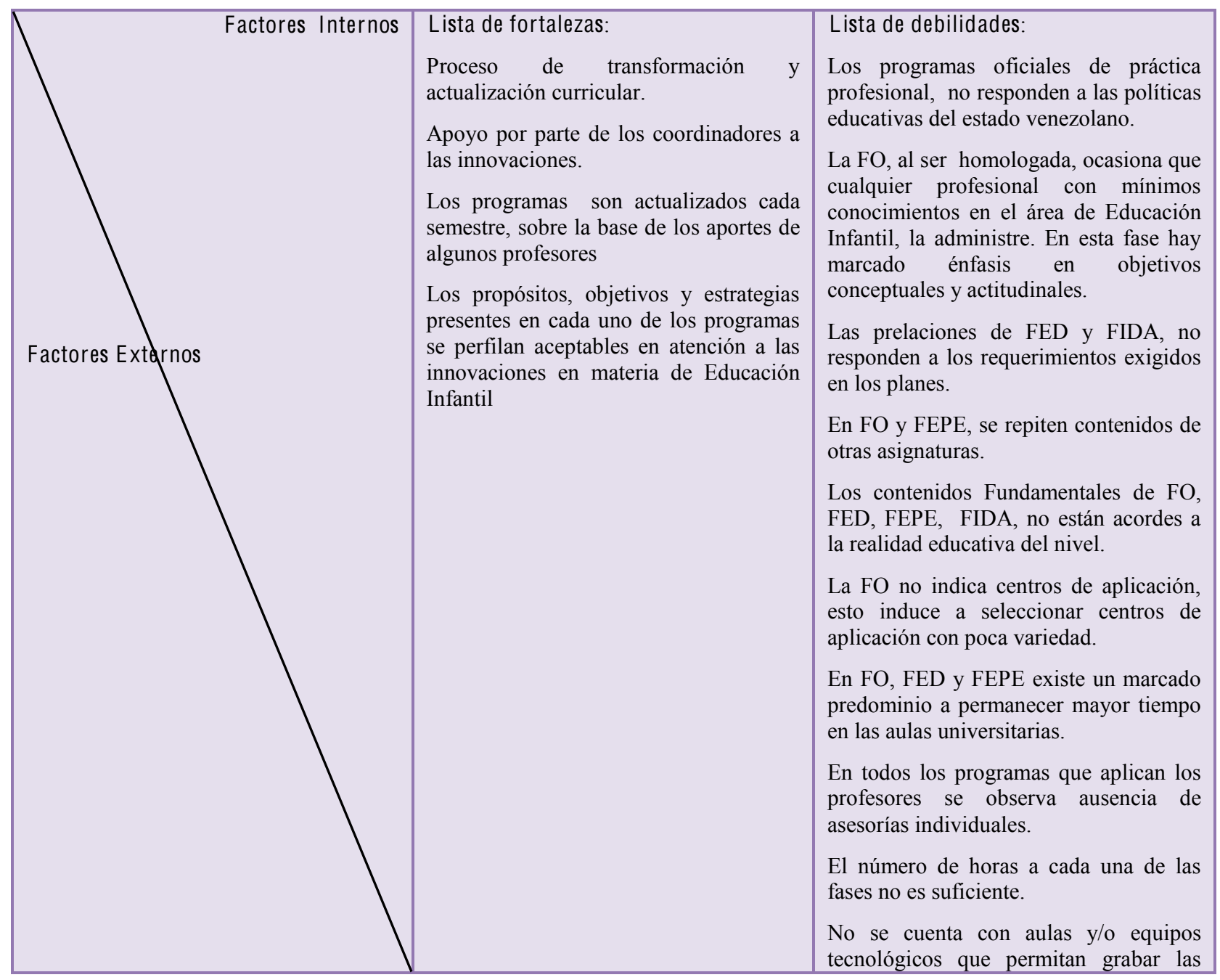

La Práctica Profesional como área para potenciar las competencias pedagógicas necesarias para la enseñanza en Educación Infantil 


\begin{tabular}{|c|c|c|}
\hline & & $\begin{array}{l}\text { ejecuciones prácticas de los alumnos. } \\
\text { No existe programas de formación } \\
\text { permanente entre el profesorado. } \\
\text { El número de profesores contratados } \\
\text { supera a los profesores ordinarios: } 12 \text { / } \\
6 \text {. }\end{array}$ \\
\hline $\begin{array}{l}\text { Lista de oportunidades: } \\
\text { Los profesores contratados se muestran } \\
\text { dispuestos a participar y producir } \\
\text { Posibilidad de solicitar la opinión y } \\
\text { apoyo de parte de representantes del } \\
\text { Ministerio de Educación, para integrar } \\
\text { sus aportes a la actualización de los } \\
\text { planes }\end{array}$ & $\begin{array}{l}\text { F0: Invitar a los profesores contratados } \\
\text { en el proceso de actualización y } \\
\text { transformación curricular. } \\
\text { Coordinar actividades ampliadas con } \\
\text { estudiantes activos y egresados, } \\
\text { representantes del ministerio de } \\
\text { educación, en el proceso de } \\
\text { actualización y transformación curricular }\end{array}$ & $\begin{array}{l}\text { D0: Aprovechar la disposición de todos } \\
\text { los actores y presentar las debilidades, } \\
\text { con el fin de incorporar las propuestas de } \\
\text { cambio en el nuevo documento de } \\
\text { actualización y transformación } \\
\text { curricular }\end{array}$ \\
\hline $\begin{array}{l}\text { Lista de amenazas: } \\
\text { La creación de la Universidad } \\
\text { Bolivariana, y su sistema de } \\
\text { incorporación a los centros de práctica } \\
\text { desde el inicio de la carrera. } \\
\text { Cambios en la legislación: Carta Magna } \\
\text { (1990), Ley Orgánica de Educación () }\end{array}$ & $\begin{array}{l}\text { FA: Incorporar las nuevas tendencias en } \\
\text { materia legal y utilizar el sistema de } \\
\text { prácticas de la Universidad Bolivariana } \\
\text { en la UPEL, aprovechando la } \\
\text { oportunidad de la actualización y } \\
\text { transformación curricular }\end{array}$ & $\begin{array}{l}\text { DA: Mantener una actitud abierta de } \\
\text { evaluación permanente, dialogo y } \\
\text { flexibilidad curricular, para minimizar } \\
\text { las desventajas. }\end{array}$ \\
\hline
\end{tabular}

Cuadro ${ }^{\circ}$ 68. Matriz Estrategias

Leyenda: FO: Estrategias para maximizar las F y las O; DO: estrategias para minimizar las D y maximizar las O; FA: Estrategias para maximizar las F y minimizar las A; DA: estrategias para minimizar las D y las A.

\subsubsection{Conclusiones Análisis Programas Practica Profesional.}

La UPEL posee un diseño curricular que requiere ser actualizado, en virtud de los cambios legales, pedagógicos, psicológicos, sociales, económicos, políticos y educativos, que han ocurrido en Venezuela y en el mundo. Este modelo de formación, a pesar de que en sus enunciados curriculares lo presentan como integrador, abierto y sensible, para asimilar los cambios que se susciten en la educación, la ciencia, la tecnología y la cultura (UPEL, 1996:8), en realidad se presenta como centrado en las asignaturas, lo cual implica un énfasis excesivo en la dimensión instrumental de la profesión y que responde al criterio de que, el egresado sea capaz de enfrentar la solución de los problemas que se planteen en su área de trabajo, y pueda 
actuar de acuerdo con las necesidades de la práctica y demandas sociales con la mayor efectividad y eficiencia posibles.

Al respecto, resulta oportuno citar a Marcelo (2008:4), para quien “ la formación docente es un proceso que no sólo incluye los denominados cursos de formación, sino que puede presentarse a través de modalidades más flexibles como grupos de trabajo, proyectos de innovación, o redes de profesores a través de Estrategias de Aprendizaje Abierto y a Distancia utilizando una estructura procesual”. Para ello propone sea organizado a través de los Estándares de Calidad para Programas de Formación Docente, el cual está compuesto por las siguientes dimensiones del proceso: Contexto, Diseño, Producción, Puesta en marcha, Implementación y Seguimiento de los estándares. El aprovechamiento de la tecnología educativa sería una herramienta valiosa para esta situación encontrada.

Con respecto a los programas del área de práctica profesional, se observan algunas debilidades las cuales son fáciles de superar si se trata solo de agregar más horas, incluir otros contenidos, o también cambiar y actualizar las estrategias, no obstante consideramos que la piedra angular en estos procesos de mejora es el mismo profesor universitario. Esto ocurre porque, si bien en algunos programas no se observan de manera explícita algunas directrices dadas en el programa oficial, no es menos cierto que en algunos casos los profesores terminan haciendo más de lo realmente aparece en los documentos. De esta suerte, no solo podemos advertir el rol protagónico del profesor en este proceso formativo, sino que también debemos introducir el imperativo de considerar algunos cambios en el proceso de formación de nuestros estudiantes.

El esfuerzo por renovar la formación de los futuros docentes debe comprometer a todos los actores responsables en el rediseño del currículo y elevar los estándares formativos en concordancia con los requerimientos de la sociedad en general, es decir volver la mirada crítica hacia nuestras propias prácticas.

333

La Práctica Profesional como área para potenciar las competencias pedagógicas necesarias para la enseñanza en Educación Infantil 


\subsubsection{Análisis de los Talleres Reflexivos}

\subsubsection{Introducción.}

Los talleres reflexivos, representan la segunda fase del presente estudio. Para ello, se realizaron dos grupos de trabajo, con el mismo propósito de investigación: darle respuesta al tercer objetivo de este estudio como lo es: Indagar las fortalezas y debilidades que distinguen los alumnos y los profesores de la especialidad de Educación Preescolar en el proceso de administración de la práctica profesional. Por una parte, se invito a la totalidad de los profesores (ordinarios y contratados) que en ese momento, administran la práctica profesional en Educación Preescolar (15 en total) de los cuales asistieron nueve (09) en la primera y segunda sesión y cinco (05) en la tercera sesión. Por otra parte, a un grupo de estudiantes cursantes del último semestre de su carrera universitaria y que además ya habían participado como informantes en la aplicación del cuestionario, pues estaban terminando de cursar la fase de integración docencia administración. El grupo estaba compuesto por diez (10) estudiantes, los cuales fueron seleccionados de forma intencional.

Cada una de las sesiones programadas tuvo una duración de cuatro (04) horas con un intervalo de realización de una semana. Por lo que en ambos grupos se trabajo durante tres semanas consecutivas.

Al final de este análisis y a modo de resumen se presenta un cuadro con las respuestas más frecuentes otorgadas a la valoración de la práctica profesional, con la respectiva explicación cualitativa.

\subsubsection{Talleres Reflexivos Realizados con los Profesores.}

En esta fase de la investigación, se describen los talleres realizados con los profesores de práctica profesional. Tal como se explicó, se procede a detallar cada uno de los tres talleres realizados.

334

La Práctica Profesional como área para potenciar las competencias pedagógicas necesarias para la enseñanza en Educación Infantil 


\begin{tabular}{|c|c|c|c|}
\hline Taller/ dimensiones & Contenido & Actividad & Recursos \\
\hline $\begin{array}{l}\text { Primer Taller } \\
\text { dimensión enseñanza } \\
\text { universitaria (DEU) } \\
\text { dimensión procesos } \\
\text { de aprendizaje } \\
\text { (DPA) }\end{array}$ & $\begin{array}{l}\text { Representación } \\
\text { gráfica de su práctica } \\
\text { pedagógica }\end{array}$ & $\begin{array}{l}\text { Charla introductoria } \\
\text { Producción escrita } \\
\text { Valorar su práctica } \\
\text { pedagógica en la } \\
\text { formación de futuros } \\
\text { profesionales para la } \\
\text { educación infantil. }\end{array}$ & $\begin{array}{l}\text { Sobre con } \\
\text { afirmaciones } \\
\text { Laptop. } \\
\text { Video beam. } \\
\text { Papel bond. } \\
\text { Marcadores. } \\
\text { Cámara fotográfica }\end{array}$ \\
\hline $\begin{array}{l}\text { Segundo Taller } \\
\text { dimensión didáctica } \\
\text { especifica educación } \\
\text { infantil (DDEEI) } \\
\text { dimensión académico } \\
\text { estudiantil } \\
\text { (DAE) }\end{array}$ & $\begin{array}{l}\text { Revisión y análisis de } \\
\text { los planes de estudio, } \\
\text { programas didácticos, } \\
\text { rendimiento } \\
\text { estudiantil, apoyo } \\
\text { institucional (UPEL, } \\
\text { centros de aplicación), } \\
\text { numero de prácticas, } \\
\text { duración, ubicación } \\
\text { dentro del currículo } \\
\text { de formación }\end{array}$ & $\begin{array}{l}\text { Preguntas generadoras } \\
\text { Evaluar programas de } \\
\text { fase y comparar con } \\
\text { lo vivido }\end{array}$ & $\begin{array}{l}\text { Producciones gráficas } \\
\text { del primer taller. } \\
\text { Formatos de planes y } \\
\text { programas. } \\
\text { Formato para } \\
\text { sistematizar las ideas. } \\
\text { Cámara fotográfica }\end{array}$ \\
\hline Tercer Taller & Propuestas de mejora & $\begin{array}{l}\text { Elaborar Propuesta de } \\
\text { mejora } \\
\text { Presentación oral y } \\
\text { escrita }\end{array}$ & $\begin{array}{l}\text { Papel Bond. } \\
\text { Cámara Fotográfica } \\
\text { Marcadores. }\end{array}$ \\
\hline
\end{tabular}

Cuadro 69. Descripción general talleres profesores

\subsection{Primer Taller con los Profesores.}

Después de dar la bienvenida, se explico a los profesores asistentes, las instrucciones para la realización del taller, los profesores asistentes se mostraron dispuestos y con apertura ante la solicitud de realizar su representación gráfica, de lo que para ellos significa su práctica pedagógica. Hubo algunas preguntas, sobre el tiempo para realizar la actividad, algunos se 
mostraban impacientes por abrir los sobres, y otras comentaban en voz alta que "hacia tiempo no trabajaba con papel, goma y marcadores", "ese trabajo es para los niños de la escuela". Se explico de nuevo, que podían usar las tarjetas entregadas, pero que además tenían otras en blanco para que escribieran sus propias frases o también tenían la libertad de desechar las que consideraran inútiles. Los profesores trabajaron individualmente por aproximadamente 30 minutos, en algunos momentos miraban las producciones de sus compañeras y hacían comentarios.

A continuación se muestran las representaciones gráficas de cada una de las informantes, así como un breve fragmento de lo que explico en relación a su construcción. Para efectos de ilustrar se recuerda que, las afirmaciones colocadas en la base constituyen lo más importante que sirve de sustento y fundamento a su práctica pedagógica. 


\section{Representaciones Gráficas de los Profesores}

Los recuadros en color negro y cursivo es lo agregado por la participante

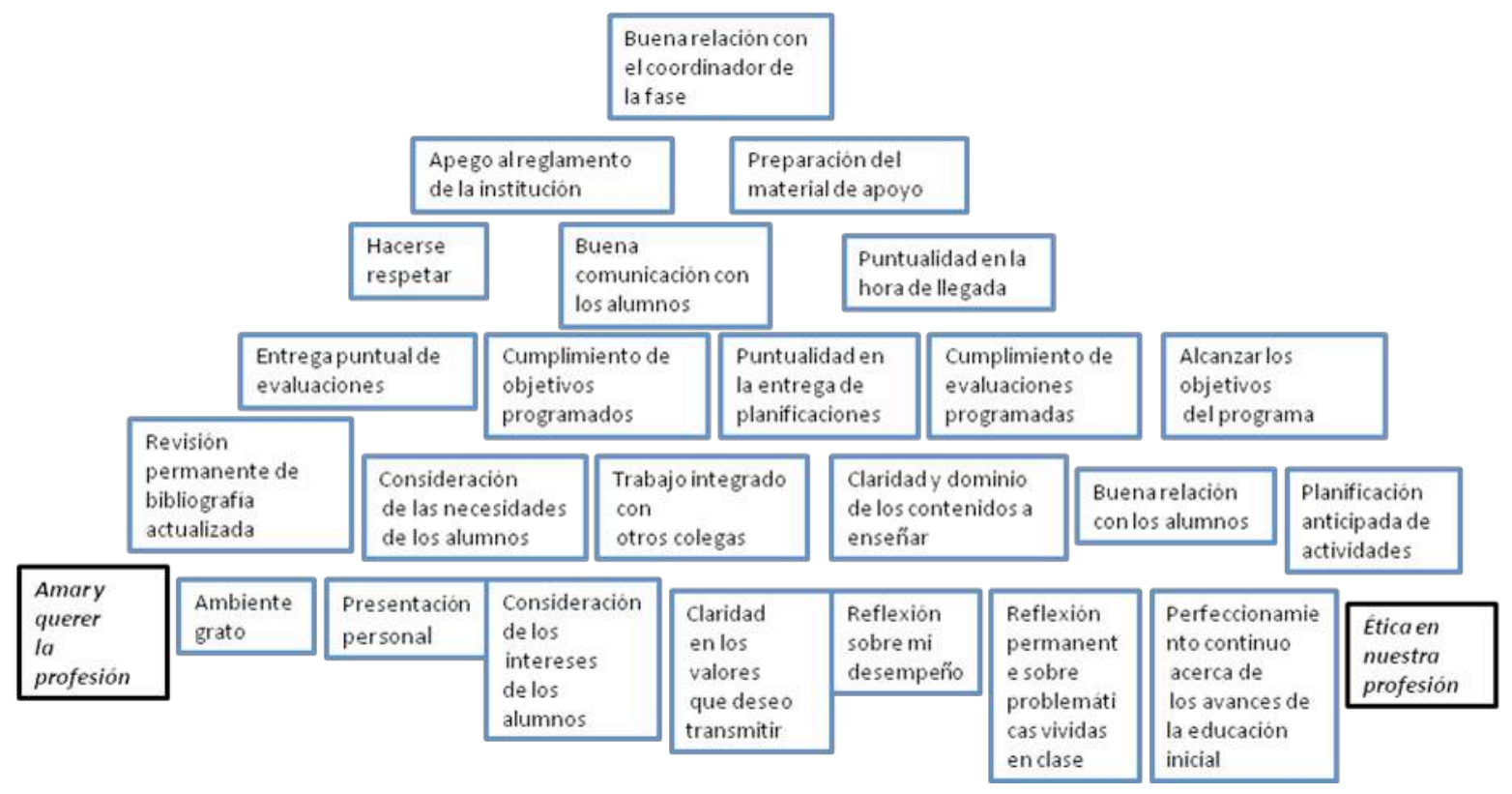

Grafico ${ }^{\circ} 58$. Representación grafica Profesora \#1.

La explicación dada por esta profesora estaba sustentada en argumentos de tipo legal, moral y pedagógico. Tales como:

"es muy importante una buena base para que todo se desarrolle muy bien: es necesario cumplir las normas, los aspectos teóricos, la vestimenta del profesor debe ser distinta de los alumnos...pero a ellas se les debe exigir buena presentación... no considero que se deba desechar ninguna tarjeta; agrego dos... Yo trabajo con las múltiples inteligencias y desde allí visualizo desde su base y por añadidura se dan las que están arriba.

337

La Práctica Profesional como área para potenciar las competencias pedagógicas necesarias para la enseñanza en Educación Infantil 
Apreciación de la investigadora.

A partir de la contrastación entre lo que explica y lo que coloco en la base de representación gráfica, puede afirmarse que le da mucha importancia a las afirmaciones relacionadas con los procesos de aprendizaje (de acuerdo con el cuadro $\mathrm{n}^{\circ} 26$, construido para tal efecto), lo cual indica que la profesora es congruente entre lo que dice y lo que representó. No obstante, es interesante la forma como coloca distancia entre la majestuosidad del profesor y la persona del alumno.

\section{Profesora \#2}

\begin{tabular}{|c|c|c|c|c|c|c|c|c|c|c|c|}
\hline & & & & & \multicolumn{2}{|c|}{$\begin{array}{l}\text { Buenarelación con } \\
\text { el coordinador de } \\
\text { la fase }\end{array}$} & & & & & \\
\hline & & & \multicolumn{3}{|c|}{$\begin{array}{l}\text { Alcanzarlos } \\
\text { objetivos } \\
\text { del programa }\end{array}$} & \multicolumn{4}{|c|}{$\begin{array}{l}\text { Reflexion permanente } \\
\text { sobre problematicas } \\
\text { vividas en clase }\end{array}$} & & \\
\hline $\begin{array}{l}\text { Cumplimiento } \\
\text { de objetivos } \\
\text { programados }\end{array}$ & $\begin{array}{l}\text { Puntualida } \\
\text { en la hora } \\
\text { llegada }\end{array}$ & $\begin{array}{l}\text { lad } \\
\text { a de }\end{array}$ & \multicolumn{2}{|c|}{$\begin{array}{l}\text { Planificacion } \\
\text { anticipada de } \\
\text { actividades }\end{array}$} & \multicolumn{2}{|c|}{$\begin{array}{l}\text { Puntualidad en } \\
\text { la entrega de } \\
\text { planificaciones }\end{array}$} & \multicolumn{3}{|c|}{$\begin{array}{l}\text { Preparación } \\
\text { del material } \\
\text { de apoyo }\end{array}$} & $\begin{array}{l}\text { Entrega } \\
\text { puntual } \\
\text { de } \\
\text { evaluaciones }\end{array}$ & $\begin{array}{l}\text { Cumplimiento de } \\
\text { evaluaciones } \\
\text { programadas }\end{array}$ \\
\hline \multirow{3}{*}{$\begin{array}{l}\text { Ambiente } \\
\text { grato }\end{array}$} & \multirow{3}{*}{$\begin{array}{l}\text { Presentación } \\
\text { personal }\end{array}$} & \multirow{3}{*}{\multicolumn{2}{|c|}{$\begin{array}{l}\text { Buena } \\
\text { relacion } \\
\text { conlos } \\
\text { alumnos }\end{array}$}} & \multirow{3}{*}{\multicolumn{2}{|c|}{$\begin{array}{l}\text { Buena } \\
\text { comunicación } \\
\text { con los } \\
\text { alumnos }\end{array}$}} & \multirow{3}{*}{\multicolumn{2}{|c|}{$\begin{array}{l}\text { Consideración } \\
\text { de las } \\
\text { necesidades } \\
\text { de los } \\
\text { alumnos }\end{array}$}} & \multirow{3}{*}{\multicolumn{2}{|c|}{$\begin{array}{l}\text { Apego al } \\
\text { reglamento } \\
\text { dela } \\
\text { institucion }\end{array}$}} & & \\
\hline & & & & & & & & & & Consideración & Trabajo integrado \\
\hline & & & & & & & & & & de los alumnos & otros colegas \\
\hline \multirow{2}{*}{\multicolumn{2}{|c|}{$\begin{array}{l}\text { Perfeccionamiento } \\
\text { continuo acerca de los } \\
\text { avances de la } \\
\text { educación inicial }\end{array}$}} & \multirow{2}{*}{\multicolumn{3}{|c|}{$\begin{array}{l}\text { Revisión } \\
\text { permanente de } \\
\text { bibliografia } \\
\text { actualizada }\end{array}$}} & \multirow{2}{*}{\multicolumn{2}{|c|}{$\begin{array}{l}\text { Claridaden los } \\
\text { valores que deseo } \\
\text { transmitir }\end{array}$}} & \multirow{2}{*}{\multicolumn{2}{|c|}{$\begin{array}{l}\text { Reflexion } \\
\text { sobremi } \\
\text { desempeño }\end{array}$}} & \multirow{2}{*}{\multicolumn{2}{|c|}{$\begin{array}{l}\text { Claridady dominio } \\
\text { de los contenidos a } \\
\text { enseñar }\end{array}$}} & \\
\hline & & & & & & & & & & & $\begin{array}{l}\text { Hacerse } \\
\text { respetar }\end{array}$ \\
\hline
\end{tabular}

Grafico $n^{\circ} 59$. Representación grafica Profesora \#2

Del extracto a la explicación dada por la profesora \#2 tenemos:

"de las dos que están en el centro, parte todo: "los valores" "la reflexión permanente". Hay que ser capaz de ver a los demás y tratarlos como se merecen. Tener domino de los 338

La Práctica Profesional como área para potenciar las competencias pedagógicas necesarias para la enseñanza en Educación Infantil 
contenidos, sentirnos a gusto en nuestro ambiente. Nosotros somos el ejemplo de nuestros niños y eso es muy importante para los alumnos. Ser empático... rescatar el reglamento, incluye la puntualidad, responsabilidad... hay alumnas que son "suma cumlaude" y cuando llegan al aula no saben desenvolverse. No desecho ninguna tarjeta, pero tampoco las agrego"

Apreciación de la investigadora.

Con respecto a la profesora \# 2 existe equilibrio en las afirmaciones que coloco en la base de su representación. Para esta informante, las afirmaciones referidas a la didáctica de educación superior, van de la mano con los procesos de aprendizaje de los alumnos. Al compara con lo que expreso oralmente, podemos ver que para ella el rescate de los valores, el respeto a los alumnos, y los procesos reflexivos del docente permiten mejorar los procesos formativos.

339

La Práctica Profesional como área para potenciar las competencias pedagógicas necesarias para la enseñanza en Educación Infantil 


\section{Profesora \#3}

Los recuadros en color negro y cursivo es lo agregado por la participante

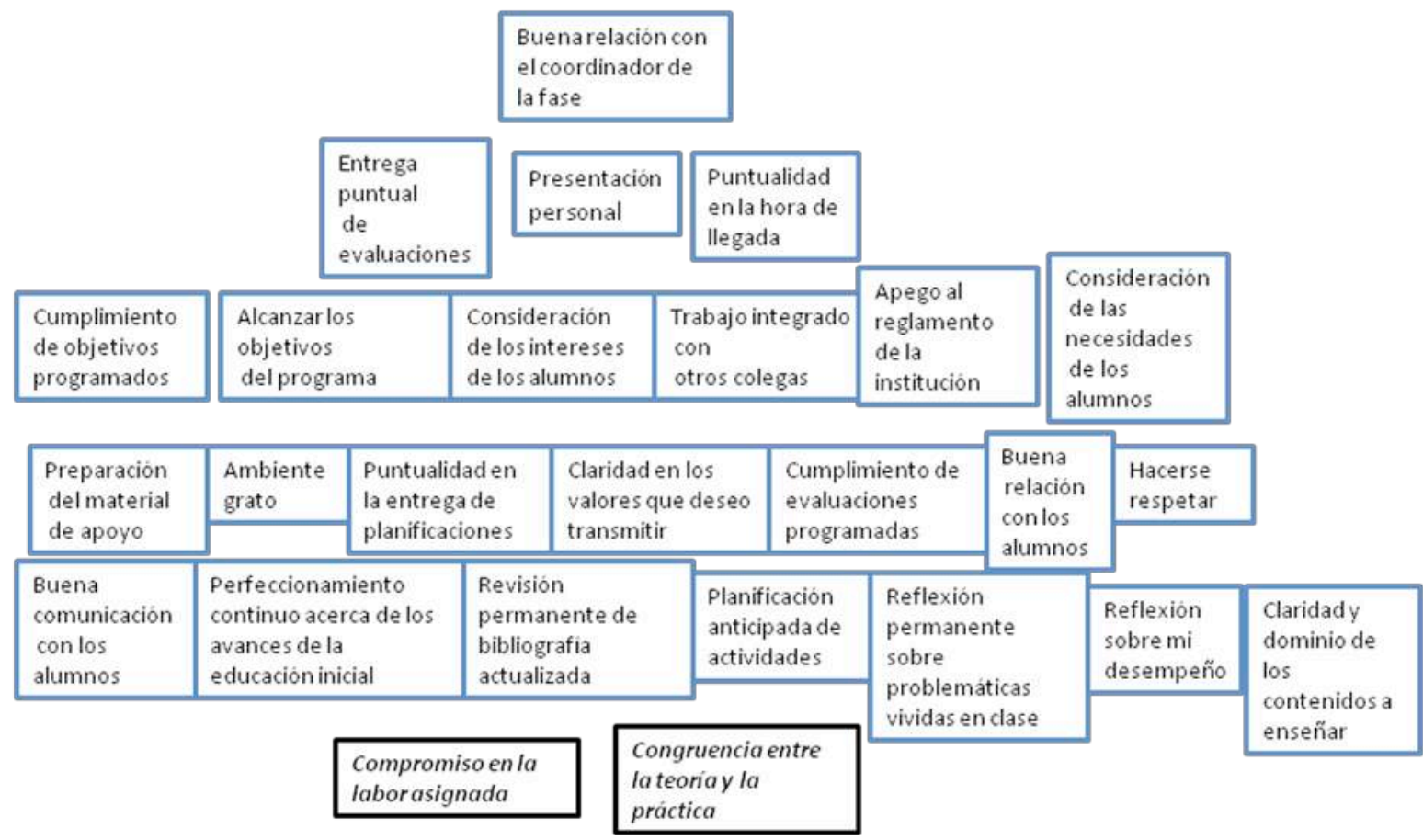

Grafico $n^{\circ} 60$. Representación grafica Profesora \#3

“asumir el compromiso que implica el formar maestros... la base es la buena comunicación con los estudiantes. Nada hacemos con perfeccionamiento profesional apartando el personal: escuchar a los alumnos. Ser amiga pero hacerse respetar. El apego a la institución no le agrada mucho. La presentación personal de la profesora de práctica es importante. Agrego dos tarjetas, no desecho ninguna"

Apreciación de la investigadora.

En lo referente a la profesora \# 3, se observa que las afirmaciones referidas a la dimensión didáctica de la enseñanza universitaria, tienen predominio sobre las relacionadas con los procesos 340

La Práctica Profesional como área para potenciar las competencias pedagógicas necesarias para la enseñanza en Educación Infantil 
de aprendizaje de los alumnos, por cuanto en la base de su representación existen cuatro afirmaciones frente a dos. Sin embargo, en su explicación a la gráfica construida, se observa marcado interés por aspectos emocionales o afectivos, relacionados con dar mucho apoyo a los alumnos para que aprendan más.

\section{Profesora \#4}

El recuadro marcado con una cruz fue eliminado por la participante.

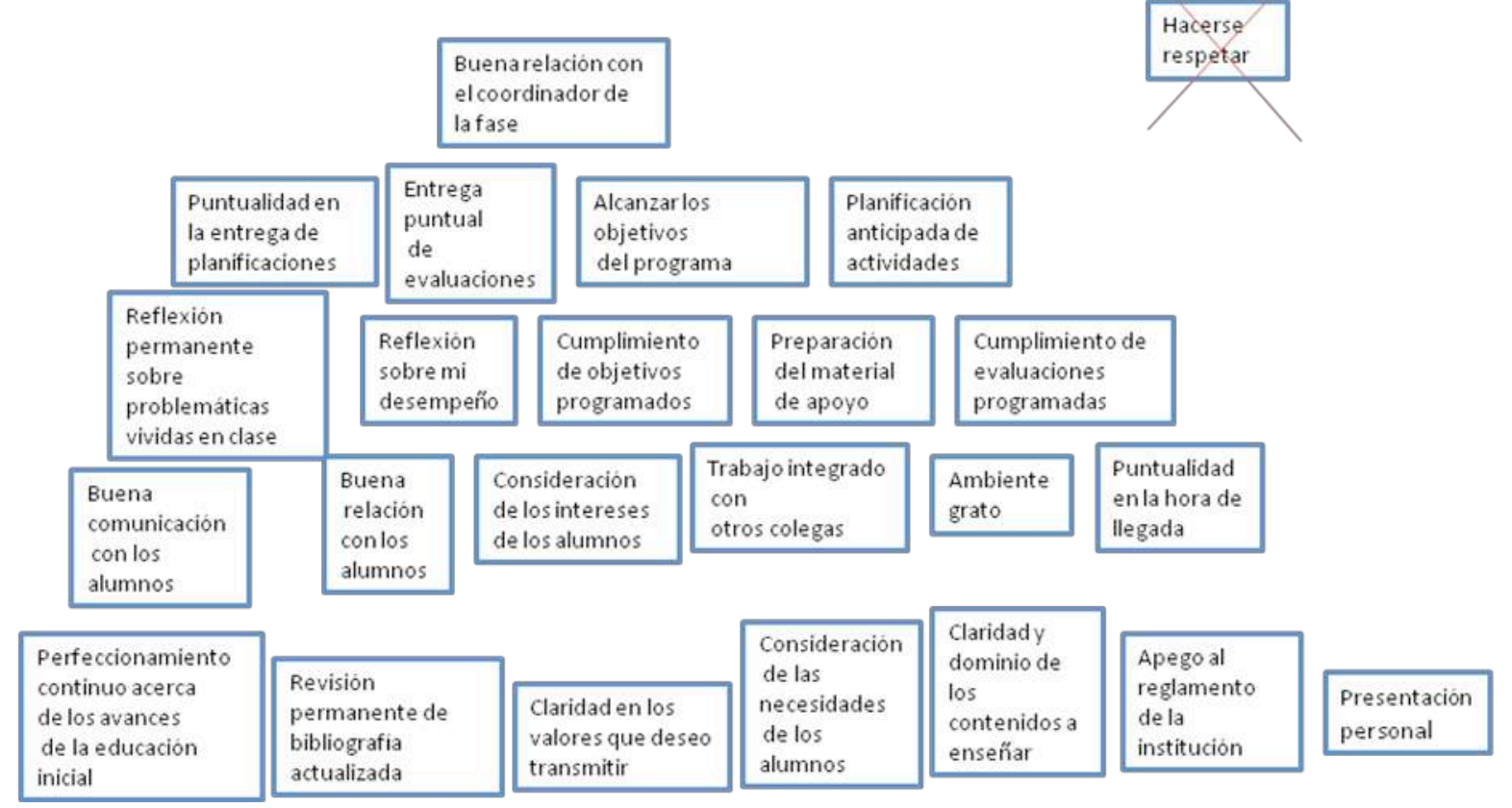

Grafico $n^{\circ}$ 61. Representación grafica Profesora \#4

"Experiencias de los años vividos en la UPEL, implica para ella que si no se tiene buena formación como se puede educar a otros, adaptarnos a las políticas educativas del estado, claridad en los valores, las necesidades de los alumnos (cada uno tiene diferente situación personal), una alumna fue con un pirsin en la nariz y se lo mando a quitar. Es importante 
reunirse en equipo para establecer criterios y lograr la excelencia. Responder de buena manera a las estudiantes para que produzcan excelencia. Pasó por todas las fases y siempre le brindaron apoyo."

Apreciación de la investigadora.

En el caso de la informante \# 4, se observa que su discurso oral, tiene marcado interés por las normas, leyes, considera que la excelencia de los alumnos va de la mano con el buen trato que los profesores puedan dispensar. Esto coincide con su representación gráfica, ya que en la base de su construcción se muestran una gran mayoría de las afirmaciones referidas a la didáctica en educación superior, frente a las que corresponden con los procesos de aprendizaje de los alumnos, los cuales coloco en segundo lugar. También es interesante mencionar el hecho de haber descartado la afirmación de "hacerse respetar", a lo cual no dio ninguna explicación del porqué la había apartado. 


\section{Profesora \#5}

Los recuadros en color negro y cursivo es lo agregado por la participante

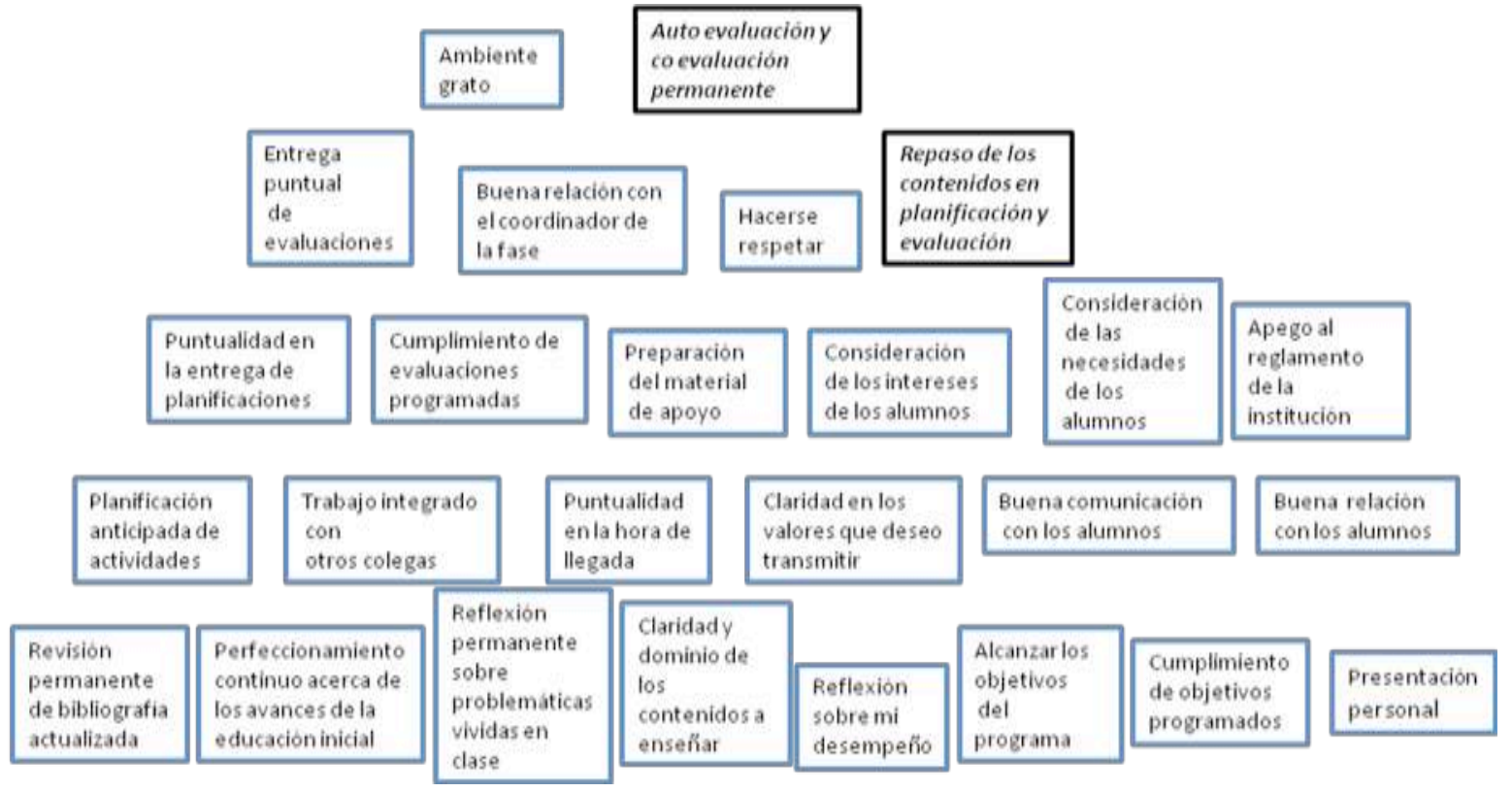

Grafico $n^{\circ}$ 62.Representación grafica Profesora \#5

"reflexionar acerca de nuestros conocimientos y la realidad que se vive en los colegios. Es importante organizar todos los recaudos con tiempo y entregarlos en las fechas acordadas. Los alumnos deben asumir su responsabilidad como estudiantes, la que no sabe algún contenido de otras asignaturas, la mando a repasar. Agrego dos aspectos: auto evaluación y coevaluación y planificación y evaluación. No elimino ninguna”.

343

La Práctica Profesional como área para potenciar las competencias pedagógicas necesarias para la enseñanza en Educación Infantil 


\section{Apreciación de la investigadora.}

Seguidamente, tenemos a la profesora \# 5, la cual explica que para ella es más importante tener todo lo referido a la enseñanza, para esta informante su prioridad se encuentra en la didáctica de la enseñanza universitaria, y reparte en cada escalón de su representación gráfica los aspectos referidos a los proceso de aprendizaje de los alumnos. Su discurso oral coincide plenamente con su representación gráfica.

\section{Profesora \#6}

Los recuadros marcados con una cruz son los eliminados por la participante.

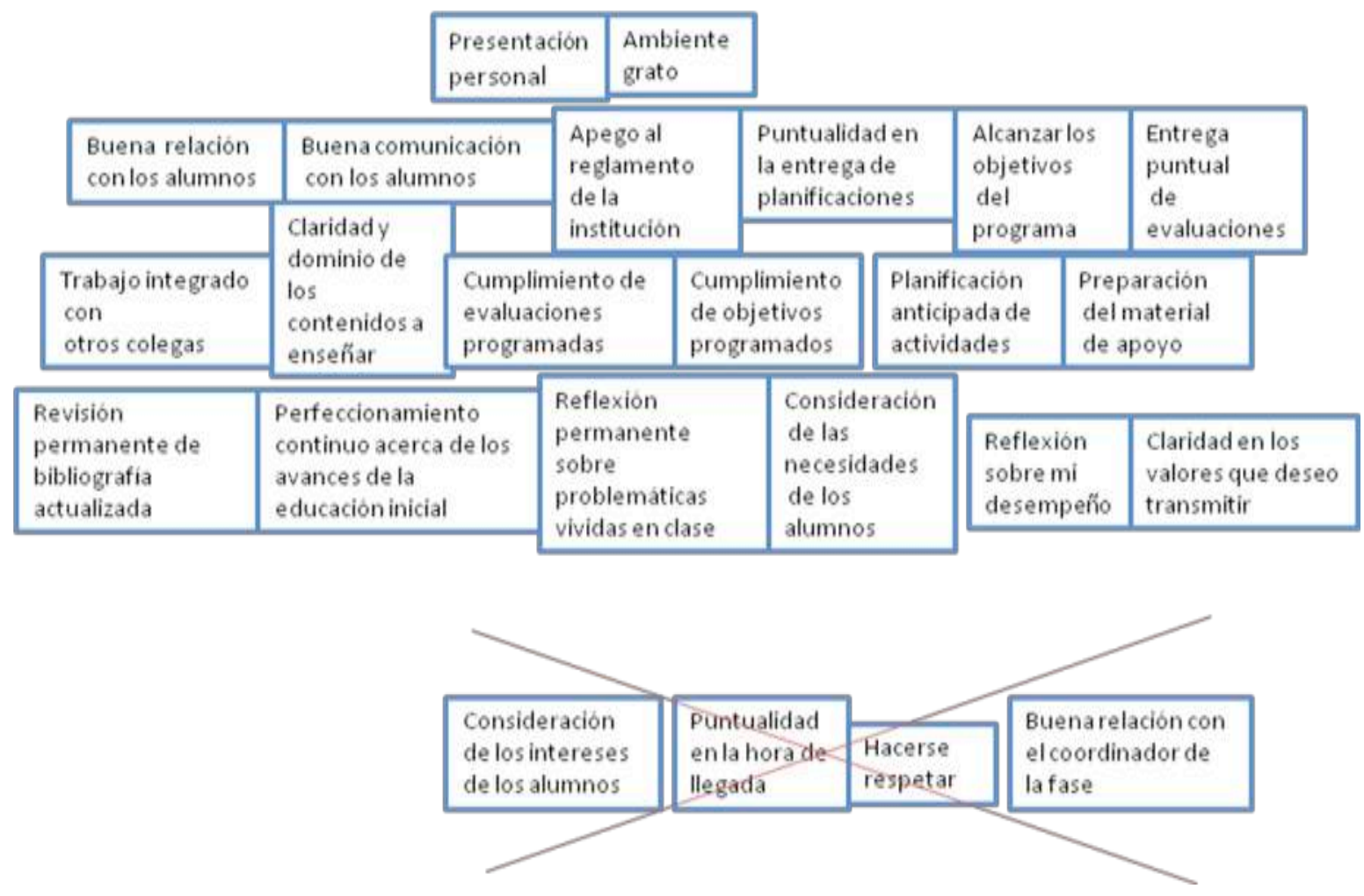

Grafico n 63.Representación grafica Profesora \#6

"elimino tres opciones: hacerse respetar (ya que forma parte del buen trato a los alumnos) la puntualidad, la buena relación con el coordinador (esto se gana con el desempeño). 
Coloco la afirmación de revisión permanente de bibliografía actualizada para mejorar, indagando, no dejando de lado a las estudiantes, luego el trabajo con los colegas, tiene que ver con la acción, con el querer, aprecia el trabajo con los colegas, en tercer lugar coloco buena relación con los alumnos".

Apreciación de la investigadora.

En el caso de la profesora \# 6, se observan detalles interesantes: en primer lugar elimina cuatro opciones, referidas a las dos dimensiones en estudio, no obstante las explica asumiendo que estas están contenidas en otras afirmaciones, por lo que considero que era repetir información; luego, asume que no se debe dejar de lado a los alumnos, lo cual se evidencia en un marcado interés al colocar mas afirmaciones de la dimensión proceso de aprendizaje en la base de su gráfica; Finalmente, es necesario destacar la lógica con la que explica su gráfica, al ir en orden creciente (de abajo hacia arriba) con una combinación de afirmaciones que van desde la formación permanente de los profesores, el trabajo en equipo y luego la atención integral a los alumnos.

345

La Práctica Profesional como área para potenciar las competencias pedagógicas necesarias para la enseñanza en Educación Infantil 


\section{Profesora \#7}

Los recuadros en color negro y cursivo es lo agregado por la participante y los marcados con una cruz son los eliminados.

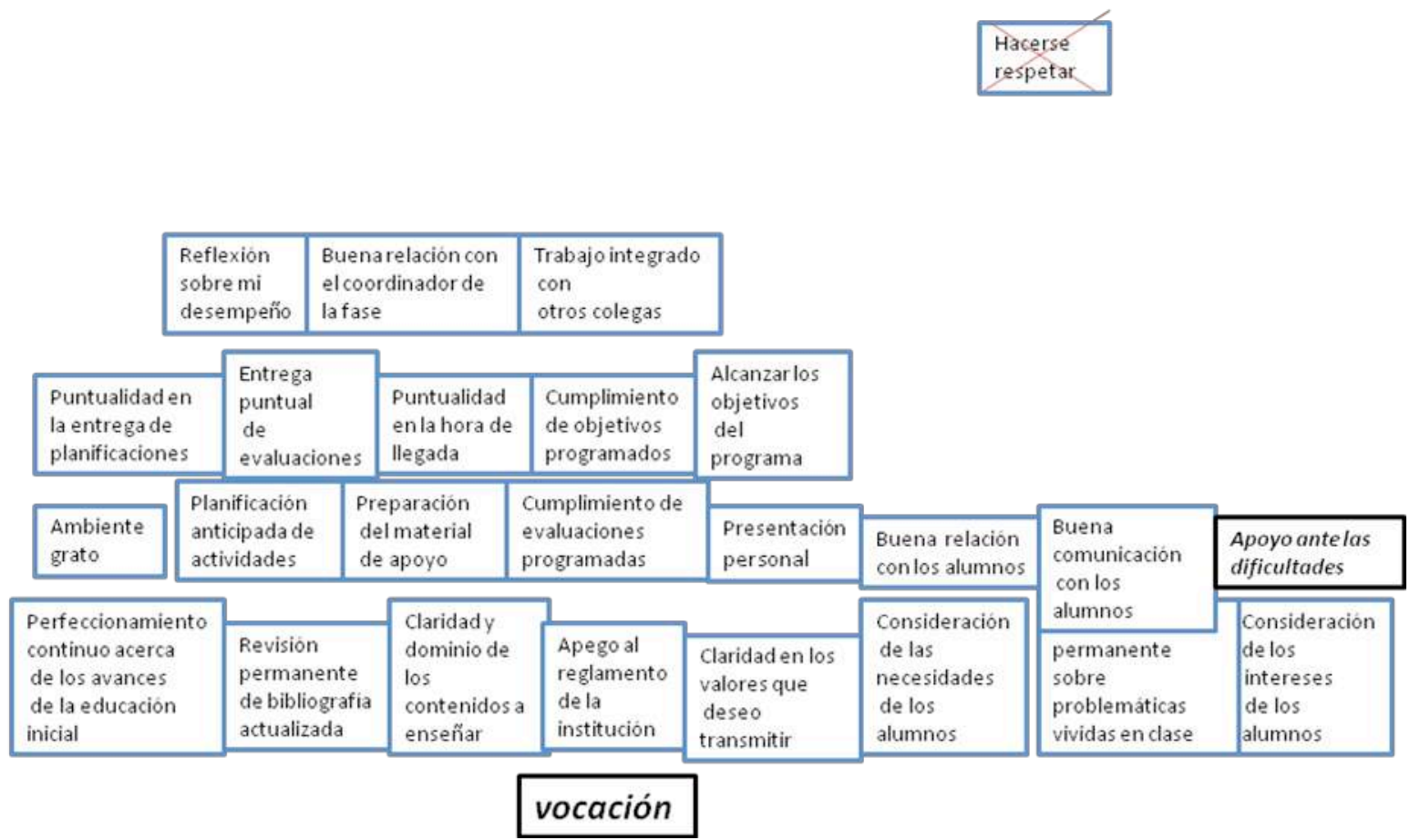

Grafico ${ }^{\circ}$ 64. Representación grafica Profesora \#7

"partir de la vocación para transmitir una enseñanza de calidad". La profe da ejemplos de su experiencia como profesora de fase "pasaba todos los días por la institución y les daba un espacio a sus alumnas para escucharlas, ayudándolas a superar los inconvenientes, buena comunicación con los alumnos y el personal de la institución. Son muy importantes los valores”.

Apreciación de la investigadora.

En cuanto a la profesora \# 7 se observa una representación gráfica que parte de una base poco común al del resto, ya que es una afirmación creada por ella misma: "vocación”, a partir de allí construye su práctica pedagógica, en la segunda línea, se observa equilibrio entre las 
afirmaciones pertenecientes a las dos dimensiones, aunque al agregar una nueva afirmación se inclina la balanza hacia los procesos de aprendizaje de los alumnos. Aunque no explica en detalle su representación, los ejemplos que cuenta son representativos de tener congruencia.

\section{Profesora \#8}

Los recuadros en color negro y cursivo es lo agregado por la participante y los marcados con una cruz son los eliminados.

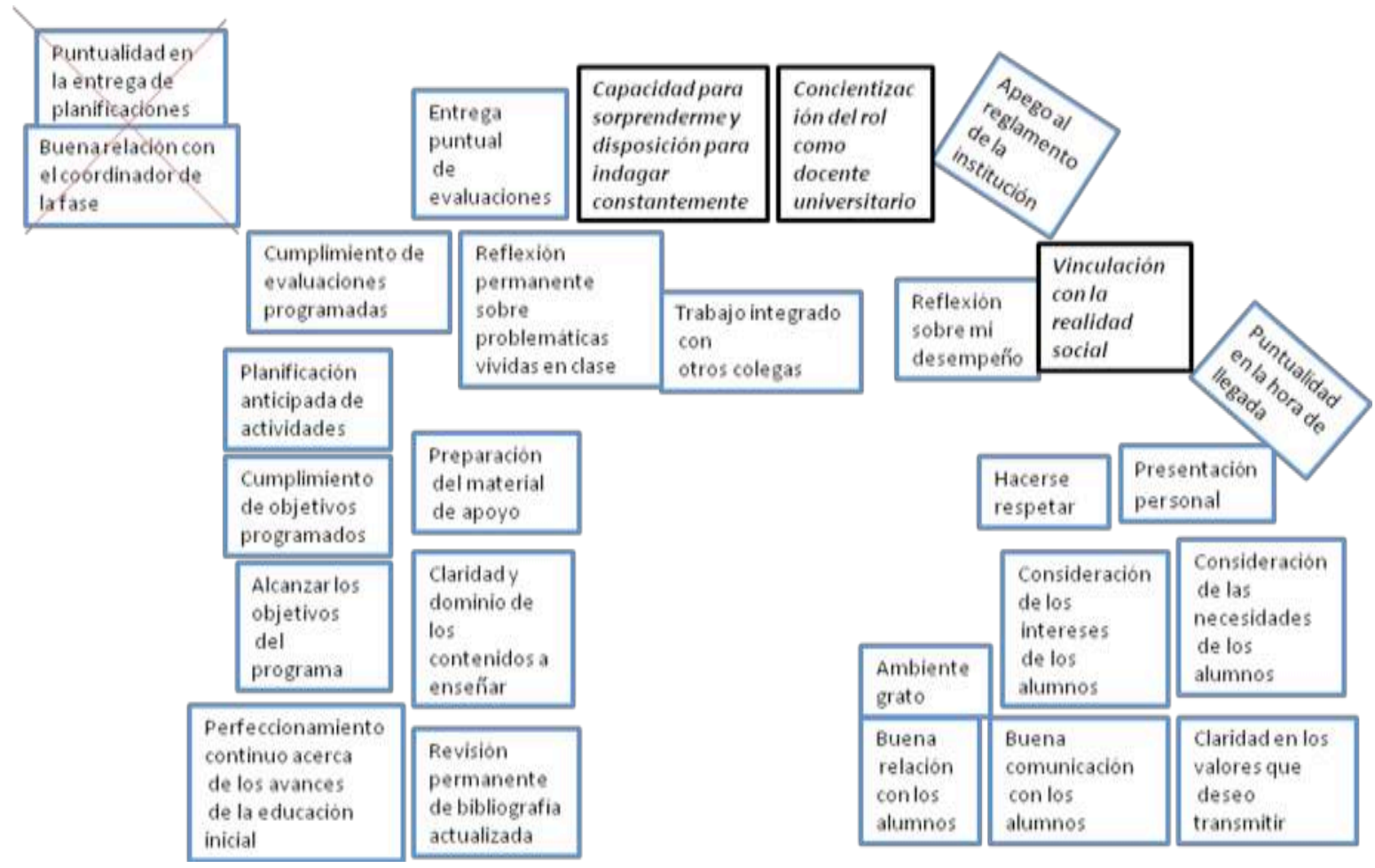

Grafico $n^{\circ}$ 65. Representación grafica Profesora \#8

"siempre procura que se cumplan todos los objetivos. La puntualidad es importante. También lo es, informar a los alumnos claramente. No se disfraza de profesora. Hace el esfuerzo por ser puntual. El trabajo integrado, no podemos desvincularnos de la realidad, agrego tres aspectos: disposición de indagar constantemente, concientización como docentes universitarios, vinculación con la realidad". Elimino dos aspectos:" puntualidad en la 
entrega de las planificaciones, porque no le gusta planificar dice que es una pérdida de tiempo, ya que al final termina haciendo otras cosas de acuerdo con lo que los alumnos y el contexto de práctica requiera, y también elimino la afirmación: "buena relación con el coordinador".

Apreciación de la investigadora.

El caso de la profesora \# 8 resulta totalmente distinto a las anteriores, por cuanto esta profesora insistió en que no se deben plantear diferencias con los alumnos, por eso ella afirma que "no le gusta disfrazarse de profesora"; así mismo se observa una representación gráfica parecida a dos muros que dan entrada a una construcción, con algunos bloques semi desprendidos. Al respecto, la profesora explica que ella se lo imagino como la entrada a una fortaleza y que en la base de los dos muros estaba su principal argumento a su práctica pedagógica, de este modo tenemos que existe un mayoría en los aspectos relacionados con los proceso de aprendizaje de los alumnos, lo cual coincide con sus argumentos. También se debe destacar cierta incongruencia cuando afirma que la puntualidad es importante, y las afirmaciones relacionadas con este criterio se encuentran descartadas o colocadas en forma declinada.

348

La Práctica Profesional como área para potenciar las competencias pedagógicas necesarias para la enseñanza en Educación Infantil 


\section{Profesora \#9}

Los recuadros en color negro y cursivo es lo agregado por la participante y los marcad con una cruz son los eliminados.

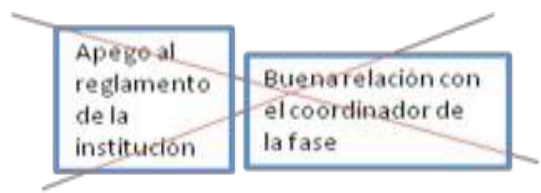

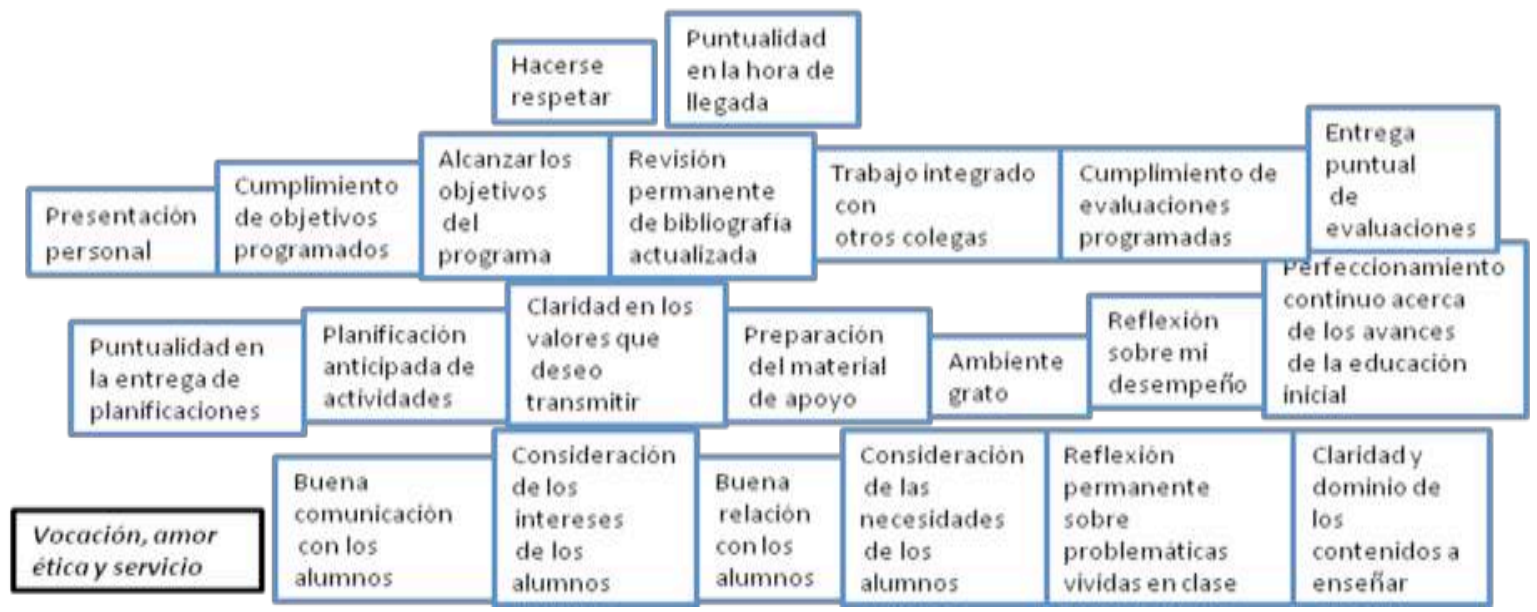

Grafico $n^{\circ}$ 66. Representación grafica Profesora \#9

“vocación-amor-ética, marca mucho nuestra práctica profesional... también lo más importante es la comunicación y el respeto. Afirma que en su formación de pregrado le dieron las herramientas necesarias para ser docente actualmente, considerar las necesidades de las estudiantes, hay que ser coherentes. Transformar la realidad que tenemos afuera”.

\section{Apreciación de la investigadora.}

Finalmente tenemos la representación gráfica de la profesora \# 9, la cual tiene un discurso de amor, respeto, comunicación, vocación; esto coincide plenamente con las afirmaciones colocadas 
en la base, ya que todas son de la dimensión procesos de aprendizaje de los alumnos, es decir, para ella el énfasis de su práctica pedagógica esta en sus alumnas.

Evidencias fotográficas primer taller.

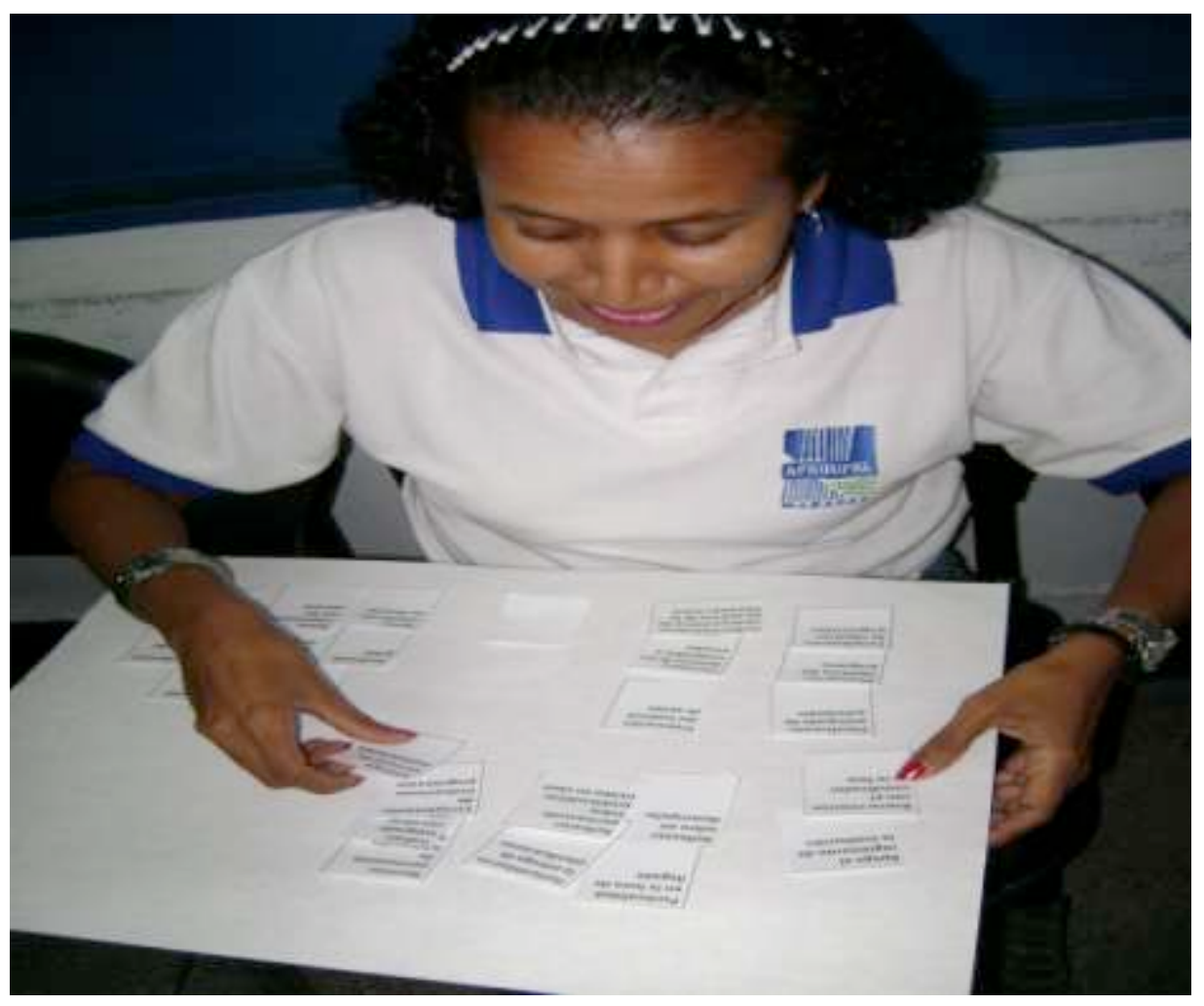




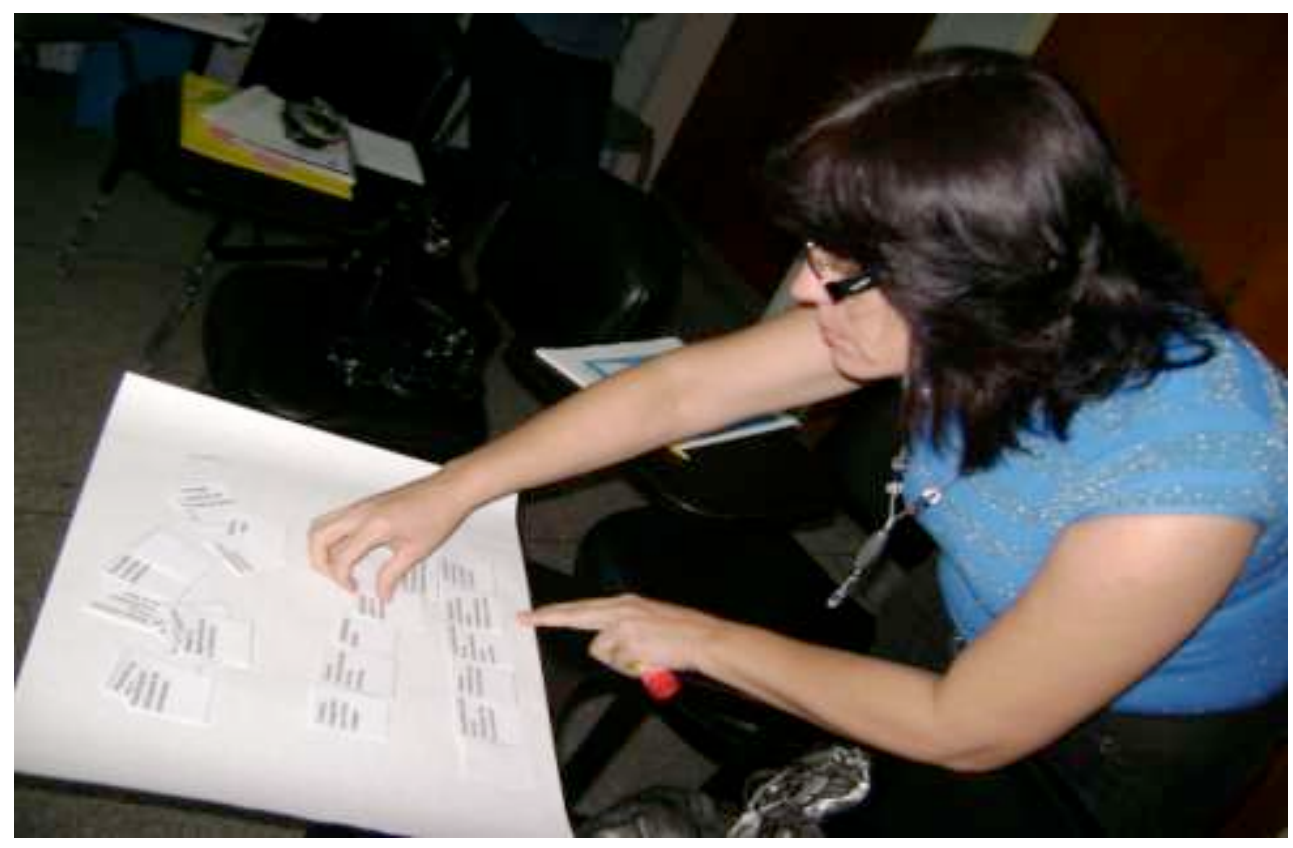

En proceso de elaboración de sus representaciones graficas

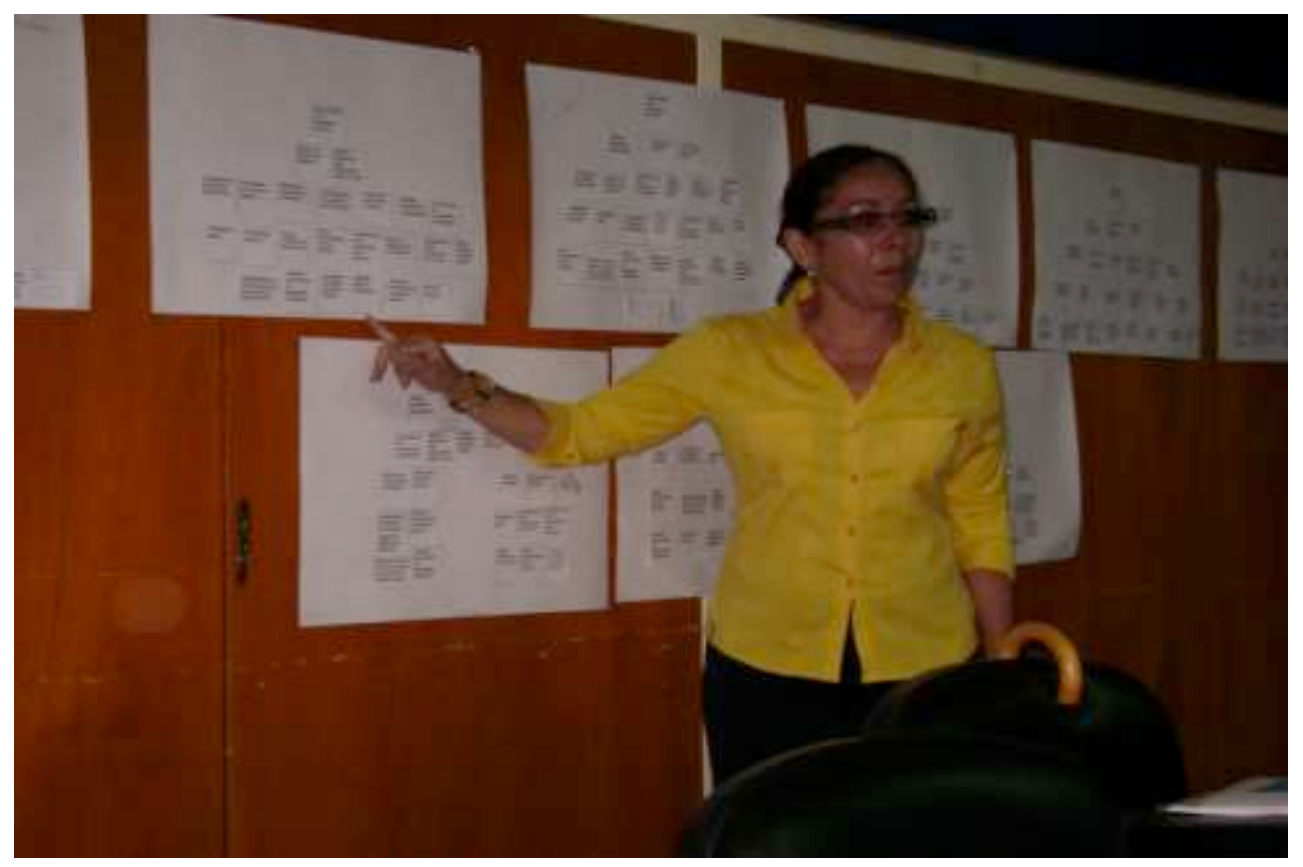

Socializando cada una de las producciones

351

La Práctica Profesional como área para potenciar las competencias pedagógicas necesarias para la enseñanza en Educación Infantil 


\subsection{Resultados Primer Taller con Profesores.}

En este momento vamos a proceder al análisis global de las producciones gráficas, las explicaciones dadas por los profesores, en consonancia con las dimensiones planteadas para esta parte del estudio y que ya fueron medidas en el cuestionario, como los son: Dimensión enseñanza universitaria (DEU) y Dimensión procesos de aprendizaje (DPA). Este análisis se hará sobre la base de la siguiente organización planteada:

\begin{tabular}{|c|c|c|}
\hline $\begin{array}{l}\text { Dimensión } \\
\text { relacionada } \\
\text { con } \\
\text { cuestionario }\end{array}$ & Afirmaciones & $\begin{array}{l}N^{\circ} \text { de veces colocadas en la } \\
\text { base de las } \\
\text { representaciones gráficas }\end{array}$ \\
\hline \multirow{14}{*}{$\begin{array}{l}\text { Dimensión } \\
\text { Enseñanza } \\
\text { Universitaria }\end{array}$} & Alcanzar los objetivos del programa. & 2 \\
\hline & 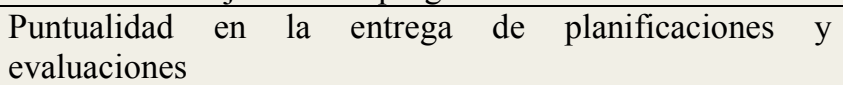 & 0 \\
\hline & Diseño permanente de actividades & 0 \\
\hline & Conexión con el coordinador de la fase & 0 \\
\hline & Presentación personal & 4 \\
\hline & Trabajo integrado con otros colegas & 0 \\
\hline & Cumplimiento de contenidos programados & 1 \\
\hline & Apego al reglamento de la institución & 2 \\
\hline & Puntualidad en la hora de llegada & 1 \\
\hline & Planificación anticipada de actividades & 2 \\
\hline & Preparación de material de apoyo & 1 \\
\hline & Claridad y dominio de los contenidos a enseñar & 5 \\
\hline & $\begin{array}{l}\text { Perfeccionamiento continúo acerca de los avances de la } \\
\text { Educación Inicial. }\end{array}$ & 8 \\
\hline & Revisión permanente de bibliografía actualizada & 8 \\
\hline \multirow{9}{*}{$\begin{array}{l}\text { Dimensión } \\
\text { Procesos de } \\
\text { Aprendizaje }\end{array}$} & Hacerse respetar & 1 \\
\hline & Buena comunicación con los alumnos & 3 \\
\hline & Claridad en los valores que deseo transmitir & 8 \\
\hline & Reflexión permanente sobre problemáticas vividas en clase & 5 \\
\hline & Ambiente grato & 1 \\
\hline & Buena relación con los alumnos & 2 \\
\hline & Consideración de los intereses de los alumnos & 3 \\
\hline & Consideración de las necesidades de los alumnos & 4 \\
\hline & Reflexión sobre mi desempeño & 5 \\
\hline
\end{tabular}

Cuadro $\mathrm{n}^{\circ}$ 70. Análisis global primer taller profesores

Del grupo de nueve profesores asistentes se tiene lo siguiente: Todas las afirmaciones relacionadas con la dimensión procesos de aprendizaje (DPA) resultaron importantes para ser 
colocadas en la base de la representación gráfica de sus prácticas pedagógicas. 10 afirmaciones de la dimensión enseñanza universitaria (DEU), fueron escogidas, solo cuatro quedaron excluidos para estar en la base. El mayor puntaje lo obtuvieron las afirmaciones: perfeccionamiento continúo acerca de los avances de educación inicial, revisión permanente de bibliografía actualizada y claridad en los valores que desea trasmitir. Esto indica que para los profesores asistentes es sumamente importante mantenerse actualizados y además tener congruencia en los aspectos que permiten un aprendizaje integral de sus alumnas.

En cuanto a las afirmaciones excluidas tenemos: tres representaciones eliminaron: a) buena relación con el coordinador de la fase y b) hacerse respetar, al parecer esta afirmación no constituye una cualidad importante para ejercer sus prácticas pedagógicas. Otras tarjetas eliminadas fueron: 1) apego al reglamento, 2) puntualidad en la entrega de las planificaciones, 3) Consideración de los intereses de los alumnos (afirma que interés es igual a necesidad, lo cual evidentemente es una confusión), f) puntualidad en la hora de llegada.

En relación con las afirmaciones que se agregaron, tenemos que muchas de ellas responden a aspectos relacionados con valores: amor, querer, compromiso, vocación, apoyo, toma de conciencia del rol docente. Otras responden a aspectos pedagógicos: auto y co evaluación, repaso de contenidos, relación teoría- práctica. Esto ratifica la marcada tendencia hacia aspectos valorativos, por sobre los cognitivos o procedimentales en el desarrollo de las prácticas pedagógicas de los profesores informantes.

353

La Práctica Profesional como área para potenciar las competencias pedagógicas necesarias para la enseñanza en Educación Infantil 


\subsection{Segundo Taller con los Profesores}

El segundo taller, estuvo dirigido a trabajar con los profesores sobre la base de las reflexiones de los diseños creados durante la primera sesión, por lo tanto, se analizaron aspectos de su experiencia en la administración de la práctica pedagógica, acerca de elementos como: planes de estudio, programas didácticos, rendimiento estudiantil, apoyo institucional (UPEL, centros de aplicación), numero de prácticas, duración, ubicación dentro del currículo de formación, entre otros. Lo que se pretende con esta actividad es que los profesores puedan expresar lo que han vivido, al guiar cada una de las prácticas profesionales.

Para ello se les entregó un formato con preguntas generadoras las cuales se redactaron tomando en consideración dos de las dimensiones del cuestionario: Dimensión Didáctica Especifica Educación Inicial (DDEEI) y Dimensión Académico Estudiantil (DAE), con el fin de completar todas las dimensiones ya valoradas en el cuestionario. Luego se les solicitó compartir oralmente sus escritos, para invitarlos a formar grupos, con el fin de que unifiquen criterios semejantes y diferentes. Los profesores decidieron agruparse con las personas a las cuales conocían con anterioridad.

En esta oportunidad asistieron 09 profesores, a los cuales se les explico la dinámica de trabajo, y se les solicito que colocaran sus representaciones construidas en el taller anterior, en un lugar visible, también se les entrego los planes de las fases, su ubicación dentro del currículo, los formatos con las preguntas y espacio en blanco, para que reflejen su opinión individual y papel bond para las conclusiones grupales, todo ello como material de apoyo para el desarrollo pleno de la actividad planificada.

\subsection{Resultados Segundo Taller.}

A continuación se presentan extractos de las respuestas escritas por los profesores, a las preguntas generadoras.

354

La Práctica Profesional como área para potenciar las competencias pedagógicas necesarias para la enseñanza en Educación Infantil 
Pregunta 1: ¿Cómo debería ser la enseñanza en Educación Infantil?

Respuestas:

P.1 “"dejar que los niños y niñas jueguen más”; P.2: “los maestros tienen que dominar las teorias del aprendizaje”; P.3 “organizar la rutina diaria, para que los niños tengan normas y hábitos de trabajo”; P.4: “ los profesores deben dominar los procesos de aprendizaje de los niños, también deben planificar y evaluar todas sus actividades; P.5: “ los niños deben jugar para prender, y los maestros deben respetar sus necesidades e intereses"; P.6: "debe haber un buen director que sea del nivel, los maestros deben conocer bien a los niños, sus características, y los padres deben ayudar y participar en su educación” ; P.7: “ se necesita mucha alegría, tolerancia, respeto, conocimiento de la teoría y vocación de servicio”; P.8 : “ en educación infantil hace falta mayor preparación de los maestros, ya no quieren evaluar procesos, solo quieren marcar listas de cotejo, tampoco les gusta planificar"; P.9: " se necesitan aulas bien organizadas, maestros bien preparados y padres más colaboradores”

Pregunta 2: ¿Exprese su opinión acerca de la planificación y la evaluación en E.I?

Respuestas:

todos los profesores coinciden en asumir que "la planificación y la evaluación constituye la columna vertebral del proceso educativo", además afirman que: "no se cumple con los parámetros que exige el ministerio de educación”; "los maestros en servicio evalúan con listas de cotejo, no les gusta registrar los avances de los niños”; “ hay muchas opiniones acerca de la planificación por proyectos, algunos maestros siguen usando el modelo anterior"; los profesores que dan esas asignaturas aquí en la UPEL no les exigen a los alumnos, por lo que el profesor de práctica debe hacer repaso de esos contenidos"

Pregunta 3: ¿Qué opinión le merece las habilidades procedimentales de las estudiantes en el desarrollo de sus PP?

355

La Práctica Profesional como área para potenciar las competencias pedagógicas necesarias para la enseñanza en Educación Infantil 
Respuestas:

P.1: “ los alumnos no saben contar cuentos, les da miedo cantar canciones o jugar con los niños”; P.2: “ algunas chicas se muestran seguras cuando tienen que demostrar habilidades, pero otras no tanto, tiemblan de pies a cabeza, creo que necesitan más práctica con niños de verdad”; P.3: “ saben hacer buenos recursos, pero luego no les dan buen uso”; P4: “ son hábiles con las manos, para crear juegos y cuentos, pero no todas lo saben usar cuando están frente a los niños”; P.5 “ los alumnos necesitan más práctica en las escuelas, algunas lo hacen bien, sin miedo, creo que se debe a que tiene hijos y saben acercarse a los niños”; P.6: “ las chicas lo hacen bien, tienen buenas habilidades para desempeñarse en las escuelas, quizás con más tiempo en los centro de aplicación, pudieran aprender a hacer más cosas”; P.7: “ en realidad considero que están un poco débiles en este aspecto, ellas demuestran buenos conocimientos teóricos, pero una vez que están haciendo sus prácticas, dicen que les da miedo”; P.8: “Tienen muchas habilidades para las manualidades, pero no les gusta cantar o leer cuentos dramatizados, eso es muy grave”; P.9: “ no están muy bien en este aspecto, creo que deben tener más práctica”

Pregunta 4: ¿Cuál es su opinión acerca de la organización curricular de práctica profesional? Respuestas:

Del grupo de 9 profesoras, siete de ellas afirmaron que no conocían muy bien la organización curricular de la práctica profesional, y que era la primera vez que tenían la oportunidad de ver la malla curricular. Tres profesoras, afirman que la conocen, desde el punto de vista de haber sido alumnas de pregrado en la UPEL y vivieron ese currículo, pero también coinciden en que es la primera vez que tienen oportunidad de ver la totalidad de la carrera, con la ubicación de las fases por semestre y sus prelaciones.

Pregunta 5: ¿Cuál es su opinión acerca de los planes y programas de práctica profesional? Respuestas:

En este punto los profesores, afirman que prefieren hacer esta evaluación en grupos, ya que algunas no han administrado la fase de ejecución de proyectos. Ante esta situación se organizan 356

La Práctica Profesional como área para potenciar las competencias pedagógicas necesarias para la enseñanza en Educación Infantil 
dos grupos en donde estuvieran profesores con experiencia en todas las fases. Las respuestas de cada grupo resultaron asi: "las fases deben tener más horas", "los contenidos deben actualizarse", "se deben colocar al inicio de la carrera", "la última fase debe estar sola, es decir los alumnos no deben cursar ninguna asignatura con ella".

Siguiendo con el proceso de análisis se procede a realizar la categorización producto de las respuestas en este segundo taller. En el cuadro ${ }^{\circ} 71$ se presentan atendiendo a las dimensiones de la investigación, las preguntas generadoras y las categorías emergentes.

\begin{tabular}{|c|c|c|}
\hline $\begin{array}{l}\text { Dimensión } \\
\text { Cuestionario }\end{array}$ & Preguntas generadoras & Categorías emergentes \\
\hline \multirow{3}{*}{$\begin{array}{l}\text { Dimensión } \\
\text { Didáctica Especifica } \\
\text { Educación Inicial } \\
\text { (DDEEI) }\end{array}$} & $\begin{array}{l}\text { ¿Cómo debería ser la enseñanza en } \\
\text { Educación Infantil? }\end{array}$ & $\begin{array}{ll}\text { - } & \text { Lúdica } \\
\text { - } & \text { Estrategias de enseñanza } \\
\text { - } & \text { Procesos de aprendizaje }\end{array}$ \\
\hline & $\begin{array}{l}\text { ¿Exprese su opinión acerca de la } \\
\text { planificación y la evaluación en E.I? }\end{array}$ & $\begin{array}{ll}\text { - } & \text { Fortalecer la } \\
\text { planificación. } \\
\text { - } \\
\text { Mejorar procesos de } \\
\text { evaluación }\end{array}$ \\
\hline & $\begin{array}{l}\text { ¿Qué opinión le merece las } \\
\text { habilidades procedimentales de las } \\
\text { estudiantes en el desarrollo de sus PP? }\end{array}$ & $\begin{array}{ll}\text { - } & \text { Aumento de prácticas } \\
\text { para los alumnos. } \\
\text { - } \\
\text { Desarrollo de estrategias } \\
\text { de enseñanza }\end{array}$ \\
\hline \multirow[t]{2}{*}{$\begin{array}{l}\text { Dimensión } \\
\text { Académico } \\
\text { Estudiantil (DAE) }\end{array}$} & $\begin{array}{l}\text { ¿Cuál es su opinión acerca de la } \\
\text { organización curricular de la P.P? }\end{array}$ & $\begin{array}{l}\text { Desconocimiento de la } \\
\text { organización curricular } \\
\text { de la especialidad } \\
\text { Educación Preescolar. }\end{array}$ \\
\hline & $\begin{array}{l}\text { ¿Cuál es su opinión acerca de los } \\
\text { planes y programas de la P.P? }\end{array}$ & $\begin{array}{ll}\text { - } & \text { Actualización de } \\
\text { programas. } \\
\text { - } & \text { Modificación de } \\
\text { programas }\end{array}$ \\
\hline
\end{tabular}

Cuadro $\mathrm{n}^{\circ} 71$. Resumen categorías emergentes segundo taller profesores 


\subsection{Tercer Taller con los Profesores}

El tercer taller estuvo destinado a formular propuestas que mantuvieran relación con las evaluaciones realizadas en el primer y segundo taller. Con el propósito de elaborar propuestas de acción que pudieran ser aplicadas a corto, mediano y largo plazo.

Entre los indicadores que se presentaron como guías para estas propuestas se tiene:

- Numero de prácticas profesionales para Educación Inicial

- Duración de cada una de ellas

- Centros de aplicación: acuerdos, convenios, normas

- Competencias de entrada para cada fase

- Competencias de salida en cada fase.

Luego de haber transcurrido una semana, se realizo el tercer taller con los profesores de práctica profesional. En esta oportunidad solo asistieron cinco (05), las inasistencias se justificaron con las siguientes razones: dos profesoras no lograron llegar debido a un clima lluvioso bastante fuerte que produjo inconvenientes en el tránsito de vehículos. Una profesora, tenía un compromiso previo y no logró cambiar la fecha y la última profesora debía aplicar pruebas recuperativas a sus alumnas, por lo que se disculpo, pero dejo algunas propuestas para que se consideraran en el taller de este día.

Se dio inicio a la actividad, ofreciendo un pequeño recuento de lo que hasta ahora se había realizado. Los profesores asistentes expresaron su satisfacción, por la oportunidad de haber reflexionado a fondo, muchos aspectos de su práctica pedagógica y de los programas de estudio, afirman que esta acción ha resultado interesante y que debíamos continuar con estos talleres. Se explico que por este momento solo llegaríamos a las propuestas, pero quedo el compromiso de promover espacios de formación permanente.

A continuación, se les solicito que en virtud de las inasistencias de cuatro profesoras, se hiciera el trabajo tipo lluvia de ideas, para lo cual se escribieron las guías en la pizarra, desde

La Práctica Profesional como área para potenciar las competencias pedagógicas necesarias para la enseñanza en Educación Infantil 
allí podíamos ir construyendo las propuestas de mejora. El grupo acepto y una profesora se ofreció a escribir en láminas de papel bond, toda la producción del día.

Durante la puesta en común los profesores emitieron los siguientes comentarios: "en el turno de la tarde no se puede administrar la fase, hay muy pocos centros de aplicación”; "las estudiantes que ya están trabajando, deben gozar del beneficio de que se les acepte hacer sus pasantías en el mismo colegio"; "las estudiantes necesitan tener todos los conocimientos teóricos de base, previos a cursar cada una de las fases”; “ nos hemos quedado solo en centros de aplicación convencionales, debemos llevar a los alumnos a maternales, programas no convencionales (comunitarios), hogaines, entre otros"; “ en la fase de observación deberíamos tener menos alumnas, ya que atender a 23 chicas en un solo día es dificil”; " aumentar el nivel de exigencia en la fase de observación”; “ debemos reconocer que hay profesores que no tienen mucha experiencia para enseñar a los alumnos, se cae en la improvisación y los alumnos no aprenden” ; “ en la universidad bolivariana los alumnos tienen más práctica, esto le está robando espacio a la UPEL”;

\subsection{Resultados Tercer Taller con Profesores.}

Con el fin de organizar este tercer taller, se presentan las propuestas que surgieron:

1.- Con respecto a los ambientes de aprendizaje para la realización de las prácticas profesionales:

a) Hogares de cuidado diario (Hogain), b) Programas no convencionales, c) Maternal, d) Simoncitos, e) Preescolares convencionales: públicos y privados.

Los ambientes de aprendizaje arriba mencionados, forman parte de la realidad educativa infantil de Venezuela y por tanto, de acuerdo con el criterio de las profesoras, deben ser considerados como centros de aplicación de práctica profesional; al respecto es importante mencionar, que los hogares de cuidado diario, los programas no convencionales y los maternales, son los menos seleccionados para la realización de prácticas profesionales de la UPEL, dada su

359

La Práctica Profesional como área para potenciar las competencias pedagógicas necesarias para la enseñanza en Educación Infantil 
condición de programas asistenciales y de cuidado infantil con personal con poca o ninguna preparación académica y en la mayoría de los casos tienen un fin de guardería infantil sin propósitos educativos; en cuanto a, los Simoncitos y los preescolares públicos y privados forman parte de los centros educativos con mayor demanda para la práctica profesional de las estudiantes UPEL

2.- En relación con la administración de las fases:

Las propuestas giran en torno a lo siguiente: a) En todas las fases se debe solicitar sustentación teórica psicológica de las planificaciones presentadas por los alumnos, b) en todas las fases las estudiantes deben usar técnicas e instrumentos de evaluación, c) En todas las fases los alumnos deben cumplir con criterios, dados por su profesor, para la elaboración de recursos, d) La fase de observación se debe administrar dos (02) veces a la semana durante un año, a partir del tercer semestre comenzar las prácticas e incluir intervenciones, e) La fase de ensayo didáctico debe administrarse dos (02) veces por semana, durante un año, preferiblemente en el quinto y sexto semestre y combinar ejecuciones tanto en las aulas de la UPEL como en los centros de aplicación.

De las propuestas anteriores se desprende la innegable necesidad de reorganizar y actualizar los programas y la administración de las fases; los profesores solicitan aumentar el nivel de exigencia académica, así como el número de horas de atención en las fases de observación y fase de ensayo didáctico.

360

La Práctica Profesional como área para potenciar las competencias pedagógicas necesarias para la enseñanza en Educación Infantil 


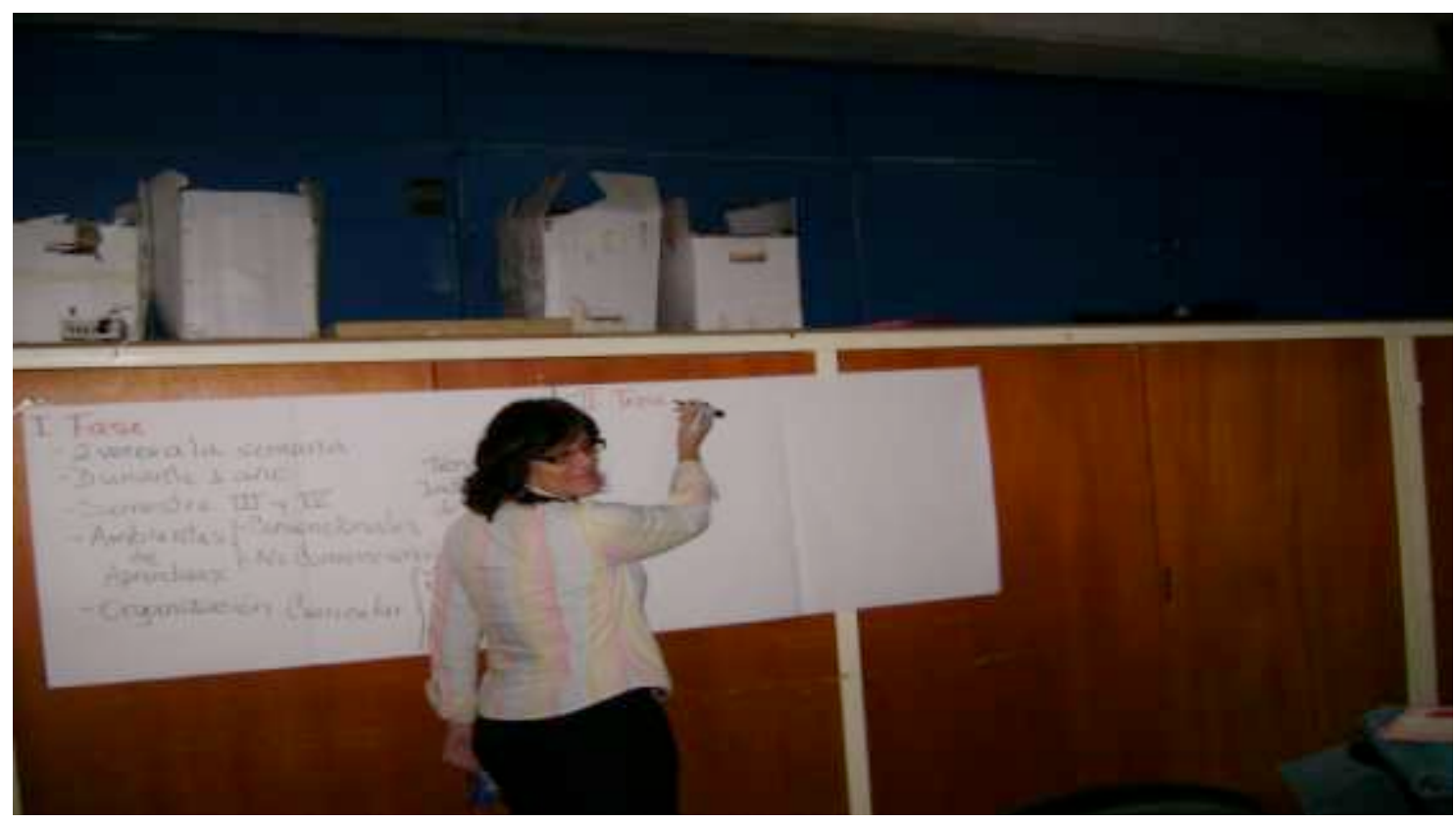

Profesora recogiendo las propuestas del grupo.

\subsubsection{Talleres Reflexivos Realizados con los Alumnos}

A continuación vamos a describir los resultados del trabajo realizado con las estudiantes de Educación Preescolar. Estas sesiones se realizaron en la forma de tres talleres, tal como se representa a continuación:

\begin{tabular}{|c|c|c|c|}
\hline Taller/ dimensiones & Contenido & Actividad & Recursos \\
\hline $\begin{array}{l}\text { Primer Taller } \\
\text { DEU } \\
\text { DPA }\end{array}$ & $\begin{array}{l}\text { Formación recibida en } \\
\text { práctica profesional } \\
\text { UPEL, } \\
\text { específicamente las } \\
\text { estrategias didácticas } \\
\text { y su utilidad en la } \\
\text { realización de sus } \\
\text { practicas }\end{array}$ & $\begin{array}{l}\text { Charla introductoria } \\
\text { Producción escrita } \\
\text { Valorar las } \\
\text { estrategias didácticas } \\
\text { y su utilidad en la } \\
\text { realización de sus } \\
\text { practicas }\end{array}$ & $\begin{array}{l}\text { Preguntas generadoras } \\
\text { Laptop. } \\
\text { Video beam. } \\
\text { Papel bond. } \\
\text { Marcadores. } \\
\text { Cámara fotográfica }\end{array}$ \\
\hline
\end{tabular}

361

La Práctica Profesional como área para potenciar las competencias pedagógicas necesarias para la enseñanza en Educación Infantil 


\begin{tabular}{|l|l|l|l|}
\hline Segundo Taller & $\begin{array}{l}\text { Revisión y análisis de } \\
\text { los planes de estudio, } \\
\text { programas didácticos, } \\
\text { DAE }\end{array}$ & $\begin{array}{l}\text { Evaluar programas de } \\
\text { fendimiento y comparar con } \\
\text { estudiantil, apoyo } \\
\text { lo vivido } \\
\text { centitucional (UPEL, } \\
\text { numero de prácticas, } \\
\text { duración, ubicación } \\
\text { dentro del currículo } \\
\text { de formación }\end{array}$ & $\begin{array}{l}\text { Producciones gráficas } \\
\text { del primer taller. } \\
\text { Formatos de planes y } \\
\text { programas. } \\
\text { Fotografías }\end{array}$ \\
\hline Tercer Taller & $\begin{array}{l}\text { Propuestas de mejora } \\
\text { Elaborar Propuesta de } \\
\text { mejora } \\
\text { Presentación oral y yarato } \\
\text { escrita }\end{array}$ & $\begin{array}{l}\text { Formato } \\
\text { sistematizar las ideas } \\
\text { Cámara Fotográfica } \\
\text { Marcadores. }\end{array}$ \\
\hline
\end{tabular}

Cuadro $\mathrm{n}^{\circ}$ 72. Descripción general talleres reflexivos con las estudiantes

En este sentido, se procede a describir cada sesión por separado y luego se presenta el análisis global de la experiencia.

\subsection{Primer Taller Estudiantes: Evaluar la Práctica Profesional en Educación Preescolar.}

En este taller, se realizo una introducción al tema, donde se les explico a las participantes el propósito de los encuentros. En segundo lugar, se realizó la presentación Power point, en la cual se resumían algunos postulados sobre la práctica profesional en educación inicial, para finalmente, plantear preguntas generadoras con el fin de que, las estudiantes realicen sus producciones consensuadas en grupo y luego presentar a sus compañeras, con el fin de promover la discusión y reflexión. La información obtenida, descubrió a través de sus formas de lenguaje las dimensiones cognitivas de las estudiantes participantes y fue organizada atendiendo al

La Práctica Profesional como área para potenciar las competencias pedagógicas necesarias para la enseñanza en Educación Infantil 
siguiente orden: informante clave, su opinión sobre la formación recibida en práctica profesional, categoría emergente, síntesis analítica.

\begin{tabular}{|c|c|c|c|c|}
\hline Dimensión & Contenido & $\begin{array}{l}\text { Preguntas } \\
\text { generadoras }\end{array}$ & Recursos & Evaluación \\
\hline DEU & $\begin{array}{l}\text { Introducción al tema } \\
\text { Formación recibida } \\
\text { en práctica } \\
\text { profesional. } \\
\text { Utilidad práctica de } \\
\text { esta formación. } \\
\text { Articulación teoría- } \\
\text { práctica }\end{array}$ & $\begin{array}{l}\text { ¿Qué opinión te } \\
\text { merece la formación } \\
\text { recibida en las fases } \\
\text { de Educación } \\
\text { Preescolar? } \\
\text { ¿Cuáles estrategias de } \\
\text { enseñanza pudiste } \\
\text { aplicar con niños y } \\
\text { niñas? } \\
\text { ¿Cuáles estrategias } \\
\text { consideras necesitas } \\
\text { aprender o } \\
\text { profundizar? }\end{array}$ & $\begin{array}{l}\text { Video beam, } \\
\text { presentación } \\
\text { power point } \\
\text { Papel bond. } \\
\text { Marcadores. } \\
\text { Cámara } \\
\text { fotográfica }\end{array}$ & $\begin{array}{l}\text { Participación } \\
\text { Respuestas }\end{array}$ \\
\hline
\end{tabular}

Cuadro $\mathrm{n}^{\circ}$ 73. Resumen acciones primer taller estudiantes

\subsection{Resultados Primer Taller con Alumnas:}

\begin{tabular}{|c|c|c|c|}
\hline $\begin{array}{l}\text { Pregunta } \\
\text { guía }\end{array}$ & $\begin{array}{l}\text { Opinión sobre práctica } \\
\text { profesional }\end{array}$ & Categoría emergente & Síntesis analítica \\
\hline $\begin{array}{l}\text { Formación } \\
\text { recibida }\end{array}$ & $\begin{array}{l}\text { A.1-“la FO, supero mis } \\
\text { expectativas y me permitió } \\
\text { sensibilizarme como persona y } \\
\text { futura docente” } \\
\text { A.2-“ la FO me sirvió para } \\
\text { aprender a realizar un diagnostico } \\
\text { a través de la observación, dentro y } \\
\text { fuera del aula de clases"” } \\
\text { A.3-“ En las fases, aprendi a } \\
\text { respetar a los niños en edad } \\
\text { preescolar”, ", } \\
\text { A.4-“ en la FED, las compañeras } \\
\text { fingieron ser niñas y eso me sirvió }\end{array}$ & $\begin{array}{l}\text { sensibilizar } \\
\text { Socialización }\end{array}$ & $\begin{array}{l}\text { La indagación acerca de } \\
\text { la formación recibida en } \\
\text { las fases que componen } \\
\text { el área de práctica } \\
\text { profesional, revela que } \\
\text { los alumnos tiene una } \\
\text { mezcla de sentimientos } \\
\text { que van desde la } \\
\text { satisfacción por la } \\
\text { oportunidad de } \\
\text { acercamiento a la } \\
\text { realidad laboral, hasta el } \\
\text { desengaño por no haber } \\
\text { tenido más } \\
\text { oportunidades, o por }\end{array}$ \\
\hline
\end{tabular}

363

La Práctica Profesional como área para potenciar las competencias pedagógicas necesarias para la enseñanza en Educación Infantil 


\begin{tabular}{|c|c|c|c|}
\hline & $\begin{array}{l}\text { para establecer relaciones con } \\
\text { ellas y además cumplir las } \\
\text { actividades" } \\
\text { A.5-“aprendi a compartir, dar y } \\
\text { recibir afecto ", " Con la FIDA } \\
\text { pude reconocer los espacios de } \\
\text { aprendizaje y la rutina que se da en } \\
\text { el aula de clases" } \\
\text { A.6-“ La FED, nos ayudo a } \\
\text { construir experiencias propias, } \\
\text { para cumplir con la labor docente, } \\
\text { mediante la realización y ejecución } \\
\text { de un plan didáctico, donde pude } \\
\text { evaluar los procesos de } \\
\text { aprendizaje de los niños } \\
\text { A.7-"supero mis aspiraciones al } \\
\text { brindarme la oportunidad de hacer } \\
\text { mi primera práctica preescolar". } \\
\text { A.8- " tuve la gran oportunidad de } \\
\text { realizar planificaciones, al igual } \\
\text { que ejecutarlas" } \\
\text { A.9-“ pude conocer directamente } \\
\text { como se trabaja y se manejan los } \\
\text { espacios de aprendizaje y como } \\
\text { dirigir y controlar los grupos, } \\
\text { aunque fue simulado"” } \\
\text { A.10-"Sirvió de gran experiencia, } \\
\text { ya que cubrió mis expectativas en } \\
\text { cuanto a cómo proyectar y ejecutar } \\
\text { las diversas estrategias" }\end{array}$ & $\begin{array}{l}\text { Productividad } \\
\text { Productividad } \\
\text { sensibilizar } \\
\text { productividad } \\
\text { contextualizar } \\
\text { productividad }\end{array}$ & $\begin{array}{l}\text { percatarse de sus } \\
\text { propias debilidades; así } \\
\text { mismo, se evidencia que } \\
\text { es en este componente } \\
\text { académico que las } \\
\text { estudiantes reconocen } \\
\text { cuanta falta hace la } \\
\text { contextualización del } \\
\text { proceso enseñanza } \\
\text { aprendizaje, en relación } \\
\text { con sus propias } \\
\text { habilidades y destrezas } \\
\text { para planificar, evaluar, } \\
\text { dirigir actividades de } \\
\text { aula, entre otros. }\end{array}$ \\
\hline $\begin{array}{l}\text { Aplicación } \\
\text { de } \\
\text { estrategias } \\
\text { con niños y } \\
\text { niñas en } \\
\text { edad } \\
\text { preescolar }\end{array}$ & $\begin{array}{l}\text { A.1- "en la FO sentí ganas de } \\
\text { involucrarme con los niños, pero } \\
\text { solo debía registrar mis } \\
\text { observaciones y ayudar a la } \\
\text { maestra" } \\
\text { A.2- "cuando hice mi primera fase, } \\
\text { sentí miedo de hacer el ridículo si } \\
\text { se me olvidaba la canción" } \\
\text { A.3- " en la FED me toco cantar } \\
\text { canciones, jugar y otras cosas, con }\end{array}$ & $\begin{array}{l}\text { Inseguridad } \\
\text { contrariedad }\end{array}$ & $\begin{array}{l}\text { Este aspecto esta en } \\
\text { intima relación con el } \\
\text { anterior. Los alumnos } \\
\text { no se sienten seguros de } \\
\text { sus propias habilidades, } \\
\text { evalúan negativamente } \\
\text { las oportunidades de } \\
\text { poner en práctica las } \\
\text { estrategias } \\
\text { enseñanza. }\end{array}$ \\
\hline
\end{tabular}

364

La Práctica Profesional como área para potenciar las competencias pedagógicas necesarias para la enseñanza en Educación Infantil 


\begin{tabular}{|c|c|c|c|}
\hline & $\begin{array}{l}\text { mis compañeras, no me gusto, para } \\
\text { nada" } \\
\text { A.4-"siento que no he aprendido } \\
\text { mucho sobre estrategias para } \\
\text { dominar a los niños más } \\
\text { tremendos", } \\
\text { A.5-“ me da pena contar cuentos si } \\
\text { hay otras personas observándome" } \\
\text { A.6-" creo que el tiempo en las } \\
\text { escuelas se va muy rápido, y } \\
\text { cuando ya me sentía segura para } \\
\text { trabajar sola con los niños, } \\
\text { debiamos retirarnos" }\end{array}$ & $\begin{array}{l}\text { Inseguridad } \\
\text { Inseguridad }\end{array}$ & \\
\hline $\begin{array}{l}\text { Necesidad } \\
\text { de } \\
\text { aprendizaje }\end{array}$ & $\begin{array}{l}\text { A.1-“me gustaría aprender más } \\
\text { estrategias para enseñarles a leer y } \\
\text { escribir" } \\
\text { A,2- " siento que no se mucho } \\
\text { acerca del trabajo con los padres" } \\
\text { A.3-“no aprendi acerca de las } \\
\text { matemáticas para niños" } \\
\text { A.4-“ los profesores deben ponerse } \\
\text { de acuerdo y mandar el mismo } \\
\text { trabajo para la fase y para la } \\
\text { teoría, así aprendemos más" }\end{array}$ & $\begin{array}{l}\text { Estrategias de lectura y } \\
\text { escritura } \\
\text { Estrategias de } \\
\text { integración } \\
\text { Estrategias procesos } \\
\text { matemáticos. } \\
\text { Integración teoría- } \\
\text { práctica }\end{array}$ & $\begin{array}{l}\text { Se corrobora la } \\
\text { exigencia de articular la } \\
\text { teoría con la práctica, es } \\
\text { evidente que para llegar } \\
\text { a cada una de las fases } \\
\text { ellas deben haber } \\
\text { aprobado las asignaturas } \\
\text { que les ayude a ejecutar } \\
\text { variadas estrategias d } \\
\text { enseñanza, entonces } \\
\text { tenemos un claro } \\
\text { divorcio entre el } \\
\text { componente de } \\
\text { formación pedagógica, } \\
\text { el de formación } \\
\text { especializada y el de } \\
\text { práctica profesional }\end{array}$ \\
\hline
\end{tabular}

Cuadro $\mathrm{n}^{\circ} 74$. Análisis del primer taller con alumnas. 


\section{Evidencias Primer Taller Alumnas}

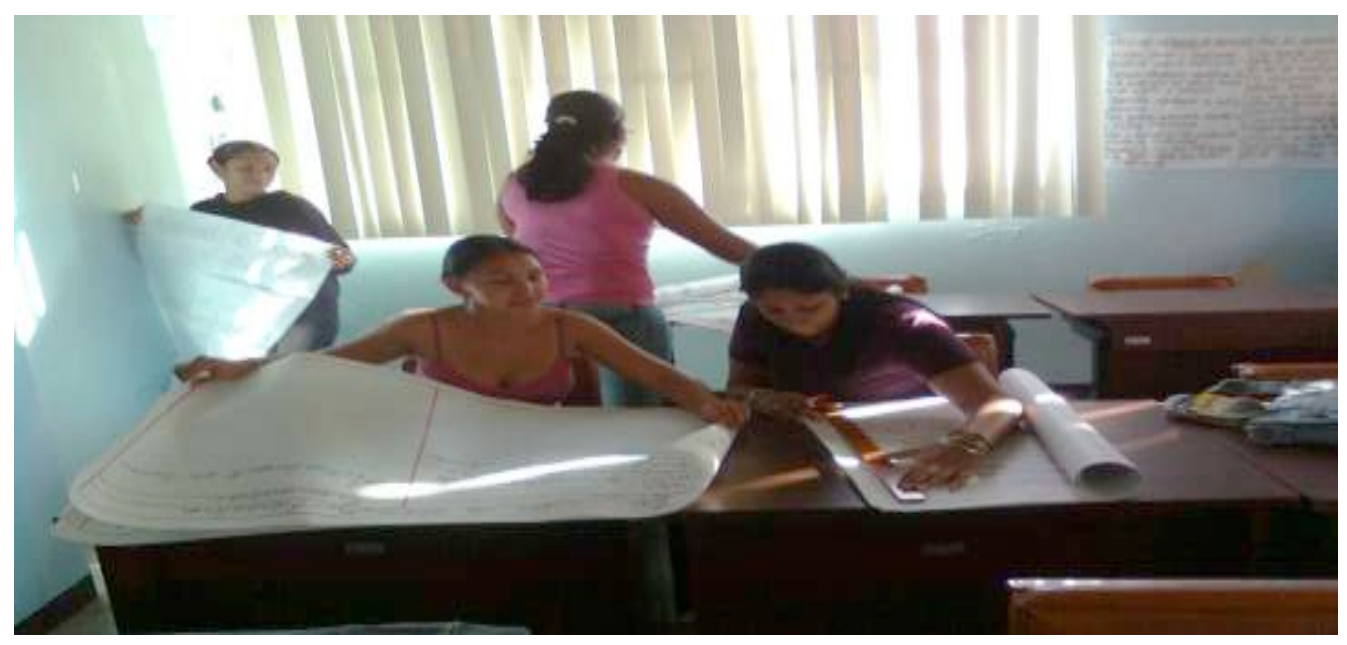

Elaborando sus producciones

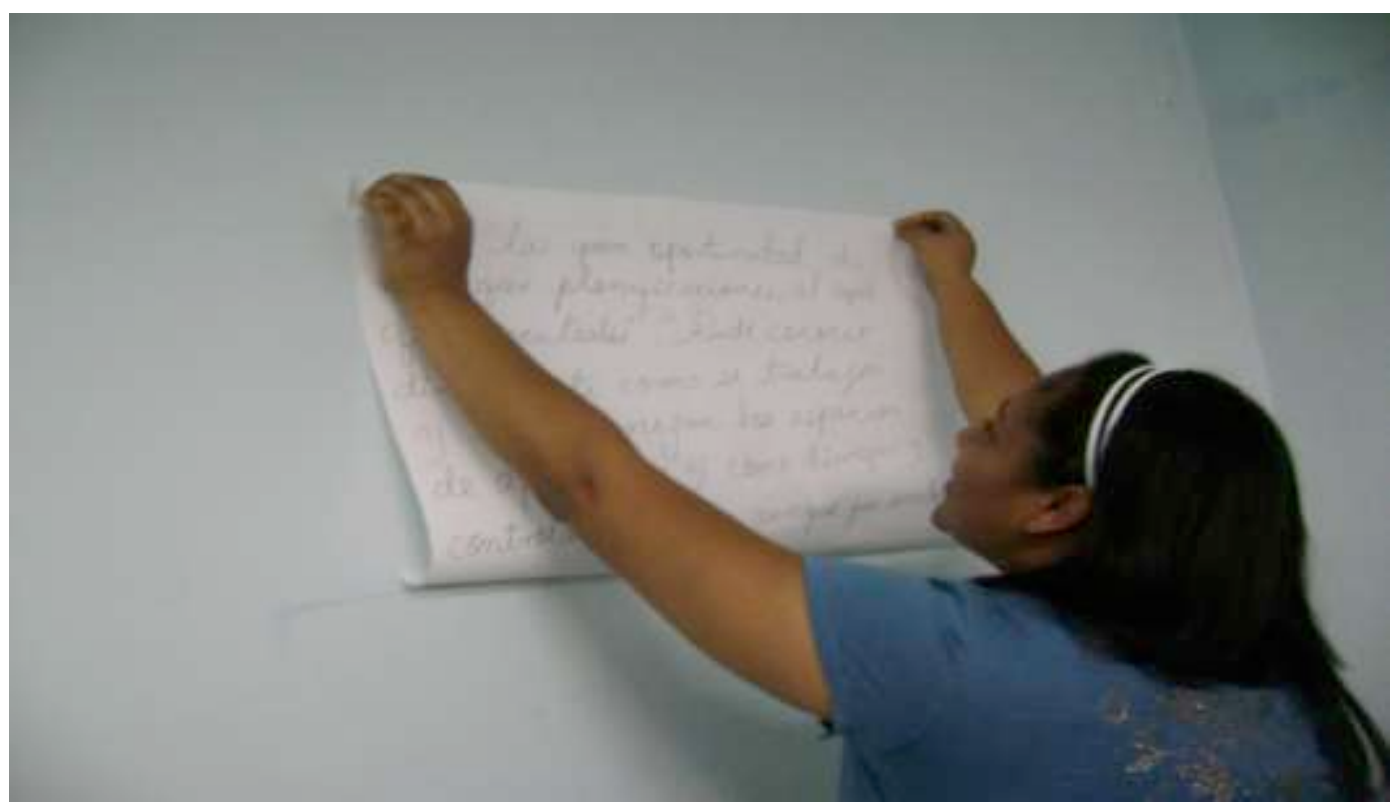

Publicando para su discusión. 


\subsection{Segundo Taller: Valorar Programas de Práctica Profesional.}

\begin{tabular}{llll}
\hline Dimensión & Preguntas generadoras & Recursos & Evaluación \\
\hline $\begin{array}{l}\text { Dimensión } \\
\text { didáctica }\end{array}$ & $\begin{array}{l}\text { ¿Qué significa para usted la } \\
\text { enseñanza en Educación }\end{array}$ & Laminas papel bond & Participación \\
$\begin{array}{l}\text { educación inicial } \\
\text { (DDEEI) }\end{array}$ & Infantil? & $\begin{array}{l}\text { Marcadores } \\
\text { ¿Exprese su opinión acerca de }\end{array}$ & $\begin{array}{l}\text { Producciones gráficas } \\
\text { del primer taller. }\end{array}$ \\
& evaluación en E.I? & Programas de fase. & \\
$\begin{array}{l}\text { Dimensión } \\
\text { Académico }\end{array}$ & ¿Cuál es su opinión acerca de & Cámara fotográfica & \\
$\begin{array}{l}\text { Estudiantil } \\
\text { (DAE) }\end{array}$ & los programas de cada fase? & & \\
& & & \\
\end{tabular}

Cuadro $\mathrm{n}^{\circ} 75$. Resumen acciones segundo taller estudiantes

\subsection{Resultado Segundo Taller Alumnos:}

A continuación se presentan extractos de las respuestas escritas por los alumnos, de manera individual a las preguntas generadoras.

Pregunta 1: ¿Qué significa para usted la enseñanza en Educación Infantil?

Respuestas:

A.1- "una gran responsabilidad" A.2- "un reto, no sé si pueda con tantos niños y sus personalidades”, A.3- "es una misión que requiere mucha preparación, hay que leer mucho y actualizarse siempre”, A.4- "tremenda responsabilidad, para con los niños y sus padres", A.5"enseñar significa estar pendiente de que los niños aprendan todo lo que necesitan para ser exitosos", A.6- "una oportunidad de ayudar",A.7 "ayudar a los niños en sus intereses y necesidades, ya que no es una tarea nada fácil”

Pregunta 2: ¿Exprese su opinión acerca de la planificación y la evaluación en E.I?

367

La Práctica Profesional como área para potenciar las competencias pedagógicas necesarias para la enseñanza en Educación Infantil 


\section{Respuestas:}

Cuatro alumnas coinciden en afirmar que para ellas: A.1-“es difícil planificar y evaluar, los profesores de esas asignaturas, solo me dieron un modelo y con eso trabaje”, A.2-“Cuando Ilegue a la fase de ensayo, me di cuenta que no sabía nada", A.3- "no se evaluar procesos de lectura y escritura y menos lo de lógico-matemática”. El resto de los alumnos asumen que: A.4"sabe un poco de planificar por proyectos, pero lo aprendí en esta última fase”, A.5-"aprendí a planificar con mi profe de fase", A.6- "la evaluación es difícil, hay que escribir muchos registros y después no se para que sirven”, A.7-“los registros descriptivos ya no se usan, no se para que los piden"

Pregunta 3: ¿Cuál es su opinión acerca de los programas de cada fase?

Respuestas:

A.1-“La FO, me permitió ver que la realidad de la Educación Preescolar se puede captar con esta primera fase", "pasamos mucho tiempo en la universidad, leyendo leyes y autores"

A.2- "en las fases se debe ir a aulas de preescolar, pero tres de ellas, las hice en las aulas UPEL, debido al poco tiempo, no pudimos ir a las escuelas, creo que me falta mucho por aprender", "hubo que crear un ambiente de preescolar en las aulas UPEL, no se ejecuto con niños, tuvimos que fingir ser niñas, esto no me ayudo mucho con mis habilidades como futura profesora"

A.3- "en FO se observa que hay objetivos que no se cumplen", "los programas oficiales del nivel inicial dicen una cosa y aqui enseñan otra”, "las asesorías individuales no se dan, porque los profesores no tienen tiempo para asesorarnos"

A.4- "la realidad del programa de FO, es que no nos permite interactuar mucho tiempo con los niños"

A.5- "Ios contenidos planteados en el programa de FO, no guardan relación con 10 experimentado, pues la observación no fue tan detallada como lo dice el plan" 
A.6- "no se realizo diagnostico social y el tema de la ética profesional, no fue discutido, ni se tomo en cuenta"

A.7- "la FED, no lleno mis expectativas como tal, ya que no se me brindo la oportunidad de una verdadera asesoría, por parte de la profesora, antes de planificar y ejecutar, y esto afecta la calificación"

A.8- "el programa de FIDA, posee muchos aspectos que no se llevan a cabo en la realidad"

A.9-"la FIDA es una de las fases con mayor debilidad pues el 90\% del tiempo lo gastamos en arreglar el salón y solo el 10\% en realizar verdadera práctica de aula"

A.10-"el proyecto que cursamos fue escogido voluntariamente, lo que me permitió adquirir conocimiento sobre la investigación, como aplicarla y donde, lo que me agrado mucho, ya que reforcé lo aprendido en investigación"

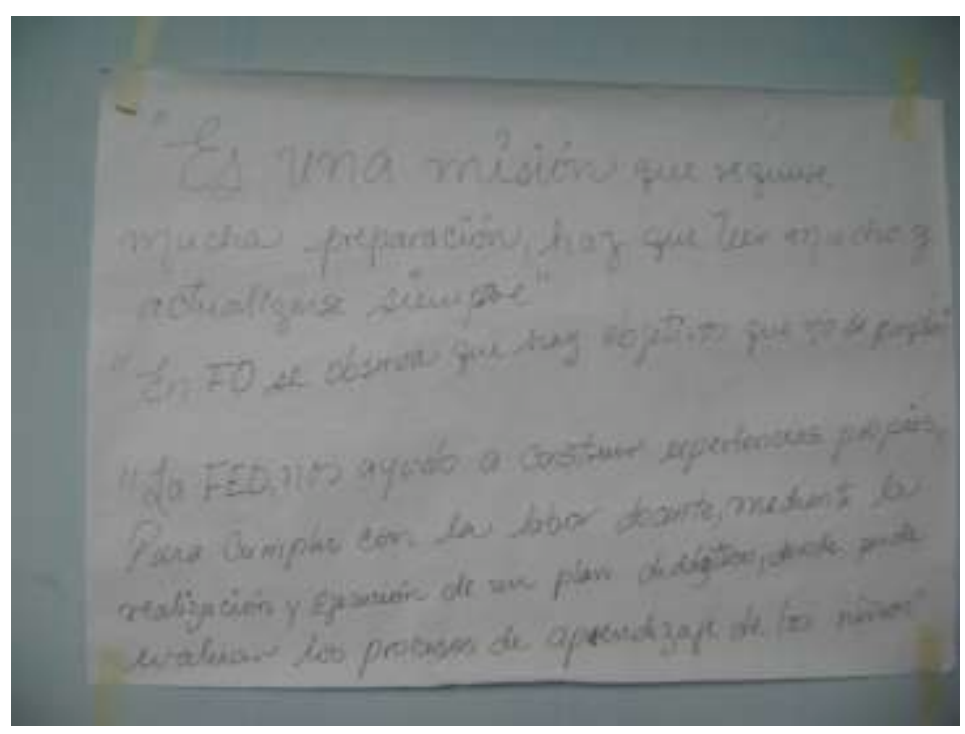

Producción grafica de las alumnas

369

La Práctica Profesional como área para potenciar las competencias pedagógicas necesarias para la enseñanza en Educación Infantil 


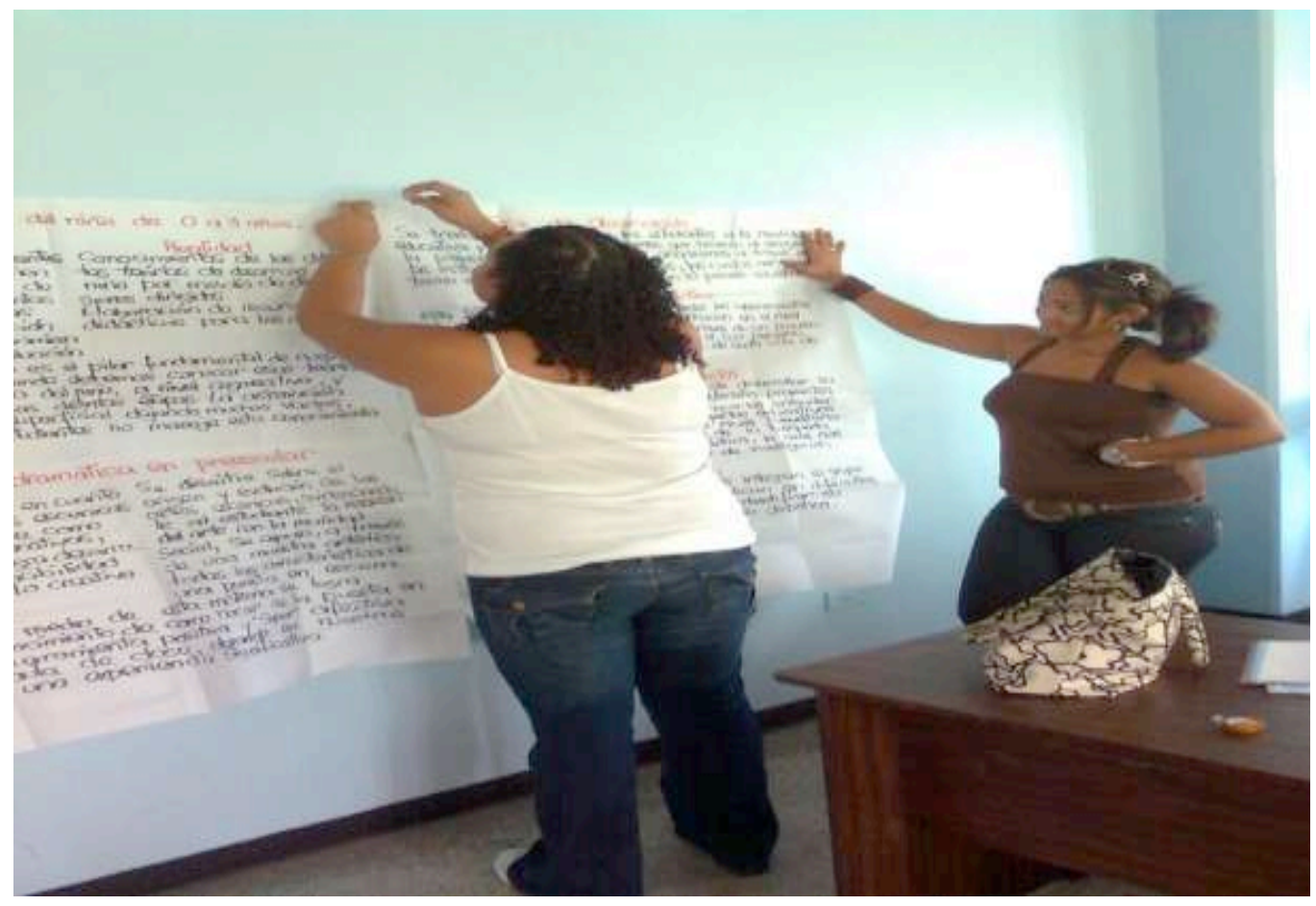

Siguiendo con el proceso de análisis se procede a realizar la categorización producto de las respuestas en este segundo taller. En el cuadro $n^{\circ} 76$, se presentan atendiendo a las dimensiones de la investigación, las preguntas generadoras, las categorías emergentes y una síntesis analítica.

\begin{tabular}{|c|c|c|c|}
\hline $\begin{array}{l}\text { Dimensión } \\
\text { Cuestionario }\end{array}$ & Preguntas generadoras & Categorías emergentes & Síntesis analítica \\
\hline $\begin{array}{l}\text { Dimensión Didáctica } \\
\text { Especifica Educación } \\
\text { Inicial (DDEEI) }\end{array}$ & $\begin{array}{l}\text { ¿Qué significa para usted la } \\
\text { enseñanza en Educación Infantil? }\end{array}$ & $\begin{array}{ll}\text { - } & \text { Responsabilidad } \\
\text { - } & \text { Reto } \\
\text { - } & \text { Compromiso } \\
\text { - } & \text { Misión } \\
\text { - } & \text { Oportunidad }\end{array}$ & $\begin{array}{l}\text { En atención a los } \\
\text { resultados encontrados } \\
\text { queda demostrado que } \\
\text { aún cuando los } \\
\text { alumnos demuestran } \\
\text { emoción al expresarse } \\
\text { sobre el significado de }\end{array}$ \\
\hline
\end{tabular}




\begin{tabular}{|c|c|c|c|}
\hline & $\begin{array}{l}\text { ¿Exprese su opinión acerca de la } \\
\text { planificación y la evaluación en } \\
\text { E.I? }\end{array}$ & $\begin{array}{l}\begin{array}{l}\text { Dificultad para la } \\
\text { planificación. }\end{array} \\
\text { - } \quad \begin{array}{l}\text { Aprender procesos de } \\
\text { evaluación }\end{array} \\
\text { - } \quad \begin{array}{l}\text { Aprender estrategias de } \\
\text { enseñanza }\end{array}\end{array}$ & $\begin{array}{l}\text { la enseñanza en } \\
\text { educación infantil, esta } \\
\text { valoración se queda en } \\
\text { el aspecto moral y } \\
\text { social, sin llegar al } \\
\text { aspecto pedagógico, } \\
\text { profesional, que esto } \\
\text { implica. Así mismo, se } \\
\text { perciben grandes dudas } \\
\text { y vacios en cuanto a la } \\
\text { planificación y la } \\
\text { evaluación, como } \\
\text { aspectos claves de la } \\
\text { didáctica del nivel, el } \\
\text { docente de esta casa de } \\
\text { estudio maneja } \\
\text { teóricamente el } \\
\text { currículo así como las } \\
\text { estrategias pedagógicas } \\
\text { sugeridas en el } \\
\text { programa, no obstante, } \\
\text { sigue desarrollando sus } \\
\text { clases bajo la figura del } \\
\text { docente tradicional lo } \\
\text { que trae como } \\
\text { consecuencia un } \\
\text { modelaje desarticulado } \\
\text { con las nuevas } \\
\text { tendencias pedagógicas. }\end{array}$ \\
\hline $\begin{array}{l}\text { Dimensión } \\
\text { Académico } \\
\text { Estudiantil (DAE) }\end{array}$ & $\begin{array}{l}\text { ¿Cuál es su opinión acerca de los } \\
\text { planes y programas de la P.P? }\end{array}$ & $\begin{array}{ll}\text { - } & \text { Actualización de programas. } \\
\text { - } & \text { Modificación de programas } \\
\text { - } & \begin{array}{l}\text { Aumento de prácticas con } \\
\text { niños en aulas preescolares }\end{array} \\
\text { - } & \text { Asesorías individuales } \\
\text { - } & \begin{array}{l}\text { Aumento de número de } \\
\text { horas de práctica }\end{array}\end{array}$ & $\begin{array}{l}\text { En la evaluación a los } \\
\text { programas de fase, las } \\
\text { informantes consideran } \\
\text { que en algunos casos de } \\
\text { cumplió todo el } \\
\text { programa y que además } \\
\text { éste estuvo ajustado con } \\
\text { todos sus contenidos, no } \\
\text { obstante, señalan que } \\
\text { existe muy poca } \\
\text { oportunidad de } \\
\text { interactuar } \\
\text { pedagógicamente con } \\
\text { niños, en detrimento de } \\
\text { sus posibilidades de } \\
\text { acercamiento e } \\
\text { intervención en } \\
\text { ambientes reales de } \\
\text { Educación Preescolar, } \\
\text { así mismo, los alumnos } \\
\text { advierten que constituye } \\
\text { una debilidad el hecho } \\
\text { de permanecer mucho } \\
\text { tiempo en las aulas de la } \\
\text { universidad y además }\end{array}$ \\
\hline
\end{tabular}




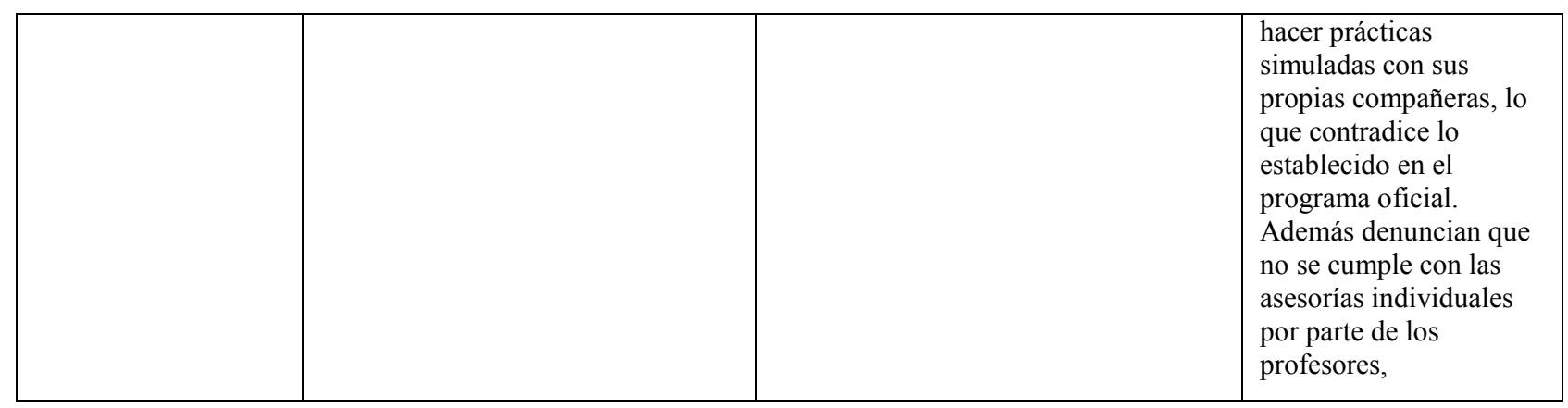

Cuadro $n^{\circ} 76$. Resumen categorías emergentes segundo taller alumnas

\subsection{Tercer Taller: Propuestas de Mejora Práctica Profesional Educación Preescolar} UPEL.

\begin{tabular}{|c|c|c|c|c|}
\hline Objetivo & Contenido & $\begin{array}{l}\text { Preguntas } \\
\text { generadoras }\end{array}$ & Recursos & Evaluación \\
\hline $\begin{array}{l}\text { Conocer las } \\
\text { fortalezas y } \\
\text { debilidades que } \\
\text { distinguen los } \\
\text { alumnos de la } \\
\text { especialidad de } \\
\text { Educación } \\
\text { Preescolar en el } \\
\text { proceso de } \\
\text { administración de } \\
\text { la práctica } \\
\text { profesional }\end{array}$ & $\begin{array}{l}\text { Propuestas de } \\
\text { mejora para la } \\
\text { administración de } \\
\text { las fases en } \\
\text { Educación } \\
\text { Preescolar }\end{array}$ & $\begin{array}{l}\text { ¿Qué propuestas } \\
\text { tienes para la } \\
\text { mejora en la } \\
\text { administración de } \\
\text { las fases de } \\
\text { Educación } \\
\text { Preescolar? }\end{array}$ & $\begin{array}{l}\text { Formato para } \\
\text { sistematizar las } \\
\text { ideas } \\
\text { Cámara } \\
\text { Fotográfica } \\
\text { Marcadores. }\end{array}$ & $\begin{array}{l}\text { Producción } \\
\text { individual } \mathrm{y} \\
\text { grupal }\end{array}$ \\
\hline
\end{tabular}

Cuadro $n^{\circ} 77$. Resumen acciones tercer taller estudiantes 


\subsection{Resultados Tercer Taller con Alumnos}

En sintonía con las respuestas dadas en los talleres 1 y 2, en este último taller los alumnos coinciden en recomendar lo siguiente:

A-1. "La recomendación que hacemos como alumnas, es que se hace necesario practicar con los niños y niñas en cada oportunidad que nos sea posible y poder estar en contacto con el contexto educativo".

A-2. "Nos sentimos satisfechas de haber logrado llegar a donde hemos Ilegado, ya que a partir de allí es donde podemos expresar nuestros puntos de vista con respecto a lo que consideramos pertinente a la hora de hacer evaluaciones a las fases".

A-4. "Como futuras docentes, quizás no nos capacitan como debe ser, ya que en muchos casos el problema reside tanto en el profesor(a), como en el alumno, ya que las estrategias que implementan no son las idóneas y por ende no se adquieren los conocimientos necesarios. Un ejemplo de ello es que a pocos días de salir de la especialidad, muchos bachilleres, no saben planificar, ni mucho menos como defenderse dentro de un salón de clases, puede que sepan la teoría, más no la práctica”.

A-5. "Los alumnos necesitamos nutrirnos de conocimientos, leer, informarnos, estar atentos a lo que pasa y lo que no, en el campo educativo. Ya que estamos en un mundo cambiante donde como docentes debemos estar al mismo compas de las innovaciones educativas".

A-6. "Como estudiantes debemos ser investigadoras antes que todo, ya que si no se comprende algún tema de la materia, pues, debemos buscar investigar aquello de lo cual dudamos".

A-7. "La Educación Preescolar es una carrera muy linda, llena de muchos matices, donde como docentes debemos ser polifacéticas y por ende, la práctica profesional, resumida en las cuatro fases nos Ilevan a estar en contacto con la realidad en el campo educativo. Es de hacer notar que

373

La Práctica Profesional como área para potenciar las competencias pedagógicas necesarias para la enseñanza en Educación Infantil 
la primera fase (observación) debe ser asignada para el primer semestre ya que hay muchos alumnos que no sienten realmente vocación por la docencia y por lo mismo cuando entran en contacto con la primera fase se darán cuenta si la docencia es lo que realmente quieren o no".

\subsubsection{Conclusiones Generales de los Talleres Reflexivos con los Alumnos y Profesores.}

Producto del análisis de los talleres realizados, podemos apreciar que para los profesores asistentes es sumamente importante mantenerse actualizados y además tener congruencia en los aspectos que permiten un aprendizaje integral de sus alumnas; marcada tendencia hacia aspectos valorativos, por sobre los cognitivos o procedimentales en el desarrollo de las prácticas pedagógicas de los profesores informantes. Con respecto a la enseñanza en educación infantil, consideran que debe estar fundamentada en lúdica, estrategias de enseñanza y procesos de aprendizaje. En cuanto a las habilidades procedimentales de las alumnas: aumento de prácticas para los alumnos. Desarrollo de estrategias de enseñanza. Así mismo las profesoras afirman que desconocen de la organización curricular de la especialidad educación preescolar. Y que se debe actualizar o modificar los programas de práctica profesional

Los ambientes de aprendizaje propuestos para la realización de las prácticas son los Hogaines, programas no convencionales, maternales, Simoncitos, preescolares públicos y privados; de estos programas hay que destacar los hogares de cuidado diario, los programas no convencionales y los maternales, como los menos seleccionados para la realización de prácticas profesionales de la UPEL, dada su condición de programas asistenciales y de cuidado infantil con personal con poca o ninguna preparación académica y en la mayoría de los casos tienen un fin de guardería infantil sin propósitos educativos; en cuanto a, los Simoncitos y los preescolares públicos y privados forman parte de los centros educativos con mayor demanda para la práctica profesional de las estudiantes UPEL. De las propuestas sobre la administración de las fases, se desprende la innegable necesidad de reorganizar y actualizar los programas y la administración de las fases; los profesores solicitan aumentar el nivel de exigencia académica, así como el número de horas de atención en las fases de observación y fase de ensayo didáctico.

374

La Práctica Profesional como área para potenciar las competencias pedagógicas necesarias para la enseñanza en Educación Infantil 
Por su parte, las estudiantes del Programa de Preescolar, revelan que tienen una mezcla de sentimientos que van desde la satisfacción por la ocasión de acercamiento a la realidad laboral, hasta el desengaño por no haber tenido más oportunidades, o por distinguir sus propias debilidades; así mismo, se evidencia que, es en éste componente académico que las estudiantes reconocen cuanta falta hace la contextualización del proceso enseñanza aprendizaje, en relación con sus propias habilidades y destrezas para planificar, evaluar, dirigir actividades de aula, así como la reivindicación de articular la teoría con la práctica, entre otros. Lo anterior, coincide con los resultados obtenidos por Lucena y Carmona (2008:8), en donde los docentes usualmente ejecutan sus actividades de clase empleando para ello el método pedagógico expositivo en detrimento de la estrategia cooperativa.

Así mismo, resulta necesario revisar los procesos formativos, específicamente la visión del tipo de educación que se está brindando, donde se privilegie una traslación hacia posturas humanistas y constructivistas en el logro de un aprendizaje más significativo para los alumnos.

Al respecto, Coll (1996: 196), plantea que “el enfoque psicogenético de Piaget, la teoría de esquema cognitivo, la teoría de Ausubel de la asimilación y el aprendizaje significativo y la Psicología sociocultural de Vygotsky, entre otras, dieron paso a la concepción constructivista del aprendizaje". Aunque estos autores tienen puntos divergentes en sus teorías, coinciden en la importancia de la actividad constructiva del alumno en el aprendizaje escolar. Según esta postura el verdadero conocimiento (aquel que es utilizable) es el fruto de una elaboración (construcción) personal, resultado de un proceso interno de pensamiento en el curso del cual el sujeto coordina entre sí diferentes nociones, atribuyéndolas y relacionándolas con otras anteriores.

Al promover este tipo de aprendizaje en las prácticas profesionales (y en todas las asignaturas de su formación académica), además de proporcionar nuevos conocimientos, se movilizará el funcionamiento intelectual del estudiante y le facilita acceso a nuevos aprendizajes, ya que además del conocimiento aprendido, utilizan determinadas estrategias intelectuales para acceder a él, que le serán de gran utilidad, no sólo en futuros aprendizajes sino también en la comprensión 375 La Práctica Profesional como área para potenciar las competencias pedagógicas necesarias para la enseñanza en Educación Infantil 
de situaciones nuevas; y en el planteamiento y la invención de soluciones a problemas que se le puedan presentar en la vida, gracias a su capacidad para generalizar.

\subsection{Comparación Resultados Análisis Talleres Reflexivos}

Como parte del análisis general, se procede a comparar los resultados obtenidos, luego de trabajar por separado los dos grupos de informantes. Para ello se procede a comparar las respuestas emitidas en los tres talleres realizados

\begin{tabular}{|c|c|c|}
\hline Taller & Profesores & Alumnas \\
\hline $\begin{array}{l}\text { Primer taller. } \\
\text { Dimensiones: } \\
\text { DPA y DEU }\end{array}$ & $\begin{array}{l}\text { Consideran un fundamento } \\
\text { importante para sus prácticas, los } \\
\text { procesos de aprendizaje de los } \\
\text { alumnos, el mantenerse actualizados, } \\
\text { en permanente revisión de } \\
\text { bibliografía actualizada sobre } \\
\text { educación infantil. Agregan } \\
\text { afirmaciones que están relacionadas } \\
\text { con valores, ética, compromiso, } \\
\text { vocación y apoyo al estudiantado. }\end{array}$ & $\begin{array}{l}\text { Piensan que la enseñanza en el nivel } \\
\text { inicial debe estar basada en valores. } \\
\text { Evalúan de manera positiva las } \\
\text { experiencias reales en contextos } \\
\text { educativos del nivel preescolar, pero } \\
\text { también le asignan una baja } \\
\text { puntuación a las pocas } \\
\text { oportunidades de intercambio } \\
\text { pedagógico real con niños. No se } \\
\text { sienten seguras de sus propias } \\
\text { habilidades y destrezas. Exigen } \\
\text { mayor articulación entre la teoría y } \\
\text { la práctica }\end{array}$ \\
\hline $\begin{array}{l}\text { Segundo taller. } \\
\text { Dimensiones: } \\
\text { DDEEI y DAE }\end{array}$ & $\begin{array}{l}\text { La enseñanza en educación infantil } \\
\text { involucra la lúdica, el uso de } \\
\text { estrategias de enseñanza y la } \\
\text { importancia a los procesos de } \\
\text { aprendizaje de los infantes. } \\
\text { Consideran que se debe fortalecer las } \\
\text { habilidades de los alumnos en } \\
\text { planificación, evaluación, estrategias } \\
\text { y recursos para el aprendizaje; así } \\
\text { mismo advierten la importancia de } \\
\text { aumentar el número de horas de } \\
\text { práctica, la actualización y } \\
\text { modificación de los programas de } \\
\text { práctica profesional. }\end{array}$ & $\begin{array}{l}\text { Para las alumnas la enseñanza en } \\
\text { educación infantil, significa } \\
\text { responsabilidad, retos, apoyo, } \\
\text { compromiso. } \\
\text { Ven como difícil la planificación y } \\
\text { la evaluación, consideran que } \\
\text { necesitan mejorar este aprendizaje. } \\
\text { Consideran una debilidad el } \\
\text { permanecer tanto tiempo en las } \\
\text { aulas universitarias y el tener que } \\
\text { hacer prácticas simuladas con sus } \\
\text { compañeras. Los profesores deben } \\
\text { cumplir con las asesorías } \\
\text { individuales }\end{array}$ \\
\hline
\end{tabular}

La Práctica Profesional como área para potenciar las competencias pedagógicas necesarias para la enseñanza en Educación Infantil 


\begin{tabular}{|c|c|c|}
\hline $\begin{array}{lr}\text { Tercer } & \text { taller. } \\
\text { Propuestas } & \text { de } \\
\text { mejora. } & \\
\end{array}$ & $\begin{array}{l}\text { Proponen incluir otros ambientes de } \\
\text { aprendizaje en la realización de las } \\
\text { fases, exigir a los alumnos la } \\
\text { sustentación teórica de sus } \\
\text { planificaciones, aumentar las horas } \\
\text { por cada fase (dos semestres cada } \\
\text { una) }\end{array}$ & $\begin{array}{l}\text { Demandan más práctica con } \\
\text { niños(as), mejor capacitación, } \\
\text { mejorar las estrategias que usan los } \\
\text { profesores, mejorar los procesos de } \\
\text { aprendizaje de los alumnos, } \\
\text { fortalecer sus hábitos de estudio. } \\
\text { Cambiar la ubicación de las fases, } \\
\text { comenzar con ellas desde el primer } \\
\text { semestre. }\end{array}$ \\
\hline
\end{tabular}

Cuadro $n^{\circ}$ 78. Comparación resultado general talleres reflexivos.

\subsection{Triangulación de los Resultados.}

Al interpretar los resultados es necesario tener en cuenta que se debe ofrecer una discusión para cada uno de los objetivos planteados, en esta etapa se puede correr el riesgo de omitir datos importantes o simplemente dejar que la subjetividad del investigador invada los resultados. Para facilitar la discusión de los resultados se recomienda la triangulación, la cual consiste en contrastar la información obtenida en el trabajo de campo, la posición teórica y la posición del investigador, en función de las dimensiones del estudio.

La técnica de la triangulación es una herramienta heurística de gran eficacia, que permite la determinación de ciertas intersecciones o coincidencias a partir de varios puntos de vista del mismo fenómeno (Martínez 1999:199, Palella y Martins 2004: 172); según estos autores, se pueden realizar varias triangulaciones que contribuyen a optimizar los resultados de la investigación, combinando diversas maneras, técnicas procedimientos cualitativos y cuantitativos, es decir que, al recoger la información desde puntos de vista distintos, permite realizar comparaciones de un mismo problema utilizando perspectivas y procedimientos diversos.

En este estudio, se utilizo la triangulación fundamentada en los datos recogidos a través de los diferentes instrumentos. Este procedimiento permitió integrar evidencias para cada dimensión:

La Práctica Profesional como área para potenciar las competencias pedagógicas necesarias para la enseñanza en Educación Infantil 
- Cuestionario dirigido a profesoras y alumnas de educación preescolar de la UPEL, Maracay.

- Talleres reflexivos, dirigidos igualmente, al mismo grupo de informantes.

- Datos obtenidos del análisis de documentos oficiales de práctica profesional de educación preescolar de la UPEL, Maracay.

Con la comparación de los resultados, se dispondrá de evidencias sobre el nivel de coincidencias y las diferencias, aunado a la opinión de algunos autores, lo cual será fundamento importante para el diseño de un programa de práctica profesional que permita potenciar las competencias pedagógicas necesarias para la enseñanza en educación infantil.

\subsubsection{Proceso de Triangulación de Resultados: Dimensión Procesos de Aprendizaje.}

\begin{tabular}{|c|c|c|c|}
\hline Dimensión & Cuestionario & Talleres reflexivos & Documentos oficiales \\
\hline \multirow[t]{2}{*}{$\begin{array}{l}\text { Procesos de } \\
\text { aprendizaje }\end{array}$} & $\begin{array}{l}\text { Alumnas: } 48 \% \text { está bastante } \\
\text { de acuerdo en haber } \\
\text { aprendido a integrar las } \\
\text { nuevas tendencias científicas, } \\
53 \% \text { integral las Tics; en la } \\
\text { actualización permanente } \\
70,4 \% \text { está en total acuerdo } \\
\text { con haber aprendido a } \\
\text { desarrollar habilidades de } \\
\text { ampliar y complementar } \\
\text { conocimientos y asistir a } \\
\text { clases con materiales leídos y } \\
\text { preparados; 70\% está } \\
\text { totalmente de acuerdo con } \\
\text { haber aprendido a trasladar a } \\
\text { otras situaciones los } \\
\text { aprendizajes teórico práctico. }\end{array}$ & $\begin{array}{lr}\text { Alumnas: no } & \text { se } \\
\text { sienten seguras de } \\
\text { sus habilidades para } \\
\text { trabajar con niños, } \\
\text { es decir, poco } \\
\text { dominio de } r \text { las } \\
\text { estrategias } & \text { de } \\
\text { enseñanza; solicitan } \\
\text { integración rro de } \\
\text { contenidos entre las } \\
\text { asignaturas } \\
\text { formación } \\
\text { pedagógica, } \\
\text { formación } \\
\text { especializada } \\
\text { práctica profesional }\end{array}$ & \multirow[t]{2}{*}{$\begin{array}{l}\text { En la revisión al diseño } \\
\text { curricular para la } \\
\text { especialidad de educación } \\
\text { preescolar de la UPEL, se } \\
\text { plantea la garantía de una } \\
\text { formación integral } \\
\text { general y una formación } \\
\text { especializada equilibrada } \\
\text { con los aportes de } \\
\text { diferentes áreas del } \\
\text { conocimiento para } \\
\text { proporcionar al estudiante } \\
\text { el desarrollo social, } \\
\text { intelectual y afectivo, así } \\
\text { como la adquisición } \\
\text { competencias que le } \\
\text { permitan educarse } \\
\text { permanentemente, } \\
\text { promover procesos de } \\
\text { investigación, a fin de }\end{array}$} \\
\hline & $\begin{array}{l}\text { Profesoras: coinciden en un } \\
66,7 \% \text { en las habilidades de } \\
\text { integración de sus alumnos }\end{array}$ & $\begin{array}{l}\text { Profesoras: } \\
\text { consideran } \\
\text { importante }\end{array}$ & \\
\hline
\end{tabular}




\begin{tabular}{|c|c|c|c|}
\hline & $\begin{array}{l}\text { de integrar las nuevas } \\
\text { tendencias científicas a sus } \\
\text { prácticas, no así con la } \\
\text { integración de las tics, existe } \\
\text { un } 67 \% \text { en desacuerdo. En } \\
\text { cuanto a actualización } \\
\text { permanente, habilidades para } \\
\text { desarrollar y ampliar } \\
\text { conocimientos, trasladar a } \\
\text { otras situaciones lo } \\
\text { aprendido, existe común } \\
\text { acuerdo con las alumnas, } \\
\text { pero no hay coincidencia con } \\
\text { la asistencia a clases con los } \\
\text { materiales leídos y la } \\
\text { integración de actividades de } \\
\text { docencia e investigación }\end{array}$ & $\begin{array}{lr}\text { hacerse } & \text { respetar, } \\
\text { buena comunicación } \\
\text { con las alumnas, } \\
\text { claridad en los } \\
\text { valores que desean } \\
\text { trasmitir, reflexión } \\
\text { permanente sobre las } \\
\text { situaciones } & \text { vividas } \\
\text { en clases, buena } \\
\text { relación con las } \\
\text { alumnas, ambiente } \\
\text { grato, reflexión } \\
\text { permanente sobre su } \\
\text { desempeño, } \\
\text { consideración } \\
\text { necesidades } \\
\text { intereses de } \\
\text { alumnas. }\end{array}$ & $\begin{array}{l}\text { permitirle adquisición de } \\
\text { variadas formas de } \\
\text { indagación } \\
\text { interpretación de la } \\
\text { realidad. }\end{array}$ \\
\hline \multicolumn{4}{|c|}{$\begin{array}{l}\text { Sustento teórico Morín (2001:38), advierte que los desarrollos propios de esta era planetaria } \\
\text { nos enfrentan cada vez más, y de manera cada vez más ineluctable, a los desafíos de la } \\
\text { complejidad, en consecuencia la educación debe utilizar los conocimientos existentes, superar } \\
\text { las antinomias provocadas por el progreso en los conocimientos especializados, a la vez que } \\
\text { identificar la falsa racionalidad. Por su parte Ríos (2004:24) opina que participamos de un } \\
\text { sistema educativo que intenta capacitarnos para desenvolvernos dentro de una sociedad, } \\
\text { aprovechándonos del conocimiento acumulado, y que además en las dificultades de los } \\
\text { estudiantes, seguramente incide una serie de factores, en los cuales se pueden mezclar } \\
\text { cuestiones personales, familiares, sociales y del propio sistema educativo, sin embargo, la zona } \\
\text { de influencia tiene sus límites y no podemos hacer mucho por cambiar el sistema educativo, } \\
\text { pero donde sí se puede intervenir y producir transformaciones y rectificaciones es con respecto } \\
\text { a nosotros mismos. En esta misma línea Quaas (2000:23) indica que es necesario comprender } \\
\text { que el aprendizaje no es una simple asimilación de conocimientos, éste supone un juego entre } \\
\text { las teorías más o menos explicitas que se poseen y que tienen que ver con las nuevas estructuras } \\
\text { incorporadas, lo importante es ampliar, modificar, justificar, reafirmar lo conocido con lo } \\
\text { nuevo. }\end{array}$} \\
\hline
\end{tabular}

Cuadro $\mathrm{n}^{\circ}$ 79. Triangulación de resultados, dimensión P.A

379

La Práctica Profesional como área para potenciar las competencias pedagógicas necesarias para la enseñanza en Educación Infantil 


\subsubsection{Proceso de Triangulación de Resultados: Dimensión DEEI}

\begin{tabular}{|c|c|c|c|}
\hline Dimensión & Cuestionario & Talleres reflexivos & $\begin{array}{l}\text { Documentos } \\
\text { oficiales }\end{array}$ \\
\hline \multirow[t]{2}{*}{$\begin{array}{l}\text { Didáctica } \\
\text { especifica } \\
\text { educación } \\
\text { inicial }\end{array}$} & $\begin{array}{l}\text { Alumnas: } 80 \% \text { de las } \\
\text { informantes está } \\
\text { totalmente de acuerdo con } \\
\text { el conocimiento de } \\
\text { organización de las } \\
\text { situaciones de enseñanza } \\
\text { aprendizaje. En la } \\
\text { categoría de planificación } \\
81 \% \text { afirma conocer sobre } \\
\text { diseño, administración y } \\
\text { ejecución de } \\
\text { planificaciones, más un } \\
18 \% \text { en desacuerdo con } \\
\text { aspectos de planificación } \\
\text { de trabajos comunitarios o } \\
\text { familiares. En relación con } \\
\text { la evaluación } 83,3 \% \text { está } \\
\text { totalmente de acuerdo en } \\
\text { conocer sobre evaluación, } \\
\text { desarrollo evolutivo del } \\
\text { niño, no ocurre igual con } \\
\text { el diseño y aplicación de } \\
\text { técnicas e instrumentos de } \\
\text { evaluación, (27\% en } \\
\text { desacuerdo) }\end{array}$ & $\begin{array}{l}\text { Alumnas: para las alumnas } \\
\text { la enseñanza en educación } \\
\text { infantil implica una gran } \\
\text { responsabilidad, un reto, } \\
\text { compromiso } \\
\text { oportunidad; manifiestan } \\
\text { debilidades en cuanto a } \\
\text { planificación y evaluación. }\end{array}$ & \multirow[t]{2}{*}{ 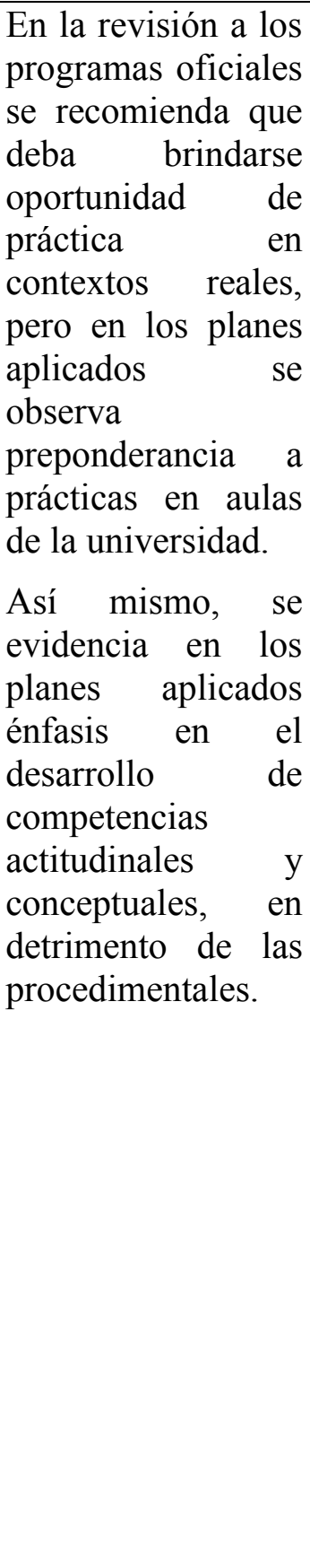 } \\
\hline & $\begin{array}{l}\text { Profesoras: se observan } \\
\text { coincidencias en las } \\
\text { opiniones a todos los } \\
\text { aspectos presentados en } \\
\text { esta dimensión, solo se } \\
\text { observa diferencias de } \\
\text { opinión en el aspecto } \\
\text { evaluación. }\end{array}$ & $\begin{array}{l}\text { Profesoras: consideran } \\
\text { importante fortalecer en las } \\
\text { alumnas la aplicación de } \\
\text { estrategias lúdicas y los } \\
\text { procesos de aprendizaje de } \\
\text { los niños. Así mismo, } \\
\text { requieren mayor } \\
\text { aprendizaje } \\
\text { planificación y evaluación, } \\
\text { consideran que necesitan } \\
\text { más oportunidades de }\end{array}$ & \\
\hline
\end{tabular}

La Práctica Profesional como área para potenciar las competencias pedagógicas necesarias para la enseñanza en Educación Infantil 


\begin{tabular}{|l|l|l|l|}
\hline & $\begin{array}{l}\text { práctica y el desarrollo de } \\
\text { estrategias de enseñanza }\end{array}$ \\
\hline
\end{tabular}

Sustento teórico: tomando como referencia las debilidades manifestadas por los dos grupos de informantes, García, Castañón, Domingo y Palou (1998:9) argumentan que para educar a un niño no basta el simple hecho de cuidar y atender sus necesidades elementales. Es preciso conocer las etapas de la evolución infantil, tanto física como psíquica, para favorecer oportuna e integralmente su desarrollo y lograr la incorporación paulatina de este ser humano al ámbito de la sociedad y la cultura.

Cuadro $n^{\circ} 80$. Triangulación de resultados, dimensión DEEI

8.3.3. Proceso de Triangulación de Resultados: Dimensión E.U.

\begin{tabular}{|c|c|c|c|}
\hline Dimensión & Cuestionario & Talleres reflexivos & $\begin{array}{l}\text { Documentos } \\
\text { oficiales }\end{array}$ \\
\hline $\begin{array}{l}\text { Enseñanza } \\
\text { universitaria }\end{array}$ & $\begin{array}{l}\text { Alumnas: al opinar sobre la } \\
\text { didáctica que llevan los } \\
\text { profesores universitarios, la } \\
\text { media más alta se sitúa en } \\
\text { dominio de aspectos } \\
\text { teóricos de los contenidos } \\
\text { de las asignaturas y la más } \\
\text { baja en la aportación de } \\
\text { fuentes actualizadas, } \\
\text { asociación de temas u } \\
\text { objetivos y transferencia de } \\
\text { contenidos. En cuanto a la } \\
\text { metodología utilizada por } \\
\text { los profesores, se muestran } \\
\text { en desacuerdo con las } \\
\text { exposiciones magistrales } \\
\text { (25\%), las prácticas } \\
\text { colectivas en el aula (25\%) } \\
\text { y las tutorías (29\%). Con } \\
\text { relación a los contextos de } \\
\text { aprendizaje refleja que la }\end{array}$ & $\begin{array}{l}\text { Alumnas: } \\
\text { satisfacción por las } \\
\text { oportunidades de acercamiento } \\
\text { a la realidad educativa del nivel } \\
\text { preescolar, pero también } \\
\text { manifiestan desengaño por no } \\
\text { haber tenido mayores } \\
\text { oportunidades de práctica real, } \\
\text { así como de percatarse de sus } \\
\text { propias debilidades }\end{array}$ & $\begin{array}{l}\text { En los } \\
\text { programas } \\
\text { oficiales esta } \\
\text { explicitado que } \\
\text { se debe ofrecer } \\
\text { horas de } \\
\text { asesoría } \\
\text { individual a los } \\
\text { alumnos, pero } \\
\text { en los } \\
\text { programas } \\
\text { aplicados esto } \\
\text { no se } \\
\text { evidencia. } \\
\text { Igualmente } \\
\text { ocurre con los } \\
\text { contextos de } \\
\text { aprendizaje, en } \\
\text { el documento } \\
\text { oficial se hace } \\
\text { mención a las }\end{array}$ \\
\hline
\end{tabular}

381

La Práctica Profesional como área para potenciar las competencias pedagógicas necesarias para la enseñanza en Educación Infantil 


\begin{tabular}{|c|c|c|c|}
\hline & $\begin{array}{l}\text { totalidad de las actividades } \\
\text { las realizan en aulas UPEL } \\
(81,5 \%) \text {, mientras que hubo } \\
\text { pocas oportunidades de } \\
\text { práctica en aula taller } \\
(20 \%) \text {, centros maternales } \\
(35 \%) \text {, centros no } \\
\text { convencionales }(29 \%) \text { y } \\
\text { contextos comunitarios } \\
(18 \%)\end{array}$ & & $\begin{array}{l}\text { prácticas en } \\
\text { centros de } \\
\text { aplicación } \\
\text { convencional y } \\
\text { no } \\
\text { convencional, } \\
\text { lo cual no se } \\
\text { observa en los } \\
\text { planes } \\
\text { aplicados por }\end{array}$ \\
\hline & $\begin{array}{l}\text { Profesoras: no coinciden } \\
\text { con los alumnos, ya que } \\
\text { ellos se autoevalúan } \\
\text { positivamente, en haber } \\
\text { proporcionado buenos } \\
\text { procesos didácticos. Así } \\
\text { mismo, afirman haber } \\
\text { proporcionado tutorías } \\
(83 \%) \text { en cuanto a los } \\
\text { contextos de aprendizaje } \\
\text { coinciden con las alumnas. }\end{array}$ & $\begin{array}{l}\text { Profesoras: } \\
\text { importante } \\
\text { objetivos del programa, la } \\
\text { planificación anticipada de } \\
\text { actividades, proporcionar } \\
\text { material de apoyo, claridad en } \\
\text { el dominio de contenidos a } \\
\text { enseñar, perfeccionamiento } \\
\text { continúo acerca de los avances } \\
\text { de la educación infantil y } \\
\text { bibliografía actualizada. }\end{array}$ & los profesores. \\
\hline $\begin{array}{l}\text { Sustento teó } \\
\text { Zeichner, y } \\
\text { aportar datos } \\
\text { no puede apc } \\
\text { haya sido inv } \\
\text { cuanto a la p } \\
\text { Solé y Zaba } \\
\text { constructivist } \\
\text { aprender, y } \\
\text { necesarios pa } \\
\text { actuación en } \\
\text { constructivist } \\
\text { zonas de des } \\
\text { esquemas de }\end{array}$ & $\begin{array}{l}\text { ico: En este caso vale la pe } \\
\text { ries (2006:106), hacen al res } \\
\text { obre decisiones importantes rel } \\
\text { tar información alguna sobre lo } \\
\text { stigado no dice mucho sobre } \\
\text { paración de programas". Por s } \\
\text { a, 1999:101), opinan sobre } \\
\text { como ayuda necesaria al proc } \\
\text { aprender de manera lo má } \\
\text { su desarrollo personal y para } \\
\text { lla. Pero solo ayuda, porque la } \\
\text { del alumno ni ocupar su lugar. } \\
\text { rrollo próximo y de asistenc } \\
\text { onocimiento de los alumnos y }\end{array}$ & $\begin{array}{l}\text { ena resaltar la advertencia que } \\
\text { pecto, "aunque la investigación } \\
\text { ativas a la investigación..., es pre } \\
\text { que debemos hacer. El simple h } \\
\text { lo que la gente hace realmente o } \\
\text { u parte, Onrubia (en Coll, Martí } \\
\text { la enseñanza entendida desde } \\
\text { eso de aprendizaje para que los a } \\
\text { s significativamente posible, lo } \\
\text { su capacidad de comprensión de } \\
\text { enseñanza no puede sustituir la } \\
\text { Coll 1990, Onrubia } 1999 \text { propon } \\
\text { ia en ellas, como una manera } \\
\text { novilizar su reestructuración. }\end{array}$ & $\begin{array}{l}\text { Cochran-Smith., } \\
\text { empírica puede } \\
\text { ciso matizar que } \\
\text { echo de que algo } \\
\text { debería hacer en } \\
\text { n, Mauri, Miras, } \\
\text { una concepción } \\
\text { umnos lleguen a } \\
\text { conocimientos } \\
\text { la realidad y de } \\
\text { actividad mental } \\
\text { en la creación de } \\
\text { de conectar los }\end{array}$ \\
\hline
\end{tabular}

Cuadro n81. Triangulación de resultados, dimensión E.U.

382

La Práctica Profesional como área para potenciar las competencias pedagógicas necesarias para la enseñanza en Educación Infantil 
8.3.4. Proceso de Triangulación de Resultados: Dimensión A.E.

\begin{tabular}{|c|c|c|c|}
\hline Dimensión & Cuestionario & Talleres reflexivos & $\begin{array}{l}\text { Documentos } \\
\text { oficiales }\end{array}$ \\
\hline $\begin{array}{l}\text { Académica } \\
\text { estudiantil }\end{array}$ & $\begin{array}{l}\text { Alumnas: en la categoría } \\
\text { créditos académicos } 66 \% \text { de } \\
\text { los alumnos de acuerdo con } \\
\text { la normativa y el reglamento } \\
\text { de evaluación; mientras que } \\
\text { un } 22 \% \text { en desacuerdo con la } \\
\text { ubicación de las prácticas en } \\
\text { el plan de estudio, el apoyo } \\
\text { institucional, los recursos } \\
\text { para el aprendizaje y el apoyo } \\
\text { en centros de aplicación. En } \\
\text { cuanto a los planes y } \\
\text { programas, total acuerdo con } \\
\text { en la relación teoría práctica, } \\
\text { la adaptación al contexto } \\
\text { (53\%), en desacuerdo con el } \\
\text { uso de las tics y las } \\
\text { innovaciones científicas } \\
\text { (31\%). Y finalmente la } \\
\text { categoría servicios } \\
\text { estudiantiles en desacuerdo } \\
\text { con las becas de estudio, } \\
\text { becas trabajo y transporte } \\
\text { institucional ( } 37 \% \text { ), para el } \\
\text { resto de los servicios la } \\
\text { opinión es positiva. } \\
\text { Profesoras: Coinciden en las } \\
\text { opiniones sobre los créditos } \\
\text { académicos, uso de las tics e } \\
\text { innovaciones científicas; en } \\
\text { desacuerdo con los aspectos } \\
\text { relacionados con la relación } \\
\text { teoría práctica ( } 33 \%) \text {, } \\
\text { innovaciones; } 35 \% \\
\text { responde acerca de los } \\
\text { servicios estudiantiles. }\end{array}$ & $\begin{array}{l}\text { Alumnas: } \\
\text { que es necesario } \\
\text { actualizar y/o modificar } \\
\text { los planes y programas, } \\
\text { aumentar el número de } \\
\text { práctica en aulas } \\
\text { infantiles, las asesorías } \\
\text { individuales y el } \\
\text { número de horas de } \\
\text { práctica profesional }\end{array}$ & $\begin{array}{l}\text { Sus enunciados } \\
\text { curriculares lo } \\
\text { presentan como } \\
\text { integrador, } \\
\text { abierto } \\
\text { sensible, } \\
\text { asimilar para } \\
\text { cambios que } \\
\text { susciten en los } \\
\text { educación, } \\
\text { ciencia la } \\
\text { tecnología y la } \\
\text { cultura (UPEL, } \\
\text { 1996:8), en la } \\
\text { actualidad } \\
\text { presenta como } \\
\text { centrado en las } \\
\text { asignaturas, lo } \\
\text { cual implica un } \\
\text { énfasis excesivo } \\
\text { en la dimensión } \\
\text { instrumental de } \\
\text { la profesión. En } \\
\text { los programas } \\
\text { oficiales } \\
\text { aplicados no se } \\
\text { observa } \\
\text { evidencias } \\
\text { integración de la } \\
\text { tics, en los } \\
\text { procesos } \\
\text { formativos de las } \\
\text { futuras } \\
\text { profesionales de } \\
\text { educación } \\
\text { infantil }\end{array}$ \\
\hline
\end{tabular}

383

La Práctica Profesional como área para potenciar las competencias pedagógicas necesarias para la enseñanza en Educación Infantil 
Sustento teórico: Esta situación encuentra sustento en los aportes de Torres (2006:32) al afirmar que una gran mayoría de las profesoras y profesores experimentan un notable desconcierto acerca de las finalidades de las etapas educativas en las que está trabajando, además este autor, considera que en los planes de estudio prima la formación psicopedagógica, pero está completamente descuidada la información cultural relacionada con los contenidos que los profesores de educación infantil trabajarán en sus aulas.

Cuadro $n^{\circ}$ 82. Triangulación de resultados, dimensión A.E.

\subsection{Limitaciones de la Investigación.}

Las limitaciones de refieren a las restricciones propias del tipo problema abordado; son predominantemente de carácter externo. Así mismo, una delimitación, indica posibles debilidades del estudio, tales como, el tiempo, el espacio, el tipo de instrumentos, la muestra seleccionada, entre otros.

\section{Limitaciones generales:}

El tema de investigación sobre la práctica profesional en educación preescolar, resulto como consecuencia de otros estudios, elaborados con anterioridad sobre aspectos relacionados, tales como: dominio conceptual del docente y calidad de su praxis didáctica (2008), elementos para la reconstrucción de la didáctica en educación inicial (2009), proyectos didácticos en educación inicial, una perspectiva socio cultural y humanista, (2009); de este modo el proceso de elaboración del instrumento de recolección de datos, en este caso el cuestionario, requirió de la articulación de las experiencias previas, pero también de la validación, y corrección, lo cual amerito tiempo extra para los arreglos y modificaciones necesarias, esto implico que la muestra de estudiantes de educación preescolar, seleccionada con anterioridad, culminasen sus estudios, es decir, hubo perdida de la muestra. Ante esta situación, surgió la necesidad de volver a

La Práctica Profesional como área para potenciar las competencias pedagógicas necesarias para la enseñanza en Educación Infantil 
contactar una nueva muestra, que cumpliera con los requisitos establecidos para el estudio: estar cursando la última fase de práctica profesional de la especialidad de educación preescolar.

Aun y cuando esta situación limito durante un semestre completo la aplicación del instrumento, al final resulto favorable, ya que en el semestre próximo siguiente, aumento el número de alumnas a cursar la última fase; de este modo una limitación se convirtió en fortaleza.

Una vez organizados los grupos de informantes (alumnas y profesoras), fue necesario establecer un cronograma, con el fin de garantizar la aplicación del instrumento a todos los grupos (distribuidos a razón de doce alumnas por sección) en los dos turnos que ofrece la UPEL: mañana y tarde. Esta situación se solvento, gracias a la colaboración de las profesoras al suministrar su horario y tiempo disponible para este fin.

Del mismo modo, se debe hacer mención a las limitaciones para la ejecución de los talleres reflexivos, en este caso el clima (lluvias torrenciales) y las situaciones propias de un entorno universitario (suspensión de actividades) la realización de los talleres, por lo que se hizo una reprogramación en las fechas. En el caso de los profesores contratados, esto no fue fácil, ya que es necesario que se ausenten de sus actividades laborales fuera de la UPEL, y los directivos se niegan a dar permisos laborales. En este caso hay que destacar el interés y la disposición por parte de ambos grupos de informantes, para brindar sus aportes y opiniones; así mismo, el apoyo institucional de los coordinadores y jefes de departamento en la UPEL, al asistir y dar apertura a los talleres, como también al Centro de Investigaciones en Educación Infantil (CIEDIN), al cual pertenece la investigadora, al certificar la participación de los asistentes con su respectiva constancia.

En referencia al análisis de documentos, no hubo ninguna limitación, ya que el programa oficial es un documento accesible a todos los interesados y los planes aplicados por los profesores, constituyen parte de los requerimientos administrativos del área de práctica 
profesional, y con la debida justificación y garantía de confidencialidad, fueron de fácil acceso para la investigadora.

\subsection{Conclusiones y Propuesta}

La práctica profesional, constituye uno de los componentes de la formación inicial de profesores, de mayor importancia y trascendencia, para la construcción de su experiencia pedagógica. Del mismo modo, es necesario considerar que en este proceso formativo intervienen factores que por lo general, afectan los pensamientos, sentimientos y conductas de profesores universitarios y alumnos. Los estudiosos del campo de la formación docente, recomiendan, en el plano académico, aumentar el carácter científico- investigador de la práctica docente y una mayor conexión entre la práctica y la realidad.

Considerando lo anterior, en esta investigación se planteo el siguiente objetivo general: Diseñar un programa de práctica profesional, que potencie las competencias pedagógicas necesarias para la enseñanza en Educación Infantil.

En este orden de ideas, y con el propósito de alcanzar este objetivo nos propusimos los siguientes objetivos específicos:

- Analizar la valoración sobre la práctica profesional del programa de Educación Preescolar de la UPEL - IPMAR, desde el punto de vista de profesores y alumnos.

- Conocer cuáles son las características pedagógicas presentes en los planes y programas de estudio del área de práctica profesional, de la especialidad Educación Preescolar de la UPEL- Maracay.

- Indagar sobre las fortalezas y debilidades que distinguen los alumnos y los profesores de la especialidad de Educación Preescolar en el proceso de administración de la práctica profesional 
- Establecer los lineamientos para la propuesta del plan de mejora, a partir de los resultados encontrados, con los elementos teóricos- prácticos necesarios a incluir en el diseño de un programa de práctica profesional que potencie las competencias pedagógicas necesarias para la enseñanza en Educación Infantil.

En este apartado, vamos a presentar las conclusiones de la investigación, teniendo como punto de referencia, cada uno de los objetivos propuestos, según los resultados obtenidos en el estudio empírico, a través de los instrumentos aplicados: cuestionario, análisis de documentos y talleres reflexivos.

\subsubsection{Analizar la Valoración sobre la Práctica Profesional.}

Valorar la práctica pedagógica, permite orientarse hacia la construcción de prospectivas pedagógicas, a partir de la revisión de experiencias de primera mano; en este caso la consulta, a través de un cuestionario, a las alumnas y profesoras del programa de educación preescolar, sobre la práctica profesional de la UPEL, Maracay, entre sus resultados se tienen:

Con respecto a la dimensión procesos de aprendizaje: Se observa diferencia de opinión en cuanto a las categorías aprender a aprender y habilidades en el manejo de las tics; las opiniones resultan contradictorias, Profesoras y alumnas coinciden en la disposición para ampliar y complementar los conocimientos, no así, en cuanto a la asistencia a clases con los materiales leídos y preparados. Las alumnas opinan no haber aprendido la habilidad de trasladar sus aprendizajes teóricos a la práctica, pero sus profesoras si lo creen. Existen algunas coincidencias en las debilidades por parte de las alumnas de integrar las actividades de docencia con investigación.

En referencia a la dimensión didáctica especifica de Educación Inicial, En esta dimensión relacionada directamente con la educación infantil y sus principios metodológicos, es importante plantearse cuál es el su objetivo fundamental; objetivo que consiste en potenciar el desarrollo en todas las capacidades físicas afectivas, intelectuales y sociales de los infantes. Para ello los 387

La Práctica Profesional como área para potenciar las competencias pedagógicas necesarias para la enseñanza en Educación Infantil 
alumnos en proceso de formación docente, deben aprender a organizar adecuadamente las actividades e interacciones, facilitando experiencias y dotando de un medio adecuado con espacios y materiales necesarios para lograr este desarrollo integral. Como resultado a este aspecto se tiene que: los dos grupos de informantes coinciden en afirmar que las alumnas poseen habilidades para diseñar recursos y ambientes de aprendizaje, Existe consenso en evaluar positivamente los aspectos referidos a la planificación, no así en aquellas acciones relacionadas con el trabajo comunitario y/o familiar y la planificación por proyectos, Mientras que las alumnas consideran que saben evaluar, las profesoras opinan lo contrario; coinciden en afirmar que aun requieren aprender sobre diseño y aplicación de técnicas e instrumentos.

Así mismo, ambos grupos opinan favorablemente sobre las habilidades que demuestran las alumnas para interacciones pedagógicas con niños y niñas; no obstante, las alumnas consideran que necesitan aprender a resolver situaciones difíciles en el aula de educación infantil. Como puede apreciarse las diferencias de opinión resultan importantes, ya que estos informantes están indicando fallas y fortalezas presentes en el proceso de enseñanza aprendizaje, que lo más probable no solo este afectando a la práctica profesional, sino que pueda proyectarse a todo el componente de formación de la universidad.

Dimensión enseñanza universitaria: con respecto a la dimensión enseñanza aprendizaje, existe coincidencia en afirmar que en general los profesores proporcionaron habilidades y procesos didácticos cónsonos con la didáctica universitaria. Mientras las profesoras confirman el uso frecuente de algunos métodos, las alumnas los valoran de manera negativa (en desacuerdo), Ambos grupos coinciden en que el contexto de aprendizaje más utilizado fue el aula de clases de la universidad, reflejando muy pocas oportunidades de prácticas en otros contextos. Acuerdo en ambos grupos acerca de los métodos y criterios de evaluación.

Dimensión académica estudiantil: en este aspecto resulta que las alumnas están en desacuerdo con la ubicación de las prácticas en el plan de estudio, por el contrario, las profesoras si están de acuerdo con su ubicación. Los grupos valoran de modo diferente los aspectos referidos 388

La Práctica Profesional como área para potenciar las competencias pedagógicas necesarias para la enseñanza en Educación Infantil 
a los planes y programas. Solo las alumnas se expresan en este aspecto, las profesoras prefieren no contestar en algunos ítems, lo cual pudiera evidenciar desconocimiento de este aspecto que influye grandemente en la calidad de la formación académica de las alumnas.

\subsubsection{Características Pedagógicas Presentes en los Planes y Programas de Estudio del Área de Práctica Profesional, de la Especialidad Educación Preescolar de la UPEL- Maracay}

La UPEL posee un diseño curricular que requiere ser actualizado, en virtud de los cambios legales, pedagógicos, psicológicos, sociales, económicos, políticos y educativos, que han ocurrido en Venezuela y en el mundo. Este modelo de formación, a pesar de que en sus enunciados curriculares lo presentan como integrador, abierto y sensible, para asimilar los cambios que se susciten en la educación, la ciencia , la tecnología y la cultura (UPEL, 1996:8), en la actualidad se presenta como centrado en las asignaturas, lo cual implica un énfasis excesivo en la dimensión instrumental de la profesión y que responde al criterio de que, el egresado sea capaz de enfrentar la solución de los problemas que se planteen en su área de trabajo, y pueda actuar de acuerdo con las necesidades de la práctica y demandas sociales con la mayor efectividad y eficiencia posibles.

Con respecto a los programas del área de práctica profesional, se observan algunas debilidades las cuales son fáciles de superar si se trata solo de agregar más horas, incluir otros contenidos, o también cambiar y actualizar las estrategias, no obstante consideramos que la piedra angular en estos procesos de mejora es el mismo profesor universitario. Esto ocurre porque, si bien en algunos programas no se observan de manera explícita algunas directrices dadas en el programa oficial, no es menos cierto que en algunos casos los profesores terminan haciendo más de lo realmente aparece en los documentos. De esta suerte, no solo podemos advertir el rol protagónico del profesor en este proceso formativo, sino que también debemos introducir el imperativo de considerar algunos cambios en el proceso de formación de nuestros estudiantes.

389

La Práctica Profesional como área para potenciar las competencias pedagógicas necesarias para la enseñanza en Educación Infantil 
El esfuerzo por renovar la formación de los futuros docentes debe comprometer a todos los actores responsables en el rediseño del currículo y elevar los estándares formativos en concordancia con los requerimientos de la sociedad en general, es decir volver la mirada crítica hacia nuestras propias prácticas.

\subsubsection{Fortalezas y Debilidades en el Proceso de Administración de la Práctica Profesional}

En las dimensiones procesos de aprendizaje y enseñanza universitaria, las profesoras consideran un fundamento importante para sus prácticas, los procesos de aprendizaje de los alumnos, el mantenerse actualizados, en permanente revisión de bibliografía actualizada sobre educación infantil. Agregan afirmaciones que están relacionadas con valores, ética, compromiso, vocación y apoyo al estudiantado. Por su parte las alumnas piensan que la enseñanza en el nivel inicial debe estar basada en valores, evalúan de manera positiva las experiencias reales en contextos educativos del nivel preescolar, pero también le asignan una baja puntuación a las pocas oportunidades de intercambio pedagógico real con niños. No se sienten seguras de sus propias habilidades y destrezas. Exigen mayor articulación entre la teoría y la práctica.

En cuanto a la dimensión didáctica especifica de educación inicial y académico estudiantil, las profesoras creen que la enseñanza en educación infantil involucra la lúdica, el uso de estrategias de enseñanza y la importancia a los procesos de aprendizaje de los infantes. Consideran que se debe fortalecer las habilidades de los alumnos en planificación, evaluación, estrategias y recursos para el aprendizaje; así mismo advierten la importancia de aumentar el número de horas de práctica, la actualización y modificación de los programas de práctica profesional.

Para las alumnas la enseñanza en educación infantil, significa responsabilidad, retos, apoyo, compromiso. Distinguen como difícil la planificación y la evaluación, piensan que necesitan mejorar este aprendizaje. Consideran una debilidad el permanecer tanto tiempo en las aulas universitarias y el tener que hacer prácticas simuladas con sus compañeras. Los profesores deben

390

La Práctica Profesional como área para potenciar las competencias pedagógicas necesarias para la enseñanza en Educación Infantil 
cumplir con las asesorías individuales. Al respecto, Coll (1996: 196), plantea que "el enfoque psicogenético de Piaget, la teoría de esquema cognitivo, la teoría de Ausubel de la asimilación y el aprendizaje significativo y la Psicología sociocultural de Vygotsky, entre otras, dieron paso a la concepción constructivista del aprendizaje”. Aunque estos autores tienen puntos divergentes en sus teorías, coinciden en la importancia de la actividad constructiva del alumno en el aprendizaje escolar. Según esta postura el verdadero conocimiento (aquel que es utilizable) es el fruto de una elaboración (construcción) personal, resultado de un proceso interno de pensamiento en el curso del cual el sujeto coordina entre sí diferentes nociones, atribuyéndolas y relacionándolas con otras anteriores.

$\mathrm{Al}$ promover este tipo de aprendizaje en las prácticas profesionales (y en todas las asignaturas de su formación académica), además de proporcionar nuevos conocimientos, se movilizará el funcionamiento intelectual del estudiante y le facilita acceso a nuevos aprendizajes, ya que además del conocimiento aprendido, utilizan determinadas estrategias intelectuales para acceder a él, que le serán de gran utilidad, no sólo en futuros aprendizajes sino también en la comprensión de situaciones nuevas; y en el planteamiento y la invención de soluciones a problemas que se le puedan presentar en la vida, gracias a su capacidad para generalizar.

\subsubsection{Lineamientos para la Propuesta del Plan de Mejora.}

\subsubsection{Propuesta de Programa de Práctica Profesional, que Potencie las Competencias Pedagógicas Necesarias para la Enseñanza en Educación Infantil (P-5).}

El diseño de un programa de práctica profesional para la especialidad de educación infantil, representa la principal aspiración, dentro de esta investigación, así mismo tiene su fundamento e importancia en los resultados precedentes, producto del análisis a documentos oficiales y las opiniones de las alumnas y profesores del área en estudio.

391

La Práctica Profesional como área para potenciar las competencias pedagógicas necesarias para la enseñanza en Educación Infantil 


\subsubsection{Propósito del Programa de Práctica Profesional (P-5).}

La propuesta de un programa de práctica profesional, está orientada a impulsar en el programa de educación preescolar de la UPEL, Maracay y en el área de práctica profesional del componente docente, el diseño y aplicación de acciones programadas que permitan, a través de las distintas fases que componen la práctica profesional, potenciar las competencias pedagógicas necesarias para la enseñanza en educación infantil.

Propósito general que se desglosa en los siguientes objetivos específicos:

$\checkmark$ Incorporar a los profesores del programa de educación preescolar, como principales responsables del proceso de formación, basándose en los resultados de la investigación, como evidencia importante y diagnostica para iniciar los cambios.

Someter al análisis crítico y reflexivo la Propuesta de programas de práctica profesional que potencie las competencias pedagógicas necesarias para la enseñanza en educación infantil (P-5).

$\checkmark$ Articular estos resultados con el proceso de transformación curricular de la UPEL y las políticas educativas del estado venezolano.

\subsubsection{Justificación del programa de práctica profesional (P-5).}

A la práctica profesional le compete abordar la globalidad y la complejidad del proceso de enseñanza aprendizaje de las estudiantes universitarias, de modo que contribuya al desarrollo de oportunas y pertinentes intervenciones didácticas. En la revisión teórica de esta investigación, se analizaron los procesos que intervienen en la didáctica del nivel de educación infantil, en el cual interactúan variables pedagógicas, psicológicas, personales y sociológicas. En consecuencia la comprensión y organización sistemática de este proceso resulta igualmente compleja y difícil de

392

La Práctica Profesional como área para potenciar las competencias pedagógicas necesarias para la enseñanza en Educación Infantil 
abordar de manera simplista, aplicando mecánicamente modelos instruccionales o prescripciones didácticas (recetas).

Por el contrario, la complejidad del abordaje de las prácticas pedagógicas, requiere de procesos deliberativos y la utilización de estrategias metodológicas que permitan valorar desde una postura científica y multireferencial, el proceso didáctico del nivel infantil; es por eso que la presente propuesta no se adscribe al comportamiento restringido que se identifica con pautas, ni recetas descontextualizadas.

Para el logro de este propósito se plantea la metodología de formación permanente, que se desarrollara en el marco del proceso de transformación curricular que actualmente se está realizando en la Universidad Pedagógica Experimental Libertador, con el objeto de que los profesores (coordinadores, y autoridades), alumnos egresados, y alumnos en proceso de formación, conozcan los resultados del estudio e intervengan en el proceso de mejoramiento y/o transformación del P-5.

Es importante mencionar, que este proceso de validación del P-5, se suscribe en la tendencia que reconoce al docente como un profesional crítico y reflexivo (aspecto abordado en páginas anteriores). En consecuencia, alumnos en formación y profesionales deben asumir el desarrollo de actitudes de apertura y de indagación deliberativa, para intervenir de manera apropiada en el proceso de validación y mejora del P-5, que nos lleve a construir creativamente soluciones a los problemas de la práctica profesional en la UPEL.

\subsubsection{Responsables}

En el proceso de validación del P-5, participaran las personas y unidades sobre las cuales recae la responsabilidad de las actividades propuestas, en este sentido serán identificadas de la siguiente manera:

Autoridades Vicerrectorado Docencia: AUD

393

La Práctica Profesional como área para potenciar las competencias pedagógicas necesarias para la enseñanza en Educación Infantil 
Comisión de currículo UPEL: CCU

Jefes de departamento: JD

Profesores UPEL: PU

Profesores egresados: PE.

Representantes de los centros de aplicación: RCA.

Alumnos en proceso de formación: A

\subsubsection{Fases del Desarrollo de la Propuesta.}

El proceso se llevara a cabo en tres fases. En cada una de ellas se describen las actividades, se formulan propósitos y se explican algunas situaciones particulares.

La Práctica Profesional como área para potenciar las competencias pedagógicas necesarias para la enseñanza en Educación Infantil 


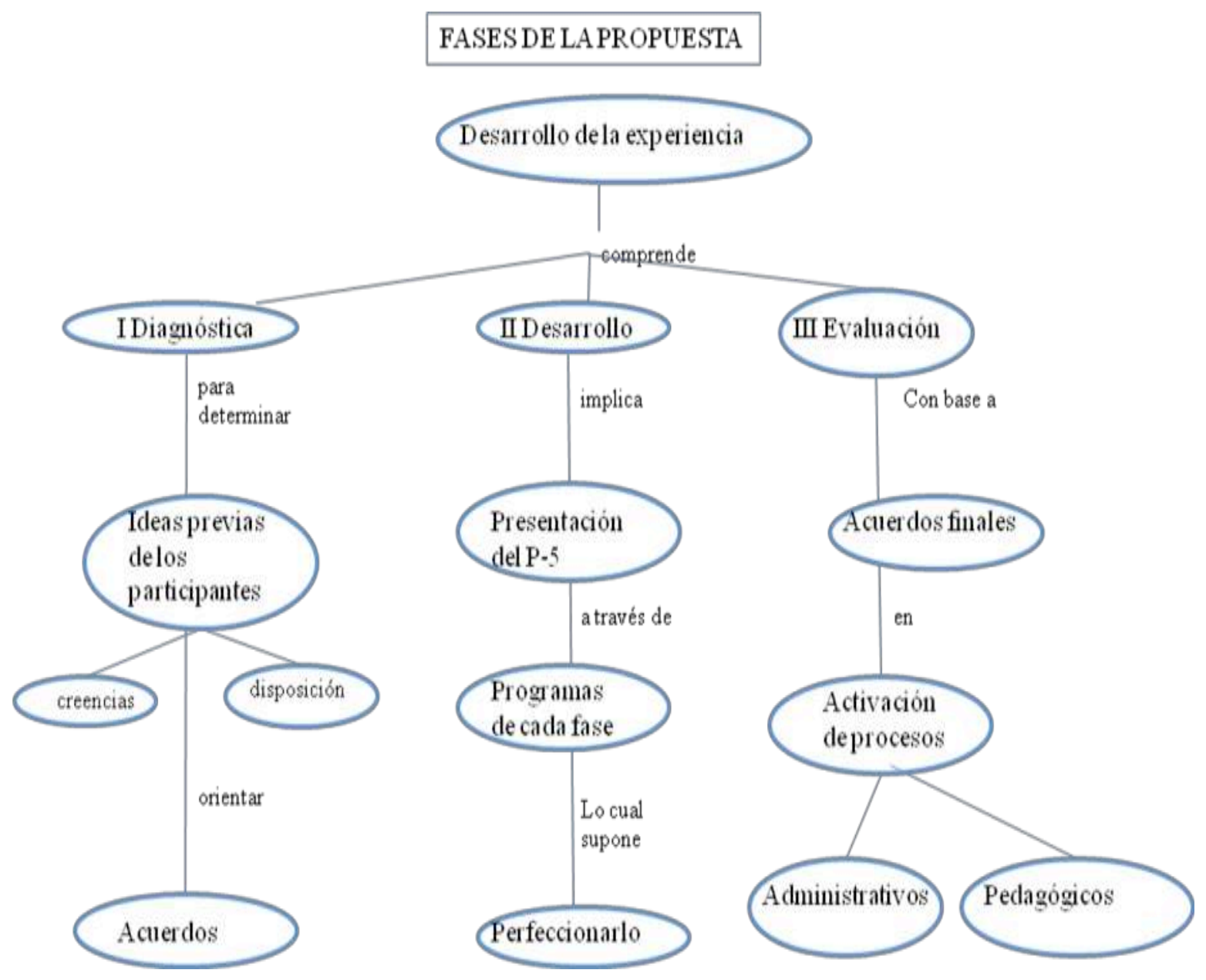

Grafico ${ }^{\circ}$ 67. Fases P- 5.

395

La Práctica Profesional como área para potenciar las competencias pedagógicas necesarias para la enseñanza en Educación Infantil 


\subsection{Fase I Diagnóstica.}

\begin{tabular}{|c|c|c|c|}
\hline \multicolumn{4}{|l|}{ Fase I Diagnóstica } \\
\hline Actividades & Propósitos & Responsables & Lapso de tiempo \\
\hline $\begin{array}{l}\text { Introducción al plan } \\
\text { de trabajo }\end{array}$ & $\begin{array}{l}\text { Presentar los } \\
\text { resultados de la } \\
\text { investigación, con el } \\
\text { fin de justificar la } \\
\text { validación del P-5 y } \\
\text { su puesta en acción. }\end{array}$ & $\begin{array}{l}\text { CCU, JD, } \\
\text { PU,PE,RCA,A. }\end{array}$ & \multirow[t]{3}{*}{$\begin{array}{l}\text { Dos semanas; un día } \\
\text { cada sesión }\end{array}$} \\
\hline $\begin{array}{l}\text { Exploración } \\
\text { experiencias previas }\end{array}$ & $\begin{array}{l}\text { Explorar la } \\
\text { representación del } \\
\text { conocimiento que } \\
\text { tienen los } \\
\text { participantes sobre la } \\
\text { práctica profesional, } \\
\text { su administración y } \\
\text { programas en uso. }\end{array}$ & $\begin{array}{l}\text { CCU, JD, } \\
\text { PU,PE,RCA,A. }\end{array}$ & \\
\hline $\begin{array}{l}\text { Determinar acuerdos } \\
\text { de trabajo }\end{array}$ & $\begin{array}{l}\text { Una vez discutidas las } \\
\text { ideas previas y } \\
\text { confirmada la } \\
\text { disposición a } \\
\text { participar, se fijaran } \\
\text { los acuerdos para los } \\
\text { siguientes encuentros }\end{array}$ & $\begin{array}{l}\text { CCU, JD, } \\
\text { PU,PE,RCA,A. }\end{array}$ & \\
\hline $\begin{array}{l}\text { Leyenda: Comisión de } \\
\text { egresados: PE. Represer }\end{array}$ & $\begin{array}{l}\text { ulo UPEL: CCU, Jefes } \\
\text { de los centros de aplicac }\end{array}$ & $\begin{array}{l}\text { departamento: JI } \\
\text { RCA, Alumnos e }\end{array}$ & $\begin{array}{l}\text { es UPEL: PU, Profesor } \\
\text { e formación: A }\end{array}$ \\
\hline
\end{tabular}

Cuadro ${ }^{\circ}{ }^{83}$. Fase I Diagnóstica P-5

La presentación del P-5, está dirigida a los responsables de la comisión de currículo de la UPEL Maracay, los jefes de departamento, los profesores UPEL que administran la práctica profesional y los de la especialidad de educación preescolar, los profesionales egresados de esta casa de estudio en educación preescolar, los representantes de los centros de aplicación (director y maestros) y los alumnos en proceso de formación de la especialidad a la cual va dirigida la propuesta. 
Esta propuesta se dará a conocer a los participantes mediante reuniones apoyadas en métodos de formación permanente que conduzcan a la participación dialógica, mediante procesos deliberativos. En este sentido, su metodología, será con un enfoque práctico, pero con el criterio del principio de flexibilidad, ya que se brindara a los participantes la oportunidad de aportar sus ideas previas, sus creencias y disposición a participar en la validación de esta propuesta. Los contenidos a explorar estarán relacionados con su opinión sobre la práctica profesional, perfil del egresado, didáctica de educación infantil, impacto de la práctica profesional en los centros de aplicación, entre otros tópicos que sustentan la propuesta, por cuanto antes de su presentación es válido conocer la postura cognoscitiva, afectiva y procedimental de los participantes, sin que esto último implique amenazas para el proceso de validación.

Esta fase de diagnóstico, representa respeto por las diferencias de los participantes por cuanto cada uno de ellos tiene niveles distintos de experiencias, por lo que resulta interesante explorar estas características y además su disposición a participar en el proceso de validación.

\subsection{Fase II Desarrollo}

\begin{tabular}{|l|l|l|l|}
\hline Fase II Desarrollo & Propósitos & Responsables & Lapso de tiempo \\
\hline Actividades & $\begin{array}{l}\text { Dar a conocer el } \\
\text { programa de práctica } \\
\text { profesional y sus } \\
\text { manuales. }\end{array}$ & $\begin{array}{l}\text { CCU, JD, } \\
\text { PU,PE,RCA,A. }\end{array}$ & $\begin{array}{l}\text { Cuatro semanas; un } \\
\text { día cada sesión }\end{array}$ \\
\hline $\begin{array}{l}\text { Exposición de los } \\
\text { programas de las fases }\end{array}$ & $\begin{array}{l}\text { Presentar cada uno de } \\
\text { los programas de fase, } \\
\text { y su posible } \\
\text { administración. }\end{array}$ & $\begin{array}{l}\text { CCU, JD, } \\
\text { PUE,RCA,A. }\end{array}$ & \\
\hline $\begin{array}{l}\text { Organización } \\
\text { definitiva de los } \\
\text { programas }\end{array}$ & $\begin{array}{l}\text { Valorar los aportes de } \\
\text { los participantes y } \\
\text { reorganizar los } \\
\text { programas. }\end{array}$ & $\begin{array}{l}\text { CCU, JD, } \\
\text { PU,PE,RCA,A. }\end{array}$ & \\
\hline
\end{tabular}

Leyenda: Comisión de currículo UPEL: CCU, Jefes de departamento: JD, Profesores UPEL: PU, Profesores

397

La Práctica Profesional como área para potenciar las competencias pedagógicas necesarias para la enseñanza en Educación Infantil 
egresados: PE. Representantes de los centros de aplicación: RCA, Alumnos en proceso de formación: A

Cuadro $n^{\circ} 84$. Fase II Desarrollo P-5

Esta segunda fase contempla las actividades orientadas hacia la presentación formal del P-5, se incluye en esta fase los programas de cada fase y su posible plan de administración.

\subsection{Esquema General del P-5}

El programa de práctica profesional estará estructurado en manuales y programas para cada una de las fases que contempla la UPEL en sus documentos oficiales, es decir Fase de observación, Fase de ensayo didáctico, Fase de ejecución de proyectos, y Fase de integración docencia administración. En nuestra propuesta estas mismas fases serán denominadas Fase I, Fase II. Fase III y Fase IV, respectivamente; así mismo se propone su administración a partir del segundo semestre de la carrera, para garantizar que durante el primer semestre los alumnos puedan participar en un curso virtual, relacionado con la preparación y sensibilización, para su acercamiento a la realidad educativa del nivel de educación infantil.

Tal como puede observarse, esta propuesta tiene la visión de aproximarse al logro de competencias pedagógicas del estudiante, la organización administrativa para su implementación y el aprovechamiento de la tecnología en función de hacer más flexible, factible y operativa su aplicación.

\section{Seminario aproximación al contexto educativo (SACE)}

Esta primera parte de preparación para la práctica profesional, contempla los siguientes aspectos y contenidos.

Aspectos generales: el SACE, se diseñara de manera virtual, con el propósito de garantizar la participación asíncrona de todos los alumnos y profesores tutores, para minimizar las limitaciones de tiempo y dinero; por tanto se tiene como objetivo general ofrecer información, formación y entrenamiento a todos los alumnos, ajustado a sus ritmos de aprendizaje, en el momento y lugar más conveniente.

398

La Práctica Profesional como área para potenciar las competencias pedagógicas necesarias para la enseñanza en Educación Infantil 
Este programa se ofrecerá en la plataforma MOODLE que la UPEL tiene a la disposición de los profesores y será administrado por los profesores tutores del programa de práctica profesional y los de la especialidad de preescolar.

Las acciones del estudiante incluirán: tomar las riendas de su proceso de formación, ajustado a su ritmo de aprendizaje, ya que el SACE permitirá adaptar el aprendizaje al tiempo de cada quien, no necesita ir a clases, la frecuencia la marca el propio alumno así que pueden practicar sus habilidades de manera individual o grupal, alrededor de los temas asignados. Del mismo modo los participantes estarán siempre interconectados.

Por su parte, los profesores tutores deben basarse en potenciar las capacidades del estudiante aspirante a cursar la práctica profesional, en situaciones de desempeño o de actuación específica, en el aprendizaje cooperativo y en el trabajo interdisciplinario; esta modalidad le permitirá disponer de su tiempo, guiar los procesos de enseñanza desde la comodidad de su hogar, o en sus ratos libres en la oficina.

Los contenidos a incluir serán los siguientes: aplicación de procesos meta cognitivos, didáctica del nivel de educación inicial, rutina diaria, ambientes y contextos de aprendizaje, programas formales y no formales en educación infantil, leyes y reglamentos de educación, rol del profesional de educación infantil.

La metodología de trabajo será a partir de módulos secuenciados, considerando un primer modulo presencial y el resto con actividades en línea y el uso de video conferencias y otras herramientas de la web.

La estructura se organizará a partir de una presentación, propósito, objetivos de aprendizaje, contenido temático, metodología, desglose de actividades con sus respectivos materiales de apoyo y medios a utilizar, evaluación y acreditación, recursos, calendario de actividades, mensajería personal, foros de discusión, chat o coloquio virtual, sistema de comunicación permanente con los tutores, portafolio de evidencias, sistema de ayuda en línea con preguntas frecuentes.

399

La Práctica Profesional como área para potenciar las competencias pedagógicas necesarias para la enseñanza en Educación Infantil 
La duración del SACE, será de ocho semanas, con un periodo extra de una semana para actividades remédiales, en aquellos casos que así lo ameriten. Al finalizar el programa los alumnos obtendrán un certificado de aprobación que les será útil para construir progresivamente su perfil curricular.

La elaboración de este programa será responsabilidad del consejo técnico del área de práctica profesional, los coordinadores de las fases y los profesores de práctica profesional y de la especialidad de educación preescolar.

\subsection{Manuales Operativos para el P-5}

Los resultados de la investigación realizada, arrojaron evidencias de vacios en cuanto al conocimiento por parte de profesores, sobre algunos aspectos académicos estudiantiles que posee la UPEL, así mismo, se reflejaron serias debilidades en cuanto a las tutorías o asesorías individuales, que los alumnos requieren para potenciar sus propios procesos de aprendizaje.

Al respecto, la idea de diseñar manuales operativos para la administración de la práctica profesional, quizás pueda contribuir a mejorar algunas debilidades encontradas y además a garantizar que todos los interesados puedan encontrar respuestas a sus inquietudes académicas, pero también la posibilidad de propiciar el aprendizaje cooperativo, con el aprovechamiento de la tecnología. No obstante, estos manuales también estarán disponibles en presentación física ya que, no se debe perder de vista que la Universidad es fundamentalmente presencial, con aspiraciones de asumir el reto de incorporarse a los cambios e innovaciones que los tiempos actuales le demandan.

En este orden de ideas, se proyecta la elaboración de varios manuales, entre los que destacan: a) manual del centro de aplicación; b) manual del profesor y c) manual del estudiante, con el fin de proporcionar información relevante sobre la administración de cada una de las fases que componen la práctica profesional de educación preescolar en la UPEL.

El diseño general de cada manual responderá a los siguientes aspectos:

- Introducción

400

La Práctica Profesional como área para potenciar las competencias pedagógicas necesarias para la enseñanza en Educación Infantil 
- Principios que fundamentan la práctica profesional UPEL.

- Elementos que conforman cada una de las fases.

- Periodos de duración de cada fase.

- Normativa general de la práctica profesional

- Normativa específica a cada una de las fases.

- Descripción da cada fase.

- Plan de trabajo a cumplir en cada fase.

- Procesos de evaluación en cada fase

- Técnicas e instrumentos de evaluación para cada fase.

- Anexos.

Estos manuales se publicaran en la página web de la Universidad Pedagógica Experimental Libertador, pero también se ofrecerán en material impreso, para su consulta. Tal como puede visualizarse, sus contenidos ofrecerán información básica y necesaria que facilitará la participación del alumno, profesor y centro de aplicación seleccionado para realizar la práctica. Esta información básica estará representada en los principios que fundamentan su aplicación, la normativa general y específica que reglamenta cada participación de los responsables de la práctica, el plan de trabajo a cumplir, así como los procesos evaluativos necesarios. Otro aspecto valioso, es el referido a los anexos; allí el profesor y el alumno, podrán encontrar los formatos para presentar cada recaudo $y / o$ informe de cada fase.

Es importante destacar que, los manuales no sustituyen la presencia activa, consciente y responsable del profesor tutor de práctica profesional.

La elaboración de estos manuales será responsabilidad del consejo técnico del área de práctica profesional, los coordinadores de las fases y los profesores de práctica profesional y de la especialidad de educación preescolar, con la asesoría jurídica del abogado de la universidad.

401

La Práctica Profesional como área para potenciar las competencias pedagógicas necesarias para la enseñanza en Educación Infantil 


\subsection{Programas de Cada Fase}

Tal como se ha venido señalando, la investigación tiene como propósito el diseño de una Propuesta de programas de práctica profesional que potencie las competencias pedagógicas necesarias para la enseñanza en educación infantil (P-5). En tal sentido, procederemos a explicar los programas para cada una de las practicas, entendiendo que solo se presentaran (en este momento) los aspectos que podrían incluirse en el programa sinóptico, y que en consonancia con los principios teóricos, epistemológicos, teleológicos y axiológicos de esta investigación, luego de su respectiva validación, se someterán a la construcción conjunta de los programas didácticos.

\section{Programa sinóptico PRÁCTICA I}

\begin{tabular}{|c|c|c|}
\hline Aspectos & Descripción & Observaciones \\
\hline Objetivos & $\begin{array}{l}\text { 1.-Sensibilizar al estudiante con la profesión docente para la } \\
\text { afirmación de su vocación y compromiso ético, a partir de la } \\
\text { aprehensión de la realidad socio educativo en el nivel y } \\
\text { modalidad en la que se desempeñará. 2.-Reflexión critica sobre } \\
\text { el diseño curricular de Educación Inicial. 3.-Intercambiar } \\
\text { información teórico-práctica sobre los elementos a considerar } \\
\text { en el proceso de observación participante en el contexto del } \\
\text { nivel de Educación inicial. 4.-Observar y registrar la realidad } \\
\text { educativa en el centro de aplicación asignado. 5.-Observar, } \\
\text { registrar e intervenir pedagógicamente en la mediación de } \\
\text { aprendizaje de un niño. 6.-Generar procesos de valoración de } \\
\text { la función docente a partir de la contrastación entre el deber ser } \\
\text { y la realidad observada. }\end{array}$ & $\begin{array}{l}\text { Se busca superar el énfasis } \\
\text { en el desarrollo de actitudes } \\
\text { conceptuales y } \\
\text { actitudinales, } \\
\text { proporcionando } \\
\text { lineamientos para fortalecer } \\
\text { aspectos procedimentales, } \\
\text { teniendo presente el nivel } \\
\text { de desarrollo real de los } \\
\text { alumnos }\end{array}$ \\
\hline Contenidos & $\begin{array}{l}\text { 1.-Observación sistemática y pedagógica. Concepción de } \\
\text { docente. Perfil Profesional Docente. Profesión Docente. } \\
\text { Contrastación del deber ser del profesional de la docencia con } \\
\text { los desempeños reales de un docente en interacción con el } \\
\text { contexto socio-educativo. 2.- Principales postulados del Diseño } \\
\text { Curricular de Educación Inicial. 3.-Observación sistemática y } \\
\text { pedagógica, tipos de observación, tipos de registro, interacción } \\
\text { con los niños en edad preescolar, rutina diaria, recursos, } \\
\text { instrumentos de recolección de datos 4.-Diagnóstico educativo. } \\
\text { Interacción: Escuela-Comunidad, Docente-Alumno, Docente- } \\
\text { Institución, Docente-Comunidad. Descripción interpretativa de } \\
\text { la realidad socio-educativa observada. 5.-Diagnostico } \\
\text { pedagógico, diseño de plan de intervención didáctica y } \\
\text { descripción fundamentada con evidencias de la experiencia. 6.- } \\
\text { Interpretación y valoración de las potencialidades del } \\
\text { estudiante como futuro profesional de la docencia. Juicio }\end{array}$ & $\begin{array}{l}\text { Se procura que los } \\
\text { contenidos guarde relación } \\
\text { con los objetivos } \\
\text { planteados }\end{array}$ \\
\hline
\end{tabular}




\begin{tabular}{|c|c|c|}
\hline & $\begin{array}{l}\text { reflexivo en la decisión voluntaria de actuación, frente a las } \\
\text { condiciones reales del contexto socio-educativo. }\end{array}$ & \\
\hline Estrategias & $\begin{array}{l}\text { Lectura, discusión, producción escrita. Análisis de casos. } \\
\text { Intervenciones orales y escritas, presentación y análisis de } \\
\text { instrumentos de recolección de datos. Observar y registrar el } \\
\text { contexto educativo utilizando los instrumentos discutidos en } \\
\text { clases, participar e interactuar en el aula preescolar. } \\
\text { Descripción y comparación de la realidad observada y lo } \\
\text { previsto en los documentos oficiales. Autoevaluación. } \\
\text { Dinámicas de grupo: talleres, foros, seminarios, videos. } \\
\text { Trabajo de campo, círculos de estudio, jornadas de reflexión, } \\
\text { plenarias, asesorías individuales y grupales }\end{array}$ & $\begin{array}{l}\text { Se proponen diversas } \\
\text { estrategias, donde se ponga } \\
\text { en acción los procesos } \\
\text { cognitivos del alumno, pero } \\
\text { también sus emociones y } \\
\text { acciones bajo el } \\
\text { acompañamiento del } \\
\text { profesor tutor }\end{array}$ \\
\hline $\begin{array}{l}\text { Propuestas } \\
\text { de } \\
\text { aplicación }\end{array}$ & $\begin{array}{l}\text { Cuatro sesiones en aulas UPEL, las cuales serán } \\
\text { complementadas con participaciones en aula virtual o blog } \\
\text { virtual, dos semanas } \\
\text { Visitas guiadas a contextos escolares convencionales y no } \\
\text { convencionales. Cuatro sesiones, dos semanas } \\
\text { Selección y ubicación en centro de aplicación definitivo, } \\
\text { duración } 11 \text { semanas } \\
\text { Cierre de experiencias en aulas UPEL, dos sesiones, una } \\
\text { semana. }\end{array}$ & $\begin{array}{l}16 \text { semanas duración del } \\
\text { semestre, a razón de dos } \\
\text { días a la semana. La } \\
\text { distribución propuesta } \\
\text { implica aumentar las } \\
\text { posibilidades de } \\
\text { conocimiento de centros de } \\
\text { aplicación y la vinculación } \\
\text { activa y efectiva con la } \\
\text { realidad social, educativa y } \\
\text { cultural del centro de } \\
\text { aplicación seleccionado }\end{array}$ \\
\hline $\begin{array}{l}\mathrm{N}^{\circ} \text { de } \\
\text { horas } \\
\text { asesoría }\end{array}$ & $\begin{array}{l}40 \text { horas asesoría grupal } \\
40 \text { horas asesoría. Individual }=80\end{array}$ & $\begin{array}{l}\text { Este número de horas está } \\
\text { sujeto al valor de unidad } \\
\text { crédito de la fase, en cuyo } \\
\text { caso seria } 10 \mathrm{UC} \text {. }\end{array}$ \\
\hline
\end{tabular}

Cuadro $\mathrm{n}^{\circ} 85$. Programa sinóptico PRACTICA I

\section{PRACTICA II}

\begin{tabular}{|l|l|l|}
\hline Aspectos & Descripción & Observaciones \\
\hline Objetivos & $\begin{array}{l}\text { 1.-Analizar los contenidos fundamentales relacionados } \\
\text { con la educación Inicial: planificación, evaluación, } \\
\text { estrategias y recursos para el aprendizaje. } \\
\text { 2.-Demostración y adquisición de las habilidades, } \\
\text { destrezas, actitudes y valores al diagnosticar, planificar, } \\
\text { intervenir y evaluar en una aula de clases del nivel de } \\
\text { educación inicial aplicando la didáctica de procesos de } \\
\text { los ejes transversales contemplados en los programas } \\
\text { oficiales del Ministerio de Educación. Reflexión de } \\
\text { acciones }\end{array}$ & $\begin{array}{l}\text { Se incluyen objetivos } \\
\text { espéicamente relacionados con la } \\
\text { didáctica del nivel inicial; } \\
\text { planificación, evaluación, } \\
\text { estrategias y recursos para el } \\
\text { aprendizaje, los cuales se } \\
\text { corresponden con las experiencias } \\
\text { previas y conocimientos alcanzados } \\
\text { en las asignaturas de la especialidad }\end{array}$ \\
\hline Contenidos & $\begin{array}{l}\text { 1.-Manejo y revisión de los programas oficiales del } \\
\text { Ministerio de Educación. 2.-Selección y aplicación en }\end{array}$ & $\begin{array}{l}\text { Se propone la justificación teórica } \\
\text { de los planes elaborados por las }\end{array}$ \\
\hline
\end{tabular}

403

La Práctica Profesional como área para potenciar las competencias pedagógicas necesarias para la enseñanza en Educación Infantil 


\begin{tabular}{|c|c|c|}
\hline & $\begin{array}{l}\text { sus planes de nuevas tendencias para el aprendizaje a } \\
\text { este nivel. 3.-Aplicación de instrumentos para elaborar } \\
\text { el diagnostico de los niños. 4.-Elaboración de } \\
\text { planificación (considerando los programas oficiales del } \\
\text { Ministerio de Educación). 5.-Elaboración de recursos } \\
\text { pedagógicos. 6.-Ejecución de planes pedagógicos. 7.- } \\
\text { Evaluación de su desempeño profesional }\end{array}$ & $\begin{array}{l}\text { alumnas; la elaboración de } \\
\text { diagnósticos donde se refleje los } \\
\text { procesos de aprendizaje de los } \\
\text { niños en términos de mediación de } \\
\text { aprendizaje. }\end{array}$ \\
\hline Estrategias & $\begin{array}{l}\text { Diagnóstico de habilidades, destrezas, competencias a } \\
\text { través de actividades prácticas en el aula taller. } \\
\text { Talleres } \\
\text { Asesorías individuales y grupales. } \\
\text { Ejecuciones prácticas } \\
\text { Presentación de informe de experiencias. } \\
\text { Seminario integrador para socializar las experiencias }\end{array}$ & $\begin{array}{l}\text { La propuesta está dirigida a } \\
\text { proporcionar el mayor número de } \\
\text { oportunidades de valoración de las } \\
\text { propias competencias del alumno, } \\
\text { bajo el acompañamiento del } \\
\text { profesor tutor }\end{array}$ \\
\hline $\begin{array}{l}\text { Propuesta } \\
\text { de } \\
\text { aplicación }\end{array}$ & $\begin{array}{l}\text { Aulas UPEL, cuatro sesiones, dos semanas } \\
\text { Centros de aplicación: } 12 \text { semanas } \\
\text { Cierre de experiencias: cuatro sesiones, dos semanas }\end{array}$ & $\begin{array}{l}\text { Se propone aumentar el número de } \\
\text { horas, lo cual permitirá al alumno, } \\
\text { la elaboración de un diagnostico de } \\
\text { los proceso de aprendizaje de cada } \\
\text { niño, la elaboración de planes y sus } \\
\text { respectivos instrumentos de } \\
\text { evaluación, la elaboración de } \\
\text { recursos para el aprendizaje y la } \\
\text { puesta en práctica de lo planificado; } \\
\text { también se considera el periodo de } \\
\text { cierre, para completar las } \\
\text { experiencias con procesos de auto } \\
\text { evaluación. }\end{array}$ \\
\hline $\begin{array}{l}\mathrm{N}^{\circ} \text { de horas } \\
\text { asesoría }\end{array}$ & $\begin{array}{l}40 \text { horas asesoría grupal } \\
40 \text { horas asesoría. Individual }=80\end{array}$ & $\begin{array}{l}\text { Este número de horas está sujeto al } \\
\text { valor de unidad crédito de la fase, } \\
\text { en cuyo caso seria } 10 \mathrm{UC} \text {. }\end{array}$ \\
\hline
\end{tabular}

Cuadro $n^{\circ}$ 86. Programa sinóptico PRACTICA II

PRACTICA III

\begin{tabular}{|l|l|l|}
\hline Aspectos & Programa proyecto de investigación & Observaciones \\
\hline Objetivos & $\begin{array}{l}\text { Ejecutar investigaciones de campo } \\
\text { preferiblemente relacionadas con la realidad social, } \\
\text { política, pedagógica y cultural de la educación } \\
\text { infantil. } \\
\text { Buscar información en centros de documentación, } \\
\text { internet, bibliotecas. }\end{array}$ & $\begin{array}{l}\text { En esta propuesta se observa el } \\
\text { en práctica de competencias } \\
\text { investigativas relacionadas con } \\
\text { la especialidad de los } \\
\text { estudiantes. }\end{array}$ \\
\hline
\end{tabular}

404

La Práctica Profesional como área para potenciar las competencias pedagógicas necesarias para la enseñanza en Educación Infantil 


\begin{tabular}{|l|l|l|}
\hline & $\begin{array}{l}\text { instrumentos de recolección de datos } \\
\text { Trabajo de campo: aplicación de instrumentos de } \\
\text { recolección de datos } \\
\text { Elaborar matrices de análisis. } \\
\text { Análisis y presentación de resultados }\end{array}$ & \\
\hline Contenidos & $\begin{array}{l}\text { Revisión y familiarización con la situación objeto } \\
\text { en estudio, Técnicas e instrumentos de recolección } \\
\text { de datos, estrategias para trabajo de campo, análisis } \\
\text { de resultados, elaboración de informe, presentación } \\
\text { oral y escrita de resultados. }\end{array}$ & $\begin{array}{l}\text { De acuerdo al propósito de la } \\
\text { fase, los contenidos son } \\
\text { eminentemente prácticos y están } \\
\text { relacionados con la formación } \\
\text { investigativa }\end{array}$ \\
\hline Estrategias & $\begin{array}{l}\text { Análisis de documentos, ensayos, trabajo de campo, } \\
\text { observación participante, aplicación de entrevistas, } \\
\text { elaboración de matrices de análisis, elaboración de } \\
\text { informe, presentación pública de resultados }\end{array}$ & $\begin{array}{l}\text { Se observa mayor variedad de } \\
\text { estrategias propias de una } \\
\text { oportunidad de práctica para los } \\
\text { estudiantes. }\end{array}$ \\
\hline $\begin{array}{l}\text { Tipo } \\
\text { Centro de } \\
\text { aplicación }\end{array}$ & $\begin{array}{l}\text { Aulas UPEL- variedad de centros de educación } \\
\text { preescolar, de acuerdo al contexto en el cual esta } \\
\text { residenciado el estudiante. }\end{array}$ & $\begin{array}{l}\text { Los estudiantes podrán } \\
\text { acercarse al contexto educativo } \\
\text { para el cual se están formando, } \\
\text { con una postura investigativa }\end{array}$ \\
\hline $\begin{array}{l}\mathrm{N}^{\circ} \text { de horas } \\
\text { asesoría }\end{array}$ & $\begin{array}{l}40 \text { horas asesoría grupal } \\
40 \text { horas asesoría. Individual = 80 }\end{array}$ & \multicolumn{2}{|l}{} \\
\hline
\end{tabular}

Cuadro ${ }^{\circ} 87$. Programa sinóptico PRACTICA III

\section{PRACTICA IV}

\begin{tabular}{|l|l|l|}
\hline Aspectos & Programa oficial & Observaciones \\
\hline Objetivos & $\begin{array}{l}\text { 1.-Evaluar y reorganizar un aula preescolar } \\
\text { aplicando principios de una educación centrada en } \\
\text { el niño. } \\
\text { 2.-Desarrollar y ejecutar planificaciones, de } \\
\text { acuerdo a las necesidades detectadas en el grupo de } \\
\text { niños, aplicando estrategias interactivas, } \\
\text { innovadoras y transformadoras en las áreas } \\
\text { pedagógicas y administrativas consideradas en el } \\
\text { contexto de la escuela, familia y comunidad. } \\
\text { 3.-Diagnosticar necesidades dentro del centro de } \\
\text { aplicación, para elaborar y desarrollar un proyecto } \\
\text { pedagógico que contribuya a satisfacer la necesidad } \\
\text { seleccionada. } \\
\text { 4.-Reflexionar acerca de las actividades realizadas } \\
\text { propone que en esta fase las alumnas } \\
\text { enmarquen sus acciones pedagógicas, } \\
\text { en armonía con las características } \\
\text { sociales, culturales y económicas del } \\
\text { centro de aplicación y las familias que } \\
\text { lo conforman }\end{array}$ & \\
\hline Contenidos & $\begin{array}{l}\text { 1.-Realizar observaciones y registros diagnósticos } \\
\text { en los diferentes ambientes de la escuela. 2.- }\end{array}$ & \\
\hline
\end{tabular}

La Práctica Profesional como área para potenciar las competencias pedagógicas necesarias para la enseñanza en Educación Infantil 


\begin{tabular}{|c|c|c|}
\hline & $\begin{array}{l}\text { Espacio físico del aula, recursos y materiales, } \\
\text { criterios para la selección de recursos y } \\
\text { materiales.3.- Diseño y aplicación de planes. } \\
\text { Aplicar la didáctica de procesos de los ejes } \\
\text { transversales. } \\
\text { 4.-Aplicación de técnicas y procedimientos } \\
\text { administrativos en las diferentes dependencias del } \\
\text { centro de aplicación. 5.-Desarrollo de planes de } \\
\text { acción donde se involucren la familia y la } \\
\text { comunidad al proceso educativo }\end{array}$ & \\
\hline Estrategias & $\begin{array}{l}\text { Taller de inducción. Visita guiada a las } \\
\text { dependencias administrativas y el contexto } \\
\text { comunitario de los centros de aplicación. Elaborar } \\
\text { el diagnóstico pedagógico y administrativo. } \\
\text { Elaborar proyectos y planes. Elaborar y manejar } \\
\text { recursos.Diseño y aplicación de estrategias } \\
\text { innovadoras donde se involucren la familia y la } \\
\text { comunidad. Supervisiones en el aula. Ejecución de } \\
\text { planes. Entrega de informes. Seminario. Evaluación } \\
\text { de la fase }\end{array}$ & \\
\hline $\begin{array}{ll}\text { Tipo de } \\
\text { Centro de } \\
\text { aplicación }\end{array}$ & $\begin{array}{l}\text { Aulas UPEL, cuatro sesiones, dos semanas } \\
\text { Centros de aplicación: } 12 \text { semanas } \\
\text { Cierre de experiencias: cuatro sesiones, dos } \\
\text { semanas }\end{array}$ & $\begin{array}{l}\text { Se propone aumentar el número de } \\
\text { horas, lo cual permitirá al alumno, la } \\
\text { elaboración de diagnostico } \\
\text { pedagógicos y administrativos, la } \\
\text { elaboración de planes y sus respectivos } \\
\text { instrumentos de evaluación, evaluación } \\
\text { y rediseño del espacio físico del aula, } \\
\text { sus recursos para el aprendizaje y la } \\
\text { puesta en práctica de lo planificado; } \\
\text { también se considera el periodo de } \\
\text { cierre, para completar las experiencias } \\
\text { con procesos de auto evaluación. }\end{array}$ \\
\hline $\begin{array}{l}\mathrm{N}^{\circ} \text { de horas } \\
\text { asesoría }\end{array}$ & $\begin{array}{l}40 \text { horas asesoría grupal } \\
40 \text { horas asesoría. Individual }=80\end{array}$ & $\begin{array}{l}\text { Este número de horas está sujeto al } \\
\text { valor de unidad crédito de la fase, en } \\
\text { cuyo caso seria } 10 \text { UC. }\end{array}$ \\
\hline
\end{tabular}

Cuadro ${ }^{\circ}{ }^{88}$. Programa sinóptico PRACTICA IV 


\subsection{Fase III Evaluación}

\begin{tabular}{|l|l|l|l|}
\hline Fase III Evaluación & Propósitos & Responsables & Lapso de tiempo \\
\hline Actividades & $\begin{array}{l}\text { Organizar los } \\
\text { informes necesarios } \\
\text { para su presentación } \\
\text { propuesta } \\
\text { ante la comisión de } \\
\text { currículo y elevar la } \\
\text { propuesta ante el } \\
\text { vicerrectorado de } \\
\text { docencia }\end{array}$ & CCU, JD, AVD & Tiempo necesario. \\
\hline $\begin{array}{l}\text { Activación de } \\
\text { procesos }\end{array}$ & $\begin{array}{l}\text { Dar seguimiento a la } \\
\text { propuesta de mejora, } \\
\text { mantener informado a } \\
\text { los interesados. } \\
\text { Continuar con los } \\
\text { procesos de } \\
\text { formación } \\
\text { permanente. }\end{array}$ & PU,PE,RCA,A. & \\
\hline
\end{tabular}

Leyenda: Autoridades vicerrectorado docencia: AVD, Comisión de currículo UPEL, C C U, Jefes de departamento: JD, Profesores UPEL: PU, Profesores egresados: PE. Representantes de los centros de aplicación: RCA, Alumnos en proceso de formación: A

Cuadro $n^{\circ} 89$. Fase III evaluación del P-5

La evaluación del diseño permitirá que los elementos del P-5 adquieran un carácter continuo. Esto último, permitirá revelar las debilidades que se presentarían de no existir una evaluación continua. La evaluación se conformará en dos partes:

(a) Organizar los informes necesarios para su presentación ante la comisión de currículo y elevar la propuesta ante el vicerrectorado de docencia, y (b) Dar seguimiento a la propuesta de mejora, manteniendo informado a los interesados. En cada uno de estos momentos la evaluación debe evidenciar los resultados que se han logrado o tal vez los que han dejado de producirse.

La Práctica Profesional como área para potenciar las competencias pedagógicas necesarias para la enseñanza en Educación Infantil 


\subsubsection{Consideraciones Finales}

Iniciar procesos de reflexión y análisis que faciliten la búsqueda de espacios para mejorar la práctica profesional en educación preescolar en la UPEL Maracay, podría constituir, junto con la puesta en marcha de esta propuesta, una de las tantas vías conducentes a favorecer la formación inicial de un profesional para la educación infantil. La propuesta P-5, refleja solo una parte de ellas.

En este estudio, se demostró que si es posible generar espacios para que alumnos y profesores se expresen y a partir de allí, construir posibilidades que permitan edificar nuevos rumbos, los cuales tienen un papel relevante en el éxito de la administración de las prácticas pedagógicas. En este sentido, el desarrollo de competencias pedagógicas, debe considerarse desde un amplio marco de referencia o guía en la formación inicial y continua del futuro profesor de educación infantil. Por tanto, las competencias pedagógicas que se requieren para la práctica profesional, deben ser consideradas en sus múltiples dimensiones y direcciones, tanto del profesor formador, como del estudiante en formación. Es decir, no puede dejarse de lado, a ninguno de los actores, como tampoco el contexto, el conocimiento científico, práctico y didáctico de la educación infantil, los procesos de enseñanza y aprendizaje, las experiencias previas, los contenidos en el cual se realice esta acción.

La propuesta P-5, posee un enfoque sistémico, investigativo, flexible, integrador y auto controlado de las condiciones básicas para potenciar las competencias pedagógicas del profesional de educación infantil; en esta propuesta la práctica profesional, se perfila como eje integrador de habilidades, conocimientos, destrezas, actitudes y valores, que se expresan en variados contextos educativos, donde se asume el aprendizaje, la enseñanza y la investigación como un ciclo ecológico que posibilite la construcción del saber pedagógico en correspondencia con la realidad social, cultural y económica del país.

El P-5, está apoyado en procesos de investigación permanente, lo cual le confiere un carácter dinámico y científico; esto se concreta en el apoyo de líneas, núcleos y centros de investigación,

408

La Práctica Profesional como área para potenciar las competencias pedagógicas necesarias para la enseñanza en Educación Infantil 
que garanticen actualización, mejoras y lo más importante vinculación social y educativa propios del nivel de educación infantil, para que profesores y alumnos asuman sus competencias de manera autónoma, participativa, flexible, que se permita investigar, planificar, asumir acciones reflexivas y evaluarse a sí mismo, a sus compañeros e institución.

A continuación, se presenta el grafico que proyecta las ideas que sustentan la propuesta F-5

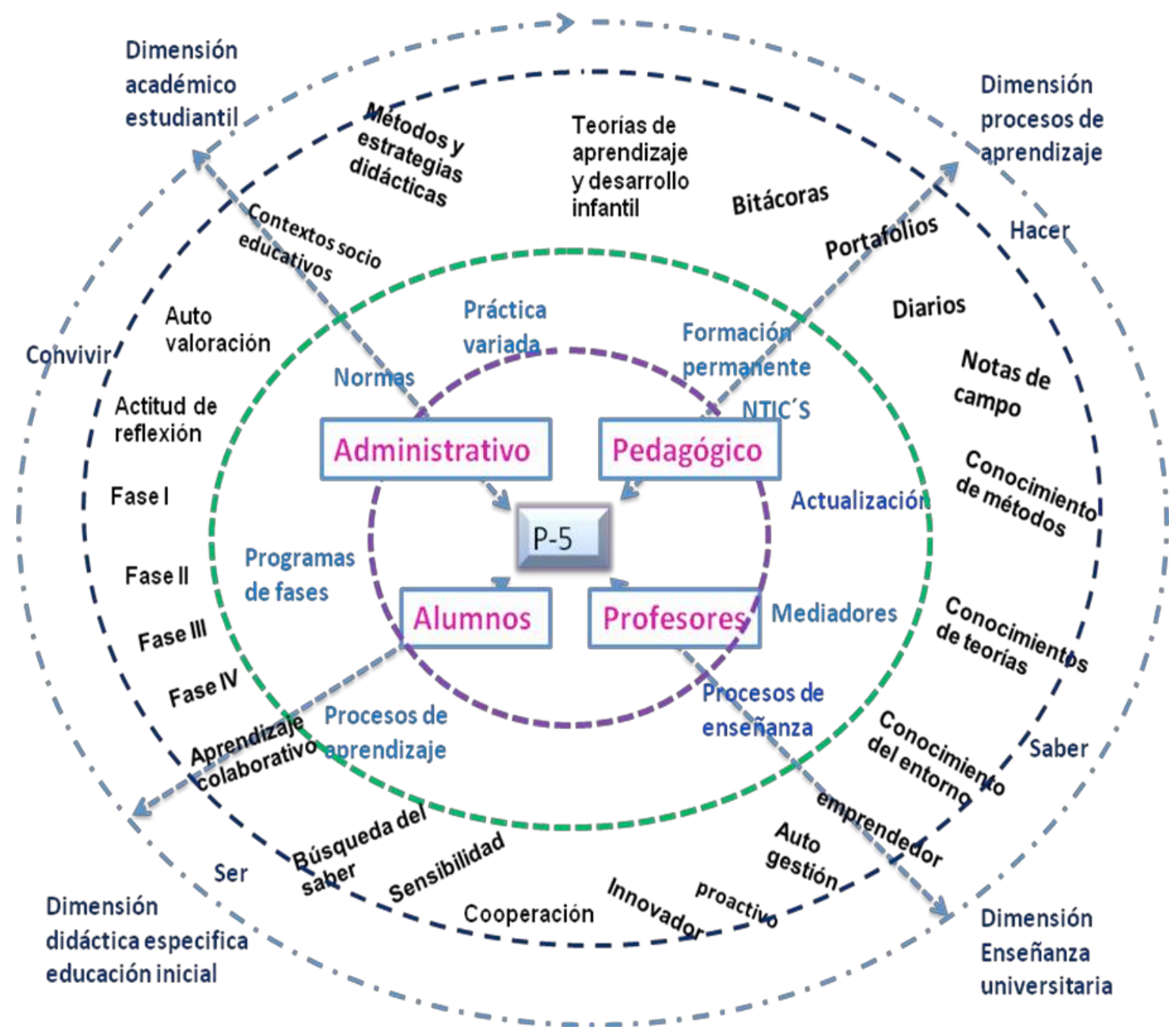

Grafico $N^{\circ}$ 68. Diseño general P-5 


\subsection{Nuevas líneas de Investigación sugeridas por los hallazgos.}

Los hallazgos de este estudio viabilizan el surgimiento de interrogantes que requieren ser resueltas, así como de temas a investigar y constructos teóricos pendientes:

Didáctica en Educación Inicial: Concepciones teórico metodológicas para su abordaje.

Concepciones del egresado UPEL, sobre su experiencia de práctica Profesional.

Didáctica del profesor universitario en la formación de profesionales para la educación Infantil.

Procesos de formación permanente en el contexto universitario: ¿Utopía o reto?

El papel de los gerentes en la optimización de los procesos formativos de profesionales para la educación infantil.

Impacto pedagógico de los practicantes UPEL, en las escuelas infantiles.

Articulación de las prácticas profesionales en el marco de proyectos comunitarios.

$>$ ¿Quién forma al profesor universitario?

> Manual de práctica profesional UPEL.

Vinculación de la UPEL, con el entorno laboral.

Hacía prácticas profesionales virtuales o aulas virtuales para práctica profesional.

Impacto de las nuevas tecnologías de información y comunicación (NTIC) en la enseñanza de educación infantil 


\section{Referencias Bibliográficas}

Alfaro, M. (2006). Planificación del aprendizaje y la enseñanza. Caracas: FEDUPEL, serie Azul.

Alles, M. (2001). Las competencias del futuro. Recuperado el 30 de Septiembre de 2011, de http://latinstocks.com y en http://marthaalles.com.

Álvarez, V. (2009) Perfiles y competencias docentes requeridos en el contexto actual de la educación universitaria. REOP. 20 (3).Recuperado el 30 noviembre de 2011 en http://www.uned.es/reop/pdfs/2009/20-3\%20-\%20Victor\%20Alvarez\%20Rojo

Ander Egg, E. (1992). Técnicas de investigación social. Buenos Aires: Hermanitas

Arboleda, J. (2011). Comprensiones y competencias pedagógicas: conceptos y estrategias. Colombia: REDIPE

Arregui, X., Bilbatua, M. y Sagasta, M. (2004). Innovación curricular en la facultad de humanidades y ciencias de la educación de Mondragón Unibertsitatea: Diseño e implementación del perfil profesional del maestro de educación infantil. Revista Interuniversitaria de Formación del profesorado, 18 (1): 109-129

Ary, D. Jacobs, L. y Razavieh, A. (1990). Introducción a la investigación pedagógica (2da ed.) México: Mc Graw- Hill.

Asensio, E., Cerezo, Y., Valbuena, C. y Rodríguez Y. (2009). El Modelo Formativo Asociado a Competencias en el Espacio Europeo de Enseñanza Superior (Eees). Cuadernos de educación y desarrollo, 1 (3). Recuperado el 16 mayo de 2011 en http://www.eumed.net/rev/ced/03/acvr.htm 
Beneitone, P., Esquetini C., González, J., Marty, M., Siufi G., y Wagenaar, R. (2007). Reflexiones y Perspectivas de la Educación Superior en América Latina. Informe FinalProyecto Tuning- América Latina 2004-2007. Universidad de Deusto, Universidad Groningen

Bravo, E. (1979). Reseña histórica de la educación preescolar en Venezuela. Caracas: autor.

Buendía, L., Colás, M. y Hernández, F. (1995). Métodos de Investigación en Psicopedagogía. Madrid: MacGraw-Hill.

Brunner, J. (1972). Hacia una teoría de la instrucción. Barcelona: Ed. Uteha.

Caballero, K. (2005). La formación inicial del profesorado de educación infantil, y primaria, dentro del marco europeo. Recuperado el 19 de marzo de 2009 en formacion2020.es/porqualCifo/do/get/binary/2005/11/application/pdf/caballerokatia.pdf .

Calsamiglia H. y Tusón, A. (2002). Las cosas del decir. Manual de análisis del discurso. España: Ariel.

Canquiz L. e Inciarte A. (2007). Competencias Genéricas como parte de los perfiles académicos profesionales. Maracaibo: LUZ

Carr, W., y Kemmis, S. (1988). Teoría crítica de la enseñanza. La investigación del profesorado. Barcelona: M. Roca

Carretero, M. (2009). Constructivismo y Educación. Buenos Aires: Paidós.

Castro, E. (2007). Escuela de Educación Parvularia. Facultad de Ciencias de la Educación. Universidad Central de Chile. Revista Perspectiva, 2 (21), 6-10

412

La Práctica Profesional como área para potenciar las competencias pedagógicas necesarias para la enseñanza en Educación Infantil 
Cejas, M. (2005). La educación basada en competencias. Un enfoque integrador entre las empresas y las instituciones educativas. Recuperado en febrero 12 de 2012 en http://servicio.bc.uc.edu.ve/educacion/revista/a5n25/5-25-7.pdf.

Cochran- Smith, M., Zeichner, K. y Fries, K. (2006). Estudio sobre la formación del profesorado en los estados Unidos: descripción del informe del comité de la AERA sobre investigación y formación del profesorado. Revista de Educación, 340, 87-116.

Coll, C., Martín, E., Mauri, T., Miras, M., Onrubia, J., Solé, I., Zabala, A. (1999). El constructivismo en el aula. España: Grao.

Constitución (1999). Gaceta Oficial de la República Bolivariana de Venezuela, 5453, Caracas: autor.

Cumbre Iberoamericana de Jefes de Estado y de Gobierno de los Países Iberoamericanos. Declaración de Panamá (2000). Unidos por la niñez y la adolescencia, base de la justicia y la equidad en el nuevo milenio. Recuperado el 22 de septiembre 2010 en http://www.oei.es/xcumbredec.htm .

Cumbre Iberoamericana- Declaración de Buenos Aires (2010). Educación con inclusión social. Recuperado el 04 de octubre 2010 en http://www.oei.es/cie20.php.

Declaración de Bolonia. (2009). Recuperado el 09 de febrero de 2011 en http://eees.umh.es/contenidos/Documentos/DeclaracionBolonia.pdf .

Declaración de los Derechos del Niño (1959). Recuperado el 19 de noviembre de 2010 en http://www.gobiernoenlinea.ve/docMgr/sharedfiles/declaracionderechosnino.pdf.

Delval, J. (1988). Temas actuales sobre psicopedagogía y didáctica. Madrid: Narcea

413

La Práctica Profesional como área para potenciar las competencias pedagógicas necesarias para la enseñanza en Educación Infantil 
Delors, J. (1996.). Los cuatro pilares de la educación, en la educación encierran un tesoro. Informe a la UNESCO de la Comisión internacional sobre la educación para el siglo XXI, Recuperado el 21 de septiembre de 2010 en http://www.unesco.org/education/pdf/DELORS_S.PDF .

Díaz, D. (2001). La Didáctica Universitaria: Una Alternativa para Transformar la Enseñanza. Acción Pedagógica, 10 (1 y 2), 64-72.

Díaz, F. (1993). Aproximaciones metodológicas al diseño curricular, hacia una propuesta integral. Tecnología y comunicación educativa, 1 (21), 19-39.

Díaz, L. y Mayz, C. (2004) La formación del profesional de educación infantil, experiencia venezolana. Revista Acción pedagógica. Recuperado el 28 noviembre de 2010 en http://www.saber.ula.ve/bitstream/123456789/17201/2/articulo6.pdf.

Díaz J. y Martins A. (1982). Estrategias de enseñanza- aprendizaje: Orientaciones didácticas para la docencia universitaria. San José, Costa Rica: Instituto Interamericano de cooperación.

Didonet, V. (2007). Formación de profesores para la Educación Inicial. Revista de Investigación, 1 (62), 15-40.

De La Herrán, A. y Paredes, J. (2008). Didáctica General. La práctica de la enseñanza en educación infantil, primaria y secundaria. Madrid: Mac Graw Hill.

Diccionario Pedagógico. (2000). Caracas: Biosfera

Diccionario de la Real Academia Española. (2009). Vigésima segunda edición .Recuperado el 23 noviembre de 2009 en http://buscon.rae.es/drael/. 
Dos Santos, J. y Sánchez, S. (2001). Investigación Educativa Cantidad-Cualidad. Un debate paradigmático. Colombia: Cooperativa Editorial Magisterio.

Education, Audiovisual and Culture Executive Agency (EACEA P9 Eurydice). (2012). Key data on education in Europe. Recuperado el 15 de febrero de 2012 en http://eacea.ec.europa.eu/education/eurydice/documents/key_data_series/134EN.pdf.

Escobar, N. (2007). La práctica profesional docente desde la perspectiva de los estudiantes practicantes y los tutores. Acción Pedagógica, 1(16). Recuperado el 19 de noviembre de 2010 en http://www.saber.ula.ve/bitstream/123456789/17286/2/articulo17.pdf.

Elliot, J. (1993). La investigación-acción en educación. Madrid: Morata.

Fernández, J., González, M., Requena, M. y De Vicuña, P. (1994). Didáctica de la Educación Infantil. Madrid: Editex

Fernández, V. (2007). Aportes de las Neurociencias a la Educación Infantil. Conferencia presentada en el Primer Curso Internacional Repensando la Educación Infantil para América Latina, Santiago de Chile, $[\mathrm{CD}]$.

Fornasari de Menegazzo, L. (2007). Pedagogía de la Escucha. Conferencia presentada en el Primer Curso Internacional Repensando la Educación Infantil para América Latina, Santiago de Chile, [CD].

Frabboni, F. (1996). La escuela infantil, entre la cultura de la infancia y la ciencia pedagógica y didáctica. Madrid: Narcea

Freire, P. (2004). Pedagogía de la autonomía. Buenos Aires, Argentina: siglo xxi Editores argentina, S .A.

415

La Práctica Profesional como área para potenciar las competencias pedagógicas necesarias para la enseñanza en Educación Infantil 
Fuentes, S. (2006). La evaluación dinámica en el aula. Cuadernos de trabajo, Universidad Central. Chile: LOM Ediciones

Gage, N. (1989). The paradigm wars and their aftermath: A "historical" sketch of research on teaching since 1989. Educational Researcher, 18(7), 4-10.

Galindo, R. (2008). Dominio Conceptual del Docente y la Calidad de su Praxis Didáctica. Trabajo de Investigación para el Diploma de Estudios Avanzados (DEA). Universidad de León- España- Universidad Pedagógica Experimental Libertador.

Galindo R. y Gómez, M. (2009). Proyectos didácticos en educación inicial: una perspectiva sociocultural y humanista. Dialógica Revista Multidisciplinaria. 6 (2), 23-38.

Galindo, R. (2009). Elementos para la reconstrucción de la didáctica en Educación Inicial. Trabajo de ascenso, no publicado. Universidad Pedagógica Experimental Libertador, Instituto Rafael Alberto Escobar Lara, Maracay

García, H. (2004). La formación inicial y permanente del profesorado de educación física a través del practicum. Revista Contextos Educativos, Recuperado el 26 de enero de 2009 en http://ftp.ceces.upr.edu.cu/centro/repositorio/Textuales/Articulos/Pedagogia_2001/Formaci _n\%20permanente\%20de\%20profesores.\%20Retos\%20del\%20siglo\%20XXI.pdf .

García, A., Castañón, N., Domingo, G., y Palou, E. (1998). Guía de orientaciones pedagógicas. Material de consulta. Caracas: Autor.

Gassó, A. (2004). La Educación Infantil. Métodos, técnicas y organización. Recuperado el27 de octubre de 2010 en http://books.google.co.ve/books?hl=es\&lr=\&id=PrDt4_Hyk_QC\&oi=fnd\&pg=PA9\&dq=C oncepto+de+educaci\%C3\%B3n+infantil\&ots=MEldO8bzZg\&sig=PQzCcSdFWYqDkA2h

416

La Práctica Profesional como área para potenciar las competencias pedagógicas necesarias para la enseñanza en Educación Infantil 
qebBWrx $1 \mathrm{Y} 2 \mathrm{~g} \# \mathrm{v}=$ onepage $\& \mathrm{q}=$ Concepto $\% 20 \mathrm{de} \% 20$ educaci $\% \mathrm{C} 3 \% \mathrm{~B} 3 \mathrm{n} \% 20$ infantil\&f $=$ fals e.

Gil, P., Contreras, O. y Gómez, I. (2006). La educación infantil según el color del cristal con el que se mire: una investigación en el marco de la innovación de la educación superior europea. Paradigma. Recuperado el 23 julio de 2011 en $<$ http://www.scielo.org.ve/scielo.php?script=sci_arttext\&pid=S101122512006000200007\& lng=es\&nrm=iso $>$. ISSN 1011-2251.

González, N. (2006). Evaluación y mejora del practicum en las titulaciones de ciencias de la educación de la UPV/EHU. Revista de Psico didáctica. 11 (1), 145-158

Gonzaga, W. (2005). Las estrategias didácticas en la formación de docentes de educación primaria. Revista Actualidades Investigativas en Educación. 5(1), 5-25

Gundry S. (1998). Producto o praxis del currículo. Madrid: Morata.

Hernández, R., Fernández, C. y Baptista, L. (1991). Metodología de la investigación. México: Mc Graw Hill

Kamii C. y De Vries R. (1991). La teoría de Piaget y la Educación Preescolar. Madrid. Visor Distribuidor S.A.

Katz, L. (2005). Perspectivas Educativas en la Primera Infancia. Santiago de Chile: LOM Ediciones.

Keeves, J. (1986). Theory, politics and experiment in educational research methodology. A response. International. Review of education, 32(4), 388-92.

Kerlinger, F.N. (1989). Investigación del comportamiento. Técnicas y Metodologías (2da Ed.) México: Mc Graw-Hill.

417

La Práctica Profesional como área para potenciar las competencias pedagógicas necesarias para la enseñanza en Educación Infantil 
Jiménez, B. (2007). La formación permanente que se realiza en los centros de apoyo al profesorado. Educación siglo XXI. 10, 160-176.

Latorre, M. (2007). El practicum como espacio para potenciar las competencias profesionales necesarias para la enseñanza. Campo Abierto, 1, 137-152

Lavanchy, S. y Suzuqui, E. (2000). El currículum cognitivo y su aporte al niño chileno. Santiago Chile: Impresos Universitaria.

Ley De Universidades (1970) Gaceta Oficial $N^{\circ}$ 1429, extraordinario del 8 de septiembre. Título I disposiciones fundamentales.

López, M. (1995). El especialista de preescolar el que tenemos y el que necesitamos. Fundación Polar. Caracas: Autor.

López de Manturana, S. (2008). Identidad y profesionalidad docente de la Educadora de Párvulos. Revista Educación Parvularia de Chile en el siglo XXI. Colegio de Educadores de Párvulos de Chile A.G. 1,23-30

Lucena, A. y Carmona, P. (2008). Estrategias didácticas utilizadas por los docentes de educación preescolar de la UPEL-IPB, para fomentar el desarrollo de la creatividad. Revista Educare. 12(3), 1-9.

Luzuriaga, L. (1991). Pedagogía. Argentina. Buenos Aires: Losada, S.A.

Madrid, J. y Lucero, L. (1999). Sobre la dimensión pedagógica y política de la formación del profesorado. Revista electrónica interuniversitaria de formación del profesorado. Recuperado el 21 de febrero de 2012 en www. Uva.es/aufop/publica/revelfop/99v2n2.htm.

418

La Práctica Profesional como área para potenciar las competencias pedagógicas necesarias para la enseñanza en Educación Infantil 
Malagón, G. y Montes (2006). Las competencias y los métodos didácticos en el jardín de niños. México: Trillas.

Marcelo, C. (2008). Evaluación de la calidad para programas completos de formación docente a través de estrategias de aprendizaje abierto y a distancia. Revista de Educación a Distancia. Número monográfico VII.- 30 de Diciembre de 2008. Número especial dedicado a la evaluación de la calidad en entornos virtuales de aprendizaje. Consultado 23 febrero de 2010 http://www.um.es/ead/red/M7/

Marín, D. (2003). Investigación y formación de docentes en la escuela normal superior. Análisis y perspectivas. Pedagogía y saberes, 19, 43-52.

Martí, E. (1991). Psicología Evolutiva: Teorías y ámbitos de investigación. Barcelona: Anthropos.

Martínez, J. (2008). Ausencias, insuficiencias y emergencias en la educación actual. España: McGraw: Hill.

Martínez, M. (1997). La investigación cualitativa etnográfica en educación. Manual teóricopráctico. México: Trillas.

Martínez, V. y Watts, B. (1997). Las prácticas pedagógicas en el nuevo contexto socio educacional chileno. Revista Perspectiva Educacional, Instituto de Educación UCV, 30(II), 43-47.

Mcmillan. J. Schumacher, S. (2005). Investigación educativa: una introducción conceptual. Madrid: Pearson Educación.

Melograno, L. (2003). La formación profesional del maestro de educación infantil. Documento $A M E I-$ WAECE. España: Editorial de la Infancia.

419

La Práctica Profesional como área para potenciar las competencias pedagógicas necesarias para la enseñanza en Educación Infantil 
Ministerio de Educación Cultura y Deportes (2005). Diseño Curricular Educación Inicial. Caracas: Autor

Ministerio de Educación Cultura y Deportes (2002). Educación. Revista para el magisterio. 185, 50-62.

Ministerio de Educación Superior (2010). Reseña Histórica. Recuperado el 09 de junio de 2011 en http://www.mes.gov.ve/mes/resena.php.

Ministerio de Educación, Cultura y Deporte (2001). Políticas y Estrategias para el desarrollo de la Educación Superior en Venezuela 2000-2006. Recuperado el 25 de febrero de 2011: http://www.mes.gob.ve/mes/documentos/descarga/politicas_estrategias.pdf.

Montero, L. (2002). La formación inicial, ¿Puerta de entrada al desarrollo profesional? Revista Educar, Recuperado el 24 de abril de 2011 en http://www.raco.cat/index.php/educar/article/viewfile/20764/20604.

Morín, E. (1999). La cabeza bien puesta. Repensar la reforma, reformar el pensamiento. Bases para una reforma educativa. Buenos Aires Argentina: Nueva Visión.

Morín, E. (2001). Los siete saberes necesarios para la educación del futuro. Buenos Aires: Nueva Visión SAIC.

Oficina de Planificación del Sector Universitario. (OPSU). (S/F). Matricula. Serie Histórica 1960-2007- .Recuperado el 18 abril de 2011 en http://www.opsu.gob.ve/extranet/descargas/01-01-01-00-00/01-01-01-01-

00/publicaciones_portal/matricula_1960_2007.pdf.

Organización de Estados Iberoamericanos. Organización y Estructura de la Formación Docente en América Latina. (S/F). Recuperado el 12 octubre 2011 en http://www.oei.es/linea6/informe.PDF. 420

La Práctica Profesional como área para potenciar las competencias pedagógicas necesarias para la enseñanza en Educación Infantil 
Organización para la Cooperación y el Desarrollo Económico (OCDE). (2002). La Definición y Selección de Competencias Clave. Resumen Ejecutivo. Recuperado el 29 de agosto de 2011 en

http://www.deseco.admin.ch/bfs/deseco/en/index/03/02.parsys.78532.downloadList.94248. DownloadFile.tmp/2005.dscexecutivesummary.sp.pdf.

(2006). Programa para la Evaluación Internacional de los Alumnos (PISA) 2006 Marco de la evaluación. Conocimientos y habilidades en ciencias, matemáticas y lectura. Recuperado el 28 de abril de 2011 en http://www.oecd.org/dataoecd/59/2/39732471.pdf.

Osorio J. y Rubio, G. (2007). La Cualidad. Reflexividad-Acción y Enfoque Inicial en Educación. Santiago de Chile: Valente.

Palella, S. y Martins, F. (2004). Metodología de la investigación cuantitativa. Caracas: FEDUPEL

Pantoja, A. (coord.), (2009). Manual básico para la realización de tesis, tesinas y trabajos de investigación. Madrid: EOS.

Parra, M. (S/F). Las transformaciones de la Educación Superior en Venezuela: en búsqueda de su identidad. Revista educación superior y sociedad. Recuperado el 23 abril de 2011 en: http://ess.iesalc.unesco.org.ve/index.php/ess/article/view/325/276 .

Paz, O. (1990). The Nobel Prize in Literature. La búsqueda del presente. Recuperado el 28 septiembre de 2011 en: www.nobelprize.org/nobel_prizes/literature/laureates/1990/pazlecture-s.html.

Peña, L. y Valdivieso F. (2007). Del fanatismo metodológico a la diversidad en la investigación educativa. La complementariedad en los diseños de investigación. UPEL, Maracay: Autor.

421

La Práctica Profesional como área para potenciar las competencias pedagógicas necesarias para la enseñanza en Educación Infantil 
Peñalver, L. (2000). La educación para el desarrollo integral de Venezuela y del hombre venezolano. Caracas: Universitas editores.

Peralta, M. y Fujimoto, G. (1998). La atención integral de la primera infancia en América Latina: Ejes centrales y los desafíos para el siglo XXI. Organización de Estados Americanos (OEA). Recuperado el 19 marzo de 2010 en http://www.oei.es/inicial/articulos/atencion_primera_infancia.pdf.

Peralta, M. (1996). El Currículo en el jardín infantil. Chile: Andrés Bello

Peralta, M. (2002). Una Pedagogía de las Oportunidades. Nuevas Ventanas para los Párvulos Latinoamericanos de/ Siglo XXI. Chile: Andrés Bello.

Peralta, M. (2008). Innovaciones Curriculares en Educación Infantil: avanzado a propuestas postmodernas. México: Trillas.

Pérez, A. (1995). La función y formación del profesor en la enseñanza para la comprensión. Diferentes perspectivas. Madrid: Morata.

Pérez, M. (1997) Las prácticas de enseñanza a debate: opinión desde los alumnos, los profesores de las escuelas universitarias y los maestros en servicio. Universidad De La Rioja. Fundación Dialnet. Recuperado el 12 de noviembre de 2010 en http://dialnet.unirioja.es/servlet/articulo?codigo $=117527$.

Perkins, D. (1995). La escuela inteligente. Barcelona: Gedisa

Quaas, C. (2000). Nuevos enfoques en la evaluación de los aprendizajes. Revista enfoques educacionales. 2 (2), 1-8.

Ramiro, M. (2001). Practicum reflexivo en la profesión docente. Escuela de postgrado Facultad de Ciencias Sociales. Universidad de Chile: Santiago de Chile.

422

La Práctica Profesional como área para potenciar las competencias pedagógicas necesarias para la enseñanza en Educación Infantil 
Redon, S. (2007). La formación de "profesionales" para la atención de párvulos en Chile. Revista Perspectiva, 1 (21), 145-156.

Reveco, O. (2007). Hablemos de evaluación. Conferencia presentada en el Primer Curso Internacional Repensando la Educación Infantil para América Latina, Santiago de Chile [CD].

Ribot, S. Varguillas C. y Báez, E. (2008). Modelo Didáctico del Profesor Universitario: una experiencia pedagógica. Vicerrectorado de Investigación y Postgrado, UPEL.

Ríos, M., Lagos, C., Walker, H. (2011) El efecto de las experiencias de práctica en el desarrollo del sentido de autoeficacia en la formación inicial de educadoras de párvulos. Estudios Pedagógicos 2011, XXXVII. Recuperado el 18 de noviembre de 2011 $<$ http://www.redalyc.org/src/inicio/ArtPdfRed.jsp?iCve=173519395008> ISSN 0716050X.

Ríos, P. (1998). Marco de referencia del curriculum en la perspectiva del desarrollo del niño menor de seis años. Papel de trabajo. Caracas: Autor.

(2004). La Aventura de aprender. Caracas: Cognitus C.A.

Rojas, R. (2005). Historia de la Universidad en Venezuela. Revista Dialnet, recuperado el 24 febrero de 2010 en: http://www.dialnet.unirioja.es/servlet/articuloodigo=2334926.

Rodríguez, E. (2009). El rol de las universidades en la sociedad del conocimiento y en la era de la globalización: evidencia desde chile. INCI. Recuperado el 27 Septiembre 2011 $<$ http://www.scielo.org.ve/scielo.php?script=sci_arttext\&pid=S037818442009001100013\& $\operatorname{lng}=\mathrm{es} \& \mathrm{nrm}=\mathrm{iso}>$. ISSN $0378-1844$.

Rodríguez, H. (2006). Práctica Pedagógica. Una tensión entre la teoría y la práctica. Revista Pedagogía y Saberes. 24 (1), 19-25.

423

La Práctica Profesional como área para potenciar las competencias pedagógicas necesarias para la enseñanza en Educación Infantil 
Rodríguez, M. (2001). Estrategias exitosas para tutorear investigaciones. Maracay: Autor.

Rodríguez, T., Reyes, M. y Peña, J. (2009). Aproximación a un modelo para evaluar el currículo de la UPEL, a partir de una propuesta de estructura curricular. Sapiens, .10 (1), 161-178.

Salas, R. (2004). Conceptos Básicos de Competencias. Compilación y Resumen. .Recuperado el 11 agosto de 2011 en http://webcache.googleusercontent.com/search?q=cache:O5imsEQo8L4J:www.sld.cu/galer ias/doc/sitios/infodir/35_conceptos_basicos_de_competencias.doc+quebee+competencias + $\mathrm{y}+$ habilidades\&cd $=1 \& \mathrm{hl}=\mathrm{es} \& \mathrm{ct}=\mathrm{clnk} \& \mathrm{gl}=\mathrm{ve}$.

Salcedo, L., Forero, F., Callejas, M., Pardo, A., Oviedo, P. (2005). Los estilos pedagógicos y la investigación acción. Implicaciones en el desarrollo profesional de los docentes universitarios. Revista Pedagogía y saberes. Universidad Nacional. Facultad de Educación, $39-44$.

Sayago, B. y Chacón M. (2007) Las prácticas profesionales en la formación docente: hacia un nuevo diario de ruta. Educere, Recuperado el 12 diciembre 2010 en http://www.scielo.org.ve/scielo.php?pid=S1316- 49102006000100008\&script=sci_arttext.

Schön, D. (1992). La formación de profesionales reflexivos. Hacia un nuevo diseño de la enseñanza y el aprendizaje de profesiones. Barcelona, España: Paidós.

Schön, D. (1987). Educating the reflective practitioner. Presentation to the 1987 meeting of the American Educational Research Association. Washington DC.

Serna, H. (2008). Planificación estratégica. Teoría metodología, alineamiento, implementación y mapas estratégicos. Índices de gestión. Bogotá: 3r editores

Simonstein, S. (2006). Perspectivas teóricas, modernidad y postmodernidad. Revista Perspectiva $20(1), 12-22$.

424

La Práctica Profesional como área para potenciar las competencias pedagógicas necesarias para la enseñanza en Educación Infantil 
Soltis, J. (1994). Teacher Research and educacional reform. Edición N.S.S.E.: Chicago

Stenhouse, L. (1987). Investigación y desarrollo de/ curriculum. Madrid: Morata.

Stenhouse, L. (1998). La investigación como base de la enseñanza. España: Morata.

Super, C.S. (1982). Cultural perspectives on child development. WH Freeman: San Francisco.

Tallaferro, D. (2006). La formación para la práctica reflexiva en las prácticas profesionales docentes. Educere, Recuperado el 19 de agosto de 2011 en http://www.scielo.org.ve/scielo.php?pid=S1316-49102006000200009\&script=sci_arttext.

Tejada, J. (2009). Competencias Docentes. Revista Profesorado. Recuperado el 28 diciembre 2008 en http://www.ugr.es/ recfpro/rev132COL2.pdf.

Teppa, S. (2006). Investigación Acción Participativa en la praxis pedagógica diaria. Universidad Pedagógica Experimental Libertador. Instituto Pedagógico de Barquisimeto "Luis Beltrán Prieto Figueroa", Subdirección de Investigación y Postgrado. Venezuela.

Thurler, M. (2002). O desenvolvimento profissional dos profesores: novos paradigmas, novas prácticas. Porto Alegre: Aritmed.

Tobón, S. (2004). Formación basada en competencias. Bogotá: Ecoe, Ediciones

Torres, J. (2006). La desmotivación del profesorado. Madrid: Morata.

UNESCO (1990). Declaración Mundial de Educación para todos, Jomtiem, Tailandia. Recuperado el 23 de septiembre de 2010 en http://www.unesco.org/education/pdf/JOMTIE_S.PDF.

425

La Práctica Profesional como área para potenciar las competencias pedagógicas necesarias para la enseñanza en Educación Infantil 
UNESCO (1998). Declaración Mundial sobre la Educación Superior en el siglo XXI. Visión y Acción. Paris 5 al 9 de Octubre de 1998. Recuperado el 20 enero 2010 en http://www.unesco.org/education/educprog/wche/declaration_spa.htm.

UNESCO (1998). Sistema de acreditación y evaluación de postgrados en América Latina y el Caribe. Informe de avance de proyecto postgrado en América Latina y el Caribe. Recuperado el 20 enero 2010 en www.iesalc.unesco.org.ve.

UNESCO (2000). Informe de países, Educación para todos. Recuperado el 13 agosto 2010 en http://www.unesco.org/education/wef/countryreports/venezuela/contents.html.

UNESCO (2009). Conferencia Mundial sobre la Educación Superior. La nueva dinámica de la educación superior y la investigación para el cambio social y el desarrollo. París, 5-8 de julio de 2009. Recuperado el 22 enero 2010 en http://www.unesco.org/education/WCHE2009/comunicado_es.pdf

Universidad Nacional Experimental Simón Rodríguez (2004). Proyecto Creación licenciatura Educación Mención Preescolar. Segunda versión. Recuperado el 23 diciembre 2011 en http://vr-academico.unesr.edu.ve/uaia/planificacion/preescolar.pdf.

Universidad Pedagógica Experimental Libertador (1996). Diseño Curricular de la especialidad de Educación Preescolar. Recuperado el 19 de diciembre de 2010 en http://www.upel.edu.ve/ Consultado.

Universidad Pedagógica Experimental Libertador. Reglamento General. (S/F). Recuperado el 22 noviembre 2010

en http://www.upel.edu.ve/documentos/ReglamentoGeneral. 
Universidad Pedagógica Experimental Libertador. Vicerrectorado de Docencia. (2005). Proyecto Transformación y Modernización del Currículo para la Formación Docente de Pregrado en la UPEL. Papel de trabajo. Caracas: Autor.

Uribe, J. (2007). El rol del educador de párvulos en el escenario de los desafíos de esta década. Revista perspectiva, 21 (1), 135-144.

Valdés, M., Mujica, A., Roque, A. y Darín S. (2007). Las competencias pedagógicas en los creativos entornos virtuales de aprendizaje universitarios. Edutec. Revista electrónica de tecnología educativa. Recuperado el 27 diciembre 2011 en http://edutec.rediris.es/Revelec2/revelec24/valdes/valdesyotros.html.

Valdivieso, M. (2001). Bases teóricas para la transformación curricular de las universidades venezolanas. Ponencia presentada en Simposio de Transformación Curricular de la Educación Superior (junio 30 y Julio 1). Recuperado el 20 abril de 2011 en http://www.ucv.ve/fileadmin/user_upload/vrac/documentos/curricular_documetos/evento/p onencia_6/valdivieso_maria.pdf.

Vivanco, M., Bravo, C., Torres, M. y Cárcamo H. (2010). Representaciones sociales de estudiantes acerca de su formación inicial docente. Universidad del Bio Bio, Chillán Chile. Horizontes Educacionales. Recuperado el 15 de noviembre de 2010 en http://redalyc.uaemex.mx/redalyc/pdf/979/97916218005.pdf.

XV Cumbre Iberoamericana de Jefes de Estado y de Gobierno Salamanca - España (2005) Declaración de Salamanca. Recuperado el 02 de octubre de 2011 en http://www.oei.es/xvcumbredec.htm.

XVI Conferencia Iberoamericana de Educación Montevideo, Uruguay (2006). Declaración de Montevideo. Recuperado el 15 de septiembre de 2010 en: http://www.oei.es/xvicie.htm. 
XVII Conferencia Iberoamericanas de Educación Valparaíso, Chile (2007). Declaración de Valparaíso. Recuperado el 17 diciembre 2009 en: http://www.oei.es/xviicie.htm.

XVIII Cumbre Iberoamericana San Salvador, El Salvador (2008). Declaración de El Salvador. Recuperado el 18 febrero de 2011 en: http://www.oei.es/xviiicumbredec.htm.

XIX Conferencia Iberoamericana de Educación, Portugal (2009). Declaración de Lisboa. Recuperado el 20 diciembre de 2011 en: http://www.oei.es/xixciedec.htm.

Zabalza, M. (1998). Los tutores en el practicum: funciones, formación, compromiso institucional. Conferencia presentada en el IV Symposium Internacional de Prácticas escolares. Santiago de Compostela: Universidad de Santiago [CD].

Zabalza, M. (2003). Competencias docentes del profesorado universitario. Calidad y desarrollo profesional. Madrid: Narcea.

Zabalza, M. (2006). Didáctica De la Educación Infantil. Recuperado el 23 octubre 2011 en : http://books.google.co.ve/books?hl=es\&lr=\&id=1 mUoG3jbNkoC\&oi=fnd\&pg=PR11\&dq= Concepto+de+educaci\%C3\%B3n+infantil\&ots=t4D61WIDQQ\&sig=1QPq9Fwq38vS7Mhf4 VoqBDhd67M\#v=onepage \&q=Concepto\%20de $\% 20$ educaci\%C3\%B3n\%20infantil\&f=fals

Zeichner, K. (1987). Preparing reflective teachers: an overview of instructional strategies which have been employed in preservice teacher education. International Journal of Educational Research. Cambridge- UK, 11 (5), 565-576.

Zeichner, K. (2009). Teacher education and the struggle for social justice. New York: Routledge.

428

La Práctica Profesional como área para potenciar las competencias pedagógicas necesarias para la enseñanza en Educación Infantil 
Zuluaga, J. (2009 Enero). Neurociencias, Neurodesarrollo y Educación. Realidades y Mitos. Conferencia presentada en el Tercer Curso Internacional Repensando la Educación Infantil para América Latina, Santiago de Chile [CD].

Zurita R. (1995). La formación de profesores, desafíos y prioridades en el Chile de hoy. Revista Perspectiva, 25 (1). 75-83.

429

La Práctica Profesional como área para potenciar las competencias pedagógicas necesarias para la enseñanza en Educación Infantil 
La Práctica Profesional como área para potenciar las competencias pedagógicas necesarias para la enseñanza en Educación Infantil 


\section{ANEXOS}

431

La Práctica Profesional como área para potenciar las competencias pedagógicas necesarias para la enseñanza en Educación Infantil 

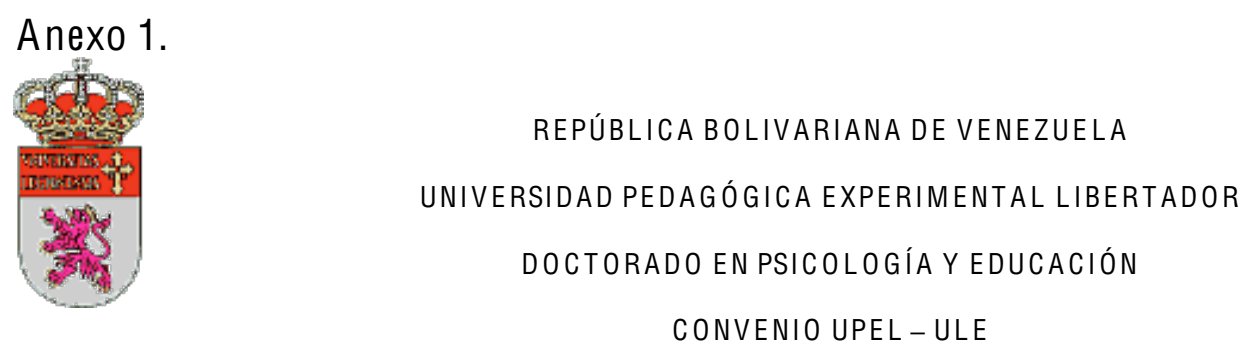

Estimado(a) Estudiante

En estos momentos estoy realizando un trabajo de investigación sobre La Práctica Profesional, como área para potenciar las competencias pedagógicas del estudiante de Educación Inicial. En tal sentido, solicito tu colaboración para que dediques unos minutos a responder este cuestionario, ya que como estudiante podrás suministrar una información de primera mano, relevante y valida sobre la práctica profesional en Educación Preescolar.

El cuestionario es anónimo, para garantizar la confidencialidad de los datos. Tú opinión sincera y objetiva será de gran utilidad para mejorar la calidad de los procesos de enseñanza impartidos hasta el momento.

El instrumento consta de dos partes, la Primera Parte está referida a Datos Personales. La Segunda Parte, son preguntas cerradas para contestar con una equis (x), según su opinión en cada caso, considerando su propia práctica y experiencia académica en esta casa de estudio.

Muchas Gracias por tu colaboración

Autora: Prof. Reina Galindo Directora: Dra. Rosa Eva Valle.

432

La Práctica Profesional como área para potenciar las competencias pedagógicas necesarias para la enseñanza en Educación Infantil 


\section{PARTE}

Coloque una $\mathrm{X}$, para indicar su situación

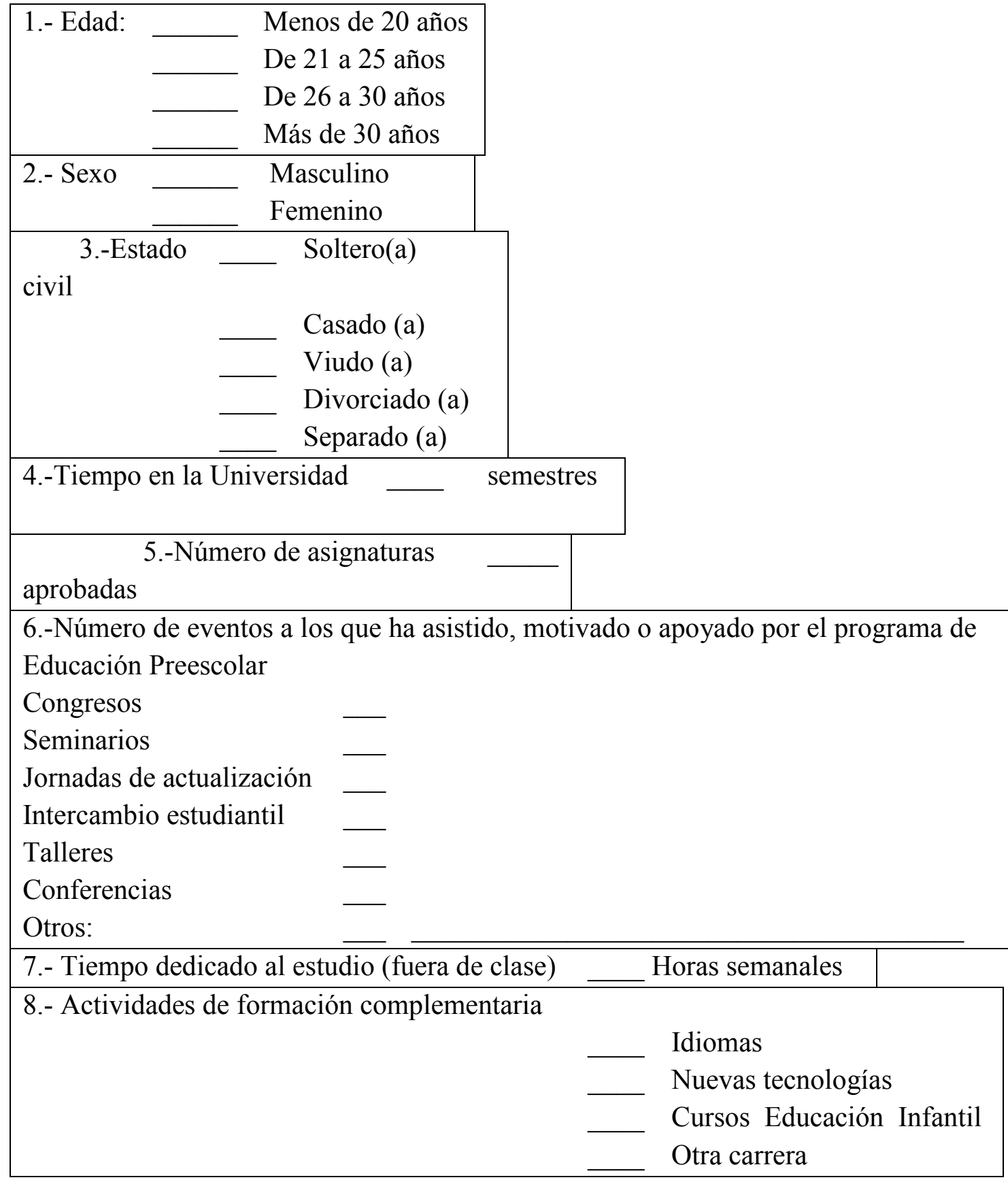

433

La Práctica Profesional como área para potenciar las competencias pedagógicas necesarias para la enseñanza en Educación Infantil 


\section{PARTE}

Marque con una equis (X), el grado en el que estás de acuerdo, con las siguientes afirmaciones: 4.- Totalmente de acuerdo (T-A). 3.- Bastante de acuerdo (B-A).2.- Poco de acuerdo (P-A). 1.- En Desacuerdo (E-D).

\begin{tabular}{|c|c|c|c|c|c|c|}
\hline Categoría & ítem & $\begin{array}{l}\text { Durante tu formación como } \\
\text { estudiante de Educación } \\
\text { Preescolar consideras que } \\
\text { aprendiste a: }\end{array}$ & $\begin{array}{l}4 \\
\text { TA }\end{array}$ & $\begin{array}{l}3 \\
B A\end{array}$ & $\begin{array}{l}2 \\
P A\end{array}$ & $\begin{array}{l}1 \\
E D\end{array}$ \\
\hline \multirow[t]{5}{*}{$\begin{array}{l}\text { Aprender a } \\
\text { aprender }\end{array}$} & 9 & $\begin{array}{l}\text { Integrar las nuevas tendencias } \\
\text { científicas a la práctica pedagógica. }\end{array}$ & & & & \\
\hline & 10 & $\begin{array}{l}\text { Integrar las nuevas tendencias } \\
\text { tecnológicas a la práctica } \\
\text { pedagógica. }\end{array}$ & & & & \\
\hline & 11 & $\begin{array}{l}\text { Desarrollar habilidades para la } \\
\text { resolución de problemas }\end{array}$ & & & & \\
\hline & 12 & $\begin{array}{l}\text { Aprender a partir de tus propias } \\
\text { experiencias }\end{array}$ & & & & \\
\hline & 13 & Aprender a partir de los errores & & & & \\
\hline \multirow[t]{2}{*}{$\begin{array}{l}\text { Actualización } \\
\text { permanente }\end{array}$} & 14 & $\begin{array}{l}\text { Ampliar y complementar los } \\
\text { conocimientos adquiridos }\end{array}$ & & & & \\
\hline & 15 & $\begin{array}{l}\text { Asistir a clases con materiales } \\
\text { leídos/ preparados }\end{array}$ & & & & \\
\hline \multirow{3}{*}{$\begin{array}{l}\text { Capacidad de } \\
\text { autoevaluar } \\
\text { sus } \\
\text { aprendizajes }\end{array}$} & 16 & $\begin{array}{l}\text { Trasladar a otras situaciones los } \\
\text { aprendizajes teóricos/prácticos }\end{array}$ & & & & \\
\hline & 17 & $\begin{array}{l}\text { Integrar actividades de docencia con } \\
\text { investigación }\end{array}$ & & & & \\
\hline & 18 & $\begin{array}{l}\text { Comprobar la relación de las } \\
\text { asignaturas cursadas con la puesta en } \\
\text { práctica de tus prácticas } \\
\text { profesionales }\end{array}$ & & & & \\
\hline
\end{tabular}

434

La Práctica Profesional como área para potenciar las competencias pedagógicas necesarias para la enseñanza en Educación Infantil 


\begin{tabular}{|c|c|c|c|c|c|c|}
\hline Categoría & ítem & $\begin{array}{l}\text { Durante tu formación como } \\
\text { estudiante de Educación } \\
\text { Preescolar consideras que } \\
\text { aprendiste a: }\end{array}$ & $\begin{array}{c}4 \\
\mathrm{TA}\end{array}$ & $\begin{array}{c}3 \\
B A\end{array}$ & $\begin{array}{c}2 \\
P A\end{array}$ & $\begin{array}{c}1 \\
E D\end{array}$ \\
\hline \multirow{4}{*}{$\begin{array}{l}\text { O rganización de } \\
\text { la situación } \\
\text { enseñanza- } \\
\text { aprendizaje en } \\
\text { Educación Inicial }\end{array}$} & 19 & $\begin{array}{l}\text { Crear ambientes que motiven a } \\
\text { los niños al descubrimiento de sus } \\
\text { propias capacidades, limitaciones, } \\
\text { intereses y necesidades }\end{array}$ & & & & \\
\hline & 20 & $\begin{array}{l}\text { Elaborar material didáctico } \\
\text { adecuado a los requerimientos de } \\
\text { las actividades planificadas y de } \\
\text { los aprendizajes esperados }\end{array}$ & & & & \\
\hline & 21 & $\begin{array}{l}\text { Crear ambientes de aprendizaje, } \\
\text { respondiendo a las exigencias del } \\
\text { Diseño Curricular Educación } \\
\text { Inicial }\end{array}$ & & & & \\
\hline & 22 & $\begin{array}{l}\text { Diseñar recursos para el } \\
\text { aprendizaje }\end{array}$ & & & & \\
\hline \multirow[t]{5}{*}{$\begin{array}{l}\text { Proceso de } \\
\text { planificación en } \\
\text { Educación Inicial }\end{array}$} & 23 & $\begin{array}{l}\text { Planificar actividades en virtud } \\
\text { del logro de los aprendizajes } \\
\text { esperados }\end{array}$ & & & & \\
\hline & 24 & $\begin{array}{l}\text { Planificar proyectos involucrando } \\
\text { activamente a niños y niñas, sus } \\
\text { familias, personal, comunidad } \\
\text { circundante }\end{array}$ & & & & \\
\hline & 25 & $\begin{array}{l}\text { Diseñar, administrar y ejecutar } \\
\text { proyectos educativos }\end{array}$ & & & & \\
\hline & 26 & $\begin{array}{l}\text { Planificar experiencias de } \\
\text { orientación a la comunidad sobre } \\
\text { temas pedagógicos }\end{array}$ & & & & \\
\hline & 27 & Planificar experiencias de & & & & \\
\hline
\end{tabular}

435

La Práctica Profesional como área para potenciar las competencias pedagógicas necesarias para la enseñanza en Educación Infantil 


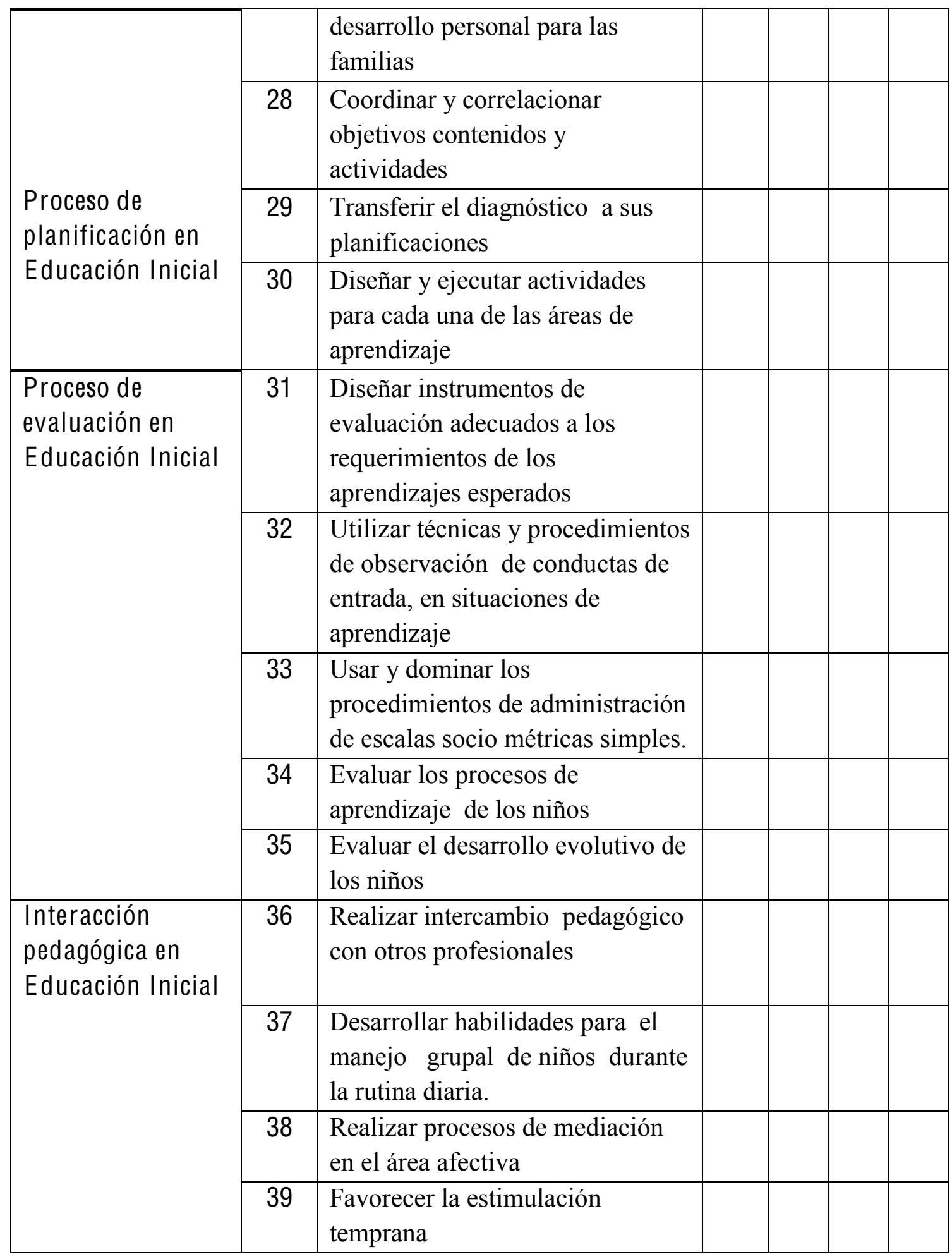

436

La Práctica Profesional como área para potenciar las competencias pedagógicas necesarias para la enseñanza en Educación Infantil 


\begin{tabular}{|l|c|l|l|l|l|l|}
\hline \multirow{5}{*}{} & 40 & $\begin{array}{l}\text { Impulsar a los niños en los } \\
\text { procesos de lectoescritura }\end{array}$ & & & \\
\hline & 41 & $\begin{array}{l}\text { Impulsar a los niños en el proceso } \\
\text { lógico-matemático }\end{array}$ & & & \\
\hline 42 & Fortalecer la autoestima del niño & & & & \\
\hline & 43 & $\begin{array}{l}\text { Fomentar la educación para la } \\
\text { salud }\end{array}$ & & & \\
\cline { 2 - 6 } $\begin{array}{l}\text { Interacción } \\
\text { pedagógica en } \\
\text { Educación Inicial }\end{array}$ & 44 & $\begin{array}{l}\text { Desarrollar habilidades para la } \\
\text { resolución de situaciones difíciles } \\
\text { de resolver: preguntas sobre } \\
\text { sexualidad, agresividad infantil. }\end{array}$ & & & & \\
\hline
\end{tabular}

\begin{tabular}{|c|c|c|c|c|c|c|}
\hline Categoría & ítem & $\begin{array}{l}\text { Con relación al proceso de } \\
\text { enseñanza universitario, } \\
\text { considera que tus profesores: }\end{array}$ & $\begin{array}{c}4 \\
\mathrm{TA}\end{array}$ & $\begin{array}{c}3 \\
B A\end{array}$ & $\begin{array}{c}2 \\
\mathrm{PA}\end{array}$ & $\begin{array}{c}1 \\
E D\end{array}$ \\
\hline \multirow[t]{8}{*}{$\begin{array}{l}\text { Didáctica } \\
\text { universitaria }\end{array}$} & 45 & $\begin{array}{l}\text { Proporcionaron fuentes de } \\
\text { información y recursos a los } \\
\text { estudiantes }\end{array}$ & & & & \\
\hline & 46 & $\begin{array}{l}\text { Los motivaron a preparar } \\
\text { actividades de aprendizaje }\end{array}$ & & & & \\
\hline & 47 & $\begin{array}{l}\text { Inician los temas } \\
\text { contextualizándolos previamente }\end{array}$ & & & & \\
\hline & 48 & $\begin{array}{l}\text { Realizan asociación de temas con } \\
\text { los objetivos planteados }\end{array}$ & & & & \\
\hline & 49 & $\begin{array}{l}\text { Aportan conocimientos } \\
\text { actualizados }\end{array}$ & & & & \\
\hline & 50 & $\begin{array}{l}\text { Dominan los aspectos teóricos de } \\
\text { los contenidos de las asignaturas }\end{array}$ & & & & \\
\hline & 51 & $\begin{array}{l}\text { Dominan los aspectos prácticos de } \\
\text { los contenidos de las asignaturas }\end{array}$ & & & & \\
\hline & 52 & $\begin{array}{l}\text { Relacionan la asignatura con otras } \\
\text { ciencias o conocimientos }\end{array}$ & & & & \\
\hline
\end{tabular}

\begin{tabular}{|l|l|l|c|c|c|c|}
\hline Categoría & ítem & $\begin{array}{l}\text { En relación a las actividades en } \\
\text { clase, consideras que tuviste la }\end{array}$ & $\begin{array}{c}4 \\
\text { TA }\end{array}$ & $\begin{array}{c}3 \\
\text { BA }\end{array}$ & PA & $\begin{array}{c}1 \\
\text { ED }\end{array}$ \\
\hline
\end{tabular}

437 


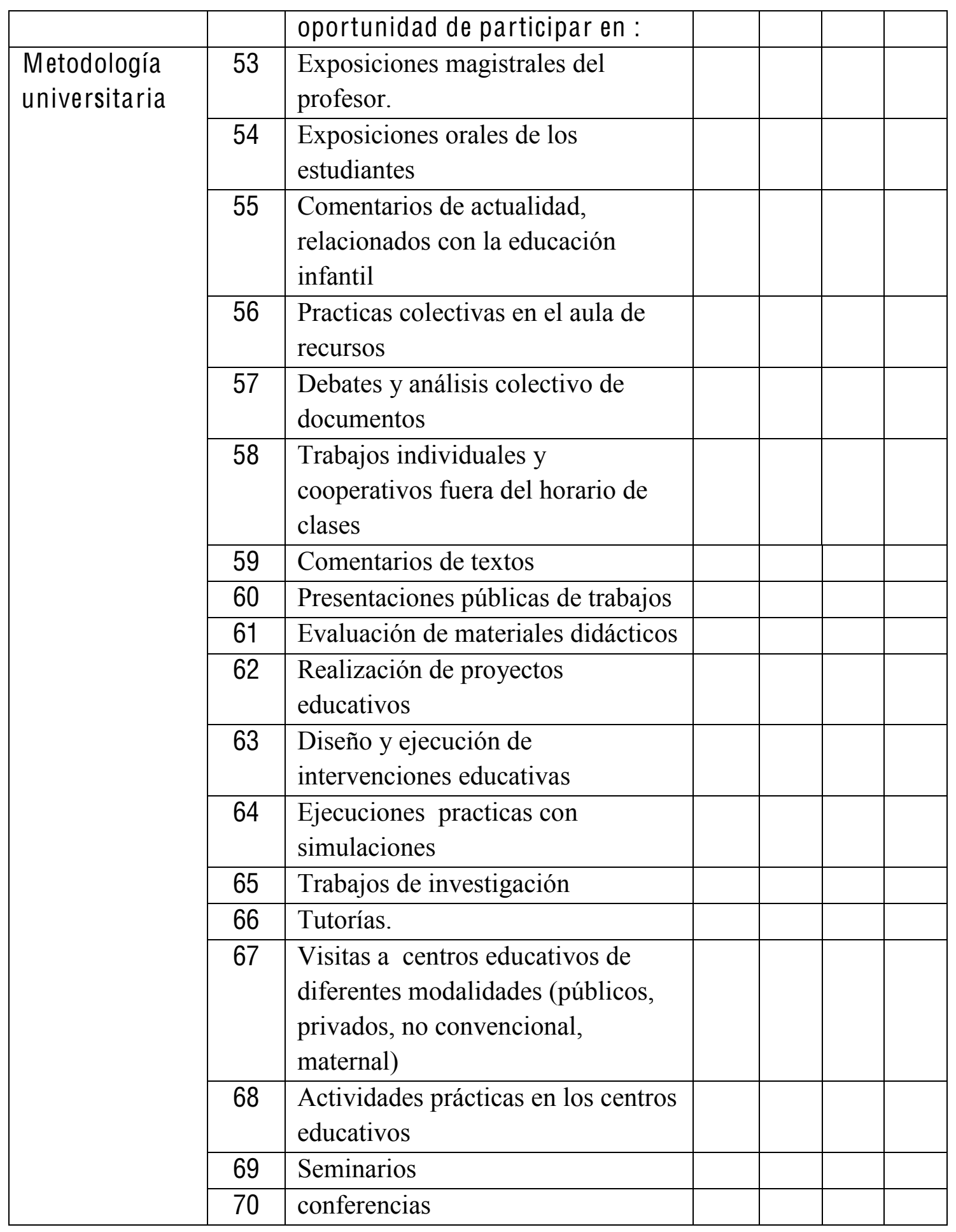

438

La Práctica Profesional como área para potenciar las competencias pedagógicas necesarias para la enseñanza en Educación Infantil 


\begin{tabular}{|l|c|l|c|c|c|c|}
\hline Categoría & ítem & $\begin{array}{l}\text { Las actividades de formación en } \\
\text { las que usted participo se } \\
\text { realizaron en los siguientes } \\
\text { lugares }\end{array}$ & $\begin{array}{c}4 \\
\text { TA }\end{array}$ & $\begin{array}{c}3 \\
\text { BA }\end{array}$ & $\begin{array}{c}\text { PA } \\
\text { ED }\end{array}$ \\
\hline $\begin{array}{l}\text { Contextos de } \\
\text { aprendizaje }\end{array}$ & 71 & Aula de clases de la Universidad & & & & \\
\hline & 72 & Aula de recursos múltiples & & & & \\
\hline & 73 & Biblioteca/ salas de documentación & & & & \\
\hline & 74 & Centros maternales & & & & \\
\hline & 75 & $\begin{array}{l}\text { Centros educativos no } \\
\text { convencionales }\end{array}$ & & & & \\
& 76 & Centros preescolares & & & & \\
\hline & 77 & Contextos comunitarios & & & & \\
\hline
\end{tabular}

\begin{tabular}{|l|c|l|c|c|c|c|}
\hline Categoría & ítem & $\begin{array}{l}\text { Entre las siguientes actividades } \\
\text { de evaluación, marque las } \\
\text { aplicadas en su proceso de } \\
\text { formación }\end{array}$ & $\begin{array}{c}4 \\
\text { TA }\end{array}$ & $\begin{array}{c}3 \\
\text { BA }\end{array}$ & $\begin{array}{c}2 \\
\text { PA }\end{array}$ & $\begin{array}{c}1 \\
\text { ED }\end{array}$ \\
\hline $\begin{array}{l}\text { Métodos y } \\
\text { criterios de } \\
\text { evaluación }\end{array}$ & 78 & Trabajos grupales e individuales & & & & \\
\hline & 79 & Proyectos de investigación & & & & \\
\cline { 2 - 7 } & 80 & Informes escritos & & & & \\
\hline & 81 & Debates & & & & \\
\hline & 82 & Exposiciones & & & & \\
\hline & 83 & Pruebas orales & & & & \\
\hline & 84 & Seguimientos desde la tutoría & & & \\
\hline & 85 & Realización de trabajos en grupo & & & & \\
\hline
\end{tabular}

439

La Práctica Profesional como área para potenciar las competencias pedagógicas necesarias para la enseñanza en Educación Infantil 


\begin{tabular}{|c|c|l|c|c|c|c|}
\hline Categoría & ítem & $\begin{array}{l}\text { Exprese su opinión sobre los } \\
\text { aspectos relacionados al proceso } \\
\text { académico de Práctica } \\
\text { Profesional }\end{array}$ & $\begin{array}{c}4 \\
\text { TA }\end{array}$ & $\begin{array}{c}3 \\
\text { BA }\end{array}$ & $\begin{array}{c}2 \\
\text { PA }\end{array}$ & $\begin{array}{c}1 \\
\text { ED }\end{array}$ \\
\hline $\begin{array}{c}\text { C réditos } \\
\text { académicos }\end{array}$ & 86 & Normativa (reglamento) & & & & \\
\hline & 87 & Ubicación en el plan de estudios & & & & \\
\hline & 88 & Apoyo institucional & & & & \\
\hline & 89 & Apoyo de los centros de aplicación & & & & \\
\hline & 90 & Recursos para el aprendizaje & & & & \\
\hline & 91 & Evaluación & & & & \\
\hline \multirow{5}{*}{$\begin{array}{c}\text { Planes y } \\
\text { Programas }\end{array}$} & 92 & Relación teoría-práctica & & & & \\
\hline & 93 & Adaptación al contexto & & & & \\
\hline & 94 & Preparación para el desempeño & & & & \\
\hline & 95 & Uso de las TIC'S & & & & \\
\hline & 96 & Innovación científica & & & & \\
\hline \multirow{5}{*}{$\begin{array}{c}\text { Servicios } \\
\text { estudiantiles }\end{array}$} & 97 & Becas de estudio & & & & \\
\hline & 98 & Beca/ Trabajo o ayudantía & & & & \\
\hline & 99 & Biblioteca & & & & \\
\hline & 100 & Transporte & & & & \\
\hline & 101 & Comedor & & & & \\
\hline & 102 & Cafetín & & & & \\
\hline & 103 & Aéreas de esparcimiento & & & \\
\hline
\end{tabular}




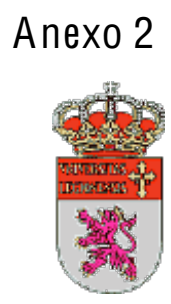

REPÚBLICA BOLIVARIANA DE VENEZUELA

UNIVERSIDAD PEDAGÓGICA EXPERIMENTAL LIBERTADOR

DOCTORADO EN PSICOLOGÍA Y EDUCACIÓN

CONVENIO UPEL - ULE

\section{CUESTIONARIO PROFESORES}

\section{Estimado(a) Colega:}

En estos momentos estoy realizando un trabajo de investigación sobre La Práctica Profesional, como área para potenciar las competencias pedagógicas del estudiante de Educación Inicial. En tal sentido, solicito su colaboración para responder este cuestionario, ya que la información que suministre, será relevante y valida sobre la práctica profesional en Educación Preescolar.

El cuestionario es anónimo, para garantizar la confidencialidad de los datos. La opinión sincera y objetiva será de gran utilidad para mejorar la calidad de los procesos de enseñanza impartidos hasta el momento.

El instrumento consta de dos partes, la Primera Parte está referida a Datos Personales. La Segunda Parte, son preguntas cerradas para contestar con una equis (x), según la opinión en cada caso, considerando su experiencia profesional en esta casa de estudio.

Muchas Gracias por su colaboración

Autora: Prof. Reina Galindo Directora: Dra. Rosa Eva Valle.

441

La Práctica Profesional como área para potenciar las competencias pedagógicas necesarias para la enseñanza en Educación Infantil 


\section{PARTE}

Coloque una $\mathrm{X}$, para indicar su situación

\begin{tabular}{|c|c|}
\hline 1.- Edad: & $\begin{array}{l}\text { Menos de } 30 \text { años } \\
\text { De } 30 \text { a } 40 \text { años } \\
\text { De } 41 \text { a } 50 \text { años } \\
\text { Más de } 50 \text { años }\end{array}$ \\
\hline
\end{tabular}

\begin{tabular}{|ll|}
\hline 2.- Sexo & Masculino \\
& \\
& Femenino \\
\hline
\end{tabular}

\begin{tabular}{|lll|}
\hline 3.-Estado civil & & Soltero(a) \\
& & Casado (a) \\
& & \\
& & Viudo (a) \\
& & Divorciado (a) \\
& & Separado (a) \\
\hline
\end{tabular}

\begin{tabular}{|lll|}
\hline 4.-Tiempo en la Universidad _ $\_$Años \\
\hline
\end{tabular}

5.-Condición: Contratado: __ Ordinario

\begin{tabular}{|lll|}
\hline 6.- Escalafón: & Instructor: & Asistente: \\
& Agregado: & Asociado: \\
& Titular:
\end{tabular}

7.- Títulos obtenidos: Pregrado

8.- Títulos obtenidos: Postgrado

442

La Práctica Profesional como área para potenciar las competencias pedagógicas necesarias para la enseñanza en Educación Infantil 


\section{PARTE}

Marque con una equis $(\mathrm{X})$, el grado en el que estás de acuerdo, con las siguientes afirmaciones: 4.- Totalmente de acuerdo (T-A). 3.- Bastante de acuerdo (B-A).2.- Poco de acuerdo (P-A). 1.- En Desacuerdo (E-D).

\begin{tabular}{|c|c|c|c|c|c|c|}
\hline Categoría & ítem & $\begin{array}{l}\text { Usted como formador de Ia UPE L } \\
\text { considera que los (as) estudiantes } \\
\text { de Educación Preescolar, } \\
\text { aprendieron a: }\end{array}$ & $\begin{array}{l}4 \\
\text { TA }\end{array}$ & $\begin{array}{l}3 \\
B A\end{array}$ & $\begin{array}{l}2 \\
P A\end{array}$ & $\begin{array}{l}1 \\
E D\end{array}$ \\
\hline \multirow[t]{5}{*}{$\begin{array}{l}\text { Aprender a } \\
\text { aprender }\end{array}$} & 9 & $\begin{array}{l}\text { Integrar las nuevas tendencias } \\
\text { científicas a la práctica pedagógica. }\end{array}$ & & & & \\
\hline & 10 & $\begin{array}{l}\text { Integrar las nuevas tendencias } \\
\text { tecnológicas a la práctica } \\
\text { pedagógica. }\end{array}$ & & & & \\
\hline & 11 & $\begin{array}{l}\text { Desarrollar habilidades para la } \\
\text { resolución de problemas }\end{array}$ & & & & \\
\hline & 12 & $\begin{array}{l}\text { Aprender a partir de sus propias } \\
\text { experiencias }\end{array}$ & & & & \\
\hline & 13 & Aprender a partir de los errores & & & & \\
\hline \multirow[t]{2}{*}{$\begin{array}{l}\text { Actualización } \\
\text { permanente }\end{array}$} & 14 & $\begin{array}{l}\text { Ampliar y complementar los } \\
\text { conocimientos adquiridos }\end{array}$ & & & & \\
\hline & 15 & $\begin{array}{l}\text { Asistir a clases con materiales } \\
\text { leídos/ preparados }\end{array}$ & & & & \\
\hline \multirow{3}{*}{$\begin{array}{l}\text { Capacidad de } \\
\text { autoevaluar } \\
\text { sus } \\
\text { aprendizajes }\end{array}$} & 16 & $\begin{array}{l}\text { Trasladar a otras situaciones los } \\
\text { aprendizajes teóricos/prácticos }\end{array}$ & & & & \\
\hline & 17 & $\begin{array}{l}\text { Integrar actividades de docencia con } \\
\text { investigación }\end{array}$ & & & & \\
\hline & 18 & $\begin{array}{l}\text { Comprobar la relación de las } \\
\text { asignaturas cursadas con la puesta en } \\
\text { acción de sus prácticas profesionales }\end{array}$ & & & & \\
\hline
\end{tabular}

443

La Práctica Profesional como área para potenciar las competencias pedagógicas necesarias para la enseñanza en Educación Infantil 


\begin{tabular}{|c|c|c|c|c|c|c|}
\hline Categoría & ítem & $\begin{array}{l}\text { Usted como formador de la } \\
\text { UPE L considera que los (as) } \\
\text { estudiantes de Educación } \\
\text { Preescolar, aprendieron a: }\end{array}$ & $\begin{array}{c}4 \\
\mathrm{TA}\end{array}$ & $\begin{array}{c}3 \\
B A\end{array}$ & $\begin{array}{c}2 \\
P A\end{array}$ & $\begin{array}{c}1 \\
E D\end{array}$ \\
\hline \multirow{4}{*}{$\begin{array}{l}\text { O rganización de } \\
\text { la situación } \\
\text { enseñanza- } \\
\text { aprendizaje en } \\
\text { Educación Inicial }\end{array}$} & 19 & $\begin{array}{l}\text { Crear ambientes que motiven a } \\
\text { los niños al descubrimiento de sus } \\
\text { propias capacidades, limitaciones, } \\
\text { intereses y necesidades. }\end{array}$ & & & & \\
\hline & 20 & $\begin{array}{l}\text { Elaborar material didáctico } \\
\text { adecuado a los requerimientos de } \\
\text { las actividades planificadas y de } \\
\text { los aprendizajes esperados. }\end{array}$ & & & & \\
\hline & 21 & $\begin{array}{l}\text { Crear ambientes de aprendizaje, } \\
\text { respondiendo a las exigencias del } \\
\text { Diseño Curricular Educación } \\
\text { Inicial. }\end{array}$ & & & & \\
\hline & 22 & $\begin{array}{l}\text { Diseñar recursos para el } \\
\text { aprendizaje. }\end{array}$ & & & & \\
\hline \multirow[t]{5}{*}{$\begin{array}{l}\text { Proceso de } \\
\text { planificación en } \\
\text { Educación Inicial }\end{array}$} & 23 & $\begin{array}{l}\text { Planificar actividades en virtud } \\
\text { del logro de los aprendizajes } \\
\text { esperados. }\end{array}$ & & & & \\
\hline & 24 & $\begin{array}{l}\text { Planificar proyectos involucrando } \\
\text { activamente a niños y niñas, sus } \\
\text { familias, personal, comunidad } \\
\text { circundante. }\end{array}$ & & & & \\
\hline & 25 & $\begin{array}{l}\text { Diseñar, administrar y ejecutar } \\
\text { proyectos educativos. }\end{array}$ & & & & \\
\hline & 26 & $\begin{array}{l}\text { Planificar experiencias de } \\
\text { orientación a la comunidad sobre } \\
\text { temas pedagógicos. }\end{array}$ & & & & \\
\hline & 27 & $\begin{array}{l}\text { Planificar experiencias de } \\
\text { desarrollo personal para las } \\
\text { familias. }\end{array}$ & & & & \\
\hline
\end{tabular}




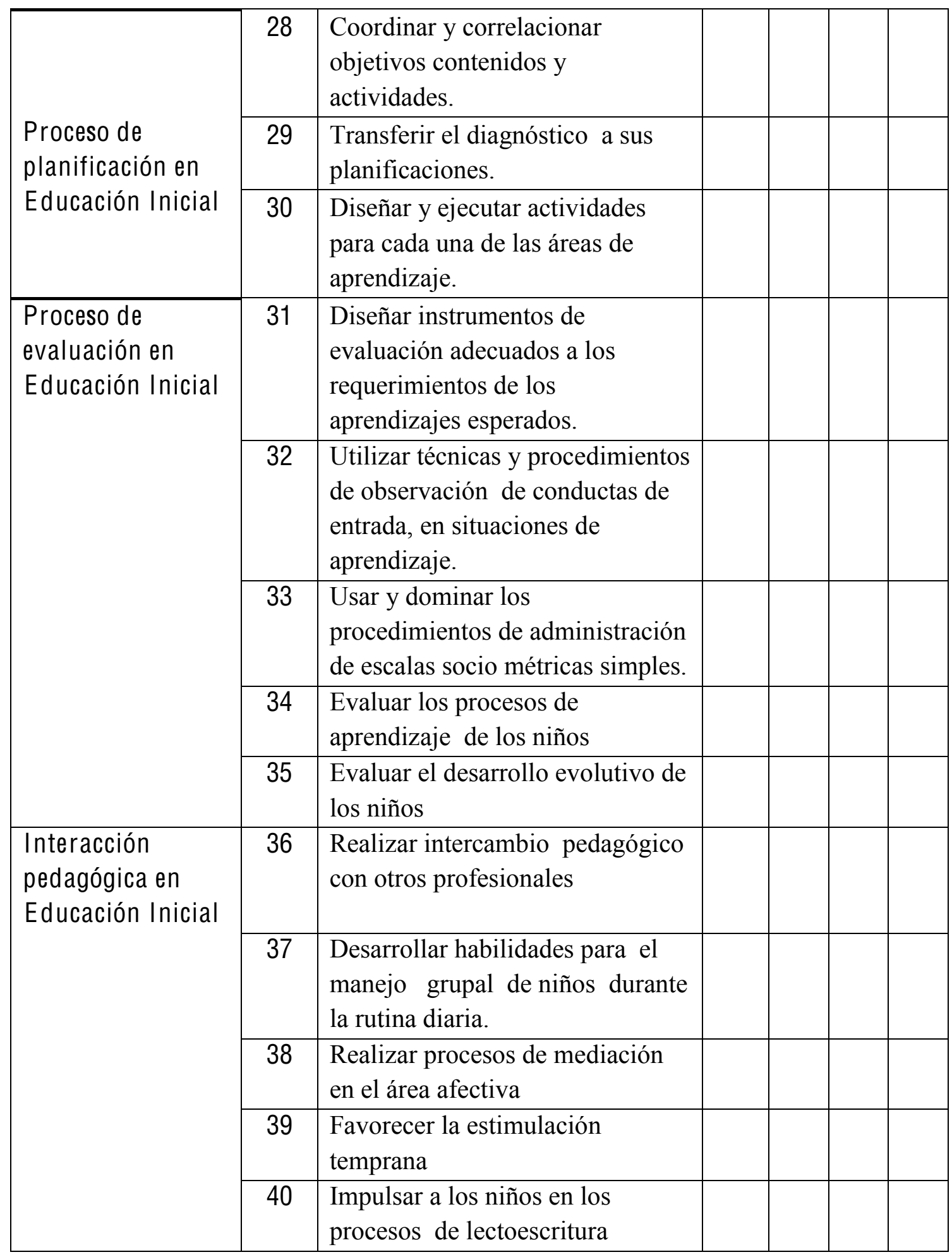




\begin{tabular}{|l|c|l|l|l|l|l|}
\hline \multirow{5}{*}{} & 41 & $\begin{array}{l}\text { Impulsar a los niños en el proceso } \\
\text { lógico-matemático }\end{array}$ & & & \\
\hline & 42 & Fortalecer la autoestima del niño & & & & \\
\hline & 43 & $\begin{array}{l}\text { Fomentar la educación para la } \\
\text { salud }\end{array}$ & & & \\
\cline { 2 - 6 } $\begin{array}{l}\text { Interacción } \\
\text { pedagógica en } \\
\text { Educación Inicial }\end{array}$ & 44 & $\begin{array}{l}\text { Desarrollar habilidades para la } \\
\text { resolución de situaciones difíciles } \\
\text { de resolver: preguntas sobre } \\
\text { sexualidad, agresividad infantil. }\end{array}$ & & & & \\
\hline
\end{tabular}

\begin{tabular}{|c|c|c|c|c|c|c|}
\hline Categoría & ítem & $\begin{array}{l}\text { Con relación al proceso de } \\
\text { enseñanza, considera que usted: }\end{array}$ & $\begin{array}{c}4 \\
\mathrm{TA}\end{array}$ & $\begin{array}{c}3 \\
B A\end{array}$ & $\begin{array}{c}2 \\
P A\end{array}$ & $\begin{array}{c}1 \\
E D\end{array}$ \\
\hline \multirow[t]{8}{*}{$\begin{array}{l}\text { Didáctica } \\
\text { universitaria }\end{array}$} & 45 & $\begin{array}{l}\text { Proporciono fuentes de } \\
\text { información y recursos a los } \\
\text { estudiantes }\end{array}$ & & & & \\
\hline & 46 & $\begin{array}{l}\text { Los motivo a preparar actividades } \\
\text { de aprendizaje }\end{array}$ & & & & \\
\hline & 47 & $\begin{array}{l}\text { Inicio los temas } \\
\text { contextualizándolos previamente }\end{array}$ & & & & \\
\hline & 48 & $\begin{array}{l}\text { Realizó asociación de temas con los } \\
\text { objetivos planteados }\end{array}$ & & & & \\
\hline & 49 & Aporto conocimientos actualizados & & & & \\
\hline & 50 & $\begin{array}{l}\text { Domina los aspectos teóricos de } \\
\text { los contenidos de las asignaturas }\end{array}$ & & & & \\
\hline & 51 & $\begin{array}{l}\text { Domina los aspectos prácticos de } \\
\text { los contenidos de las asignaturas }\end{array}$ & & & & \\
\hline & 52 & $\begin{array}{l}\text { Relaciona la asignatura con otras } \\
\text { ciencias o conocimientos }\end{array}$ & & & & \\
\hline
\end{tabular}

\begin{tabular}{|l|c|l|c|c|c|c|}
\hline Categoría & ítem & $\begin{array}{l}\text { En relación a las actividades en } \\
\text { clase, se realizaron: }\end{array}$ & $\begin{array}{c}4 \\
\text { TA }\end{array}$ & $\begin{array}{c}3 \\
\text { BA }\end{array}$ & $\begin{array}{c}1 \\
\text { PA }\end{array}$ \\
\hline $\begin{array}{l}\text { Metodología } \\
\text { universitaria }\end{array}$ & 53 & $\begin{array}{l}\text { Exposiciones magistrales del } \\
\text { profesor. }\end{array}$ & & & & \\
\cline { 2 - 6 } & 54 & $\begin{array}{l}\text { Exposiciones orales de los } \\
\text { estudiantes }\end{array}$ & & & \\
\hline
\end{tabular}




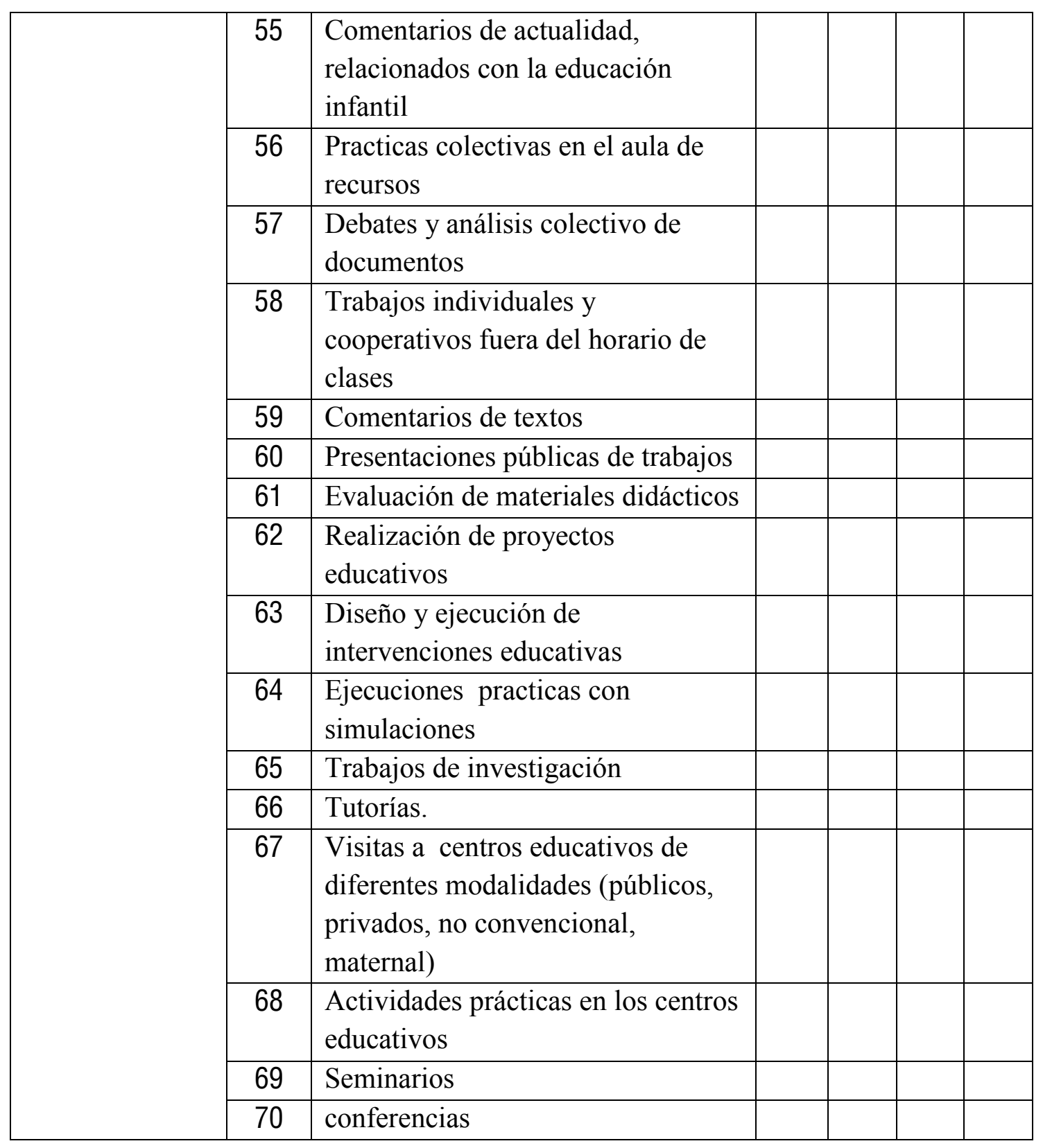

447

La Práctica Profesional como área para potenciar las competencias pedagógicas necesarias para la enseñanza en Educación Infantil 


\begin{tabular}{|l|c|l|c|c|c|c|}
\hline Categoría & ítem & $\begin{array}{l}\text { Las actividades de formación se } \\
\text { realizaron en los siguientes } \\
\text { lugares }\end{array}$ & $\begin{array}{c}4 \\
\text { TA }\end{array}$ & $\begin{array}{c}3 \\
\text { BA }\end{array}$ & $\begin{array}{c}2 \\
\text { PA }\end{array}$ & $\begin{array}{c}1 \\
\text { ED }\end{array}$ \\
\hline $\begin{array}{l}\text { Contextos de } \\
\text { aprendizaje }\end{array}$ & 71 & Aula de clases de la Universidad & & & & \\
\hline & 72 & Aula de recursos múltiples & & & & \\
\hline & 73 & Biblioteca/ salas de documentación & & & & \\
\hline & 74 & Centros maternales & & & & \\
\hline & 75 & $\begin{array}{l}\text { Centros educativos no } \\
\text { convencionales }\end{array}$ & & & \\
& 76 & Centros preescolares & & & & \\
\hline & 77 & Contextos comunitarios & & & \\
\hline
\end{tabular}

\begin{tabular}{|l|c|l|c|c|c|c|}
\hline Categoría & ítem & $\begin{array}{l}\text { Entre las siguientes actividades } \\
\text { de evaluación, marque las } \\
\text { aplicadas en el proceso de } \\
\text { formación }\end{array}$ & $\begin{array}{c}4 \\
\text { TA }\end{array}$ & $\begin{array}{c}3 \\
\text { BA }\end{array}$ & $\begin{array}{c}2 \\
\text { PA }\end{array}$ & $\begin{array}{c}1 \\
\text { ED }\end{array}$ \\
\hline $\begin{array}{l}\text { Métodos y } \\
\text { criterios de } \\
\text { evaluación }\end{array}$ & 78 & Trabajos grupales e individuales & & & & \\
\cline { 2 - 7 } & 79 & Proyectos de investigación & & & & \\
\cline { 2 - 7 } & 80 & Informes escritos & & & & \\
\hline & 81 & Debates & & & & \\
\hline & 82 & Exposiciones & & & & \\
\hline & 83 & Pruebas orales & & & & \\
\hline & 84 & Seguimientos desde la tutoría & & & \\
\hline & 85 & Realización de trabajos en grupo & & & & \\
\hline
\end{tabular}

\begin{tabular}{|l|c|l|c|c|c|c|}
\hline Categoría & ítem & $\begin{array}{l}\text { Exprese su opinión sobre los } \\
\text { aspectos relacionados al proceso } \\
\text { académico de Práctica } \\
\text { Profesional }\end{array}$ & $\begin{array}{c}4 \\
\text { TA }\end{array}$ & BA & PA & $\begin{array}{c}1 \\
\text { ED }\end{array}$ \\
\hline Créditos & 86 & Normativa (reglamento) & & & & \\
\hline
\end{tabular}




\begin{tabular}{|c|c|l|l|l|l|l|}
\hline académicos & 87 & Ubicación en el plan de estudios & & & & \\
\hline & 88 & Apoyo institucional & & & & \\
\hline & 89 & Apoyo de los centros de aplicación & & & & \\
\hline & 90 & Recursos para el aprendizaje & & & & \\
\hline & 91 & Evaluación & & & & \\
\hline Planes y & 92 & Relación teoría-práctica & & & & \\
\hline & 93 & Adaptación al contexto & & & & \\
\hline & 94 & Preparación para el desempeño & & & & \\
\hline & 95 & Uso de las TIC'S & & & & \\
\hline & 96 & Innovación científica & & & & \\
\hline Servicios & 97 & Becas de estudio & & & & \\
\hline & 98 & Beca/ Trabajo o ayudantía & & & & \\
\hline & 99 & Biblioteca & & & & \\
\hline & 100 & Transporte & & & & \\
\hline & 101 & Comedor & & & & \\
\hline & 102 & Cafetín & & & & \\
\hline & 103 & Aéreas de esparcimiento & & & & \\
\hline
\end{tabular}


ANEXO 3. Matriz de Categoría, Dimensiones, Indicadores e Ítems.

\begin{tabular}{|c|c|c|c|c|}
\hline $\begin{array}{l}\text { Objetivo } \\
\text { General }\end{array}$ & Categoría & Dimensiones & Indicadores & $N^{\circ}$ de ítems \\
\hline \multirow{14}{*}{$\begin{array}{l}\text { Diseñar un } \\
\text { programa de } \\
\text { práctica } \\
\text { profesional, } \\
\text { que potencie } \\
\text { las } \\
\text { competencias } \\
\text { pedagógicas } \\
\text { necesarias } \\
\text { para el } \\
\text { ejercicio de la } \\
\text { función } \\
\text { docente en el } \\
\text { nivel de } \\
\text { Educación } \\
\text { Inicial. }\end{array}$} & \multirow{14}{*}{$\begin{array}{l}\text { Práctica } \\
\text { profesional en } \\
\text { Educación } \\
\text { Inicial: Proceso } \\
\text { educativo } \\
\text { universitario, } \\
\text { orientado para } \\
\text { que los futuros } \\
\text { maestros } \\
\text { adquieran, } \\
\text { desarrollen y/o } \\
\text { potencien las } \\
\text { habilidades y } \\
\text { competencias } \\
\text { vinculadas con } \\
\text { el desempeño } \\
\text { profesional en } \\
\text { educación } \\
\text { inicial }\end{array}$} & \multirow{3}{*}{$\begin{array}{l}\text { Dimensión } \\
\text { Procesos de } \\
\text { Aprendizaje }\end{array}$} & $\begin{array}{l}\text { Aprender } \\
\text { Aprender }\end{array}$ & $\begin{array}{l}09-10-11-12- \\
13\end{array}$ \\
\hline & & & $\begin{array}{l}\text { Actualización } \\
\text { Permanente }\end{array}$ & $14-15$ \\
\hline & & & $\begin{array}{lr}\text { Capacidad } & \text { de } \\
\text { Autoevaluar } & \text { sus } \\
\text { Aprendizajes } & \\
\end{array}$ & $16-17-18$ \\
\hline & & \multirow{4}{*}{$\begin{array}{l}\text { Dimensión } \\
\text { Didáctica } \\
\text { Especifica de } \\
\text { Educación } \\
\text { Inicial }\end{array}$} & $\begin{array}{l}\text { Organización de la } \\
\text { Situación Enseñanza- } \\
\text { Aprendizaje }\end{array}$ & $19-20-21-22$ \\
\hline & & & $\begin{array}{ll}\text { Proceso } & \mathrm{de} \\
\text { Planificación } & \end{array}$ & $\begin{array}{l}23-24-25-26- \\
27-28-29-30\end{array}$ \\
\hline & & & $\begin{array}{ll}\text { Procesos } & \text { de } \\
\text { Evaluación } & \end{array}$ & $\begin{array}{l}31-32-33-34- \\
35 .\end{array}$ \\
\hline & & & $\begin{array}{l}\text { Interacción } \\
\text { Pedagógica }\end{array}$ & $\begin{array}{l}36-37-38-39- \\
40-41-42-43- \\
44 .\end{array}$ \\
\hline & & \multirow[t]{4}{*}{$\begin{array}{l}\text { Dimensión } \\
\text { Enseñanza } \\
\text { Universitaria }\end{array}$} & $\begin{array}{l}\text { Didáctica } \\
\text { Universitaria }\end{array}$ & $\begin{array}{l}45-46-47-48- \\
49-50-51-52\end{array}$ \\
\hline & & & $\begin{array}{l}\text { Metodología } \\
\text { Universitaria }\end{array}$ & $\begin{array}{l}53-54-55-56- \\
57-58-59-60- \\
61-62-63-64- \\
65-66-67-68- \\
69-70\end{array}$ \\
\hline & & & $\begin{array}{ll}\text { Contextos } & \text { de } \\
\text { aprendizaje } & \\
\end{array}$ & $\begin{array}{l}71-72-73-74- \\
75-76-77\end{array}$ \\
\hline & & & $\begin{array}{l}\text { Métodos y criterios } \\
\text { para evaluar }\end{array}$ & $\begin{array}{l}78-79-80-81- \\
82-83-84-85\end{array}$ \\
\hline & & \multirow{3}{*}{$\begin{array}{l}\text { Dimensión } \\
\text { Académico } \\
\text { Estudiantil }\end{array}$} & Créditos Académicos & $\begin{array}{l}86-87-88-89- \\
90-91\end{array}$ \\
\hline & & & Planes y Programas & $\begin{array}{l}92-93-94-95- \\
96\end{array}$ \\
\hline & & & $\begin{array}{l}\text { Servicios } \\
\text { Estudiantiles }\end{array}$ & $\begin{array}{l}97-98-99-100- \\
101-102-103\end{array}$ \\
\hline
\end{tabular}




\section{ANEXO 4.}

Criterios de decisión para la confiabilidad de un instrumento.

\begin{tabular}{|l|l|}
\hline \multicolumn{1}{|c|}{ Rango } & \multicolumn{1}{c|}{ Confiabilidad (Dimensión) } \\
\hline $0,81-1$ & Muy alta \\
\hline $0,61-0,80$ & Alta \\
\hline $0,41-0,60$ & Media* \\
\hline $0,21-0,40$ & Baja* \\
\hline $0-0,20$ & Muy baja* \\
\hline
\end{tabular}

Fuente: Palella y Martins 2006. *Se sugiere repetir la validación del instrumento puesto que es recomendable que el resultado sea mayor o igual que 0,61 .

Análisis de fiabilidad al cuestionario

$$
\begin{aligned}
& \text { Estudiantes }
\end{aligned}
$$

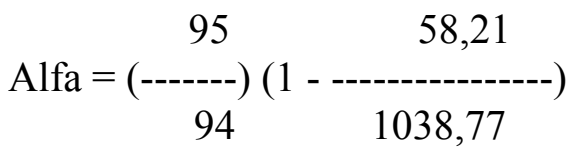

$A L F A=0,954$

\section{Profesores}

$$
\text { Alfa }=\left(\begin{array}{cc}
88 & 73,77 \\
-----) & (1 \\
87 & -------)
\end{array}\right.
$$

$A L F A=0,853$ 


\section{Anexo 5.}
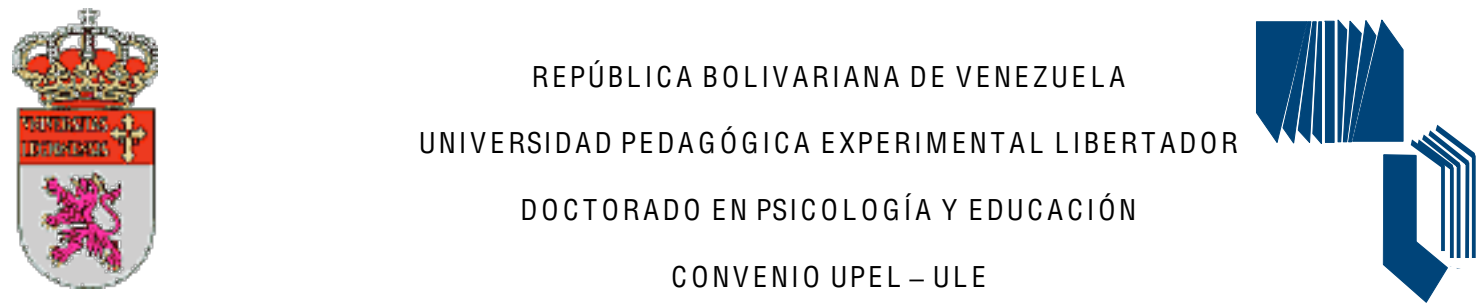

\section{Validación del Instrumento}

El suscrito, profesional universitario reconocido y competente para validar instrumentos de recolección de datos, hace constar que ha evaluado el cuestionario de la tesis para optar al grado de Doctora en Educación, titulado: La Práctica Profesional como área para potenciar las competencias pedagógicas del estudiante de Educación Preescolar, cuya autoría corresponde a Reina Lisbeth Galindo Navas, titular de la cédula de identidad $\mathrm{N}^{\circ}$ 716611, para lo cual completé un formulario previamente diseñado para validar dicho instrumento desde el punto de vista de contenido, pertinencia y relevancia.

Maracay, 05 Febrero 2010.

Nombre y apellido:

$\mathrm{N}^{\circ}$ de Cédula de identidad

Profesión:

Firma: 
Estimado experto(a):

Reciba un cordial saludo, en la oportunidad de comunicarle que dada la necesidad de contar con datos confiables para lograr la ejecución del trabajo de investigación denominado: La Práctica Profesional como área para potenciar las competencias pedagógicas del estudiante de Educación Preescolar, solicito su valiosa colaboración en el sentido de obtener la validez del instrumento anexo, que será utilizado en el mencionado trabajo.

Se agradece de antemano su aporte, que será de mucha importancia en la aplicación y verificación de los resultados de la investigación.

Los criterios para su evaluación son los siguientes:

\begin{tabular}{|l|l|}
\hline Contenido & $\begin{array}{l}\text { El contenido es claro y permite entender toda la afirmación de la misma } \\
\text { forma. Marque (SI) o (NO) }\end{array}$ \\
\hline Pertinencia & $\begin{array}{l}\text { Si la afirmación sirve para aclarar lo que se pregunta y se corresponde con } \\
\text { ello. Marque (SI) o (NO) }\end{array}$ \\
\hline Relevancia & $\begin{array}{l}\text { Se refiere a la importancia del tema. Marque (1) muy importante, (2) } \\
\text { Importante, (3) Nada importante }\end{array}$ \\
\hline
\end{tabular}

Atentamente:

Reina Galindo

453

La Práctica Profesional como área para potenciar las competencias pedagógicas necesarias para la enseñanza en Educación Infantil 


\section{Cuestionario para analizar por el grupo de expertos}

\section{La Práctica Profesional como área para potenciar las competencias pedagógicas del estudiante de Educación Inicial.}

\begin{tabular}{|l|l|}
\hline Contenido & $\begin{array}{l}\text { El contenido es claro y permite entender toda la afirmación de la misma forma. Marque (SI) } \\
\text { o (NO) }\end{array}$ \\
\hline Pertinencia & $\begin{array}{l}\text { Si la afirmación sirve para aclarar lo que se pregunta y se corresponde con ello. Marque } \\
\text { (SI) o (NO) }\end{array}$ \\
\hline Relevancia & $\begin{array}{l}\text { Se refiere a la importancia del tema. Marque (1) muy importante, (2) Importante, (3) Nada } \\
\text { importante }\end{array}$ \\
\hline
\end{tabular}

\begin{tabular}{|c|c|c|c|c|c|c|c|c|c|}
\hline \multirow[t]{2}{*}{ Categoría } & \multirow[t]{2}{*}{ ítem } & \multirow{2}{*}{$\begin{array}{l}\text { Durante tu formación como } \\
\text { estudiante de Educación Preescolar } \\
\text { consideras que aprendiste a: }\end{array}$} & \multicolumn{2}{|c|}{ Contenido } & \multicolumn{2}{|c|}{ Pertinencia } & \multicolumn{3}{|c|}{ Relevancia } \\
\hline & & & $\mathrm{Si}$ & No & $\mathrm{Si}$ & No & 1 & 2 & 3 \\
\hline \multirow[t]{5}{*}{$\begin{array}{l}\text { Aprender a } \\
\text { aprender }\end{array}$} & 9 & $\begin{array}{l}\text { Integrar las nuevas tendencias } \\
\text { científicas a la práctica pedagógica. }\end{array}$ & & & & & & & \\
\hline & 10 & $\begin{array}{l}\text { Integrar las nuevas tendencias } \\
\text { tecnológicas a la práctica pedagógica. }\end{array}$ & & & & & & & \\
\hline & 11 & $\begin{array}{l}\text { Desarrollar habilidades para la } \\
\text { resolución de problemas }\end{array}$ & & & & & & & \\
\hline & 12 & $\begin{array}{l}\text { Aprender a partir de tus propias } \\
\text { experiencias }\end{array}$ & & & & & & & \\
\hline & 13 & Aprender a partir de los errores & & & & & & & \\
\hline \multirow[t]{2}{*}{$\begin{array}{l}\text { Actualización } \\
\text { permanente }\end{array}$} & 14 & $\begin{array}{l}\text { Ampliar y complementar los } \\
\text { conocimientos adquiridos }\end{array}$ & & & & & & & \\
\hline & 15 & $\begin{array}{l}\text { Asistir a clases con materiales leídos/ } \\
\text { preparados }\end{array}$ & & & & & & & \\
\hline \multirow{3}{*}{$\begin{array}{l}\text { Capacidad de } \\
\text { autoevaluar sus } \\
\text { aprendizajes }\end{array}$} & 16 & $\begin{array}{l}\text { Trasladar a otras situaciones los } \\
\text { aprendizajes teóricos/prácticos }\end{array}$ & & & & & & & \\
\hline & 17 & $\begin{array}{l}\text { Integrar actividades de docencia con } \\
\text { investigación }\end{array}$ & & & & & & & \\
\hline & 18 & $\begin{array}{l}\text { Comprobar la relación de las } \\
\text { asignaturas cursadas con la puesta en } \\
\text { práctica de tus prácticas profesionales }\end{array}$ & & & & & & & \\
\hline
\end{tabular}

Observaciones: 


\begin{tabular}{|c|c|c|c|c|c|c|c|c|c|}
\hline \multirow[t]{2}{*}{ Categoría } & \multirow[t]{2}{*}{ ítem } & \multirow{2}{*}{$\begin{array}{l}\text { Durante tu formación como } \\
\text { estudiante de Educación } \\
\text { Preescolar consideras que } \\
\text { aprendiste a: }\end{array}$} & \multicolumn{2}{|c|}{ Contenido } & \multicolumn{2}{|c|}{ Relevancia } & \multicolumn{3}{|c|}{ Pertinencia } \\
\hline & & & $\mathrm{Si}$ & No & Si & No & 1 & 2 & 3 \\
\hline \multirow[t]{4}{*}{$\begin{array}{l}\text { Organización de la } \\
\text { situación enseñanza- } \\
\text { aprendizaje en } \\
\text { Educación Inicial }\end{array}$} & 19 & $\begin{array}{l}\text { Crear ambientes que motiven a los } \\
\text { niños al descubrimiento de sus } \\
\text { propias capacidades, limitaciones, } \\
\text { intereses y necesidades }\end{array}$ & & & & & & & \\
\hline & 20 & $\begin{array}{l}\text { Elaborar material didáctico } \\
\text { adecuado a los requerimientos de } \\
\text { las actividades planificadas y de los } \\
\text { aprendizajes esperados }\end{array}$ & & & & & & & \\
\hline & 21 & $\begin{array}{l}\text { Crear ambientes de aprendizaje, } \\
\text { respondiendo a las exigencias del } \\
\text { Diseño Curricular Educación Inicial }\end{array}$ & & & & & & & \\
\hline & 22 & $\begin{array}{l}\text { Diseñar recursos para el } \\
\text { aprendizaje }\end{array}$ & & & & & & & \\
\hline \multirow{7}{*}{$\begin{array}{l}\text { Proceso de } \\
\text { planificación en } \\
\text { Educación Inicial }\end{array}$} & 23 & $\begin{array}{l}\text { Planificar actividades en virtud del } \\
\text { logro de los aprendizajes esperados }\end{array}$ & & & & & & & \\
\hline & 24 & $\begin{array}{l}\text { Planificar proyectos involucrando } \\
\text { activamente a niños y niñas, sus } \\
\text { familias, personal, comunidad } \\
\text { circundante }\end{array}$ & & & & & & & \\
\hline & 25 & $\begin{array}{l}\text { Diseñar, administrar y ejecutar } \\
\text { proyectos educativos }\end{array}$ & & & & & & & \\
\hline & 26 & $\begin{array}{l}\text { Planificar experiencias de } \\
\text { orientación a la comunidad sobre } \\
\text { temas pedagógicos }\end{array}$ & & & & & & & \\
\hline & 27 & $\begin{array}{l}\text { Planificar experiencias de } \\
\text { desarrollo personal para las familias }\end{array}$ & & & & & & & \\
\hline & 28 & $\begin{array}{l}\text { Coordinar y correlacionar objetivos } \\
\text { contenidos y actividades }\end{array}$ & & & & & & & \\
\hline & 29 & $\begin{array}{l}\text { Transferir el diagnóstico a sus } \\
\text { planificaciones }\end{array}$ & & & & & & & \\
\hline $\begin{array}{l}\text { Proceso de } \\
\text { planificación en } \\
\text { Educación Inicial }\end{array}$ & 30 & $\begin{array}{l}\text { Diseñar y ejecutar actividades para } \\
\text { cada una de las áreas de aprendizaje }\end{array}$ & & & & & & & \\
\hline
\end{tabular}




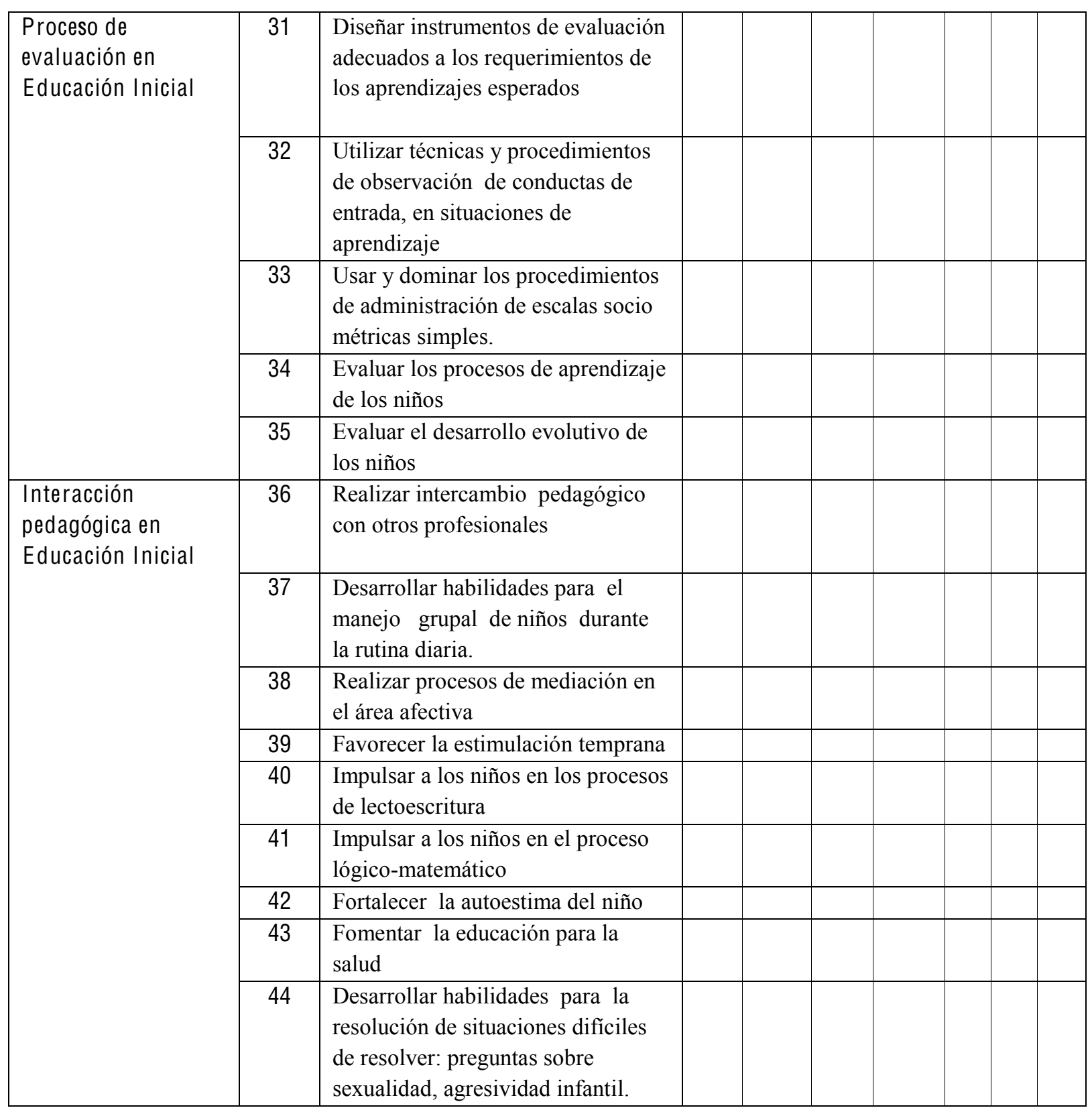

Observaciones: 


\begin{tabular}{|c|c|c|c|c|c|c|c|c|c|}
\hline \multirow[t]{2}{*}{ Categoría } & \multirow[t]{2}{*}{ ítem } & \multirow{2}{*}{$\begin{array}{l}\text { Con relación al proceso de } \\
\text { enseñanza universitario, considera } \\
\text { que tus profesores: }\end{array}$} & \multicolumn{2}{|c|}{ Contenido } & \multicolumn{2}{|c|}{ Relevancia } & \multicolumn{3}{|c|}{ Pertinencia } \\
\hline & & & $\mathrm{Si}$ & No & $\mathrm{Si}$ & No & 1 & 2 & 3 \\
\hline \multirow[t]{8}{*}{$\begin{array}{l}\text { Didáctica } \\
\text { universitaria }\end{array}$} & 45 & $\begin{array}{l}\text { Proporcionaron fuentes de } \\
\text { información y recursos a los } \\
\text { estudiantes }\end{array}$ & & & & & & & \\
\hline & 46 & $\begin{array}{l}\text { Los motivaron a preparar actividades } \\
\text { de aprendizaje }\end{array}$ & & & & & & & \\
\hline & 47 & $\begin{array}{l}\text { Inician los temas contextualizándolos } \\
\text { previamente }\end{array}$ & & & & & & & \\
\hline & 48 & $\begin{array}{l}\text { Realizan asociación de temas con los } \\
\text { objetivos planteados }\end{array}$ & & & & & & & \\
\hline & 49 & Aportan conocimientos actualizados & & & & & & & \\
\hline & 50 & $\begin{array}{l}\text { Dominan los aspectos teóricos de los } \\
\text { contenidos de las asignaturas }\end{array}$ & & & & & & & \\
\hline & 51 & $\begin{array}{l}\text { Dominan los aspectos prácticos de los } \\
\text { contenidos de las asignaturas }\end{array}$ & & & & & & & \\
\hline & 52 & $\begin{array}{l}\text { Relacionan la asignatura con otras } \\
\text { ciencias o conocimientos }\end{array}$ & & & & & & & \\
\hline
\end{tabular}

Observaciones:

\begin{tabular}{|c|c|c|c|c|c|c|c|c|c|}
\hline \multirow[t]{2}{*}{ Categoría } & \multirow[t]{2}{*}{ ítem } & \multirow{2}{*}{$\begin{array}{l}\text { En relación a las actividades en } \\
\text { clase, consideras que tuviste la } \\
\text { oportunidad de participar en : }\end{array}$} & \multicolumn{2}{|c|}{ Contenido } & \multicolumn{2}{|c|}{ Relevancia } & \multicolumn{3}{|c|}{ Pertinencia } \\
\hline & & & $\mathrm{Si}$ & No & Si & No & 1 & 2 & 3 \\
\hline \multirow{6}{*}{$\begin{array}{l}\text { Metodología } \\
\text { universitaria }\end{array}$} & 53 & Exposiciones magistrales del profesor. & & & & & & & \\
\hline & 54 & Exposiciones orales de los estudiantes & & & & & & & \\
\hline & 55 & $\begin{array}{l}\text { Comentarios de actualidad, } \\
\text { relacionados con la educación infantil }\end{array}$ & & & & & & & \\
\hline & 56 & $\begin{array}{l}\text { Practicas colectivas en el aula de } \\
\text { recursos }\end{array}$ & & & & & & & \\
\hline & 57 & $\begin{array}{l}\text { Debates y análisis colectivo de } \\
\text { documentos }\end{array}$ & & & & & & & \\
\hline & 58 & $\begin{array}{l}\text { Trabajos individuales y cooperativos } \\
\text { fuera del horario de clases }\end{array}$ & & & & & & & \\
\hline
\end{tabular}

457

La Práctica Profesional como área para potenciar las competencias pedagógicas necesarias para la enseñanza en Educación Infantil 


\begin{tabular}{|l|l|l|l|l|l|l|l|l|l|}
\hline 59 & Comentarios de textos & & & & & \\
\hline & 60 & Presentaciones públicas de trabajos & & & & & & & \\
\hline 61 & Evaluación de materiales didácticos & & & & & & & \\
\hline 62 & Realización de proyectos educativos & & & & & & & \\
\hline 63 & $\begin{array}{l}\text { Diseño y ejecución de intervenciones } \\
\text { educativas }\end{array}$ & & & & & & & \\
\hline 64 & $\begin{array}{l}\text { Ejecuciones practicas con } \\
\text { simulaciones }\end{array}$ & & & & & & \\
\hline 65 & Trabajos de investigación & & & & & & & \\
\hline 66 & Tutorías. & & & & & & \\
\hline 67 & $\begin{array}{l}\text { Visitas a centros educativos de } \\
\text { diferentes modalidades (públicos, } \\
\text { privados, no convencional, maternal) }\end{array}$ & & & & & & & \\
\hline 68 & $\begin{array}{l}\text { Actividades prácticas en los centros } \\
\text { educativos }\end{array}$ & & & & & & & \\
\hline 6 & Seminarios & & & & & & & \\
\hline & Conferencias & & & & & & & \\
\hline
\end{tabular}

Observaciones:

\begin{tabular}{|c|c|c|c|c|c|c|c|c|c|}
\hline \multirow[t]{2}{*}{ Categoría } & \multirow[t]{2}{*}{ ítem } & \multirow{2}{*}{$\begin{array}{l}\text { Las actividades de formación en las } \\
\text { que usted participo se realizaron en } \\
\text { los siguientes lugares }\end{array}$} & \multicolumn{2}{|c|}{ Contenido } & \multicolumn{2}{|c|}{ Relevancia } & \multicolumn{3}{|c|}{ Pertinencia } \\
\hline & & & $\mathrm{Si}$ & No & $\mathrm{Si}$ & No & 1 & 2 & 3 \\
\hline \multirow{7}{*}{$\begin{array}{l}\text { Contextos de } \\
\text { aprendizaje }\end{array}$} & 71 & Aula de clases de la Universidad & & & & & & & \\
\hline & 72 & Aula de recursos múltiples & & & & & & & \\
\hline & 73 & Biblioteca/ salas de documentación & & & & & & & \\
\hline & 74 & Centros maternales & & & & & & & \\
\hline & 75 & Centros educativos no convencionales & & & & & & & \\
\hline & 76 & Centros preescolares & & & & & & & \\
\hline & 77 & Contextos comunitarios & & & & & & & \\
\hline
\end{tabular}

Observaciones:

\begin{tabular}{|c|c|c|c|c|c|c|c|c|c|}
\hline \multirow[t]{2}{*}{ Categoría } & \multirow[t]{2}{*}{ ítem } & \multirow{2}{*}{$\begin{array}{l}\text { Entre las siguientes actividades de } \\
\text { evaluación, marque las aplicadas en } \\
\text { su proceso de formación }\end{array}$} & \multicolumn{2}{|c|}{ Contenido } & \multicolumn{2}{|c|}{ Relevancia } & \multicolumn{3}{|c|}{ Pertinencia } \\
\hline & & & $\mathrm{Si}$ & No & $\mathrm{Si}$ & No & 1 & 2 & 3 \\
\hline Métodos y & 78 & Trabajos grupales e individuales & & & & & & & \\
\hline
\end{tabular}

458

La Práctica Profesional como área para potenciar las competencias pedagógicas necesarias para la enseñanza en Educación Infantil 


\begin{tabular}{|l|c|l|l|l|l|l|l|l|l|}
\hline $\begin{array}{l}\text { criterios de } \\
\text { evaluación }\end{array}$ & 79 & Proyectos de investigación & & & & & & & \\
\hline & 80 & Informes escritos & & & & & & & \\
\hline & 81 & Debates & & & & & & & \\
\hline 82 & Exposiciones & & & & & & & \\
\hline & 83 & Pruebas orales & & & & & & & \\
\hline & 84 & Seguimientos desde la tutoría & & & & & & & \\
\hline & 85 & Realización de trabajos en grupo & & & & & & & \\
\hline
\end{tabular}

Observaciones:

\begin{tabular}{|c|c|c|c|c|c|c|c|c|c|}
\hline \multirow[t]{2}{*}{ Categoría } & \multirow[t]{2}{*}{ ítem } & \multirow{2}{*}{$\begin{array}{l}\text { Exprese su opinión sobre los } \\
\text { aspectos relacionados al proceso } \\
\text { académico de Práctica Profesional }\end{array}$} & \multicolumn{2}{|c|}{ Contenido } & \multicolumn{2}{|c|}{ Relevancia } & \multicolumn{3}{|c|}{ Pertinencia } \\
\hline & & & $\mathrm{Si}$ & No & $\mathrm{Si}$ & No & 1 & 2 & 3 \\
\hline \multirow{6}{*}{$\begin{array}{l}\text { Créditos } \\
\text { académicos }\end{array}$} & 86 & Normativa (reglamento) & & & & & & & \\
\hline & 87 & Ubicación en el plan de estudios & & & & & & & \\
\hline & 88 & Apoyo institucional & & & & & & & \\
\hline & 89 & Apoyo de los centros de aplicación & & & & & & & \\
\hline & 90 & Recursos para el aprendizaje & & & & & & & \\
\hline & 91 & Evaluación & & & & & & & \\
\hline \multirow{5}{*}{$\begin{array}{l}\text { Planes y } \\
\text { Programas }\end{array}$} & 92 & Relación teoría-práctica & & & & & & & \\
\hline & 93 & Adaptación al contexto & & & & & & & \\
\hline & 94 & Preparación para el desempeño & & & & & & & \\
\hline & 95 & Uso de las TIC'S & & & & & & & \\
\hline & 96 & Innovación científica & & & & & & & \\
\hline \multirow{7}{*}{$\begin{array}{c}\text { Servicios } \\
\text { estudiantiles }\end{array}$} & 97 & Becas de estudio & & & & & & & \\
\hline & 98 & Beca/ Trabajo o ayudantía & & & & & & & \\
\hline & 99 & Biblioteca & & & & & & & \\
\hline & 100 & Transporte & & & & & & & \\
\hline & 101 & Comedor & & & & & & & \\
\hline & 102 & Cafetín & & & & & & & \\
\hline & 103 & Áreas de esparcimiento & & & & & & & \\
\hline
\end{tabular}

Observaciones:

459

La Práctica Profesional como área para potenciar las competencias pedagógicas necesarias para la enseñanza en Educación Infantil 
Anexo 6. Matriz de Ubicación y Secuencia de los Cursos y Fases. Especialidad: Educación Preescolar. DISEÑ 0 CURRICULAR 1996

\begin{tabular}{|c|c|c|c|c|c|c|c|c|c|c|}
\hline SEM & $\begin{array}{l}\text { FORMACION } \\
\text { GENERAL }\end{array}$ & U.C & $\begin{array}{c}\text { FORMACION } \\
\text { ESPECIALIZADA }\end{array}$ & U.C & $\begin{array}{l}\text { FORMACION } \\
\text { PEDAGOGICA }\end{array}$ & U.C & $\begin{array}{c}\text { PRACTICA } \\
\text { PROFESIONAL }\end{array}$ & U.C & $\mathrm{T} / \mathrm{C}$ & T/U.C \\
\hline$X$ & & & Optativo de Profundización. & 3 & $\begin{array}{ll}\text { Optativo } & \text { área } \\
\text { metodológica. } & \end{array}$ & 3 & $\begin{array}{l}\text { Fase integración docencia } \\
\text { administración. }\end{array}$ & 7 & 3 & 13 \\
\hline IX & $\begin{array}{l}\text { Optativo área } \\
\text { biopsicosocial. }\end{array}$ & 3 & $\begin{array}{l}\text { Optativo de Profundización. } \\
\text { Optativo de Profundización. } \\
\text { Optativo de Integración. }\end{array}$ & $\begin{array}{l}3 \\
3 \\
3\end{array}$ & $\begin{array}{l}\text { Optativo } \\
\text { metodológica. }\end{array}$ & 3 & & & 5 & 15 \\
\hline VIII & & & $\begin{array}{lcc}\text { Expresión } & \text { Dramática } & \text { en } \\
\text { Preescolar. } & & \\
\text { Procesos } & \text { Grupales } & \text { en } \\
\text { Educación } & \text { Preescolar. } & \end{array}$ & $\begin{array}{l}3 \\
3\end{array}$ & $\begin{array}{l}\text { Optativo área teórico- } \\
\text { educativa. }\end{array}$ & 3 & $\begin{array}{lll}\text { Fase de } & \text { Ejecución } & \text { de } \\
\text { Proyectos Educativos } & \end{array}$ & 6 & 4 & 15 \\
\hline VII & $\begin{array}{l}\text { Venezuela } \\
\text { Contemporánea. }\end{array}$ & 3 & $\begin{array}{l}\text { Estrategias para el desarrollo } \\
\text { integral del niño de 0-3 años. } \\
\text { Correspondencia Básica y } \\
\text { Preescolar. }\end{array}$ & $\begin{array}{l}3 \\
3\end{array}$ & $\begin{array}{l}\begin{array}{l}\text { Gerencia de la } \\
\text { Educación. }\end{array} \\
\text { Currículo. }\end{array}$ & $\begin{array}{l}3 \\
3\end{array}$ & & & 5 & 15 \\
\hline VI & $\begin{array}{|lrr|}\text { Optativo } & \text { del } & \text { área } \\
\text { Rescate } & \text { de } & \text { la } \\
\text { cultura } & & \\
\end{array}$ & 2 & $\begin{array}{l}\text { Literatura Infantil y Educ. } \\
\text { Preescolar. } \\
\text { Expresión Plástica en el niño en } \\
\text { edad Preescolar. }\end{array}$ & $\begin{array}{l}3 \\
3\end{array}$ & & & Fase Docencia Integrada $(* *)$ & $\begin{array}{c}(* *) \\
5\end{array}$ & $\begin{array}{c}(* *) \\
4\end{array}$ & 08 \\
\hline V & $\begin{array}{l}\text { Educación } \\
\text { Ambiental. }\end{array}$ & 3 & $\begin{array}{l}\text { Desarrollo Social, emocional } \\
\text { y moral del niño de } 0 \text { a } 7 \text { años. } \\
\text { Desarrollo Psicomotor del niño } \\
\text { de } 0 \text { a } 7 \text { años. } \\
\begin{array}{l}\text { Familia, comunidad } \\
\text { Educación Preescolar. }\end{array} \\
\text { Taller Recursos para el }\end{array}$ & $\begin{array}{l}3 \\
4\end{array}$ & $\begin{array}{l}\text { Sociología } \\
\text { Educación. }\end{array}$ & 3 & & & 6 & 20 \\
\hline
\end{tabular}

460

La Práctica Profesional como área para potenciar las competencias pedagógicas necesarias para la enseñanza en Educación Infantil 


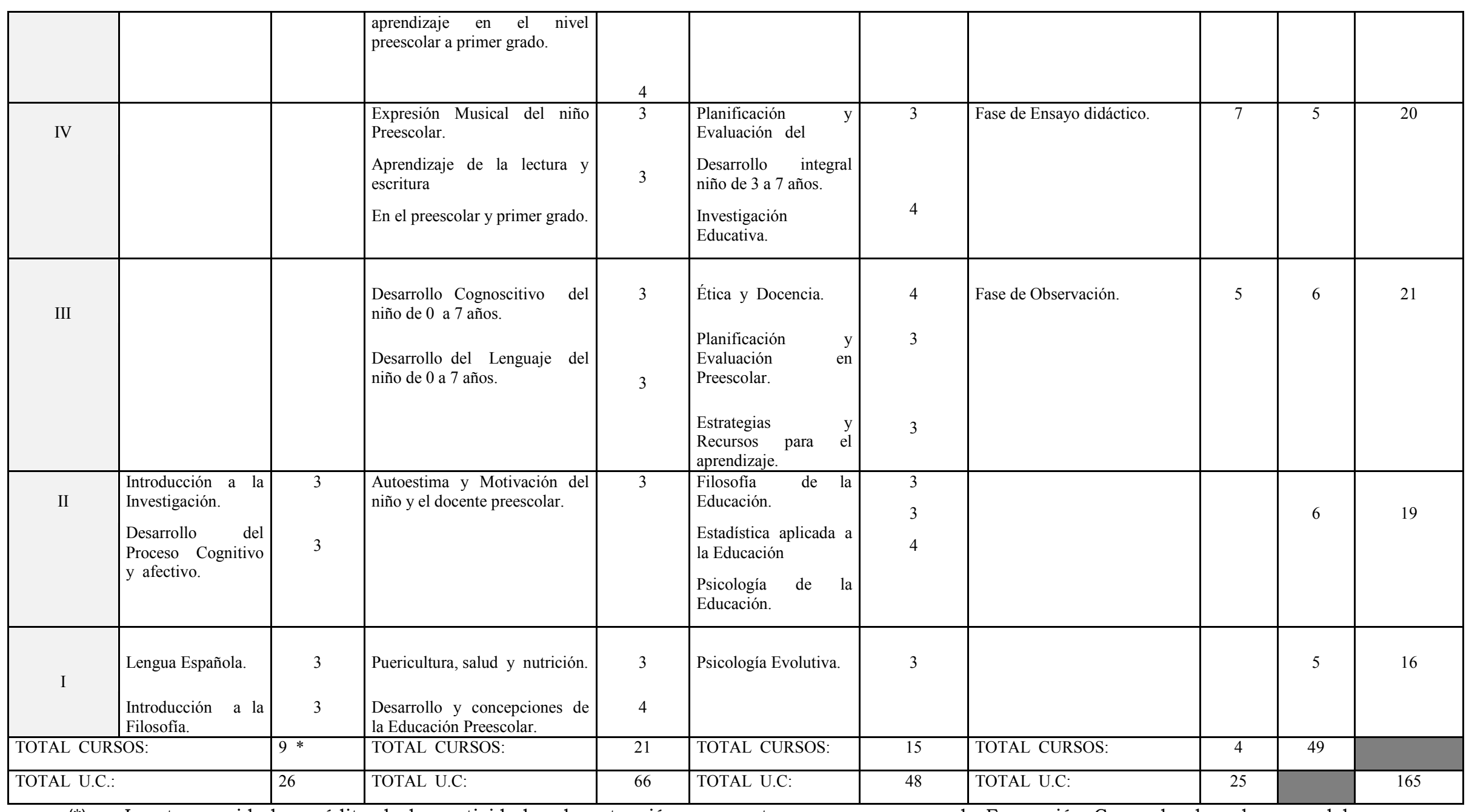

$\left({ }^{*}\right) \quad$ Las tres unidades crédito de las actividades de extensión se cuentan como un curso de Formación General y los alumnos deben realizarla entre el $2^{\circ}$ y $7^{\circ}$ semestre.

$(* *)$ La Fase Docencia Integrada sólo se considera para la salida intermedia. Nota: La salida intermedia equivale 110 u.c. Ver cuadro Cursos correspondientes a la Salida 